Cochrane Database of Systematic Reviews

\title{
Polyclonal and monoclonal antibodies for induction therapy in kidney transplant recipients (Review)
}

Hill P, Cross NB, Barnett ANR, Palmer SC, Webster AC

Hill P, Cross NB, Barnett ANR, Palmer SC, Webster AC.

Polyclonal and monoclonal antibodies for induction therapy in kidney transplant recipients.

Cochrane Database of Systematic Reviews 2017, Issue 1. Art. No.: CD004759.

DOI: 10.1002/14651858.CD004759.pub2.

www.cochranelibrary.com 
TABLE OF CONTENTS

HEADER

ABSTRACT

PLAIN LANGUAGE SUMMARY

SUMMARY OF FINDINGS

BACKGROUND

OBJECTIVES

METHODS

RESULTS

Figure 1.

Figure 2.

Figure 3.

DISCUSSION

AUTHORS' CONCLUSIONS

ACKNOWLEDGEMENTS

REFERENCES

CHARACTERISTICS OF STUDIES

DATA AND ANALYSES

Analysis 1.1. Comparison 1 ATG versus placebo/no treatment, Outcome 1 Death.

Analysis 1.2. Comparison 1 ATG versus placebo/no treatment, Outcome 2 Graft loss (all cause).

Analysis 1.3. Comparison 1 ATG versus placebo/no treatment, Outcome $3 \mathrm{Graft}$ loss (death censored).

Analysis 1.4. Comparison 1 ATG versus placebo/no treatment, Outcome 4 Acute rejection.

Analysis 1.5. Comparison 1 ATG versus placebo/no treatment, Outcome 5 Delayed graft function.

Analysis 1.6. Comparison 1 ATG versus placebo/no treatment, Outcome 6 Infection.

Analysis 1.7. Comparison 1 ATG versus placebo/no treatment, Outcome 7 Leucopenia.

Analysis 1.8. Comparison 1 ATG versus placebo/no treatment, Outcome 8 Thrombocytopenia.

Analysis 1.9. Comparison 1 ATG versus placebo/no treatment, Outcome 9 Malignancy or PTLD.

Analysis 1.10. Comparison 1 ATG versus placebo/no treatment, Outcome 10 Other adverse outcomes.

Analysis 1.11. Comparison 1 ATG versus placebo/no treatment, Outcome 11 Serum creatinine.

Analysis 2.1. Comparison 2 Rabbit ATG versus horse ATG, Outcome 1 Main outcomes.

Analysis 2.2. Comparison 2 Rabbit ATG versus horse ATG, Outcome 2 Other adverse outcomes.

Analysis 2.3. Comparison 2 Rabbit ATG versus horse ATG, Outcome 3 Serum creatinine.

Analysis 3.1. Comparison 3 Alemtuzumab + early steroid withdrawal (ESW) or minimisation versus ATG \pm ESW, Outcome 1 Death and graft loss.

Analysis 3.2. Comparison 3 Alemtuzumab + early steroid withdrawal (ESW) or minimisation versus ATG \pm ESW, Outcome 2 Rejection.

Analysis 3.3. Comparison 3 Alemtuzumab + early steroid withdrawal (ESW) or minimisation versus ATG \pm ESW, Outcome 3 Infection.

Analysis 3.4. Comparison 3 Alemtuzumab + early steroid withdrawal (ESW) or minimisation versus ATG \pm ESW, Outcome 4 Other adverse effects.

Analysis 3.5. Comparison 3 Alemtuzumab + early steroid withdrawal (ESW) or minimisation versus ATG \pm ESW, Outcome 5 Creatinine clearance.

Analysis 4.1. Comparison 4 Alemtuzumab + early steroid withdrawal (ESW) versus no induction, Outcome 1 Main outcomes. ... Analysis 4.2. Comparison 4 Alemtuzumab + early steroid withdrawal (ESW) versus no induction, Outcome 2 Other adverse outcomes.

Analysis 4.3. Comparison 4 Alemtuzumab + early steroid withdrawal (ESW) versus no induction, Outcome 3 Serum creatinine. .

Analysis 5.1. Comparison 5 Rituximab versus placebo, Outcome 1 Main outcomes.

Analysis 5.2. Comparison 5 Rituximab versus placebo, Outcome 2 Other adverse outcomes.

Analysis 5.3. Comparison 5 Rituximab versus placebo, Outcome 3 Graft function at 6 months (eGFR).

Analysis 6.1. Comparison 6 ATG versus OKT3, Outcome 1 Main outcomes.

Analysis 6.2. Comparison 6 ATG versus OKT3, Outcome 2 Other adverse outcomes.

Analysis 6.3. Comparison 6 ATG versus OKT3, Outcome 3 Serum creatinine at 1 year.

Analysis 7.1. Comparison 7 OKT3 versus placebo/no induction, Outcome 1 Main outcomes. 
Analysis 7.2. Comparison 7 OKT3 versus placebo/no induction, Outcome 2 Other adverse effects.

Analysis 7.3. Comparison 7 OKT3 versus placebo/no induction, Outcome 3 Serum creatinine.

Analysis 8.1. Comparison 8 ALG versus OKT3, Outcome 1 Main outcomes.

Analysis 8.3. Comparison 8 ALG versus OKT3, Outcome 3 Serum creatinine.

Analysis 9.1. Comparison 9 ALG versus placebo/no induction, Outcome 1 Main outcomes.

Analysis 9.2. Comparison 9 ALG versus placebo/no induction, Outcome 2 Other adverse outcomes.

Analysis 9.3. Comparison 9 ALG versus placebo/no induction, Outcome 3 Serum creatinine. 
[Intervention Review]

\section{Polyclonal and monoclonal antibodies for induction therapy in kidney transplant recipients}

Penny Hill1 ${ }^{1}$, Nicholas B Cross ${ }^{1}$, A Nicholas R Barnett 2 , Suetonia C Palmer 3 , Angela C Webster $4,5,6$

1Department of Nephrology, Christchurch Public Hospital, Christchurch, New Zealand. 2Renal \& Transplant Department, Guy's and St Thomas' NHS Foundation Trust, London, UK. 'ㄹepartment of Medicine, University of Otago Christchurch, Christchurch, New Zealand. ${ }^{4}$ Sydney School of Public Health, The University of Sydney, Sydney, Australia. ${ }^{5}$ Centre for Transplant and Renal Research, Westmead Millennium Institute, The University of Sydney at Westmead, Westmead, Australia. ${ }^{6}$ Cochrane Kidney and Transplant, Centre for Kidney Research, The Children's Hospital at Westmead, Westmead, Australia

Contact address: Penny Hill, Department of Nephrology, Christchurch Public Hospital, Christchurch, New Zealand. pennymorgan@doctors.org.uk.

Editorial group: Cochrane Kidney and Transplant Group.

Publication status and date: New, published in Issue 1, 2017.

Citation: Hill P, Cross NB, Barnett ANR, Palmer SC, Webster AC. Polyclonal and monoclonal antibodies for induction therapy in kidney transplant recipients. Cochrane Database of Systematic Reviews 2017, Issue 1. Art. No.: CD004759. DOI: 10.1002/14651858.CD004759.pub2.

Copyright @ 2017 The Cochrane Collaboration. Published by John Wiley \& Sons, Ltd.

\section{A B S T R A C T}

\section{Background}

Prolonging kidney transplant survival is an important clinical priority. Induction immunosuppression with antibody therapy is recommended at transplantation and non-depleting interleukin-2 receptor monoclonal antibodies (IL2Ra) are considered first line. It is suggested that recipients at high risk of rejection should receive lymphocyte-depleting antibodies but the relative benefits and harms of the available agents are uncertain.

\section{Objectives}

We aimed to: evaluate the relative and absolute effects of different antibody preparations (except IL2Ra) when used as induction therapy in kidney transplant recipients; determine how the benefits and adverse events vary for each antibody preparation; determine how the benefits and harms vary for different formulations of antibody preparation; and determine whether the benefits and harms vary in specific subgroups of recipients (e.g. children and sensitised recipients).

\section{Search methods}

We searched the Cochrane Kidney and Transplant's Specialised Register to 29 August 2016 through contact with the Information Specialist using search terms relevant to this review.

\section{Selection criteria}

Randomised controlled trials (RCTs) comparing monoclonal or polyclonal antibodies with placebo, no treatment, or other antibody therapy in adults and children who had received a kidney transplant.

\section{Data collection and analysis}

Two authors independently extracted data and assessed risk of bias. Dichotomous outcomes are reported as relative risk (RR) and continuous outcomes as mean difference (MD) together with their 95\% confidence intervals $(\mathrm{Cl})$. 


\section{Main results}

We included 99 studies (269 records; 8956 participants; 33 with contemporary agents). Methodology was incompletely reported in most studies leading to lower confidence in the treatment estimates.

Antithymocyte globulin (ATG) prevented acute graft rejection (17 studies: RR $0.63,95 \% \mathrm{Cl} 0.51$ to 0.78 ). The benefits of ATG on graft rejection were similar when used with (12 studies: RR $0.61,0.49$ to 0.76 ) or without (5 studies: RR $0.65,0.43$ to 0.98 ) calcineurin inhibitor (CNI) treatment. ATG (with CNI therapy) had uncertain effects on death ( 3 to 6 months, 3 studies: RR 0.41, 0.13 to $1.22 ; 1$ to 2 years, 5 studies: RR $0.75,0.27$ to 2.06 ; 5 years, 2 studies: RR $0.94,0.11$ to 7.81 ) and graft loss ( 3 to 6 months, 4 studies: RR $0.60,0.34$ to $1.05 ; 1$ to 2 years, 3 studies: RR $0.65,0.36$ to 1.19). The effect of ATG on death-censored graft loss was uncertain at 1 to 2 years and 5 years. In non-CNI studies, ATG had uncertain effects on death but reduced death-censored graft loss ( 6 studies: RR $0.55,0.38$ to 0.78 ). When CNI and older non-CNI studies were combined, a benefit was seen with ATG at 1 to 2 years for both all-cause graft loss ( 7 studies: RR $0.71,0.53$ to 0.95 ) and death-censored graft loss ( 8 studies: RR $0.55,0.39$ to 0.77 ) but not sustained longer term. ATG increased cytomegalovirus (CMV) infection ( 6 studies: RR 1.55 , 1.24 to 1.95 ), leucopenia (4 studies: RR 3.86, 2.79 to 5.34) and thrombocytopenia (4 studies: RR 2.41, 1.61 to 3.61) but had uncertain effects on delayed graft function, malignancy, post-transplant lymphoproliferative disorder (PTLD), and new onset diabetes after transplantation (NODAT).

Alemtuzumab was compared to ATG in six studies (446 patients) with early steroid withdrawal (ESW) or steroid minimisation. Alemtuzumab plus steroid minimisation reduced acute rejection compared to ATG at one year (4 studies: RR 0.57, 0.35 to 0.93 ). In the two studies with ESW only in the alemtuzumab arm, the effect of alemtuzumab on acute rejection at 1 year was uncertain compared to ATG (RR $1.27,0.50$ to 3.19). Alemtuzumab had uncertain effects on death ( 1 year, 2 studies: RR $0.39,0.06$ to $2.42 ; 2$ to 3 years, 3 studies: RR $0.67,95 \% \mathrm{Cl} 0.15$ to 2.95), graft loss (1 year, 2 studies: RR $0.39,0.13$ to 1.30; 2 to 3 years, 3 studies: RR $0.98,95 \% \mathrm{Cl} 0.47$ to 2.06 ), and death-censored graft loss ( 1 year, 2 studies: RR $0.38,0.08$ to $1.81 ; 2$ to 3 years, 3 studies: RR $2.45,95 \% \mathrm{Cl} 0.67$ to 8.97 ) compared to ATG. Creatinine clearance was lower with alemtuzumab plus ESW at 6 months ( 2 studies: MD $-13.35 \mathrm{~mL} / \mathrm{min},-23.91$ to -2.80 ) and 2 years ( 2 studies: MD $-12.86 \mathrm{~mL} / \mathrm{min}$, -23.73 to -2.00) compared to ATG plus triple maintenance. Across all 6 studies, the effect of alemtuzumab versus ATG was uncertain on allcause infection, CMV infection, BK virus infection, malignancy, and PTLD. The effect of alemtuzumab with steroid minimisation on NODAT was uncertain, compared to ATG with steroid maintenance.

Alemtuzumab plus ESW compared with triple maintenance without induction therapy had uncertain effects on death and all-cause graft loss at 1 year, acute rejection at 6 months and 1 year. CMV infection was increased ( 2 studies: RR 2.28, 1.18 to 4.40). Treatment effects were uncertain for NODAT, thrombocytopenia, and malignancy or PTLD.

Rituximab had uncertain effects on death, graft loss, acute rejection and all other adverse outcomes compared to placebo.

\section{Authors' conclusions}

ATG reduces acute rejection but has uncertain effects on death, graft survival, malignancy and NODAT, and increases CMV infection, thrombocytopenia and leucopenia. Given a $45 \%$ acute rejection risk without ATG induction, seven patients would need treatment to prevent one having rejection, while incurring an additional patient experiencing CMV disease for every 12 treated. Excluding non-CNI studies, the risk of rejection was $37 \%$ without induction with six patients needing treatment to prevent one having rejection.

In the context of steroid minimisation, alemtuzumab prevents acute rejection at 1 year compared to ATG. Eleven patients would require treatment with alemtuzumab to prevent 1 having rejection, assuming a $21 \%$ rejection risk with ATG.

Triple maintenance without induction therapy compared to alemtuzumab combined with ESW had similar rates of acute rejection but adverse effects including NODAT were poorly documented. Alemtuzumab plus steroid withdrawal would cause one additional patient experiencing CMV disease for every six patients treated compared to no induction and triple maintenance, in the absence of any clinical benefit. Overall, ATG and alemtuzumab decrease acute rejection at a cost of increased CMV disease while patient-centred outcomes (reduced death or lower toxicity) do not appear to be improved.

\section{PLAIN LANGUAGE SUMMARY}

\section{Polyclonal and monoclonal antibodies for induction therapy in kidney transplant recipients}

\section{What is the issue?}

A kidney transplant is the best treatment for many people who have severe kidney disease to allow patients to return to work and feel better. Patients who receive a kidney transplant receive drugs to prevent their own body from rejecting the transplant - the aim of treatment is to prolong the function of the kidney transplant while minimising common long-term side effects of treatment such as cancer, infection, and diabetes. For some patients who have a much higher risk of rejection, additional treatment is given at the time of the operation (which may lower the body's ability to attack the kidney transplant and increase kidney function but can increase the risk of complications such as infection and cancer).

\section{What did we do?}


We searched the Cochrane Kidney and Transplant's Specialised Register to 29 August 2016 for randomised controlled trials (RCTs) comparing monoclonal or polyclonal antibodies with placebo, no treatment, or other antibody therapy in adults and children who had received a kidney transplant.

\section{What did we find?}

We identified 99 studies (265 records; 8956 participants; 33 with contemporary agents). From the available studies in this area, an antibody against human immune cells (ATG) reduces the chances of a patient having a kidney rejection by one-third, but it is uncertain whether this prolongs the function of the kidney transplant or survival for the patient. ATG significantly increases viral infections including cytomegalovirus. In addition, the effects of ATG treatment on cancer are not well understood. Alemtuzumab is another treatment which has been compared to ATG in patients who have received less or no steroid therapy as part of their transplant treatment. Treatment with alemtuzumab with lower steroid doses or no steroid treatment at all may lower a patient's risk of kidney rejection within a year after transplantation when compared to ATG but overall the information about treatment benefits and harms of alemtuzumab in many clinical situations are not certain. This means we are not confident about the effects of alemtuzumab on kidney function, patient survival or treatment side-effects.

\section{Conclusions}

Overall the available research on antibody treatment for kidney transplantation is limited when clinicians and patients make joint decisions about antibody therapy at the time of a kidney transplant because of the uncertain long term benefits and hazards of these treatments. 
SUMMARY OF FINDINGS

Summary of findings for the main comparison.

ATG compared with placebo or no induction for kidney transplant recipients

Patient or population: kidney transplant recipients

Settings:

Intervention: ATG

Comparison: placebo/no treatment

\begin{tabular}{|c|c|c|c|c|c|c|}
\hline \multirow[t]{3}{*}{ Outcomes } & \multicolumn{2}{|c|}{ Illustrative comparative risks* $(95 \% \mathrm{Cl})$} & \multirow{3}{*}{$\begin{array}{l}\text { Relative effect } \\
(95 \% \mathrm{CI})\end{array}$} & \multirow{3}{*}{$\begin{array}{l}\text { No of partici- } \\
\text { pants } \\
\text { (studies) }\end{array}$} & \multirow{3}{*}{$\begin{array}{l}\text { Quality of the } \\
\text { evidence } \\
\text { (GRADE) }\end{array}$} & \multirow[t]{3}{*}{ Comments } \\
\hline & Assumed risk & Corresponding risk & & & & \\
\hline & $\begin{array}{l}\text { Placebo/no treat- } \\
\text { ment }\end{array}$ & ATG & & & & \\
\hline Death (including CNI) & \multicolumn{2}{|c|}{ Medium risk population } & \multirow{2}{*}{$\begin{array}{l}\text { RR } 0.75 \\
(0.27 \text { to } 2.06)\end{array}$} & \multirow[t]{2}{*}{$632(5)$} & \multirow{2}{*}{$\begin{array}{l}\oplus \oplus \oplus \ominus \\
\text { low } 1,2\end{array}$} & \\
\hline $\begin{array}{l}\text { Follow-up: median } 24 \text { months (IQR } \\
\text { 12-24) }\end{array}$ & 31 per 1000 & $\begin{array}{l}23 \text { per } 1000 \\
\text { (8 to } 64)\end{array}$ & & & & \\
\hline \multirow{2}{*}{$\begin{array}{l}\text { All-cause graft loss (including CNI) } \\
\text { Follow-up: median } 1 \text { year (IQR 12-24) }\end{array}$} & \multicolumn{2}{|c|}{ Medium risk population } & \multirow{2}{*}{$\begin{array}{l}\text { RR } 0.65 \\
\text { (0.36 to } 1.19)\end{array}$} & \multirow[t]{2}{*}{$549(3)$} & \multirow{2}{*}{$\begin{array}{l}\oplus \oplus \ominus \ominus \\
\text { low } 1,2\end{array}$} & \\
\hline & 109 per 1000 & $\begin{array}{l}\mathbf{7 1} \text { per } 1000 \\
\text { (39 to } 129)\end{array}$ & & & & \\
\hline \multirow{2}{*}{$\begin{array}{l}\text { Delayed graft function } \\
\text { Follow-up: N/A (immediate) }\end{array}$} & \multicolumn{2}{|c|}{ Medium risk population } & \multirow{2}{*}{$\begin{array}{l}\mathbf{R R} 0.93 \text { (0.78 to } \\
1.10)\end{array}$} & \multirow[t]{2}{*}{$1304(9)$} & \multirow{2}{*}{$\begin{array}{l}\oplus \oplus \ominus \ominus \\
\text { low } 1,2\end{array}$} & \\
\hline & 283 per 1000 & $\begin{array}{l}\mathbf{2 6 3} \text { per } 1000 \\
\text { ( } 221 \text { to } 311)\end{array}$ & & & & \\
\hline \multirow{2}{*}{$\begin{array}{l}\text { Acute rejection (including CNI) } \\
\text { Follow-up: median } 1 \text { year (IQR 6-24) }\end{array}$} & \multicolumn{2}{|c|}{ Medium risk population } & \multirow{2}{*}{$\begin{array}{l}\text { RR } \mathbf{0 . 6 1} \\
(0.49 \text { to } 0.76)\end{array}$} & \multirow[t]{2}{*}{$1491(12)$} & \multirow{2}{*}{$\begin{array}{l}\oplus \oplus \oplus \ominus \\
\text { moderate } 1\end{array}$} & \\
\hline & 365 per 1000 & $\begin{array}{l}\mathbf{2 2 2} \text { per } \mathbf{1 0 0 0} \\
\text { (179 to } 277)\end{array}$ & & & & \\
\hline \multirow{2}{*}{$\begin{array}{l}\text { Infection: CMV infection } \\
\text { Follow-up: median } 1 \text { year (IQR 4.5-13.5) }\end{array}$} & \multicolumn{2}{|c|}{ Medium risk population } & \multirow{2}{*}{$\begin{array}{l}\text { RR } 1.55 \\
\text { (1.24 to } 1.95)\end{array}$} & \multirow[t]{2}{*}{$1072(6)$} & \multirow{2}{*}{$\begin{array}{l}\oplus \oplus \oplus \ominus \\
\text { moderate } 1\end{array}$} & \\
\hline & 176 per 1000 & 273 per 1000 & & & & \\
\hline
\end{tabular}

moderate 


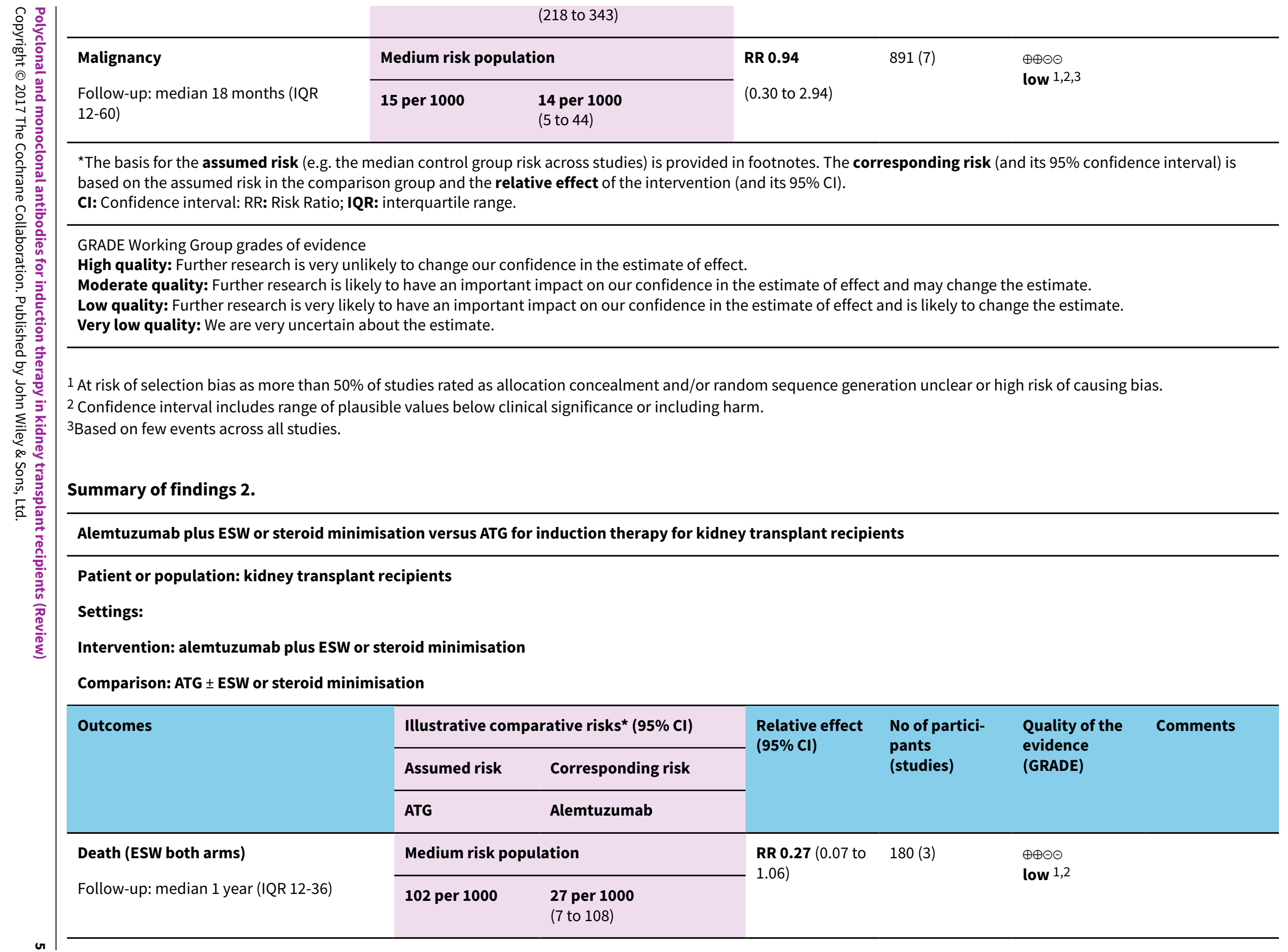




\begin{tabular}{|c|c|c|c|c|c|c|}
\hline \multirow{4}{*}{ 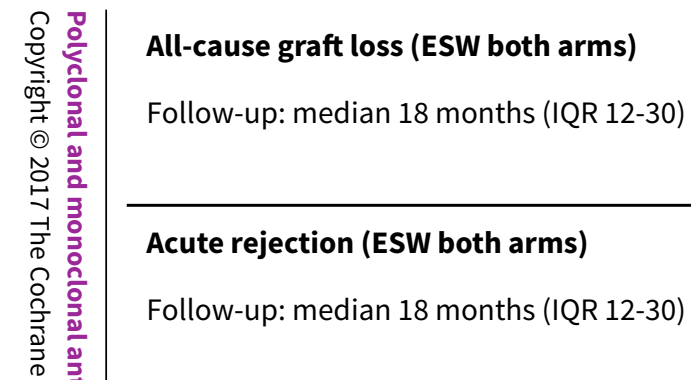 } & \multicolumn{2}{|c|}{ Medium risk population } & \multirow{2}{*}{$\begin{array}{l}\text { RR } 0.60 \\
(0.34 \text { to } 1.08)\end{array}$} & \multirow[t]{2}{*}{$360(4)$} & \multirow{2}{*}{$\begin{array}{l}\oplus \oplus \ominus \ominus \\
\text { low } 1,2\end{array}$} & \\
\hline & 148 per 1000 & $\begin{array}{l}89 \text { per } 1000 \\
\text { (50 to } 160)\end{array}$ & & & & \\
\hline & \multicolumn{2}{|c|}{ Medium risk population } & \multirow{2}{*}{$\begin{array}{l}\text { RR } \mathbf{0 . 5 7} \\
\text { (0.35 to } 0.93)\end{array}$} & \multirow[t]{2}{*}{$360(4)$} & \multirow{2}{*}{$\begin{array}{l}\oplus \oplus \oplus \ominus \\
\text { moderate } 1\end{array}$} & \\
\hline & 208 per 1000 & $\begin{array}{l}\mathbf{1 1 9} \text { per } \mathbf{1 0 0 0} \\
\text { (73 to } 193 \text { ) }\end{array}$ & & & & \\
\hline Biopsy-proven CAN (ESW with alem- & \multicolumn{2}{|c|}{ Medium risk population } & \multirow{2}{*}{$\begin{array}{l}\text { RR } 2.45 \\
\text { (1.02 to } 5.94)\end{array}$} & \multirow[t]{2}{*}{$86(2)$} & \multirow{2}{*}{$\begin{array}{l}\oplus \oplus \ominus \ominus \\
\text { low } 1,2\end{array}$} & \\
\hline Follow-up: median 30 months (IQR 24-36) & 116 per 1000 & $\begin{array}{l}\mathbf{2 8 4} \text { per } \mathbf{1 0 0 0} \\
\text { (118 to } 689)\end{array}$ & & & & \\
\hline CMV infection (all studies) & \multicolumn{2}{|c|}{ Medium risk population } & \multirow{2}{*}{$\begin{array}{l}\text { RR } 1.08 \\
(0.46 \text { to } 2.56)\end{array}$} & \multirow[t]{2}{*}{$225(3)$} & \multirow{2}{*}{$\begin{array}{l}\oplus \oplus \ominus \ominus \\
\text { low } 1,2\end{array}$} & \\
\hline $\begin{array}{l}\text { Follow-up: median } 30 \text { months } \\
\text { (IQR 24-36) }\end{array}$ & 80 per 1000 & $\begin{array}{l}\mathbf{8 6} \text { per } \mathbf{1 0 0 0} \\
(37 \text { to } 205)\end{array}$ & & & & \\
\hline NODAT (ESW alemtuzumab only) & \multicolumn{2}{|c|}{ Medium risk population } & \multirow{2}{*}{$\begin{array}{l}\text { RR } 0.41 \\
(0.12 \text { to } 1.40)\end{array}$} & \multirow[t]{2}{*}{$69(2)$} & \multirow{2}{*}{$\begin{array}{l}\oplus \oplus \ominus \ominus \\
\text { low } 1,2\end{array}$} & \\
\hline Follow-up: median 30 months (IQR 24-36) & 237 per 1000 & $\begin{array}{l}\mathbf{9 7} \text { per } \mathbf{1 0 0 0} \\
(28 \text { to } 332)\end{array}$ & & & & \\
\hline \multirow{2}{*}{$\begin{array}{l}\text { Malignancy (all studies) } \\
\text { Follow-up: median } 36 \text { months (IQR 12-36) }\end{array}$} & \multicolumn{2}{|c|}{ Medium risk population } & \multirow{2}{*}{$\begin{array}{l}\text { RR } 4.93 \\
(0.59 \text { to } 41.11)\end{array}$} & \multirow[t]{2}{*}{$187(3)$} & \multirow{2}{*}{$\begin{array}{l}\oplus \Theta \Theta \Theta \\
\text { very low 1,2,3 }\end{array}$} & \multirow{2}{*}{$\begin{array}{l}\text { All reported } \\
\text { events from } \\
\text { single study } \\
\text { (other } 2 \text { stud- } \\
\text { ies reported } 0 \\
\text { events) }\end{array}$} \\
\hline & 11 per 1000 & $\begin{array}{l}\mathbf{5 4} \text { per } 1000 \\
(6 \text { to } 452)\end{array}$ & & & & \\
\hline
\end{tabular}

${ }^{*}$ The basis for the assumed risk (e.g. the median control group risk across studies) is provided in footnotes. The corresponding risk (and its $95 \%$ confidence interval) is based on the assumed risk in the comparison group and the relative effect of the intervention (and its $95 \% \mathrm{Cl}$ ).

Cl: Confidence interval: RR: Risk Ratio; IQR: interquartile range.

GRADE Working Group grades of evidence

High quality: Further research is very unlikely to change our confidence in the estimate of effect.

Moderate quality: Further research is likely to have an important impact on our confidence in the estimate of effect and may change the estimate.

Low quality: Further research is very likely to have an important impact on our confidence in the estimate of effect and is likely to change the estimate.

Very low quality: We are very uncertain about the estimate.

1 At risk of selection bias as more than $50 \%$ of studies rated as allocation concealment and/or random sequence generation unclear or high risk of causing bias 
2 Confidence interval includes range of plausible values below clinical significance or including harm ${ }^{3}$ Based on few events across all studies.

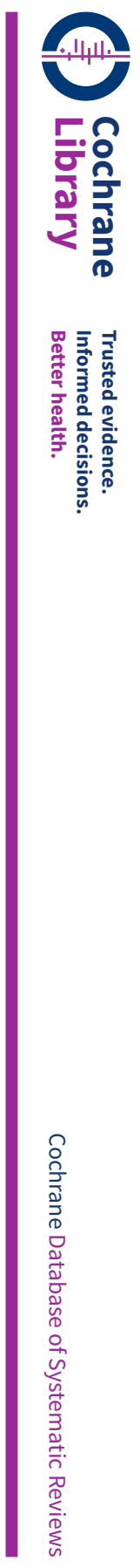




\section{B A C K G R O U N D}

\section{Description of the condition}

Kidney transplantation is the treatment of choice for many patients with end-stage kidney disease (ESKD) but demand exceeds supply from organ donors. Increasing this supply and prolonging kidney transplant survival are therefore important for patients and health systems (Tonelli 2011).

\section{Description of the intervention}

Immunosuppressive therapy consists of initial induction and maintenance regimens to prevent rejection. Induction may be defined as treatment with a biologic agent either before, at the time of, or immediately after transplantation to deplete or modulate $T$ cell responses at the time of antigen presentation. Maintenance immunosuppression protocols usually involve three drugs acting on different parts of the T-cell activation or proliferation cascade: calcineurin inhibitors (CNI) (e.g. cyclosporin (CSA), tacrolimus), antiproliferative agents (e.g. azathioprine, mycophenolate mofetil) and corticosteroids (e.g. prednisolone) (Denton 1999; Hong 2000).

Induction immunosuppression with antibody therapy is now recommended at the time of transplantation for all patients (KDIGO 2009). Antibody therapies are monoclonal or polyclonal, and depleting or non-depleting of lymphocytes. Non-depleting interleukin-2 receptor monoclonal antibodies (IL2Ra) are considered first line but it is suggested that recipients at high risk of rejection (e.g. children, subsequent transplants, certain racial groups such as African-Americans, and other sensitised patients) should receive lymphocyte-depleting antibodies. Depleting antibodies are also used for those at risk of delayed graft function to delay the introduction of full dose CNI, which can prolong the duration of acute tubular necrosis (Denton 1999). Depleting antibodies include polyclonal antibodies against the human lymphocyte (antilymphocyte globulin (ALG); antithymocyte globulin (ATG)).

\section{How the intervention might work}

Depleting antibodies bind to target immune effector cells leading to complement mediated destruction. Non-depleting antibodies bind to targets on effector cells preventing their interaction with other cells rendering them ineffective, but do not lead to cell destruction.

Most antibodies used in transplantation have been directed at $\mathrm{T}$ cells. Significant reduction in circulating T-effector cells is rapidly observed, leading to impaired cell mediated immunity (the desired effect to prevent kidney transplant rejection). A number of different preparations of ATG have been produced over the last few decades. These can be broadly divided into horse ATG (hATG), derived from horse serum after immunisation of horses with human thymocytes, and rabbit ATG (rATG), derived from rabbit serum. There are currently two or three standardised preparations available globally. Historical ATG preparations used in early studies were less standardised compared to the preparations currently available. Even though both hATG and rATG contain antibodies to a wide variety of T-cell antigens and $\mathrm{MHC}$ antigens, it is likely that the effects are not equal given that the two types are prepared differently. One study assessing both efficacy and safety clearly showed differences between these two preparations (Brennan 1999).
Monomurab-CD3 is a murine monoclonal antibody against the CD3 receptor on activated T cells (Orthoclone OKT3) which became available in the late 1980s. OKT3 removes the functional Tcell population from circulation, producing immunosuppression useful for both induction therapy and the management of acute rejection. However, this profound immunosuppression is associated with immediate toxicity (cytokine release syndrome) and higher rates of infection and malignancy than standard triple therapy (Soulillou 2001). Use of these preparations may also be limited by the development of neutralising antibodies to their xenogeneic components (Kreis 1992). Use of OKT3 for both induction and treatment of acute rejection has declined in many countries over recent years due to the side effect profile. JanssenCilag discontinued the manufacture of OKT3 in 2010 due to a combination of declining sales and evidence from a Cochrane review on treatment of acute rejection confirming that OKT3 was associated with increased side effects compared to newer biologic agents (Webster 2006).

More recently, the IL2Ra basiliximab and daclizumab have been used in the induction phase. IL2Ra are IgG monoclonal antibodies to the interleukin-2 receptor found only on activated $T$ cells. IL2Ra are more specific immunosuppressants, with no immediate toxicity, and are increasingly used as induction agents, but not for treating acute rejection (Cibrik 2001). These agents are investigated in a separate Cochrane review (Webster 2010) and so will not be considered here.

Other antibodies have also been introduced for kidney transplantation induction such as alemtuzumab. This humanised CD-52 specific complement fixing monoclonal antibody was first used for induction by Calne 1999. Alemtuzumab causes profound depletion of T-cells from peripheral blood and also less marked depletion of other mononuclear cells.

Although the majority of current anti-rejection therapies are targeted at T-cell mechanisms, there is increasing evidence that B-cells may have a role due to their ability to act as antigen presenting cells and T-cell activators (Zand 2007). For this reason the B-cell depleting anti-CD20 antibody, rituximab is also being used in kidney transplantation. Initially this was used in studies for ABO-incompatible kidney transplants at induction (Tyden 2003) but is now being considered for selected patients in some centres.

\section{Why it is important to do this review}

Favoured antibody preparations and rates of use differ from country to country and among transplant units. In 2007 in the USA, $78 \%$ of recipients received an antibody preparation as part of induction immunosuppression. Forty five per cent of kidney recipients received ATG, $1 \%$ OKT3, 27\% IL2Ra and $10 \%$ received alemtuzumab (UNOS 2011). In Australia, 93\% of patients received an IL2Ra in 2008 and $5 \%$ to $10 \%$ received an additional or alternative antibody preparation (ANZDATA 2009). There has clearly been an increase in use of antibody induction therapy over the last decade (ANZDATA 2009; UNOS 2011) but there is still a large amount of variability in the type of antibody preparation used. This reflects local policies to some extent but there is also uncertainty, in particular in patients at high risk of rejection, as to whether one agent is superior to another. In patients at higher risk of rejection, increased risk of side effects may be acceptable if a treatment is more effective at reducing the risk of acute rejection, leading to improved rates of allograft and patient survival. 
The aim of this systematic review is to summarise the relative short and long-term beneficial and adverse effects of different antibody preparations (except IL2Ra) used as induction in kidney transplant recipients. A previous Cochrane review looks at the use of antibodies for treatment of acute rejection episodes (Webster 2006).

\section{OB JECTIVES}

- To evaluate the relative and absolute effects of different antibody preparations (except IL2Ra) when used as induction therapy in kidney transplant recipients.

- To determine how the benefits and adverse events vary for each antibody preparation.

- To determine how the benefits and harms vary for different formulations of antibody preparation.

- To determine whether the benefits and harms vary in specific subgroups of recipients (e.g. children and sensitised recipients).

\section{METHODS}

\section{Criteria for considering studies for this review}

\section{Types of studies}

All randomised controlled trials (RCTs) and quasi-RCTs (RCTs in which allocation to treatment was obtained by alternation, use of alternate medical records, date of birth or other predictable methods) looking at different antibody preparations (except IL2Ra) used as induction in kidney transplant recipients.

\section{Types of participants}

Adults and children who are kidney transplant recipients.

Recipients of multi-organ transplants were excluded from this review.

\section{Types of interventions}

We included studies using antibody preparations given in combination with any other immunosuppressive agents for induction therapy.

Exclusions were IL2Ra, as they are the subject of a separate Cochrane Review (Webster 2010). The authors also note that the manufacture of OKT3 was discontinued in January 2010 but have decided to include this agent in the interventions for historical purposes.

We examined the following comparisons.

- ATG versus placebo/no treatment

- ATG versus ALG

- ATG versus a different ATG (e.g. rabbit versus horse)

- ATG versus monomurab-CD3

- ALG versus placebo/no treatment

- ALG versus monomurab-CD3

- Monomurab-CD3 versus placebo/no treatment

- Alemtuzumab/anti-CD52 versus placebo/no treatment

- Alemtuzumab/anti-CD52 versus other poly- or monoclonal antibody

- Rituximab/anti-CD20 versus placebo/no treatment
- Rituximab/anti-CD20 versus other poly-or monoclonal antibody

- Other poly- or monoclonal antibody versus placebo/no treatment

- Other poly- or monoclonal antibody versus other poly- or monoclonal antibody

- Antibody versus non-antibody intervention

The 'class effect' of anti-lymphocyte preparations was initially assumed but differences in formulation were also examined (e.g. rabbit versus horse-based ATG formulations). All dosage regimens were included and low versus high dose regimens were examined.

\section{Types of outcome measures}

Where possible, outcome events were assessed at one, three and six months, and at one, two, three and five years posttransplantation.

\section{Primary outcomes}

- Death (all cause)

- Graft loss (defined as dependence on dialysis, graft loss censored for death with a functioning allograft)

- Graft loss including death with a functioning graft

- Incidence of acute rejection of kidney (analysed as combined outcome for clinical suspicion, biopsy-proven and steroid resistant).

\section{Secondary outcomes}

- Kidney allograft function: glomerular filtration rate (GFR), serum creatinine ( $\mathrm{SCr})$, creatinine clearance $(\mathrm{CrCl})$, or as defined by authors

- Incidence of delayed graft function

- Incidence of bacterial, fungal and viral infectious complications specifically including cytomegalovirus (CMV) (both asymptomatic CMV viraemia and true cases of CMV infection with tissue invasion were analysed as reported by the individual studies) and Polyoma BK virus

- Incidence of new-onset diabetes after transplantation (NODAT)

- Incidence of any malignancy

- Incidence of post-transplant lymphoproliferative disorders (PTLD) and lymphoma

- Incidence of treatment-related adverse reactions (gastrointestinal, neurological, haematological, biochemical) and recognised syndromes (e.g. serum sickness, cytokine release syndrome).

\section{Search methods for identification of studies}

\section{Electronic searches}

We searched the Cochrane Kidney and Transplant Specialised Register up to 29 August 2016 through contact with the Information Specialist using search terms relevant to this review. The Cochrane Kidney and Transplant Specialised Register contains studies identified from the following sources

1. Quarterly searches of the Cochrane Central Register of Controlled Trials CENTRAL

2. Weekly searches of MEDLINE OVID SP

3. Handsearching of kidney-related journals \& the proceedings of major kidney conferences 
4. Searching of the current year of EMBASE OVID SP

5. Weekly current awareness alerts for selected kidney-journals

6. Searches of the International Clinical Trials Register (ICTRP) Search Portal \& ClinicalTrials.gov

Studies contained in the Specialised register are identified through search strategies for CENTRAL, MEDLINE, and EMBASE based on the scope of Cochrane kidney and Transplant. Details of these strategies as well as a list of handsearched journals, conference proceedings and current awareness alerts are available in the 'Specialised Register' section of information about the Cochrane Kidney and Transplant.

See Appendix 1 for search terms used in strategies for this review.

\section{Data collection and analysis}

\section{Selection of studies}

The search strategy described was used to obtain titles and abstracts of studies that might have been relevant to the review. The titles and abstracts were screened independently by two authors, who discarded studies that were not applicable. However, studies and reviews that might include relevant data or information on studies were retained initially. Two authors independently assessed retrieved abstracts and, if necessary the full text, of these studies to determine which studies satisfy the inclusion criteria.

\section{Data extraction and management}

Data extraction was carried out independently by two authors using standard data extraction forms. Studies reported in nonEnglish language journals were translated before assessment. Where more than one publication of one study existed, records were grouped together and the publication with the most complete data was used in the analyses. Where relevant outcomes were only published in earlier versions these data were used. Any discrepancy between published versions was to be highlighted. Where duplicate publication was suspected authors were contacted for clarification and if duplication was confirmed the initial full publication together with any subsequent publication which adds additional information (e.g. longer term follow-up data) was included in the review.

\section{Assessment of risk of bias in included studies}

The following items were independently assessed by two authors using the risk of bias assessment tool (Higgins 2011) (see Appendix 2).

- Was there adequate sequence generation (selection bias)?

- Was allocation adequately concealed (selection bias)?

- Was knowledge of the allocated interventions adequately prevented during the study?

* Participants and personnel (performance bias)

* Outcome assessors(detection bias)

- Were incomplete outcome data adequately addressed (attrition bias)?

- Are reports of the study free of suggestion of selective outcome reporting (reporting bias)?

- Was the study apparently free of other problems that could put it at a risk of bias?

\section{Measures of treatment effect}

For dichotomous outcomes (e.g. rejection) results were expressed as risk ratios $(\mathrm{RR})$ with $95 \%$ confidence intervals $(95 \% \mathrm{Cl})$.

Where continuous scales of measurement were used to assess the effects of treatment (e.g. $\mathrm{CrCl}$ ), the mean difference (MD) was used, or the standardised mean difference (SMD) if different scales were used. For count data (such as total number of infections/personyear of follow-up) the rate ratio was used. Where time-to-event data could not be dichotomised, survival analysis methods were used and the results expressed as hazard ratio (HR).

Where outcomes were not amenable to meta-analysis, i.e. if reported idiosyncratically (e.g. drug-related specific adverse reactions), they were tabulated and assessed with descriptive techniques, and the risk difference (RD) with $95 \% \mathrm{Cl}$ was calculated. Quality of life and economic data was analysed using descriptive techniques.

\section{Assessment of heterogeneity}

Clinical and methodological heterogeneity was analysed using a Cochran $\mathrm{Q}$ test $\left(\mathrm{Chi}^{2}\right.$ with $\mathrm{N}-1$ degrees of freedom and a $\mathrm{P}$ value of 0.05 used for statistical significance) and with the $\mathrm{I}^{2}$ test (Higgins 2003). $I^{2}$ values of $25 \%, 50 \%$ and $75 \%$ correspond to low, medium and high levels of heterogeneity.

\section{Assessment of reporting biases}

Funnel plots were used to assess for the potential existence of small study bias (Higgins 2011).

\section{Data synthesis}

Data was pooled using the random effects model (Higgins 2011).

\section{Subgroup analysis and investigation of heterogeneity}

Subgroup analysis was used to explore possible clinical sources of heterogeneity.

- Baseline maintenance immunosuppression

- Antibody formulation (e.g. rabbit versus horse ATG)

- Duration and dose of antibody treatment.

\section{'Summary of findings' tables}

We have presented the main results of the review in 'Summary of findings' tables. These tables present key information concerning the quality of the evidence, the magnitude of the effects of the interventions examined, and the sum of the available data for the main outcomes (Schünemann 2011a). The 'Summary of findings' tables also include an overall grading of the evidence related to each of the main outcomes using the GRADE (Grades of Recommendation, Assessment, Development and Evaluation) approach (GRADE 2008). The GRADE approach defines the quality of a body of evidence as the extent to which one can be confident that an estimate of effect or association is close to the true quantity of specific interest. The quality of a body of evidence involves consideration of within-trial risk of bias (methodological quality), directness of evidence, heterogeneity, precision of effect estimates and risk of publication bias (Schünemann 2011b). We presented the following outcomes in the 'Summary of findings' tables.

- Death 
- Graft loss

- Delayed graft function

- Acute rejection

- CMV infection

- Malignancy

- NODAT

\section{RES U L T S}

\section{Description of studies}

See: Characteristics of included studies; Characteristics of excluded studies; Characteristics of studies awaiting classification; Characteristics of ongoing studies.

\section{Results of the search}

After searching the Specialised Register we identified 452 records. After duplicates were removed and titles and abstracts screened we retrieved 285 full-text articles for further assessment. Of these, 99 studies (268 records) were included and five studies (8 records) were excluded. Three ongoing studies (NCT00733733; NCT01154387; ReMIND Study 2013) were identified, and five studies (NCT00089947; NCT00861536; NCT01046955; NCT01354301; Stevens 2016) were identified prior to publication. These eight studies and will be assessed in a future update of this review (Figure 1 ). 
Figure 1. Flow diagram of included and excluded studies.

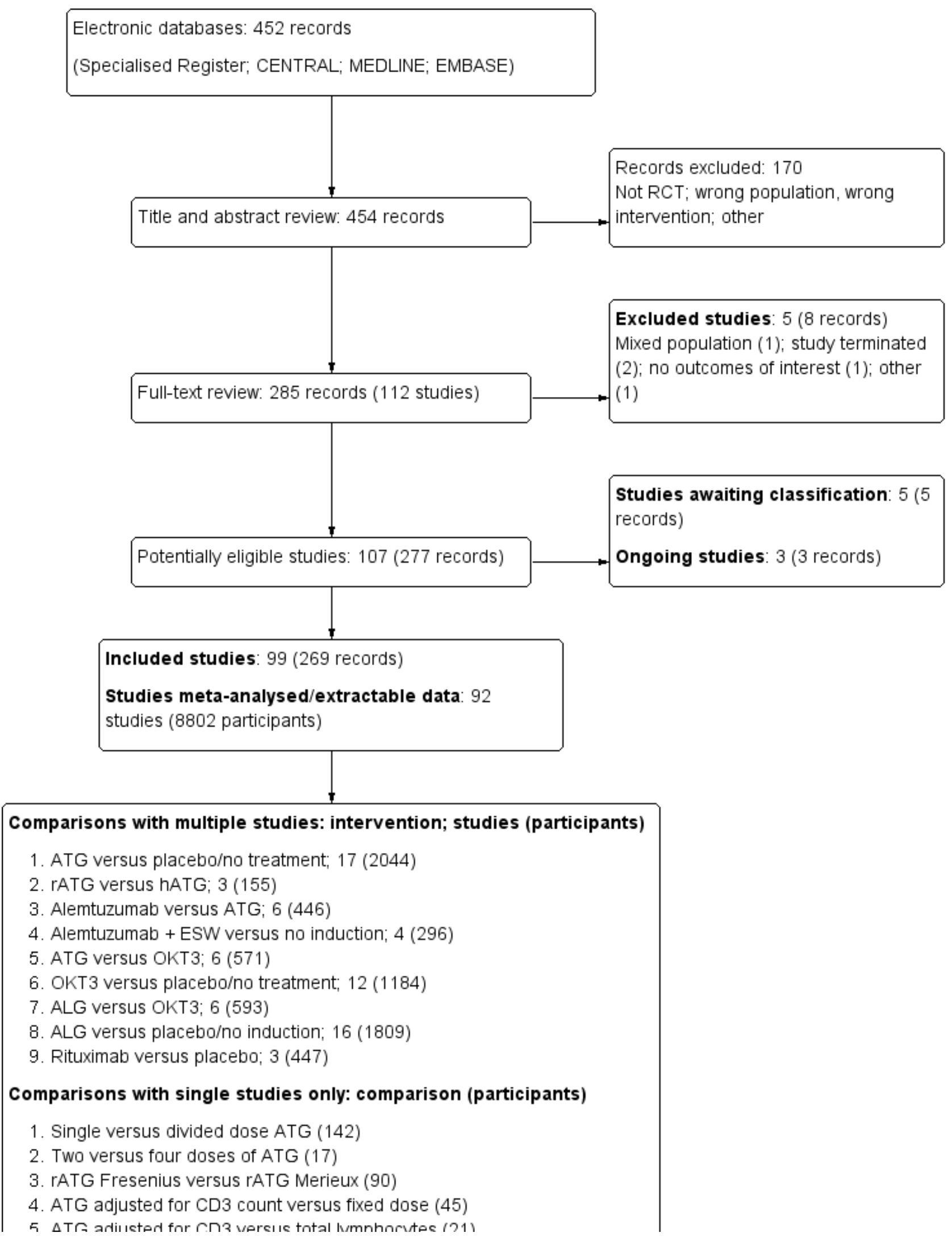


Figure 1. (Continued)

4. ATG adjusted for $\mathrm{CD} 3$ count versus fixed dose (45)

5. ATG adjusted for $\mathrm{CD} 3$ versus total lymphocytes (21)

6. Standard dose ATG versus low dose ATG (43)

7. ATG versus ATG + rituximab versus ATG + bortezomib versus ATG + rituximab + bortezomib (40)

8. OKT3 standard versus low dose (26)

9. OKT3 standard versus high dose (29)

10. ALG versus ATG (50)

11. Anti CD2 rat MAb versus placebo (40)

12. ALG versus OKT3 for delayed graft function (51)

13. Low versus high dose ALG (83)

14. High versus low potency ALG (71)

15. Anti-CD7 versus OKT3 (20)

16. Anti-LFA-1 MAb versus placebo (22)

17. Anti LFA-1 MAb versus ATG (101)

18. ALG 14 versus 7 days (100)

19. Anti-ICAM-1 MAb versus placebo (266)

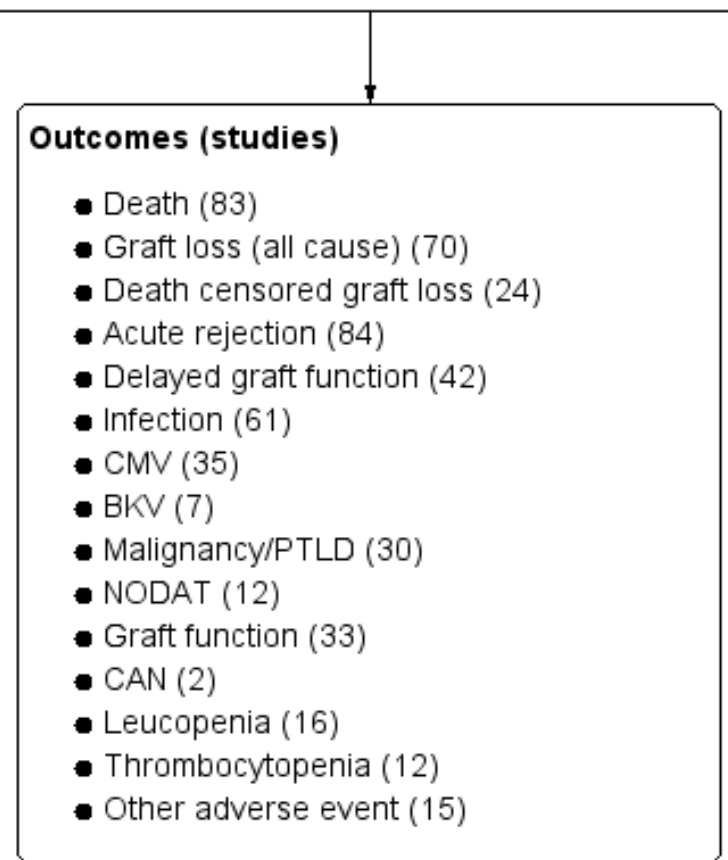

\section{Included studies}

Of the 99 included studies, 92 had data that could be used for metaanalysis and these combined studies represented a total of 8802 randomised participants. ATG was used in 41 studies, alemtuzumab in 11, OKT3 in 27, ALG in 26, rituximab in 3 and other antibodies in 5 studies.

There were 19 comparisons of an antibody versus placebo or antibody versus other antibody that were studied in a single study only. These are briefly discussed in the text below but have not been meta-analysed.

\section{Interventions}

Number of studies (participants) in included studies by comparison 


\begin{tabular}{llllllll} 
& ATG & ALG & $\begin{array}{l}\text { Alemtuzum- } \\
\text { ab }\end{array}$ & Rituximab & oKT3 & Othera & Placebo \\
\cline { 2 - 7 } & & & & & \\
\hline
\end{tabular}


a Includes the following; anti CD2 rat monoclonal antibody, anti CD7 monoclonal antibody, anti-LFA-1 monoclonal antibody, anti-ICAM-1 monoclonal antibody, rituximab combined with ATG, bortezomib combined with ATG, both rituximab and bortezomib combined with ATG.

b Indicates studies comparing different doses or formulations of same agent.

\section{ATG versus placebo/no treatment}

Twelve studies (1491 participants) compared ATG with placebo or no treatment in a CNI-based regimen (Banhegyi 1991; Charpentier 2002; Kasiske 1997; Khosroshahi 2008; Martins 2004; Mourad 1998; Samsel 1999; Sheashaa 2008; Thibaudin 1998; TRIMS Study 2010; van den Hoogen 2013; Yussim 2000), and a further five studies (553 participants) in a non-CNI-based regimen (Cosimi 1976; Diethelm 1979; Kountz 1977; Kreis 1986; Wechter 1979).

\section{Rabbit ATG versus horse ATG}

Three studies (155 participants) compared rATG with hATG in a CNIbased regimen (Bock 1999; Brennan 1999; Rostaing 2010).

\section{ATG versus alemtuzumab}

Six studies (446 participants) compared ATG with alemtuzumab. Four studies had early steroid withdrawal (ESW) or steroid minimisation in both arms in a CNI-based regimen (Farney 2008; Hanaway 2011; Lu 2011; Thomas 2007) and two studies had ESW in the alemtuzumab arm only (Ciancio 2005; Ciancio 2010) and triple maintenance in the ATG groups.

\section{Alemtuzumab versus placebo/no treatment}

Four studies (296 participants) compared alemtuzumab with placebo or no treatment. Three of four studies used ESW with either single or double agent maintenance immunosuppression in the alemtuzumab group (CAMPASIA Study 2005; Margreiter 2008; Sharaf El Din 2006) versus triple therapy maintenance in the control group, and one study (Friend 1987) used ESW and single agent CSA maintenance in both groups.

\section{Rituximab versus placebo}

Three studies (447 participants) compared rituximab with placebo (Smeekens 2013; Tsai 2012; Tyden 2009).

\section{ATG versus OKT3}

Six studies (571 participants) compared ATG with OKT3 (Bock 1995; Cole 1994; Fukuuchi 1996; Kumar 1998a; Perez-Tamajon 1996; Raffaele 1991). Maintenance immunosuppression was CNI-based triple therapy and the same in both arms for all six studies.

\section{OKT3 versus placebo/no treatment}

Twelve studies (1184 participants) compared OKT3 with placebo or no treatment (Abramowicz 1992; Ackermann 1988; Benfield 1999; Debure 1987; De Pauw 1990; Henry 2001; Kreis 1986; Morales 1994a; Norman 1988; Norman 1993; Shield 1993; Vigeral 1986).

\section{ALG versus OKT3}

Polyclonal and monoclonal antibodies for induction therapy in kidney transplant recipients (Review)

Copyright (c) 2017 The Cochrane Collaboration. Published by John Wiley \& Sons, Ltd.
Six studies (593 participants) compared ALG with OKT3 (Broyer 1993; Frey 1991; Grino 1991; Hanto 1991; Niaudet 1990; Vela 1994).

\section{ALG versus placebo/no treatment}

Sixteen studies (1809 participants) compared ALG with placebo or no treatment (Belitsky 1991; Bell 1983; Cantarovich 2008; Condie 1985; Gianello 1987; Grundmann 1984; Halloran 1982; Jakobsen 1981; Grino 1990; Launois 1977; Maiorca 1984; Minnesota Study 1982; Novick 1983; Sansom 1976; Slakey 1993; Taylor 1976).

\section{Other antibodies}

Five studies looked at single antibody comparisons each: anti-CD2 rat monoclonal antibody versus placebo (40 participants, Squifflet 1997), anti-CD7 monoclonal antibody versus OKT3 (20 participants, Lazarovits 1993), anti-LFA-1 monoclonal antibody versus placebo (22 participants, Spillner 1998), anti-LFA-1 monoclonal antibody versus ATG (101 participants, Hourmant 1996), and anti-ICAM-1 monoclonal antibody versus placebo (266 participants, EARTS Study 1999). One small pilot study compared ATG with 3 other combination induction regimens; ATG + rituximab, ATG + bortezomib; ATG + rituximab + bortezomib (40 participants, Ejaz 2013).

\section{Other comparisons}

A further thirteen studies looked at other ATG, OKT3 or ALG comparisons but each of these had only a single study for each comparison. The ATG studies were:

- Single versus divided dose ATG (142 participants, Stevens 2008)

- Two versus four doses (same total) of ATG (17 participants, Buchler 2013)

- rATG Fresenius versus rATG Merieux (90 participants, Norrby 1997)

- ATG adjusted for CD3 count versus fixed dose (45 participants, Abouna 1995)

- ATG adjusted for CD3 count versus adjusted for total lymphocyte count (21 participants, Ata 2013)

- standard versus low dose ATG (43 participants, Grafals 2014)

- ATG versus ALG (50 participants, Toledo-Pereyra 1985).

The OKT3 studies were:

- Standard versus low dose (26 participants, Norman 1993a)

- Standard versus high dose (29 participants, Abramowicz 1994)

- OKT3 versus ALG given only for delayed graft function (51 participants, Steinmuller 1991).

The remaining ALG studies were:

- Low versus high dose (83 participants, Sakhrani 1992)

- Low potency versus high potency ALG (71 participants, Thomas 1977)

- Fourteen versus 7 days induction (100 participants, Grundmann 1987).

\section{Reported outcome measures}

The reporting of outcome measures was variable across studies: 83 reported patient death, 70 reported all-cause graft loss and 24 death-censored graft loss while 84 reported acute rejection and 
42 reported delayed graft function (see Figure 1). Acute rejection was reported in a further seven studies but could not be used in meta-analysis as rejection was either reported without actual figures or reported as total number of episodes rather than number of participants. Graft function was reported at a variety of time points in 33 studies. Some studies reporting graft function could not be included in meta-analysis as there was no SD or SE reported. Reporting of harms was more limited and inconsistent among studies. Participants with any serious infection were reported in $61(66 \%)$ studies, however a further 7 studies also assessed infection, but expressed their results as 'infectious episodes', or reported no actual figures and so this data could not be easily meaningfully combined. CMV infection was reported in 35 studies and BKV infection in only 7 studies. Malignancy and PTLD were reported in only 30 studies and NODAT in 12 . Haematological effects were reported in very few studies; 16 reported leucopenia and 12 thrombocytopenia. Very small numbers of studies reported other adverse outcomes including serum sickness, tremor, headache, chronic allograft nephropathy (on biopsy) and failure to complete induction therapy.

\section{Excluded studies}

Five studies were excluded (Alloway 1993; Kirsch 2006; Kumar 2002b; NCT00000936; NCT01312064). The reasons for exclusion were:

- Mixed population and data could not be separated (Alloway 1993)

- No outcomes of interest were reported (Kirsch 2006)

- Not a true randomisation (Kumar 2002b)

- Study terminated and no results published (NCT00000936; NCT01312064).

\section{Risk of bias in included studies}

Reporting of details of study methodology was incomplete for the majority of studies. Details are summarised in Figure 2 and Figure 3. 
Figure 2. Risk of bias summary: review authors' judgements about each risk of bias item for each included study.

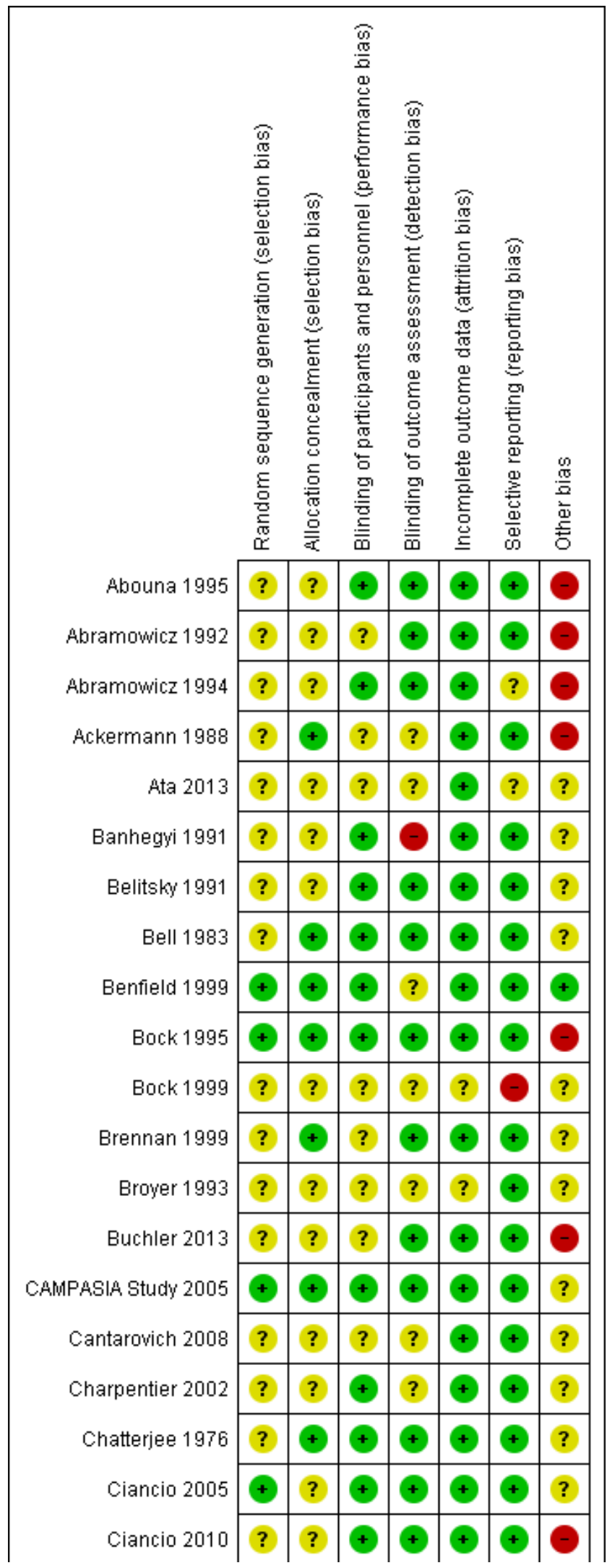


Figure 2. (Continued)

\begin{tabular}{|c|c|c|c|c|c|c|c|}
\hline Ciancio 2010 & $?$ & $?$ & $\odot$ & $\oplus$ & $\oplus$ & $\oplus$ & $\odot$ \\
\hline Cole 1994 & $?$ & $?$ & $\odot$ & $\odot$ & $\oplus$ & $\odot$ & $?$ \\
\hline Condie 1985 & $?$ & $?$ & $\odot$ & $?$ & $\odot$ & $\odot$ & ? \\
\hline Cosimi 1976 & $\odot$ & $\odot$ & $\odot$ & $?$ & $\odot$ & $\odot$ & - \\
\hline Debure 1987 & $\odot$ & - & $\odot$ & $\oplus$ & $\oplus$ & + & $\odot$ \\
\hline De Pauw 1990 & $?$ & $?$ & $?$ & $?$ & $\odot$ & $\odot$ & $?$ \\
\hline Diethelm 1979 & $?$ & $?$ & $?$ & $?$ & + & $\odot$ & $?$ \\
\hline EARTS Study 1999 & + & + & $\odot$ & $\oplus$ & $\oplus$ & $?$ & $?$ \\
\hline Ejaz 2013 & $\odot$ & $\odot$ & $\odot$ & $\odot$ & $\oplus$ & $\odot$ & $\odot$ \\
\hline Farney 2008 & $\odot$ & $\odot$ & $\odot$ & $\odot$ & $\oplus$ & $\odot$ & + \\
\hline Frey 1991 & $?$ & $\odot$ & $\odot$ & $\oplus$ & 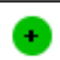 & $\odot$ & + \\
\hline Friend 1987 & + & + & $\odot$ & $?$ & + & $\oplus$ & + \\
\hline Fries 1988a & $?$ & $?$ & $?$ & $?$ & $?$ & $?$ & $?$ \\
\hline Fukuuchi 1996 & $?$ & $?$ & + & + & $\odot$ & $\odot$ & ? \\
\hline Gianello 1987 & $?$ & $?$ & $?$ & $?$ & + & + & - \\
\hline Grafals 2014 & $\odot$ & $\odot$ & $\odot$ & + & $\oplus$ & + & + \\
\hline Grino 1990 & $\odot$ & - & $\odot$ & $\odot$ & $\oplus$ & $?$ & $?$ \\
\hline Grino 1991 & $?$ & $\odot$ & $\odot$ & + & + & + & ? \\
\hline Grundmann 1984 & $?$ & $?$ & $\odot$ & $?$ & $?$ & $?$ & $?$ \\
\hline Grundmann 1987 & $?$ & $?$ & $\odot$ & $?$ & $\odot$ & $?$ & ? \\
\hline Guttmann 1997 & $?$ & $?$ & $?$ & $?$ & ? & - & $\Theta$ \\
\hline Halloran 1982 & + & + & + & + & ? & $\odot$ & + \\
\hline Hanaway 2011 & $?$ & $?$ & $\odot$ & $\oplus$ & $\oplus$ & $\odot$ & + \\
\hline Hanto 1991 & $?$ & $?$ & $\odot$ & + & + & $\odot$ & $?$ \\
\hline Henry 2001 & $\odot$ & $?$ & + & ? & + & - & - \\
\hline Hourmant 1985a & $?$ & $?$ & $?$ & $?$ & $?$ & $\odot$ & $?$ \\
\hline Hourmant 1996 & $?$ & $?$ & $\odot$ & $\oplus$ & + & $\odot$ & $?$ \\
\hline Jakobsen 1981 & $\Theta$ & $\odot$ & $?$ & $?$ & + & + & $?$ \\
\hline Kasiske 1997 & $?$ & $?$ & $\odot$ & + & + & - & $?$ \\
\hline Khosroshahi 2008 & $?$ & $?$ & $\odot$ & ? & 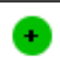 & $\odot$ & - \\
\hline Kounte 1977 & $?$ & $?$ & $\odot$ & $?$ & $?$ & $?$ & 7 \\
\hline
\end{tabular}


Figure 2. (Continued)

\begin{tabular}{|c|c|c|c|c|c|c|c|}
\hline Kountz 1977 & $?$ & $?$ & + & $?$ & $?$ & $?$ & - \\
\hline Kreis 1980 & + & + & 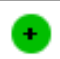 & $?$ & 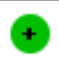 & $\odot$ & $\odot$ \\
\hline Kreis 1986 & $?$ & $?$ & $?$ & $?$ & $?$ & ? & $?$ \\
\hline Kumar 1998a & $?$ & $?$ & $?$ & $?$ & $?$ & $?$ & $?$ \\
\hline Launois 1977 & $?$ & $?$ & + & + & + & + & + \\
\hline Lazarovits 1993 & $?$ & $?$ & $\Theta$ & $\odot$ & + & + & $?$ \\
\hline Lu 2011 & $?$ & $?$ & $\odot$ & $\odot$ & + & $\Theta$ & + \\
\hline Maiorca 1984 & ? & ? & + & ? & ? & - & ? \\
\hline Margreiter 2008 & $?$ & $?$ & + & + & + & $\Theta$ & - \\
\hline Martins 2004 & ? & $?$ & + & ? & ? & - & - \\
\hline Michael 1989 & + & $?$ & + & $?$ & - & - & ? \\
\hline Minnesota Study 1982 & ? & ? & + & + & + & - & ? \\
\hline Morales 1994a & $?$ & $?$ & + & $?$ & ? & $\Theta$ & ? \\
\hline Mourad 1998 & $\odot$ & + & $\odot$ & $\odot$ & ? & + & $\odot$ \\
\hline Niaudet 1990 & $?$ & $?$ & + & + & + & + & ? \\
\hline Norman 1988 & ? & ? & + & + & - & $\Theta$ & ? \\
\hline Norman 1993 & ? & ? & + & + & ? & + & $\odot$ \\
\hline Norman 1993a & $?$ & $\odot$ & + & + & + & $\Theta$ & ? \\
\hline Norrby 1997 & ? & ? & + & + & $\odot$ & - & ? \\
\hline Novick 1983 & $?$ & + & + & + & ? & + & + \\
\hline Perez-Tamajon 1996 & $?$ & $?$ & + & + & + & $\odot$ & $?$ \\
\hline Pernin 2012 & $?$ & $?$ & $?$ & $?$ & $\Theta$ & - & - \\
\hline Raffaele 1991 & ? & $?$ & + & $?$ & + & $\odot$ & ? \\
\hline Rostaing 2010 & $?$ & $?$ & + & + & $\odot$ & + & $?$ \\
\hline Sakhrani 1992 & $?$ & $?$ & $?$ & $?$ & $?$ & - & $?$ \\
\hline Samsel 1999 & ? & ? & + & ? & + & + & ? \\
\hline Sansom 1976 & ? & ? & $?$ & ? & - & - & ? \\
\hline Sharaf EI Din 2006 & ? & $?$ & + & $?$ & $?$ & ? & ? \\
\hline Sheashaa 2008 & ? & $\odot$ & + & + & + & + & ? \\
\hline Shield 1993 & - & - & + & + & - & - & ? \\
\hline Slakey 1993 & ? & ? & + & + & + & + & $?$ \\
\hline
\end{tabular}


Figure 2. (Continued)

\begin{tabular}{|c|c|c|c|c|c|c|c|}
\hline Slakey 1993 & $?$ & $?$ & + & + & $\oplus$ & $\odot$ & $?$ \\
\hline Smeekens 2013 & + & + & $\oplus$ & $\odot$ & 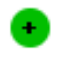 & $\odot$ & + \\
\hline Spillner 1998 & $?$ & $?$ & $\oplus$ & $\odot$ & $\odot$ & $\odot$ & $?$ \\
\hline Squifflet 1997 & $?$ & $?$ & + & + & + & $\odot$ & - \\
\hline Steinmuller 1991 & $?$ & $?$ & $\odot$ & + & $?$ & $\odot$ & $?$ \\
\hline Stevens 2008 & $\odot$ & $\odot$ & + & $\odot$ & + & $\Theta$ & $?$ \\
\hline Taylor 1976 & + & + & $\oplus$ & $?$ & $\odot$ & $\Theta$ & $\odot$ \\
\hline Thibaudin 1998 & $?$ & $?$ & + & $?$ & + & + & $?$ \\
\hline Thomas 1977 & $\odot$ & $?$ & + & $\odot$ & ? & $\Theta$ & $\odot$ \\
\hline Thomas 2007 & $?$ & $?$ & + & $\odot$ & $\odot$ & $\odot$ & $?$ \\
\hline Toledo-Pereyra 1985 & $?$ & $?$ & $\oplus$ & $\odot$ & + & $\odot$ & ? \\
\hline TRIMS Study 2010 & $?$ & $?$ & + & + & + & + & $\odot$ \\
\hline Tsai 2012 & $?$ & $?$ & + & + & $?$ & $\odot$ & + \\
\hline Turcotte 1973 & $\odot$ & + & + & $\odot$ & $\odot$ & $\odot$ & $?$ \\
\hline Tyden 2009 & $?$ & + & + & + & $?$ & + & $\Theta$ \\
\hline van den Hoogen 2013 & + & + & $?$ & $?$ & + & $\odot$ & - \\
\hline Vela 1994 & $?$ & $?$ & + & $\oplus$ & + & + & $?$ \\
\hline Vigeral 1986 & $?$ & $?$ & + & $?$ & $\odot$ & + & $\Theta$ \\
\hline Wechter 1979 & $?$ & $?$ & + & $\odot$ & $?$ & + & $\odot$ \\
\hline Yussim 2000 & $?$ & $?$ & $\odot$ & $\oplus$ & $\oplus$ & $\odot$ & $?$ \\
\hline
\end{tabular}


Figure 3. Risk of bias graph: review authors' judgements about each risk of bias item presented as percentages across all included studies.

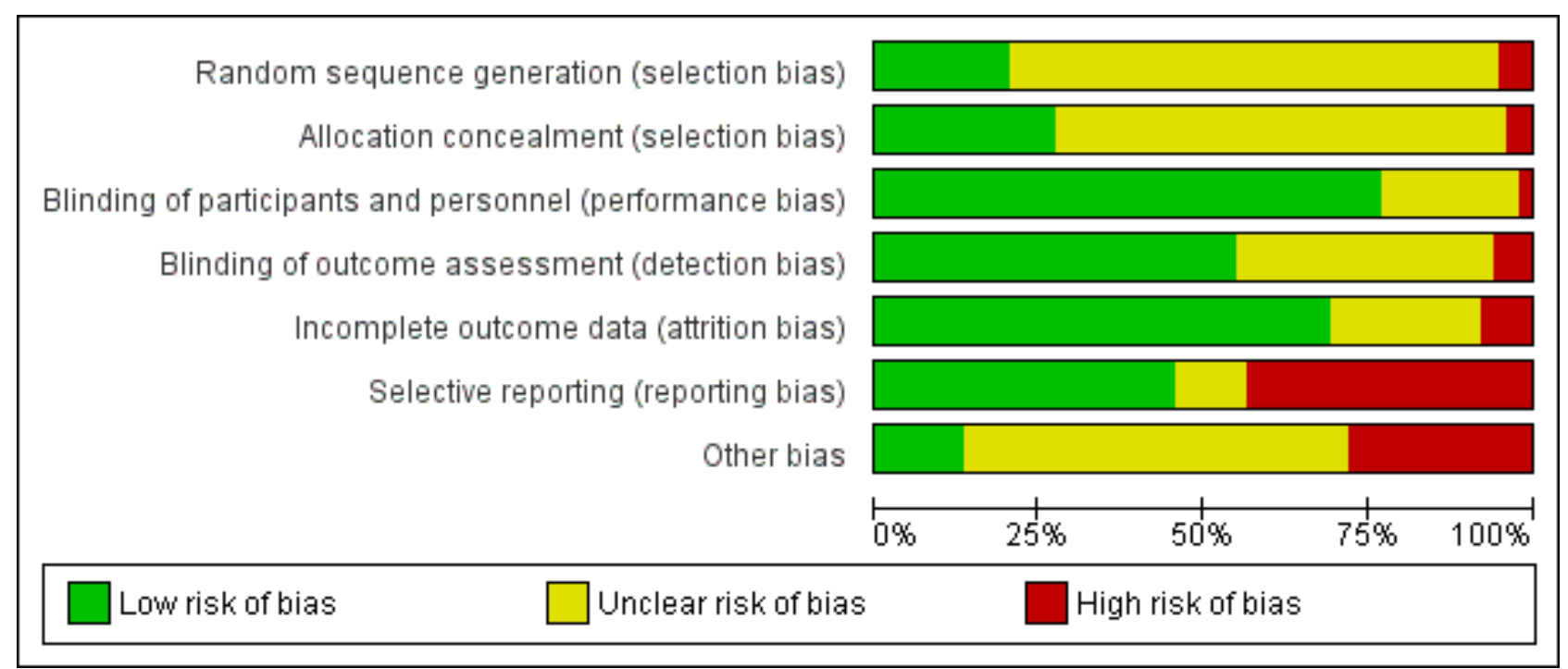

\section{Allocation}

Twenty studies reported adequate sequence generation, and 27 reported adequate allocation concealment. Five studies used inadequate methods of sequence generation and four used inadequate allocation concealment. The remainder (74 studies for sequence generation and 68 for allocation concealment) used unclear methodology.

\section{Blinding}

Seventy-six studies adequately reported blinding of participants and personnel, and 54 studies adequately reported blinding of outcome assessment. Two studies had inadequate blinding of participants and personnel and six studies had inadequate blinding of outcome assessment. The remainder had unclear methods.

\section{Incomplete outcome data}

Incomplete outcome data was adequately addressed in 68 studies, and inadequately in eight studies. The remainder were unclear.

\section{Selective reporting}

Forty-five studies were free of selective reporting, 43 studies were inadequate, while the remainder of studies were unclear.

\section{Other potential sources of bias}

Thirteen studies declared their funding source to be independent or academic funding body, and so were judged free of other potential biases. Twenty-eight studies were deemed to be high risk of other bias due to funding from a pharmaceutical company or author links to industry or other reasons not covered by above bias assessments. Others did not disclose the funding source of the study or gave limited information about funding and were judged unclear.

\section{Effects of interventions}

See: Summary of findings for the main comparison; Summary of findings 2

Polyclonal and monoclonal antibodies for induction therapy in kidney transplant recipients (Review)

Copyright @ 2017 The Cochrane Collaboration. Published by John Wiley \& Sons, Ltd.

\section{ATG versus placebo/no induction treatment}

ATG had little or no effect on death at 1 to 2 years compared to placebo or no treatment in older studies without CNI maintenance (Analysis 1.1.3 (6 studies, 621 participants): RR 1.03, 95\% Cl 0.86 to $\left.1.22 ; 1^{2}=0 \%\right)$ and uncertain effect in more contemporary studies including CNI maintenance (Analysis 1.1.2 (5 studies, 632 participants): RR $0.75,95 \% \mathrm{Cl} 0.27$ to $\left.2.06 ; 1^{2}=0 \%\right)$. In the CNI studies, there was also uncertain effect on death at 3 to 6 months (Analysis 1.1 .1 (3 studies, 523 participants): RR 0.41, 95\% Cl 0.13 to $1.22 ; 1^{2}=0 \%$ ) and at 5 years (Analysis 1.1 .4 (2 studies, 159 participants): RR $0.94,95 \% \mathrm{Cl} 0.11$ to $7.81 ;\left.\right|^{2}=48 \%$ ).

Treatment with ATG had uncertain effect on all-cause graft loss in CNI studies at 3 to 6 months (Analysis 1.2 .1 (4 studies, 638 participants): RR $0.60,95 \% \mathrm{Cl} 0.34$ to $\left.1.05 ; \mathrm{I}^{2}=0 \%\right)$, at 1 to 2 years (Analysis 1.2.2 (3 studies, 549 participants): RR 0.65, 95\% Cl 0.36 to $1.19 ;\left.\right|^{2}=6 \%$ ) and at 5 years (Analysis 1.2.4 ( 2 studies, 159 participants): RR $1.13,95 \% \mathrm{Cl} 0.62$ to $2.05 ; 12=0 \%$ ). However, ATG reduced graft loss in the non-CNI studies at 1 to 2 years (Analysis 1.2 .3 (4 studies, 500 participants): RR $0.70,95 \% \mathrm{Cl} 0.49$ to $1.01 ; \mathrm{I}^{2}=$ $50 \%$ ). When $\mathrm{CNI}$ and non-CNI studies were combined, ATG reduced all-cause graft loss at 1 to 2 years (Analysis 1.2.5 (7 studies, 1049 participants): RR $0.71,95 \% \mathrm{Cl} 0.53$ to $\left.0.95 ;\left.\right|^{2}=35 \%\right)$.

Death-censored graft loss was reduced at 1 to 2 years in non-CNI studies (Analysis 1.3.2 (6 studies, 299 participants): RR 0.55, 95\% Cl 0.38 to $0.78 ; 1^{2}=0 \%$ ) but there was uncertain effect in CNI studies at 2 years (Analysis 1.3.1 (2 studies, 82 participants): RR 0.57, 95\% $\mathrm{Cl} 0.19$ to $1.75 ; \mathrm{I}^{2}=0 \%$ ) and at 5 years (Analysis 1.3 .3 (2 studies, 148 participants): RR $1.64,95 \% \mathrm{Cl} 0.20$ to $13.18 ; \mathrm{I}^{2}=71 \%$ ). Again, if $\mathrm{CNI}$ and non-CNI studies were combined then death censored graft loss was significantly reduced with ATG at 1 to 2 years (Analysis 1.3 .4 (8 studies, 381 participants): RR $0.55,95 \% \mathrm{Cl} 0.39$ to $0.77 ;\left.\right|^{2}=0 \%$ ).

ATG prevented acute rejection (Analysis 1.4 (17 studies, 2044 participants): $\mathrm{RR} 0.63,95 \% \mathrm{Cl} 0.51$ to $\left.0.78 ; \mathrm{I}^{2}=65 \%\right)$. The relative reduction in risk of rejection was similar in studies including $\mathrm{CNI}$ maintenance (Analysis 1.4.1 (12 studies, 1491 participants): RR 0.61, 
$95 \% \mathrm{Cl} 0.49$ to $0.76 ; 1^{2}=35 \%$ ) compared to non-CNI studies (Analysis 1.4.2 (5 studies, 553 participants): RR $0.65,95 \% \mathrm{Cl} 0.43$ to $0.98 ; \mathrm{I}^{2}=$ $73 \%)\left(P=0.79 ;\left.\right|^{2}=0 \%\right.$ for subgroup analysis $)$.

ATG had little or no effect on delayed graft function (Analysis 1.5 (9 studies, 1304 participants): RR $0.93,95 \% \mathrm{Cl} 0.78$ to $1.10 ; \mathrm{I}^{2}=0 \%$ ).

ATG increased CMV infection (Analysis 1.6.2 (6 studies, 1072 participants): $\mathrm{RR} 1.55, \mathrm{Cl} 1.24$ to $1.95 ; \mathrm{I}^{2}=0 \%$ ) but had uncertain effects on all-cause viral infection (Analysis 1.6.4 (3 studies, 197 participants): RR $1.38,95 \% \mathrm{Cl} 0.56$ to $3.39 ; \mathrm{I}^{2}=46 \%$ ) and bacterial infection (Analysis 1.6.5 (5 studies, 775 participants): RR 1.15, 95\% $\mathrm{Cl} 0.96$ to $\left.1.37 ;\left.\right|^{2}=0 \%\right)$.

Leucopenia (Analysis 1.7 (4 studies, 920 participants): RR 3.86, 95\% $\mathrm{Cl} 2.79$ to $5.34 ; \mathrm{I}^{2}=0 \%$ ) and thrombocytopenia (Analysis 1.8 (4 studies, 848 participants): $\mathrm{RR} 2.41,95 \% \mathrm{Cl} 1.61$ to $3.61 ;\left.\right|^{2}=0 \%$ ) were both increased by ATG.

ATG had uncertain effects on both early malignancy at 1 to 2 years (Analysis 1.9.1 (3 studies, 611 participants): RR $0.94,95 \% \mathrm{Cl} 0.22$ to $3.94 ; 1^{2}=0 \%$ ) and on late malignancy at 5 years (Analysis $1.9 .2(2$ studies, 159 participants): RR $0.94,95 \% \mathrm{Cl} 0.14$ to $6.23 ; 12=0 \%$ ). The single study (151 participants) that reported PTLD had no events at 1 year in either arm (Analysis 1.9).

ATG had uncertain effect on development of NODAT (Analysis 1.10.1 (6 studies, 935 participants): RR $1.01,95 \% \mathrm{Cl} 0.56$ to $1.84 ; \mathrm{I}^{2}=39 \%$ ).

There was no difference in $\mathrm{SCr}$ at 6 months (Analysis 1.11 .1 (2 studies, 503 participants): MD $-5.34 \mu \mathrm{mol} / \mathrm{L}, 95 \% \mathrm{Cl}-13.44$ to 2.75 ; $\mathrm{I}^{2}=0 \%$ ), 1 year (Analysis 1.11 .2 (2 studies, 222 participants): MD $-10.56 \mu \mathrm{mol} / \mathrm{L}, 95 \% \mathrm{Cl}-21.81$ to 0.69 ) or 5 years (Analysis 1.11 .5 (1 study, 55 participants): MD $-32.70 \mu \mathrm{mol} / \mathrm{L}, 95 \% \mathrm{Cl}-68.98$ to 3.58) following ATG therapy in studies including CNI maintenance. There was also no difference in $\mathrm{SCr}$ at 1 year in the single non CNI study that assessed graft function (Turcotte 1973). Graft function measured by eGFR was only assessed in one study (Sheashaa 2008) and was similar between treatment groups at 5 years ( 1 study, 71 participants: $\mathrm{MD} 4.80 \mathrm{~mL} / \mathrm{min}, 95 \% \mathrm{Cl}-2.57$ to 12.17 ).

\section{Rabbit ATG versus horse ATG}

There was sparse data for meta-analyses comparing rATG versus hATG. rATG had uncertain effects on death at 1 year (Analysis 2.1.1 ( 2 studies, 139 participants): RR $0.41,95 \% \mathrm{Cl} 0.07$ to $2.30 ; \mathrm{I}^{2}=$ $0 \%$ ) and on long-term death at 10 years (Analysis 2.2.2 (1 study, 72 participants): $\mathrm{RR} 0.75,95 \% \mathrm{Cl} 0.35$ to 1.59 ) compared to hATG. The effect on all-cause graft loss was also uncertain at both 1 year (Analysis 2.1.3 (2 studies, 139 participants: RR $0.31,95 \% \mathrm{Cl}$ 0.08 to $1.27 ; I^{2}=14 \%$ ) and at 10 years (Analysis 2.1.4 ( 1 study, 72 participants: RR $0.96,95 \% \mathrm{Cl} 0.58$ to 1.58$)$.

rATG prevented acute rejection ( 2 studies, 88 participants: RR 0.17 , $95 \% \mathrm{Cl} 0.04$ to 0.76 ) compared to hATG although one study reported no events (Rostaing 2010).

Single studies reported uncertain effects of rATG compared to hATG with respect to delayed graft function (Rostaing 2010) (Analysis 2.1.7, 16 participants: RR $0.50,95 \% \mathrm{Cl} 0.06$ to 4.47 ), all-cause infection (Rostaing 2010) (Analysis 2.2.1, 16 participants: RR 1.67, $95 \% \mathrm{Cl} 0.59$ to 4.73 ), and malignancy (Brennan 1999) (Analysis 2.2.4, 72 participants: RR $0.40,95 \% \mathrm{Cl} 0.12$ to 1.35 ).
Brennan 1999 reported CMV disease was reduced with rATG at 1 year (Analysis 2.2.2, 72 participants: RR $0.38,95 \% \mathrm{Cl} 0.15$ to 0.96 ), more leucopenia with rATG compared to hATG (analysis 2.2.3, 72 participants: RR $13.50,95 \% \mathrm{Cl} 1.95$ to 93.46 ), and graft function was better at 10 years with a lower SCr in the hATG group (Analysis 2.3, 35 participants: MD $44.0 \mu \mathrm{mol} / \mathrm{L}, 95 \% \mathrm{Cl} 20.41$ to 67.59 ).

\section{Alemtuzumab versus ATG}

The effects of alemtuzumab (with ESW or minimisation) compared to ATG on death were uncertain both at 1 year (Analysis 3.1.1 (2 studies, 41 participants): RR $0.39,95 \% \mathrm{Cl} 0.06$ to $2.42 ; 1^{2}=0 \%$ ) and at 2 to 3 years (Analysis 3.1.2 (3 studies, 225 participants): RR 0.67, 95\% $\mathrm{Cl} 0.15$ to $2.95 ; \mathrm{I}^{2}=33 \%$ ). Similarly, alemtuzumab had uncertain effect on all-cause graft loss at 1 year (Analysis 3.1.3 (2 studies, 41 participants): $\mathrm{RR} 0.39,95 \% \mathrm{Cl} 0.12$ to $1.30 ; \mathrm{I}^{2}=0 \%$ ) and at 2 to 3 years (Analysis 3.1.4 (3 studies, 379 participants): RR 0.98, 95\% Cl 0.47 to 2.06; $\mathrm{I}^{2}=42 \%$ ) and on death-censored graft loss at 1 year (Analysis 3.1.5 (2 studies, 37 participants): RR $0.38,95 \% \mathrm{Cl} 0.08$ to $1.81 ;\left.\right|^{2}=$ $0 \%$ ) and at 2 to 3 years (Analysis 3.1.6 (2 studies, 186 participants): RR $2.45,95 \% \mathrm{Cl} 0.67$ to $8.97 ; \mathrm{I}^{2}=17 \%$ ) compared to ATG. There was also uncertain effect of alemtuzumab versus ATG on delayed graft function (Analysis 3.1.7 (2 studies, 86 participants): RR $0.62,95 \% \mathrm{Cl}$ 0.13 to $\left.3.07 ;\left.\right|^{2}=0 \%\right)$.

Alemtuzumab had uncertain effect on acute rejection in the first 6 months (Analysis 3.2.1 (3 studies, 341 participants): RR 0.47, 95\% $\mathrm{Cl} 0.17$ to $\left.1.30 ; \mathrm{I}^{2}=32 \%\right)$ and at 1 year or more (Analysis $3.2 .2(6$ studies, 446 participants: RR $0.68,95 \% \mathrm{Cl} 0.44$ to $\left.1.05 ; \mathrm{I}^{2}=0 \%\right)$. Two of these 6 studies favoured ATG (Ciancio 2005; Ciancio 2010) while the other four favoured alemtuzumab (Farney 2008; Hanaway 2011; Lu 2011; Thomas 2007). This difference may be explained by ESW in the alemtuzumab group but not the ATG group in two studies (Ciancio 2005; Ciancio 2010), compared to ESW in both arms in the other four studies. Subgroup analysis of these four studies showed acute rejection was reduced at 1 year and beyond by alemtuzumab compared to ATG in studies with ESW in both arms (Analysis 3.2.3 (4 studies, 360 participants: RR $0.57,95 \% \mathrm{Cl} 0.35$ to $0.93 ; 1^{2}=0 \%$ ) (test for subgroup differences, $P=0.13$ ). Subgroup analysis of the two studies with alemtuzumab plus ESW versus ATG and steroid continuation showed the effect of alemtuzumab and ESW on acute rejection at 1 year was uncertain (Analysis 3.2.4 (2 studies, 86 participants): RR $1.27,95 \% \mathrm{Cl} 0.50$ to $3.19 ; \mathrm{I}^{2}=0 \%$ ). The results of all outcomes other than acute rejection were not significantly altered when subgroup analysis was done including only studies with steroid avoidance in both the alemtuzumab and ATG arms.

There was an increased rate of chronic allograft nephropathy (CAN) on biopsy with alemtuzumab plus ESW but this was only assessed in the 2 studies that had triple maintenance immunosuppression in the ATG arms (Analysis 3.2.5 (2 studies, 86 participants): RR $2.64,95 \% \mathrm{Cl} 1.09$ to $\left.6.36 ; 1^{2}=0 \%\right)$. The classification of CAN is a historical one, present in the original Banff 1997 diagnostic categories (Racusen 1999) but removed in the 2005 update (Solez 2007).

Alemtuzumab had uncertain effect on all-cause infection (Analysis 3.3.1 (4 studies, 247 participants): RR $0.94,95 \% \mathrm{Cl} 0.63$ to $1.41 ; \mathrm{I}=$ $0 \%$ ), CMV infection (Analysis 3.3.2 (3 studies, 225 participants): RR $1.08,95 \% \mathrm{Cl} 0.46$ to $2.56 ; \mathrm{I}^{2}=0 \%$ ), and BKV infection (Analysis 3.3 .3 
(2 studies, 86 participants: RR $3.0095 \% \mathrm{Cl} 0.13$ to $70.83 ; \mathrm{I}^{2}=0 \%$ ), when compared to ATG.

Risk of leucopenia was assessed in one study (Ciancio 2005) and was increased at one month with alemtuzumab compared to ATG (Analysis 3.4.1 (60 participants): RR 21.00, 95\% Cl 1.29 to 342.93 ) but not at two years (Analysis 3.4.2 (53 participants): RR 3.12, 95\% Cl 0.13 to 70.83 )

The effect of alemtuzumab plus ESW and dual maintenance (tacrolimus and mycophenolate) versus ATG and triple maintenance (CNI, steroid and either azathioprine or mycophenolate) on NODAT was uncertain (Analysis 3.4.3 (2 studies, 69 participants): $\mathrm{RR} 0.41,95 \% \mathrm{Cl} 0.12$ to $1.40 ; \mathrm{I}^{2}=0 \%$ ).

There was uncertain effect of alemtuzumab compared to ATG for other harms including malignancy (Analysis 3.4.4 (3 studies, 187 participants): RR $4.93,95 \% \mathrm{Cl} 0.59$ to 41.11 ), PTLD (Analysis 3.4 .5 ( 2 studies, 165 participants): no events), cytokine release syndrome (Analysis 3.4.6 (1 study, 22 participants): RR $0.20,95 \% \mathrm{Cl} 0.01$ to 3.74), or occurrence of any serious adverse event (Analysis 3.4.7 (1 study, 139 participants): RR $0.81,95 \% \mathrm{Cl} 0.59$ to 1.12 ).

Graft function measured by $\mathrm{CrCl}$ was lower with alemtuzumab plus ESW and dual maintenance at six months (Analysis 3.5.1 (2 studies, 83 participants): $\mathrm{MD}-13.35 \mathrm{~mL} / \mathrm{min}, 95 \% \mathrm{Cl}-23.91$ to $\left.-2.80 ; \mathrm{I}^{2}=0 \%\right)$ and two years (Analysis 3.5.2 (2 studies, 77 participants): MD -12.86 $\mathrm{mL} / \mathrm{min}, 95 \% \mathrm{Cl}-23.73$ to $-2.00 ; 12=0 \%$ ) compared to ATG plus triple maintenance.

\section{Alemtuzumab (and ESW) versus no induction}

Three of the four studies used triple maintenance immunosuppression including steroids in the control group (CAMPASIA Study 2005; Margreiter 2008; Sharaf El Din 2006), Friend 1987 used only CSA. Sensitivity analyses excluding Friend 1987 did not significantly alter the summary risk ratio for any outcomes for the remaining studies. Results are therefore reported including all four studies.

Alemtuzumab and ESW had uncertain effect on death (Analysis 4.1.1 (4 studies, 296 participants): RR $1.54,95 \% \mathrm{Cl} 0.60$ to 4.00 ; $1^{2}=0 \%$ ) and all-cause graft loss (Analysis 4.1.2 (4 studies, 296 participants): RR $0.86,95 \% \mathrm{Cl} 0.47$ to $1.59 ; \mathrm{I}^{2}=0 \%$ ) at 6 to 12 months compared to no induction.

Alemtuzumab and ESW had little or no effect on acute rejection within 6 months compared with no induction (Analysis 4.1.3 (3 studies, 213 participants): $\mathrm{RR} 0.72,95 \% \mathrm{Cl} 0.48$ to $1.08 ; 1^{2}=0 \%$ ) and had uncertain effect at 1 year or later (Analysis 4.1.4 (4 studies, 244 participants): RR $0.89,95 \% \mathrm{Cl} 0.42$ to $\left.1.87 ;\left.\right|^{2}=32 \%\right)$.

CAMPASIA Study 2005 showed uncertain effects of alemtuzumab on delayed graft function (Analysis 4.1.5 (30 participants): RR 2.00, 95\% $\mathrm{Cl} 0.26$ to 15.62 )

The risk of CMV infection was increased with alemtuzumab (Analysis 4.2.1 (2 studies, 161 participants): RR 2.28, 95\% Cl 1.18 to $4.40 ; 1^{2}=0 \%$ ) compared with control.

The effect of alemtuzumab was imprecise for all-cause infection (Analysis 4.2.2 (3 studies, 213 participants): RR 1.15, 95\% Cl 0.46 to 2.89; $\left.\right|^{2}=71 \%$ ), NODAT (Analysis 4.2 .3 ( 2 studies, 161 participants):
RR $0.57,95 \% \mathrm{Cl} 0.13$ to $2.46 ; 1^{2}=0 \%$ ), and thrombocytopenia (Analysis 4.2 .4 (1 study, 30 participants): RR $1.33,95 \% \mathrm{Cl} 0.45$ to 3.96). Malignancy and PTLD were assessed in CAMPASIA Study 2005 and there were no events reported in either group.

There was little or no effect on graft function measured by $\mathrm{SCr}$ with alemtuzumab and ESW compared to no induction both at 6 months (Analysis 4.3.1 (1 study, 27 participants): MD $-5.00 \mu \mathrm{mol} /$ L, $95 \% \mathrm{Cl}-28.90$ to 18.90 ) and 1 year (Analysis 4.3 .2 (2 studies, 108 participants): $\mathrm{MD}-2.89 \mu \mathrm{mol} / \mathrm{L}, 95 \% \mathrm{Cl}-43.29$ to $37.52 ; \mathrm{I}^{2}=0 \%$ ).

\section{Rituximab versus placebo}

Only death and acute rejection were reported in all three studies comparing rituximab versus placebo.

Rituximab had uncertain effect on death both at 6 months (Analysis 5.1.1 (3 studies, 447 participants): RR 0.55 , 95\% Cl 0.18 to $1.71 ; 1^{2}=$ $0 \%$ ) and at 3 to 4 years (Analysis 5.1.2 (2 studies, 381 participants): RR $2.06,95 \% \mathrm{Cl} 0.27$ to $15.64 ;\left.\right|^{2}=74 \%$ ) when compared to placebo.

There was uncertain effects of rituximab on all-cause graft loss (Analysis 5.1.3 (2 studies, 416 participants): RR $0.58,95 \% \mathrm{Cl} 0.26$ to $1.28 ; 1^{2}=0 \%$ ) and death-censored graft loss (Analysis 5.1.4 (2 studies, 405 participants): RR $0.55,95 \% \mathrm{Cl} 0.21$ to $1.46 ; \mathrm{I}=0 \%$ ) at 6 months.

Acute rejection was not reduced at 6 months with rituximab compared to placebo (Analysis 5.1.5 (3 studies, 447 participants): RR $0.73,95 \% \mathrm{Cl} 0.48$ to $1.10 ; 12=0 \%)$.

Leucopenia at 6 months was increased (Analysis 5.2.4 (2 studies, 416 participants): $\mathrm{RR} 8.15,95 \% \mathrm{Cl} 2.00$ to $33.15 ; \mathrm{I}^{2}=21 \%$ ) with rituximab compared to placebo.

The effect of rituximab on CMV infection, BKV infection, fungal infection and malignancy was also uncertain (Analysis 5.2).

There was little or no effect of rituximab on graft function (eGFR) at 6 months (Analysis 5.3 (2 studies, 388 participants): MD $0.32 \mathrm{~mL}$ / $\min , 95 \% \mathrm{Cl}-3.34$ to $\left.3.97 ; \mathrm{I}^{2}=0 \%\right)$.

\section{ATG versus OKT3}

ATG had uncertain effect on death at 6 to 12 months compared with OKT3 (Analysis 6.1 .1 (5 studies, 451 participants): RR 1.29, 95\% Cl 0.64 to $2.60 ;\left.\right|^{2}=0 \%$ ) and no effect on death-censored graft loss at 6 to 12 months (Analysis 6.1 .2 (5 studies, 439 participants): RR 1.00, $95 \% \mathrm{Cl} 0.64$ to $\left.1.57 ; 1^{2}=0 \%\right)$.

There was little or no effect on acute rejection with ATG compared to OKT3 at 1 year (Analysis 6.1.3 (4 studies, 450 participants): RR 0.76, $95 \% \mathrm{Cl} 0.53$ to $1.09 ; 1^{2}=67 \%$ ) and on delayed graft function (Analysis 6.1.4 (3 studies, 235 participants): RR $0.80,95 \% \mathrm{Cl} 0.52$ to $1.24 ; \mathrm{I}^{2}=$ $0 \%)$.

ATG had no effect compared to OKT3 on CMV infection (Analysis 6.2.1 (3 studies, 274 participants): RR $1.13,95 \% \mathrm{Cl} 0.88$ to 1.46 ; $1^{2}=4 \%$ ) and uncertain effects on bacterial infection (Analysis 6.2 .2 (1 study, 50 participants): RR $0.51,95 \% \mathrm{Cl} 0.20$ to 1.32 ), leucopenia (Analysis 6.2.3 (1 study, 104 participants): RR 1.92, 95\% $\mathrm{Cl} 0.78$ to 4.74 ), thrombocytopenia (Analysis 6.2.4 (1 study, 104 participants): RR $4.81,95 \% \mathrm{Cl} 0.24$ to 97.91 ), and the inability to complete induction due to side effects (Analysis 6.2.6 (2 studies, 131 
participants): RR $1.96,95 \% \mathrm{Cl} 0.10$ to $39.72 ; \mathrm{I}^{2}=50 \%$ ). Malignancy was only reported in Bock 1995 and there were no events reported in either group (Analysis 6.2.5).

Bock 1995 reported ATG had uncertain effects compared to OKT3 on graft function at 1 year $(\mathrm{SCr}$ ) (Analysis 6.3 (88 participants): MD $0.00 \mu \mathrm{mol} / \mathrm{L}, 95 \% \mathrm{Cl}-3.56$ to 3.56$)$.

\section{OKT3 versus placebo/no treatment}

A reduction in death was seen with OKT 3 compared to no induction at 1 to 2 years (Analysis 7.1.1 (6 studies, 491 participants): RR 0.41, $95 \% \mathrm{Cl} 0.18$ to $0.97 ; \mathrm{I}^{2}=0 \%$ ) but the benefit was uncertain at 3 to 5 years (Analysis 7.1 .2 ( 5 studies, 768 participants): RR $0.72,95 \% \mathrm{Cl}$ 0.37 to $\left.1.44 ;\left.\right|^{2}=38 \%\right)$.

The effect of OKT3 compared to no induction on graft loss was uncertain both at 1 to 2 years (Analysis 7.1 .3 (7 studies, 416 participants): $\mathrm{RR} 0.55,95 \% \mathrm{Cl} 0.30$ to $1.02 ; \mathrm{I}^{2}=0 \%$ ) and at 3 to 5 years (Analysis 7.1 .4 ( 5 studies, 768 participants): RR $0.73,95 \% \mathrm{Cl} 0.47$ to $\left.1.14 ;\left.\right|^{2}=65 \%\right)$.

Acute rejection was decreased with OKT3 compared to no induction for CNI studies (Analysis 7.1.5 (8 studies, 968 participants): RR 0.60, $95 \% \mathrm{Cl} 0.43$ to $0.83 ; 12=79 \%$ ) but the effect was uncertain in non $\mathrm{CNI}$ studies (Analysis 7.1 .6 (3 studies, 85 participants): RR $0.70,95 \% \mathrm{Cl}$ 0.33 to $\left.1.46 ; 1^{2}=86 \%\right)$.

The effect of OKT3 compared to placebo on delayed graft function was uncertain (Analysis 7.1.7 (6 studies, 494 participants): RR 1.08, $95 \% \mathrm{Cl} 0.70$ to $\left.1.65 ;\left.\right|^{2}=63 \%\right)$

Abramowicz 1992 showed an increased risk of all-cause infection with OKT3 (Analysis 7.2.1 (108 participants): RR 1.38, 95\% Cl 1.04 to 1.82 ). OKT3 had uncertain effects on all other infection subtypes including bacterial infection (Analysis 7.2.2 (3 studies, 366 participants): RR $1.01,95 \% \mathrm{Cl} 0.76$ to $1.34 ; \mathrm{I}^{2}=0 \%$ ), all-cause viral infection (Analysis 7.2.3 (2 studies, 353 participants: RR 0.99, 95\% $\mathrm{Cl} 0.72$ to $1.37 ; \mathrm{I}^{2}=0 \%$ ), CMV infection (Analysis 7.2 .4 ( 3 studies, 332 participants): RR $1.52,95 \% \mathrm{Cl} 0.82$ to $2.84 ; \mathrm{I}^{2}=0 \%$ ), Herpes Simplex virus infection (Analysis 7.2.5 (1 study, 215 participants): RR 1.45, $95 \% \mathrm{Cl} 0.89$ to 2.38 ), and fungal infection (Analysis 7.2.6 (3 studies, 568 participants): RR $1.26,95 \% \mathrm{Cl} 0.33$ to $4.89 ; 1^{2}=68 \%$ ).

The effect of OKT3 compared to placebo on malignancy and PTLD was uncertain (Analysis 7.2.7 (3 studies, 610 participants): RR 1.34, $95 \% \mathrm{Cl} 0.52$ to $\left.3.50 ; 1^{2}=0 \%\right)$.

There was no difference in graft function measured by $\mathrm{SCr}$ with OKT3 compared to placebo both at 3 months (Analysis 7.3.1 (3 studies, 226 participants): MD $-0.93 \mu \mathrm{mol} / \mathrm{L}, 95 \% \mathrm{Cl}-15.78$ to 13.93 ; $\mathrm{I}^{2}=0 \%$ ) and at 1 year (Analysis 7.3.2 (2 studies, 261 participants): $\mathrm{MD}-6.22 \mu \mathrm{mol} / \mathrm{L}, 95 \% \mathrm{Cl}-18.21$ to $5.76 ; 12=0 \%)$. The effect on graft function at 3 to 4 years was uncertain with only 2 studies reporting for a total of 38 participants at this time point (Analysis 7.3.3 (2 studies, 38 participants): $-21.10 \mu \mathrm{mol} / \mathrm{L}, 95 \% \mathrm{Cl}-49.81$ to $7.61 ; 1^{2}=$ $60 \%)$.

\section{ALG versus OKT3}

ALG had uncertain effects on death at 1 to 2 years (Analysis 8.1.1 (3 studies, 300 participants): $\mathrm{RR} 2.00,95 \% \mathrm{Cl} 0.62$ to $6.47 ; 12=0 \%$ ) and 3 years (Analysis 8.1 .2 (2 studies, 265 participants): RR 1.03, 95\% Cl
0.13 to $\left.8.09 ; 1^{2}=41 \%\right)$ and also uncertain effect on all-cause graft loss at 1 to 2 years (Analysis 8.1.3 (3 studies, 300 participants): RR $1.01,95 \% \mathrm{Cl} 0.57$ to $1.80 ; \mathrm{I}^{2}=18 \%$ ) and 3 years (Analysis $8.1 .4(2$ studies, 265 participants): RR $1.08,95 \% \mathrm{Cl} 0.68$ to $1.70 ; \mathrm{I}^{2}=0 \%$ ) compared with OKT3.

There was little or no effect on acute rejection with ALG compared to OKT3 (Analysis 8.1.5 (6 studies, 593 participants): RR 0.97, 95\% Cl 0.83 to $\left.1.13 ;\left.\right|^{2}=0 \%\right)$.

Delayed graft function was less with ALG compared to OKT3 (Analysis 8.1 .6 (3 studies, 310 participants): RR $0.78,95 \% \mathrm{Cl} 0.61$ to $\left.0.99 ; 1^{2}=0 \%\right)$

ALG had uncertain effect on CMV infection (Analysis 8.2.1 (4 studies, 431 participants): $\mathrm{RR} 1.53,95 \% \mathrm{Cl} 0.82$ to $2.85 ; \mathrm{I}^{2}=57 \%$ ) and all other infection outcomes (Analysis 8.2).

ALG treatment was associated with lower $\mathrm{SCr}$ values at 1 year (Analysis 8.3.1 (2 studies, 245 participants): MD $-15.85 \mu \mathrm{mol} / \mathrm{L}, 95 \%$ $\mathrm{Cl}-28.55$ to $-3.15 ; \mathrm{I}^{2}=0 \%$ ) but this was not sustained at 2 years (Analysis 8.3.2 (2 studies, 223 participants): MD $12.50 \mu \mathrm{mol} / \mathrm{L}, 95 \%$ $\mathrm{Cl}-13.52$ to $\left.38.52 ;\left.\right|^{2}=59 \%\right)$.

\section{ALG versus placebo/no treatment}

ALG had little or no effect on all-cause death or all-cause graft loss at any time point after transplantation compared to placebo or no induction (Analysis 9.1).

Acute rejection was prevented with ALG compared to placebo or no induction (Analysis 9.1.7 (13 studies, 1575 participants): RR 0.69, $95 \% \mathrm{Cl} 0.53$ to $\left.0.92 ; 1^{2}=87 \%\right)$ and ALG reduced delayed graft function (Analysis 9.1.8 (5 studies, 615 participants): RR 0.55, 95\% Cl 0.31 to $0.97 ;\left.\right|^{2}=73 \%$ ).

ALG markedly increased both CMV infection (Analysis 9.2.1 (3 studies, 289 participants): $\mathrm{RR} 2.45,95 \% \mathrm{Cl} 1.23$ to $4.85 ; \mathrm{I}=0 \%$ ) and all-cause viral infections (Analysis 9.2.2 (2 studies, 324 participants): RR $2.71,95 \% \mathrm{Cl} 1.86$ to $3.95 ; \mathrm{I}^{2}=0 \%$ ), and may increase bacterial infection rates (Analysis 9.2.3 (4 studies, 742 participants): RR $1.18,95 \% \mathrm{Cl} 0.92$ to $\left.1.52 ; 1^{2}=43 \%\right)$. The treatment effect on fungal infection rates was uncertain (Analysis 9.2.4 (1 study, 230 participants): RR $1.11,95 \% \mathrm{Cl} 0.63$ to 1.95$)$.

ALG markedly increased thrombocytopenia (Analysis 9.2.5 (1 study, 67 participants): RR $12.19,95 \% \mathrm{Cl} 3.10$ to 47.92 ) and leucopenia (Analysis 9.2.6 (2 studies, 297 participants): RR 20.31, 95\% Cl 0.61 to $676.54 ;\left.\right|^{2}=83 \%$ ). ALG had uncertain effects on malignancy or PTLD (Analysis 9.2.7 (4 studies, 623 participants): RR $0.60,95 \% \mathrm{Cl} 0.27$ to $1.31 ; \mid 2=0 \%$ ) and NODAT (Analysis 9.2.8 (1 study, 105 participants): RR $0.93,95 \%$ Cl 0.22 to 3.93 ).

ALG had uncertain effect on both early graft function at 1-2 years and long term graft function at 10-20 years compared to placebo or no induction (Analysis 9.3).

\section{Other studies}

The remainder of comparisons (Figure 1) involved only a single study and therefore could not be used for meta-analysis. The results are summarised briefly below. 


\section{Dose comparisons}

Stevens 2008 assessed single versus divided dose ATG. There were no differences in any reported outcomes. Abouna 1995 compared ATG adjusted for the CD3 count with fixed dose ATG and again there was no difference in outcomes. One very small study by Ata 2013 compared ATG with dose adjusted by CD3 count compared to dose adjusted for total lymphocyte count and there was no difference in outcomes. Grafals 2014 compared 'standard' dose ATG ( $3.75 \mathrm{mg} / \mathrm{kg}$ total) with low dose ATG $(2.25 \mathrm{mg} / \mathrm{kg}$ total) and found no significant difference in outcomes. Another very small study by Buchler 2013 compared a split of four versus two doses of ATG (same total dose of $6 \mathrm{mg} / \mathrm{kg}$ ) and found no difference in outcomes.
Two studies compared different OKT3 dose regimens: standard versus low dose (Norman 1993a) and standard versus high dose (Abramowicz 1994). There were no significant differences in either of these small studies. Low versus high dose ALG was also assessed in Sakhrani 1992 and seven days versus 14 days ALG was addressed in Grundmann 1987. There were no differences in the low versus high dose study. Treatment was frequently stopped early in the 14 day group but there were no other differences in outcomes. One older study by Thomas 1977 comparing low potency ALG with high potency ALG found increased acute rejection at three months (RR $4.14,95 \% \mathrm{Cl} 1.55$ to 11.00 ) and increased graft loss at 1 year (RR 2.53, $95 \% \mathrm{Cl} 1.30$ to 4.90 ) with the low potency ALG.

Table summarising single studies of different dose comparisons

\begin{tabular}{llll}
\hline $\begin{array}{l}\text { Comparison } / \\
\begin{array}{l}\text { Study ID (num- } \\
\text { ber of partici- } \\
\text { pants) }\end{array}\end{array}$ & Outcome & $95 \% \mathrm{CI}$ & $95 \% \mathrm{Cl}$ \\
\hline
\end{tabular}

rATG: single $6 \mathrm{mg} / \mathrm{kg}$ versus 4 x $1.5 \mathrm{mg} / \mathrm{kg}$ doses (same total dose)

\begin{tabular}{|c|c|c|c|c|}
\hline \multirow{9}{*}{$\begin{array}{l}\text { Stevens } 2008 \\
(142)\end{array}$} & Death at 6 months & 0.34 & 0.01 & 8.27 \\
\hline & Graft loss (all cause) at 6 months & 0.21 & 0.01 & 4.21 \\
\hline & Acute rejection & 0.69 & 0.26 & 1.83 \\
\hline & Delayed graft function & 2.40 & 0.65 & 8.91 \\
\hline & Malignancy/PTLD & 0.21 & 0.01 & 4.21 \\
\hline & BKV & 0.15 & 0.01 & 2.79 \\
\hline & Severe febrile reaction (anaphylaxis requiring ICU) & 1.03 & 0.15 & 7.10 \\
\hline & Serum sickness & 0.21 & 0.01 & 4.21 \\
\hline & NODAT & 0.82 & 0.47 & 1.42 \\
\hline
\end{tabular}

ATG: $2 \times 3 \mathrm{mg} / \mathrm{kg}$ versus $4 \times 1.5 \mathrm{mg} / \mathrm{kg}$ doses (same total)

Buchler $2013(17) \quad$ **

\section{ATG: adjusted for CD3 count versus fixed dose of $15 \mathrm{mg} / \mathrm{kg} / \mathrm{d}$}

\begin{tabular}{|c|c|c|c|c|}
\hline \multirow[t]{6}{*}{ Abouna 1995 (45) } & Death at 2 years & 0.96 & 0.06 & 14.37 \\
\hline & Graft loss (all cause) 2 years & 0.72 & 0.18 & 2.85 \\
\hline & Acute rejection & 0.96 & 0.5 & 1.84 \\
\hline & Leucopenia & 0.36 & 0.11 & 1.18 \\
\hline & Thrombocytopenia & 0.14 & 0.01 & 2.51 \\
\hline & Viral infection (all cause) & 0.96 & 0.15 & 6.21 \\
\hline
\end{tabular}


Bacterial infection (all cause)

0.64

0.21

1.96

\section{ATG: adjusted by CD3 count versus adjusted by total lymphocytes}

Ata 2013 (21)

\section{ATG: standard (3.75 mg/kg total) versus low dose $(2.25 \mathrm{mg} / \mathrm{kg}$ total)}

\begin{tabular}{|c|c|c|c|c|}
\hline \multirow[t]{10}{*}{ Grafals 2014 (43) } & Acute rejection at 1 year & 0.57 & 0.12 & 2.81 \\
\hline & Leucopenia & 0.69 & 0.31 & 1.56 \\
\hline & Severe infection & 0.77 & 0.14 & 4.14 \\
\hline & CMV infection & 0.23 & 0.01 & 4.50 \\
\hline & BKV infection & 0.38 & 0.02 & 8.86 \\
\hline & Death at 1 year & 8.00 & 0.44 & 146.08 \\
\hline & Delayed graft function & 3.07 & 0.94 & 10.02 \\
\hline & Malignancy at 1 year & 2.30 & 0.23 & 23.51 \\
\hline & PTLD at 1 year & 0 events & not estimable & \\
\hline & Graft function at 1 year $(\mathrm{SCr}, \mu \mathrm{mol} / \mathrm{L})$ & $6.00^{\star}$ & 1.07 & 10.93 \\
\hline
\end{tabular}

\section{OKT3: standard dose (5 mg) versus low dose ( $2 \mathrm{mg}$ )}

\begin{tabular}{|c|c|c|c|c|}
\hline \multirow{9}{*}{$\begin{array}{l}\text { Norman 1993a } \\
(26)\end{array}$} & Death at 1 year & 0 events & not es & \\
\hline & Graft loss at 1 year & 3 & 0.13 & 67.51 \\
\hline & Acute rejection & 0.2 & 0.01 & 3.8 \\
\hline & Delayed graft function & 1.25 & 0.43 & 3.63 \\
\hline & CMV & 4 & 0.51 & 31.13 \\
\hline & Herpes Simplex virus & 0.5 & 0.05 & 4.86 \\
\hline & Bacterial & 0.86 & 0.4 & 1.86 \\
\hline & Fungal & 1 & 0.16 & 6.07 \\
\hline & Malignancy & 4.72 & 0.23 & 96.59 \\
\hline
\end{tabular}

OKT3: standard dose (5 mg) versus high dose (10 mg)

\begin{tabular}{lllll}
\hline $\begin{array}{l}\text { Abramowicz } \\
1994(29)\end{array}$ & \multicolumn{1}{l}{ Death at 3 months } & 0 events & not estimable & \\
\cline { 2 - 5 } & Graft loss at 3 months & 4.69 & 0.24 & 89.88 \\
\cline { 2 - 5 } & Acute rejection to 3 months & 0.47 & 0.1 & 2.16 \\
\cline { 2 - 5 } & Delayed graft function & 0.93 & 0.34 & 2.54 \\
\hline
\end{tabular}




\section{ALG: low versus high dose}

\begin{tabular}{lllll}
\hline $\begin{array}{l}\text { Sakhrani } 1992 \\
\text { (83) }\end{array}$ & Death at 1 year & 0.89 & 0.41 & 1.97 \\
\cline { 2 - 5 } & Acute rejection & 0.86 & 0.48 & 1.55 \\
\cline { 2 - 5 } & Leucopenia & 0.5 & 0.18 & 1.41 \\
\cline { 2 - 5 } & Severe infection & 1.05 & 0.52 & 2.11 \\
\hline
\end{tabular}

\section{ALG: 14 days versus 7 days}

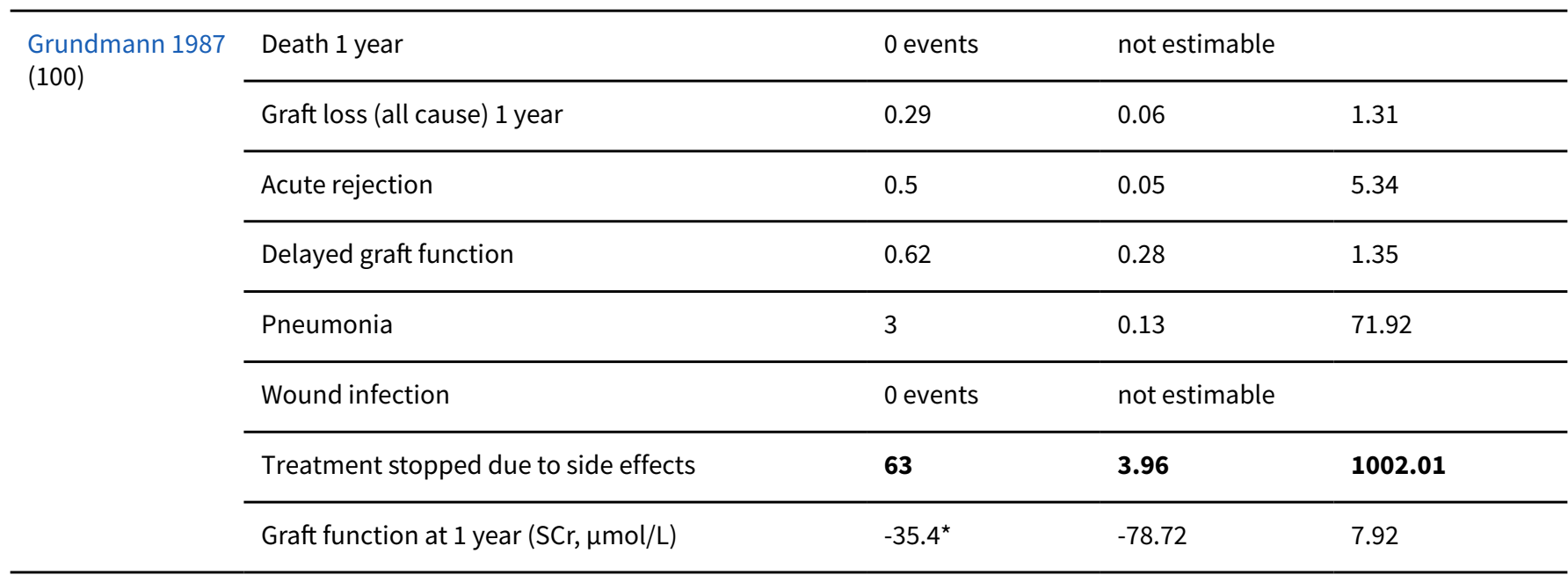

\section{ALG: high versus low potency}

\begin{tabular}{llcc}
\hline $\begin{array}{l}\text { Thomas } 1977 \\
\text { (71) }\end{array}$ & Acute rejection at 3 months & $\mathbf{4 . 1 4}$ & $\mathbf{1 . 5 5}$ \\
\cline { 2 - 4 } & Graft loss at 1 year & $\mathbf{2 . 5 3}$ & $\mathbf{1 1 . 0 0}$ \\
\hline
\end{tabular}

* MD and SD for continuous variables (not RR and 95\% Cl).

** Results not converted to RR for extremely small studies with 10 or fewer participants in each group.

Significant results shown in bold.

\section{Other antibody preparations}

Anti-CD2 rat monoclonal antibody was compared with no induction treatment in Squifflet 1997. This small study (40 participants) showed acute rejection was decreased by anti-CD2 (RR $0.42,95 \% \mathrm{Cl}$ 0.18 to 0.96 ) but no difference in any other outcomes. Another small study compared anti CD7 with OKT3 (Lazarovits 1993) and there were no differences. Two studies assessed anti-LFA-1 monoclonal antibody: one in comparison with no induction agent (Spillner 1998) and the other in comparison with ATG (Hourmant 1996). Other than decreased fever with anti-LFA-1 compared to ATG, differences were not significant in either of these studies. One small pilot study (Ejaz 2013) comparing four different interventions (ATG versus ATG + rituximab versus ATG + bortezomib versus
ATG + rituximab + bortezomib) did not show any significant differences in outcomes other than an increase in new-onset peripheral neuropathy in the bortezomib groups. There were only 10 participants in each group and follow-up only reported to one year at the time of this review. One final study compared antiICAM-1 monoclonal antibody with placebo (EARTS Study 1999) but again there were no differences in outcomes.

Norrby 1997 compared two rabbit ATG preparations made by different manufacturers. There was no difference for the only reported outcomes of acute rejection and CMV infection. One small (51 participants) study by Steinmuller 1991 compared OKT3 with ALG but antibody therapy was only given for patients with delayed graft function. For this reason it was considered separately from the other studies comparing OKT3 and ALG. Side effects were reduced with ALG compared to OKT3 (RR $0.41,95 \% \mathrm{Cl} 0.24$ to 0.72 ) but there were no other significant differences in outcomes. Finally ToledoPereyra 1985 compared ATG with ALG also showed no significant differences in outcomes.

Table summarising single studies of other antibody preparations 


\begin{tabular}{llll}
\hline $\begin{array}{l}\text { Comparison } / \\
\begin{array}{l}\text { Study ID (num- } \\
\text { ber of partici- }\end{array} \\
\text { pants) }\end{array}$ & Outcome & $95 \% \mathrm{Cl}$ & $95 \% \mathrm{Cl}$ \\
\hline
\end{tabular}

Rabbit ATG Fresenius versus rabbit ATG Merieux

\begin{tabular}{lllll}
\hline Norrby $1997(90)$ & Acute rejection & 0.87 & 0.63 & 1.20 \\
\cline { 2 - 5 } & CMV infection & 0.56 & 0.29 & 1.07 \\
\hline
\end{tabular}

\section{ALG versus ATG}

\begin{tabular}{lllll}
\hline $\begin{array}{l}\text { Toledo-Pereyra } \\
1985(50)\end{array}$ & Death at 1 year & 0.5 & 0.10 & 2.49 \\
\cline { 2 - 5 } & Graft loss at 1 year & 0.92 & 0.50 & 1.67 \\
\cline { 2 - 5 } & Acute rejection & 0.95 & 0.73 & 1.24 \\
\cline { 2 - 5 } & Thrombocytopenia & 1 & 0.15 & 1.11 \\
\cline { 2 - 5 } & Leucopenia & 0.07 & 0 & 2.55 \\
\cline { 2 - 5 } & HSV infection & 2 & 0.19 & 20.67 \\
\hline
\end{tabular}

\section{ALG vs OKT3 (given only if delayed graft functionpost-operatively)}

\begin{tabular}{|c|c|c|c|c|}
\hline \multirow{6}{*}{$\begin{array}{l}\text { Steinmuller } 1991 \\
\text { (51) }\end{array}$} & Death at 6 months & 0.48 & 0.05 & 4.98 \\
\hline & Graft loss (all cause) at 6 months & 0.96 & 0.27 & 3.43 \\
\hline & Acute rejection & 0.61 & 0.28 & 1.32 \\
\hline & Side effects (any reported) & 0.41 & 0.24 & 0.72 \\
\hline & Any infection & 0.89 & 0.51 & 1.55 \\
\hline & CMV & 0.89 & 0.51 & 1.55 \\
\hline
\end{tabular}

\section{Anti-CD7 versus OKT3}

\begin{tabular}{lllll}
\hline $\begin{array}{l}\text { Lazarovits } 1993 \\
(20)\end{array}$ & Death 5 years & 1 & 0.07 & 13.87 \\
\cline { 2 - 5 } & Graft loss 5 years & 0.11 & 0.01 & 1.83 \\
\cline { 2 - 5 } & Acute rejection & 1.4 & 0.67 & 2.94 \\
\cline { 2 - 5 } & Serious infection & 0.25 & 0.03 & 1.86 \\
\hline
\end{tabular}

\section{Anti-CD2 rat monoclonal antibody versus no induction}

\begin{tabular}{lllll}
\hline $\begin{array}{l}\text { Squifflet } 1997 \\
\text { (40) }\end{array}$ & Death at 6 months & 0.2 & 0.01 & 3.92 \\
\cline { 2 - 5 } & \multicolumn{2}{l}{ Graft loss (death censored) at 6 months } & 0 events & Not estimable \\
\cline { 2 - 4 } & Acute rejection & $\mathbf{0 . 4 2}$ & $\mathbf{0 . 1 8}$ & $\mathbf{0 . 9 6}$ \\
\hline
\end{tabular}




\begin{tabular}{llll} 
Delayed graft function & 0.17 & 0.02 & 1.26 \\
\hline Bacterial infection & 0.25 & 0.03 & 2.05 \\
\hline CMV & 0.5 & 0.05 & 5.08 \\
\hline EB virus & 3 & 0.13 & 69.52 \\
\hline Herpes Simplex virus & 4 & 0.49 & 32.72 \\
\hline Other viral infection & 0.33 & 0.01 & 7.72 \\
\hline Malignancy & 3 & 0.13 & 69.52 \\
\hline Graft function at 6 months $(\mathrm{SCr}, \mu \mathrm{mol} / \mathrm{L})$ & $8^{*}$ & -20.99 & 36.99
\end{tabular}

\section{Anti-LFA-1 monoclonal antibody versus no induction 1}

\begin{tabular}{|c|c|c|c|c|}
\hline \multirow[t]{6}{*}{ Spillner 1998 (22) } & Death at 1 year & 3 & 0.14 & 66.53 \\
\hline & Graft loss (all cause) at 1 year & 1 & 0.17 & 5.89 \\
\hline & Serious infection & 1 & 0.07 & 14.05 \\
\hline & CMV infection & 1 & 0.17 & 5.89 \\
\hline & Delayed graft function & 1.5 & 0.31 & 7.3 \\
\hline & Graft function at 1 year $(\mathrm{SCr}, \mu \mathrm{mol} / \mathrm{L})$ & $-17.6^{\star}$ & -62.69 & 27.49 \\
\hline
\end{tabular}

\section{Anti-LFA-1 monoclonal antibody versus ATG}

\begin{tabular}{|c|c|c|c|c|}
\hline \multirow{10}{*}{$\begin{array}{l}\text { Hourmant } 1996 \\
\text { (101) }\end{array}$} & Death at 1 year & 4.72 & 0.23 & 95.86 \\
\hline & Graft loss (death censored) at 1 year & 0.39 & 0.08 & 1.93 \\
\hline & Acute rejection & 1.05 & 0.62 & 1.78 \\
\hline & Delayed graft function & 0.55 & 0.28 & 1.09 \\
\hline & Any episode of infection & 1.05 & 0.74 & 1.48 \\
\hline & CMV disease & 0.94 & 0.5 & 1.77 \\
\hline & Treatment stopped due to side effects & 0.24 & 0.03 & 2.04 \\
\hline & Leucopenia & 0.4 & 0.11 & 1.47 \\
\hline & Thrombocytopenia & 0.57 & 0.22 & 1.44 \\
\hline & Fever (1st 10 days) & 0.58 & 0.36 & 0.94 \\
\hline
\end{tabular}

\section{Anti-ICAM-1 monoclonal antibody versus placebo}

\begin{tabular}{llccc}
\hline EARTS Study & Death at 1 year & 1.71 & 0.7 & 4.22 \\
\cline { 2 - 5 } $1999(266)$ & Graft loss at 1 year & 1.4 & 0.76 & 2.59 \\
\cline { 2 - 5 } & & &
\end{tabular}




\begin{tabular}{lccc} 
Acute rejection at 3 months & 1.18 & 0.88 & 1.57 \\
\hline Acute rejection at 1 year & 1.07 & 0.82 & 1.41 \\
\hline Primary non function & 1.2 & 0.38 & 3.83 \\
\hline Delayed graft function & 1.21 & 0.82 & 1.77 \\
\hline Any infection & 1.13 & 0.98 & 1.3 \\
\hline Sepsis & 1.3 & 0.59 & 2.86 \\
\hline Malignancy & 0.5 & 0.05 & 5.45
\end{tabular}

\section{ATG versus ATG + rituximab vs ATG + bortezomib versus ATG + rituximab + bortezomib}

\begin{tabular}{llll}
\hline Ejaz $2013(40) \quad * *$ & - & - \\
\hline
\end{tabular}

* MD and SD for continuous variables (not RR and 95\% Cl).

** Results not converted to RR for extremely small studies with 10 or fewer participants in each group

Significant results shown in bold.

1. Acute rejection was reported for anti-LFA 1 versus no induction but was reported as total number of episodes rather than total number of patients with any episode (results were 5 episodes with anti-LFA 1 versus 12 episodes with no induction)

\section{DISCUSSION}

\section{Summary of main results}

Many antibody preparations are now available for induction immunosuppression in kidney transplantation and we sought to summarise the evidence in this review to help inform clinical decision making and policy. Our inclusion criteria were deliberately broad resulting in 28 different pairwise comparisons and studies spanning over many decades. This review provides the best summary available of all RCTs (excluding IL2Ra) and highlights several issues.

Firstly, the evidence basis for decision making is poorly informed by studies in this area. The effects of polyclonal antibody induction remain uncertain for many important outcomes including graft loss and death. Many relevant, well recognised potential harms are not reported frequently in RCTs and more well designed studies reporting patient-centred outcomes (benefits and harms) are required. Some effects of antibody induction could be quantified.

ATG reduced acute rejection rates by roughly one third when compared to placebo or no treatment, at the cost of approximately $50 \%$ increase in the risk of CMV complications and an uncertain impact on future malignancy risk. rATG reduces acute rejection compared to hATG but data supporting this is weak as all events were only reported in a single study. The only significant difference seen in comparisons between alemtuzumab and ATG in steroid avoidance studies was that alemtuzumab reduces rejection at one year; in comparison alemtuzumab increased CMV infection but had similar rejection rates when compared to no induction and triple maintenance. NODAT was not reduced with alemtuzumab plus ESW compared to triple maintenance. OKT3 decreases acute rejection compared to placebo or no treatment but has been withdrawn from clinical use due to a poor side effect profile. ALG prevented acute rejection and led to better kidney function at one year posttransplant compared with placebo or no treatment but increased the rates of all viral infections.

See Summary of findings for the main comparison; Summary of findings 2.

\section{Overall completeness and applicability of evidence}

A decision was made to include any co-intervention immunosuppression regimens to ensure all relevant studies were included. As a result, a large number of studies from the pre-CNI era were included which may not be relevant to clinical practice today. Where possible, results were separated into $\mathrm{CNI}$ or non$\mathrm{CNI}$ maintenance as combining these groups was not felt to be clinically useful. As a result, there were multiple subgroups for outcomes of death and graft loss for most comparisons as studies frequently reported these outcomes at a variety of time points. There were no benefits seen for improved patient or graft survival with ATG despite decreased rejection rates when $\mathrm{CNI}$ and non$\mathrm{CNI}$ studies were separated. This lack of benefit may be due to small numbers of studies in each subgroup. When CNI and non$\mathrm{CNI}$ studies were combined, a reduction in both all-cause graft loss and death-censored graft loss was seen at one to two years posttransplant. This benefit was not sustained however in the studies that assessed longer term graft survival at five years. Results for acute rejection were generally more robust as this was reported in nearly all studies and time points were more standardised resulting in larger subgroups and greater statistical power. New studies are required to see if the absence of benefit is due to a lack of power or whether there really is no effect of one antibody compared to another antibody or placebo on patient and graft survival.

The main aim of using alemtuzumab has been to try to reduce the doses of maintenance immunosuppression required to prevent 
rejection, especially steroids. It is hoped that this will reduce some of the long term side effects of steroids, including NODAT. However, NODAT was not reduced with alemtuzumab plus ESW compared to ATG and triple maintenance or with alemtuzumab plus ESW compared to triple maintenance alone. This may be partly due to small numbers in these studies or may be due to the role of CNI, especially tacrolimus also causing increased rates of NODAT. Other steroid side effects have generally not been well reported in these studies. In the absence of any data to confirm a reduction in side effects, it is difficult to support the use of alemtuzumab and ESW currently compared to another antibody with triple maintenance.

The applicability of the results of this meta-analysis to the general transplant population may be limited by the individual studies. The majority of studies included patient groups with mixed immunological risk and a small number studied higher risk groups. Benefits and harms of individual treatments generally seemed homogenous across studies despite these apparent differences in risk. Harms are frequently under-reported in clinical studies compared to benefits and this review may therefore underestimate some of the potential harms of treatments due to possible underreporting in the individual studies.

\section{Quality of the evidence}

Overall, the quality of the evidence was generally low to only moderately good by GRADE criteria. Figure 2 shows the individual biases for each study. The most common problem was potential selection bias due to unclear methods of both randomisation and allocation concealment. Only $20 \%$ to $27 \%$ of included studies were low risk of bias for either random sequence generation or allocation concealment (see Figure 3).

For the main comparison of ATG versus placebo, quality of evidence according to GRADE criteria was moderate for outcomes of acute rejection and CMV infection but low for all other outcomes. The evidence for acute rejection and CMV was graded as moderate rather than high as more than $50 \%$ of studies rated methods of allocation concealment and/or random sequence generation as 'unclear' or 'high risk' as a potential source of bias. For the comparison of alemtuzumab plus ESW versus ATG with and without ESW, the evidence for acute rejection was rated as moderate quality but evidence for all other outcomes was either low or very low quality by GRADE criteria. Again the main reason for acute rejection evidence being graded as moderate rather than high was a significant risk of selection bias due to poor reporting of randomisation and allocation concealment.

\section{Potential biases in the review process}

The review was conducted with standard Cochrane methodology and there were no changes from the original protocol.

\section{Agreements and disagreements with other studies or reviews}

One study of registry data of transplant recipients in the US also failed to show any improvement in all-cause graft survival despite decreasing rates of acute rejection (Meier-Kriesche 2004). More alarmingly, this study showed a trend towards worsening death censored graft survival, despite more potent maintenance immunosuppression. However, given these trends are taken from registry data, it is hard to interpret what this really means, especially with older and more co-morbid patients being transplanted in recent years.

Many antibody therapies have now shown a reduction in acute rejection but it remains uncertain as to whether this translates into increased patient or graft survival for any of the antibodies in this review. In comparison, there was a reduction in graft loss at one year (but not after) for IL2Ra compared to placebo (24 studies, 4672 participants: $\mathrm{RR} 0.75,95 \% \mathrm{Cl} 0.62$ to 0.90 ) in a systematic review by Webster 2010 . However, there was no difference for graft loss when IL2Ra and ATG were compared in the same review and clinically diagnosed acute rejection rates were also similar for IL2Ra and ATG. However, ATG increased early malignancy at one year compared to IL2Ra (7 studies, 1067 participants: RR $0.25,95 \% \mathrm{Cl}$ 0.07 to 0.87 ) but had no effect on malignancy at other time points (Webster 2010). It is possible that malignancy is influenced more by maintenance immunosuppression than induction agents given it is a relatively late complication after transplantation. However, under-reporting of late harms is common in RCTs and malignancy rates may therefore be grossly underestimated in existing studies of induction agents leading to insufficient power to determine true cancer risk.

In steroid avoidance studies, alemtuzumab reduced acute rejection compared to ATG when ESW was used in both arms. These results would support using alemtuzumab over ATG in patients deemed to be at particularly high risk of steroid side effects and where maintenance with ESW is planned. Further studies of alemtuzumab and ESW compared to no induction and triple maintenance showed similar rates of acute rejection but an increased risk of CMV infection with alemtuzumab. There was no other difference in harms but this may need larger studies to show potential benefits of alemtuzumab relating to steroid avoidance. Reduction of maintenance immunosuppression certainly has theoretical benefits, including reduction in antihypertensives, antihyperlipidaemics, cholesterol, cataracts and NODAT requiring treatment as well as possible reduction of late complications such as malignancy. However, none of the studies to date have been long enough duration or large enough to confirm any of these suggested benefits.

\section{AUTHORS' CONCLUSIONS}

\section{Implications for practice}

Given a $45 \%$ acute rejection risk with no induction (assumed risk from control group in Analysis 1.4), seven patients would need ATG to prevent one from experiencing acute transplant rejection, while one additional patient would experience CMV disease for every 12 patients treated with ATG. Where only studies including CNI maintenance were assessed, the acute rejection rate was $37 \%$ with no induction and six patients would need treatment with ATG to prevent one person having acute rejection. In steroid withdrawal studies, 11 patients would require alemtuzumab to prevent one patient experiencing rejection given a $21 \%$ rejection risk with ATG. Alemtuzumab treatment combined with steroid withdrawal would cause one additional patient experiencing CMV disease for every six patients treated when compared with no antibody induction and triple maintenance, and without apparent benefits to patient-centred outcomes. ATG and alemtuzumab decreased acute rejection at a cost of increased CMV while patient-centred outcomes including survival or side effects do not appear to be improved. 
In kidney transplant recipients deemed to be at high risk of rejection, the evidence remains unclear as to whether one particular antibody preparation is better than any other at preventing acute rejection. However, this review does suggest that the perceived benefit of induction immunosuppression in reducing acute rejection may not actually lead to any long-term benefits or improvements in patient-centred outcomes.

\section{Implications for research}

Longer term follow-up is always a problem when assessing study data. Although some of the studies in this review have reported fairly long-term data, the numbers are generally too small to draw conclusions. Longer term follow-up is needed to really establish whether the benefit of reduced acute rejection with ATG has a significant impact on graft survival or indeed patient survival. In the absence of this information, is it possible to say that decreasing acute rejection is truly a benefit? Reducing the risk of acute rejection becomes less important to an individual patient if this fails to improve long-term graft or patient survival, especially if the treatment causes potential severe side effects and other harms. We need to find better ways of monitoring long-term harmful outcomes such as malignancy in any future studies. This may require an ongoing observational cohort study of patients once the initial RCT phase of a study is completed. Another response to this issue is follow up within established registries combined with core patient outcome sets.

If ESW or steroid minimisation is planned in an individual patient, the data in this review would support use of alemtuzumab over ATG due to a reduction in acute rejection. Further studies with long-term follow-up or ongoing follow-up of existing studies are needed to show if there is sustained benefit to steroid reduction therapy and indeed if the benefits outweigh risks of increased chronic rejection and potential increased long-term graft loss.

When assessing outcomes in transplantation it is difficult to separate the contribution of induction immunosuppression versus maintenance immunosuppression. The appropriate question for future studies may relate to maintenance rather than induction immunosuppression. Increasing knowledge in the field of transplant immunology has led to continual reassessment of the Banff diagnostic criteria and a much greater understanding of antibody-mediated rejection over recent years. Future studies comparing different immunosuppression regimens need to assess for not only differences in all cause rejection but also differences in the different subgroups of rejection. Ideally study designs should also include some measure of adherence to maintenance immunosuppression as this is particularly relevant for antibodymediated rejection in the presence of de novo donor-specific antibodies. Adherence can be difficult to measure and is generally poorly reported or not measured at all in studies. However, this may be the area that really needs to be studied if we want to increase long term patient and graft survival in kidney transplantation.

\section{ACKNOWLEDGEMENTS}

We wish to thank the referees for the comments and feedback during the preparation of this review. We would also like to Jonathan Craig who contributed to the protocol of this review.

NB acknowledges the support of the Medical Research Council (MRC) Centre for Transplantation, King's College London, UK MRC grant no. MR/J006742/1. His research was supported by the National Institute for Health Research (NIHR) Biomedical Research Centre at Guy's and St Thomas' NHS Foundation Trust and King's College London. The views expressed are those of the author(s) and not necessarily those of the NHS, the NIHR or the Department of Health.

SP is supported by a Rutherford Discovery Fellowship from the Royal Society of New Zealand.

$\mathrm{PH}$ acknowledges support from staff at the Department of Renal Medicine, Whangarei Hospital, New Zealand. 


\section{R E F E R E N C E S}

\section{References to studies included in this review}

\section{Abouna 1995 \{published data only\}}

Abouna GM, Kumar MS, al-Abdullah IH, Loose J, Sullivan DK, Phillips K, et al. Induction immunosuppression with antithymocyte globulin in renal transplantation using a variable dose according to the absolute number of CD3+ T cells. Transplantation Proceedings 1995;27(5):2676-8. [MEDLINE: 7482872]

Abouna GM, al-Abdullah IH, Kelly-Sullivan D, Kumar MS, Loose J, Phillips K, et al. Randomized clinical trial of antithymocyte globulin induction in renal transplantation comparing a fixed daily dose with dose adjustment according to T cell monitoring. Transplantation 1995;59(11):1564-8. [MEDLINE: 7778170]

\section{Abramowicz 1992 \{published data only\}}

Abramowicz D, Goldman M, De Pauw L, Vanherweghem JL, Kinnaert P, Vereerstraeten P. The long-term effects of prophylactic OKT3 monoclonal antibody in cadaver kidney transplantation--a single-center, prospective, randomized study. Transplantation 1992;54(3):433-7. [MEDLINE: 1412723]

Abramowicz D, Norman DJ, Goldman M, De Pauw L, Kinnaert P, Kahana $\mathrm{L}$, et al. OKT3 prophylaxis improves long-term renal graft survival in high-risk patients as compared to cyclosporine: combined results from the prospective, randomized Belgian and US studies. Transplantation Proceedings 1995;27(1):852-3. [MEDLINE: 7879204]

Abramowicz D, Norman DJ, Vereerstraeten P, Goldman M, De Pauw L, Vanherweghem JL, et al. OKT3 prophylaxis in renal grafts with prolonged cold ischemia times: association with improvement in long-term survival. Kidney International 1996;49(3):768-72. [MEDLINE: 8648918]

Goldman M, Abramowicz D, De Pauw L, Marecaux G, Vanderwinden JM, Kinnaert P, et al. Beneficial effects of prophylactic OKT3 in cadaver kidney transplantation: comparison with cyclosporin $A$ in a single-center prospective randomized study. Transplantation Proceedings 1991;23(1 Pt 2):1046-7. [MEDLINE: 1899148]

\section{Abramowicz 1994 \{published data only\}}

Abramowicz D, Goldman M, Mat O, Estermans G, Crusiaux A, Vanherweghem JL, et al. OKT3 serum levels as a guide for prophylactic therapy: a pilot study in kidney transplant recipients. Transplant International 1994;7(4):258-63. [MEDLINE: 7916925]

\section{Ackermann 1988 \{published data only\}}

Ackermann JR, Lefor WM, Kahana L, Weinstein S, Shires DL. Prophylactic use of OKT3 in renal transplantation: Part of a prospective randomized multicenter trial. Transplantation Proceedings 1988;20(1 Suppl 1):242-4. [EMBASE: 1988111881]

Kahana L, Ackermann J, Lefor W, Weinstein S, Wright C, DeQuesada A, et al. Uses of orthoclone OKT3 for prophylaxis of rejection and induction in initial nonfunction in kidney transplantation. Transplantation Proceedings 1990;22(4):1755-8. [MEDLINE: 2117799]

Kahana L, Narvarte J, Ackermann J, Lefor W, Weinstein S, Wright $\mathrm{C}$, et al. OKT3 prophylaxis versus conventional drug therapy: single-center perspective, part of a multicenter trial. American Journal of Kidney Diseases 1989;14(5 Suppl 2):5-9. [MEDLINE: 2510510]

\section{Ata 2013 \{published data only\}}

Ata P, Kara M, Ozdemir E, Canbakan M, Gokce AM, Bayraktar FA, et al. Monitoring of $\mathrm{CD} 3(+)$ T-cell count in patients receiving antithymocyte globulin induction after cadaveric renal transplantation. Transplantation Proceedings 2013;45(3):929-31. [MEDLINE: 23622590]

\section{Banhegyi 1991 \{published data only\}}

Banhegyi C, Rockenschaub S, Muhlbacher F, Kovarik J, Balcke $P$, Gotzinger $P$, et al. Preliminary results of a prospective randomized clinical trial comparing cyclosporine $A$ to antithymocyte globulin immunosuppressive induction therapy in kidney transplantation. Transplantation Proceedings 1991;23(4):2207-8. [MEDLINE: 1871846]

\section{Belitsky 1991 \{published data only\}}

Belitsky P, MacDonald AS, Cohen AD, Crocker J, Hirsch D, Jindal K, et al. Comparison of antilymphocyte globulin and continuous i.v. cyclosporine $A$ as induction immunosuppression for cadaver kidney transplants: a prospective randomized study. Transplantation Proceedings 1991;23(1 Pt 2):999-1000. [MEDLINE: 1989359]

Gulanikar AC, MacDonald AS, Sungurtekin U, Belitsky P. The incidence and impact of early rejection episodes on graft outcome in recipients of first cadaver kidney transplants. Transplantation 1992;53(2):323-8. [MEDLINE: 1738926]

Gulanikar AC, Sungurtekin U, MacDonald AS, Belitsky P, BitterSuermann $\mathrm{H}$, Cohen A, et al. Sequential discontinuation of azathioprine and prednisone in renal transplantation. Transplantation Proceedings 1991;23(4):2226-7. [MEDLINE: 1871856]

\section{Bell 1983 \{published data only\}}

Bell PR, Blamey RW, Briggs JD, Castro JE, Hamilton DN, Knapp MS, et al. Medical research council trial of antilymphocyte globulin in renal transplantation. A multicenter randomized double-blind placebo controlled clinical investigation. Transplantation 1983;35(6):539-45. [MEDLINE: 6346595]

\section{Benfield 1999 \{published data only\}}

Benfield MR, Herrin J, Feld L, Rose S, Stablein D, Tejani A. Safety of kidney biopsy in pediatric transplantation: a report of the Controlled Clinical Trials in Pediatric Transplantation Trial of Induction Therapy Study Group. Transplantation 1999;67(4):544-7. [MEDLINE: 10071025]

Benfield MR, Symons JM, Bynon S, Eckhoff D, Herrin J, Harmon W, et al. Mycophenolate mofetil in pediatric renal 
transplantation. Pediatric Transplantation 1999;3(1):33-7. [MEDLINE: 10359029]

Benfield MR, Tejani A, Harmon WE, McDonald R, Stablein DM, McIntosh $\mathrm{M}$, et al. A randomized multicenter trial of OKT3 mAbs induction compared with intravenous cyclosporine in pediatric renal transplantation. Pediatric Transplantation 2005;9(3):282-92. [MEDLINE: 15910382]

Tejani A. A randomized prospective multicenter trial of T-cell antibody induction therapy in pediatric renal transplantation [abstract]. XVIII International Congress of the Transplantation Society; 2000 Aug 27-Sept 1; Rome, Italy. 2000.

Tejani A, Harmon W, Benfield M, Elshihabi I, McDonald R, Stablein $D$, et al. A randomized prospective multicenter trial of $\mathrm{t}$-cell antibody induction therapy in pediatric renal transplantation [abstract]. Transplantation 2000;69(8 Suppl):S111. [CENTRAL: CN-00402826]

Tejani A, Harmon W, Benfield M, Rose S, Stablein D, Strom T, et al. A randomized prospective multicenter trial of $t$-cell antibody induction therapy in pediatric renal transplantation [abstract]. Journal of the American Society of Nephrology 2000;11(Sept):709A.

\section{Bock 1995 \{published data only\}}

Bock HA, Gallati H, Zurcher RM, Bachofen M, Mihatsch MJ, Landmann J, et al. A randomized prospective trial of prophylactic immunosuppression with ATG-Fresenius versus OKT3 after renal transplantation. Transplantation 1995;59(6):830-40. [MEDLINE: 7701577]

Bock HA, Zurcher R, Mihatsch M, Landmann J, Thiel G. A randomized prospective trial of prophylactic immunosuppression with OKT3 vs. ATG-Fresenius (ATG-F) after renal transplantation [abstract]. 12th International Congress of Nephrology; 1993 June 13-18; Jerusalem, Israel. 1993:165. [CENTRAL: CN-00550381]

Bock HA, Zurcher R, Mihatsch M, Landmann J, Thiel G. A randomized prospective trial of prophylactic therapy with OKT3 vs ATG-Fresenius (ATG-F) after renal transplantation [abstract]. Journal of the American Society of Nephrology 1992;3(3):852. [CENTRAL: CN-00460418]

\section{Bock 1999 \{published data only\}}

Bock HA, Tsinalis D, Nickeleit V, Mihatsch M, Thiel G. Randomized prospective study of polyclonal antilymphocyte globulin induction after renal transplantation: ATGAM vs ATGFresenius [abstract no: A3646]. Journal of the American Society of Nephrology 1999;10(Program \& Abstracts):720A. [CENTRAL: CN-00583882]

\section{Brennan 1999 \{published data only\}}

Brennan DC, Flavin K, Burgess S, Dolan S, Kano JM, Mahon M, et al. A randomized, double-blinded comparison of thymoglobulin vs ATGAM for induction in adult renal transplant recipients [abstract no: 710]. Transplantation 1998;65(12):S180. [CENTRAL: CN-00602088]

Brennan DC, Flavin K, Lowell JA, Howard TK, Shenoy S, Burgess $\mathrm{S}$, et al. A randomized, double-blinded comparison of
Thymoglobulin versus Atgam for induction immunosuppressive therapy in adult renal transplant recipients. [erratum appears in Transplantation 1999 May 27;67(10):1386.]. Transplantation 1999;67(7):1011-8. [MEDLINE: 10221486]

Brennan DC, Flavin K, Lowell JA, Howard TK, Shenoy S, Burgess S, et al. Leukocyte response to thymoglobulin or ATGAM for induction immunosuppression in a randomized, doubleblind clinical trial in renal transplant recipients. Transplantation Proceedings 1999;31(3B Suppl):16S-8S. [MEDLINE: 10330962]

Hardinger KL, Rhee S, Buchanan P, Koch M, Miller B, Enkvetchakul D, et al. A prospective, randomized, doubleblinded comparison of thymoglobulin versus ATGAM for induction immunosuppressive therapy: 10-year results. Transplantation 2008;86(7):947-52. [MEDLINE: 18852661]

Hardinger KL, Schnitzler MA, Miller B, Lowell J, Shenoy S, Brennan DC. Long-term comparison of thymoglobulin versus ATGAM for induction in adult renal transplantation: evidence of improved allograft survival at 5 years [abstract]. American Journal of Transplantation 2003;3(Suppl 5):556. [CENTRAL: CN-00445642]

Hardinger KL, Schnitzler MA, Miller B, Lowell JA, Shenoy S, Koch MJ, et al. Five-year follow up of thymoglobulin versus ATGAM induction in adult renal transplantation. Transplantation 2004;78(1):136-41. [MEDLINE: 15257052]

\section{Broyer 1993 \{published data only\}}

Broyer M, Gagnadoux MF, Guest G, Arsan A, Beurton D, Revillon $\mathrm{Y}$, et al. Prophylactic OKT3 monoclonal antibody versus antilymphocyte globulins: a prospective, randomized study in 148 first cadaver kidney grafts. Transplantation Proceedings 1993;25(1 Pt 1):570-1. [MEDLINE: 8438418]

\section{Buchler 2013 \{published data only\}}

Buchler M, Longuet $\mathrm{H}$, Lemoine R, Herr F, Gatault P, Thibault G, et al. Pharmacokinetic and pharmacodynamic studies of two different rabbit antithymocyte globulin dosing regimens: results of a randomized trial. Transplant Immunology 2013;28(2-3):120-6. [MEDLINE: 23507258]

Longuet H, Buchler M, Lemoine R, Herr F, Gatault P, Thibault G, et al. Pharmacokinetic and pharmacodynamic studies of two different rabbit antithymocyte antiglobulin dosing regimens [abstract no: 0069]. Transplant International 2013;26(Suppl 2):44-5. [EMBASE: 71359107]

\section{CAMPASIA Study 2005 \{published data only\}}

Munoz AS, Cabanayan-Casasola CB, Danguilan RA, Padua FB, Ona ET. Campath-1H (alemtuzumab) as an induction agent for the prevention of graft rejection and preservation of renal function in kidney transplant patients: Philippine 3-year followup. Transplantation Proceedings 2008;40(7):2230-3. [MEDLINE: 18790200]

Vathsala A, CAMPASIA Study Group. Safety and efficacy of campath-1h (mabcampath ${ }^{\circledR}$ ) with low dose cyclosprorine monotherapy in patients receiving kidney transplants - 6 month analysis of the pilot randomised controlled [abstract]. Transplantation 2004;78(2 Suppl):56. [CENTRAL: CN-00509538] 
Vathsala A, Campasia Study Group. One year results of a pilot randomised controlled trial of the effectiveness of alemtuzumab as an induction agent for prevention of graft rejection and preservation of renal function in patients receiving kidney transplants [abstract no: T-P050029]. Nephrology 2005;10(Suppl):A215. [CENTRAL: CN-00583367]

Vathsala A, Ona ET, Tan S, Suresh S, Chan Y, Lou H, et al. Campasia: a pilot randomised controlled trial of the effectiveness of campath-1h (mabcampath ${ }^{\circledR}$ ) as an induction agent for prevention of graft rejection and preservation of renal function in patients receiving kidney transplants [abstract]. American Journal of Transplantation 2004;4(Suppl 8):406. [CENTRAL: CN-00509539]

Vathsala A, Ona ET, Tan SY, Suresh S, Lou HX, Cabanayan Casasola CB, et al. Randomized trial of Alemtuzumab for prevention of graft rejection and preservation of renal function after kidney transplantation. Transplantation 2005;80(6):765-74. [MEDLINE: 16210963]

Vathsala A, Ona ET, Tan SY, Suresh S, Lou HX, CabanayanCasasola CB, et al. Induction therapy with alemtuzumab together with low dose cyclosporine monotherapy permits steroid-free immunosuppression, mitigates drug-related, non-immune toxicities and improves quality of life [abstract no: TH-P0550]. Journal of the American Society of Nephrology 2006;17(Abstracts):224A. [CENTRAL: CN-00644285]

Vathsala A, Ona ET, Tan SY, Suresh S, Lou HX, CabanayanCasasola CB, et al. Lymphocyte recovery after depletion by alemtuzumab in renal transplant recipients: impact on outcome [abstract no: 1015]. American Journal of Transplantation 2005;5(Suppl 11):415. [CENTRAL: CN-00644284]

\section{Cantarovich 2008 \{published data only\}}

Cantarovich M, Durrbach A, Hiesse C, Benoit G, Charpentier B. Short and long-term impact of anti-thymocyte globulin induction on clinical outcomes in renal transplant patients: 15year results of a prospective and randomized trial [abstract no: 1034]. American Journal of Transplantation 2002;2(Suppl 3):398. [CENTRAL: CN-00415382]

Cantarovich M, Durrbach A, Hiesse C, Ladouceur M, Benoit G, Charpentier B. 20-year follow-up results of a randomized controlled trial comparing antilymphocyte globulin induction to no induction in renal transplant patients. Transplantation 2008;86(12):1732-7. [MEDLINE: 19104413]

Cantarovich M, Durrbach A, Ladouceur M, Hiesse C, Benoit G, Charpentier B. 20 year follow-up results of a randomized controlled trial comparing anti-lymphocyte globulin-induction to no induction in renal transplant patients [abstract no: 535 ]. American Journal of Transplantation 2008;8(Suppl 2):321.

Cantarovich M, Durrbach A, Ladouceur M, Hiesse C, Benoit G, Charpentier B. 20 year follow-up results of a randomized controlled trial comparing anti-lymphocyte globulin-induction to no induction in renal transplant patients [abstract no: 879]. Transplantation 2008;86(2S):307.

Durrbach A, Cantarovich M, Hiesse C, Benoir G, Charpentier B. Short and long-term impact of anti-lymphocyte globulin induction on clinical outcomes in renal transplant patients: 15-year results of a prospective and randomized trial [abstract no: 2341]. XIXth International Congress of the Transplantation Society; 2002 Aug 25-30; Miami, FL. 2002. [CENTRAL: CN-00420825]

\section{Charpentier 2002 \{published data only\}}

Charpentier B, European Tacrolimus vs Microemulsified Cyclosporin Study Group. A three arm study comparing immediate tacrolimus therapy with ATG induction therapy followed by either tacrolimus or cyclosporine in adult renal transplant recipients. Transplantation Proceedings 2002;34(5):1625-6. [MEDLINE: 12176511]

Charpentier B, Rostaing L, Berthoux F, Lang P, Civati G, Touraine JL, et al. A three-arm study comparing immediate tacrolimus therapy with antithymocyte globulin induction therapy followed by tacrolimus or cyclosporine $A$ in adult renal transplant recipients. Transplantation 2003;75(6):844-51. [MEDLINE: 12660513]

Rostaing L, Tacrolimus versus Microemulsified Cyclosporin Study Group. Comparison of ATG induction followed by tacrolimus therapy with ATG induction followed by cyclosporine therapy, and immediate tacrolimus-based triple therapy [abstract]. Journal of the American Society of Nephrology 2001;12(Program \& Abstracts):916A. [CENTRAL: CN-00433645]

\section{Chatterjee 1976 \{published data only\}}

Chatterjee SN. Antithymocyte globulin in renal transplant recipients. Report of a prospective randomized controlled trial. Archives of Surgery 1976;111(6):680-3. [MEDLINE: 58651]

\section{Ciancio 2005 \{published data only\}}

Baruqui JA, Ciancio G, Gaynor J, Guerra G, Sageshima J, Chen L, et al. Randomized trial of three induction antibodies in kidney transplantation: long-term results [abstract no: P-37]. American Journal of Transplantation 2014;14(Suppl 3):80. [EMBASE: 71388259]

Carreno MR, Ciancio G, Burke GW, Rosen A, Ricordi C, Tzakis A, et al. Cellular phenotypes affected by induction therapy with campath-1h vs thymoglobulin vs zenapax in kidney allograft recipients [abstract]. American Journal of Transplantation 2004;4(Suppl 8):405. [CENTRAL: CN-00509121]

Ciancio G, Burke GW, Gaynor JJ, Carreno MR, Cirocco RE, Mathew JM, et al. A randomized trial of three renal transplant induction antibodies: early comparison of tacrolimus, mycophenolate mofetil, and steroid dosing, and newer immune-monitoring. Transplantation 2005;80(4):457-65. [MEDLINE: 16123718]

Ciancio G, Burke GW, Gaynor JJ, Mattiazzi AD, Carreno MR, Rosen $A$, et al. Randomized trial of three different induction regimens to prevent acute renal allograft rejection: early results [abstract]. American Journal of Transplantation 2004;4(Suppl 8):266. [CENTRAL: CN-00509135]

Ciancio G, Burke GW, Gaynor JJ, Roth D, Kupin W, Rosen A, et al. A randomized trial of thymoglobulin vs. alemtuzumab (with lower dose maintenance immunosuppression) vs. daclizumab 
in renal transplantation at 24 months of follow-up. Clinical Transplantation 2008;22(2):200-10. [MEDLINE: 18339140]

Ciancio G, Burke GW, Mattiazzi AD, Illanes HG, Gaynor JJ, Carreno $\mathrm{M}$, et al. A randomized trial of three different antibody induction regimens in renal transplantation [abstract no: 1625]. American Journal of Transplantation 2005;5(Suppl 11):569. [CENTRAL: CN-00644195]

Ciancio G, Gaynor JJ, Guerra G, Sageshima J, Chen L, Mattiazzi A, et al. Randomized trial of three induction antibodies in kidney transplantation: long-term results. Transplantation 2014;97(11):1128-38. [MEDLINE: 24477186]

Ciancio G, Gaynor JJ, Sageshima J, Chen L, Roth D, Kupin W. Machine perfusion in kidney transplantation: better outcomes in the presence of longer pump time [abstract no: 1011]. American Journal of Transplantation 2010;10(Suppl 4):333. [EMBASE: 70464387]

Ciancio G, Gaynor JJ, Sageshima J, Roth D, Kupin W, Guerra G, et al. Machine perfusion following static cold storage preservation in kidney transplantation: donor-matched pair analysis of the prognostic impact of longer pump time. Transplant International 2012;25(1):34-40. [MEDLINE: 21981661]

\section{Ciancio 2010 \{published data only\}}

Baruqui JA, Ciancio G, Gaynor J, Guerra G, Sageshima J, Chen L, et al. Randomized trial of three induction antibodies in kidney transplantation: long-term results [abstract no: P-37]. American Journal of Transplantation 2014;14(Suppl 3):80. [EMBASE: 71388259]

Ciancio G, Gaynor JJ, Guerra G, Sageshima J, Chen L, Mattiazzi A, et al. Randomized trial of three induction antibodies in kidney transplantation: long-term results. Transplantation 2014;97(11):1128-38. [MEDLINE: 24477186]

Ciancio G, Gaynor JJ, Roth D, Kupin W, Hanson L, Tueros L, et al. Randomized trial of thymoglobulin versus alemtuzumab (with lower dose maintenance immunosuppression) versus daclizumab in living donor renal transplantation. Transplantation Proceedings 2010;42(9):3503-6. [MEDLINE: 21094804]

\section{Cole 1994 \{published data only\}}

Cole EH, Cattran DC, Farewell VT, Aprile M, Bear RA, Pei YP, et al. A comparison of rabbit antithymocyte serum and OKT3 as prophylaxis against renal allograft rejection. Transplantation 1994;57(1):60-7. [MEDLINE: 8291115]

\section{Condie 1985 \{published data only\}}

Condie RM, Waskosky KE, Hall BL. Efficacy of Minnesota antilymphoblast globulin in renal transplantation: a multicenter, placebo-controlled, prospective, randomized, double-blind study. Transplantation Proceedings 1985;17(1 Pt 2):1304-10. [EMBASE: 1985078723]

\section{Cosimi 1976 \{published data only\}}

Cosimi AB. The clinical value of antilymphocyte antibodies. Transplantation Proceedings 1981;13(1 Pt 1):462-8. [MEDLINE: 7022874]
Cosimi AB, Wortis HH, Delmonico FL, Russell PS. Randomized clinical trial of antithymocyte globulin in cadaver renal allograft recipients: importance of T cell monitoring. Surgery 1976;80(2):155-63. [MEDLINE: 781887]

Wechter WJ, Brodie JA, Morrell RM, Rafi M, Schultz JR. Antithymocyte globulin (ATGAM) in renal allograft recipients. Multicenter trials using a 14-dose regimen. Transplantation 1979;28(4):294-302. [MEDLINE: 388762]

\section{Debure 1987 \{published data only\}}

Debure A, Chkoff N, Chatenoud L, Lacombe M, Campos H, Noel LH, et al. One-month prophylactic use of OKT3 in cadaver kidney transplant recipients. Transplantation 1988;45(3):546-53. [MEDLINE: 3279578]

Debure A, Chkoff N, Chatenoud L, Lacombe M, Campos H, Noel $\mathrm{LH}$, et al. Preventive treatment of rejection by the prolonged administration of OKT3: decrease of the immune response of the host [Traitement prophylactique du rejet par l'administration prolongee d'OKT3: diminution de la reponse immune de l'hote]. Nephrologie 1987;8(3):87-94. [MEDLINE: 3116443]

\section{De Pauw 1990 \{published data only\}}

De Pauw L, Abramowicz D, Goldman M, Vereerstraeten P, Kinnaert $P$, Toussaint $C$. Comparison between prophylactic use of OKT3 and cyclosporine in cadaveric renal transplantation. Transplantation Proceedings 1990;22(4):1759-60. [MEDLINE: 2117800]

\section{Diethelm 1979 \{published data only\}}

Diethelm AG, Blackstone E, Whelchel JD, Pass RF, Chambers L, Phillips SJ, et al. The adjunctive value of equine antithymocyte membrane globulin in a randomized study of patients undergoing cadaveric renal transplantation. Transplantation Proceedings 1979;11(1):27-30. [MEDLINE: 377644]

\section{EARTS Study 1999 \{published data only\}}

Salmela K, Wramner L, Ekberg H, Hauser I, Bentdal O, Lins LE, et al. A randomized multicenter trial of the anti-ICAM-1 monoclonal antibody (enlimomab) for the prevention of acute rejection and delayed onset of graft function in cadaveric renal transplantation: a report of the European Anti-ICAM-1 Renal Transplant Study Group. Transplantation 1999;67(5):729-36. [MEDLINE: 10096530]

\section{Ejaz 2013 \{published data only\}}

Ejaz N, Shields A, Alloway R, Sadaka B, Girnita A, Mogilishetty G, et al. A prospective, randomized pilot study of B-cell targeted induction therapy in sensitized kidney transplant recipients: final report [abstract no: 175]. American Journal of Transplantation 2013;13(Suppl S5):84. [EMBASE: 71056751]

Ejaz NS, Shields AR, Alloway RR, Sadaka B, Girnita AL, Mogilishetty $G$, et al. Randomized controlled pilot study of B cell-targeted induction therapy in HLA sensitized kidney transplant recipients. American Journal of Transplantation 2013;13(12):3142-54. [MEDLINE: 24266968]

Schmidt N, Shields AR, Alloway RR, Sadaka B, Mogilishetty G, Kremer J, et al. Randomized controlled trial of B-cell targeted 
induction therapy in HLA sensitized kidney transplant recipients: preliminary results [abstract no: 100]. American Journal of Transplantation 2012;12(Suppl S3):56. [EMBASE: 70746047]

\section{Farney 2008 \{published data only\}}

Doares W, Ashcraft E, Singh R, Hart L, Farney A, Hartmann E, et al. Prospective, randomized, single-center trial of alemtuzumab vs rabbit anti-thymocyte globulin induction in renal and pancreas transplant: infectious complications update [abstract no: 315]. American Journal of Transplantation 2009;9(Suppl 2):282-3. [EMBASE: 70010188]

Farney A, Rogers J, Doares W, Iskandar S, Orlando G, Adams P, et al. 7 year results of a prospective randomized study of alemtuzumab vs rabbit anti-thymocyte globulin induction in kidney and kidney pancreas transplantation [abstract]. Transplantation 2014;98(Suppl 1):90. [EMBASE: 71543817]

Farney A, Rogers J, Hart L, Doares W, Iskandar S, Orlando G, et al. Long-term results of a prospective randomized study of alemtuzumab vs rabbit anti-thymocyte globulin induction in kidney and kidney pancreas transplantation [abstract no: 101]. American Journal of Transplantation 2012;12(Suppl S3):56. [EMBASE: 70746048]

Farney A, Singh R, Rogers J, Ashcroft E, Hartmann E, Hart L, et al. A prospective randomized trial of alemtuzumab versus rabbit anti-thymocyte globulin induction in kidney and pancreas transplantation: minimum 6 months follow up [abstract no: 796]. Transplantation 2008;86(2S):278. [CENTRAL: CN-00740550]

Farney A, Sundberg A, Moore P, Hartmann E, Rogers J, Doares W, et al. A randomized trial of alemtuzumab vs. anti-thymocyte globulin induction in renal and pancreas transplantation. Clinical Transplantation 2008;22(1):41-9. [MEDLINE: 18217904]

Farney AC, Doares W, Rogers J, Singh R, Hartmann E, Hart L, et al. A randomized trial of alemtuzumab versus antithymocyte globulin induction in renal and pancreas transplantation. Transplantation 2009;88(6):810-9. [MEDLINE: 19920781]

Farney AC, Singh R, Rogers J, Ashcroft E, Hartmann E, Hart L, et al. A prospective randomized study of alemtuzumab vs rabbit anti-thymocyte globulin induction in kidney and pancreas transplantation [abstract no: 532]. American Journal of Transplantation 2008;8(Suppl 2):320. [CENTRAL: CN-00653719]

Hartmann EL, Doares W, Reeves-Daniel A, Rogers J, Singh R, Hart L, et al. Safety and efficacy of lymphocyte-depleting induction therapy in older transplant recipients: should grandpa receive campath? [abstract no: 1755]. American Journal of Transplantation 2009;9(Suppl 2):675. [CENTRAL: CN-00795687]

Singh R, Farney A, Rogers J, Doares W, Hartmann E, ReevesDaniel A, et al. A randomized, prospective trial of alemtuzumab versus rabbit anti-thymocyte globulin induction in kidneypancreas transplantation: a single center experience [abstract no: 87]. American Journal of Transplantation 2009;9(Suppl 2):216. [CENTRAL: CN-00790946]

Stratta R, Ashcraft E, Hartmann E, Rogers J, Doares W, Hart L, et al. A prospective randomized comparison of alemtuzumab versus rabbit anti-thymocyte globulin induction in renal and pancreas transplantation [abstract no: P132]. Transplant International 2007;20(Suppl 2):127. [CENTRAL: CN-00740553]

Stratta R, Rogers J, Orlando G, Farooq U, Al-Shraideh Y, Doares W, et al. 5 year results of a prospective, randomized single center study of alemtuzumab compared to rabbit antithymocyte globulin induction in simultaneous kidney-pancreas transplantation [abstract]. Transplantation 2014;98(Suppl 1):215. [EMBASE: 71544175]

Stratta R, Singh R, Farney A, Rogers J, Doares W, Hartman E. $A$ randomized, prospective trial of alemtuzumab versus rabbit anti-thymocyte globulin induction in kidney-pancrease transplantation: a single center experience [abstract no: 0-289]. Transplant International 2009;22(Suppl 2):76-7.

Stratta RJ, Rogers J, Hart L, Doares W, Kaczmorski S, ReevesDaniel A, et al. 5 year results of a prospective randomized single center study of alemtuzumab compared to rabbit anti-thymocyte globulin induction in kidney-pancreas transplantation [abstract]. Transplantation 2013;96(Suppl 6):S86. [EMBASE: 71249227]

Stratta RJ, Rogers J, Orlando G, Farooq U, Al-Shraideh Y, Doares W, et al. Depleting antibody induction in simultaneous pancreas-kidney transplantation: a prospective singlecenter comparison of alemtuzumab versus rabbit antithymocyte globulin. Expert Opinion on Biological Therapy 2014;14(12):1723-30. [MEDLINE: 25156622]

Stratta RJ, Rogers J, Orlando G, Farooq U, Al-Shraideh Y, Farney AC. 5-year results of a prospective, randomized, single-center study of alemtuzumab compared with rabbit antithymocyte globulin induction in simultaneous kidneypancreas transplantation. Transplantation Proceedings 2014;46(6):1928-31. [MEDLINE: 25131073]

\section{Frey 1991 \{published data only\}}

Frey DJ, Matas AJ, Gillingham KJ, Canafax D, Payne WD, Dunn DL, et al. MALG vs OKT3 following renal transplantation: a randomized prospective trial. Transplantation Proceedings 1991;23(1 Pt 2):1048-9. [MEDLINE: 1899149]

Frey DJ, Matas AJ, Gillingham KJ, Canafax D, Payne WD, Dunn DL, et al. Sequential therapy--a prospective randomized trial of MALG versus OKT3 for prophylactic immunosuppression in cadaver renal allograft recipients. Transplantation 1992;54(1):50-6. [MEDLINE: 1631944]

\section{Friend 1987 \{published data only\}}

Friend PJ, Calne RY, Hale G, Waldmann H, Evans DB, Rolles K, et al. Prophylactic use of an antilymphocyte monoclonal antibody following renal transplantation: a randomized controlled trial. Transplantation Proceedings 1987;19(1 Pt 3):1898-900. [MEDLINE: 3079058]

Friend PJ, Hale G, Waldmann H, Gore S, Thiru S, Joysey V, et al. Campath-1M--prophylactic use after kidney transplantation. A randomized controlled clinical trial. Transplantation 1989;48(2):248-53. [MEDLINE: 2667209]

Polyclonal and monoclonal antibodies for induction therapy in kidney transplant recipients (Review)

Copyright (c) 2017 The Cochrane Collaboration. Published by John Wiley \& Sons, Ltd. 
Friend PJ, Waldmann H, Hale G, Tighe H, Calne R. The use of anti-lymphocyte monoclonal antibodies following organ transplantation [abstract]. Nephrology Dialysis Transplantation 1988;3(1):97-8. [CENTRAL: CN-00796675]

\section{Fries 1988a \{published data only\}}

Fries D. Optimal results in cadaver renal transplantation using prophylactic ALG, cyclosporin (CSA) and prednisone $(\mathrm{P})$ [abstract]. Nephrology Dialysis Transplantation 1988;3(1):95. [CENTRAL: CN-00260355]

Fries D, Hiesse C, Charpentier B, Lantz O, Bensadoun $\mathrm{H}$, Benoit G. A single center experience with "low-dose" cyclosporine in cadaveric renal transplantation. Clinical Transplants 1988:115-29. [MEDLINE: 3154465]

\section{Fukuuchi 1996 \{published data only\}}

Fukuuchi F, Lefrancois N, Bosshard S, Chapuis F, Dubernard JM, Touraine JL. Comparison of prophylactic OKT3 versus ATG in immunologic high risk cadaver renal transplant recipients [abstract]. Journal of the American Society of Nephrology 1995;6(3):1084. [CENTRAL: CN-00484030]

Fukuuchi F, Lefrancois N, Chapuis F, Gebuhrer L, Bosshard S, Dubernard JM, et al. Comparative efficacy of prophylactic monoclonal (OKT3) and polyclonal antibodies (ATG) in immunologic high-risk renal transplant recipients. Transplantation Proceedings 1996;28(5):2808-9. [MEDLINE: 8908070]

\section{Gianello 1987 \{published data only\}}

Gianello P, Squifflet JP, Pirson Y, Stoffel M, Dereme T, Alexandre GP. Cyclosporine-steroids versus conventional therapy in cadaver kidney transplantation: analysis of a randomized trial at two years. Transplantation Proceedings 1987;19(1 Pt 3):1867-72. [MEDLINE: 3547891]

\section{Grafals 2014 \{published data only\}}

Grafals M, Simpson M, Gilligan H, Pomposelli J, Akoad M, Kwaja K, et al. Prospective randomized study of low dose antithymocyte globulin as induction in non sensitized adult renal transplant recipients [abstract no: C1351]. American Journal of Transplantation 2013;13(Suppl 5):430. [EMBASE: 71057927]

Grafals M, Smith B, Murakami N, Trabucco A, Hamill K, Marangos $E$, et al. Immunophenotyping and efficacy of low dose ATG in non-sensitized kidney recipients undergoing early steroid withdrawal: a randomized pilot study. PLOS ONE [Electronic Resource] 2014;9(8):e104408. [MEDLINE: 25111080]

Smith B, Grafals M, Murakami N, Trabucco A, Hamill K, Marangos $E$, et al. Immune phenotyping and efficacy of low dose ATG in non-sensitized kidney recipients undergoing early steroid withdrawal: a randomized pilot study [abstract]. Transplantation 2014;98(Suppl 1):580. [EMBASE: 71545491]

\section{Grino 1990 \{published data only\}}

Grino JM, Alsina J, Sabater R, Castelao AM, Gil-Vernet S, Andres E, et al. Antilymphoblast globulin, cyclosporine, and steroids in cadaveric renal transplantation. Transplantation 1990;49(6):1114-7. [2360253]
Koga A, Moreso FJ, Seron D, Gil-Vernet S, Cruzado JM, Castelao AM, et al. Beneficial effect of concomitant induction with antilymphoblast globulin, cyclosporine, and steroids on long-term renal allograft outcome. Transplantation Proceedings 2004;36(5):1305-7. [MEDLINE: 15251318]

\section{Grino 1991 \{published data only\}}

Gonzalez C, Grino JM, Castelao AM, Seron D, Gil-Vernet S, Andres $E$, et al. Pre-transplant ALG, low dose cyclosporine (CsA) and steroids versus pre-transplant OKT3, CsA and steroids in kidney cadaveric transplantation [abstract]. Kidney International 1990;37(6):1601. [CENTRAL: CN-00601919]

Grino JM, Castelao AM, Gonzalez C, Seron D, Gil-Vernet S, Andres E, et al. Pre-transplant ALG, low dose cyclosporine (CYA) and steroids in kidney cadaveric transplantation [abstract]. 11th International Congress of Nephrology; 1990 Jul 15-20; Tokyo, Japan. 1990:513A. [CENTRAL: CN-00601920]

Grino JM, Castelao AM, Seron D, Gonzalez C, Galceran JM, GilVernet S, et al. Antilymphocyte globulin versus OKT3 induction therapy in cadaveric kidney transplantation: a prospective randomized study. American Journal of Kidney Diseases 1992;20(6):603-10. [MEDLINE: 1462990]

Grino JM, Castelao AM, Seron D, Gonzalez C, Galceran JM, GilVernet S, et al. Prophylactic OKT3, CyA, and steroids versus antilymphoblast globulin, CyA, and steroids in cadaveric kidney transplantation. Transplantation Proceedings 1992;24(1):39-41. [MEDLINE: 1539329]

Grino JM, Castelao AM, Seron D, Gonzalez C, Gil-Vernet S, Andres $\mathrm{E}$, et al. Antilymphocyte serum, cyclosporine and corticoids, versus OKT3, cyclosporine, and corticoids in kidney transplantation [Serum anti-lymphocyte, ciclosporine et corticoides, versus OKT3, ciclosporine et corticoides en transplantation renale]. Presse Medicale 1991;20(40):2039-42. [MEDLINE: 1837121]

Mestre M, Gonzalez C, Grino JM, Valls A, Bonete J, Mane E, et al. Sequential monitoring of immunoregulatory $T$ cell subsets in renal transplantation. Transplantation Proceedings 1992;24(1):73-5. [MEDLINE: 1539351]

\section{Grundmann 1984 \{published data only\}}

Grundmann R. Infectious diseases under prophylactic ALG treatment and their prevention in a prospectively randomized trial. Scandinavian Journal of Urology \& Nephrology Supplementum 1985;92:33-5. [MEDLINE: 3008314]

Grundmann R, Wienand P, Hesse U. Improvement in cyclosporine handling by anti-lymphocyte globulin in the early post-operative period. Proceedings of the European Dialysis \& Transplant Association - European Renal Association 1985;21:987-91. [MEDLINE: 3887394]

Grundmann R, Wienand P, Hesse U. Improvement of the cyclosporin A handling by ALG in the early postoperative period [abstract]. Kidney International 1984;26(4):637. [CENTRAL: CN-00601926]

Grundmann R, Wienand P, Meider G, Vlaho V, Pichlmaier H. Use and limits of preventive antilymphocyte globulin 
therapy following kidney transplantation. A prospective randomized study [Nutzen und grenzen einer prophylaktischen antilymphozytenglobulin-therapie nach nierentransplantation. Eine prospektiv randomisierte studie]. Klinische Wochenschrift 1984;62(20):979-85. [MEDLINE: 6389973]

\section{Grundmann 1987 \{published data only\}}

Grundmann R, Hesse U, Wienand P, Baldamus C, Arns W. Graft survival and long-term renal function after sequential conventional cyclosporin A therapy in cadaver kidney transplantation--a prospective randomized trial. Klinische Wochenschrift 1987;65(18):879-84. [MEDLINE: 3312789]

Grundmann R, Wienand P, Hesse U. Sequential conventional and cyclosporine therapy in cadaver renal transplantation-a prospective randomized trial. Transplantation Proceedings 1987;19(5):4033-4. [MEDLINE: 3313993]

\section{Guttmann 1997 \{published data only\}}

Guttmann RD, TEAMS1 Group (Transplant European Antilfa Multicenter Study Group). Randomized clinical trial of antiIfa-1 monoclonal antibody in cadaveric renal transplantation: a European multicenter study [abstract]. 16th Annual Meeting. American Society of Transplant Physicians (ASTP); 1997 May 10-14; Chicago (ILL). 1997:258. [CENTRAL: CN-00509222]

\section{Halloran 1982 \{published data only\}}

Halloran P, Ludwin D, Aprile M. Randomized comparison between cyclosporine and conventional therapy plus Minnesota antilymphocyte globulin in cadaveric renal transplantation. Transplantation Proceedings 1983;15(4 Suppl 1-2):2513-6. [EMBASE: 1984089086]

Halloran PF, Lien J, Aprile M, White N. Preliminary results of a randomized comparison of cyclosporine and Minnesota antilymphoblast globulin. Transplantation Proceedings 1982;14(4):627-30. [MEDLINE: 6301117]

\section{Hanaway 2011 \{published data only\}}

Hanaway M, Woodle ES, Mulgaonkar S, Peddi R, Harrison G, Vandeputte $\mathrm{K}$, et al. 12 month results of a multicenter, randomized trial comparing three induction agents (alemtuzumab, thymoglobulin and basiliximab) with tacrolimus, mycophenolate mofetil and a rapid steroid withdrawal in renal transplantation [abstract no: 135]. American Journal of Transplantation 2008;8(Suppl 2):215.

Hanaway MJ, Woodle ES, Mulgaonkar S, Peddi VR, Kaufman DB, First MR, et al. Alemtuzumab induction in renal transplantation. New England Journal of Medicine 2011;364(20):1909-19. [MEDLINE: 21591943]

Holman J, Harrison G, Vandeputte K, First R, Fitzsimmons W. Immune cell activation comparing three induction agents (alemtuzumab, thymoglobulin and basiliximab) with tacrolimus, mycophenolate mofetil and a rapid steroid withdrawal in renal transplantation [abstract no: 553]. Transplantation 2008;86(2 Suppl):194. [CENTRAL: CN-00676047]

Mulgaonkar S, Hanaway M, Woodle ES, Peddi R, Harrison G, Vandeputte $\mathrm{K}$, et al. Continuing 24 month results of a multicenter, randomized trial comparing three induction agents (alemtuzumab, thymoglobulin and basiliximab) with tacrolimus, mycophenolate mofetil and a rapid steroid withdrawal in renal transplantation [abstract no: 312]. American Journal of Transplantation 2009;9(Suppl 2):282. [EMBASE: 70010185]

Peddi R, Hanaway M, Woodle S, Mulgaonkar S, Harrison G, Vandeputte $\mathrm{K}$, et al. Final 36 month results of a randomized trial comparing three induction agents (alemtuzumab, thymoglobulin and basiliximab) with tacrolimus, mycophenolate mofetil and rapid steroid withdrawal in renal transplantation [abstract no: 35]. American Journal of Transplantation 2010;10(Suppl 4):49. [EMBASE: 70463396]

Woodle S, Hanaway M, Mulgaonkar S, Peddi R, Harrison G, Vandeputte $\mathrm{K}$, et al. 12 month results of a multicenter, randomized trial comparing three induction agents (alemtuzumab, thymoglobulin and basiliximab) with tacrolimus, mycophenolate mofetil and a rapid steroid withdrawal in renal transplantation [abstract no: 876]. Transplantation 2008;86(2 Suppl):306. [CENTRAL: CN-00653740]

\section{Hanto 1991 \{published data only\}}

Hanto DW, Jendrisak MD, McCullough CS, So SK, Marsh JW, Rush T, et al. A prospective randomized comparison of prophylactic ALG and OKT3 in cadaver kidney allograft recipients. Transplantation Proceedings 1991;23(1 Pt 2):1050-1. [MEDLINE: 1899150]

Hanto DW, Jendrisak MD, So SK, McCullough CS, Rush TM, Michalski SM, et al. Induction immunosuppression with antilymphocyte globulin or OKT3 in cadaver kidney transplantation. Results of a single institution prospective randomized trial. Transplantation 1994;57(3):377-84. [MEDLINE: 8108873]

\section{Henry 2001 \{published data only\}}

Henry ML, Elkhammas EA, Bumgardner G, Davies EA, Pelletier RP, et al. A prospective randomized trial of neoral and cellcept with and without OKT3 induction [abstract]. Transplantation 1998;65(12):S191. [CENTRAL: CN-00445692]

Henry ML, Pelletier RP, Elkhammas EA, Bumgardner GL, Davies EA, Ferguson RM. A randomized prospective trial of OKT3 induction in the current immunosuppression era. Clinical Transplantation 2001;15(6):410-4. [MEDLINE: 11737118]

\section{Hourmant 1985a \{published data only\}}

Hourmant M, Soulillou JP, Guenel J. Comparison of three immuno-suppressive regimens in kidney transplantation: CyA, ATG and CyA, ATG and conventional treatment - a onecenter randomized study [abstract]. Kidney International 1984;26(4):639. [CENTRAL: CN-00626072]

Hourmant M, Soulillou JP, Guenel J. Comparison of three immunosuppressive regimens in kidney transplantation: a single-centre randomised study. Proceedings of the European Dialysis \& Transplant Association - European Renal Association 1985;21:982-6. [MEDLINE: 3887393]

Hourmant M, Soulillou JP, Guenel J. Comparison of three immunosuppressive strategies in kidney transplantation: Antithymocyte globulin and conventional treatment, antithymocyte globulin and cyclosporine, and cyclosporine.

Polyclonal and monoclonal antibodies for induction therapy in kidney transplant recipients (Review) 
A one-center randomized study. Transplantation Proceedings 1985;17(1 Pt 2):1158-61. [EMBASE: 1985079646]

\section{Hourmant 1996 \{published data only\}}

Hourmant M. Multicenter comparative study of an anti-lfa1 adhesion molecule monoclonal antibody and thymoglobulin in prophylaxis of acute rejection in kidney transplantation. [abstract]. ISN XIII International Congress of Nephrology; 1995 Jul 2-6; Madrid, Spain. 1995:336. [CENTRAL: CN-00509239]

Hourmant M, Bedrossian J, Durand D, Kessler M, Le Branchu Y, Caudrelier $\mathrm{P}$, et al. Multicenter comparative study of an anti-LFA-1 adhesion molecule monoclonal antibody and antithymocyte globulin in prophylaxis of acute rejection in kidney transplantation. Transplantation Proceedings 1995;27(1):864. [MEDLINE: 7879209]

Hourmant M, Bedrossian J, Durand D, Kessler M, Lebranchu Y, Caudrelier P, et al. Multicenter study of an anti-LFA1 adhesion molecule monoclonal antibody (Moab) and anti-thymocyte globulin (ATG) in prophylaxis of acute rejection (AR) in kidney transplantation (KT) [abstract]. 14th Annual Meeting. American Society of Transplant Physicians (ASTP); 1995 May 14-17; Chicago (ILL). 1995.

Hourmant M, Bedrossian J, Durand D, Lebranchu Y, Renoult E, Caudrelier $\mathrm{P}$, et al. A randomized multicenter trial comparing leukocyte function-associated antigen-1 monoclonal antibody with rabbit antithymocyte globulin as induction treatment in first kidney transplantations. Transplantation 1996;62(11):1565-70. [MEDLINE: 8970608]

Jakobsen 1981 \{published data only\}

Jakobsen A, Flatmark A, Lundgren G, Solheim B, Groth CG. A controlled trial with AHLG Behring: lack of effect on cadaveric renal graft survival. Scandinavian Journal of Urology \& Nephrology Supplementum 1981;64:205-12. [MEDLINE: 6755682]

\section{Kasiske 1997 \{published data only\}}

Kasiske BL, Goerdt PJ, Heim-Duthoy K, Rao KV, Dahl DC, Ney AL, et al. Interim results of a randomized controlled trial comparing antithymocyte globulin (ATG) with cyclosporine (CSA) induction [abstract]. Journal of the American Society of Nephrology 1995;6(3):1097. [CENTRAL: CN-00484599]

Kasiske BL, Johnson HJ, Goerdt PJ, Heim-Duthoy KL, Rao VK, Dahl DC, et al. A randomized trial comparing cyclosporine induction with sequential therapy in renal transplant recipients. American Journal of Kidney Diseases 1997;30(5):639-45. [MEDLINE: 9370178]

\section{Khosroshahi 2008 \{published data only\}}

Khosroshahi HT, Tubbs RS, Shoja MM, Ghafari A, Noshad H, Ardalan MR. Effect of prophylaxis with low-dose anti-thymocyte globulin on prevention of acute kidney allograft rejection. Transplantation Proceedings 2008;40(1):137-9. [MEDLINE: 18261569]

\section{Kountz 1977 \{published data only\}}

Butt KM, Zielinski CM, Parsa I, Elberg AJ, Wechter W, Kountz SL. Trends in immunosuppression for kidney transplantation.
Kidney International - Supplement 1978;13(Suppl 8):S95-8. [MEDLINE: 357820]

Kountz SL, Butt KH, Rao TK, Zielinski CM, Rafi M, Schultz JR. Antithymocyte globulin (ATG) dosage and graft survival in renal transplantation. Transplantation Proceedings 1977;9(1):1023-5. [MEDLINE: 325728]

\section{Kreis 1980 \{published data only\}}

Crosnier J, Kreis H, Descamps JM, Mansouri R. Are there nonsteroid-dependent rejection episodes?. Proceedings of the European Dialysis \& Transplant Association 1980;17:391-5. [MEDLINE: 7017680]

Kreis H, Mansouri R, Descamps JM, Dandavino R, N'Guyen AT, Bach JF, et al. Antithymocyte globulin in cadaver kidney transplantation: a randomized trial based on T-cell monitoring. Kidney International 1981;19(3):438-44. [MEDLINE: 7017244]

\section{Kreis 1986 \{published data only\}}

Kreis H, Chkoff N, Chatenoud L. Prolonged administration of a monoclonal anti-T3 cell antibody (ORTHOCLONE OKT3) to kidney allograft recipients. Transplantation Proceedings 1986;18(4):954-6. [EMBASE: 1986223864]

\section{Kumar 1998a \{published data only\}}

Kumar MS, Cahill K, Kumar AM, Panigrahi D, Seirka D, Singleton $\mathrm{R}$, et al. ATGAM versus OKT3 induction therapy in cadaveric kidney transplantation: patient and graft survival, CD3 subset, infection, and cost analysis. Transplantation Proceedings 1998;30(4):1351-2. [MEDLINE: 9636549]

Kumar MS, Laskow DA, Panigrahi D, Kumar AM, Cahill K, Pankewyez $\mathrm{O}$, et al. Correlation of CD3 counts and serum $\mathrm{IL}-10$ levels during induction to incidence of rejections and infections in cadaveric kidney recipients [abstract]. Journal of the American Society of Nephrology 1998;9(Program \& Abstracts):683A. [CENTRAL: CN-00446225]

\section{Launois 1977 \{published data only\}}

Launois B, Campion JP, Fauchet R, Kerbaol M, Cartier F. Prospective randomized clinical trial in patients with cadaver-kidney transplants. Transplantation Proceedings 1977;9(1):1027-30. [MEDLINE: 325729]

\section{Lazarovits 1993 \{published data only\}}

Lazarovits AI, Rochon J, Banks L, Hollomby DJ, Muirhead N, Jevnikar AM, et al. Human mouse chimeric CD7 monoclonal antibody (SDZCHH380) for the prophylaxis of kidney transplant rejection. Journal of Immunology 1993;150(11):5163-74. [MEDLINE: 7684422]

Lazarovits AI, Rochon J, Banks L, Hollomby DJ, Muirhead N, Jevnikar AM, et al. Human mouse chimeric CD7 monoclonal antibody (SDZCHH380) for the prophylaxis of kidney transplant rejection. Transplantation Proceedings 1993;25(1 Pt 1):820-2. [MEDLINE: 7679844]

Sharma L, Muirhead N, Lazarovits Al. Human mouse chimeric $\mathrm{Cd} 7$ monoclonal antibody (SCZCHH380) for the prophylaxis of kidney transplant rejection: no transplant losses and absence of chronic rejection at 4 years [abstract]. 15th Annual Meeting 
American Society of Transplant Physicians (ASTP); 1996 May 10-14; Chicago Ill. 1996.

\section{Lu 2011 \{published data only\}}

Lu TM, Yang SL, Wu WZ, Tan JM. Alemtuzumab induction therapy in highly sensitized kidney transplant recipients. Chinese Medical Journal 2011;124(5):664-8. [MEDLINE: 21518554]

\section{Maiorca 1984 \{published data only\}}

Maiorca R, Cristinelli L, Scolari S, Sandrini S, Brunori G, Tonini G, et al. Prospective controlled trial with antilynfocytic globulin (A.L.G.), in first cadaveric renal transplants treated with lowdose steroids both in prophylaxis and rejection therapy [abstract]. Kidney International 1984;26(4):644. [CENTRAL: CN-00775915]

\section{Margreiter 2008 \{published data only\}}

Margreiter R, Klempnauer J, Neuhaus P, Muehlbacher F. Alemtuzumab (Campath-1H) induction followed by tacrolimus monotherapy vs tacrolimus based triple drug immunosuppression in cadaveric renal transplantation - results of a multicenter trial [abstract no: 333]. American Journal of Transplantation 2007;7(Suppl 2):234. [CENTRAL: CN-00644175]

* Margreiter R, Klempnauer J, Neuhaus P, Muehlbacher F, Boesmueller C, Calne RY. Alemtuzumab (Campath-1H) and tacrolimus monotherapy after renal transplantation: results of a prospective randomized trial. American Journal of Transplantation 2008;8(7):1480-5. [MEDLINE: 18510632]

\section{Martins 2004 \{published data only\}}

Martins LS, Sarmento AM, Dias L, Henriques AC, Borner G, Cabrita A. Results of safety and efficacy of two ATG bolustherapy regimen vs standard therapy in prophylaxis after renal transplantation in end stage renal disease patients [abstract]. Transplantation 2004;78(2 Suppl):266. [CENTRAL: CN-00509341]

\section{Michael 1989 \{published data only\}}

Michael H, Francos G, Burke J, Besarab A, Jarrell B, Moritz M, et al. Effect of cyclosporine (CYA) versus antilymphocyte globulin (ALG) on delayed graft function (DGF) in renal transplant patients [abstract]. Kidney International 1989;35(1):520. [CENTRAL: CN-00626110]

* Michael HJ, Francos GC, Burke JF, Besarab A, Moritz M, Gillum D, et al. A comparison of the effects of cyclosporine versus antilymphocyte globulin on delayed graft function in cadaver renal transplant recipients. Transplantation 1989;48(5):805-8. [MEDLINE: 2683263]

\section{Minnesota Study 1982 \{published data only\}}

Boudreaux JP, McHugh L, Canafax DM, Ascher N, Sutherland DE, Payne W, et al. The impact of cyclosporine and combination immunosuppression on the incidence of posttransplant diabetes in renal allograft recipients. Transplantation 1987;44(3):376-81. [MEDLINE: 3307061]

Canafax DM, Min DI, Gruber SA, Matas AJ, Payne WD, Dunn DL, et al. Immunosuppression for cadaveric renal allograft recipients: a risk-factor matched comparison of the Minnesota randomized trial with an antilymphoblast globulin, azathioprine, cyclosporine, and prednisone protocol. Clinical Transplantation 1989;3(2):110-9. [EMBASE: 1989138098]

Canafax DM, Simmons RL, Sutherland DE, Fryd DS, Strand MH, Ascher NL, et al. Early and late effects of two immunosuppressive drug protocols on recipients of renal allografts: results of the Minnesota randomized trial comparing cyclosporine versus antilymphocyte globulin-azathioprine. Transplantation Proceedings 1986;18(2 Suppl 1):192-6. [MEDLINE: 3515687]

Canafax DM, Torres A, Fryd DS, Heil JE, Strand MH, Ascher NL, et al. The effects of delayed function on recipients of cadaver renal allografts. A study of 158 patients randomized to cyclosporine or ALG-azathioprine. Transplantation 1986;41(2):177-81. [MEDLINE: 3511581]

Ferguson RM, Rynasiewicz JJ, Sutherland DE, Simmons RL, Najarian JS. Cyclosporin A in renal transplantation: a prospective randomized trial. Surgery 1982;92(2):175-82. [MEDLINE: 6285533]

Frick T, Fryd DS, Goodale RL, Simmons RL, Sutherland DE, Najarian JS. Incidence and treatment of candida esophagitis in patients undergoing renal transplantation. Data from the Minnesota prospective randomized trial of cyclosporine versus antilymphocyte globulin-azathioprine. American Journal of Surgery 1988;155(2):311-3. [MEDLINE: 3277475]

Frick TW, Fryd DS, Goodale RL, Simmons RL, Sutherland DE, Najarian JS. Lack of association between azathioprine and acute pancreatitis in renal transplantation patients. Lancet 1991;337(8735):251-2. [MEDLINE: 1670892]

Frick TW, Fryd DS, Sutherland DE, Goodale RL, Simmons RL, Najarian JS. Hypercalcemia associated with pancreatitis and hyperamylasemia in renal transplant recipients. Data from the Minnesota randomized trial of cyclosporine versus antilymphoblast azathioprine. American Journal of Surgery 1987;154(5):487-9. [MEDLINE: 2445214]

Gores PF, Fryd DS, Sutherland DE, Najarian JS, Simmons RL. Hyperuricemia after renal transplantation. American Journal of Surgery 1988;156(5):397-400. [MEDLINE: 3056057]

Gruber S, Pescovitz M, Simmons R, Fryd D. Cyclosporine use lowers risk of thromboembolism in diabetic renal allograft recipients [abstract]. Kidney International 1987;31(1):458. [CENTRAL: CN-00550666]

Gruber SA, Chavers B, Payne WD, Fryd DS, Canafax DM, Simmons RL, et al. Allograft renal vascular thrombosis-lack of increase with cyclosporine immunosuppression. Transplantation 1989;47(3):475-8. [MEDLINE: 2646779]

Gruber SA, Chavers B, Payne WD, Fryd DS, Canafax DM, Simmons RL, et al. Frequency of allograft renal vascular thrombosis under three immunosuppressive regimens at a single institution. Transplantation Proceedings 1989;21(1 Pt 2):2139-40. [MEDLINE: 2652690]

Gruber SA, Pescovitz M, Simmons RL, Najarian JS, Ascher NL, Payne WD, et al. Thromboembolic complications after renal transplantation: results from the randomized trial 
of cyclosporine $v$ azathioprine-antilymphocyte globulin. Transplantation Proceedings 1987;19(1 Pt 2):1815-6. [MEDLINE: 3079041]

Gruber SA, Pescovitz MD, Simmons RL, Najarian JS, Ascher NL, Payne WD, et al. Thromboembolic complications in renal allograft recipients. A report from the prospective randomized study of cyclosporine versus azathioprine-antilymphocyte globulin. Transplantation 1987;44(6):775-8. [MEDLINE: 3321586]

Gruber SA, Simmons RL, Najarian JS, Vercellotti G, Ascher NL, Dunn DL, et al. Erythrocytosis and thromboembolic complications after renal transplantation: results from a randomized trial of cyclosporine versus azathioprineantilymphocyte globulin. Transplantation Proceedings 1988;20(3 Suppl 3):948-50. [MEDLINE: 3291331]

Hesse UJ, Fryd DS, Chatterjee SN, Simmons RL, Sutherland DE, Najarian JS. Pulmonary infections. The Minnesota randomized prospective trial of cyclosporine vs azathioprineantilymphocyte globulin for immunosuppression in renal allograft recipients. Archives of Surgery 1986;121(9):1056-60. [MEDLINE: 3527111]

Johnson CP, Simmons RL, Sutherland DE, Canafax DM, Ascher NL, Payne WD, et al. A randomized trial comparing cyclosporine with antilymphoblast-globulin-azathioprine for renal allograft recipients. Results at $21 / 2-6$ years. Transplantation 1988;45(2):380-5. [MEDLINE: 3278431]

Najarian JS, Ferguson RM, Sutherland DE. A prospective trial of the efficacy of cyclosporine in renal transplantation at the University of Minnesota. Transplantation Proceedings 1983;15(1):438-41. [EMBASE: 1983156214]

* Najarian JS, Fryd DS, Strand M, Canafax DM, Ascher NL, Payne WD, et al. A single institution, randomized, prospective trial of cyclosporin versus azathioprine-antilymphocyte globulin for immunosuppression in renal allograft recipients. Annals of Surgery 1985;201(2):142-57. [MEDLINE: 3882063]

Pescovitz MD, Gruber SA, Ascher NL, Kruse LV, Najarian JS, Payne WD, et al. Frequency of diabetes-related complications in renal allograft recipients prospectively randomized to cyclosporine or azathioprine. Transplantation Proceedings 1987;19(1 Pt 2):1537-8. [MEDLINE: 3274376]

Rynasiewicz JJ, Sutherland DE, Ferguson RM, Squifflet JP, Morrow CE, Goetz FC, et al. Cyclosporin A for immunosuppression: observations in rat heart, pancreas, and islet allograft models and in human renal and pancreas transplantation. Diabetes 1982;31 Suppl 4:92-108. [MEDLINE: 6819969]

Simmons RL, Canafax DM, Strand M, Ascher NL, Payne WD, Sutherland DE, et al. Management and prevention of cyclosporine nephrotoxicity after renal transplantation: use of low doses of cyclosporine, azathioprine, and prednisone. Transplantation Proceedings 1985;17(4 Suppl 1):266-75. [MEDLINE: 3895665]

Sutherland DE, Fryd DS, Strand M, Ascher N, Simmons RL, Najarian JS. Results of renal transplantation in diabetics at the University of Minnesota since 1979, including a comparison of outcome in diabetic and nondiabetic recipients randomized to cyclosporine versus azathioprine for immunosuppression. Transplantation Proceedings 1984;16(3):629-32. [MEDLINE: 6375030]

Sutherland DE, Fryd DS, Strand MH, Canafax DM, Ascher NL, Payne WD, et al. Results of the Minnesota randomized prospective trial of cyclosporine versus azathioprineantilymphocyte globulin for immunosuppression in renal allograft recipients. American Journal of Kidney Diseases 1985;5(6):318-27. [MEDLINE: 3893106]

Sutherland DE, Payne WD, Fryd DS. Comparison of cyclosporine and azathioprine for immunosuppression in diabetic and nondiabetic renal allograft recipients. Transplantation Proceedings 1985;17(1 Pt 2):1204-11. [EMBASE: 1985079661]

Sutherland DE, Strand M, Fyd DS, Ferguson RM, Simmons RL, Ascher NL, et al. Comparison of azathioprine-antilymphocyte globulin versus cyclosporine in renal transplantation. American Journal of Kidney Diseases 1984;3(6):456-61. [MEDLINE: 6372449]

\section{Morales 1994a \{published data only\}}

* Anonymous. Cyclosporine monotherapy versus OKT3 and cyclosporine versus prednisone and cyclosporine as induction therapy in older renal transplant patients: a multicenter randomized study. Spanish Monotherapy Study Group. Transplantation Proceedings 1994;26(5):2522-4. [MEDLINE: 7940775]

Morales JM, Marcen R, Grino JM, Arias M, Vilardell J. Comparison of three induction protocols in older renal transplant patients: cyclosporine (CYA) monotherapy (M) vs OKT3 and CYNA vs prednisone $(\mathrm{P})$ and CYA. A multicenter randomized study [abstract]. Journal of the American Society of Nephrology 1993;4(Program \& Abstracts):950. [CENTRAL: CN-00485149]

\section{Mourad 1998 \{published data only\}}

Anonymous. Tacrolimus in renal transplantation: a comparison of induction vs noninduction therapy (triple therapy): threemonth results. Transplantation Proceedings 1999;31(1-2):330-1. [MEDLINE: 10083131]

Antoine C, Thakur S, Daugas E, Fraoui R, Boudjeltia S, Julia $P$, et al. Vascular microthrombosis in renal transplant recipients treated with tacrolimus. Transplantation Proceedings 1998;30(6):2813-4. [MEDLINE: 9745577]

Charpentier B. An induction versus no-induction protocol in anticalcineurin-based immunosuppression using very low-dose steroids. Transplantation Proceedings 2001;33(4 Suppl):3S-10S. [MEDLINE: 11406262]

Charpentier B. Induction versus non-induction protocols in anti-calcineurin-based immunosuppression. Transplantation Proceedings 2001;33(7-8):3334-6. [MEDLINE: 11750425]

Mourad G, French and Belgian Tacrolimus Renal Transplantation Study Group. ATG-Induction vs. noninduction with tacrolimus-based immunosuppression in renal transplantation [abstract]. XVIII International Congress of the 
Transplantation Society; 2000 Aug 27-Sept 1; Rome, Italy. 2000. [CENTRAL: CN-00446848]

* Mourad G, Garrigue V, Squifflet JP, Besse T, Berthoux F, Alamartine $E$, et al. Induction versus noninduction in renal transplant recipients with tacrolimus-based immunosuppression. Transplantation 2001;72(6):1050-5. [MEDLINE: 11579299]

\section{Niaudet 1990 \{published data only\}}

Niaudet P, Murcia I, Jean G, Broyer M. A comparative trial of OKT3 and antilymphocyte serum in the preventive treatment of rejection after kidney transplantation in children [Essai comparatif de l'OKT3 et du serum antilymphocytaire dans le traitement preventif du rejet apres transplantation renale chez l'enfant]. Annales de Pediatrie 1990;37(2):83-5. [MEDLINE: 2138866]

\section{Norman 1988 \{published data only\}}

Norman DJ, Shield CF 3rd, Barry J, Bennett WM, Henell K, Kimball J, et al. Early use of OKT3 monoclonal antibody in renal transplantation to prevent rejection. American Journal of Kidney Diseases 1988;11(2):107-10. [MEDLINE: 3277400]

\section{Norman 1993 \{published data only\}}

Abramowicz D, Norman DJ, Goldman M, De Pauw L, Kinnaert P, Kahana $L$, et al. OKT3 prophylaxis improves long-term renal graft survival in high-risk patients as compared to cyclosporine: combined results from the prospective, randomized Belgian and US studies. Transplantation Proceedings 1995;27(1):852-3. [MEDLINE: 7879204]

Abramowicz D, Norman DJ, Vereerstraeten P, Goldman M, De Pauw L, Vanherweghem JL, et al. OKT3 prophylaxis in renal grafts with prolonged cold ischemia times: association with improvement in long-term survival. Kidney International 1996;49(3):768-72. [MEDLINE: 8648918]

* Norman DJ, Kahana L, Stuart FP Jr, Thistlethwaite JR Jr, Shield CF 3rd, Monaco A, et al. A randomized clinical trial of induction therapy with OKT3 in kidney transplantation. Transplantation 1993;55(1):44-50. [MEDLINE: 8420063]

Shield CF 3rd, Jacobs RJ, Wyant S, Das A. A cost-effectiveness analysis of OKT3 induction therapy in cadaveric kidney transplantation. American Journal of Kidney Diseases 1996;27(6):855-64. [MEDLINE: 8651251]

\section{Norman 1993a \{published data only\}}

Norman DJ, Kimball JA, Barry JM. Cytokine-release syndrome: differences between high and low doses of OKT3. Transplantation Proceedings 1993;25(2 Suppl 1):35-8. [MEDLINE: 8465420]

Norman DJ, Kimball JA, Bennett WM, Shihab F, Batiuk TD, Meyer MM, et al. A prospective, double-blind, randomized study of high-versus low-dose OKT3 induction immunosuppression in cadaveric renal transplantation. Transplant International 1994;7(5):356-61. [MEDLINE: 7993573]

\section{Norrby 1997 \{published data only\}}

Norrby J, Olausson M. A randomized clinical trial using ATG Fresenius or ATG Merieux as induction therapy in kidney transplantation. Transplantation Proceedings 1997;29(7):3135-6. [MEDLINE: 9365697]

\section{Novick 1983 \{published data only\}}

Novick AC, Braun WE, Steinmuller D, Buszta C, Greenstreet R, Kiser W. A controlled randomized double-blind study of antilymphoblast globulin in cadaver renal transplantation. Transplantation 1983;35(2):175-9. [MEDLINE: 6338636]

\section{Perez-Tamajon 1996 \{published data only\}}

Perez-Tamajon L, González JM, Torres A, Rodriguez A, Hernandez D, Losada M, et al. Induction treatment with sequential quadruple therapy in renal transplantation: polyclonal vs. monoclonal AC at low doses [abstract]. Nefrología 1996;16:97. [CENTRAL: CN-00602023]

\section{Pernin 2012 \{published data only\}}

Pernin V, Portales P, Szwarc I, Garrigue V, Vetromile F, Delmas S, et al. Lymphocyte reconstitution after induction with thymoglobulin in renal transplantation: Impact of the mode of administration (daily vs intermittent treatment based on T lymphocyte monitoring) [abstract no: SAP671]. Nephrology Dialysis Transplantation 2012;27(Suppl 2):ii533-4. [EMBASE: 70766907]

\section{Raffaele 1991 \{published data only\}}

Raffaele P, Pouteil-Noble C, Lefrancois N, Bosshard S, Betuel H, Aymard M, et al. Influence of a randomized monoclonal or polyclonal program of therapy on cytomegalovirus infection in kidney transplantation. Transplantation Proceedings 1991;23(1 Pt 2):1361-2. [MEDLINE: 1846465]

\section{Rostaing 2010 \{published data only\}}

Rostaing L, Lavayssiere L, Kamar N. Hematologic adverse effects of 2 different polyclonal antilymphocyte preparations in de novo kidney transplant patients. Experimental \& Clinical Transplantation 2010;8(2):178-80. [MEDLINE: 20565376]

\section{Sakhrani 1992 \{published data only\}}

Sakhrani L, Aswad S, Obispo E, Mendez RG, Khetan U, Asai P, et al. Optimal dose of Minnesota antilymphocyte globulin for induction immunosuppression in cadaveric renal transplants. Transplantation Proceedings 1992;24(5):1730-1. [MEDLINE: 1412814]

\section{Samsel 1999 \{published data only\}}

Samsel R, Chmura A, Korczak-Kowalska G, Wlodarczyk Z, Pliszczynski J, Adadynski L, et al. Long term results of single perioperative high dose of ATG as induction in kidney transplantation [abstract]. American Journal of Transplantation 2004;4(Suppl 8):351. [CENTRAL: CN-00509456]

Samsel R, Chmura A, Wlodarczyk Z, Wyzgal J, Cieciura T, Lagiewska B, et al. Perioperative single high dose ATG-Fresenius $S$ administration as induction immunosuppressive therapy in cadaveric renal transplantation--preliminary results. Annals of Transplantation 1999;4(2):37-9. [MEDLINE: 10850589] 
* Samsel R, Pliszczynski J, Chmura A, Korczak G, Wlodarczyk Z, Cieciura T, et al. Safety and efficacy of high dose ATG bolus administration on rewascularization in kidney graft patients-long term results. Annals of Transplantation 2008;13(1):32-9. [MEDLINE: 18344941]

Samsel R, Rowinski W, Chmura A, Wlodarczyk Z, Wyzgal J, Cieciura T, et al. Perioperative administration of single, highdose of ATG-Fresenius-S as an induction immunosuppressive therapy in cadaveric renal transplantation: preliminary results. Transplantation Proceedings 2001;33(6):2952-4. [MEDLINE: 11543807]

\section{Sansom 1976 \{published data only\}}

Sansom JR, Barnes AD, Hall CL. A randomized prospective clinical trial of antilymphocyte globulin in 100 cadaveric renal transplants. Postgraduate Medical Journal 1976;52 (5 Suppl):75-8. [MEDLINE: 792851]

\section{Sharaf El Din 2006 \{published data only\}}

Sharaf EI Din UA, Sharaf EI Din BA, El Damanhoury HA. Alemtuzumab induction as steroid sparing agent in living kidney transplantation: a randomized prospective controlled trial [abstract no: SA-P0449]. Journal of the American Society of Nephrology 2006;17(Abstracts):670A. [CENTRAL: CN-00644281]

\section{Sheashaa 2008 \{published data only\}}

Sheashaa HA, Hamdy AF, Bakr MA, Abdelbaset SF, Ghoneim MA. Long-term evaluation of single bolus high dose ATG induction therapy for prophylaxis of rejection in live donor kidney transplantation. International Urology \& Nephrology 2008;40(2):515-20. [MEDLINE: 17978857]

\section{Shield 1993 \{published data only\}}

Shield CF 3rd, Beilman G. Safety of OKT3 use in the operating room. Transplantation Proceedings 1993;25(2 Suppl 1):43-4. [MEDLINE: 8465423]

\section{Slakey 1993 \{published data only\}}

Johnson CP, Slakey DP, Callaluce RD, Browne BJ, Roza AM, Adams MB. Prospective randomized comparison of quadruple vs triple therapy for first cadaver transplants with immediate function. Transplantation Proceedings 1993;25(1 Pt 1):585-6. [MEDLINE: 8438425]

* Slakey DP, Johnson CP, Callaluce RD, Browne BJ, Zhu YR, Roza AM, et al. A prospective randomized comparison of quadruple versus triple therapy for first cadaver transplants with immediate function. Transplantation 1993;56(4):827-31. [MEDLINE: 8212201]

\section{Smeekens 2013 \{published data only\}}

Joosten I, Baas MC, Kamburova EG, van den Hoogen MW, Koenen HJ, Hilbrands LB. Anti-B cell therapy with rituximab as induction therapy in renal transplantation. Transplant Immunology 2014;31(4):207-9. [MEDLINE: 25270152]

Kamburova E, Koenen $\mathrm{H}$, van den Hoogen M, Joosten I, Hilbrands $L$. A single dose of rituximab results in a long lasting B-cell depletion in peripheral blood, without affecting the peripheral T-cell compartment [abstract no: 186]. American
Journal of Transplantation 2013;13(Suppl S5):87. [EMBASE: 71056762]

Kamburova EG, Koenen HJ, van den Hoogen MW, Baas MC, Joosten I, Hilbrands LB. Longitudinal analysis of $T$ and $B$ cell phenotype and function in renal transplant recipients with or without rituximab induction therapy. PLOS ONE [Electronic Resource] 2014;9(11):e112658. [MEDLINE: 25393622]

Kamburova EG, van den Hoogen MW, Koenen HJ, Baas MC, Hilbrands LB, Joosten I. Cytokine release after treatment with rituximab in renal transplant recipients. Transplantation 2015;99(9):1907-11. [MEDLINE: 25675201]

Smeekens SP, van den Hoogen MW, Kamburova EG, van de Veerdonk FL, Joosten I, Koenen HJ, et al. The effects of in vivo B-cell depleting therapy on ex-vivo cytokine production. Transplant Immunology 2013;28(4):183-8. [MEDLINE: 23651756]

van den Hoogen M, Kamburova E, Baas M, Steenbergen E, Florquin $\mathrm{S}$, Koenen $\mathrm{H}$, et al. Type of rejection and biopsy findings after induction therapy with a single dose of rituximab [abstract]. Transplantation 2014;98(Suppl 1):463. [EMBASE: 71545077]

van den Hoogen M, Steenbergen E, Hoitsma A, Hilbrands L. Placebo-controlled trial [abstract no: 266.1]. American Journal of Transplantation 2013;13(Suppl S5):112-3. [EMBASE: 71056843]

* van den Hoogen MW, Kamburova EG, Baas MC, Steenbergen EJ, Florquin S, Koenen $\mathrm{H}$, et al. Rituximab as induction therapy after renal transplantation: a randomized, double-blind, placebo-controlled study of efficacy and safety. American Journal of Transplantation 2015;15(2):407-16. [MEDLINE: 25612493]

\section{Spillner 1998 \{published data only\}}

Spillner J, Kohnle M, Albrecht KH, Heemann U. Anti-LFA-1 monoclonal antibody in renal transplantation: renal function, infections, and other complications. Transplantation Proceedings 1998;30(5):2163. [MEDLINE: 9723427]

\section{Squifflet 1997 \{published data only\}}

* Squifflet JP, Besse T, Malaise J, Mourad M, Delcorde C, Hope JA, et al. BTI-322 for induction therapy after renal transplantation: a randomized study. Transplantation Proceedings 1997;29(1-2):317-9. [MEDLINE: 9123018]

Squifflet JP, Besse T, Mourad M, Malaise J, Delcorde C, Pirson Y, et al. A randomized study of BTI-322 for the prevention of renal allograft rejection: one year follow up [abstract]. 16th Annual Meeting. American Society of Transplant Physicians (ASTP); 1997 May 10-14; Chicago (ILL). 1997:258. [CENTRAL: CN-00509490]

\section{Steinmuller 1991 \{published data only\}}

Steinmuller DR, Hayes J, Novick AC, Streem SB, Hodge E, Slavis S, et al. Comparison of OKT3 to ALG for prophylaxis for patients with acute renal failure after cadaver renal transplantation [abstract]. 11th International Congress of Nephrology; 1990 Jul 15-20; Tokyo, Japan. 1990:512A. [CENTRAL: CN-00716029] 
* Steinmuller DR, Hayes JM, Novick AC, Streem SB, Hodge E, Slavis S, et al. Comparison of OKT3 with ALG for prophylaxis for patients with acute renal failure after cadaveric renal transplantation. Transplantation 1991;52(1):67-71. [MEDLINE: 1677502]

\section{Stevens 2008 \{published data only\}}

Stevens R, Foster K, Miles C, Rigley T, Kalil A, Wrenshall L. A randomized $2 \times 2$ factorial trial: Part 1 , single-dose rATG induction improves long-term renal transplant outcomes [abstract]. Transplantation 2014;98(Suppl 1):91. [EMBASE: 71543822]

Stevens R, Foster K, Miles C, Rigley T, Wrenshall L. A randomized trial of renal transplantation: Steroid and calcineurin-inhibitor withdrawal after rabbit anti-thymocyte globulin induction [abstract]. Transplantation 2014;98(Suppl 1):476. [EMBASE: 71545124]

Stevens RB. Modern approaches to combining sirolimus with calcineurin inhibitors. Transplantation Proceedings 2008;40(10 Suppl):S21-4. [MEDLINE: 19100901]

Stevens RB, Foster KW, Miles CD, Kalil AC, Florescu DF, Sandoz JP, et al. A randomized $2 \times 2$ factorial clinical trial of renal transplantation: steroid-free maintenance immunosuppression with calcineurin inhibitor withdrawal after six months associates with improved renal function and reduced chronic histopathology. PLOS ONE [Electronic Resource] 2015;10(10):e0139247. [MEDLINE: 26465152]

* Stevens RB, Foster KW, Miles CD, Lane JT, Kalil AC, Florescu DF, et al. A randomized $2 \times 2$ factorial trial, part 1 : single-dose rabbit antithymocyte globulin induction may improve renal transplantation outcomes. Transplantation 2015;99(1):197-209. [MEDLINE: 25083614]

Stevens RB, Kalil AC, Miles CD, Florescu DF, Lane JT, Skorupa AJ, et al. Reduced patient mortality and infectious complications, and superior graft function, in renal transplant patients after single-dose RATG induction; 5-year data from a prospective, randomized trial [abstract no: 38]. American Journal of Transplantation 2010;10(Suppl 4):49-50. [EMBASE: 70463399]

Stevens RB, Lane JT, Boerner BP, Miles CD, Rigley TH, Sandoz JP, et al. Single-dose rATG induction at renal transplantation: superior renal function and glucoregulation with less hypomagnesemia. Clinical Transplantation 2012;26(1):123-32. [MEDLINE: 21401720]

Stevens RB, Lane JT, Boerner BP, Miles CD, Rigley TH, Sandoz JP, et al. Single-dose rabbit anti-thymocyte globulin (rATG) induction reduces tubular injury after renal transplantation, resulting in superior renal function, serum $\mathrm{Mg++}$ retention, and glucose regulation [abstract no: 1703]. American Journal of Transplantation 2010;10(Suppl 4):522. [EMBASE: 70465078]

Stevens RB, Mercer D, Rigley T, Nielsen K, Henning M, Skorupa A, et al. Single-dose induction with rabbit anti-thymocyte globulin (rATG) safely improves renal allograft function and reduces chronic allograft nephropathy [abstract no: 538]. American Journal of Transplantation 2008;8(Suppl 2):322. [CENTRAL: CN-00653788]
Stevens RB, Mercer DF, Grant WJ, Freifeld AG, Lane JT, Groggel GC, et al. Randomized trial of single-dose versus divided-dose rabbit anti-thymocyte globulin induction in renal transplantation: an interim report. Transplantation 2008;85(10):1391-9. [MEDLINE: 18497677]

Stevens RB, Rigley T, Skorupa J, Nielsen K, Wrenshall L. Successful calcineurin-inhibitor $(\mathrm{Cl})$ discontinuation following early steroid withdrawal (ESW) in renal allograft recipients: reduced chronic allograft nephropathy (CAN) and improved renal function without increased rejection or graft loss [abstract no: 2123]. Transplantation 2008;86(2S):695.

Stevens RB, Rigley TH, Nielsen KJ, Skorupa A, Sandoz J, Kellogg A, et al. Single-dose induction with rabbit antithymocyte globulin (rATG; $6 \mathrm{mg} / \mathrm{kg}$ over 24 hours) is safer and improves immediate and long-term renal allograft function [abstract no: 616]. American Journal of Transplantation 2009;9(Suppl 2):369.

Stevens RB, Rigley TH, Nielsen KJ, Skorupa JY, Skorupa A, Sandoz J, et al. Calcineurin-inhibitor (CI) discontinuation following early steroid withdrawal (ESW) in renal allograft recipients without increase rejection or graft loss [abstract no: 1100]. American Journal of Transplantation 2009;9(Suppl 2):501.

Stevens RB, Skorupa JY, Rigley TH, Sandoz JP, Kellogg A, Miller N, et al. Calcineurin-inhibitor withdrawal vs minimization after kidney transplantation is safe but does not improve renal function; 5-year results of a prospective, randomized trial [abstract no: 1643]. American Journal of Transplantation 2010;10(Suppl 4):505.

Stevens RB, Wrenshall L, Mercer D, Rigley T, Nielsen K, Henning M, et al. Successful calcineurin-inhibitor (CI) discontinuation following early steroid withdrawal (ESW) in renal allograft recipients; reduced chronic allograft nephropathy (CAN) and improved renal function without increased rejection or graft loss [abstract no: 289]. American Journal of Transplantation 2008;8(Suppl 2):255. [CENTRAL: CN-00653790]

\section{Taylor 1976 \{published data only\}}

Ackman CF, Taylor HE, Schual RS. Long-term follow up of Canadian clinical trial of antilymphocyte globulin in renal transplantation [abstract]. Kidney International 1979;15(6):709. [CENTRAL: CN-00444100]

MacDonald AS, Belitsky P, Lannon SG, Cohen A, White J. Antithymocyte globulin in cadaver renal grafts: prophylaxis and antirejection therapy with three different preparations. Transplantation Proceedings 1982;14(4):631-4. [MEDLINE: 6762719]

* Taylor HE, Ackman CF, Horowitz I. Canadian clinical trial of antilymphocyte globulin in human cadaver renal transplantation. Canadian Medical Association Journal 1976;115(12):1205-8. [MEDLINE: 793705]

\section{Thibaudin 1998 \{published data only\}}

Thibaudin D, Alamartine E, de Filippis JP, Diab N, Laurent B, Berthoux F. Advantage of antithymocyte globulin induction in sensitized kidney recipients: a randomized prospective 
study comparing induction with and without antithymocyte globulin. Nephrology Dialysis Transplantation 1998;13(3):711-5. [MEDLINE: 9550651]

\section{Thomas 1977 \{published data only\}}

Thomas F, Mendez-Picon G, Thomas J, Peace K, Flora R, Lee HM. Effect of antilyphocyte-globulin potency on survival of cadaver renal transplants. Prospective randomised double-blind trial. Lancet 1977;2(8040):671-4. [MEDLINE: 71492]

\section{Thomas 2007 \{published data only\}}

Thomas PG, Woodside KJ, Lappin JA, Vaidya S, Rajaraman S, Gugliuzza KK. Alemtuzumab (Campath $1 \mathrm{H}$ ) induction with tacrolimus monotherapy is safe for high immunological risk Renal transplantation. Transplantation 2007;83(11):1509-12. [MEDLINE: 17565326]

\section{Toledo-Pereyra 1985 \{published data only\}}

Toledo-Pereyra LH, Bergren C, Mittal VK, Whitten JI, Baskin S, McNichol L. A prospective randomized comparison of antilymphoblast globulin versus antithymocyte globulin for cadaver kidney transplantation. Transplantation 1985;40(4):448-50. [MEDLINE: 3901446]

Toledo-Pereyra LH, Bergren C, Whitten J. Comparison of ALG and ATG for renal transplantation [abstract]. Kidney International 1985;28(2):388. [CENTRAL: CN-00583280]

\section{TRIMS Study 2010 \{published data only\}}

* Woodle ES, Peddi VR, Tomlanovich S, Mulgaonkar S, Kuo PC, TRIMS Study Investigators. A prospective, randomized, multicenter study evaluating early corticosteroid withdrawal with thymoglobulin in living-donor kidney transplantation. Clinical Transplantation 2010;24(1):73-83. [MEDLINE: 19930408]

Woodle ES, TRIMS Study Group. A randomized, prospective, multicenter comparative study evaluating a thymoglobulinbased early corticosteroid cessation regime in renal transplantation [abstract no: 673]. American Journal of Transplantation 2006;6(Suppl 2):294. [CENTRAL: CN-00716028]

Woodle ES, TRIMS Study Group. A randomized, prospective, multicenter study of thymoglobulin in renal transplantation for induction and minimization of steroids (TRIMS) [abstract no: 1632]. American Journal of Transplantation 2005;5(Suppl 11):571. [CENTRAL: CN-00716027]

Tsai 2012 \{published data only\}

Tsai MK, Lee CY, Yang CY, Yeh CC, Hu RH, Lee PH. Rituximab induction therapy provided additional immunosuppressive effect and functional benefit to non-sensitized renal transplant recipients: an interim report [abstract no: 997]. American Journal of Transplantation 2012;12(Suppl S3):319. [EMBASE: 70746950]

\section{Turcotte 1973 \{published data only\}}

Turcotte JG, Feduska NJ, Haines RF, Freier DT, Gikas PW, McDonald FD, et al. Antithymocyte globulin in renal transplant recipients. A clinical trial. Archives of Surgery 1973;106(4):484-8. [MEDLINE: 4572345]
Tyden 2009 \{published data only\}

* Tyden G, Genberg H, Tollemar J, Ekberg H, Persson NH, Tufveson G, et al. A randomized, doubleblind, placebocontrolled, study of single-dose rituximab as induction in renal transplantation. Transplantation 2009;87(9):1325-9. [MEDLINE: 19424032]

Tyden G, Mjornstedt L, Ekberg H, Tufveson G. A prospective, randomised, placebo controlled, multicenter study of the efficacy and safety of rituximab as induction therapy together with tacrolimus, mycophenolate mofetil and steroids in renal transplantation [abstract no: 861]. Transplantation 2008;86(2S):300. [CENTRAL: CN-00763744]

Tyden G, Mjornstedt L, Ekberg H, Tufveson G. Is rituximab safe to use in kidney transplant patients?. American Journal of Transplantation 2010;10(8):1949. [MEDLINE: 20659100]

Tydén G, Ekberg H, Tufveson G, Mjörnstedt L. A randomized, double-blind, placebo-controlled study of single dose rituximab as induction in renal transplantation: a 3-year follow-up. Transplantation. 2012;94(3):e21-2. [MEDLINE: 22872297]

\section{van den Hoogen 2013 \{published data only\}}

van den Hoogen MW, Kho MM, Abrahams AC, van Zuilen AD, Sanders JS, van Dijk M, et al. Effect of a single intraoperative high-dose ATG-Fresenius on delayed graft function in donation after cardiac-death donor renal allograft recipients: a randomized study. Experimental \& Clinical Transplantation 2013;11(2):134-41. [MEDLINE: 23431996]

\section{Vela 1994 \{published data only\}}

Vela C, Cristol JP, Chong G, Okamba A, Lorho R, Mion C, et al. Antilymphocyte globulins versus OKT3 as prophylactic treatment in highly sensitized renal transplant recipients. Transplant International 1994;7 Suppl 1:S259-62. [MEDLINE: 11271219]

\section{Vigeral 1986 \{published data only\}}

Vigeral P, Chkoff N, Chatenoud L, Campos H, Lacombe M, Droz D, et al. Prophylactic use of OKT3 monoclonal antibody in cadaver kidney recipients. Utilization of OKT3 as the sole immunosuppressive agent. Transplantation 1986;41(6):730-3. [MEDLINE: 3520988]

\section{Wechter 1979 \{published data only\}}

Wechter WJ, Morrell RM, Bergan J, Rosenberg JC, Turcotte J, Schultz JR. Extended treatment with antithymocyte globulin (ATGAM) in renal allograft recipients. Transplantation 1979;28(5):365-7. [MEDLINE: 392832]

\section{Yussim 2000 \{published data only\}}

Yussim A, Shapira Z. Single-bolus high-dose ATG for prophylaxis of rejection in renal transplantation--a prospective, randomized study. Transplant International 2000;13 Suppl 1:S293-4. [MEDLINE: 11112016] 


\section{References to studies excluded from this review}

\section{Alloway 1993 \{published data only\}}

Alloway R, Kotb M, Hathaway D, Ohman M, Strain S, Gaber AO. The pharmacokinetic profile of standard and low-dose OKT3 induction immunosuppression in renal transplant recipients. Transplantation 1994;58(2):249-53. [MEDLINE: 8042244]

Alloway R, Kotb M, Hathaway DK, Gaber LW, Vera SR, Gaber AO. Randomized double-blind study of standard versus low-dose OKT3 induction therapy in renal allograft recipients. American Journal of Kidney Diseases 1993;22(1):36-43. [MEDLINE: 8322791]

Alloway R, Kotb M, Hathaway DK, Gaber LW, Vera SR, Gaber AO. Results of a prospective, randomized double-blind study comparing standard vs low-dose OKT3 induction therapy. Transplantation Proceedings 1993;25(1 Pt 1):550-2. [MEDLINE: 8438410]

Chaballa M, Alloway RR, Kotb M, Hathaway DK, Gaber L, Vera SR, et al. Five year follow up of prospective, randomized double-blind study comparing standard versus low dose OKT3 induction therapy in renal allograft recipients [abstract]. 16th Annual Meeting. American Society of Transplant Physicians (ASTP); 1997 May 10-14; Chicago (ILL). 1997:259. [CENTRAL: CN-00509127]

\section{Kirsch 2006 \{published data only\}}

Kirsch BM, Haidinger M, Zeyda M, Bohmig GA, Tombinsky J, Muhlbacher F, et al. Alemtuzumab (Campath-1H) induction therapy and dendritic cells: impact on peripheral dendritic cell repertoire in renal allograft recipients. Transplant Immunology 2006;16(3-4):254-7. [MEDLINE: 17138063]

\section{Kumar 2002b \{published data only\}}

Kumar A, Zaman W, Chaurasia D, Gupta A, Sharma RK, Gulati S. Prospective randomized trial to evaluate the efficacy of single low dose ATG induction in renal transplant recipient with spousal kidney. Indian Journal of Urology 2002;19(1):58-62. [EMBASE: 36347895]

\section{NCT00000936 \{unpublished data only\}}

Blechman-Krom I. Controlled trial of induction therapy in renal transplantation. www.clinicaltrials.gov/ct2/show/NCT00000936 (accessed 3 November 2016).

\section{NCT01312064 \{unpublished data only\}}

Tsai MK. Clinical outcome of de novo everolimus-based immunosuppressive therapy for renal transplantation using rituximab induction. www.clinicaltrials.gov/ct2/show/ NCT01312064 (accessed 22 August 2016).

\section{References to studies awaiting assessment}

\section{NCT00089947 \{published data only\}}

NCT00089947. Randomized, prospective, phase 2 study comparing thymoglobulin in a rapid discontinuation of corticosteroids protocol with standard corticosteroid therapy in living donor renal transplantation using mycophenolate mofetil and tacrolimus maintenance therapy. clinicaltrials.gov/ct2/ show/NCT00089947 (accessed 22 August 2016).

\section{NCT00861536 \{published data only\}}

Steiger J. An open, multicenter, randomised, parallel group pilot study to investigate two different polyclonal rabbit immunoglobulin preparations for safety and efficacy: a comparison of ATG-fresenius to thymoglobulin in prophylaxis for immunological high risk patients following renal transplantation. www.clinicaltrials gov/ct2/show/NCT00861536 (accessed 22 August 2016).

\section{NCT01046955 \{unpublished data only\}}

Burke GW. Head-to-head comparison of thymoglobulin vs. campath-1h vs. our standard center treatment protocol in living donor renal transplantation - a study to evaluate the avoidance of long-term nephrotoxic calcineurin inhibitor therapy. www.clinicaltrials.gov/ct2/show/NCT01046955 (accessed 3 November 2016).

\section{NCT01354301 \{unpublished data only\}}

Tedesco H. Efficacy and safety of induction strategies combined with low tacrolimus exposure in kidney transplant recipients receiving everolimus or sodium mycophenolate. www.clinicaltrials.gov/ct2/show/NCT01354301 (accessed 3 November 2016).

\section{Stevens 2016 \{published data only\}}

Stevens RB, Wrenshall LE, Miles CD, Farney AC, Jie T, Sandoz JP, et al. A double-blind, double-dummy, flexible-design randomized multicenter trial: early safety of single- versus divided-dose rabbit anti-thymocyte globulin induction in renal transplantation. American Journal of Transplantation 2016;16(6):1858-67. [MEDLINE: 26696251]

\section{References to ongoing studies}

\section{NCT00733733 \{published data only\}}

Hoitsma AJ. A prospective, randomized, open, multicenter study to evaluate the efficacy and tolerability of induction therapy with a single high-dose anti-t-lymphocyte globulin (ATG) in renal transplant patients with a kidney from a non-heart-beating donor and tacrolimus, mycophenolate mofetil, and steroids as basic immunosuppression. www.clinicaltrials.gov/ct2/show/NCT00733733 (accessed 22 August 2016).

\section{NCT01154387 \{unpublished data only\}}

Flechner S. A two part, phase $1 / 2$, safety, PK and PD study of TOL101, an anti-TCR monoclonal antibody for prophylaxis of acute organ rejection in patients receiving renal transplantation. www.clinicaltrials.gov/ct2/show/NCT01154387 (accessed 22 August 2016).

\section{ReMIND Study 2013 \{unpublished data only\}}

Mamode M. A randomized trial of rituximab in induction therapy for living donor renal transplantation. www.clinicaltrials.gov/ ct2/show/NCT01095172 (accessed 22 August 2016).

Polyclonal and monoclonal antibodies for induction therapy in kidney transplant recipients (Review)

Copyright @ 2017 The Cochrane Collaboration. Published by John Wiley \& Sons, Ltd. 


\section{Additional references}

\section{ANZDATA 2009}

ANZDATA. [direct communication]. Australian and New Zealand Dialysis and Transplant Registry 2009.

\section{Calne 1999}

Calne R, Moffatt SD, Friend PJ, Jamieson NV, Bradley JA, Hale G, et al. Campath IH allows low-dose cyclosporine monotherapy in 31 cadaveric renal allograft recipients. Transplantation 1999;68(10):613-6. [MEDLINE: 10589966]

\section{Cibrik 2001}

Cibrik DM, Kaplan B, Meier-Kriesche HU. Role of antiinterleukin-2 receptor antibodies in kidney transplantation. Biodrugs 2001;15(10):655-66. [MEDLINE: 11604047]

\section{Denton 1999}

Denton MD, Magee CC, Sayegh MH. Immunosuppressive strategies in transplantation. Lancet 1999;353(9158):1083-91. [MEDLINE: 10199367]

\section{GRADE 2008}

Guyatt GH, Oxman AD, Vist GE, Kunz R, Falck-Ytter Y, AlonsoCoello $P$, et al. GRADE: an emerging consensus on rating quality of evidence and strength of recommendations. $B M J$ 2008;336(7650):924-6. [MEDLINE: 18436948]

\section{Higgins 2003}

Higgins JPT, Thompson SG, Deeks JJ, Altman DG. Measuring inconsistency in meta-analyses. BMJ 2003;327(7414):557-60. [MEDLINE: 12958120]

\section{Higgins 2011}

Higgins JP, Green S (editors). Cochrane Handbook for Systematic Reviews of Interventions Version 5.1.0 [updated February 2011]. The Cochrane Collaboration, 2011. Available from www.cochrane-handbook.org.

\section{Hong 2000}

Hong JC, Kahan BD. Sirolimus-induced thrombocytopenia and leukopenia in renal transplant recipients: risk factors, incidence, progression, and management. Transplantation 2000;69(10):2085-90. [MEDLINE: 10852601]

\section{KDIGO 2009}

Kidney Disease: Improving Global Outcomes (KDIGO) Transplant Work Group. KDIGO clinical practice guideline for the care of kidney transplant recipients. American Journal of Transplantation 2009;9 Suppl 3:S1-155. [MEDLINE: 19845597]

\section{Kreis 1992}

Kreis H. Antilymphocyte globulins in kidney transplantation. Kidney International - Supplement 1992;38:188-92. [MEDLINE: 1405373]

\section{Meier-Kriesche 2004}

Meier-Kriesche HU, Schold JD, Srinivas TR, Kaplan B. Lack of improvement in renal allograft survival despite a marked decrease in acute rejection rates over the most recent era.
American Journal of Transplantation 2004;4(3):378-83.

[MEDLINE: 14961990]

\section{Racusen 1999}

Racusen LC, Solez K, Colvin RB, Bonsib SM, Castro MC, Cavallo T, et al. The Banff 97 working classification of renal allograft pathology. Kidney international 1999;55(2):713-23. [MEDLINE: 9987096]

\section{Schünemann 2011a}

Schünemann HJ, Oxman AD, Higgins JP, Vist GE, Glasziou P, Guyatt GH. Chapter 11: Presenting results and 'Summary of findings' tables. In: Higgins JP, Green S (editors). Cochrane Handbook for Systematic Reviews of Interventions Version 5.1.0 [updated March 2011]. The Cochrane Collaboration, 2011. Available from www.cochrane-handbook.org.

\section{Schünemann 2011b}

Schünemann HJ, Oxman AD, Higgins JP, Deeks JJ, Glasziou P, Guyatt GH. Chapter 12: Interpreting results and drawing conclusions. In: Higgins JP, Green S (editors). Cochrane Handbook for Systematic Reviews of Interventions Version 5.1.0 [updated March 2011]. The Cochrane Collaboration, 2011. Available from www.cochrane-handbook.org.

\section{Solez 2007}

Solez K, Colvin RB, Racusen LC, Sis B, Halloran PF, Birk PE, et al. Banff '05 Meeting Report: differential diagnosis of chronic allograft injury and elimination of chronic allograft nephropathy ('CAN'). American Journal of Transplantation 2007; Vol. 7, issue 3:518-26. [MEDLINE: 17352710]

\section{Soulillou 2001}

Soulillou JP, Giral M. Controlling the incidence of infection and malignancy by modifying immunosuppression. Transplantation 2001;72(12 Suppl):S89-93. [MEDLINE: 11833147]

\section{Tonelli 2011}

Tonelli M, Wiebe N, Knoll G, Bello A, Browne S, Jadhav D, et al. Systematic review: kidney transplantation compared with dialysis in clinically relevant outcomes. American Journal of Transplantation 2011;11(10):2093-109. [MEDLINE: 21883901]

\section{Tyden 2003}

Tyden G, Kumlien G, Fehrman I. Successful ABO-incompatible kidney transplantations without splenectomy using antigen specific immunoadsorption and rituximab. Transplantation 2003;76(4):730-1. [MEDLINE: 12973118]

\section{UNOS 2011}

United Network for Organ Sharing. OPTN data [direct communication]. www.unos.org (accessed 4 November 2016).

\section{Webster 2006}

Webster A, Pankhurst T, Rinaldi F, Chapman JR, Craig JC. Polyclonal and monoclonal antibodies for treating acute rejection episodes in kidney transplant recipients. Cochrane Database of Systematic Reviews 2006, Issue 2. [DOI: 10.1002/14651858.CD004756.pub3] 


\section{Webster 2010}

Webster AC, Ruster LP, McGee R, Matheson SL, Higgins GY, Willis NS, et al. Interleukin 2 receptor antagonists for kidney transplant recipients. Cochrane Database of Systematic Reviews 2010, Issue 1. [DOI: 10.1002/14651858.CD003897.pub3]

\section{Zand 2007}

Zand MS. Therapeutic antibody agents for B-cell immunomodulation in renal transplantation. Transplantation 2007;84(11 S Suppl):S11-9. [EMBASE: 350294707]

\section{CHARACTERISTICS OF STUDIES}

Characteristics of included studies [ordered by study ID]

\section{References to other published versions of this review Morgan 2004}

Morgan P, Cross NB, Barnett AN, Craig JC, Webster AC.

Polyclonal and monoclonal antibodies for induction therapy in kidney transplant recipients. Cochrane Database of Systematic Reviews 2004, Issue 2. [DOI: 10.1002/14651858.CD004759]

* Indicates the major publication for the study

\section{Abouna 1995}

\begin{tabular}{ll}
\hline Methods & Study design: parallel RCT \\
& - Study duration: February 1993 to June 1994 \\
& - Study follow-up: 2 years \\
\hline Participants & - Country: USA \\
- Setting: single centre \\
- Inclusion criteria: adult DD kidney transplant recipients \\
- Number: treatment group (23); control group (22) \\
- Mean age \pm SD (years): treatment group (43 \pm 9$)$; control group $(53 \pm 12)$ \\
- Sex (M/F): treatment group $(17 / 6) ;$ control group $(17 / 5)$ \\
- Exclusion criteria: not reported
\end{tabular}

- ATG: $15 \mathrm{mg} / \mathrm{kg}$ on day 1 then adjusted as per CD3 cell count (to maintain count 50 to $100 / \mu \mathrm{L}$ )

* ATG given for at least 3 days after CSA started or at least 7 days post-transplant

Treatment group 2

- ATG: fixed dose $(15 \mathrm{mg} / \mathrm{kg} / \mathrm{d})$

Immunosuppression (both groups)

- CSA: $8 \mathrm{mg} / \mathrm{kg}$ and started when $\mathrm{SCr} \leq 3 \mathrm{mg} / \mathrm{dL}$

- PRED: dosage not reported

- AZA: dosage not reported

\begin{tabular}{ll}
\hline Outcomes & - Death \\
- Graft loss \\
- Graft function \\
- Acute rejection \\
- Teucopenia \\
- Viral infection \\
- Bacterial infection
\end{tabular}


Abouna 1995 (Continued)

\section{Bias Authors' judgement Support for judgement}

Random sequence genera- Unclear risk Insufficient information to permit judgement
tion (selection bias)

Allocation concealment Unclear risk Insufficient information to permit judgement
(selection bias)

(selection bias)

Blinding of participants Low risk Unlikely to influence outcomes
and personnel (perfor-
mance bias)
All outcomes

Blinding of outcome as- Low risk Unlikely to influence outcomes
sessment (detection bias)

All outcomes

\begin{tabular}{lll}
\hline $\begin{array}{l}\text { Incomplete outcome data } \\
\text { (attrition bias) } \\
\text { All outcomes }\end{array}$ & Low risk & All patient outcome data reported \\
\hline $\begin{array}{l}\text { Selective reporting (re- } \\
\text { porting bias) }\end{array}$ & Low risk & All expected outcomes included \\
\hline Other bias & High risk & Study supported by Upjohn Company \\
\hline
\end{tabular}

Abramowicz 1992

\begin{tabular}{|c|c|}
\hline Methods & $\begin{array}{l}\text { - Study design: parallel RCT } \\
\text { - Study duration: September } 1987 \text { to September } 1989 \\
\text { - Study follow-up: } 36 \text { months }\end{array}$ \\
\hline Participants & $\begin{array}{l}\text { - Country: Belgium } \\
\text { - Setting: single centre (Brussels) } \\
\text { - Inclusion criteria: adult DD kidney transplant recipients } \\
\text { - Number: treatment group } 1(56) \text {; treatment group } 2(52) \\
\text { - Mean age } \pm \text { SEM (years): treatment group } 1(34 \pm 1.3) \text {; treatment group } 2(35.3 \pm 1.2) \\
\text { - Sex (M/F): treatment group } 1 \text { ( } 39 / 47) \text {; treatment group } 2(37 / 15) \\
\text { - Exclusion criteria: not reported }\end{array}$ \\
\hline Interventions & $\begin{array}{l}\text { Treatment group } 1 \\
\text { - OKT3: } 5 \mathrm{mg} / \mathrm{d} \text { for } 14 \text { days post-op, CSA started day } 11 \\
\text { * Dose increased to } 10 \mathrm{mg} / \mathrm{d} \text { if serum level < } 500 \mathrm{ng} / \mathrm{mL} \\
\text { - AZA: } 2 \mathrm{mg} / \mathrm{kg} / \mathrm{d} \text {, then } 1 \mathrm{mg} / \mathrm{kg} / \mathrm{d} \text { by day } 14 \\
\text { - MP: } 1.3 \mathrm{mg} / \mathrm{kg} \text { before } 1 \mathrm{st} \text { OKT3 dose for } 1 \mathrm{st} 31 \text { patients, increased to } 8 \mathrm{mg} / \mathrm{kg} \text { for next } 25 \text { patients to } \\
\text { try to decrease cytokine release syndrome } \\
\text { - PRED: } 0.3 \mathrm{mg} / \mathrm{kg} \text { day } 1 \text { to } 14 \\
\text { Treatment group } 2 \\
\text { - CSA: day } 1 \text { post-op, dose } 6 \mathrm{mg} / \mathrm{kg} / \mathrm{d} \text {, then as per trough level }(150 \text { to } 250 \mathrm{ng} / \mathrm{mL}) \\
\text { - AZA: } 1 \mathrm{mg} / \mathrm{kg} / \mathrm{d}\end{array}$ \\
\hline
\end{tabular}


Abramowicz 1992 (Continued)

- MP: $1.5 \mathrm{mg} / \mathrm{kg}$ on day $0 ; 1 \mathrm{mg} / \mathrm{kg}$ on day $1 ; 0.5 \mathrm{mg} / \mathrm{kg}$ on day $2 ; 0.4 \mathrm{mg} / \mathrm{kg}$ on day $14 ; 0.17 \mathrm{mg} / \mathrm{kg}$ after 3 months

\begin{tabular}{ll}
\hline Outcomes & Death \\
& - Graft loss \\
& - Acute rejection \\
& - Infection \\
& - Malignancy \\
\hline Notes & CSA delayed until day 11 in OKT3 group \\
& - Funding source: "This work was supported by Cilag Benelux and the Fonds de la Recherche Scien- \\
& tifique Medicale (Belgium)" \\
\hline
\end{tabular}

\section{Risk of bias}

\begin{tabular}{|c|c|c|}
\hline Bias & Authors' judgement & Support for judgement \\
\hline $\begin{array}{l}\text { Random sequence genera- } \\
\text { tion (selection bias) }\end{array}$ & Unclear risk & Insufficient information to permit judgement \\
\hline $\begin{array}{l}\text { Allocation concealment } \\
\text { (selection bias) }\end{array}$ & Unclear risk & Insufficient information to permit judgement \\
\hline $\begin{array}{l}\text { Blinding of participants } \\
\text { and personnel (perfor- } \\
\text { mance bias) } \\
\text { All outcomes }\end{array}$ & Unclear risk & Insufficient information to permit judgement \\
\hline $\begin{array}{l}\text { Blinding of outcome as- } \\
\text { sessment (detection bias) } \\
\text { All outcomes }\end{array}$ & Low risk & $\begin{array}{l}\text { No blinding of outcome assessment, but the review authors judge that the out- } \\
\text { come measurement is not likely to be influenced by lack of blinding }\end{array}$ \\
\hline $\begin{array}{l}\text { Incomplete outcome data } \\
\text { (attrition bias) } \\
\text { All outcomes }\end{array}$ & Low risk & All patient outcome data reported \\
\hline $\begin{array}{l}\text { Selective reporting (re- } \\
\text { porting bias) }\end{array}$ & Low risk & All expected outcomes reported \\
\hline Other bias & High risk & $\begin{array}{l}\text { Baseline imbalance. PRA, donor age and HLA mismatch all higher in OKT3 } \\
\text { group; funded by Cilag }\end{array}$ \\
\hline
\end{tabular}

\section{Abramowicz 1994}

\begin{tabular}{ll}
\hline Methods & Study design: parallel RCT \\
& - Study duration: not reported \\
& - Study follow-up: only reported to 3 months \\
\hline Participants & - Country: Belgium \\
- Setting: single centre (Brussels) \\
- Inclusion criteria: adult DD kidney transplant recipients \\
- Mean age \pm SEM (years): treatment group 1 (40.6 \pm 1.9$)$; treatment group 2 (40.6 \pm 3.5$)$
\end{tabular}


Abramowicz 1994 (Continued)

- Sex (M/F): not reported

- Exclusion criteria: not reported

Treatment group 1
Interventions
Treatment group 2
- OKT3: $10 \mathrm{mg}$ for $1 \mathrm{st} 3$ doses
Dose adjustment as per level from day 3 post-op 3 doses
- Above $1000 \mathrm{ng} / \mathrm{mL}$ : next dose $5 \mathrm{mg}$
- 800 to $1000 \mathrm{ng} / \mathrm{mL}:$ next dose $10 \mathrm{mg}$
- Below $800 \mathrm{ng} / \mathrm{mL}$ : evening $5 \mathrm{mg}$ dose, then $10 \mathrm{mg}$ next day
Immunosuppression (both groups)
- As per Abramowicz 1992
- Death
- Graft loss
- DGF
- Acute rejection

Risk of bias

\begin{tabular}{|c|c|c|}
\hline Bias & Authors' judgement & Support for judgement \\
\hline $\begin{array}{l}\text { Random sequence genera- } \\
\text { tion (selection bias) }\end{array}$ & Unclear risk & Insufficient information to permit judgement \\
\hline $\begin{array}{l}\text { Allocation concealment } \\
\text { (selection bias) }\end{array}$ & Unclear risk & Insufficient information to permit judgement \\
\hline $\begin{array}{l}\text { Blinding of participants } \\
\text { and personnel (perfor- } \\
\text { mance bias) } \\
\text { All outcomes }\end{array}$ & Low risk & $\begin{array}{l}\text { No blinding but the review authors judge that the outcomes are not likely to be } \\
\text { influenced by lack of blinding }\end{array}$ \\
\hline $\begin{array}{l}\text { Blinding of outcome as- } \\
\text { sessment (detection bias) } \\
\text { All outcomes }\end{array}$ & Low risk & $\begin{array}{l}\text { No blinding of outcome assessment, but the review authors judge that the out- } \\
\text { come measurement is not likely to be influenced by lack of blinding }\end{array}$ \\
\hline $\begin{array}{l}\text { Incomplete outcome data } \\
\text { (attrition bias) } \\
\text { All outcomes }\end{array}$ & Low risk & All patient outcome data reported \\
\hline $\begin{array}{l}\text { Selective reporting (re- } \\
\text { porting bias) }\end{array}$ & Unclear risk & Short-term follow-up reported only \\
\hline Other bias & High risk & Supported by Cilag Bennelux \\
\hline
\end{tabular}


Ackermann 1988

\begin{tabular}{ll}
\hline Methods & Study design: parallel RCT \\
- Study duration: not reported \\
- Study follow-up: 3 to 12 months \\
\hline Participants & - Country: USA \\
- Setting: single centre (Florida) \\
- Inclusion criteria: adult (> 16 years) DD kidney transplant recipients (100\%); financial resources for \\
- CSA therapy after discharge \\
- Number: treatment group (33); control group (33) \\
- Sex (M/F): treatment group (21/12); control group (23/12) \\
- Ethnicity (other/African American): treatment group (23/10); control group (21/12) \\
- Exclusion criteria: fluid overload (unresolved by dialysis); previous exposure to OKT3, pregnant or lac- \\
tating women
\end{tabular}

\begin{tabular}{ll}
\hline Tnterventions & OKT3: $5 \mathrm{mg} / \mathrm{d}$ IV for 14 days \\
- CSA: started day 11 , target trough 300 to $500 \mathrm{ng} / \mathrm{mL}$ \\
Control group \\
- CSA: twice daily started day 1 (unsure), target trough level 300 to $500 \mathrm{ng} / \mathrm{mL}$ \\
Immunosuppression (both groups) \\
- AZA: $2.5 \mathrm{mg} / \mathrm{kg}$ (adjusted per WCC and kidney function) \\
- MP-PRED: $2 \mathrm{~g}$ IV intra-op then PRED $0.25 \mathrm{mg} / \mathrm{kg} / \mathrm{d}$ \\
\hline - Death \\
- Graft loss \\
- Acute rejection \\
- DGF \\
- Infection
\end{tabular}

\section{Risk of bias}

Bias Authors' judgement Support for judgement

Random sequence genera- Unclear risk Insufficient information to permit judgement
tion (selection bias)

\begin{tabular}{lll}
\hline $\begin{array}{l}\text { Allocation concealment } \\
\text { (selection bias) }\end{array}$ & Low risk & 'Randomized by sealed envelope draw' \\
\hline $\begin{array}{l}\text { Blinding of participants } \\
\text { and personnel (perfor- } \\
\text { mance bias) }\end{array}$ & Unclear risk & $\begin{array}{l}\text { Unblinded but not likely to influence most outcomes; may influence reporting } \\
\text { of infections }\end{array}$ \\
All outcomes & \\
\hline
\end{tabular}


Ackermann 1988 (Continued)

Blinding of outcome as- Unclear risk Not certain if acute rejection was biopsy-proven or clinically diagnosed sessment (detection bias)

All outcomes

Incomplete outcome data Low risk $\quad$ All patient outcome data reported
(attrition bias)

(attrition bias)

All outcomes

$\begin{aligned} & \text { Selective reporting (re- Low risk } \quad \text { All expected outcomes reported } \\ & \text { porting bias) }\end{aligned}$

Other bias High risk Grant from Ortho Pharmaceutical Corp (OKT3 manufacturer)

Ata 2013

\begin{tabular}{ll}
\hline Methods & Study design: parallel RCT \\
& - Study duration: January 2009 to January 2012 \\
\hline Participants & - Country: Tollow-up: 3 months \\
- Setting: single centre (Istanbul) \\
- Inclusion criteria: adults DD kidney transplant recipients \\
- Number: treatment group 1 (11); treatment group $2(10)$ \\
- Mean age \pm SD (years): treatment group 1 (43.6 \pm 4$) ;$ treatment group $2(37 \pm 3.8)$ \\
- Sex (M/F): treatment group $1(3 / 8) ;$ treatment group $2(4 / 6)$ \\
\hline
\end{tabular}

Interventions

Treatment group 1

- ATG modified by CD3 count: $1 \mathrm{mg} / \mathrm{kg}$ at time of transplant

* Continued daily for 10 days with dose as follows as per CD3 count
$\square>150 / \mathrm{mL}$ : no adjustment
$\square 50$ to $150 / \mathrm{mL}$ : half dose
$\square<50 / \mathrm{mL}$ : dose skipped

Treatment group 2

- ATG standard dose: $1 \mathrm{mg} / \mathrm{kg}$ at time of transplant

* Continued same dose daily for 10 days

* Dose skipped if lymphocyte count $<300 / \mathrm{mL}$

Maintenance immunosuppression

- Not specified for either group

\begin{tabular}{ll}
\hline Outcomes & - ATG dose \\
& - Side effects \\
& - Graft function at 3 months \\
- Acute rejection & Infection \\
& - Cost (CD3+ analysis + ATG) \\
\hline \multirow{2}{*}{ Notes } & - Brief report only \\
& - Funding source: not reported
\end{tabular}


Ata 2013 (Continued)

\section{Risk of bias}

\begin{tabular}{|c|c|c|}
\hline Bias & Authors' judgement & Support for judgement \\
\hline $\begin{array}{l}\text { Random sequence genera- } \\
\text { tion (selection bias) }\end{array}$ & Unclear risk & Insufficient information to permit judgement \\
\hline $\begin{array}{l}\text { Allocation concealment } \\
\text { (selection bias) }\end{array}$ & Unclear risk & Insufficient information to permit judgement \\
\hline $\begin{array}{l}\text { Blinding of participants } \\
\text { and personnel (perfor- } \\
\text { mance bias) } \\
\text { All outcomes }\end{array}$ & Unclear risk & Not reported but likely not blinded \\
\hline $\begin{array}{l}\text { Blinding of outcome as- } \\
\text { sessment (detection bias) } \\
\text { All outcomes }\end{array}$ & Unclear risk & Not reported but likely not blinded \\
\hline $\begin{array}{l}\text { Incomplete outcome data } \\
\text { (attrition bias) } \\
\text { All outcomes }\end{array}$ & Low risk & All patient outcome data reported \\
\hline $\begin{array}{l}\text { Selective reporting (re- } \\
\text { porting bias) }\end{array}$ & Unclear risk & Brief report only \\
\hline Other bias & Unclear risk & Funding not reported \\
\hline
\end{tabular}

\section{Banhegyi 1991}

\begin{tabular}{ll}
\hline Methods & Study design: parallel RCT \\
& - Study duration: September 1989 to June 1990 \\
\hline Participants & Study follow-up: 6 months \\
\hline & - Country: Austria \\
- Setting: single centre (Vienna) \\
- Number: treatment group (55); control group (60) \\
- Mean age (years): treatment group (49.7); control group (47.3) \\
- Sex (M/F): treatment group (32/23); control group (35/25) \\
- Exclusion criteria: not reported
\end{tabular}

- ATG (Thymozytenglobuline-Biotest)

* $200 \mathrm{mg}$ during implantation, repeat dose days 1, 2, 4, 6 and 8 (100 mg if low weight)

- CSA started day 8 at $4 \mathrm{mg} / \mathrm{kg} / \mathrm{d}$

- Steroids: IV DEX $40 \mathrm{mg}, 32,24,16,8$ then PRED $20 \mathrm{mg}$ once daily

Control group

- CSA: $2 \mathrm{mg} / \mathrm{kg} / \mathrm{d}$ IV infusion, starting during implantation

* Switch to oral CSA day 2 to $3 ; 4 \mathrm{mg} / \mathrm{kg} / \mathrm{d}$

- Steroids as for treatment group 
Banhegyi 1991 (Continued)

CSA adjusted according to levels in both groups

\begin{tabular}{ll}
\hline Outcomes & DGF \\
& - Acute rejection \\
& - Graft failure \\
\hline Notes & - Funding source: not reported
\end{tabular}

\section{Risk of bias}

\begin{tabular}{|c|c|c|}
\hline Bias & Authors' judgement & Support for judgement \\
\hline $\begin{array}{l}\text { Random sequence genera- } \\
\text { tion (selection bias) }\end{array}$ & Unclear risk & Insufficient information to permit judgement \\
\hline $\begin{array}{l}\text { Allocation concealment } \\
\text { (selection bias) }\end{array}$ & Unclear risk & Insufficient information to permit judgement \\
\hline $\begin{array}{l}\text { Blinding of participants } \\
\text { and personnel (perfor- } \\
\text { mance bias) } \\
\text { All outcomes }\end{array}$ & Low risk & Unlikely to influence outcomes \\
\hline $\begin{array}{l}\text { Blinding of outcome as- } \\
\text { sessment (detection bias) } \\
\text { All outcomes }\end{array}$ & High risk & Acute rejection episodes were not biopsy-proven \\
\hline $\begin{array}{l}\text { Incomplete outcome data } \\
\text { (attrition bias) } \\
\text { All outcomes }\end{array}$ & Low risk & All patient outcome data reported \\
\hline $\begin{array}{l}\text { Selective reporting (re- } \\
\text { porting bias) }\end{array}$ & Low risk & All expected outcomes reported \\
\hline \multirow[t]{3}{*}{ Other bias } & Unclear risk & $\begin{array}{l}7 \text { patients excluded: vascular complications (2), trauma (1), ABO-incompatible } \\
\text { transplant (1), 'therapy protocol not followed' (2). }\end{array}$ \\
\hline & & Not clear which group these patients were from; possibly all from one group \\
\hline & & $\begin{array}{l}\text { This appears to be a preliminary report, however no further publication has } \\
\text { been identified }\end{array}$ \\
\hline
\end{tabular}

Belitsky 1991

\begin{tabular}{ll}
\hline Methods & Study design: parallel RCT \\
& - Study duration: June 1987 to March 1990 \\
& - Study follow-up: 2 to 3 years \\
\hline Participants & - Country: Canada \\
- Setting: single centre \\
- Inclusion criteria: adults and children (> 10 years); 1st kidney transplant; all DD \\
- Mean age, range: $41.5,10$ to 65 years \\
- Sex (M/F): $72 / 38$ \\
- Exclusion criteria: not reported
\end{tabular}


Belitsky 1991 (Continued)

Treatment group
- ALG (Lymphoglobuline, Merieux) at $10 \mathrm{mg} / \mathrm{kg} / \mathrm{d}$ until serum $\mathrm{Cr}<300$
- Then switched to CSA as per control
Control group
- CSA: IV 3 to $4 \mathrm{mg} / \mathrm{kg}$ started post-op, continuous IV infusion for 5 days then oral $5 \mathrm{mg} / \mathrm{kg}$ twice daily,
target levels 300 to $450 \mathrm{ng} / \mathrm{mL}$ for 3 months, then 100 to $250 \mathrm{ng} / \mathrm{mL}$ there after
Immunosuppression (both groups)
- AZA: $2 \mathrm{mg} / \mathrm{kg}$ IV during surgery, then $1.5 \mathrm{mg} / \mathrm{kg}$ orally for 30 days only
- MP: $500 \mathrm{mg}$ in OT, then oral PRED $1 \mathrm{mg} / \mathrm{kg}$, decrease to $20 \mathrm{mg}$ over 2 to 3 weeks, decrease further
at 60 days, stopped at 105 days
- If Cr $>200$ at 105 days, CSA reduced. If no benefit, PRED and/or AZA re-added
- Graft survival
- Death
- Acute rejection (confirmed by biopsy or FNA)
- Kidney function
- Infection
- Complications

\section{Risk of bias}

\begin{tabular}{lll}
\hline Bias & Authors' judgement & Support for judgement \\
\hline $\begin{array}{l}\text { Random sequence genera- } \\
\text { tion (selection bias) }\end{array}$ & Unclear risk & Insufficient information to permit judgement \\
\hline $\begin{array}{l}\text { Allocation concealment } \\
\text { (selection bias) }\end{array}$ & Unclear risk & Insufficient information to permit judgement \\
\hline $\begin{array}{l}\text { Blinding of participants } \\
\text { and personnel (perfor- } \\
\text { mance bias) }\end{array}$ & Low risk & Unlikely to influence outcomes \\
$\begin{array}{l}\text { All outcomes } \\
\text { Blinding of outcome as- } \\
\text { sessment (detection bias) }\end{array}$ & Low risk & \\
All outcomes & & Unlikely to influence outcomes \\
\hline $\begin{array}{l}\text { Incomplete outcome data } \\
\text { (attrition bias) } \\
\text { All outcomes }\end{array}$ & Low risk & All patient outcome data reported \\
\hline $\begin{array}{l}\text { Selective reporting (re- } \\
\text { porting bias) }\end{array}$ & Low risk & All expected outcomes reported \\
\hline \begin{tabular}{l} 
Other bias \\
\hline
\end{tabular} & Unclear risk & Funding source not reported \\
\hline
\end{tabular}




\begin{tabular}{ll}
\hline Methods & Study design: parallel RCR \\
& - Study duration: not reported \\
\hline & Study follow-up: 2 years \\
\hline Participants & Country: UK \\
- Setting: multicentre (5) \\
- Inclusion criteria: adult LD or DD kidney transplant recipients \\
- Number: treatment group (86); control group (87) \\
- Mean age, range (years): treatment group (39.6, 17 to 63); control group (33.7, 16 to 66) \\
- Sex (M/F): treatment group (56/30); control group (51/36) \\
- DD/LD: treatment group (70/16); control group (70/17) \\
- Exclusion criteria: identical matches for HLA-A and HLA-B antigens; ABO blood group donor/recipient \\
incompatibility; circulating donor-specific leukocytotoxicity; oxalosis; not available follow-up due to \\
geographical reasons
\end{tabular}

\begin{tabular}{|c|c|}
\hline Interventions & $\begin{array}{l}\text { Treatment group } \\
\text { - ALG: IV infusion ( } 30 \mathrm{mg} / \mathrm{kg} / \mathrm{d} \text {, max } 2 \mathrm{~g} \text { ) for } 10 \text { days (in } 15 \mathrm{~mL} / \mathrm{kg} \text { in } 5 \% \text { dextrose); IV infusion stopped if } \\
\text { severe vasomotor disturbance } \\
\text { Control group } \\
\text { - Placebo: } 15 \mathrm{~mL} / \mathrm{kg} \text { in } 5 \% \text { dextrose for } 10 \text { days } \\
\text { Immunosuppression (both groups) } \\
\text { - AZA: } 5 \mathrm{mg} / \mathrm{kg} \text { day } 1 \text {, then } 1 \text { to } 2 \mathrm{mg} / \mathrm{kg} \text {, increased every } 10 \text { days up to } 3 \text { to } 4 \mathrm{mg} / \mathrm{kg} \text { (depending on WCC } \\
\text { and platelet count) } \\
\text { - MP: } 1 \mathrm{~g} \text { at operation, then PRED } 150,100,80,60,50,40 \text { down to } 20 \mathrm{mg} \text { by } 3 \text { months, then further to } \\
10 \mathrm{mg}\end{array}$ \\
\hline Outcomes & $\begin{array}{ll}\text { - } & \text { Death } \\
\text { - } & \text { Graft failure } \\
\text { - } & \text { Acute rejection } \\
\text { - Infection }\end{array}$ \\
\hline Notes & $\begin{array}{l}\text { - Randomisation balanced within each centre and for DD versus LD } \\
\text { - Funding source: not reported }\end{array}$ \\
\hline
\end{tabular}

\section{Risk of bias}

Bias Authors' judgement Support for judgement

Random sequence genera- Unclear risk 'Random number code' stated, no other information provided tion (selection bias)

\begin{tabular}{lll}
\hline $\begin{array}{l}\text { Allocation concealment } \\
\text { (selection bias) }\end{array}$ & Low risk & $\begin{array}{l}\text { Pharmacy controlled; fluids supplied by pharmacists, under double-blind con- } \\
\text { ditions }\end{array}$ \\
\hline $\begin{array}{l}\text { Blinding of participants } \\
\text { and personnel (perfor- } \\
\text { mance bias) }\end{array}$ & Low risk & Double-blinded \\
All outcomes & & \\
\hline
\end{tabular}

\begin{tabular}{lll}
\hline Blinding of outcome as- & Low risk & Unlikely to influence outcomes \\
sessment (detection bias)
\end{tabular}


Bell 1983 (Continued)

All outcomes

Incomplete outcome data Low risk $\quad$ All patient outcome data reported
(attrition bias)

(attrition bias)

All outcomes

\begin{tabular}{lll}
\hline $\begin{array}{l}\text { Selective reporting (re- } \\
\text { porting bias) }\end{array}$ & Low risk & All expected outcomes reported \\
\hline Other bias & Unclear risk & Funding not reported \\
\hline
\end{tabular}

\section{Benfield 1999}

\begin{tabular}{ll}
\hline Methods & Study design: parallel $2 \times 2$ factorial RCT \\
- Study duration: April 1995 to August 1999 \\
- Study follow-up: 4 years \\
\hline Participants & Country: USA \\
- Setting: multicentre (21) \\
- Inclusion criteria: children; LD and DD kidney transplant recipients \\
- Number: treatment group (147); control group (140) \\
- Mean age \pm SD (years): not reported \\
- Sex (M/F): treatment group (92/55); control group (84/56) \\
- White/black/Hispanic/other (\%): treatment group (54/22/19/4); control group (59/19/15/7) \\
- DD/LD: treatment group (82/65); control group (77/63) \\
- Exclusion criteria: recipients of more than 1 organ; pregnant females; females of child-bearing age \\
who were not willing to practice an acceptable method of birth control during the 1 st year after trans- \\
plantation; HIV positive; positive Hep B surface antigen
\end{tabular}

\begin{tabular}{|c|c|}
\hline Interventions & $\begin{array}{l}\text { Treatment group } \\
\text { - OKT3: } 2.5 \text { to } 5 \mathrm{mg} / \mathrm{kg} \text { (< or }>30 \mathrm{~kg} \text { ) IV infusion peri-op then daily for } 10 \text { days } \\
\text { - Oral CSA: day } 7 \text { at } 250 \mathrm{mg} / \mathrm{m}^{2} \\
\text { - PRED and AZA until } 1996 \text { then MMF and PRED from } 1996 \\
\text { Control group } \\
\text { - IV CSA: } 165 \mathrm{mg} / \mathrm{m}^{2} \text { or } 4.5 \mathrm{mg} / \mathrm{m}^{2}(<\text { or }>6 \text { years), continuous IV infusion over } 24 \text { hours, continued for } \\
3 \text { days due to concern over Gl absorption } \\
\text { - Oral CSA day } 3 \text { at } 500 \mathrm{mg} / \mathrm{m}^{2}(<6 \text { years) or } 15 \mathrm{mg} / \mathrm{kg} \text { (> } 6 \text { years) }\end{array}$ \\
\hline Outcomes & $\begin{array}{l}\text { - Kidney function at } 1 \text { year } \\
\text { - } \text { Death } \\
\text { - Graft loss } \\
\text { - Acute rejection } \\
\text { - infection } \\
\text { - PTLD }\end{array}$ \\
\hline Notes & $\begin{array}{l}\text { - Different maintenance of AZA early on and MMF later } \\
\text { - Some also switched induction therapy } \\
\text { - } 292 \text { patients randomised, } 287 \text { transplanted } \\
\text { - CSA group: } 12 / 140(9 \%) \text { received OKT3 in } 1 \text { st week, } 2 \text { for early acute rejection } \\
\text { - OKT3 group: OKT3 was stopped early in } 21 / 147(14 \%), 6 \text { due to early graft failure }\end{array}$ \\
\hline
\end{tabular}


Benfield 1999 (Continued)

- ITT analysis used

- Funding source: National Institutes of Health, National Institute of Allergy and Infectious Diseases, 5U01Al37206

\section{Risk of bias}

\begin{tabular}{|c|c|c|}
\hline Bias & Authors' judgement & Support for judgement \\
\hline $\begin{array}{l}\text { Random sequence genera- } \\
\text { tion (selection bias) }\end{array}$ & Low risk & $\begin{array}{l}\text { "Randomization in a 1:1 ratio occurred preoperatively by contacting the cen- } \\
\text { tral data center" }\end{array}$ \\
\hline $\begin{array}{l}\text { Allocation concealment } \\
\text { (selection bias) }\end{array}$ & Low risk & "Central data center" \\
\hline $\begin{array}{l}\text { Blinding of participants } \\
\text { and personnel (perfor- } \\
\text { mance bias) } \\
\text { All outcomes }\end{array}$ & Low risk & Unlikely to influence outcomes \\
\hline $\begin{array}{l}\text { Blinding of outcome as- } \\
\text { sessment (detection bias) } \\
\text { All outcomes }\end{array}$ & Unclear risk & Not clear for outcome of acute rejection; not all episodes were biopsy-proven \\
\hline $\begin{array}{l}\text { Incomplete outcome data } \\
\text { (attrition bias) } \\
\text { All outcomes }\end{array}$ & Low risk & All patient outcome data reported \\
\hline $\begin{array}{l}\text { Selective reporting (re- } \\
\text { porting bias) }\end{array}$ & Low risk & All expected outcomes reported \\
\hline Other bias & Low risk & Appears free of other biases \\
\hline
\end{tabular}

\section{Bock 1995}

\begin{tabular}{|c|c|}
\hline Methods & $\begin{array}{l}\text { - Study design: parallel RCT; stratified according to immunological risk ('R' at risk; 'N' normal risk) } \\
\text { - Study duration: not reported } \\
\text { - Study follow-up: } 1 \text { year }\end{array}$ \\
\hline Participants & $\begin{array}{l}\text { - Country: Switzerland } \\
\text { - Setting: single centre } \\
\text { - Inclusion criteria: adults, LD or DD kidney transplant recipients } \\
\text { - Number: treatment group } 1(53) \text {; treatment group } 2(51) \\
\text { - Mean age } \pm \text { SEM (years): treatment group } 1(46 \pm 2) \text {; treatment group } 2(49 \pm 2) \\
\text { - Sex (M/F): treatment group } 1(35 / 18) \text {; treatment group } 2(30 / 21) \\
\text { - DD/LD: treatment group } 1(46 / 7) \text {; treatment group } 2(44 / 7) \\
\text { - Exclusion criteria: HLA-identical LD; pre-existing antibodies against mouse globulin }\end{array}$ \\
\hline Interventions & $\begin{array}{l}\text { Treatment group } 1 \\
\text { - } \text { rATG (Fresenius): } 4 \mathrm{mg} / \mathrm{kg} / \mathrm{d} \\
\text { * } \mathrm{N} \text { patients received } 7 \text { doses, R patients received } 14 \text { doses } \\
\text { - IV MP: higher doses in R patients } \\
\text { - PRED tapered by } 5 \mathrm{mg} \text { every } 2 \text { weeks until } 15 \mathrm{mg} \text { then } 2.5 \mathrm{mg} \text { reductions; tapered to } 0 \text { unless } \mathrm{R} \text { patients } \\
\text { or those with vascular rejection } \\
\text { - AZA: given for } 8 \text { weeks for } \mathrm{N} \text { patients or } 8 \text { months in } \mathrm{R} \text { patients }\end{array}$ \\
\hline
\end{tabular}


Bock 1995 (Continued)

- CSA adjusted as per level, $\mathrm{R}$ patients had higher target level than $\mathrm{N}$ patients

- Maintenance of AZA and PRED from day 0, CSA from day 4

Treatment group 2

- OKT3: $5 \mathrm{mg} / \mathrm{d}$

- Doses and other immunosuppression as per treatment group 1

\begin{tabular}{ll}
\hline Outcomes & Graft survival \\
- Death \\
- Acute rejection \\
- Infection \\
- Malignancy \\
- Graft function \\
- Low WCC \\
- Low platelets \\
- DGF \\
- Immunological risk: high risk (previous acute rejection causing graft loss in 1 st year or $>80 \%$ PRA at \\
- time of transplantation (R)); all others considered normal risk (N) \\
\hline \multirow{2}{*}{ Fotes }
\end{tabular}

\section{Risk of bias}

\begin{tabular}{lll}
\hline Bias & Authors' judgement & Support for judgement \\
\hline $\begin{array}{l}\text { Random sequence genera- } \\
\text { tion (selection bias) }\end{array}$ & Low risk & $\begin{array}{l}\text { Random sequences established prior to start of study such that within each set } \\
\text { of } 4 \text { consecutive patients } 2 \text { received ATGF and 2 received OKT3 }\end{array}$ \\
\hline $\begin{array}{l}\text { Allocation concealment } \\
\text { (selection bias) }\end{array}$ & Low risk & $\begin{array}{l}\text { "assigned treatments were kept in sealed envelopes that were opened when } \\
\text { the patient was admitted to the hospital for transplantation." }\end{array}$ \\
$\begin{array}{l}\text { Blinding of participants } \\
\begin{array}{l}\text { and personnel (perfor- } \\
\text { mance bias) }\end{array}\end{array}$ & Low risk & Unlikely to influence outcomes \\
All outcomes &
\end{tabular}

Blinding of outcome as- Low risk Unlikely to influence outcomes

sessment (detection bias)

All outcomes

Incomplete outcome data Low risk $\quad$ All patient outcome data reported
(attrition bias)

All outcomes

Selective reporting (re- Low risk $\quad$ All expected outcomes reported
porting bias)

\begin{tabular}{ll}
\hline Other bias $\quad$ High risk $\quad$ Funded by Cilag and Fresenius \\
\hline
\end{tabular}

Bock 1999

$\begin{array}{ll}\text { Methods } & \text { - Study design: parallel RCT } \\ & \text { - Study duration: not reported }\end{array}$


Bock 1999 (Continued)

$$
\text { - Study follow-up: } 6 \text { months }
$$

\begin{tabular}{|c|c|}
\hline Participants & $\begin{array}{l}\text { - Country: Switzerland } \\
\text { - Setting: single centre } \\
\text { - Inclusion criteria: not reported } \\
\text { - Number: treatment group } 1 \text { (35); treatment group } 2 \text { (32) } \\
\text { - Mean age } \pm \text { SD (years): not reported } \\
\text { - Sex (M/F): treatment group } 1 \text { not reported } \\
\text { - Exclusion criteria: not reported }\end{array}$ \\
\hline Interventions & $\begin{array}{l}\text { Treatment group } 1 \\
\text { - hATG (ATGAM): } 15 \mathrm{mg} / \mathrm{kg} / \mathrm{d} \text { for } 7 \text { days from day } 0 \text { to } 6 \text { (or } 14 \text { days if 'high risk') } \\
\text { - Triple maintenance immunosuppression with CSA, AZA, PRED } \\
\text { Treatment group } 2 \\
\text { - rATG (Fresenius): } 4 \mathrm{mg} / \mathrm{kg} / \mathrm{d} \text { for } 7 \text { days (or } 14 \text { days if 'high risk') } \\
\text { - Triple Immunosuppression with CSA, AZA, PRED }\end{array}$ \\
\hline Outcomes & $\begin{array}{l}\text { - Death } \\
\text { - Graft loss } \\
\text { - Acute rejection } \\
\text { - Side effects (headache) } \\
\text { - Infection }\end{array}$ \\
\hline Notes & $\begin{array}{l}\text { - Abstract only publication } \\
\text { - No table } 1 \text { but abstract states baseline and risk characteristics were similar } \\
\text { - Total number of patients with acute rejection in each group not given, therefore results not included } \\
\text { in analyses of this review } \\
\text { - Infection reported as 'similar' in both groups but figures not given } \\
\text { - Side effects other than headache reported as no significant difference between groups } \\
\text { - Funding source: not reported }\end{array}$ \\
\hline
\end{tabular}

\section{Risk of bias}

\begin{tabular}{lll}
\hline Bias & Authors' judgement & Support for judgement \\
\hline $\begin{array}{l}\text { Random sequence genera- } \\
\text { tion (selection bias) }\end{array}$ & Unclear risk & Insufficient information to permit judgement \\
\hline $\begin{array}{l}\text { Allocation concealment } \\
\text { (selection bias) }\end{array}$ & Unclear risk & Insufficient information to permit judgement \\
\hline $\begin{array}{l}\text { Blinding of participants } \\
\text { and personnel (perfor- } \\
\text { mance bias) }\end{array}$ & Unclear risk & Insufficient information to permit judgement \\
All outcomes & \\
\hline
\end{tabular}

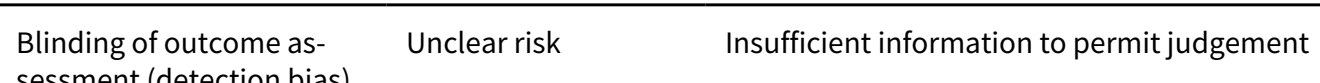
sessment (detection bias) All outcomes

Incomplete outcome data Unclear risk Insufficient information to permit judgement
(attrition bias)


Bock 1999 (Continued)

All outcomes

$\begin{array}{ll}\begin{array}{l}\text { Selective reporting (re- High risk } \\ \text { porting bias) }\end{array} & \begin{array}{l}\text { Abstract only, limited outcomes reported and not able to be included in meta- } \\ \text { analyses }\end{array}\end{array}$

Other bias Unclear risk Insufficient information to permit judgement; funding source not reported

\section{Brennan 1999}

\begin{tabular}{ll}
\hline Methods & Study design: parallel RCT; 2:1 randomisation (thymoglobulin:ATG) \\
- Study duration: May 1996 to March 1997 \\
- Study follow-up: 10 years \\
\hline Participants & Country: USA \\
- Setting: single centre \\
- Inclusion criteria: all patients eligible for induction agent; adult LD and DD kidney transplant recipients \\
- Number: treatment group 1 (48); treatment group 2 (24) \\
- Mean age \pm SD (years): treatment group 1 (45 \pm 14$) ;$ treatment group 2 (52 \pm 12$)$ \\
- Sex (M/F): treatment group 1 (30/18); treatment group 2 (15/7) \\
- Ethnicity (white/black/other): treatment group 1 (30/18/0); treatment group 2 (17/6/1) \\
- DD/LD: treatment group 1 (35/13); treatment group 2 (19/5) \\
- Exclusion criteria: previous treatment with horse or rabbit anti-T-cell polyclonal agents; had a known \\
allergy to rabbit or horse proteins; documentation of malignancy within 2 years, with the exception \\
of skin malignancies; pregnant women, nursing mothers or women of childbearing potential or who \\
were not practicing a reliable form of birth control; serological evidence of infection with HIV-1, human \\
T-lymphotropic virus-1; presence of serum Hep B surface antigen
\end{tabular}

- rATG: $1.5 \mathrm{mg} / \mathrm{kg} \mathrm{IV} \mathrm{for} \mathrm{at} \mathrm{least} 7$ days, 1 st dose intra-op through central line

Treatment group 2

- hATG (ATGAM): $15 \mathrm{mg} / \mathrm{kg}$ IV for at least 7 days

Immunosuppression (both groups)

- AZA: IV then oral

* MMF instead of AZA if on allopurinol or 2nd transplant or ESKD due to immunologic cause

- MP then PRED: tapered over 9 months to $0.1 \mathrm{mg} / \mathrm{kg}$

- CSA: started 2/7 pre-op if LD or after good urine output if DD; adjust as per levels; TAC if CSA not tolerated

\begin{tabular}{ll}
\hline Outcomes & - Death \\
& - Graft failure \\
& - Acute rejection \\
& - PTLD /malignancy \\
& - Graft function \\
\hline Notes & - Funding source: not reported
\end{tabular}

\section{Risk of bias}


Brennan 1999 (Continued)

\begin{tabular}{lll} 
Bias & Authors' judgement & Support for judgement \\
\hline $\begin{array}{l}\text { Random sequence genera- } \\
\text { tion (selection bias) }\end{array}$ & Unclear risk & Random sequence used but not reported \\
\hline $\begin{array}{l}\text { Allocation concealment } \\
\text { (selection bias) }\end{array}$ & Low risk & Not reported, however appears to be coordinated by the pharmacist \\
\hline $\begin{array}{l}\text { Blinding of participants } \\
\text { and personnel (perfor- } \\
\text { mance bias) } \\
\text { All outcomes }\end{array}$ & Unclear risk & $\begin{array}{l}\text { "Only the pharmacist was unblinded and responsible } \\
\text { for maintaining that the investigator, staff, laboratory, and pathologists re- } \\
\text { mained blinded to patient study drug } \\
\text { group for greater than 1 year after transplantation" }\end{array}$ \\
\hline
\end{tabular}

\begin{tabular}{|c|c|c|}
\hline $\begin{array}{l}\text { Blinding of outcome as- } \\
\text { sessment (detection bias) } \\
\text { All outcomes }\end{array}$ & Low risk & $\begin{array}{l}\text { "Only the pharmacist was unblinded and responsible } \\
\text { for maintaining that the investigator, staff, laboratory, and pathologists re- } \\
\text { mained blinded to patient study drug } \\
\text { group for greater than } 1 \text { year after transplantation" }\end{array}$ \\
\hline
\end{tabular}

Incomplete outcome data Low risk All patient outcome data reported

(attrition bias)

All outcomes

\begin{tabular}{lll}
\hline $\begin{array}{l}\text { Selective reporting (re- } \\
\text { porting bias) }\end{array}$ & Low risk & All expected outcomes reported \\
\hline Other bias & Unclear risk & Funding not reported \\
\hline
\end{tabular}

\section{Broyer 1993}

\begin{tabular}{ll}
\hline Methods & - Study design: parallel RCT \\
& - Study duration: September 1987 to December 1990 \\
\hline Participants & - Country follow-up: 3 years \\
- Setting: single centre (Paris) \\
- Inclusion criteria: children; all 1st transplant, all DD \\
- Number: treatment group 1 (77); treatment group 2(71) \\
- Mean age \pm SD (years): not reported \\
- Sex (M/F): not reported \\
- Exclusion criteria: not reported
\end{tabular}

Interventions Treatment group 1

- OKT3 (Orthoclone): $0.1 \mathrm{mg} / \mathrm{kg} / \mathrm{d}$ start dose, adjusted as per circulating CD3 cells; given for 21 days, later reduced to 15 days (after 6 months into study)

Treatment group 2

- ALG (Lymphoglobuline, Merieux): 1 to $5 \mathrm{mg} / \mathrm{kg} / \mathrm{d}$, to maintain total lymphocyte count < $500 \mathrm{~mm}^{3}$; given for 15 to 21 days

Immunosuppression (both groups)

- AZA: $3 \mathrm{mg} / \mathrm{kg}$, decreased to $1.5 \mathrm{mg} / \mathrm{kg}$ after CSA started

- CSA started when OKT3 stopped; dose $150 \mathrm{mg} / \mathrm{mL} / \mathrm{d}$ (trough level not reported) 
Broyer 1993 (Continued)

- PRED: $60 \mathrm{mg}$, tapered to $30 \mathrm{mg}$ by one month, tapered to $7.5 \mathrm{mg}$ at 6 months

\begin{tabular}{|c|c|}
\hline Outcomes & $\begin{array}{l}\text { - } \text { Death } \\
\text { - Graft loss } \\
\text { - Acute rejection } \\
\text { - } \text { DGF } \\
\text { - Infection } \\
\text { - Graft function }\end{array}$ \\
\hline Notes & $\begin{array}{l}\text { - No table } 1 \text {; reported as no significant differences in age, donor age, cold ischaemia time, HLA mis- } \\
\text { match, blood transfusions, or PRA } \\
\text { - Funding source: not reported }\end{array}$ \\
\hline
\end{tabular}

\section{Risk of bias}

\begin{tabular}{|c|c|c|}
\hline Bias & Authors' judgement & Support for judgement \\
\hline $\begin{array}{l}\text { Random sequence genera- } \\
\text { tion (selection bias) }\end{array}$ & Unclear risk & Insufficient information to permit judgement \\
\hline $\begin{array}{l}\text { Allocation concealment } \\
\text { (selection bias) }\end{array}$ & Unclear risk & Insufficient information to permit judgement \\
\hline $\begin{array}{l}\text { Blinding of participants } \\
\text { and personnel (perfor- } \\
\text { mance bias) } \\
\text { All outcomes }\end{array}$ & Unclear risk & Insufficient information to permit judgement \\
\hline $\begin{array}{l}\text { Blinding of outcome as- } \\
\text { sessment (detection bias) } \\
\text { All outcomes }\end{array}$ & Unclear risk & $\begin{array}{l}\text { Most outcomes unlikely to influence outcomes but unclear whether acute re- } \\
\text { jection was biopsy proven or clinically diagnosed }\end{array}$ \\
\hline $\begin{array}{l}\text { Incomplete outcome data } \\
\text { (attrition bias) } \\
\text { All outcomes }\end{array}$ & Unclear risk & Insufficient information to permit judgement \\
\hline $\begin{array}{l}\text { Selective reporting (re- } \\
\text { porting bias) }\end{array}$ & Low risk & All expected outcomes reported \\
\hline Other bias & Unclear risk & Insufficient information to permit judgement; funding source not reported \\
\hline
\end{tabular}

\section{Buchler 2013}

\begin{tabular}{ll}
\hline Methods & Study design: parallel, open-label RCT \\
& - Study duration: October 2009 to October 2010 \\
\hline Participants & - Country: France \\
- Setting: single centre \\
- Inclusion criteria: 1 st or 2 nd DD kidney transplant recipients 12 months \\
- Number: treatment group (9); control group (9) \\
- Mean age \pm SD (years): treatment group $1(47 \pm 9)$; treatment group $2(56 \pm 9)$ \\
- Sex (M/F): treatment group $1(4 / 5) ;$ treatment group $2(7 / 1)$ \\
- Pre-emptive transplant: treatment group 1 (4); treatment group $2(2)$
\end{tabular}


Buchler 2013 (Continued)

- Dialysis vintage (months): treatment group 1 (13.7 \pm 10$)$; treatment group 2 (32.7 \pm 25$)$

- Exclusion criteria: $<18$ years; previous exposure to lymphocyte-depleting therapies, evidence of HIV infection, active Hep B or C or tuberculosis; PRA $>20 \%$, and recent or current exposure to other investigational drugs

\begin{tabular}{|c|c|}
\hline Interventions & $\begin{array}{l}\text { Treatment group } 1 \\
\text { - ATG: } 2 \text { × } 3 \mathrm{mg} / \mathrm{kg} \text { doses day } 0 \text { and } 3 \text { (started intra-op), } 24 \mathrm{~h} \text { IV infusion } \\
\text { - MP: } 250 \mathrm{mg} \text { pretransplant, second dose before } 2 \text { nd ATG } \\
\text { Treatment group } 2 \\
\text { - ATG: } 4 \text { x } 1.5 \mathrm{mg} / \mathrm{kg} \text { doses day } 0,1,2,3,12 \mathrm{~h} \text { IV infusion } \\
\text { - MP: } 250 \mathrm{mg} \text { pretransplant } \\
\text { Maintenance immunosuppression (both groups) } \\
\text { - PRED: } 1 \mathrm{mg} / \mathrm{kg} / \mathrm{d} \\
\text { - MMF: } 1000 \mathrm{mg} \text { twice/d } \\
\text { - TAC: started day } 3 \text { at dose of } 0.1 \mathrm{mg} / \mathrm{kg} \text { twice/d (target trough } 8 \text { to } 15 \mathrm{ng} / \mathrm{mL} \text { ) } \\
\text { Prophylaxis (both groups) } \\
\text { - Co-trimoxazole: for } 3 \mathrm{months} \text { for all patients } \\
\text { - Valganciclovir: } 450 \mathrm{mg} / \mathrm{d} \text {, adjusted for eGFR, for all patients for } 3 \text { months unless CMV negative to neg- } \\
\text { ative }\end{array}$ \\
\hline Outcomes & $\begin{array}{l}\text { - Pharmacokinetics and pharmacodynamics of different doses } \\
\text { - Side effects } \\
\text { - DGF } \\
\text { - Acute rejection } \\
\text { - BKV } \\
\text { - CMV } \\
\text { - Death } \\
\text { - Graft survival }\end{array}$ \\
\hline Notes & - Funding source: grant from Genzyme \\
\hline
\end{tabular}

Risk of bias

\begin{tabular}{lll}
\hline Bias & Authors' judgement & Support for judgement \\
\hline $\begin{array}{l}\text { Random sequence genera- } \\
\text { tion (selection bias) }\end{array}$ & Unclear risk & Insufficient information to permit judgement \\
\hline $\begin{array}{l}\text { Allocation concealment } \\
\text { (selection bias) }\end{array}$ & Unclear risk & Insufficient information to permit judgement \\
\hline $\begin{array}{l}\text { Blinding of participants } \\
\text { and personnel (perfor- } \\
\text { mance bias) } \\
\text { All outcomes }\end{array}$ & Unclear risk & Not reported but likely unblinded, possible bias for some outcomes \\
\hline $\begin{array}{l}\text { Blinding of outcome as- } \\
\text { sessment (detection bias) } \\
\text { All outcomes }\end{array}$ & Low risk & Likely unblinded but low risk in view of hard outcomes \\
\hline $\begin{array}{l}\text { Incomplete outcome data } \\
\text { (attrition bias) }\end{array}$ & Low risk & \\
\hline
\end{tabular}

Polyclonal and monoclonal antibodies for induction therapy in kidney transplant recipients (Review) 
Buchler 2013 (Continued)

All outcomes

Selective reporting (re- Low risk All expected outcomes reported
porting bias)

$\begin{array}{ll}\text { Other bias } \quad \text { High risk } & \begin{array}{l}\text { Two authors from Genzyme (manufacturer of ATG); however ATG dose same in } \\ \text { both groups }\end{array}\end{array}$

\section{CAMPASIA Study 2005}

\begin{tabular}{|c|c|}
\hline Methods & $\begin{array}{l}\text { - Study design: parallel RCT; 2:1 randomisation (alemtuzumab: standard) } \\
\text { - Study duration: October 2001 to September } 2003 \\
\text { - Study follow-up: } 6 \text { months }\end{array}$ \\
\hline Participants & $\begin{array}{l}\text { - Country: Asia } \\
\text { - Setting: multicentre (3) } \\
\text { - Inclusion criteria: adult LD or DD kidney transplant recipients; randomised only after graft was con- } \\
\text { firmed as functioning post-op; either by urine output }>50 \mathrm{~mL} / \mathrm{h} \text { or perfusion on Doppler } \\
\text { - Number: treatment group (20); control group (10) } \\
\text { - Median age, range (years): treatment group }(37.6,21.2 \text { to } 56.0) \text {; control group }(41.1,25.1 \text { to } 54.2) \\
\text { - Sex (M/F): treatment group (10/10); control group (5/5) } \\
\text { - Ethnicity (Chinese/Filipino/Malay/Indian) (\%): treatment group (30/45/15/10); control group } \\
\text { (50/50/0/0) } \\
\text { - DD/LD: treatment group ( } 10 / 10) \text {; control group (4/6) } \\
\text { - Exclusion criteria: positive lymphocyte cytotoxicity cross-match against donor cells; PRA }>85 \% \text {; previ- } \\
\text { ous transplant; multi-organ transplant; patients deemed to require MMF as primary immunosuppres- } \\
\text { sion; prior treatment with alemtuzumab; use of other investigational agents within } 6 \text { weeks; history } \\
\text { of anaphylaxis after exposure to humanized monoclonal antibodies, pregnant or nursing women, un- } \\
\text { willingness or inability to practice an acceptable form of birth control; presence of major systemic or } \\
\text { other illness likely to interfere with the patient's compliance with the protocol or compromise patient } \\
\text { safety; active infection; HIV antibody positive; Hep B surface antigen or anti-Hep C antibody positive, } \\
\text { who had autoimmune haemolytic anaemia, or who were unable to undergo transplant biopsy, includ- } \\
\text { ing patients who would require anticoagulation }\end{array}$ \\
\hline
\end{tabular}

Interventions

Treatment group

- Alemtuzumab: $2 \times 20 \mathrm{mg}$ doses IV over $2 \mathrm{~h}$, with pre-med of $500 \mathrm{mg}$ MP

* 1 st dose within $6 \mathrm{~h}$ post-op, 2 nd dose $24 \mathrm{~h}$ after 1 st

- CSA: started $48 \mathrm{~h}$ after 2 nd dose alemtuzumab

* $5 \mathrm{mg} / \mathrm{kg}$ twice/d for $48 \mathrm{~h}$, then $4 \mathrm{mg} / \mathrm{kg}$. Dose reduced to $3 \mathrm{mg} / \mathrm{kg}$ twice $/ \mathrm{d}$ if DGF (dialysis in week 1)

* Adjusted to maintain low trough of 90 to $110 \mathrm{ng} / \mathrm{mL}$.

- MP: $500 \mathrm{mg}$ at time of surgery

- \pm pre-med before alemtuzumab with chlorpheniramine, pethidine, or paracetamol

- Maintenance PRED only allowed after treatment of steroid resistant rejection or recurrent acute rejection

Control group

- CSA: 6 to $8 \mathrm{mg} / \mathrm{kg} / \mathrm{d}$ (dependent if DGF); adjusted to trough 180 to $225 \mathrm{ng} / \mathrm{mL}$

- AZA: $1 \mathrm{mg} / \mathrm{kg} / \mathrm{d}$ (titrated to WCC $>4$ and platelet $>100$ )

- PRED: according to local practice

\begin{tabular}{ll}
\hline Outcomes & Graft loss \\
& - Death \\
& - Graft function
\end{tabular}

Polyclonal and monoclonal antibodies for induction therapy in kidney transplant recipients (Review) 
CAMPASIA Study 2005 (Continued)

- Acute rejection

- Infection

- NODAT

- PTLD/malignancy

- Only short-term follow-up reported for most outcomes; small numbers
- Planned follow up for 3 years but only 6 month follow up reported so far
- No PTLD or malignancy documented (but unlikely in 6 months)
- Funding source: partly funded by the National Medical Research Council, Ministry of Health, Singapore
and partially funded by ILEX pharmaceuticals (Alemtuzumab manufacturer)

\section{Risk of bias}

\begin{tabular}{|c|c|c|}
\hline Bias & Authors' judgement & Support for judgement \\
\hline $\begin{array}{l}\text { Random sequence genera- } \\
\text { tion (selection bias) }\end{array}$ & Low risk & Random sequence used in balanced blocks of 3 \\
\hline $\begin{array}{l}\text { Allocation concealment } \\
\text { (selection bias) }\end{array}$ & Low risk & $\begin{array}{l}\text { Sealed envelopes placed with the principal investigator of each centre; the en- } \\
\text { velopes were opened in serial order within } 5 \mathrm{hr} \text { post-transplant }\end{array}$ \\
\hline $\begin{array}{l}\text { Blinding of participants } \\
\text { and personnel (perfor- } \\
\text { mance bias) } \\
\text { All outcomes }\end{array}$ & Low risk & Outcome is not likely to be influenced by lack of blinding \\
\hline $\begin{array}{l}\text { Blinding of outcome as- } \\
\text { sessment (detection bias) } \\
\text { All outcomes }\end{array}$ & Low risk & Outcome is not likely to be influenced by lack of blinding \\
\hline $\begin{array}{l}\text { Incomplete outcome data } \\
\text { (attrition bias) } \\
\text { All outcomes }\end{array}$ & Low risk & All patient outcome data reported \\
\hline $\begin{array}{l}\text { Selective reporting (re- } \\
\text { porting bias) }\end{array}$ & Low risk & All expected outcomes reported (to 6 months) \\
\hline Other bias & Unclear risk & Partially funded by ILEX pharmaceuticals (Alemtuzumab manufacturer) \\
\hline
\end{tabular}

Cantarovich 2008

\begin{tabular}{ll}
\hline Methods & Study design: parallel RCT \\
& - Study duration: January 1985 to January 1986 \\
\hline Participants & Study follow-up: 20 years \\
\hline & - Country: France \\
& - Inclusion criteria: adult DD kidney transplant recipients \\
& - Number: treatment group (60); control group (63) \\
& - Sex (M/F): treatment group (41/19); control group (47/16) \\
& - Exclusion criteria: not reported \\
\hline Interventions & Treatment group
\end{tabular}


- ALG: $300 \mathrm{mg} / \mathrm{d}$ for 14 days

- AZA: added day 45 to 90 if CSA dose was below $4 \mathrm{mg} / \mathrm{kg}$; given at lower dose of $1 \mathrm{mg} / \mathrm{kg}$

Control group

- AZA: started post-op at dose of $1.5 \mathrm{mg} / \mathrm{kg}$

Immunosuppression (both groups)

- CSA: $4 \mathrm{mg} / \mathrm{kg}$ IV started pre-op, then switched to oral and levels of 150 to $250 \mathrm{ng} / \mathrm{mL}$ targeted

- PRED: $2 \mathrm{mg} / \mathrm{kg}$ intra-op, then tapered to $5 \mathrm{mg}$ by day 90

\begin{tabular}{ll}
\hline Outcomes & Death \\
& - Graft survival \\
- Acute rejection & Infection \\
- Malignancy & Graft function \\
\hline Notes & Outcomes to 20 years \\
& Primary disease/sensitised patients/HLA mismatch/cold ischaemia time all similar. More DGF in group \\
& 1 but not significant (26/63 versus $17 / 60)$ \\
\hline & Funding source: not reported \\
\hline
\end{tabular}

\section{Risk of bias}

\begin{tabular}{|c|c|c|}
\hline Bias & Authors' judgement & Support for judgement \\
\hline $\begin{array}{l}\text { Random sequence genera- } \\
\text { tion (selection bias) }\end{array}$ & Unclear risk & Insufficient information to permit judgement \\
\hline $\begin{array}{l}\text { Allocation concealment } \\
\text { (selection bias) }\end{array}$ & Unclear risk & Insufficient information to permit judgement \\
\hline $\begin{array}{l}\text { Blinding of participants } \\
\text { and personnel (perfor- } \\
\text { mance bias) } \\
\text { All outcomes }\end{array}$ & Unclear risk & Insufficient information to permit judgement \\
\hline $\begin{array}{l}\text { Blinding of outcome as- } \\
\text { sessment (detection bias) } \\
\text { All outcomes }\end{array}$ & Unclear risk & $\begin{array}{l}\text { Outcome assessors probably not blinded but unlikely to influence outcome } \\
\text { however, less than } 50 \% \text { of acute rejection was biopsy-proven. Therefore, pos- } \\
\text { sible source of bias in making 'clinical' diagnosis of acute rejection }\end{array}$ \\
\hline $\begin{array}{l}\text { Incomplete outcome data } \\
\text { (attrition bias) } \\
\text { All outcomes }\end{array}$ & Low risk & All patient outcome data reported \\
\hline $\begin{array}{l}\text { Selective reporting (re- } \\
\text { porting bias) }\end{array}$ & Low risk & All expected outcomes reported \\
\hline Other bias & Unclear risk & Funding source not reported \\
\hline
\end{tabular}

Charpentier 2002

$\begin{array}{ll}\text { Methods } & \text { - Study design: parallel RCT } \\ & \text { - Study duration: not reported }\end{array}$


- Country: France/Belgium/Italy/Switzerland

- Setting: multicentre (30)

- Inclusion criteria: $\geq 18$ years DD kidney transplant recipients; donor was 60 years or younger and the patient was not older than 65 years and HIV-negative; no evidence of drug addiction; no previous or current malignancy; no known hypersensitivity or incompatibility with TAC, CSA, macrolides, polyoxyethylene hydrogenated castor oil, steroids, or AZA

- Number: treatment group 1 (185); treatment group 2 (186); treatment group 3 (184)

- Mean age \pm SD (years): treatment group 1 (44.5 \pm 11.0$)$; treatment group 2 (44.7 \pm 12.4$)$; treatment group $3(43.6 \pm 10.9)$

- Sex (M/F): treatment group 1 (121/64); treatment group 2 (118/66); treatment group $3(116 / 68)$

- Ethnicity (white/black/other) (\%): treatment group 1 (91.9/2.7/5.4); treatment group 2 (90.9/3.8/5.4); treatment group $3(88.8 / 6.0 / 6.0)$

- Exclusion criteria: ABO incompatible graft, had received another solid organ transplant or required multiple organ transplantation; positive T-cell crossmatch on their most recent serum specimen; required immunosuppressive drug therapy for other reasons than transplantation; systemic infections requiring therapy at the time of transplantation; significant thrombocytopenia $(50,000$ thrombocytes/L); elevated liver enzymes (> than 3 times the upper limit of the normal range) at study entry

- TAC triple group (no induction)

* TAC: day 0 ( $0.30 \mathrm{mg} / \mathrm{kg} / \mathrm{d}$ in 2 divided doses) then adjusted according to trough levels (days 1 to 42 : 10 to $42 \mathrm{ng} / \mathrm{mL}$; days 43 to $180: 5$ to $15 \mathrm{ng} / \mathrm{mL}$ )

* MP: day 0 (500 mg IV); day 1 (125 mg IV)

* PRED: days 2 to 14 (20 mg); days 15 to 28 (15 mg); days 29 to 90 (10 g); days 91 to 180 ( $\leq 10 \mathrm{mg}$ )

* AZA: day 0 ( $2 \mathrm{mg} / \mathrm{kg} \mathrm{IV)}$ ) days 1 to 90 ( 1 to $2 \mathrm{mg} / \mathrm{kg}$ orally); then stopped

Treatment group 2

- ATG induction-TAC

* ATG: $1.25 \mathrm{mg} / \mathrm{kg}$ with 12 hours of operation; subsequent doses form day 1 to 10 adjusted according to clinical condition of patient. Stopped on day 11

* TAC: 1 st dose on day 9 and adjusted as per treatment group 1

* MP, PRED and AZA as per treatment group 1

Treatment group 3

- ATG induction-CSA

* ATG as for treatment group 2

* CSA: 1 st dose on day 9 ( $8 \mathrm{mg} / \mathrm{kg} / \mathrm{s}$ in 2 divided doses); adjusted according to trough levels (days 9 to $42: 150$ to $300 \mathrm{ng} / \mathrm{mL}$; days 43 to $180: 100$ to $200 \mathrm{ng} / \mathrm{mL}$ )

* MP, PRED and AZA as per treatment group 1

\begin{tabular}{ll}
\hline Outcomes & - Biopsy-proven acute rejection \\
& - Geath \\
& - Leuft loss \\
& - Infection \\
& - Serum sickness \\
& - Tremor \\
& - Malignancy \\
& NODAT \\
& Graft function
\end{tabular}


- Funding source: not reported

\section{Risk of bias}

\begin{tabular}{|c|c|c|}
\hline Bias & Authors' judgement & Support for judgement \\
\hline $\begin{array}{l}\text { Random sequence genera- } \\
\text { tion (selection bias) }\end{array}$ & Unclear risk & Insufficient information to permit judgement \\
\hline $\begin{array}{l}\text { Allocation concealment } \\
\text { (selection bias) }\end{array}$ & Unclear risk & Insufficient information to permit judgement \\
\hline $\begin{array}{l}\text { Blinding of participants } \\
\text { and personnel (perfor- } \\
\text { mance bias) } \\
\text { All outcomes }\end{array}$ & Low risk & Unlikely to influence outcomes \\
\hline $\begin{array}{l}\text { Blinding of outcome as- } \\
\text { sessment (detection bias) } \\
\text { All outcomes }\end{array}$ & Unclear risk & Insufficient information to permit judgement \\
\hline $\begin{array}{l}\text { Incomplete outcome data } \\
\text { (attrition bias) } \\
\text { All outcomes }\end{array}$ & Low risk & All patient outcome data reported \\
\hline $\begin{array}{l}\text { Selective reporting (re- } \\
\text { porting bias) }\end{array}$ & Low risk & All expected outcomes reported \\
\hline Other bias & Unclear risk & Appears free from other bias except that funding source not reported \\
\hline
\end{tabular}

\section{Chatterjee 1976}

\begin{tabular}{ll}
\hline Methods & - Study design: parallel RCT \\
& - Study duration: April 1972 to April 1975 \\
& - Study follow-up: 18 months \\
\hline Participants & - Country: USA \\
- Setting: single centre \\
- Inclusion criteria: adult DD kidney transplant recipients \\
- Age range: 19 to 56 years \\
- Sex (M/F): not reported \\
- Exclusion criteria: double-haplotype HLA-identical match
\end{tabular}

- hATG: $15 \mathrm{mg} / \mathrm{kg}$ IV for 14 days.

- PRED and AZA as per control

Control group

- PRED: $2 \mathrm{mg} / \mathrm{kg} / \mathrm{d}$, tapered to $0.5 \mathrm{mg} / \mathrm{kg}$ by one month, then to maintenance of 15 to $17.5 \mathrm{mg} / \mathrm{d}$

- AZA: $5 \mathrm{mg} / \mathrm{kg}$ for $48 \mathrm{~h}$, then maintenance of $2.5 \mathrm{mg} / \mathrm{kg}$ if WCC ok 
Chatterjee 1976 (Continued)

\begin{tabular}{ll} 
Outcomes & Death \\
& - Graft survival \\
& Malignancy \\
\hline \multirow{2}{*}{ Notes } & hATG, no CNI in either group \\
& - Funding source: Upjohn Company prepared and supplied hATG
\end{tabular}

\section{Risk of bias}

\begin{tabular}{lll}
\hline Bias & Authors' judgement & Support for judgement \\
\hline $\begin{array}{l}\text { Random sequence genera- } \\
\text { tion (selection bias) }\end{array}$ & Unclear risk & Patients assigned a number, however method not described \\
\hline $\begin{array}{l}\text { Allocation concealment } \\
\text { (selection bias) }\end{array}$ & Low risk & $\begin{array}{l}\text { "sealed envelope containing directions for randomization to the treated } \\
\text { (HAHTG) or nontreated (non-HAHTG) group." }\end{array}$ \\
\hline $\begin{array}{l}\text { Blinding of participants } \\
\text { and personnel (perfor- } \\
\text { mance bias) } \\
\text { All outcomes }\end{array}$ & Low risk & Outcome is not likely to be influenced by lack of blinding \\
\hline $\begin{array}{l}\text { Blinding of outcome as- } \\
\text { sessment (detection bias) }\end{array}$ & Low risk & Outcome is not likely to be influenced by lack of blinding \\
$\begin{array}{l}\text { All outcomes } \\
\begin{array}{l}\text { Incomplete outcome data } \\
\text { (attrition bias) }\end{array}\end{array}$ & Low risk & All patient outcome data reported \\
$\begin{array}{l}\text { All outcomes } \\
\begin{array}{l}\text { Selective reporting (re- } \\
\text { porting bias) }\end{array}\end{array}$ & Low risk & All expected outcomes reported \\
\hline \begin{tabular}{l} 
Other bias \\
\hline
\end{tabular} & Unclear risk & Upjohn prepared and supplied hATG \\
\hline
\end{tabular}

Ciancio 2005

\begin{tabular}{|c|c|}
\hline Methods & $\begin{array}{l}\text { - Study design: parallel RCT } \\
\text { - Study duration: November } 2002 \text { to September } 2004 \\
\text { - Study follow-up: } 24 \text { months }\end{array}$ \\
\hline Participants & $\begin{array}{l}\text { - } \text { Country: USA } \\
\text { - Setting: single centre } \\
\text { - Inclusion criteria: adult } 1 \text { st DD kidney transplant recipients } \\
\text { - Number: treatment group } 1(30) \text {; treatment group } 2(30) \text {; treatment group } 3(30) \\
\text { - Mean age } \pm \text { SE (years): treatment group } 1(49.3 \pm 2.5) \text {; treatment group } 2(50.2 \pm 2.1) \text {; treatment group } \\
3(49.9 \pm 2.4) \\
\text { - Sex }(\mathrm{M} / \mathrm{F}) \text { : treatment group } 1(19 / 11) \text {; treatment group } 2(19 / 11) \text {; treatment group } 3(18 / 12) \\
\text { - Ethnicity (White/Hispanic/African-American/Other): treatment group } 1(15 / 7 / / 7 / 1) \text {; treatment group } 2 \\
\text { (10/7/12/1); treatment group } 3(14 / 3 / 12 / 0) \\
\text { - Exclusion criteria: not reported }\end{array}$ \\
\hline
\end{tabular}


Ciancio 2005 (Continued)

- ATG: $1 \mathrm{mg} / \mathrm{kg} /$ day for 7 days

- TAC: $0.1 \mathrm{mg} / \mathrm{kg}$ twice daily when $\mathrm{SCr}<4 \mathrm{mg} / \mathrm{dL}$; trough target was 8 to $10 \mathrm{ng} / \mathrm{mL}$

- MMF: $1 \mathrm{~g}$ twice daily as tolerated

- MP: $500 \mathrm{mg}$ for 3 days then weaned to $0.3 \mathrm{mg} / \mathrm{kg}$ at one month and $0.15 \mathrm{mg} / \mathrm{kg}$ at 3 months

Treatment group 2

- Alemtuzumab: $0.3 \mathrm{mg} / \mathrm{kg}$ on day 0 and day 4

- MP preceded alemtuzumab (day 0: $500 \mathrm{mg}$; day 4: $250 \mathrm{mg}$ )

- TAC started when $\mathrm{SCr}<4 \mathrm{mg} / \mathrm{dL}$; trough target was 4 to $7 \mathrm{ng} / \mathrm{mL}$ at one month post-transplant, and 4 to $6 \mathrm{ng} / \mathrm{mL}$ at 6 months post-transplant

- MMF: 500 mg twice daily

- Plan to avoid long-term steroids after 1 st week

Treatment group 3

- Daclizumab: $1 \mathrm{mg} / \mathrm{kg}$ day 0 and 4 additional doses once every 2 weeks

- TAC: $0.1 \mathrm{mg} / \mathrm{kg}$ twice daily when $\mathrm{SCr}<4 \mathrm{mg} / \mathrm{dL}$; trough target 8 to $10 \mathrm{ng} / \mathrm{mL}$

- MMF: $1 \mathrm{~g}$ twice daily as tolerated

- MP: $500 \mathrm{mg}$ for 3 days then weaned to $0.3 \mathrm{mg} / \mathrm{kg}$ at one month and $0.15 \mathrm{mg} / \mathrm{kg}$ at 3 months

\begin{tabular}{ll}
\hline Outcomes & Death \\
- Graft survival & - Acute rejection \\
- Graft function & Infection \\
\hline Notes & Only treatment groups 1 and 2 were included in this review as IL-2RA included in separate review \\
& - Funding source: this work was supported by the National Institutes of Health grant No. R01D- \\
& K25243-24, Miami Veterans Affairs Medical Center research support, and Fujisawa Pharmaceuticals, \\
& Tokyo, Japan
\end{tabular}

\section{Risk of bias}

\begin{tabular}{|c|c|c|}
\hline Bias & Authors' judgement & Support for judgement \\
\hline $\begin{array}{l}\text { Random sequence genera- } \\
\text { tion (selection bias) }\end{array}$ & Low risk & $\begin{array}{l}\text { "Randomization was performed using a standard randomized block design } \\
\text { with block sizes of three or six patients (ordering of the block sizes was also } \\
\text { randomized), ensuring a balance of patients across treatment arms after each } \\
\text { block of patients was randomized" }\end{array}$ \\
\hline $\begin{array}{l}\text { Allocation concealment } \\
\text { (selection bias) }\end{array}$ & Unclear risk & Insufficient information to permit judgement \\
\hline $\begin{array}{l}\text { Blinding of participants } \\
\text { and personnel (perfor- } \\
\text { mance bias) } \\
\text { All outcomes }\end{array}$ & Low risk & Outcome is not likely to be influenced by lack of blinding \\
\hline $\begin{array}{l}\text { Blinding of outcome as- } \\
\text { sessment (detection bias) } \\
\text { All outcomes }\end{array}$ & Low risk & Outcome is not likely to be influenced by lack of blinding \\
\hline $\begin{array}{l}\text { Incomplete outcome data } \\
\text { (attrition bias) } \\
\text { All outcomes }\end{array}$ & Low risk & All patient outcome data reported \\
\hline
\end{tabular}


Ciancio 2005 (Continued)

Selective reporting (re- Low risk All expected outcomes reported
porting bias)

Other bias Unclear risk Funded by National Institutes of Health grant No. R01DK25243-24, Miami Veterans Affairs Medical Center research support, and Fujisawa Pharmaceuticals, Tokyo, Japan

\section{Ciancio 2010}

\begin{tabular}{|c|c|}
\hline Methods & $\begin{array}{l}\text { - Study design: parallel RCT } \\
\text { - Study duration: September } 2002 \text { to October } 2006 \\
\text { - Study follow-up: } 29 / 36 \text { followed beyond } 36 \text { months }\end{array}$ \\
\hline Participants & $\begin{array}{l}\text { - Country: USA } \\
\text { - Setting: single centre } \\
\text { - Inclusion criteria: LD 1st kidney transplant recipients aged } 16 \text { to } 66 \text { years } \\
\text { - Number: treatment group } 1(13) \text {; treatment group } 2(13) \text {; treatment group } 3(12) \\
\text { - Mean age } \pm \text { SE (years): treatment group } 1(44.5 \pm 3.1) \text {; treatment group } 2(40.0 \pm 3.7) \text {; treatment group } \\
3(47.2 \pm 2.8) \\
\text { - Sex (M/F):treatment group } 1(10 / 3) \text {; treatment group } 2(9 / 4) \text {; treatment group } 3(7 / 5) \\
\text { - Ethnicity (White/Hispanic/African-American/Other): treatment group } 1(7 / 4 / 2 / 0) \text {; treatment group } 2 \\
\text { (5/3/4/1); treatment group } 3(5 / 4 / 2 / 1) \\
\text { - Exclusion criteria: "similar to other prospective randomized trials performed at our center" }\end{array}$ \\
\hline
\end{tabular}

Interventions

Treatment group 1

- Thymoglobulin: $1 \mathrm{mg} / \mathrm{kg} / \mathrm{d}$ for 7 days

- TAC: $0.1 \mathrm{mg} / \mathrm{kg}$ twice daily when $\mathrm{SCr}<4 \mathrm{mg} / \mathrm{dL}$; trough target was 6 to $8 \mathrm{ng} / \mathrm{mL}$

- MMF: $1 \mathrm{~g}$ twice daily as tolerated

- MP: $500 \mathrm{mg}$ for 3 days then weaned to $0.3 \mathrm{mg} / \mathrm{kg}$ at one month and $0.15 \mathrm{mg} / \mathrm{kg}$ at 3 months

Treatment group 2

- Alemtuzumab: $0.3 \mathrm{mg} / \mathrm{kg}$ on day 0 and day 4

- MP: preceded alemtuzumab (day 0: $500 \mathrm{mg}$; day 4: $250 \mathrm{mg}$ )

- TAC: $0.1 \mathrm{mg} / \mathrm{kg}$ twice daily when $\mathrm{SCr}<4 \mathrm{mg} / \mathrm{dL}$; trough target was 4 to $6 \mathrm{ng} / \mathrm{mL}$

- MMF: 500 mg twice daily as tolerated

- Aim to totally avoid steroids after the 1 st week

Treatment group 3

- Daclizumab: $1 \mathrm{mg} / \mathrm{kg}$ day 0 and 4 additional doses once every 2 weeks

- TAC: $0.1 \mathrm{mg} / \mathrm{kg}$ twice daily when $\mathrm{SCr}<4 \mathrm{mg} / \mathrm{dL}$; trough target was 6 to $8 \mathrm{ng} / \mathrm{mL}$

- MMF: $1 \mathrm{~g}$ twice daily as tolerated

- MP: $500 \mathrm{mg}$ for 3 days then weaned to $0.3 \mathrm{mg} / \mathrm{kg}$ at one month and $0.15 \mathrm{mg} / \mathrm{kg}$ at 3 months

\begin{tabular}{ll}
\hline Outcomes & Death \\
& - Biopsy-proven acute rejection \\
& - DGF \\
- Infection \\
- NODAT \\
- Graft function
\end{tabular}


Ciancio 2010 (Continued)

Notes

- Only treatment groups 1 and 2 were included in this review as IL-2RA included in separate review

- Funding source: "Salary support for the Principal Investigator(Dr. Burke), the biostatistician (Dr. Gaynor), research coordinator(Ms. Hanson), and data coordinator (Ms. Tueros and Dr. Zarak)was provided by Roche Laboratories, Inc. via a Clinical Research Agreement to fund part of the costs of conducting and evaluating the results of this clinical trial"

\section{Risk of bias}

\begin{tabular}{|c|c|c|}
\hline Bias & Authors' judgement & Support for judgement \\
\hline $\begin{array}{l}\text { Random sequence genera- } \\
\text { tion (selection bias) }\end{array}$ & Unclear risk & Insufficient information to permit judgement \\
\hline $\begin{array}{l}\text { Allocation concealment } \\
\text { (selection bias) }\end{array}$ & Unclear risk & Insufficient information to permit judgement \\
\hline $\begin{array}{l}\text { Blinding of participants } \\
\text { and personnel (perfor- } \\
\text { mance bias) } \\
\text { All outcomes }\end{array}$ & Low risk & Open-label, unlikely to influence outcomes \\
\hline $\begin{array}{l}\text { Blinding of outcome as- } \\
\text { sessment (detection bias) } \\
\text { All outcomes }\end{array}$ & Low risk & Open-label, unlikely to influence outcomes \\
\hline $\begin{array}{l}\text { Incomplete outcome data } \\
\text { (attrition bias) } \\
\text { All outcomes }\end{array}$ & Low risk & All patient outcome data reported \\
\hline $\begin{array}{l}\text { Selective reporting (re- } \\
\text { porting bias) }\end{array}$ & Low risk & All expected outcomes reported \\
\hline Other bias & High risk & Investigators funded by Roche \\
\hline
\end{tabular}

Cole 1994

\begin{tabular}{ll}
\hline Methods & Study design: parallel RCT, stratified for the DM and for each centre \\
- Study duration: not reported \\
- Study follow-up: 1 year \\
\hline Participants & - Country: USA \\
- Setting: multicentre (3) \\
- Inclusion criteria: adult 1st DD kidney transplant recipients \\
- Number: treatment group 1 (83); treatment group 2 (83) \\
- Mean age, range (years): treatment group 1 (48.43, 22 to 72$)$; treatment group 2 (47.31, 22 to 70$)$ \\
- Males: treatment group 1 (66\%); treatment group 2 (60\%) \\
- Exclusion criteria: refused consent; positive skin test to rATG
\end{tabular}

Interventions

Treatment group 1

- RATG: $0.15 \mathrm{~mL} / \mathrm{kg} / \mathrm{d}$ as continuous IV infusion within $12 \mathrm{~h}$ of transplant; adjusted to keep lymphocyte count $<200 / \mathrm{mL}^{3}$; given for 10 to 14 days

- CSA initiated at $2 \mathrm{mg} / \mathrm{kg}$ twice daily once kidney function was established ( $\mathrm{SCr}<250 \mu \mathrm{mol} / \mathrm{L}$ ) but at least 7 days after surgery; target trough of 100 to $300 \mathrm{ng} / \mathrm{mL}$ 
Cole 1994 (Continued)

Treatment group 2

- OKT3: $5 \mathrm{mg}$ given during operation prior to anastomosis, then $5 \mathrm{mg} / \mathrm{d}$ IV infusion

* MP: $1 \mathrm{mg} / \mathrm{kg}$ IV plus $50 \mathrm{mg}$ oral or IV Benadryl and $650 \mathrm{mg}$ acetaminophen every $6 \mathrm{~h}$ were given 1 $\mathrm{h}$ before OKT3 administration for the 1st 2 or 3 doses

* CD3 levels not routinely monitored

Immunosuppression (both groups)

- MP: $1 \mathrm{mg} / \mathrm{kg}$ IV within $1 \mathrm{~h}$ of transplant; $0.25 \mathrm{mg} / \mathrm{kg}$ every $6 \mathrm{~h}$ post-op for $48 \mathrm{~h}$; converted to PRED (0.5 $\mathrm{mg} / \mathrm{kg} / \mathrm{d}$ ) then tapered to $0.2 \mathrm{mg} / \mathrm{kg} / \mathrm{d}$ by day $11,0.15 \mathrm{mg} / \mathrm{kg} / \mathrm{d}$ by week 6 and continued for 1 year

- AZA: $1 \mathrm{mg} / \mathrm{kg}$ IV within $1 \mathrm{~h}$ of transplant and then continued at $1 \mathrm{mg} / \mathrm{kg} / \mathrm{d}$ for 1 year unless WCC > $3000 / \mathrm{mL}^{3}$

\begin{tabular}{ll}
\hline Outcomes & Death \\
& - Graft loss \\
- Acute rejection & Infection (not able to be included in review as reported as total number of infections rather than total \\
& number of patients with infection) \\
\hline Notes & - Kidney function: SCr at 1, 3, 6 and 12 months 'similar' both groups (numbers not given) \\
& Funding source: not reported \\
\hline
\end{tabular}

\section{Risk of bias}

\begin{tabular}{|c|c|c|}
\hline Bias & Authors' judgement & Support for judgement \\
\hline $\begin{array}{l}\text { Random sequence genera- } \\
\text { tion (selection bias) }\end{array}$ & Unclear risk & Insufficient information to permit judgement \\
\hline $\begin{array}{l}\text { Allocation concealment } \\
\text { (selection bias) }\end{array}$ & Unclear risk & Insufficient information to permit judgement \\
\hline $\begin{array}{l}\text { Blinding of participants } \\
\text { and personnel (perfor- } \\
\text { mance bias) } \\
\text { All outcomes }\end{array}$ & Low risk & Unlikely to influence outcomes \\
\hline $\begin{array}{l}\text { Blinding of outcome as- } \\
\text { sessment (detection bias) } \\
\text { All outcomes }\end{array}$ & High risk & Clinically diagnosed acute rejection (no biopsy-proven acute rejection) \\
\hline $\begin{array}{l}\text { Incomplete outcome data } \\
\text { (attrition bias) } \\
\text { All outcomes }\end{array}$ & Low risk & All patient outcome data reported \\
\hline $\begin{array}{l}\text { Selective reporting (re- } \\
\text { porting bias) }\end{array}$ & High risk & $\begin{array}{l}\text { Expected outcomes reported, however infection data cannot be included in } \\
\text { our meta-analysis }\end{array}$ \\
\hline Other bias & Unclear risk & Funding source not reported \\
\hline
\end{tabular}

Condie 1985

$\begin{array}{ll}\text { Methods } & \text { - Study design: parallel RCT; stratified according to age, histocompatibility, transfusion history } \\ \text { - Study duration: not reported }\end{array}$


Condie 1985 (Continued)

$$
\text { - Study follow-up: } 3 \text { years }
$$

\begin{tabular}{|c|c|}
\hline Participants & $\begin{array}{l}\text { - Country: USA } \\
\text { - Setting: multicentre (4) } \\
\text { - Inclusion criteria: adults 1st DD kidney transplant recipients } \\
\text { - Number: treatment group (81); control group (79) } \\
\text { - Mean age: treatment group ( } 37.8) ; \text { control group ( } 35.5) \\
\text { - Sex (males): treatment group ( } 75.3 \%) \text {; control group }(74.7 \%) \\
\text { - Exclusion criteria: contraindication of positive skin test; presence of circulating antibodies to horse } \\
\text { products }\end{array}$ \\
\hline Interventions & $\begin{array}{l}\text { Treatment group } \\
\text { - Minnesota equine ALG: } 30 \mathrm{mg} / \mathrm{kg} / \mathrm{d} \text { IV for } 14 \text { days } \\
\text { - PRED and AZA: dosing regimen not reported } \\
\text { Control group } \\
\text { - Human albumin } 30 \mathrm{mg} / \mathrm{kg} / \mathrm{d} \text { IV for } 14 \text { days } \\
\text { - PRED and AZA: dosing regimen not reported }\end{array}$ \\
\hline Outcomes & $\begin{array}{l}\text { - } \text { Death } \\
\text { - Graft loss } \\
\text { - } \text { Acute rejection } \\
\text { - Infection } \\
\text { - Malignancy } \\
\text { - Side effects }\end{array}$ \\
\hline
\end{tabular}

\section{Risk of bias}

\begin{tabular}{lll}
\hline Bias & Authors' judgement & Support for judgement \\
\hline $\begin{array}{l}\text { Random sequence genera- } \\
\text { tion (selection bias) }\end{array}$ & Unclear risk & Not described \\
\hline $\begin{array}{l}\text { Allocation concealment } \\
\text { (selection bias) }\end{array}$ & Unclear risk & Not described \\
\hline $\begin{array}{l}\text { Blinding of participants } \\
\text { and personnel (perfor- } \\
\text { mance bias) } \\
\text { All outcomes }\end{array}$ & Low risk & Double blind \\
\hline
\end{tabular}

\begin{tabular}{|c|c|c|}
\hline $\begin{array}{l}\text { Blinding of outcome as- } \\
\text { sessment (detection bias) } \\
\text { All outcomes }\end{array}$ & Unclear risk & Not blinded, may affect some but not all outcomes \\
\hline $\begin{array}{l}\text { Incomplete outcome data } \\
\text { (attrition bias) } \\
\text { All outcomes }\end{array}$ & Low risk & All patient outcome data reported \\
\hline $\begin{array}{l}\text { Selective reporting (re- } \\
\text { porting bias) }\end{array}$ & High risk & $\begin{array}{l}\text { Expected outcomes reported, however acute rejection rates and SCr not fully } \\
\text { reported (short-term only) }\end{array}$ \\
\hline Other bias & Unclear risk & Funding not reported \\
\hline
\end{tabular}


Cosimi 1976

\begin{tabular}{ll}
\hline Methods & Study design: parallel RCT \\
- Study duration: January 1973 to November 1975 \\
- Study follow-up: 12 to 24 months (graft loss: 12 months; death: 24 months) \\
\hline - Country: USA \\
- Setting: multicentre \\
- Inclusion criteria: adult and children LD and DD kidney transplant recipients; aged 10 to 60 years \\
- Number: treatment group (183); control group (175) \\
- Mean age: treatment group (36.3 years); control group (34.4 years) \\
- Sex (M/F): treatment group (123/60); control group (149/60) \\
- DD/LD: treatment group (173/10); control group (165/10) \\
- Exclusion criteria: history of cancer; reaction to ATG skin test
\end{tabular}

\begin{tabular}{|c|c|}
\hline \multirow[t]{7}{*}{ Interventions } & Treatment group \\
\hline & $\begin{array}{l}\text { - hATG (ATGAM): } 2 \text { different protocols used } \\
\text { * Protocol } 119: 10 \text { to } 20 \mathrm{mg} / \mathrm{kg} / \mathrm{d} \text { ATG, starting at transplant day } 0 \text {, continued for } 14 \text { days } \\
\square \text { AZA: } 3 \mathrm{mg} / \mathrm{kg} \text { from day } 0 \text { and continued for } 16 \text { weeks }\end{array}$ \\
\hline & $\square \mathrm{MP}: 1.2 \mathrm{mg} / \mathrm{kg}$, starting day 0, continued for 1 week, taper to $24 \mathrm{mg} / \mathrm{d}$ by week 17 (or oral PRED) \\
\hline & $\begin{array}{l}\text { * Protocol } 122: 20 \text { to } 30 \mathrm{mg} / \mathrm{kg} / \mathrm{d} \text { ATG } \\
\square \text { AZA: } 2 \text { to } 3 \mathrm{mg} / \mathrm{kg}\end{array}$ \\
\hline & $\square \mathrm{MP}: 1.2 \mathrm{mg} / \mathrm{kg}$, starting day 0, continued for 1 week, taper to $24 \mathrm{mg} / \mathrm{d}$ by week 17 (or oral PRED) \\
\hline & Control group \\
\hline & - AZA and MP or oral PRED (doses not reported) \\
\hline \multirow[t]{4}{*}{ Outcomes } & - Death \\
\hline & - Graft loss \\
\hline & - Time of onset of acute rejection \\
\hline & - Serious infections \\
\hline Notes & $\begin{array}{l}\text { - Funding source: Upjohn company and from General Research Support Grants RR-05486-12 and } \\
\text { HL1-18646-01 }\end{array}$ \\
\hline
\end{tabular}

\section{Risk of bias}

\begin{tabular}{lll}
\hline Bias & Authors' judgement & Support for judgement \\
\hline $\begin{array}{l}\text { Random sequence genera- } \\
\text { tion (selection bias) }\end{array}$ & Low risk & Random number table used \\
\hline $\begin{array}{l}\text { Allocation concealment } \\
\text { (selection bias) }\end{array}$ & Low risk & $\begin{array}{l}\text { Central allocation via Upjohn company - list kept by "Hypersensitivity Dis- } \\
\text { eases Research's co-ordinating center for ATG studies" }\end{array}$ \\
\hline $\begin{array}{l}\text { Blinding of participants } \\
\text { and personnel (perfor- } \\
\text { mance bias) }\end{array}$ & Low risk & Open-label; unlikely to influence outcomes \\
$\begin{array}{l}\text { All outcomes } \\
\begin{array}{l}\text { Blinding of outcome as- } \\
\text { sessment (detection bias) } \\
\text { All outcomes }\end{array}\end{array}$ & Unclear risk & $\begin{array}{l}\text { Most outcomes not likely to be affected but not all acute rejection was biop- } \\
\text { sy-proven acute rejection }\end{array}$ \\
\hline
\end{tabular}


Cosimi 1976 (Continued)
Incomplete outcome data
Low risk
All patient outcome data reported

(attrition bias)

All outcomes

Selective reporting (re- High risk
porting bias)

Side effects not reported for controls. Authors felt likely to be under-reported in controls as not double blinded study, therefore data not given (likely to be much higher rate of side effects in ATG group, even if double blinded, therefore, probably not acceptable reason for not reporting

Also, some hard outcomes such as WCC and platelets could be easily collected for both groups

$\begin{array}{ll}\text { Other bias } & \text { High risk } \\ & \text { Cosimi paper- supported in part by research grants from the Upjohn Co and } \\ & \begin{array}{l}\text { from General Research Support Grants RR-05486-12 and HL1-18646-01, both } \\ \text { from US Public health service }\end{array}\end{array}$

De Pauw 1990

\begin{tabular}{ll}
\hline Methods & - Study design: parallel RCT \\
& - Study duration: not reported \\
& - Study follow-up: not reported \\
\hline Participants & - Country: Belgium \\
- Setting: single centre \\
- Numblusion criteria: non-hyperimmunised patients receiving 1st DD kidney transplant \\
- Mean age \pm SD (years): not reported \\
- Sex (M/F): not reported \\
- Exclusion criteria: not reported
\end{tabular}

\begin{tabular}{ll}
\hline Tnterventions & Treatment group \\
- OKT3: $5 \mathrm{mg} / \mathrm{d}$ from day 0 to day 14 \\
- CSA: started day 12 and adjusted to tough level between 100 to $150 \mathrm{ng} / \mathrm{mL}$ \\
- AZA: tapered from $1 \mathrm{mg} / \mathrm{kg}$ to $2 \mathrm{mg} / \mathrm{kg}$ on day 15 \\
- PRED: gradually tapered from day 14 \\
Control group \\
- CSA: 4 to $8 \mathrm{mg} / \mathrm{kg} / \mathrm{d}$ from day 0 , adjusted to tough level between 100 to $150 \mathrm{mg} / \mathrm{kg} / \mathrm{d}$ from day 0 \\
- PRED: gradually tapered from day 14 \\
\hline - Acute rejection \\
- DGF \\
- Graft loss \\
\hline - Notcomes \\
- time, HLA mismatch \\
- Graft function reported as similar in both groups but no figures given \\
- Funding source: not reported
\end{tabular}


De Pauw 1990 (Continued)

Risk of bias

\begin{tabular}{|c|c|c|}
\hline Bias & Authors' judgement & Support for judgement \\
\hline $\begin{array}{l}\text { Random sequence genera- } \\
\text { tion (selection bias) }\end{array}$ & Unclear risk & Insufficient information to permit judgement \\
\hline $\begin{array}{l}\text { Allocation concealment } \\
\text { (selection bias) }\end{array}$ & Unclear risk & Insufficient information to permit judgement \\
\hline $\begin{array}{l}\text { Blinding of participants } \\
\text { and personnel (perfor- } \\
\text { mance bias) } \\
\text { All outcomes }\end{array}$ & Unclear risk & Unlikely to influence outcomes \\
\hline $\begin{array}{l}\text { Blinding of outcome as- } \\
\text { sessment (detection bias) } \\
\text { All outcomes }\end{array}$ & Unclear risk & Unclear if acute rejection episodes were biopsy-proven acute rejection \\
\hline $\begin{array}{l}\text { Incomplete outcome data } \\
\text { (attrition bias) } \\
\text { All outcomes }\end{array}$ & Low risk & All patient outcome data reported \\
\hline $\begin{array}{l}\text { Selective reporting (re- } \\
\text { porting bias) }\end{array}$ & High risk & $\begin{array}{l}\text { Death not reported at all and only limited reporting of some other outcomes; } \\
\text { data for graft function and infectious complications not available to meta- } \\
\text { analyse }\end{array}$ \\
\hline Other bias & Unclear risk & Insufficient information to permit judgement and funding source not specified \\
\hline
\end{tabular}

Debure 1987

\begin{tabular}{|c|c|}
\hline Methods & $\begin{array}{l}\text { - Study design: parallel RCT } \\
\text { - Study duration: not reported } \\
\text { - Study follow-up: } 4 \text { years }\end{array}$ \\
\hline Participants & $\begin{array}{l}\text { - Country: France } \\
\text { - Setting: single centre (Paris) } \\
\text { - Inclusion criteria: } 1 \text { st DD kidney transplant recipients } \\
\text { - Number: treatment group (18); control group } 1(18) \text {; control group } 2(19) \\
\text { - Mean age } \pm \text { SD (years): treatment group }(35.4 \pm 1.9) \text {; control group } 1(36.8 \pm 2.0) \text {; control group } 2 \text { (36.3 } \\
\pm 202) \\
\text { - Sex (M/F): treatment group (14/4); control group } 1(9 / 9) \text {; control group } 2(15 / 4) \\
\text { - Exclusion criteria: not reported }\end{array}$ \\
\hline
\end{tabular}

Interventions

Treatment group

- OKT3: $5 \mathrm{mg} / \mathrm{d}$ For 14 days minimum, up to 30 days

- AZA: $3 \mathrm{mg} / \mathrm{kg} / \mathrm{d}$ as long as tolerated

- PRED: taper from $1 \mathrm{mg} / \mathrm{kg}$ to $0.25 \mathrm{mg} / \mathrm{kg} / \mathrm{d}$

Control group 1

- AZA: $3 \mathrm{mg} / \mathrm{kg} / \mathrm{d}$ as long as tolerated

- PRED: taper from $1 \mathrm{mg} / \mathrm{kg}$ to $0.25 \mathrm{mg} / \mathrm{kg} / \mathrm{d}$ 
Debure 1987 (Continued)

\section{Control group 2}

- $A Z A: 3 \mathrm{mg} / \mathrm{kg} / \mathrm{d}$ as long as tolerated

- PRED: $5 \mathrm{mg} / \mathrm{kg} / \mathrm{d}$ for 5 days then tapered over next 2 to 3 weeks

\begin{tabular}{ll}
\hline Outcomes & Death \\
& - Graft loss \\
- Acute rejection & Graft function \\
\hline Notes & - Control group 1 used as had identical co-interventions to OKT3 group \\
- Side effects also reported but only for OKT3 group. Cytokine release syndrome common with 1st 2 \\
- doses of OKT3 \\
- Fo PTLD or malignancy observed
\end{tabular}

\section{Risk of bias}

\begin{tabular}{lll}
\hline Bias & Authors' judgement & Support for judgement \\
\hline $\begin{array}{l}\text { Random sequence genera- } \\
\text { tion (selection bias) }\end{array}$ & Low risk & '..the randomisation schedule was computer generated' \\
\hline $\begin{array}{l}\text { Allocation concealment } \\
\text { (selection bias) }\end{array}$ & High risk & $\begin{array}{l}\text { No comment in paper about whether treatment allocations were concealed } \\
\text { Imbalance in HLA mismatches (see above) favouring controls suggesting prob- } \\
\text { lems with randomisation, but would potentially bias results in favour of con- } \\
\text { trols }\end{array}$ \\
\hline
\end{tabular}

Blinding of participants Low risk Not blinded, unlikely to influence outcomes

and personnel (perfor-

mance bias)

All outcomes

\begin{tabular}{ll}
\hline Blinding of outcome as- & Low risk
\end{tabular}

All outcomes

\begin{tabular}{l}
\hline $\begin{array}{l}\text { Incomplete outcome data } \\
\text { (attrition bias) }\end{array}$ \\
All outcomes
\end{tabular}

Selective reporting (re- Low risk All expected outcomes reported
porting bias)

$\begin{array}{ll}\text { Other bias } \quad \text { High risk } & \begin{array}{l}\text { Funding source not declared, however } 1 \text { author was an employee of Ortho } \\ \text { Pharmaceuticals }\end{array}\end{array}$

\section{Diethelm 1979}

\begin{tabular}{ll}
\hline Methods & - Study design: parallel RCT \\
& - Study duration: not reported \\
& - Study follow-up: 3 to 31 months \\
\hline Participants & - Country: USA
\end{tabular}


Diethelm 1979 (Continued)

- Setting: single centre

- Inclusion criteria: DD kidney transplant recipients

- Number: treatment group (26); control group (27)

- Mean age \pm SD (years): not reported

- Sex (M/F): not reported

- Exclusion criteria: not reported

\begin{tabular}{|c|c|}
\hline Interventions & $\begin{array}{l}\text { Treatment group } \\
\text { - ATG: } 10 \text { to } 15 \mathrm{mg} / \mathrm{kg} / \mathrm{d} \text { from day } 0 \text { for } 28 \text { days } \\
\text { Control group } \\
\text { - No ATG } \\
\text { Immunosuppression (both groups) } \\
\text { - AZA: } 5 \mathrm{mg} / \mathrm{kg} \text { for } 2 \text { days, tapered to } 3 \mathrm{mg} \text { over } 1 \text { week, maintained at } 75 \text { to } 200 \mathrm{mg} \text { (depending on WCC) } \\
\text { - PRED: } 5 \mathrm{mg} / \mathrm{kg} / \mathrm{d} \text {, tapered over } 1 \text { week, tapered to } 15 \text { to } 20 \mathrm{mg} \text { by } 1 \text { year }\end{array}$ \\
\hline Outcomes & $\begin{array}{l}\text { - } \text { Death } \\
\text { - Graft survival } \\
\text { - Infection }\end{array}$ \\
\hline Notes & $\begin{array}{l}\text { - No table 1; age, sex, race were the 'same' in two groups } \\
\text { - Death and graft loss reported but not at a consistent time point (some only followed for } 3 \text { months); } \\
\text { cannot be included in review analyses } \\
\text { - Only irreversible acute rejection reported, therefore not included in review analyses. (reversible } \\
\text { episodes reported as similar but no figures given) } \\
\text { - } 2 \text { kidneys taken from non-heart beating donors - never functioned due to ATN, these } 2 \text { patients were } \\
\text { excluded } \\
\text { - Funding source: not reported }\end{array}$ \\
\hline
\end{tabular}

\section{Risk of bias}

\begin{tabular}{lll} 
Bias & Authors' judgement & Support for judgement \\
\hline $\begin{array}{l}\text { Random sequence genera- } \\
\text { tion (selection bias) }\end{array}$ & Unclear risk & Insufficient information to permit judgement \\
\hline $\begin{array}{l}\text { Allocation concealment } \\
\text { (selection bias) }\end{array}$ & Unclear risk & Insufficient information to permit judgement \\
\hline $\begin{array}{l}\text { Blinding of participants } \\
\begin{array}{l}\text { and personnel (perfor- } \\
\text { mance bias) }\end{array}\end{array}$ & Unclear risk & Unblinded; unlikely to influence most outcomes but may influence some \\
All outcomes & &
\end{tabular}

\begin{tabular}{lll}
$\begin{array}{l}\text { Blinding of outcome as- } \\
\text { sessment (detection bias) } \\
\text { All outcomes }\end{array}$ & Unclear risk & Not clear if acute rejection was biopsy-proven acute rejection \\
\hline $\begin{array}{l}\text { Incomplete outcome data } \\
\text { (attrition bias) }\end{array}$ & Low risk & $\begin{array}{l}\text { Missing patients unlikely to affect results (2 with never functioned kidneys ex- } \\
\text { cluded) }\end{array}$ \\
\hline All outcomes &
\end{tabular}

\begin{tabular}{|c|c|c|}
\hline $\begin{array}{l}\text { Selective reporting (re- } \\
\text { porting bias) }\end{array}$ & High risk & $\begin{array}{l}\text { Acute rejection, death and graft loss reported but could not be included in } \\
\text { meta-analyses }\end{array}$ \\
\hline
\end{tabular}


Diethelm 1979 (Continued)

Other bias Unclear risk $\quad$ Funding source not reported

EARTS Study 1999

\begin{tabular}{ll}
\hline Methods & Study design: parallel RCT \\
- Study duration: not reported \\
- Study follow-up: 1 year \\
\hline Participants & Country: Finland/Sweden/Norway/Germany \\
- Setting: multicentre (10) \\
- Inclusion criteria: adult DD kidney transplant recipients \\
- Number: treatment group (131); control group (131) \\
- Mean age, range (years): treatment group (48.0, 21 to 78$)$; control group (45.1, 16 to 77$)$ \\
- Exclusion criteria: history of malignancy; previous exposure to murine antibodies; active infection; \\
ongoing pregnancy
\end{tabular}

\begin{tabular}{ll}
\hline Interventions & Treatment group \\
- Enlimomab: $160 \mathrm{mg}$ IV 3 hours prior to transplant, then $40 \mathrm{mg} / \mathrm{d}$ for 5 days \\
- CSA/AZA/PRED per local protocol \\
Placebo \\
- CSA/AZA/PRED per local protocol \\
17 patients across both groups got ATG for DGF \\
\hline Outcomes \\
- Death \\
- Graft loss \\
- DGF \\
- Infections \\
\hline Malignancy \\
\hline Notes
\end{tabular}

\section{Risk of bias}

\begin{tabular}{|c|c|c|}
\hline Bias & Authors' judgement & Support for judgement \\
\hline $\begin{array}{l}\text { Random sequence genera- } \\
\text { tion (selection bias) }\end{array}$ & Low risk & $\begin{array}{l}\text { 'Performed in blocks of } 6 \text { to ensure balanced distribution of treatment per cen- } \\
\text { tre' }\end{array}$ \\
\hline $\begin{array}{l}\text { Allocation concealment } \\
\text { (selection bias) }\end{array}$ & Low risk & Central allocation \\
\hline $\begin{array}{l}\text { Blinding of participants } \\
\text { and personnel (perfor- } \\
\text { mance bias) } \\
\text { All outcomes }\end{array}$ & Low risk & Double-blinded \\
\hline $\begin{array}{l}\text { Blinding of outcome as- } \\
\text { sessment (detection bias) }\end{array}$ & Low risk & $\begin{array}{l}\text { Double-blinded; pathologist reviewing biopsies for suspected acute rejection } \\
\text { was also blinded }\end{array}$ \\
\hline
\end{tabular}


EARTS Study 1999 (Continued)

All outcomes

Incomplete outcome data Low risk $\quad$ All patient outcome data reported
(attrition bias)

(attrition bias)

All outcomes

Selective reporting (re- Unclear risk $\quad$ All expected outcomes reported
porting bias)

\begin{tabular}{ll}
\hline Other bias $\quad$ Unclear risk $\quad$ Appears free from other bias but funding source not declared \\
\hline
\end{tabular}

Ejaz 2013

$\begin{array}{ll}\text { Methods } & \text { - Study design: pilot parallel RCT } \\ \text { - Study duration: August } 2008 \text { to December } 2011 \\ \text { - Study follow-up: } 12 \text { months }\end{array}$

Participants

- Country: USA

- Setting: multicentre (2)

- Inclusion criteria: kidney transplant recipients aged 18 to 65 years old considered high immunologic risk by at least one of the following criteria: (1) current cytotoxic PRA $\geq 20 \%$ or peak cytotoxic PRA $\geq 50$, (2) T or B cell positive crossmatch (by flow cytometry) with confirmed DSA on solid-phase assay, (3) historical positive serologic or cytotoxic crossmatch or donor specific antibody to donor or (4) prior allograft loss with a history of more than one acute rejection episode

- Number: treatment group 1 (10); treatment group 2 (10); treatment group 3 (10); control group (10)

- Mean age (years): treatment group 1 (52.8); treatment group 2 (50.6); treatment group 3 (50.1); control group (49.9)

- Sex (M/F): treatment group 1 (5/5); treatment group 2 (2/8); treatment group 3 (6/4); control group $(5 / 5)$

- Exclusion criteria: contraindications to bortezomib, rituximab or rATG; HLA identical living-related kidney transplants; previously received or were receiving a transplant other than kidney; previous allograft loss due to disease recurrence; history of allergic/anaphylactic reactions to humanized or murine mAbs or polyclonal antibodies; ANC $<1000 / \mathrm{mm}^{3}$ or platelet count $<100,000 / \mathrm{mm}^{3}$ within 30 days; grade 2 peripheral neuropathy within 14 days; MI within 6 months; class III or IV heart failure; uncontrolled angina; uncontrolled ventricular arrhythmias; electrocardiographic evidence of acute ischaemia or active conduction system abnormalities; anti-HIV-positive, Hep B surface antigen-positive or anti-Hep C virus-positive within 1 year; malignancy within 3 years; systemic infections within 2 weeks; live vaccine within 4 weeks; investigational drugs within 30 days or five half-lives; severe liver disease with abnormal liver profile within 30 days; pregnant or lactating women; women of childbearing potential must have negative serum pregnancy test within $48 \mathrm{~h}$ prior to receiving study medication; EBV serologic mismatch; CMV serologic mismatch

Interventions

Treatment group 1

- rATG: $1.5 \mathrm{mg} / \mathrm{kg} /$ dose, 5 doses on alternate days

- Rituximab: $375 \mathrm{mg} / \mathrm{m}^{2}, 1$ dose on day 1

Treatment group 2

- rATG: $1.5 \mathrm{mg} / \mathrm{kg} /$ dose, 5 doses on alternate days

- Bortezomib: $1.3 \mathrm{mg} / \mathrm{m}^{2} /$ dose, 4 doses on days $0,3,7,10$

Treatment group 3

- rATG: $1.5 \mathrm{mg} / \mathrm{kg} /$ dose, 5 doses on alternate days

- Rituximab: $200 \mathrm{mg} / \mathrm{m}^{2}, 1$ dose on day 1 
Ejaz 2013 (Continued)

- Bortezomib: $1.3 \mathrm{mg} / \mathrm{m}^{2} /$ dose, 4 doses on days $0,3,7,10$

Control group

- rATG: $1.5 \mathrm{mg} / \mathrm{kg} /$ dose, 6 doses on alternate days

Immunosuppression (all groups)

- TAC: started within $72 \mathrm{~h}$ of transplant, target of 8 to $15 \mathrm{ng} / \mathrm{mL}$ for 3 months, then target 5 to $12 \mathrm{ng} / \mathrm{mL}$

- MMF: $1000 \mathrm{mg}$ twice daily, could increase to $1500 \mathrm{mg}$ in African-American patients

- PRED: rapid taper to $5 \mathrm{mg}$ daily by 7 days and then continued for 1 year post transplant

Prophylaxis (all groups)

- Valganciclovir: 90 days if recipient CMV +ve, if CMV -ve to -ve then 30 days only

- Nystatin: 90 days

- Co-trimoxazole/pentamidine/dapsone: 1 year

\begin{tabular}{ll}
\hline Outcomes & Death \\
& - Graft loss \\
& - Acute rejection \\
& - Graft function \\
& Malignancy \\
& PTLD \\
\hline Notes & - Funding source: "Bortezomib (Velcade \\
& grant support for this study was provided by Genzyme (now Sanofi)"
\end{tabular}

\section{Risk of bias}

\begin{tabular}{|c|c|c|}
\hline Bias & Authors' judgement & Support for judgement \\
\hline $\begin{array}{l}\text { Random sequence genera- } \\
\text { tion (selection bias) }\end{array}$ & Low risk & $\begin{array}{l}\text { Central computerised block randomisation, generated by independent statis- } \\
\text { tician }\end{array}$ \\
\hline $\begin{array}{l}\text { Allocation concealment } \\
\text { (selection bias) }\end{array}$ & Low risk & Sealed envelopes, sequential order as consented \\
\hline $\begin{array}{l}\text { Blinding of participants } \\
\text { and personnel (perfor- } \\
\text { mance bias) } \\
\text { All outcomes }\end{array}$ & High risk & $\begin{array}{l}\text { Open-label, some outcomes (e.g. reporting of side effects) likely to be influ- } \\
\text { enced }\end{array}$ \\
\hline
\end{tabular}

\begin{tabular}{lll}
\hline Blinding of outcome as- & High risk & Open-label, may affect assessment of toxicities \\
sessment (detection bias) &
\end{tabular}

All outcomes

\begin{tabular}{l}
\hline Incomplete outcome data Low risk $\quad$ All patient outcome data reported \\
(attrition bias) \\
All outcomes
\end{tabular}

Selective reporting (re- Low risk $\quad$ All expected outcomes reported
porting bias)

Other bias High risk Two authors received research funds from both Genzyme and Millennium


Ejaz 2013 (Continued)

Research grant support from Genzyme, Bortezomib provided by Millennium Pharm

Farney 2008

\begin{tabular}{|c|c|}
\hline Methods & $\begin{array}{l}\text { - Study design: parallel RCT; divided into high or low immunologic risk and then randomised } \\
\text { - Study duration: } 1 \text { February } 2005 \text { to } 15 \text { June } 2006 \\
\text { - Study follow-up: median } 2 \text { years }\end{array}$ \\
\hline Participants & $\begin{array}{l}\text { - Country: USA } \\
\text { - Setting: single centre } \\
\text { - Inclusion criteria: adult (> } 18 \text { years) kidney and pancreas transplant recipients } \\
\text { - Number: treatment group (113); control group }(109) \\
\text { - Mean age (years): treatment group }(51 \pm 12) \text {; control group }(51 \pm 13) \\
\text { - Sex (M/F): treatment group }(67 / 46) ; \text { control group }(62 / 47) \\
\text { - Black/white: treatment group }(34 / 74) \text {; control group }(36 / 69) \\
\text { - Exclusion criteria: not reported }\end{array}$ \\
\hline
\end{tabular}

Interventions

Treatment group

- Alemtuzumab: 30 mg single dose, started intra-operatively

Control group

- rATG: $1.5 \mathrm{mg} / \mathrm{kg}$, via CVC, 1st dose started intra-operatively; subsequent infusions same dose, to 3 to 7 in total, on alternate days until 50\% drop in $\mathrm{SCr}$ and CNI started

Immunosuppression (both groups)

- TAC or CSA: targets dependent on immunologic risk

* High risk trough levels: TAC (10 to $12 \mathrm{ng} / \mathrm{mL}$ ) or CSA (250 to $350 \mathrm{ng} / \mathrm{mL}$ ) for 3 months, then TAC (8 to $10 \mathrm{ng} / \mathrm{mL}$ ) or CSA (150 to $250 \mathrm{ng} / \mathrm{mL}$ )

* Low: risk tough levels: TAC ( 8 to $10 \mathrm{ng} / \mathrm{mL}$ ) or CSA ( 250 to $325 \mathrm{ng} / \mathrm{mL}$ ) for 3 months, then TAC (6 to $8 \mathrm{ng} / \mathrm{mL}$ ) or CSA (150 to $250 \mathrm{ng} / \mathrm{mL}$ )

- MMF: 500 to $1000 \mathrm{mg}$ twice daily (500 if > 60yrs and on TAC)

- PRED: dose dependent on immunologic risk

* High risk or DGF: rapid taper to $5 \mathrm{mg}$ by 2 months

* Low risk: 6 doses max

Prophylaxis (both groups)

- PCP: prophylaxis for 1 year

- Valganciclovir: 3 months minimum

- Nystatin: 1 month

\begin{tabular}{ll}
\hline Outcomes & Biopsy-proven acute rejection \\
& $\cdot$ Graft survival
\end{tabular}

Notes

- Enrolment of kidney alone recipients discontinued in Sept 2007 due to higher incidence of biopsy-proven acute rejection in the rATG group (? due to steroid withdrawal)

- Other outcomes reported for kidney and pancreas patients combined, therefore cannot be included in this review

- Funding source: self-funded by Wake Forest University Baptist Medical Center

\section{Risk of bias}

Polyclonal and monoclonal antibodies for induction therapy in kidney transplant recipients (Review) 
Farney 2008 (Continued)

\begin{tabular}{lll} 
Bias & Authors' judgement & Support for judgement \\
\hline $\begin{array}{l}\text { Random sequence genera- } \\
\text { tion (selection bias) }\end{array}$ & Low risk & '2 distinct randomly generated lists' \\
\hline $\begin{array}{l}\text { Allocation concealment } \\
\text { (selection bias) }\end{array}$ & Low risk & $\begin{array}{l}\text { Allocation done independently by research co-ordinator. Co-ordinator in- } \\
\text { formed transplant surgeon just before surgery which agent to use. }\end{array}$ \\
\hline $\begin{array}{l}\text { Blinding of participants } \\
\text { and personnel (perfor- } \\
\text { mance bias) }\end{array}$ & Low risk & Unlikely to influence outcomes \\
$\begin{array}{l}\text { All outcomes } \\
\end{array}$ &
\end{tabular}

\begin{tabular}{ll}
\hline Blinding of outcome as- & Low risk
\end{tabular} Unlikely to influence outcomes

All outcomes

Incomplete outcome data Low risk $\quad$ All patient outcome data reported
(attrition bias)

\begin{tabular}{lll}
\hline $\begin{array}{l}\text { Selective reporting (re- } \\
\text { porting bias) }\end{array}$ & High risk & Unable to meta-analyse death, DGF, infection due to combined data \\
\hline Other bias & Low risk & $\begin{array}{l}\text { Appears free from other bias; study self-funded (by Wake Forest University } \\
\text { Baptist Medical Center) }\end{array}$ \\
\hline
\end{tabular}

\section{Frey 1991}

\begin{tabular}{|c|c|}
\hline Methods & $\begin{array}{l}\text { - Study design: parallel RCT; patients stratified by age (18 to } 49 \text { versus } \geq 50 \text { years), diabetes, previous } \\
\text { transplant, graft survival if previous transplant } \\
\text { - Study duration: July } 1987 \text { to September } 1990 \\
\text { - Study follow-up: } 2 \text { years }\end{array}$ \\
\hline Participants & $\begin{array}{l}\text { - Country: USA } \\
\text { - Setting: single centre } \\
\text { - Inclusion criteria: kidney and kidney-pancreas DD transplant recipients } \\
\text { - Number (kidney/kidney-pancreas): treatment group }(67 / 17) \text {; control group }(71 / 18) \\
\text { - Mean age } \pm \text { SD (years): treatment group }(41 \pm 1.3) \text {; control group }(42 \pm 1.3) \\
\text { - Sex (M/F): treatment group ( } 45 / 39) \text {; control group }(51 / 38) \\
\text { - Ethnicity (white): treatment group ( } 90 \%) \text {; control group }(93 \%) \\
\text { - Exclusion criteria: Initially excluded kidney transplant patients who had rejected a previous transplant } \\
\text { in the } 1 \text { st year; this was changed } 1 \text { year into the study toot include all kidney transplant recipients; } \\
\text { kidney-pancreas recipients excluded if }>50 \text { years or were undergoing a retransplant of either a kidney } \\
\text { or pancreas }\end{array}$ \\
\hline
\end{tabular}

- OKT3: $5 \mathrm{mg} / \mathrm{d}$ for 7 days; given 1st dose in operating theatre after pre-med with steroids

Control group

- $\mathrm{mALG}: 20 \mathrm{mg} / \mathrm{kg} / \mathrm{d}$ for 7 days; 1 st dose 1 day post-op; ALG continued for up to 10 days with delayed CSA start if oliguria

Immunosuppression (both groups) 
Frey 1991 (Continued)

- PRED: $1 \mathrm{mg} / \mathrm{kg} / \mathrm{d}$, taper to $0.5 \mathrm{mg} / \mathrm{kg}$ by day 10

- AZA: $5 \mathrm{mg} / \mathrm{kg}$ taper to $2.5 \mathrm{mg} / \mathrm{kg}$

- CSA: $4 \mathrm{mg} / \mathrm{kg}$ twice daily from day 5 post-op

\begin{tabular}{ll}
\hline Outcomes & Death up to 2 years \\
- Graft survival up to 2 years \\
- Acute rejection \\
- Malignancy \\
- CMV infection \\
\hline Notes \\
- Result function up to 2 years \\
- All acute rejection were biopsy-proven acute rejection \\
- Funding source: supported by NIH Research Grant 5P01-DK 13083
\end{tabular}

\section{Risk of bias}

\begin{tabular}{|c|c|c|}
\hline Bias & Authors' judgement & Support for judgement \\
\hline $\begin{array}{l}\text { Random sequence genera- } \\
\text { tion (selection bias) }\end{array}$ & Unclear risk & Insufficient information to permit judgement \\
\hline $\begin{array}{l}\text { Allocation concealment } \\
\text { (selection bias) }\end{array}$ & Low risk & Sealed envelopes used \\
\hline $\begin{array}{l}\text { Blinding of participants } \\
\text { and personnel (perfor- } \\
\text { mance bias) } \\
\text { All outcomes }\end{array}$ & Low risk & Unlikely to influence outcomes \\
\hline $\begin{array}{l}\text { Blinding of outcome as- } \\
\text { sessment (detection bias) } \\
\text { All outcomes }\end{array}$ & Low risk & Unlikely to influence outcomes, all acute rejection was biopsy-proven \\
\hline $\begin{array}{l}\text { Incomplete outcome data } \\
\text { (attrition bias) } \\
\text { All outcomes }\end{array}$ & Low risk & All patient outcome data reported \\
\hline $\begin{array}{l}\text { Selective reporting (re- } \\
\text { porting bias) }\end{array}$ & Low risk & Expected outcomes reported \\
\hline Other bias & Low risk & Supported by NIH research grant \\
\hline
\end{tabular}

\section{Friend 1987}

\begin{tabular}{ll}
\hline Methods & Study design: parallel RCT \\
& - Study duration: not reported \\
& - Study follow-up: 1 year \\
\hline Participants & Country: UK \\
- Setting: single centre \\
- Inclusion criteria: adult (> 16 years) DD kidney transplant recipients \\
- Mean age, range (years): treatment group $(45,21$ to 67$)$; control group $(40.4,16$ to 68$)$
\end{tabular}


Friend 1987 (Continued)

- Sex (M/F): treatment group (18/8); control group (18/8)

- Exclusion criteria: Hep B carriers; multiorgan recipients; already entered study with previous transplant; transplant biopsy not possible; could not be treated with standard immunosuppressive protocol; refused consent

\begin{tabular}{|c|c|}
\hline Interventions & $\begin{array}{l}\text { Treatment group } \\
\text { - Alemtuzumab: } 25 \mathrm{mg} \text { (IV), twice daily for } 10 \text { days } \\
\text { - MP: } 0.5 \mathrm{~g} \\
\text { - } \mathrm{CSA}: 4 \mathrm{mg} / \mathrm{kg} \text { (IV) for } 2 \text { to } 3 \text { days, then } 17 \mathrm{mg} / \mathrm{kg} \text { (oral) to maintain trough levels } 200 \text { to } 400 \mathrm{U} \\
\text { Control group } \\
\text { - No alemtuzumab } \\
\text { Immunosuppression (both groups) } \\
\text { - MP: } 0.5 \mathrm{~g} \\
\text { - CSA: } 4 \mathrm{mg} / \mathrm{kg} \text { (IV) for } 2 \text { to } 3 \text { days, then } 17 \mathrm{mg} / \mathrm{kg} \text { (oral) to maintain trough levels } 200 \text { to } 400 \mathrm{U} \\
\text { If steroid-resistant acute rejection (after } 2 \text { or more courses of steroids) switched to either: } \\
\text { - CSA + PRED + AZA on alternate days, or daily PRED + AZA }\end{array}$ \\
\hline Outcomes & $\begin{array}{l}\text { - } \text { Acute rejection } \\
\text { - Infections } \\
\text { - } \text { Reactions } \\
\text { - } \text { Graft survival } \\
\text { - } \text { Patient survival } \\
\text { - } \text { Graft function }\end{array}$ \\
\hline Notes & $\begin{array}{l}\text { - Funding source: supported by the Medical Research Council, The British Technology Group, the Ben } \\
\text { Hardwick Memorial Fund, the Addenbrooke's Children's Liver Transplant Fund, and the East Anglian } \\
\text { Regional Heath Authority }\end{array}$ \\
\hline
\end{tabular}

\section{Risk of bias}

\begin{tabular}{lll}
\hline Bias & Authors' judgement & Support for judgement \\
\hline $\begin{array}{l}\text { Random sequence genera- } \\
\text { tion (selection bias) }\end{array}$ & Low risk & Permuted block randomisation \\
\hline $\begin{array}{l}\text { Allocation concealment } \\
\text { (selection bias) }\end{array}$ & Low risk & Sealed envelopes used \\
\hline $\begin{array}{l}\text { Blinding of participants } \\
\text { and personnel (perfor- } \\
\text { mance bias) } \\
\text { All outcomes }\end{array}$ & Low risk & Unlikely to influence outcomes \\
\hline $\begin{array}{l}\text { Blinding of outcome as- } \\
\text { sessment (detection bias) } \\
\text { All outcomes }\end{array}$ & Unclear risk & $\begin{array}{l}\text { Mainly low risk but not all acute rejection was biopsy-proven acute rejection. } \\
\text { Some was diagnosed and treated even when no evidence on biopsy but high } \\
\text { clinical suspicion }\end{array}$ \\
\hline $\begin{array}{l}\text { Incomplete outcome data } \\
\text { (attrition bias) } \\
\text { All outcomes }\end{array}$ & Low risk & All patient outcome data reported \\
\hline
\end{tabular}


Friend 1987 (Continued)

Selective reporting (re- Low risk $\quad$ All expected outcomes reported
porting bias)

Other bias Low risk Appears free from other bias

Fries 1988a

\begin{tabular}{ll}
\hline Methods & Study design: parallel RCT \\
- Study duration: January 1985 to May 1986 \\
- Study follow-up: 1 year
\end{tabular}

\begin{tabular}{ll}
\hline Participants & - Country: France \\
- Setting: single centre \\
- Inclusion criteria: adult DD kidney transplant recipients \\
- Mean age \pm SD (years): not reported \\
- Sex (M/F): not reported \\
- Exclusion criteria: not reported
\end{tabular}

Interventions Treatment group

- ALG: for 15 days (dose not reported)

- CSA: $8 \mathrm{mg} / \mathrm{kg} / \mathrm{d}$

- PRED: $2 \mathrm{mg} / \mathrm{kg} / \mathrm{d}$, taper to 10 to $15 \mathrm{mg} /$ day at 1 month

- AZA: added for maintenance if CSA reduced to $4 \mathrm{mg} / \mathrm{kg} / \mathrm{d}$ for nephrotoxicity

Control group

- Triple therapy: low dose combination of AZA, CSA and PRED (doses not reported)

\begin{tabular}{ll}
\hline Outcomes & Death \\
- & Graft loss \\
- Acute rejection & CMV infection \\
\hline Notes & No information, other than 3 re-transplant patients, others all 1st transplant. All DD transplant recip- \\
ients. & Abstract only \\
- Cannot use any results for reporting; 29 versus 27 patients were randomised to treatment groups. \\
However, 51 patients were given ALG altogether (therefore, 22 of these were not randomised). Results \\
are given including the 51 patients for the ALG group, therefore including the non-randomised pa- \\
tients. Cannot use for review outcomes \\
- funding source: not reported
\end{tabular}

\section{Risk of bias}

Bias Authors' judgement Support for judgement

Random sequence genera- Unclear risk Insufficient information to permit judgement, abstract only tion (selection bias)

\begin{tabular}{l}
$\begin{array}{l}\text { Allocation concealment } \\
\text { (selection bias) }\end{array}$ \\
\hline
\end{tabular}


Fries 1988a (Continued)

Blinding of participants Unclear risk Insufficient information to permit judgement, abstract only and personnel (perfor-

mance bias)

All outcomes

\begin{tabular}{|c|c|c|}
\hline $\begin{array}{l}\text { Blinding of outcome as- } \\
\text { sessment (detection bias) } \\
\text { All outcomes }\end{array}$ & Unclear risk & Insufficient information to permit judgement, abstract only \\
\hline $\begin{array}{l}\text { Incomplete outcome data } \\
\text { (attrition bias) } \\
\text { All outcomes }\end{array}$ & Unclear risk & Insufficient information to permit judgement, abstract only \\
\hline $\begin{array}{l}\text { Selective reporting (re- } \\
\text { porting bias) }\end{array}$ & Unclear risk & Insufficient information to permit judgement, abstract only \\
\hline Other bias & Unclear risk & Insufficient information to permit judgement, abstract only \\
\hline
\end{tabular}

Fukuuchi 1996

\begin{tabular}{ll}
\hline Methods & Study design: parallel RCT \\
- Study duration: October 1987 to December 1989 \\
- Study follow-up: 1 year \\
\hline Participants & Country: France \\
- Setting: single centre \\
- Inclusion criteria: for 2 years all patients having DD transplant were recruited then only 'high \\
risk' (highly sensitised with PRA $>75$ or re-transplant) were included; 36 'high risk' included from 1st \\
period but these were really a subgroup of all the randomised patients; 46 truly randomised patients \\
from second period (when only 'high risk' patients were eligible for randomisation) \\
- Number (randomised/analysed): treatment group 1 (45/44); treatment group 2 (37/37) \\
- Mean age \pm SD (years): not reported \\
- Sex (M/F): not reported
\end{tabular}

Interventions

\section{Treatment group 1}

- OKT3: $5 \mathrm{mg} / \mathrm{d}$ for 10 days

- PRED, AZA and CSA (doses not reported)

Treatment group 2

- ATG: 3775 mg/d (Thymoglobulin, Merieux) for 10 days

- PRED, AZA and CSA (doses not reported)

\begin{tabular}{ll}
\hline Outcomes & - Death \\
& - Graft loss \\
- Acute rejection \\
- Infection \\
- Graft function
\end{tabular}

Notes

- Protocol changed half way through study 
- Results reported include combination of high risk subgroup from 1st protocol and randomised high risk patients from 2 nd protocol. Therefore, not included in review analyses

- Recipient age and PRA were not evenly distributed, 5 recipients over 50 years in OKT3 versus 13 recipients in ATG

- Funding source: not reported

\section{Risk of bias}

\begin{tabular}{lll}
\hline Bias & Authors' judgement & Support for judgement \\
\hline $\begin{array}{l}\text { Random sequence genera- } \\
\text { tion (selection bias) }\end{array}$ & Unclear risk & Insufficient information to permit judgement \\
\hline $\begin{array}{l}\text { Allocation concealment } \\
\text { (selection bias) }\end{array}$ & Unclear risk & Insufficient information to permit judgement \\
\hline $\begin{array}{l}\text { Blinding of participants } \\
\begin{array}{l}\text { and personnel (perfor- } \\
\text { mance bias) }\end{array}\end{array}$ & Low risk & Unlikely to influence outcomes \\
\begin{tabular}{l} 
All outcomes \\
\hline
\end{tabular} & & \\
\hline
\end{tabular}

Blinding of outcome as- Low risk Unlikely to influence outcomes

sessment (detection bias)

All outcomes

Incomplete outcome data High risk

Change in eligibility for randomisation part way through

(attrition bias)

All outcomes

Selective reporting (re- High risk $\quad$ Change in eligibility for randomisation part way through
porting bias)

\begin{tabular}{ll}
\hline Other bias $\quad$ Unclear risk $\quad$ Funding source not reported \\
\hline
\end{tabular}

\section{Gianello 1987}

\begin{tabular}{|c|c|}
\hline Methods & $\begin{array}{l}\text { - Study design: parallel RCT } \\
\text { - Study duration: January } 1983 \text { to February } 1986 \\
\text { - Study follow-up: } 2 \text { years }\end{array}$ \\
\hline Participants & $\begin{array}{l}\text { - Country: Belgium } \\
\text { - Setting: single centre } \\
\text { - Inclusion criteria: } 1 \text { st and } 2 \text { nd DD kidney transplant recipients } \\
\text { - Number: treatment group }(66) \text {; control group }(58) \\
\text { - Mean age } \pm S D \text { (years): treatment group }(33.3 \pm 35.1) \text {; control group }(33.1 \pm 35.4) \\
\text { - Sex ratio }(\mathrm{M} / \mathrm{F}) \text { : treatment group }(3 / 1) \text {; control group }(2.8 / 1) \\
\text { - Exclusion criteria: causative nephropathy was diabetes or oxalosis; positive T cell crossmatch with } \\
\text { donor lymphocytes }\end{array}$ \\
\hline Interventions & $\begin{array}{l}\text { Treatment group } \\
\text { - CSA: } 3 \mathrm{mg} / \mathrm{kg} \text { IV infusion for } 24 \text { hours, then oral } 14 \mathrm{mg} / \mathrm{kg} \text { for } 1 \text { week (subsequently reduced to } 1 \text { to } 3 \\
\text { days only), then } 12 \mathrm{mg} / \mathrm{kg} / \mathrm{d} \text {, then adjusted by levels; target < } 100 \mathrm{ng} / \mathrm{mL} \\
\text { - MP: } 1 \mathrm{~g} \text { IV on day of transplant } \\
\text { - PRED: } 0.4 \mathrm{mg} / \mathrm{kg} / \mathrm{d} \text {, tapered to } 0.1 \mathrm{mg} / \mathrm{kg} / \mathrm{d} \text { by } 9 \text { months }\end{array}$ \\
\hline
\end{tabular}


Gianello 1987 (Continued)

\section{Control group}

- ALG: started pre-op, given $50 \mathrm{mg} / \mathrm{kg} / \mathrm{d}$ for 3 days, then $25 \mathrm{mg} / \mathrm{kg} / \mathrm{d}$ for 11 days

- AZA: 1.5 to $2.5 \mathrm{mg} / \mathrm{kg} / \mathrm{d}$ IV for 1 st day then oral, adjusted for WCC

- MP: IV, total dose $4.5 \mathrm{~g}$ over 6 days

- PRED: at $0.7 \mathrm{mg} / \mathrm{kg} / \mathrm{d}$ tapered to $0.1 \mathrm{mg} / \mathrm{kg} / \mathrm{d}$ by 1 year

\begin{tabular}{ll}
\hline Outcomes & Death \\
- Graft loss & - Acute rejection \\
- DGF & - Graft function at 2 years \\
\hline Notes & - Age, 1st/2nd graft, gender, dialysis vintage, previous blood transfusion, HLA match, total ischaemic \\
& time, cause of ESRD all similar in both groups \\
& Funding source: not reported
\end{tabular}

\section{Risk of bias}

\begin{tabular}{|c|c|c|}
\hline Bias & Authors' judgement & Support for judgement \\
\hline $\begin{array}{l}\text { Random sequence genera- } \\
\text { tion (selection bias) }\end{array}$ & Unclear risk & Insufficient information to permit judgement \\
\hline $\begin{array}{l}\text { Allocation concealment } \\
\text { (selection bias) }\end{array}$ & Unclear risk & Insufficient information to permit judgement \\
\hline $\begin{array}{l}\text { Blinding of participants } \\
\text { and personnel (perfor- } \\
\text { mance bias) } \\
\text { All outcomes }\end{array}$ & Unclear risk & $\begin{array}{l}\text { Not reported but likely not blinded; low risk of bias for hard outcomes but bias } \\
\text { possible for some outcomes }\end{array}$ \\
\hline $\begin{array}{l}\text { Blinding of outcome as- } \\
\text { sessment (detection bias) } \\
\text { All outcomes }\end{array}$ & Unclear risk & $\begin{array}{l}\text { Likely not blinded; some acute rejection was biopsy-proven acute rejection } \\
\text { but some was clinical }\end{array}$ \\
\hline $\begin{array}{l}\text { Incomplete outcome data } \\
\text { (attrition bias) } \\
\text { All outcomes }\end{array}$ & Low risk & All patient outcome data reported \\
\hline $\begin{array}{l}\text { Selective reporting (re- } \\
\text { porting bias) }\end{array}$ & Low risk & All expected outcomes reported \\
\hline Other bias & High risk & $\begin{array}{l}\text { Seems results are combined here for } 2 \text { separate studies; one study of } 1 \text { st DD } \\
\text { transplant recipients, another study of } 2 \text { nd DD transplant recipients. 'we have } \\
\text { concurrently conducted a similar studyin secondary cadaver grafts... we analyse } \\
\text { in this report the outcome of both...... }\end{array}$ \\
\hline
\end{tabular}

Grafals 2014

$\begin{array}{ll}\text { Methods } & \text { - Study design: open-label, parallel, pilot RCT } \\ \text { - Study duration: November } 2010 \text { to April } 2013 \\ \text { - Study follow-up: } 12 \text { months }\end{array}$

\section{Participants}

- Country: USA 
Grafals 2014 (Continued)

- Setting: single centre

- Inclusion criteria: > 18 years LD or DD kidney transplant recipients

- Number: treatment group 1 (23); treatment group 2 (20)

- Mean age \pm SD (years): treatment group 1 (52.9 \pm 12.1 ); treatment group 2 (56.6 \pm 11.6$)$

- Sex (M/F): treatment group 1 (16/7); treatment group 2 (16/4)

- White/Hispanic/African American/other: treatment group 1 (13/6/2/2); treatment group 2 (16/2/2/0)

- DD/LD: treatment group 1 (14/9); treatment group 2 (12/8)

- Exclusion criteria: multiorgan transplant; current or historic panel reactive antibody $>20 \%$; presence of donor specific anti-HLA antibodies; contraindication to ATG use

\begin{tabular}{|c|c|}
\hline Interventions & $\begin{array}{l}\text { Treatment group } 1 \\
\text { - Standard dose ATG: } 3.75 \mathrm{mg} / \mathrm{kg} \text { total dose; } 1.25 \mathrm{mg} / \mathrm{kg}, 3 \text { doses on days } 0,1,2 \\
\text { Treatment group } 2 \\
\text { - Low dose ATG: } 2.25 \mathrm{mg} / \mathrm{kg} \text { total dose; } 0.75 \mathrm{mg} / \mathrm{kg}, 3 \text { doses on days } 0,1,2 \\
\text { Immunosuppression (both groups) } \\
\text { - TAC } 2 \mathrm{mg} \text { twice a day, target level } 8 \text { to } 10 \mathrm{ng} / \mathrm{mL} \text { for } 1 \text { st } 6 \text { months } \\
\text { - MMF: } 1000 \mathrm{mg} \text { twice a day } \\
\text { - } 7 \text { day steroid taper: } 3 \text { days MP, } 4 \text { days PRED } \\
\text { - Co-trimoxazole prophylaxis: } 480 \mathrm{mg} \text { once/day for } 6 \text { months (pentamidine if allergic) } \\
\text { - Valganciclovir: } 450 \text { mg once/d, adjusted for eGFR for } 6 \text { months for high risk patients for CMV (donor } \\
\text { positive to negative recipient), or for } 3 \text { months for all other patients }\end{array}$ \\
\hline Outcomes & $\begin{array}{l}\text { - } \text { Death } \\
\text { - Graft loss } \\
\text { - } \text { Biopsy-proven acute rejection } \\
\text { - } \text { DGF } \\
\text { - Graft function } \\
\text { - Adverse outcomes }\end{array}$ \\
\hline Notes & $\begin{array}{l}\text { - Funding source: "Robert Weiss Grant (MG) and American Heart Association (LVR). The funders had no } \\
\text { role in study design, data collection and analysis, decision to publish, or preparation of the manu- } \\
\text { script." }\end{array}$ \\
\hline
\end{tabular}

\section{Risk of bias}

\begin{tabular}{lll}
\hline Bias & Authors' judgement & Support for judgement \\
\hline $\begin{array}{l}\text { Random sequence genera- } \\
\text { tion (selection bias) }\end{array}$ & Low risk & Computer generated protocols used for randomisation \\
\hline $\begin{array}{l}\text { Allocation concealment } \\
\text { (selection bias) }\end{array}$ & Low risk & $\begin{array}{l}\text { Randomisation performed by research coordinator, sealed envelopes used } \\
\text { (see clinical trials website) }\end{array}$ \\
\hline $\begin{array}{l}\text { Blinding of participants } \\
\begin{array}{l}\text { and personnel (perfor- } \\
\text { mance bias) } \\
\text { All outcomes }\end{array}\end{array}$ & Low risk & Open label but low risk in view of outcomes \\
\hline $\begin{array}{l}\text { Blinding of outcome as- } \\
\text { sessment (detection bias) } \\
\text { All outcomes }\end{array}$ & Low risk & Open label but low risk in view of outcomes \\
\hline
\end{tabular}


Grafals 2014 (Continued)
Incomplete outcome data
Low risk
All patient outcome data reported
(attrition bias)

All outcomes

Selective reporting (re- Low risk all expected outcomes reported
porting bias)

\begin{tabular}{ll}
\hline Other bias $\quad$ Low risk $\quad$ Appears free of other biases \\
\hline
\end{tabular}

Grino 1990

\begin{tabular}{ll}
\hline Methods & Study design: parallel RCT \\
& - Study duration: January 1986 to January 1988 \\
& - Study follow-up: 15 years \\
\hline Participants & Country: Spain \\
- Setting: single centre \\
- Inclusion criteria: adult 1 st DD kidney transplant recipients \\
- Mean age \pm SD (years): treatment group $(40 \pm 11)$; control group $(37 \pm 13)$ \\
- Sex (M/F): treatment group (37/13); control group (32/18) \\
- Exclusion criteria: diabetic and highly sensitized patients (PRA $>70 \%)$
\end{tabular}

Interventions

Treatment group

- ALG (horse, Merieux): $10 \mathrm{mg} / \mathrm{kg}$ IV, 1 day post-op, then alternate days, maximum 6 doses

- MP: $1 \mathrm{~g}$, then PRED $0.25 \mathrm{mg} / \mathrm{kg}$, taper to $0.1 \mathrm{mg} / \mathrm{kg}$ by 6 months

- CSA: $3 \mathrm{mg} / \mathrm{kg}$ IV pre transplant, then $1 \mathrm{mg} / \mathrm{kg}$ twice daily until able to take oral, then $8 \mathrm{mg} / \mathrm{kg} / \mathrm{d}$, trough target 300 to $600 \mathrm{ng} / \mathrm{mL}$

Control group

- CSA: $5 \mathrm{mg} / \mathrm{kg}$ pre-op IV, then $2.5 \mathrm{mg} / \mathrm{kg}$ twice daily, then oral $15 \mathrm{mg} / \mathrm{kg}$; trough target of 300 to 800 $\mathrm{ng} / \mathrm{mL}$

- MP or PRED: $0.5 \mathrm{mg} / \mathrm{kg}$ 'during surgery', taper to $0.1 \mathrm{mg} / \mathrm{kg} / \mathrm{d}$ by 6 months

Immunosuppression (both groups)

- Oral PD: 7.5 to $15 \mathrm{mg} / \mathrm{d}$

- CSA: 3 to $8 \mathrm{mg} / \mathrm{kg} / \mathrm{d}$

\begin{tabular}{ll}
\hline Outcomes & Death at 15 years \\
& - Graft loss at 15 years \\
\hline Notes & - Control rejection \\
\hline & - Death censored graft survival excluded as only reported as percentages \\
& - Fenominator not clear \\
\hline
\end{tabular}

\section{Risk of bias}

Bias Authors' judgement Support for judgement


Grino 1990 (Continued)

Random sequence genera- High risk 'the allocation to treatment groups was done alternately'
tion (selection bias)

$\begin{array}{lll}\begin{array}{l}\text { Allocation concealment } \\ \text { (selection bias) }\end{array} & \text { High risk above }\end{array}$

Blinding of participants Low risk Unlikely to influence outcomes
and personnel (perfor-
mance bias)
All outcomes

\begin{tabular}{lll}
\hline $\begin{array}{l}\text { Blinding of outcome as- } \\
\text { sessment (detection bias) } \\
\text { All outcomes }\end{array}$ & High risk & Acute rejection episodes diagnosed clinically (no biopsy) \\
\hline $\begin{array}{l}\text { Incomplete outcome data } \\
\text { (attrition bias) } \\
\text { All outcomes }\end{array}$ & Low risk & All patient outcome data reported \\
\hline $\begin{array}{l}\text { Selective reporting (re- } \\
\text { porting bias) }\end{array}$ & Unclear risk & $\begin{array}{l}\text { Some expected outcomes not reported such as infection and other adverse } \\
\text { outcomes }\end{array}$ \\
\hline Other bias & Unclear risk & Funding source not reported \\
\hline
\end{tabular}

\section{Grino 1991}

\begin{tabular}{ll}
\hline Methods & Study design: parallel RCT \\
& - Study duration: March 1988 to December 1990 \\
\hline Participants & - Coudy follow-up: 2 years \\
- Setting: single centre \\
- Inclusion criteria: 1 st DD kidney transplant recipients \\
- Number: treatment group 1 (68); treatment group $2(72)$ \\
- Mean age \pm SD (years): treatment group 1 (42.6 \pm 13$) ;$ treatment group $2(39 \pm 11)$ \\
- Sex (M): treatment group 1 (59\%); treatment group 2 (57\%) \\
\hline
\end{tabular}

Treatment group 1

- Horse ALG: $15 \mathrm{mg} / \mathrm{kg}$ pre-transplant, $12 \mathrm{mg} / \mathrm{kg}$ day 1 , then $10 \mathrm{mg} / \mathrm{kg}$ alternate days for 4 doses * Dose adjusted to maintain CD3 counts $10 \%$ to $20 \%$

Treatment group 2

- OKT3: $5 \mathrm{mg}$ IV at induction, continued daily for 5 doses total

Immunosuppression (both groups)

- MP: $1 \mathrm{mg} / \mathrm{kg}$ in operating theatre, then $0.25 \mathrm{mg} / \mathrm{kg}$, then taper to $0.1 \mathrm{mg} / \mathrm{kg}$

- CSA: $3 \mathrm{mg} / \mathrm{kg}$ IV pre-op, then $3 \mathrm{mg} / \mathrm{kg}$ in 2 doses post-op, then oral $8 \mathrm{mg} / \mathrm{kg}$ in 2 doses

\begin{tabular}{ll}
\hline Outcomes & $\cdot$ Death \\
& $\cdot$ Graft loss \\
& $\cdot$ DGF
\end{tabular}


Grino 1991 (Continued)

- Acute rejection

- Serious infection

Notes Funding source: not reported

\section{Risk of bias}

\begin{tabular}{|c|c|c|}
\hline Bias & Authors' judgement & Support for judgement \\
\hline $\begin{array}{l}\text { Random sequence genera- } \\
\text { tion (selection bias) }\end{array}$ & Unclear risk & Insufficient information to permit judgement \\
\hline $\begin{array}{l}\text { Allocation concealment } \\
\text { (selection bias) }\end{array}$ & Low risk & "randomly allocated by a closed-envelope technique" \\
\hline $\begin{array}{l}\text { Blinding of participants } \\
\text { and personnel (perfor- } \\
\text { mance bias) } \\
\text { All outcomes }\end{array}$ & Low risk & Unlikely to influence outcomes \\
\hline $\begin{array}{l}\text { Blinding of outcome as- } \\
\text { sessment (detection bias) } \\
\text { All outcomes }\end{array}$ & Low risk & Unlikely to influence outcomes \\
\hline $\begin{array}{l}\text { Incomplete outcome data } \\
\text { (attrition bias) } \\
\text { All outcomes }\end{array}$ & Low risk & All patient outcome data reported \\
\hline $\begin{array}{l}\text { Selective reporting (re- } \\
\text { porting bias) }\end{array}$ & Low risk & All expected outcomes reported \\
\hline Other bias & Unclear risk & Funding source not reported \\
\hline
\end{tabular}

\section{Grundmann 1984}

\begin{tabular}{ll}
\hline Methods & Study design: parallel RCT \\
& - Study duration: May 1981 to July 1983 \\
\hline Participants & Study follow-up: 1 year \\
\hline & - Country: Germany \\
- Setting: single centre \\
- Number: treatment group (47); control group (47) \\
- Mean age \pm SD (years): not reported \\
- Sex (M/F): not reported \\
- Exclusion criteria: not reported
\end{tabular}

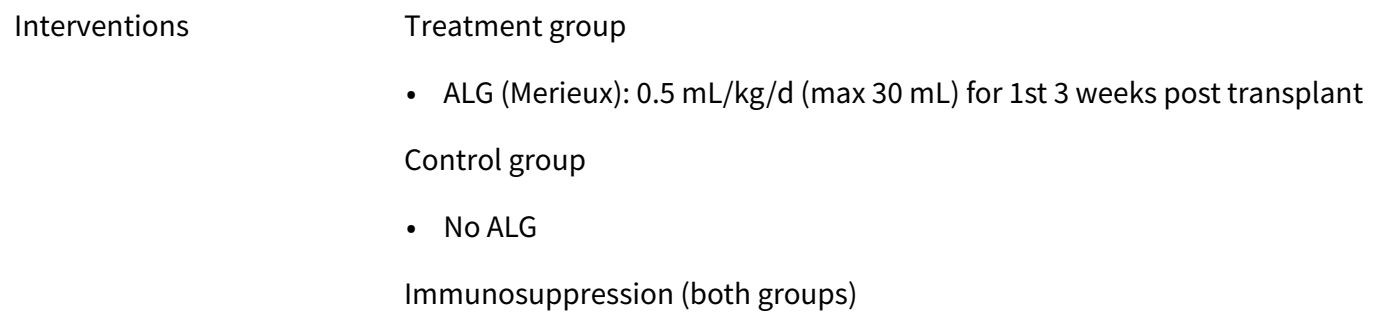


Grundmann 1984 (Continued)

- PRED: $250 \mathrm{mg}$ day 1 , reduced by $25 \mathrm{mg} /$ day to $100 \mathrm{mg}$, then by $5 \mathrm{mg}$ every other day to $10 \mathrm{mg}$

- AZA: $\max 3 \mathrm{mg} / \mathrm{kg} /$ day but dose adjusted for WCC/platelets/side effects

\begin{tabular}{ll}
\hline Outcomes & Death \\
- Graft loss & DGF \\
- Infection & Acute rejection \\
\hline Notes & - No table 1 but states 2 groups were similar in terms of age, time on dialysis, HLA mismatch and cold \\
& ischaemia time \\
& Funding source: not reported
\end{tabular}

\section{Risk of bias}

\begin{tabular}{|c|c|c|}
\hline Bias & Authors' judgement & Support for judgement \\
\hline $\begin{array}{l}\text { Random sequence genera- } \\
\text { tion (selection bias) }\end{array}$ & Unclear risk & Insufficient information to permit judgement \\
\hline $\begin{array}{l}\text { Allocation concealment } \\
\text { (selection bias) }\end{array}$ & Unclear risk & Insufficient information to permit judgement \\
\hline $\begin{array}{l}\text { Blinding of participants } \\
\text { and personnel (perfor- } \\
\text { mance bias) } \\
\text { All outcomes }\end{array}$ & Low risk & Outcomes not likely to be influenced \\
\hline $\begin{array}{l}\text { Blinding of outcome as- } \\
\text { sessment (detection bias) } \\
\text { All outcomes }\end{array}$ & Unclear risk & May affect some outcomes and not reported if blinded \\
\hline $\begin{array}{l}\text { Incomplete outcome data } \\
\text { (attrition bias) } \\
\text { All outcomes }\end{array}$ & Unclear risk & Insufficient information to permit judgement \\
\hline $\begin{array}{l}\text { Selective reporting (re- } \\
\text { porting bias) }\end{array}$ & Unclear risk & Insufficient information to permit judgement \\
\hline Other bias & Unclear risk & $\begin{array}{l}\text { Insufficient information to assess whether an important risk of bias exists; } \\
\text { funding source not reported }\end{array}$ \\
\hline
\end{tabular}

Grundmann 1987

\begin{tabular}{ll} 
Methods & Study design: parallel RCT \\
& - Study duration: September 1983 to November 1985 \\
& - Study follow-up: all followed to November 1986 \\
\hline Participants & Country: Germany \\
- Setting: single centre \\
- Inclusion criteria: 1 st DD kidney transplant recipients \\
- Number: treatment group 1 (50); treatment group 2 (50) \\
- Mean age \pm SD (years): treatment group 1 (38.5 \pm 10.8$)$; treatment group $2(38.7 \pm 12.0)$ \\
- Sex ratio (M/F): treatment group 1 (1.9/1); treatment group 2 (1.6/1)
\end{tabular}


Grundmann 1987 (Continued)

\author{
- Exclusion criteria: not reported
}

Interventions Treatment group 1

- ALG: 14 days; dose $5 \mathrm{~mL} / \mathrm{kg} / \mathrm{d}$ to max of $30 \mathrm{~mL} / \mathrm{d}$ via CVC continuous IV infusion

- PRED: $250 \mathrm{mg}$ day 1 , taper by $25 \mathrm{mg} / \mathrm{d}$ till $100 \mathrm{mg}$, then taper by $5 \mathrm{mg} / \mathrm{d}$ to 5 to $10 \mathrm{mg} / \mathrm{d}$ achieved

- AZA: $\max 3 \mathrm{mg} / \mathrm{kg} / \mathrm{d}$, depending on WCC platelet count

- AZA and ALG switched to CSA at day 14 or earlier if unable to tolerate complete ALG course

- CSA: $8 \mathrm{mg} / \mathrm{kg}$ (2 doses), aim for trough levels of $300 \mathrm{ng} / \mathrm{mL}$

Treatment group 2

- ALG, AZA and steroids: given for 7 days post-op; thereafter ALG and AZA switched to CSA

\begin{tabular}{ll}
\hline Outcomes & Death \\
& - Graft loss \\
& - DGF \\
& - Acute rejection \\
& - Tolerability of treatment \\
\hline Notes & - Funding source: not reported
\end{tabular}

\title{
Risk of bias
}

\begin{tabular}{|c|c|c|}
\hline Bias & Authors' judgement & Support for judgement \\
\hline $\begin{array}{l}\text { Random sequence genera- } \\
\text { tion (selection bias) }\end{array}$ & Unclear risk & Insufficient information to permit judgement \\
\hline $\begin{array}{l}\text { Allocation concealment } \\
\text { (selection bias) }\end{array}$ & Unclear risk & Insufficient information to permit judgement \\
\hline $\begin{array}{l}\text { Blinding of participants } \\
\text { and personnel (perfor- } \\
\text { mance bias) } \\
\text { All outcomes }\end{array}$ & Low risk & Unlikely to influence outcomes \\
\hline $\begin{array}{l}\text { Blinding of outcome as- } \\
\text { sessment (detection bias) } \\
\text { All outcomes }\end{array}$ & Unclear risk & Not specified if diagnosis of acute rejection was biopsy proven or clinical \\
\hline $\begin{array}{l}\text { Incomplete outcome data } \\
\text { (attrition bias) } \\
\text { All outcomes }\end{array}$ & Low risk & All patient outcome data reported \\
\hline $\begin{array}{l}\text { Selective reporting (re- } \\
\text { porting bias) }\end{array}$ & Unclear risk & $\begin{array}{l}\text { Unsure why acute rejection not reported beyond } 3 \text { weeks if there were any in- } \\
\text { cidences of any other side effects such as malignancy/PTLD }\end{array}$ \\
\hline Other bias & Unclear risk & Funding source not reported \\
\hline
\end{tabular}

$\begin{array}{ll}\text { Methods } & \text { - Study design: parallel RCT } \\ & \text { - Study duration: not reported }\end{array}$


Guttmann 1997 (Continued)

- Study follow-up: 3 months

\begin{tabular}{|c|c|}
\hline Participants & $\begin{array}{l}\text { - Country: European } \\
\text { - Setting: multicentre } \\
\text { - Inclusion criteria: DD kidney transplant recipients } \\
\text { - Number: treatment group (147); control group (154) } \\
\text { - Mean age } \pm \text { SD (years): not reported } \\
\text { - Sex (M/F): not reported } \\
\text { - Exclusion criteria: not reported }\end{array}$ \\
\hline Interventions & $\begin{array}{l}\text { Treatment group } \\
\text { - Anti-LFA-1: } 15 \text { to } 30 \mathrm{mg} / \text { day for } 10 \text { days } \\
\text { - AZA and PRED } \\
\text { - CSA: from day } 9 \\
\text { Control group } \\
\text { - CSA-based 'triple therapy' from day } 0\end{array}$ \\
\hline Outcomes & $\begin{array}{l}\text { - } \text { Patient survival } \\
\text { - } \text { - Incidence of acute rejection } \\
\text { - Infection } \\
\text { - Adverse events }\end{array}$ \\
\hline Notes & $\begin{array}{l}\text { - Abstract-only publication } \\
\text { - } 2 \text { groups were 'demographically comparable' } \\
\text { - No figures reported for results } \\
\text { - States patient survival, graft survival, incidence of acute rejection, infection and adverse events all } \\
\text { similar at } 3 \text { months } \\
\text { - Reports trend towards decreased DGF in Anti-LFA-1 group } \\
\text { - No extractable data for review analyses }\end{array}$ \\
\hline
\end{tabular}

\section{Risk of bias}

\begin{tabular}{lll}
\hline Bias & Authors' judgement & Support for judgement \\
\hline $\begin{array}{l}\text { Random sequence genera- } \\
\text { tion (selection bias) }\end{array}$ & Unclear risk & Insufficient information to permit judgement; abstract only \\
\hline $\begin{array}{l}\text { Allocation concealment } \\
\text { (selection bias) }\end{array}$ & Unclear risk & Insufficient information to permit judgement; abstract only \\
\hline $\begin{array}{l}\text { Blinding of participants } \\
\text { and personnel (perfor- } \\
\text { mance bias) } \\
\text { All outcomes }\end{array}$ & Unclear risk & Insufficient information to permit judgement; abstract only \\
\hline
\end{tabular}

\begin{tabular}{lll}
\hline $\begin{array}{l}\text { Blinding of outcome as- } \\
\text { sessment (detection bias) }\end{array}$ & Unclear risk & Insufficient information to permit judgement; abstract only \\
All outcomes & \\
\hline $\begin{array}{l}\text { Incomplete outcome data } \\
\text { (attrition bias) }\end{array}$ & Unclear risk & Insufficient information to permit judgement; abstract only \\
All outcomes & \\
\hline
\end{tabular}


Guttmann 1997 (Continued)

Selective reporting (re- High risk No actual figures reported for any outcomes porting bias)

Other bias

High risk

Abstract only publication, no full-text publication identified

Halloran 1982

\begin{tabular}{|c|c|}
\hline Methods & $\begin{array}{l}\text { - Study design: parallel RCT } \\
\text { - Study duration: not reported } \\
\text { - Study follow-up: all patients have been followed for at least } 1 \text { month (ALG: mean } 5.7 \text { months; CSA: } \\
\text { mean } 7.4 \text { months) }\end{array}$ \\
\hline Participants & 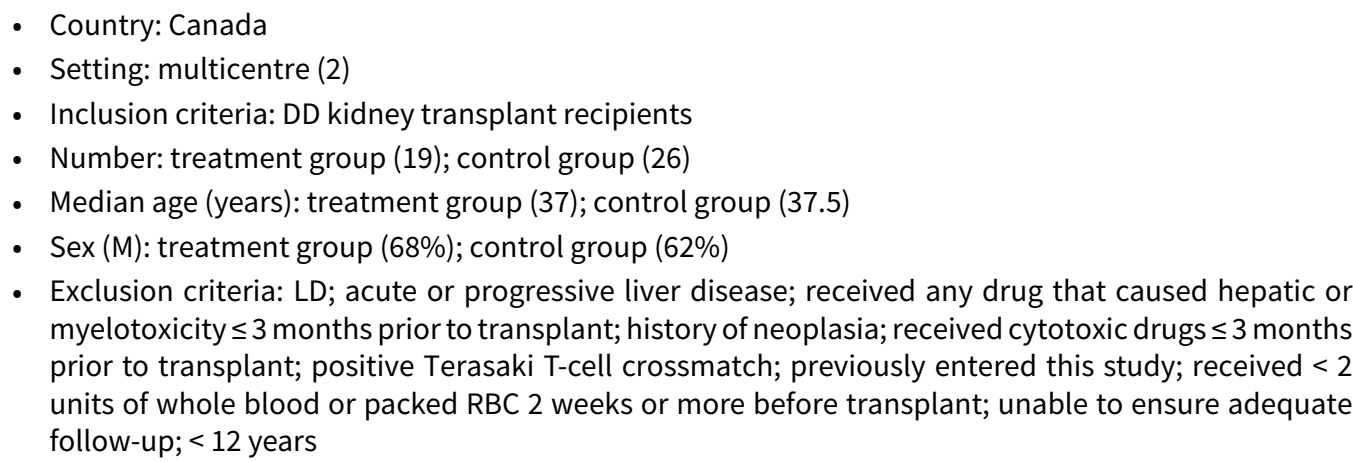 \\
\hline
\end{tabular}

Interventions

Treatment group

- mALG: pre-op $10 \mathrm{mg} / \mathrm{kg}$ then $20 \mathrm{mg} / \mathrm{kg} / \mathrm{d}$ via CVC over 8 to 24 hours

* Usually 14 to 21 doses over 14 to 28 days (could be alternate day after day 14)

* Adjusted as per WCC, platelet and lymphocyte counts.

- AZA: $1 \mathrm{mg} / \mathrm{kg}$ during ALG, then increased as per WCC

- PRED: dose not reported

Control group

- CSA: $20 \mathrm{mg} / \mathrm{kg}$ pre-op, then $20 \mathrm{mg} / \mathrm{kg}$ in 2 divided doses to maintain level of 100 to $400 \mathrm{ng} / \mathrm{mL}$

- PRED: alternate days from day 14 (dose not reported)

\begin{tabular}{ll}
\hline Outcomes & Death \\
- Graft loss & CMV infection \\
- Acute rejection & \\
\hline Notes & 2 centres used mALG for all 'control' (non CSA) patients. Results of these 2 centres combined in this \\
& report \\
- Acute rejection reported as number of episodes per patient. Not included in review as analyses \\
\hline
\end{tabular}

\section{Risk of bias}

\section{Bias}

Authors' judgement Support for judgement 
Halloran 1982 (Continued)

$\begin{array}{ll}\begin{array}{l}\text { Allocation concealment } \\ \text { (selection bias) }\end{array} & \text { Low risk } \\ \end{array}$
(selection bias)

Low risk

Unlikely to influence outcomes

Blinding of participants and personnel (performance bias)

All outcomes

$\begin{array}{lll}\text { Blinding of outcome as- } & \text { Low risk } & \text { Unlikely to influence outcomes } \\ \text { sessment (detection bias) } & \end{array}$

(detection bias)

All outcomes

\begin{tabular}{lll}
\hline $\begin{array}{l}\text { Incomplete outcome data } \\
\text { (attrition bias) } \\
\text { All outcomes }\end{array}$ & Unclear risk & 3 patients switched groups from control to mALG, not clear how analysed \\
\hline $\begin{array}{l}\text { Selective reporting (re- } \\
\text { porting bias) }\end{array}$ & High risk & Unable to include acute rejection results in the meta-analysis \\
\hline Other bias & Low risk & $\begin{array}{l}\text { Appears free of other bias. Funded by grant from Medical Research council of } \\
\text { Canada. Also grant from Conacher foundation }\end{array}$
\end{tabular}

Hanaway 2011

\begin{tabular}{|c|c|}
\hline Methods & $\begin{array}{l}\text { - Study design: parallel RCT } \\
\text { - Study duration: May } 2005 \text { to February } 2006 \\
\text { - Study follow-up: } 3 \text { years }\end{array}$ \\
\hline Participants & $\begin{array}{l}\text { - } \text { Country: USA } \\
\text { - Setting: multicentre ( } 30) \\
\text { - Inclusion criteria: } \geq 18 \text { years; LD or DD recipient, high risk subgroup } \\
\text { - Number: treatment group } 1(70) \text {; treatment group } 2(69) \\
\text { - Mean age } \pm \text { SD (years): treatment group } 1(44.7 \pm 12.8) \text {; treatment group } 2(48.5 \pm 11.0) \\
\text { - Sex (M/F): treatment group } 1(37 / 33) \text {; treatment group } 2(39 / 30) \\
\text { - Ethnicity (White/black/other }(\%)) \text { : treatment group } 1(26 / 71 / 3) \text {; treatment group } 2(29 / 68 / 3) \\
\text { - LD/DD: treatment group } 1(28 / 42) \text {; treatment group } 2(26 / 43) \\
\text { - Exclusion criteria: expanded criteria donors; kidneys from donors without a heartbeat; kidneys with is- } \\
\text { chaemic times exceeding } 36 \text { hours; positive cytotoxic or flow-cytometric cross-matches; kidneys from } \\
\text { HLA-identical live donors }\end{array}$ \\
\hline
\end{tabular}

- Alemtuzumab: $30 \mathrm{mg}$ single IV infusion

Treatment group 2

- rATG: $1.5 \mathrm{mg} / \mathrm{kg}$ given for 4 doses daily from day 0

Maintenance immunosuppression (both groups)

- MMF: $1 g$ twice a day

- TAC: within 48 hours (or later if DGF), dose 0.1 to $0.2 \mathrm{mg} / \mathrm{kg} / \mathrm{d}, 2$ divided doses; trough target 7 to 14 $\mathrm{ng} / \mathrm{mL}$ for 90 days, then 4 to $12 \mathrm{ng} / \mathrm{mL}$

- PRED: 1 g or less over 5 days 
Hanaway 2011 (Continued)

\begin{tabular}{ll} 
- & Biopsy-proven acute rejection \\
- & Death \\
- Graft loss \\
- Infection \\
- Adverse events \\
- Cancer \\
\hline Notes \\
- Graft function - reported as SCr similar at 1 year but actual figures not given \\
designed by two academic and two industry authors. The manuscript was written by five academic \\
and two industry authors, and all these authors made the decision to submit the manuscript for pub- \\
lication. The sponsor held the data, to which all authors had free access. Three academic and two in- \\
dustry authors analyzed the data"
\end{tabular}

\section{Risk of bias}

\begin{tabular}{|c|c|c|}
\hline Bias & Authors' judgement & Support for judgement \\
\hline $\begin{array}{l}\text { Random sequence genera- } \\
\text { tion (selection bias) }\end{array}$ & Unclear risk & 'Automated system' used but not really clear. \\
\hline $\begin{array}{l}\text { Allocation concealment } \\
\text { (selection bias) }\end{array}$ & Unclear risk & $\begin{array}{l}\text { Randomisation stated but no information on method used is available. Even } \\
\text { after reading supplementary appendix, info is still vague. }\end{array}$ \\
\hline $\begin{array}{l}\text { Blinding of participants } \\
\text { and personnel (perfor- } \\
\text { mance bias) } \\
\text { All outcomes }\end{array}$ & Low risk & Unlikely to influence outcomes \\
\hline
\end{tabular}

\begin{tabular}{ll}
\hline Blinding of outcome as- & Low risk \\
sessment (detection bias) & \\
All outcomes & \\
\hline
\end{tabular}

\begin{tabular}{lll}
$\begin{array}{l}\text { Incomplete outcome data } \\
\text { (attrition bias) } \\
\text { All outcomes }\end{array}$ & Low risk & All patient outcome data reported \\
\hline $\begin{array}{l}\text { Selective reporting (re- } \\
\text { porting bias) }\end{array}$ & High risk & $\begin{array}{l}\text { All expected outcomes reported however SCr similar at 1 year but actual fig- } \\
\text { ures not given and cannot be meta-analysed }\end{array}$ \\
\hline Other bias & Low risk & $\begin{array}{l}\text { Study appears free form other bias. Funding by Astellas Pharma Global Devel- } \\
\text { opment }\end{array}$ \\
\hline
\end{tabular}

\section{Hanto 1991}

\begin{tabular}{ll}
\hline Methods & Study design: parallel RCT \\
& - Study duration: May 1987 to December 1989 \\
& - Study follow-up: 3 years \\
\hline Participants & Country: USA \\
- Setting: single centre \\
- Inclusion criteria: adult 1st DD kidney transplant recipients \\
- Mean age \pm SD (years): treatment group 1 (43 \pm 11$)$; treatment group $2(44 \pm 11)$
\end{tabular}


Hanto 1991 (Continued)

- $\operatorname{Sex}(M / F)$ : treatment group 1 (31/28); treatment group 2 (40/18)

- Ethnicity (white/black/other): treatment group 1 (40/19/0); treatment group 2 (31/26/1)

- Exclusion criteria: not reported

\begin{tabular}{|c|c|}
\hline Interventions & $\begin{array}{l}\text { Treatment group } 1 \\
\text { - ALG (Minnesota): } 20 \mathrm{mg} / \mathrm{kg} / \mathrm{d} \text { for } 7 \text { days, ALG given } 6 \text { to } 12 \text { hours post-op (risk of low platelets and } \\
\text { bleeding) } \\
\text { Treatment group } 2 \\
\text { - OKT3: } 5 \mathrm{mg} / \mathrm{d} \text { for } 7 \text { days (given intra-op) } \\
\text { Maintenance immunosuppression (both groups) } \\
\text { - AZA: } 2.5 \mathrm{mg} / \mathrm{kg} \text { pre-op then } 2 \text { to } 2.5 \mathrm{mg} / \mathrm{kg} / \mathrm{d} \text { to maintain } \mathrm{WCC}>3000 / \mathrm{mm}^{3} \\
\text { - MP: } 7 \mathrm{mg} / \mathrm{kg} \text { pre-op, then PRED } 1 \mathrm{mg} / \mathrm{kg} \text {, tapered to } 0.3 \mathrm{mg} / \mathrm{kg} \text { by } 3 \mathrm{months} \text {, and } 0.15 \mathrm{mg} / \mathrm{kg} \text { by } 12 \\
\text { months } \\
\text { - CSA: } 8 \mathrm{mg} / \mathrm{kg} / \mathrm{d} \text { from day } 5 \text { post-op, trough level } 175 \text { to } 200 \mathrm{ng} / \mathrm{mL} \text { trough, tapered to } 5 \mathrm{mg} / \mathrm{kg} \text { by } 9 \\
\text { months }\end{array}$ \\
\hline Outcomes & $\begin{array}{l}\text { - } \text { Death } \\
\text { - } \text { - } \text { Acute rejection } \\
\text { - } \text { CMV disease } \\
\text { - Graft function }\end{array}$ \\
\hline Notes & $\begin{array}{l}\text { - Infections reported but only as total number and number per patient (not reported as number of pa- } \\
\text { tients with infection) } \\
\text { - Monitoring of } \mathrm{CD} 3,4 \text { and } 8 \text { cells in both groups } \\
\text { - Funding source; not reported }\end{array}$ \\
\hline
\end{tabular}

\section{Risk of bias}

\begin{tabular}{lll}
\hline Bias & Authors' judgement & Support for judgement \\
\hline $\begin{array}{l}\text { Random sequence genera- } \\
\text { tion (selection bias) }\end{array}$ & Unclear risk & Insufficient information to permit judgement \\
\hline $\begin{array}{l}\text { Allocation concealment } \\
\text { (selection bias) }\end{array}$ & Unclear risk & Insufficient information to permit judgement \\
\hline $\begin{array}{l}\text { Blinding of participants } \\
\text { and personnel (perfor- } \\
\text { mance bias) }\end{array}$ & Low risk & Unlikely to influence outcomes \\
All outcomes & & \\
\hline
\end{tabular}

Blinding of outcome as- Low risk Unlikely to influence outcomes

Incomplete outcome data Low risk All patient outcome data reported
(attrition bias)

All outcomes 
Hanto 1991 (Continued)

Other bias Unclear risk Funding source not reported

Henry 2001

\begin{tabular}{ll}
\hline Methods & Study design: parallel quasi-RCT \\
& - Study duration: December 1995 to March 1997 \\
\hline Participants & - Coudy follow-up: minimum 24 months \\
- Setting: single centre & - Inclusion criteria: LD and DD kidney transplant recipients; only patients with good post-op diuresis \\
& included (DGF excluded) 'to avoid disadvantaging patients if in control group and getting immediate \\
& CSA with early dysfunction' \\
- Number: treatment group (55); control group (49) & - Mean age, range (years): treatment group (49, 16 to 76); control group (45, 16 to 74) \\
- Sex (M/F): treatment group (40/15); control group (30/9) \\
- Ethnicity (white/black): treatment group (43/12); control group (37/12) \\
- LD/DD: treatment group (18/37); control group (10/39) \\
- Exclusion criteria: DGF; not surviving past 3 months
\end{tabular}

Treatment group

- OKT3: given for 5 to 7 days (dose not reported), until SCr 2.5 to $3 \mathrm{mg} / \mathrm{dL}$

- CSA: started with 1 day overlap with OKT3, trough target $250 \mathrm{mg} / \mathrm{mL}$

Control group

- CSA: started within 12 hours post-op, trough target $250 \mathrm{mg} / \mathrm{mL}$

Immunosuppression (both groups)

- PRED: $2 \mathrm{mg} / \mathrm{kg}$, weaned to $0.15 \mathrm{mg} / \mathrm{kg}$ by 3 months

- MMF: 1 g twice daily

\begin{tabular}{ll}
\hline Outcomes & Death \\
& - Graft loss (death-censored) \\
& - Acute rejection \\
& CMV disease \\
\hline Notes & - Graft function reported but no SD or SE given, therefore cannot be included in analysis of this review \\
& - Funding source: supported by a grant from Orthi-BioTech
\end{tabular}

\section{Risk of bias}

\begin{tabular}{lll}
\hline Bias & Authors' judgement & Support for judgement \\
\hline $\begin{array}{l}\text { Random sequence genera- } \\
\text { tion (selection bias) }\end{array}$ & High risk & $\begin{array}{l}\text { Randomised according to whether patient record number ended in odd or } \\
\text { even number }\end{array}$ \\
\hline $\begin{array}{l}\text { Allocation concealment } \\
\text { (selection bias) }\end{array}$ & Unclear risk & $\begin{array}{l}\text { Randomised according to whether patient record number ended in odd or } \\
\text { even number. }\end{array}$ \\
\hline $\begin{array}{l}\text { Blinding of participants } \\
\text { and personnel (perfor- } \\
\text { mance bias) }\end{array}$ & Low risk & Unlikely to influence outcomes \\
\hline
\end{tabular}

Polyclonal and monoclonal antibodies for induction therapy in kidney transplant recipients (Review) 
Henry 2001 (Continued)

All outcomes

\begin{tabular}{|c|c|c|}
\hline $\begin{array}{l}\text { Blinding of outcome as- } \\
\text { sessment (detection bias) }\end{array}$ & Unclear risk & $\begin{array}{l}\text { Unlikely to influence outcomes although uncertain if acute rejection episodes } \\
\text { were biopsy proven or clinically diagnosed }\end{array}$ \\
\hline
\end{tabular}

All outcomes

Incomplete outcome data Low risk All patient outcome data reported
(attrition bias)
All outcomes

\begin{tabular}{lll}
\hline $\begin{array}{l}\text { Selective reporting (re- } \\
\text { porting bias) }\end{array}$ & High risk & $\begin{array}{l}\text { All expected outcomes reported however unable to included graft function in } \\
\text { the meta-analyses as no SD or SE reported }\end{array}$ \\
\hline Other bias & High risk & $\begin{array}{l}\text { Potential bias due to funding from OKT3 (Grant from Ortho Bio-Tech - OKT3 } \\
\text { manufacturer) }\end{array}$ \\
\hline
\end{tabular}

Hourmant 1985a

\begin{tabular}{ll}
\hline Methods & Study design: parallel RCT; initial randomisation took place of the day of transplantation; a 2nd ran- \\
domisation took place in the 3rd month post-transplant \\
- Study duration: not reported \\
- Study follow-up: 3 to 24 months \\
\hline Participants \\
- Country: France \\
- Setting: single centre \\
- Number: treatment group 1 (32); treatment group 2 (21); control group (35) \\
- Mean age \pm SD (years): not reported \\
- Sex (M/F): not reported \\
- Exclusion criteria: not reported
\end{tabular}

\begin{tabular}{ll}
\hline Interventions & Treatment group 1 \\
- High dose CSA (Cys group II): $15 \mathrm{mg} / \mathrm{kg} / \mathrm{d}$ \\
Control group \\
- ATG (standard group): for 3 weeks (dose and manufacturer not reported) \\
- PRED: $1 \mathrm{mg} / \mathrm{kg}$ \\
- AZA: 2 to $3 \mathrm{mg} / \mathrm{kg} / \mathrm{d}$ \\
2nd randomisation at 3 months of the control group only to continue with standard treatment or \\
switch to low dose CSA monotherapy (6 mg/kg/d) (treatment group 2 - Cys group I) \\
- Death \\
- Graft loss \\
- Acute rejection \\
- Graft function \\
- Infection \\
- Decision made not to use results in review analyses given double intervention of both induction and \\
maintenance \\
Funding source: not reported
\end{tabular}


Hourmant 1985a (Continued)

Risk of bias

\begin{tabular}{|c|c|c|}
\hline Bias & Authors' judgement & Support for judgement \\
\hline $\begin{array}{l}\text { Random sequence genera- } \\
\text { tion (selection bias) }\end{array}$ & Unclear risk & Insufficient information to permit judgement \\
\hline $\begin{array}{l}\text { Allocation concealment } \\
\text { (selection bias) }\end{array}$ & Unclear risk & Insufficient information to permit judgement \\
\hline $\begin{array}{l}\text { Blinding of participants } \\
\text { and personnel (perfor- } \\
\text { mance bias) } \\
\text { All outcomes }\end{array}$ & Unclear risk & Insufficient information to permit judgement \\
\hline $\begin{array}{l}\text { Blinding of outcome as- } \\
\text { sessment (detection bias) } \\
\text { All outcomes }\end{array}$ & Unclear risk & Insufficient information to permit judgement \\
\hline $\begin{array}{l}\text { Incomplete outcome data } \\
\text { (attrition bias) } \\
\text { All outcomes }\end{array}$ & Unclear risk & Some outcomes reported with insufficient detail to fully assess e.g. infection \\
\hline $\begin{array}{l}\text { Selective reporting (re- } \\
\text { porting bias) }\end{array}$ & High risk & Some outcomes reported with insufficient detail to fully assess \\
\hline Other bias & Unclear risk & Insufficient information to permit judgement \\
\hline
\end{tabular}

\section{Hourmant 1996}

\begin{tabular}{ll}
\hline Methods & Study design: parallel RCT \\
- Study duration: not reported \\
- Study follow-up: 1 year \\
\hline Participants & Country: France \\
- Setting: multicentre $(5)$ \\
- Inclusion criteria: adults 1 st DD kidney transplant recipients; cold ischaemia time < 48 hours \\
- Number: treatment group 1 (52); treatment group 2 (49) \\
- Sean age \pm SD (years): treatment group 1 (46 \pm 11$)$; treatment group $2(45 \pm 11)$ \\
- Exclusion criteria: hyperimmunized patients ( $>75 \%$ PRA), patients transplanted across a positive his- \\
torical cross-match, focal glomerulosclerosis as the initial kidney disease, documented hepatopathy \\
or a past history of malignancy
\end{tabular}

Interventions

Treatment group 1

- Anti-LFA-1: $30 \mathrm{mg}$ via peripheral vein, over $30 \mathrm{~min}, 2$ hours pre-op; further daily dose of $15 \mathrm{mg}$ days 2 to 10 ; circulating trough levels of anti-LFA-1 mAb measured

Treatment group 2

- rATG: $1.25 \mathrm{mg} / \mathrm{kg} / \mathrm{d}$ over 4 hours via CVC/AVF; dose adjusted as per local protocols

Maintenance immunosuppression (both groups)

- $A Z A: 2 \mathrm{mg} / \mathrm{kg}$ 
Hourmant 1996 (Continued)

- MP: $5 \mathrm{mg} / \mathrm{kg}$ day before operation, then $1 \mathrm{mg} / \mathrm{kg}$ PRED, taper by $10 \mathrm{mg} /$ week

- CSA: $8 \mathrm{mg} / \mathrm{kg} / \mathrm{d}$, from morning of 9th day; adjusted as per levels, as per each centre

- Ongoing maintenance as per centre (either AZA/PRED or AZA/CSA or triple). 'Distribution balanced between the 2 groups'

\begin{tabular}{ll}
\hline Outcomes & Death \\
- Graft loss \\
- Acute rejection \\
- DGF \\
- Tolerability \\
- CMV disease \\
- Infection \\
\hline Notes \\
- Graft function at 3 months given but graft survival at 3 months not reported. Therefore, cannot be \\
- Funding source: not reported
\end{tabular}

\section{Risk of bias}

\begin{tabular}{|c|c|c|}
\hline Bias & Authors' judgement & Support for judgement \\
\hline $\begin{array}{l}\text { Random sequence genera- } \\
\text { tion (selection bias) }\end{array}$ & Unclear risk & Insufficient information to permit judgement \\
\hline $\begin{array}{l}\text { Allocation concealment } \\
\text { (selection bias) }\end{array}$ & Unclear risk & Insufficient information to permit judgement \\
\hline $\begin{array}{l}\text { Blinding of participants } \\
\text { and personnel (perfor- } \\
\text { mance bias) } \\
\text { All outcomes }\end{array}$ & Low risk & Unlikely to influence outcomes \\
\hline $\begin{array}{l}\text { Blinding of outcome as- } \\
\text { sessment (detection bias) } \\
\text { All outcomes }\end{array}$ & Low risk & Unlikely to influence outcomes; all acute rejection was biopsy-proven \\
\hline $\begin{array}{l}\text { Incomplete outcome data } \\
\text { (attrition bias) } \\
\text { All outcomes }\end{array}$ & Low risk & All patient outcome data reported \\
\hline $\begin{array}{l}\text { Selective reporting (re- } \\
\text { porting bias) }\end{array}$ & High risk & Graft survival at 3 months not reported \\
\hline Other bias & Unclear risk & Funding source not reported \\
\hline
\end{tabular}

Jakobsen 1981

\begin{tabular}{ll}
\hline Methods & - Study design: parallel RCT \\
& - Study duration: February 1978 to September 1979 \\
& - Study follow-up: 2 years \\
\hline Participants & - Country: Norway, Sweden \\
& - Setting: multicentre (2) \\
& - Inclusion criteria: adult 1st DD kidney transplant recipients
\end{tabular}


Jakobsen 1981 (Continued)

- Number: treatment group (30); control group (30)

- Mean age, range (years): treatment group (52, 19 to 68$)$; control group $(47,19$ to 70$)$

- Sex (M/F): treatment group (16/14); control group (20/10)

- Exclusion criteria: not reported

Interventions

Treatment group

- ALG: $30 \mathrm{mg} / \mathrm{kg} / \mathrm{d}$ for 21 days, starting day of transplant; given IV in 200 to $300 \mathrm{~mL}$ saline

Control group

- No ALG

Immunosuppression (both groups)

- AZA: 2 to $3 \mathrm{mg} / \mathrm{kg}$, adjust as per WCC

- PRED: $120 \mathrm{mg} / \mathrm{d}$, taper to $40 \mathrm{mg} / \mathrm{d}$ by $1 \mathrm{month}$, taper to $15 \mathrm{mg} / \mathrm{d}$ by 1 year

\begin{tabular}{ll}
\hline Outcomes & - Death \\
& - Graft loss \\
& - Acute rejection \\
\hline Notes & - Patients over 60 years: treatment group (10); control group (5) \\
& - Funding source: not reported
\end{tabular}

\section{Risk of bias}

\begin{tabular}{lll}
\hline Bias & Authors' judgement & Support for judgement \\
\hline $\begin{array}{l}\text { Random sequence genera- } \\
\text { tion (selection bias) }\end{array}$ & High risk & $\begin{array}{l}\text { 'patients allotted by drawing cards marked yes or no'; Half patients in each } \\
\text { group in each centre }\end{array}$ \\
\hline $\begin{array}{l}\text { Allocation concealment } \\
\text { (selection bias) }\end{array}$ & High risk & Drawing cards \\
\hline $\begin{array}{l}\text { Blinding of participants } \\
\text { and personnel (perfor- } \\
\text { mance bias) }\end{array}$ & Unclear risk & Unlikely to influence outcomes \\
$\begin{array}{l}\text { All outcomes } \\
\text { Blinding of outcome as- } \\
\text { sessment (detection bias) }\end{array}$ & Unclear risk & $\begin{array}{l}\text { Unclear if acute rejection was biopsy-proven acute rejection or clinical diagno- } \\
\text { All outcomes }\end{array}$ \\
\hline $\begin{array}{l}\text { Incomplete outcome data } \\
\text { (attrition bias) }\end{array}$ & Low risk & sis \\
All outcomes & All patient outcome data reported \\
\hline $\begin{array}{l}\text { Selective reporting (re- } \\
\text { porting bias) }\end{array}$ & Low risk & All expected outcomes reported \\
\hline \begin{tabular}{l} 
Other bias \\
\hline
\end{tabular} & Unclear risk & Funding source not reported \\
\hline
\end{tabular}

Kasiske 1997

Methods - Study design: parallel RCT


Kasiske 1997 (Continued)

- Study duration: October 1994 to January 1996

- Study follow-up: 3 months

\begin{tabular}{ll}
\hline Participants & Country: USA \\
- Setting: single centre \\
- Inclusion criteria: adult DD or LD with one haplotype mismatch kidney transplant recipients \\
- Number: treatment group (50); control group (50) \\
- Mean age \pm SD (years): treatment group $(47.5 \pm 13.1)$; control group $(44.7 \pm 14.5)$ \\
- Sex (M): treatment group (66\%); control group (52\%) \\
- DD/LD: treatment group (25/25) control group (33/17) \\
- Exclusion criteria: allergy to diltiazem, ATG, or CSA; medical contraindication to diltiazem, such as sick \\
sinus syndrome or second- or third degree atrioventricular block without a functioning ventricular \\
pacemaker
\end{tabular}

Interventions

Treatment group

- hATG (ATGAM): $20 \mathrm{mg} / \mathrm{kg}$ IV daily for 7 to 14 days; withheld if platelet count $<70,000 / \mathrm{mm}^{3}$

* ATG stopped after 4th dose CSA or dose 14 of ATG

- CSA: $8 \mathrm{mg} / \mathrm{kg} / \mathrm{d}$ (2 divided doses) once $\mathrm{CrCl}$ reached $30 \mathrm{~mL} / \mathrm{min}$; trough level 150 to $200 \mathrm{ng} / \mathrm{mL}$ until 8 weeks, then 75 to $100 \mathrm{ng} / \mathrm{mL}$

Control group

- CSA: $8 \mathrm{mg} / \mathrm{kg}$ at induction, then $8 \mathrm{mg} / \mathrm{kg} / \mathrm{d}$ (2 divided doses)

- Diltiazem: $0.28 \mathrm{mg} / \mathrm{kg}$ IV, then $0.002 \mathrm{mg} / \mathrm{kg} / \mathrm{min}$ for 24 hours, then $60 \mathrm{mg}$ oral sustained release twice $/ \mathrm{d}$

Immunosuppression (both groups)

- MP: 1 g IV day 0; $500 \mathrm{mg}$ IV day 1; /250 mg IV day 2; $125 \mathrm{mg}$ IV day 3, then PRED $0.75 \mathrm{mg} / \mathrm{kg}$ tapered to $0.2 \mathrm{mg} / \mathrm{kg}$ by day 120

- AZA: $5 \mathrm{mg} / \mathrm{kg}$, decrease to $2 \mathrm{mg} / \mathrm{kg}$ day 3

\begin{tabular}{ll}
\hline Outcomes & Death \\
- Graft loss \\
- Acute rejection \\
- DGF \\
\hline CMV disease \\
\hline Notes & - Graft function up to 90 days reported as similar but actual values not given \\
\hline
\end{tabular}

\section{Risk of bias}

\begin{tabular}{lll}
\hline Bias & Authors' judgement & Support for judgement \\
\hline $\begin{array}{l}\text { Random sequence genera- } \\
\text { tion (selection bias) }\end{array}$ & Unclear risk & Insufficient information to permit judgement \\
\hline $\begin{array}{l}\text { Allocation concealment } \\
\text { (selection bias) }\end{array}$ & Unclear risk & Insufficient information to permit judgement \\
\hline $\begin{array}{l}\text { Blinding of participants } \\
\text { and personnel (perfor- } \\
\text { mance bias) }\end{array}$ & Low risk & Unlikely to influence outcomes \\
\begin{tabular}{l} 
All outcomes \\
\hline
\end{tabular} & \\
\hline
\end{tabular}


Kasiske 1997 (Continued)
Blinding of outcome as-
Low risk
Unlikely to influence outcomes; all acute rejection was biopsy proven sessment (detection bias)

All outcomes

Incomplete outcome data Low risk All patient outcome data reported
(attrition bias)
All outcomes

\begin{tabular}{lll}
\hline $\begin{array}{l}\text { Selective reporting (re- } \\
\text { porting bias) }\end{array}$ & High risk & Expected outcomes reported; unable to meta-analyse graft function \\
\hline Other bias & Unclear risk & Funding source not reported \\
\hline
\end{tabular}

Khosroshahi 2008

\begin{tabular}{|c|c|}
\hline Methods & $\begin{array}{l}\text { - Study design: parallel RCT } \\
\text { - Study duration: } 2004 \text { to } 2006 \\
\text { - Study follow-up: } 1 \text { month }\end{array}$ \\
\hline Participants & $\begin{array}{l}\text { - Country: Iran } \\
\text { - Setting: single centre } \\
\text { - Inclusion criteria: }>14 \text { years, LD kidney transplant recipients; PRA }<30 \% \\
\text { - Number: treatment group }(31) \text {; control group }(37) \\
\text { - Mean age } \pm \text { SD (years): treatment group }(36.4 \pm 13.6) \text {; control group }(36.0 \pm 10.9) \\
\text { - Sex (M/F): treatment group }(12 / 19) \text {; control group }(20 / 17) \\
\text { - Exclusion criteria: simultaneous treatment with IL-2RA; significant intraoperative or postoperative } \\
\text { complications of transplantation }\end{array}$ \\
\hline
\end{tabular}

Interventions
- ATG: single dose ( 4 to $5 \mathrm{mg} / \mathrm{kg}$ given roughly 12 hours pre-op)
Control group
- No ATG
Immunosuppression (both groups)
- CSA: 5 to $8 \mathrm{mg} / \mathrm{kg}$
- AZA ( $100 \mathrm{mg}$ ) or MMF $(2 \mathrm{~g})$
- MP: $1 \mathrm{~g}$ for 3 days, then $1 \mathrm{mg} / \mathrm{kg}$, then tapered dose

\begin{tabular}{ll}
\hline Outcomes & Acute rejection in 1st month \\
& - Graft loss \\
\hline \multirow{2}{*}{ Notes } & - SCr reported as similar at 1 month but actual values not given \\
& - Funding source: not reported
\end{tabular}

\section{Risk of bias}

\section{Bias}

Random sequence genera- Unclear risk tion (selection bias) 
Khosroshahi 2008 (Continued)

\begin{tabular}{l}
$\begin{array}{l}\text { Allocation concealment } \\
\text { (selection bias) }\end{array}$ \\
\hline
\end{tabular}

Blinding of participants Low risk Unlikely to influence outcomes

and personnel (perfor-

mance bias)

All outcomes

Blinding of outcome as-
sessment (detection bias) $\quad$ Unclear risk $\quad$ Acute rejection was both biopsy-proven acute rejection and clinical

sessment (detection bias)

All outcomes

\begin{tabular}{lll}
\hline $\begin{array}{l}\text { Incomplete outcome data } \\
\text { (attrition bias) } \\
\text { All outcomes }\end{array}$ & Low risk & All patient outcome data reported \\
\hline $\begin{array}{l}\text { Selective reporting (re- } \\
\text { porting bias) }\end{array}$ & High risk & Limited outcomes reported and only very short-term follow-up \\
\hline Other bias & High risk & $\begin{array}{l}\text { Exclusion criteria included intra-op and post-op problems; patients would al- } \\
\text { ready have been entered prior to this. Therefore, were patients withdrawn af- } \\
\text { ter randomisation? No real details about this. Funding source not reported }\end{array}$ \\
\hline
\end{tabular}

\section{Kountz 1977}

\begin{tabular}{ll}
\hline Methods & Study design: parallel RCT \\
& - Study duration: not reported \\
& - Study follow-up: 2 years \\
\hline Participants & Country: USA \\
- Setting: single centre \\
- Number: treatment group (34); control group (32) \\
- Mean age \pm SD (years): not reported \\
- Sex (M/F): not reported \\
- Exclusion criteria: not reported
\end{tabular}

\begin{tabular}{ll}
\hline Interventions & Treatment group \\
- ATG (Upjohn Company): $750 \mathrm{mg}$ IV daily for 14 days, then 7 doses on alternate days (1 month therapy \\
total) \\
- AZA: $150 \mathrm{mg} / \mathrm{d}$ \\
- PRED: $120 \mathrm{mg} / \mathrm{d}$, taper to $30 \mathrm{mg}$ over $1 \mathrm{month}$ \\
Control group \\
- AZA: $150 \mathrm{mg} / \mathrm{d}$ \\
- PRED: $120 \mathrm{mg} / \mathrm{d}$, taper to $30 \mathrm{mg}$ over 1 month \\
\hline Outcomes & Death \\
- Graft loss & Acute Rejection \\
\hline Notes & Limited data given about other side effects
\end{tabular}


Kountz 1977 (Continued)

- Funding source: Upjohn Company

\section{Risk of bias}

\begin{tabular}{|c|c|c|}
\hline Bias & Authors' judgement & Support for judgement \\
\hline $\begin{array}{l}\text { Random sequence genera- } \\
\text { tion (selection bias) }\end{array}$ & Unclear risk & Insufficient information to permit judgement \\
\hline $\begin{array}{l}\text { Allocation concealment } \\
\text { (selection bias) }\end{array}$ & Unclear risk & Insufficient information to permit judgement \\
\hline $\begin{array}{l}\text { Blinding of participants } \\
\text { and personnel (perfor- } \\
\text { mance bias) } \\
\text { All outcomes }\end{array}$ & Low risk & Unlikely to influence outcomes \\
\hline $\begin{array}{l}\text { Blinding of outcome as- } \\
\text { sessment (detection bias) } \\
\text { All outcomes }\end{array}$ & Unclear risk & Limited info about how acute rejection was diagnosed \\
\hline $\begin{array}{l}\text { Incomplete outcome data } \\
\text { (attrition bias) } \\
\text { All outcomes }\end{array}$ & Unclear risk & Insufficient information to permit judgement \\
\hline $\begin{array}{l}\text { Selective reporting (re- } \\
\text { porting bias) }\end{array}$ & Unclear risk & Insufficient information to permit judgement \\
\hline Other bias & High risk & $\begin{array}{l}\text { Results seem to be a mixture of } 2 \text { studies. Initial study had } 4 \text { groups, including } \\
2 \times \text { low dose ATG }(1 \times \text { IV, } 1 \text { x IM). These } 2 \text { groups excluded after } 15 \text { patients in } \\
\text { each group. Results combined with this study. Upjohn company funded study } \\
\text { and provided the ATG; result in favour of ATG }\end{array}$ \\
\hline
\end{tabular}

Kreis 1980

\begin{tabular}{ll}
\hline Methods & Study design: parallel RCT \\
- Study duration: March 1977 to August 1978 \\
- Study follow-up: 2 years \\
\hline Participants & Country: France \\
- Setting: single centre \\
- Inclusion criteria: DD kidney transplant recipients \\
- Number: treatment group (24); control group (25) \\
- Mean age \pm SD (years): treatment group ( $34.7 \pm 1.7)$; control group $(30.9 \pm 1.5)$ \\
- Sex (M/F): treatment group (18/6); control group (16/9) \\
- Exclusion criteria: positive ATG skin test \\
Treatment group \\
- hATG: 500 to 1250 mg (weight adjusted) daily for 2 weeks then alternate days for 2 weeks \\
$*$ Dose adjust according to level of rosette forming cells aiming to maintain at $10 \%$ of baseline \\
- MP: $40 \mathrm{mg}$ IV, immediately prior to each ATG (this was subtracted from total daily PRED dose) \\
- PRED: 3 mg/kg/d, tapered over 10 weeks to $0.25 \mathrm{mg} / \mathrm{kg}$ \\
Control group
\end{tabular}


Kreis 1980 (Continued)

- PRED: $3 \mathrm{mg} / \mathrm{kg} / \mathrm{d}$, tapered over 10 weeks to $0.25 \mathrm{mg} / \mathrm{kg}$

\begin{tabular}{ll}
\hline Outcomes & Death \\
& Graft loss \\
& Bacterial infections \\
\hline Notes & 'Reversible kidney failure episodes' but not specifically acute rejection reported, therefore not includ- \\
& ed in results of this review
\end{tabular}

\section{Risk of bias}

\begin{tabular}{|c|c|c|}
\hline Bias & Authors' judgement & Support for judgement \\
\hline $\begin{array}{l}\text { Random sequence genera- } \\
\text { tion (selection bias) }\end{array}$ & Low risk & Random-number table used \\
\hline $\begin{array}{l}\text { Allocation concealment } \\
\text { (selection bias) }\end{array}$ & Low risk & $\begin{array}{l}\text { 'Physicians in charge of the patients were not aware of the list kept at the Up- } \\
\text { john Company' }\end{array}$ \\
\hline $\begin{array}{l}\text { Blinding of participants } \\
\text { and personnel (perfor- } \\
\text { mance bias) } \\
\text { All outcomes }\end{array}$ & Low risk & Unlikely to influence outcomes \\
\hline
\end{tabular}

\begin{tabular}{lll}
\hline $\begin{array}{l}\text { Blinding of outcome as- } \\
\text { sessment (detection bias) } \\
\text { All outcomes }\end{array}$ & Unclear risk & Not clear for 'reversible renal failure episodes' or acute rejection \\
\hline $\begin{array}{l}\text { Incomplete outcome data } \\
\text { (attrition bias) } \\
\text { All outcomes }\end{array}$ & Low risk & All patient outcome data reported \\
\hline $\begin{array}{l}\text { Selective reporting (re- } \\
\text { porting bias) }\end{array}$ & High risk & $\begin{array}{l}\text { Expected outcomes reported, however unsure if reversible kidney failure } \\
\text { episodes is acute rejection and therefore results were not used }\end{array}$ \\
\hline Other bias & High risk & ATG provided by Upjohn co and computer analysis also done by them \\
\hline
\end{tabular}

\section{Kreis 1986}

\begin{tabular}{ll}
\hline Methods & Study design: parallel RCT \\
& - Study duration: not reported \\
\hline Participants & Study follow-up: 1 year \\
- Country: France \\
- Setting: single centre \\
- Inclusion criteria: not reported \\
- Mean age \pm SD (years): not reported \\
- Sex (M/F): not reported \\
- Exclusion criteria: not reported \\
Treatment group \\
- OKT3: 5 mg/d IV for 15 days minimum, continued to 30 days if no antibodies (if T3 marker remained \\
$\leq 30 \%)$
\end{tabular}


Kreis 1986 (Continued)

Control group

- No OKT3

Immunosuppression (both groups)

- AZA: dose not reported

- Low dose PRED: dose not reported

\begin{tabular}{ll}
\hline Outcomes & Death \\
- & Graft loss \\
- Acute rejection & \\
\hline Notes & 60 patients into 3 groups, 4 patients excluded early for technical reasons (immediately after randomi- \\
& sation) \\
- & Low dose PRED group to be used for comparisons in this review as maintenance identical to OKT3 \\
& group \\
- & Funding source: not reported \\
\hline
\end{tabular}

\section{Risk of bias}

\begin{tabular}{|c|c|c|}
\hline Bias & Authors' judgement & Support for judgement \\
\hline $\begin{array}{l}\text { Random sequence genera- } \\
\text { tion (selection bias) }\end{array}$ & Unclear risk & Insufficient information to permit judgement \\
\hline $\begin{array}{l}\text { Allocation concealment } \\
\text { (selection bias) }\end{array}$ & Unclear risk & Insufficient information to permit judgement \\
\hline $\begin{array}{l}\text { Blinding of participants } \\
\text { and personnel (perfor- } \\
\text { mance bias) } \\
\text { All outcomes }\end{array}$ & Unclear risk & Unlikely to influence outcomes \\
\hline $\begin{array}{l}\text { Blinding of outcome as- } \\
\text { sessment (detection bias) } \\
\text { All outcomes }\end{array}$ & Unclear risk & $\begin{array}{l}\text { Insufficient information to permit judgement if acute rejection episodes were } \\
\text { biopsy proven or not }\end{array}$ \\
\hline $\begin{array}{l}\text { Incomplete outcome data } \\
\text { (attrition bias) } \\
\text { All outcomes }\end{array}$ & Unclear risk & Insufficient information to permit judgement \\
\hline $\begin{array}{l}\text { Selective reporting (re- } \\
\text { porting bias) }\end{array}$ & Unclear risk & Insufficient information to permit judgement \\
\hline Other bias & Unclear risk & Insufficient information to permit judgement and funding source not declared \\
\hline
\end{tabular}

Kumar 1998a

\begin{tabular}{ll}
\hline Methods & - Study design: parallel RCT \\
& - Study duration: March 1996 to March 1997 \\
& - Study follow-up: 1 year \\
\hline Participants & - Country: USA \\
& - Setting: single centre \\
& - Inclusion criteria: DD kidney transplant recipients \\
\hline
\end{tabular}


Kumar 1998a (Continued)

- Number: treatment group 1 (26); treatment group 2 (24)

- Mean age \pm SD (years): treatment group 1 (42.21 \pm 18.82$)$; treatment group 2 (44.22 \pm 16.56$)$

- Sex (M/F): treatment group 1 (14/10); treatment group 2 (15/11)

- Exclusion criteria: not reported

\begin{tabular}{|c|c|}
\hline Interventions & $\begin{array}{l}\text { Treatment group } 1 \\
\text { - hATG (ATGAM): daily dose adjusted to maintain peripheral CD3 count between } 50 \text { to } 100 / \mu \mathrm{L} \\
\text { Treatment group } 2 \\
\text { - OKT3: daily dose adjusted to maintain peripheral CD3 count between } 50 \text { to } 100 / \mu \mathrm{L} \\
\text { Immunosuppression (both groups) } \\
\text { - } \mathrm{CNI} \text { (CSA or TAC): started } 5 \text { to } 7 \text { days post-transplant, troughs CSA: } 250 \text { to } 300 \mathrm{ng} / \mathrm{mL}, \mathrm{TAC}: 10 \text { to } 15 \\
\text { ng/mL } \\
\text { - PRED: does not reported } \\
\text { - MMF or AZA: dose not reported }\end{array}$ \\
\hline Outcomes & $\begin{array}{l}\text { - Death } \\
\text { - Graft loss } \\
\text { - Acute rejection } \\
\text { - Infection }\end{array}$ \\
\hline Notes & ce: not reported \\
\hline
\end{tabular}

\section{Risk of bias}

\begin{tabular}{lll}
\hline Bias & Authors' judgement & Support for judgement \\
\hline $\begin{array}{l}\text { Random sequence genera- } \\
\text { tion (selection bias) }\end{array}$ & Unclear risk & Insufficient information to permit judgement \\
\hline $\begin{array}{l}\text { Allocation concealment } \\
\text { (selection bias) }\end{array}$ & Unclear risk & Insufficient information to permit judgement \\
\hline $\begin{array}{l}\text { Blinding of participants } \\
\text { and personnel (perfor- } \\
\text { mance bias) }\end{array}$ & Unclear risk & Insufficient information to permit judgement \\
$\begin{array}{l}\text { All outcomes } \\
\text { Blinding of outcome as- } \\
\text { sessment (detection bias) } \\
\text { All outcomes }\end{array}$ & Unclear risk & \\
\hline $\begin{array}{l}\text { Incomplete outcome data } \\
\text { (attrition bias) } \\
\text { All outcomes }\end{array}$ & Unclear risk & Insufficient information to permit judgement \\
\hline $\begin{array}{l}\text { Selective reporting (re- } \\
\text { porting bias) }\end{array}$ & Unclear risk & Insufficient information to permit judgement \\
\hline \begin{tabular}{l} 
Other bias \\
\hline
\end{tabular} & Unclear risk & Funding source not specified \\
\hline
\end{tabular}


Launois 1977

\begin{tabular}{ll}
\hline Methods & Study design: parallel RCT \\
& - Study duration: not reported \\
\hline Participants & Study follow-up: 2 years \\
- Country: France \\
- Setting: single centre \\
- cross-match \\
- Number: treatment group (21); control group (15) \\
- Sex (M/F): not reported \\
- 2nd transplant: treatment group (2); control group (1) \\
- Exclusion criteria: not reported
\end{tabular}

- ALG (horse, Merieux, Lyon): $10 \mathrm{mg} / \mathrm{kg} / \mathrm{d}$ IV for 14 days, then $252 \mathrm{mg}$ IM every other day for 14 days, then twice/week until end of 4 th month

Control group

- No ALG

Immunosuppression (both groups)

- AZA: $5 \mathrm{mg} / \mathrm{kg}$ day 1 , then 1 to $2 \mathrm{mg} / \mathrm{kg}$, adjusted for WCC

- PRED: $1 \mathrm{mg} / \mathrm{kg} / \mathrm{d}$, reduced by $5 \mathrm{mg}$ every 5 days to $30 \mathrm{mg}$ by 1 month, then $25 \mathrm{mg}$ by 6 months

\begin{tabular}{ll}
\hline Outcomes & Death \\
& $\cdot$ Graft loss \\
& Acute rejection \\
\hline Notes & - Limited information on additional outcomes \\
& - Funding source: supported in part by a grant from the University of Rennes \\
\hline
\end{tabular}

\section{Risk of bias}

\begin{tabular}{|c|c|c|}
\hline Bias & Authors' judgement & Support for judgement \\
\hline $\begin{array}{l}\text { Random sequence genera- } \\
\text { tion (selection bias) }\end{array}$ & Unclear risk & Insufficient information to permit judgement \\
\hline $\begin{array}{l}\text { Allocation concealment } \\
\text { (selection bias) }\end{array}$ & Unclear risk & Insufficient information to permit judgement \\
\hline $\begin{array}{l}\text { Blinding of participants } \\
\text { and personnel (perfor- } \\
\text { mance bias) } \\
\text { All outcomes }\end{array}$ & Low risk & Unlikely to influence outcomes \\
\hline $\begin{array}{l}\text { Blinding of outcome as- } \\
\text { sessment (detection bias) } \\
\text { All outcomes }\end{array}$ & Low risk & Unlikely to influence outcomes \\
\hline $\begin{array}{l}\text { Incomplete outcome data } \\
\text { (attrition bias) } \\
\text { All outcomes }\end{array}$ & Low risk & All patient outcome data reported \\
\hline
\end{tabular}


Launois 1977 (Continued)

Selective reporting (re- Low risk All expected outcomes reported
porting bias)

Other bias Low risk Supported by a grant from University of Rennes

\section{Lazarovits 1993}

\begin{tabular}{ll}
\hline Methods & Study design: parallel RCT \\
- Study duration: February 1991 to August 1991 \\
- Study follow-up: 4 to 10 months \\
\hline Participants & Country: Canada \\
- Setting: single centre \\
- Inclusion criteria: 1 st DD kidney transplant recipients aged 18 to 65 years \\
- Mean age \pm SD (years): not reported \\
- Sex (M/F): not reported \\
- Exclusion criteria: participation in another study using an investigational immunosuppressive new \\
drug within 8 wk before entry into or during participation in the study; significant liver or cardiac im- \\
pairment or total lymphocyte count < 1000 cells/mm 3 active infection; current positive T cell cross- \\
match against the donor; multiple organ transplant (heart/kidney, liver/kidney); history of malignan- \\
cy: HIV or Hep B positive serologies; pregnancy
\end{tabular}

\footnotetext{
Interventions
}

Treatment group

- CD7 human-mouse chimeric mAb (SDZCHH380): $30 \mathrm{mg}$ IV, 6 doses, days 0 (1 to 6 h pre-op), days 2, 6 , 11,17 and 24

- CSA: $3 \mathrm{mg} / \mathrm{kg}$ IV infusion in recovery, switch to oral $8 \mathrm{mg} / \mathrm{kg}$ when able, aim for target trough of 250 to $450 \mathrm{ng} / \mathrm{mL}$

Control group

- OKT3: 10 doses, $5 \mathrm{mg}$ dose, day 0 (in theatre), then once/d

- CSA: $2 \mathrm{mg} / \mathrm{kg}$ IV, then $6 \mathrm{mg} / \mathrm{kg}$ oral, target level 150 to $350 \mathrm{ng} / \mathrm{mL}$, then target 250 to $450 \mathrm{ng} / \mathrm{mL}$ once OKT3 complete

- AZA: 25 mg pre-op and while on OKT3 to try to prevent anti-mouse antibodies

Immunosuppression (both groups)

- MP-PRED: $250 \mathrm{mg} 1$ hour before 1st dose of SDZCHH380, then $1 \mathrm{mg} / \mathrm{kg}$, decreased by $5 \mathrm{mg} / \mathrm{d}$ until 20 $\mathrm{mg}$, then decreased until $15 \mathrm{mg}$ on alternate days

\begin{tabular}{ll}
\hline Outcomes & Death \\
- Graft loss \\
- Acute rejection \\
- Infection \\
\hline - Small numbers only \\
- Clinical tolerance better in CD7 group but not reported in these results as not pre-specified outcome \\
- Acute rejection diagnosis was clinical and/or biopsy (FNA or core) \\
- Funding source: supported in part by a grant from the Kidney Foundation of Canada and by Sandoz \\
Canada Inc
\end{tabular}

\section{Risk of bias}

Polyclonal and monoclonal antibodies for induction therapy in kidney transplant recipients (Review) 
Lazarovits 1993 (Continued)

\begin{tabular}{lll} 
Bias & Authors' judgement & Support for judgement \\
\hline $\begin{array}{l}\text { Random sequence genera- } \\
\text { tion (selection bias) }\end{array}$ & Unclear risk & Insufficient information to permit judgement \\
\hline $\begin{array}{l}\text { Allocation concealment } \\
\text { (selection bias) }\end{array}$ & Unclear risk & Insufficient information to permit judgement \\
\hline $\begin{array}{l}\text { Blinding of participants } \\
\text { and personnel (perfor- } \\
\text { mance bias) }\end{array}$ & High risk & $\begin{array}{l}\text { Not blinded and therefore high risk for certain outcomes, e.g. tolerance of anti- } \\
\text { body therapy }\end{array}$ \\
\hline $\begin{array}{l}\text { Blinding of outcomes } \\
\text { sessment (detection bias) } \\
\text { All outcomes }\end{array}$ & High risk & No blinding and acute rejection could be diagnosed clinically \\
\hline $\begin{array}{l}\text { Incomplete outcome data } \\
\text { (attrition bias) } \\
\text { All outcomes }\end{array}$ & Low risk & All patient outcome data reported \\
\hline $\begin{array}{l}\text { Selective reporting (re- } \\
\text { porting bias) }\end{array}$ & Low risk & All expected outcomes reported \\
\hline $\begin{array}{l}\text { Other bias } \\
\text { Unclear risk }\end{array}$ & $\begin{array}{l}\text { Funded by grants from Kidney Foundation of Canada and Sandoz Canada Inc } \\
\text { (CD7 manufacturer) }\end{array}$ \\
\hline
\end{tabular}

\section{Lu 2011}

\begin{tabular}{|c|c|}
\hline Methods & $\begin{array}{l}\text { - Study design: parallel RCT } \\
\text { - Study duration: October } 2007 \text { to December } 2009 \\
\text { - Study follow-up: median follow-up } 338 \text { days }\end{array}$ \\
\hline Participants & $\begin{array}{l}\text { - } \text { Country: China } \\
\text { - Setting: single centre } \\
\text { - Inclusion criteria: DD kidney transplant recipients; high immunological risk PRA } \geq 10 \% \\
\text { - Number: treatment group } 1(11) \text {; treatment group } 2(11) \\
\text { - Mean age } \pm \text { SD (years): treatment group } 1(38.9 \pm 4.2) \text {; treatment group } 2(40.8 \pm 4.4) \\
\text { - Sex (M/F): treatment group } 1(5 / 6) ; \text { treatment group } 2(4 / 7) \\
\text { - } 1 \text { st/2nd/3rd transplant: treatment group } 1(6 / 5 / 0) ; \text { treatment group } 2(5 / 5 / 1) \\
\text { - } \text { Exclusion criteria: not reported }\end{array}$ \\
\hline
\end{tabular}

Treatment group 1

- Alemtuzumab: $15 \mathrm{mg}$ before reperfusion and $15 \mathrm{mg} 24$ hours post op

- MP: $500 \mathrm{mg}$ bolus prior to completion of anastomoses and $8 \mathrm{mg} / \mathrm{kg} / \mathrm{d}$ for 3 days post-op

Treatment group 2

- rATG: $9 \mathrm{mg} / \mathrm{kg}$ single bolus given 2 hours pre-op

- MP: $500 \mathrm{mg}$ bolus prior to completion of anastomoses and $8 \mathrm{mg} / \mathrm{kg} / \mathrm{d}$ for 3 days post-op

Maintenance immunosuppression (both groups)

- MMF: $1 \mathrm{~g}$ twice daily started 1 day pre-op, then 0.5 to $1 \mathrm{~g}$ twice daily 
Lu 2011 (Continued)

- TAC: started 2 days post-op, $0.1 \mathrm{mg} / \mathrm{kg} / \mathrm{d}$ aiming for trough of 10 to $13 \mathrm{ng} / \mathrm{mL}$ for month 1,8 to $10 \mathrm{ng} /$ $\mathrm{mL}$ to month 3,6 to $8 \mathrm{ng} / \mathrm{mL}$ to month 6,4 to $6 \mathrm{ng} / \mathrm{mL}$ to month 12

\begin{tabular}{ll}
\hline Outcomes & Death \\
- Graft loss \\
- Acute rejection \\
- Infection \\
- Malignancy \\
- Cumulative graft survival \\
\hline - Graft function and WCC count reported but not able to be used for review analysis as no figures given \\
- Reported as SCr and urea similar both groups \\
- WCC counts significantly reduced in alemtuzumab group at most time points up to 6 months \\
- Funding source: Supported by grant from Fujian Key Laboratory of Transplant Biology (No. 2008J1006)
\end{tabular}

\section{Risk of bias}

\begin{tabular}{|c|c|c|}
\hline Bias & Authors' judgement & Support for judgement \\
\hline $\begin{array}{l}\text { Random sequence genera- } \\
\text { tion (selection bias) }\end{array}$ & Unclear risk & Insufficient information to permit judgement \\
\hline $\begin{array}{l}\text { Allocation concealment } \\
\text { (selection bias) }\end{array}$ & Unclear risk & Insufficient information to permit judgement \\
\hline $\begin{array}{l}\text { Blinding of participants } \\
\text { and personnel (perfor- } \\
\text { mance bias) } \\
\text { All outcomes }\end{array}$ & Low risk & Open label but probably low risk given hard outcomes \\
\hline $\begin{array}{l}\text { Blinding of outcome as- } \\
\text { sessment (detection bias) } \\
\text { All outcomes }\end{array}$ & Low risk & As above; all acute rejection was biopsy-proven acute rejection \\
\hline $\begin{array}{l}\text { Incomplete outcome data } \\
\text { (attrition bias) } \\
\text { All outcomes }\end{array}$ & Low risk & All patient outcome data reported \\
\hline $\begin{array}{l}\text { Selective reporting (re- } \\
\text { porting bias) }\end{array}$ & High risk & $\begin{array}{l}\text { All expected outcomes reported; graft function, WCC count could not be in- } \\
\text { cluded in our meta-analyses }\end{array}$ \\
\hline Other bias & Low risk & $\begin{array}{l}\text { None apparent. Supported by grant from Fujian Key Laboratory of Transplant } \\
\text { Biology (No. 2008J1006) }\end{array}$ \\
\hline
\end{tabular}

Maiorca 1984

\begin{tabular}{ll} 
Methods & - Study design: parallel RCT \\
& - Study duration: not reported \\
& - Study follow-up: 12 months \\
\hline Participants & - Country: Italy \\
& - Setting: single centre \\
- Number: not reported
\end{tabular}


Maiorca 1984 (Continued)

- Mean age \pm SD (years): not reported

- Sex (M/F): not reported

- Exclusion criteria: not reported

\begin{tabular}{|c|c|}
\hline Interventions & $\begin{array}{l}\text { Treatment group } \\
\text { - ALG: } 20 \mathrm{mg} / \mathrm{kg} \text { for } 1 \text { st } 14 \text { days } \\
* 20 \mathrm{mg} / \mathrm{kg} \text { for } 10 \text { days if any acute rejection episode } \\
\text { Control group } \\
\text { - No ALG } \\
\text { Immunosuppression (both groups) } \\
\text { - AZA: } 5 \mathrm{mg} / \mathrm{kg} \\
\text { - MP: } 200 \mathrm{mg} \text { IV on induction then } 6 \text { hourly for } 3 \text { further doses } \\
\text { - AZA: after MP } 1.5 \mathrm{mg} / \mathrm{kg} \text { and PRED } 20 \mathrm{mg} \text {; AZA increased to } 3 \mathrm{mg} / \mathrm{kg} \text { when } \mathrm{CrCl}>20 \mathrm{~mL} / \mathrm{min} \\
\text { - PRED: taper to } 10 \mathrm{mg} \text { after } 6 \text { months }\end{array}$ \\
\hline Outcomes & $\begin{array}{l}\text { - Death } \\
\text { - Graft loss }\end{array}$ \\
\hline Notes & $\begin{array}{l}\text { - Abstract-only publication } \\
\text { - Acute rejection reported in study as number of rejection episodes/patient. Total number of patients } \\
\text { with acute rejection not reported, therefore this outcome is not included in the review } \\
\text { - Reported as higher percent of bacterial infections in ALG group but not statistically significant. Viral } \\
\text { infections same. Types of infection and figures not disclosed } \\
\text { - Funding source: not reported }\end{array}$ \\
\hline
\end{tabular}

\section{Risk of bias}

\begin{tabular}{lll}
\hline Bias & Authors' judgement & Support for judgement \\
\hline $\begin{array}{l}\text { Random sequence genera- } \\
\text { tion (selection bias) }\end{array}$ & Unclear risk & Insufficient information to permit judgement \\
\hline $\begin{array}{l}\text { Allocation concealment } \\
\text { (selection bias) }\end{array}$ & Unclear risk & Insufficient information to permit judgement \\
\hline $\begin{array}{l}\text { Blinding of participants } \\
\begin{array}{l}\text { and personnel (perfor- } \\
\text { mance bias) }\end{array}\end{array}$ & Low risk & Unlikely to influence outcomes \\
\begin{tabular}{l} 
All outcomes \\
\hline
\end{tabular} & \\
\hline
\end{tabular}

\begin{tabular}{|c|c|c|}
\hline $\begin{array}{l}\text { Blinding of outcome as- } \\
\text { sessment (detection bias) } \\
\text { All outcomes }\end{array}$ & Unclear risk & Unlikely to influence outcomes \\
\hline
\end{tabular}

Incomplete outcome data Unclear risk $\quad$ Insufficient information to permit judgement
(attrition bias)

All outcomes

\begin{tabular}{lll}
\hline $\begin{array}{l}\text { Selective reporting (re- } \\
\text { porting bias) }\end{array}$ & High risk & Acute rejection, infection could not be used in our meta-analyses \\
\hline Other bias & Unclear risk & Insufficient information to permit judgement, funding not reported \\
\hline
\end{tabular}


Margreiter 2008

\begin{tabular}{ll}
\hline Methods & Study design: parallel RCT \\
- Study duration: January 2004 to June 2005 \\
- Study follow-up: 1 year \\
\hline Participants & Country: Germany, Austria \\
- Setting: multicentre (4) \\
- Inclusion criteria: 1 st DD kidney transplant recipients aged 18 to 65 \\
- Number: treatment group (65); control group (66) \\
- Mean age \pm SD (years): treatment group (50 \pm 13.1 ); control group $(45 \pm 14.9)$ \\
- Sex (M/F): treatment group (37/28); control group (34/32) \\
- Exclusion criteria: positive cross match against donor cells; PRA $>25 \%$; previous kidney transplant; \\
multiorgan recipients previous treatment with alemtuzumab; the use of other investigational agents \\
within 6 weeks; active systemic infection; HIV-positive patients or donors, autoimmune haemolytic \\
anaemia; history of anaphylaxis following exposure to humanized monoclonal antibodies; pregnant \\
or breast-feeding women; LD recipients
\end{tabular}

Treatment group
Interventions
- MP: $250 \mathrm{mg}$ immediately post-op and on day 1
- TAC: on day $3,0.05 \mathrm{mg} / \mathrm{kg}$ twice daily, trough target levels 8 to $12 \mathrm{ng} / \mathrm{mL}$ for $6 \mathrm{months}$ then 5 to $8 \mathrm{ng} /$
mL, aimed for above $10 \mathrm{ng} / \mathrm{mL}$ in $1 \mathrm{st} 3 \mathrm{months}$
Control group
- TAC: pre-op or immediately post theatre same dose, same targets as treatment group
- MMF: 1 to $1.5 \mathrm{~g} / \mathrm{d}$ (adjusted if evidence of clinical toxicity)
- Steroids as per local regimen
$* 3$ centres: $500 \mathrm{mg}$ on day 2 , tapered to $25 \mathrm{mg}$ by day 10 , tapered to $5 \mathrm{mg}$ at 1 year
$* 4$ th centre: $200 \mathrm{mg}$ PRED day of transplant, reduced to $20 \mathrm{mg}$ by day 10 and $5 \mathrm{mg}$ by 1 year

\begin{tabular}{ll}
\hline Outcomes & Biopsy-proven acute rejection (6 and 12 months) \\
- Patient survival at 12 months \\
- Graft survival at 12 months \\
\hline Notes & - Graft function for both groups similar at 12 months. Figures not able to be used as no SD given in study \\
& - All clinical suspected acute rejection had to have biopsy, all later confirmed by $1 \times$ histopathologist \\
& - Funding source: supported by Astellas Pharma GmbH, Munich \\
\hline
\end{tabular}

\section{Risk of bias}

\begin{tabular}{lll}
\hline Bias & Authors' judgement & Support for judgement \\
\hline $\begin{array}{l}\text { Random sequence genera- } \\
\text { tion (selection bias) }\end{array}$ & Unclear risk & Insufficient information to permit judgement \\
\hline $\begin{array}{l}\text { Allocation concealment } \\
\text { (selection bias) }\end{array}$ & Unclear risk & Insufficient information to permit judgement \\
\hline $\begin{array}{l}\text { Blinding of participants } \\
\text { and personnel (perfor- } \\
\text { mance bias) }\end{array}$ & Low risk & Unlikely to influence outcomes \\
All outcomes & \\
\hline \hline
\end{tabular}


Margreiter 2008 (Continued)

Blinding of outcome as- Low risk Unlikely to influence outcomes but not clear if the biopsy reviewer was blinded sessment (detection bias)

All outcomes

\begin{tabular}{lll}
$\begin{array}{l}\text { Incomplete outcome data } \\
\text { (attrition bias) } \\
\text { All outcomes }\end{array}$ & Low risk & All patient outcome data reported \\
\hline $\begin{array}{l}\text { Selective reporting (re- } \\
\text { porting bias) }\end{array}$ & High risk & $\begin{array}{l}\text { Outcomes reported as per protocol (as per Clinicaltrials.gov); however unable } \\
\text { to meta-analyse the graft function results (no SD) }\end{array}$
\end{tabular}

Other bias High risk Supported by Astellas Pharma GmbH, Munich (Tacrolimus supplier)

Martins 2004

\begin{tabular}{ll}
\hline Methods & - Study design: parallel RCT \\
& - Study duration: not reported \\
& - Study follow-up: 24 months \\
\hline Participants & - Country: Portugal \\
- Setting: single centre \\
- Inclusion criteria: \\
- Number: treatment group (22); control group (23) \\
- Mean age, range: 39,19 to 67 years \\
- Sex (F): 63\% \\
- Exclusion criteria: not reported
\end{tabular}

Treatment group
- ATG: single bolus $9 \mathrm{mg} / \mathrm{kg}$ prior to surgery
Control group
- No ATG
Immunosuppression (both groups)
- AZA, CSA, PRED (dosage not reported)
- Graft survival
- Patient survival
- Acute rejection
- Steroid-resistant acute rejection
- Abstract-only publication; stated 'groups were comparable'
- or normal righ risk bolus (10): high risk standard (5); normal risk bolus (22); normal risk standard (23). Only 'nor-
- mal risk' patient groups will be compared in this review
- 'ATG did not increase infection rate', figures not given
- Funding source: not reported - one author and employee of Fresenius

\section{Risk of bias}

Polyclonal and monoclonal antibodies for induction therapy in kidney transplant recipients (Review) 
Martins 2004 (Continued)

\section{Bias Authors' judgement Support for judgement}

Random sequence genera- Unclear risk Insufficient information to permit judgement

tion (selection bias)

Allocation concealment Unclear risk Insufficient information to permit judgement

(selection bias)

Blinding of participants Low risk Unlikely to influence outcomes

and personnel (perfor-

mance bias)

All outcomes

\begin{tabular}{|c|c|c|}
\hline $\begin{array}{l}\text { Blinding of outcome as- } \\
\text { sessment (detection bias) } \\
\text { All outcomes }\end{array}$ & Unclear risk & $\begin{array}{l}\text { Unlikely to influence outcomes but unclear if acute rejection was clinical diag- } \\
\text { nosis or biopsy-proven acute rejection }\end{array}$ \\
\hline
\end{tabular}

\begin{tabular}{|c|c|c|}
\hline $\begin{array}{l}\text { Incomplete outcome data } \\
\text { (attrition bias) } \\
\text { All outcomes }\end{array}$ & Unclear risk & $\begin{array}{l}\text { Insufficient information to permit judgement; } 2 \text { patients excluded from analy- } \\
\text { ses due to death with a functioning graft; probably should have been included }\end{array}$ \\
\hline
\end{tabular}

\begin{tabular}{lll}
\hline $\begin{array}{l}\text { Selective reporting (re- } \\
\text { porting bias) }\end{array}$ & High risk & SCr and infection could not be included in our meta-analyses \\
\hline Other bias & High risk & Funding not reported, but one of the co-authors is from Fresenius Biotech \\
\hline
\end{tabular}

Michael 1989

\begin{tabular}{ll}
\hline Methods & Study design: parallel RCT \\
- Study duration: December 1985 to March 1988 \\
- Study follow-up: 1 year \\
\hline Participants & Country: USA \\
- Setting: single centre \\
- Inclusion criteria: DD kidney transplant recipients with DGF at 24 hours post-op (urine output < 700 \\
- ML over 1st 24 hours and no fall in SCr) \\
- Mean age \pm SD (years): not reported \\
- Sex (M/F): not reported \\
- Exclusion criteria: not reported
\end{tabular}

Interventions Initial treatment (both groups)

- CSA: $12 \mathrm{mg} / \mathrm{kg} / \mathrm{d}$ (oral) or $4 \mathrm{mg} / \mathrm{kg} / \mathrm{d}$ (IV) for 24 hours

Treatment group

- ALG: $20 \mathrm{mg} / \mathrm{kg} / \mathrm{d}$ with dose adjustment based on WCC and platelet counts

- Upon resolution of DGF CSA reinstated at $10 \mathrm{mg} / \mathrm{kg} / \mathrm{d}$ and adjusted to levels of 100 to $150 \mathrm{ng} / \mathrm{mL}$

Control group

- CSA: dose lowered to $10 \mathrm{mg} / \mathrm{kg} / \mathrm{d}$ adjusted to keep levels of 100 to $150 \mathrm{ng} / \mathrm{mL}$

Reassessment after 2 weeks 
Michael 1989 (Continued)

\begin{tabular}{ll} 
Outcomes & Duration of DGF \\
- Mean length of hospital stay \\
- $\mathrm{SCr}$ at $1,3,6$ and 12 months (SCr figures given but no SD or SE therefore \\
review analyses) \\
- Graft survival (shown as graph only but no figures given) \\
\hline Notes \\
- No extractable data available for review outcomes \\
- Patients whose grafts never functioned were excluded form analyses \\
- Funding source: not reported
\end{tabular}

\section{Risk of bias}

\begin{tabular}{|c|c|c|}
\hline Bias & Authors' judgement & Support for judgement \\
\hline $\begin{array}{l}\text { Random sequence genera- } \\
\text { tion (selection bias) }\end{array}$ & Low risk & Randomisation via computerised random number generation \\
\hline $\begin{array}{l}\text { Allocation concealment } \\
\text { (selection bias) }\end{array}$ & Unclear risk & Insufficient information to permit judgement \\
\hline $\begin{array}{l}\text { Blinding of participants } \\
\text { and personnel (perfor- } \\
\text { mance bias) } \\
\text { All outcomes }\end{array}$ & Low risk & Unlikely to influence outcomes \\
\hline $\begin{array}{l}\text { Blinding of outcome as- } \\
\text { sessment (detection bias) } \\
\text { All outcomes }\end{array}$ & Unclear risk & $\begin{array}{l}\text { Unclear whether all acute rejection was biopsy proven (likely yes while patient } \\
\text { had DGF but unclear if diagnosed after graft started functioning) }\end{array}$ \\
\hline $\begin{array}{l}\text { Incomplete outcome data } \\
\text { (attrition bias) } \\
\text { All outcomes }\end{array}$ & High risk & Patients whose grafts never functioned were excluded from the analyses \\
\hline $\begin{array}{l}\text { Selective reporting (re- } \\
\text { porting bias) }\end{array}$ & High risk & $\begin{array}{l}\text { No extractable data available for review outcomes, SD and SE not reported; } \\
\text { several results only presented as figures }\end{array}$ \\
\hline Other bias & Unclear risk & Funding not reported \\
\hline
\end{tabular}

Minnesota Study 1982

\begin{tabular}{ll}
\hline Methods & Study design: parallel RCT; stratified for age (18 to $40 ; 41$ to 55), diabetes, donor source, 1 st or 2 nd \\
transplant \\
- Study duration: September 1980 to December 1983 \\
- Study follow-up: 2.5 to 6 years (mean 46 months) \\
\hline Participants & Country: USA \\
- Setting: single centre \\
- Inclusion criteria: 1st or 2nd LD or DD kidney transplant recipients from HLA mismatched donors; aged \\
& 18 and 55 years; no previous history of malignancy or liver disease; in the retransplant group, the 1 st \\
& graft must have functioned for at least 1 year \\
- Number: treatment group (109); control group (121) & Mean age \pm SD (years): treatment group (34.9 \pm 8.7$) ;$ control group (35.0 \pm 8.6$)$ \\
- Sex (M/F): treatment group (69/40); control group (76/45) \\
- LD/DD: treatment group (40/69); control group (48/73)
\end{tabular}




\begin{tabular}{|c|c|}
\hline Interventions & $\begin{array}{l}\text { Treatment group } \\
\text { - } \mathrm{mALG}: 30 \mathrm{mg} / \mathrm{kg} / \mathrm{d} \text { as IV infusion for } 14 \text { doses } \\
\text { - AZA: } 5 \mathrm{mg} / \mathrm{kg} / \mathrm{d} \text { for } 3 \text { days, tapered by } 0.5 \mathrm{mg} / \mathrm{kg} / \mathrm{d} \text { to } 2.5 \mathrm{mg} / \mathrm{kg} / \mathrm{d} \text {, dose adjusted further to maintain } \\
\text { a WCC } \geq 4000 / \mathrm{mm}^{3} \\
\text { - PRED: } 2 \mathrm{mg} / \mathrm{kg} / \mathrm{d} \text { for } 3 \text { days, then tapered to } 0.5 \mathrm{mg} / \mathrm{kg} / \mathrm{d} \text { by } 3 \text { months } \\
\text { Control group } \\
\text { - CSA: } 14 \mathrm{mg} / \mathrm{kg} / \text { day for } 1 \text { week post-op, then } 12 \mathrm{mg} / \mathrm{kg} / \mathrm{d} \text {, trough level of } 100 \text { to } 200 \mathrm{ng} / \mathrm{mL} \text { and SCr } \\
<2 \mathrm{mg} / \mathrm{dL} \\
\text { - PRED: } 2 \mathrm{mg} / \mathrm{kg} / \mathrm{d} \text { for } 3 \text { days, decreased until } 0.5 \mathrm{mg} / \mathrm{kg} / \mathrm{d} \text { by } 1 \text { month, then gradual taper to } 0.2 \mathrm{mg} / \\
\mathrm{kg} / \mathrm{d} \text { by } 1 \mathrm{year}\end{array}$ \\
\hline Outcomes & $\begin{array}{l}\text { - } \text { Death } \\
\text { - Graft loss } \\
\text { - } \text { DGF } \\
\text { - Acute rejection } \\
\text { - Graft function } \\
\text { - Bacterial, viral, fungal infections } \\
\text { - CMV } \\
\text { - PTLD } \\
\text { - Leucopenia } \\
\text { - NODAT }\end{array}$ \\
\hline Notes & $\begin{array}{l}\text { - Multiple different reports of the same study, patient numbers in each group seems to vary in the dif- } \\
\text { ferent reports } \\
\text { - Funding source: supported in part by a grant from NIH }\end{array}$ \\
\hline
\end{tabular}

\section{Risk of bias}

\begin{tabular}{|c|c|c|}
\hline Bias & Authors' judgement & Support for judgement \\
\hline $\begin{array}{l}\text { Random sequence genera- } \\
\text { tion (selection bias) }\end{array}$ & Unclear risk & Stratified but method not specified \\
\hline $\begin{array}{l}\text { Allocation concealment } \\
\text { (selection bias) }\end{array}$ & Unclear risk & Insufficient information to permit judgement \\
\hline $\begin{array}{l}\text { Blinding of participants } \\
\text { and personnel (perfor- } \\
\text { mance bias) } \\
\text { All outcomes }\end{array}$ & Low risk & Unlikely to influence outcomes \\
\hline $\begin{array}{l}\text { Blinding of outcome as- } \\
\text { sessment (detection bias) } \\
\text { All outcomes }\end{array}$ & Low risk & Unlikely to influence outcomes \\
\hline $\begin{array}{l}\text { Incomplete outcome data } \\
\text { (attrition bias) } \\
\text { All outcomes }\end{array}$ & Low risk & All patient outcome data reported \\
\hline $\begin{array}{l}\text { Selective reporting (re- } \\
\text { porting bias) }\end{array}$ & High risk & $\begin{array}{l}\text { All expected outcomes reported, however patient numbers vary in the differ- } \\
\text { ent reports of this study }\end{array}$ \\
\hline
\end{tabular}


Minnesota Study 1982 (Continued)
Other bias
Unclear risk
Funding not fully disclosed. Supported in part by a grant from NIH

Morales 1994a

\begin{tabular}{|c|c|}
\hline Methods & $\begin{array}{l}\text { - Study design: parallel RCT } \\
\text { - Study duration: not reported } \\
\text { - Study follow-up: } 2 \text { years }\end{array}$ \\
\hline Participants & $\begin{array}{l}\text { - Country: Spain } \\
\text { - Setting: multicentre (14) } \\
\text { - Inclusion criteria: } 1 \text { st DD kidney transplant recipients, aged }>50 \text { years } \\
\text { - Number: treatment group }(41) \text {; control group }(44) \\
\text { - Mean age } \pm \text { SD (years): treatment group }(59 \pm 4) \text {; control group }(58 \pm 6) \\
\text { - Sex (M/F): treatment group }(23 / 18) \text {; control group }(29 / 15) \\
\text { - Exclusion criteria: hyperimmunised patients (HLA }>50 \%) \text {; chronic hepatopathy; Hep B-antigen posi- } \\
\text { tive; diabetes, haemolytic uraemic syndrome }\end{array}$ \\
\hline
\end{tabular}

\begin{tabular}{ll}
\hline Interventions & Treatment group \\
- OKT3: $5 \mathrm{mg} / \mathrm{d}$ for 4 days \\
- CSA: $10 \mathrm{mg} / \mathrm{kg} / \mathrm{d}$, tapered slowly to maintain trough of 150 to $250 \mathrm{ng} / \mathrm{mL}$ \\
Control group \\
- CSA: $10 \mathrm{mg} / \mathrm{kg} / \mathrm{d}$, tapered slowly to maintain trough of 150 to $250 \mathrm{ng} / \mathrm{mL}$ \\
- PRED: $0.3 \mathrm{mg} / \mathrm{kg} / \mathrm{d}$, lower by $2.5 \mathrm{mg}$ every 15 days until $10 \mathrm{mg} / \mathrm{d}$ \\
\hline Outcomes & Death \\
- Graft loss & Acute rejection \\
\hline DGF & - Graft function also reported but no SD or SE included, therefore cannot be used in review analyses \\
\hline Notes & Funding source: not reported \\
\hline
\end{tabular}

\section{Risk of bias}

\begin{tabular}{|c|c|c|}
\hline Bias & Authors' judgement & Support for judgement \\
\hline $\begin{array}{l}\text { Random sequence genera- } \\
\text { tion (selection bias) }\end{array}$ & Unclear risk & Insufficient information to permit judgement \\
\hline $\begin{array}{l}\text { Allocation concealment } \\
\text { (selection bias) }\end{array}$ & Unclear risk & Insufficient information to permit judgement \\
\hline $\begin{array}{l}\text { Blinding of participants } \\
\text { and personnel (perfor- } \\
\text { mance bias) } \\
\text { All outcomes }\end{array}$ & Low risk & Unlikely to influence outcomes \\
\hline $\begin{array}{l}\text { Blinding of outcome as- } \\
\text { sessment (detection bias) } \\
\text { All outcomes }\end{array}$ & Unclear risk & $\begin{array}{l}\text { Insufficient information to permit judgement if acute rejection episodes were } \\
\text { biopsy-proven acute rejection }\end{array}$ \\
\hline
\end{tabular}


Morales 1994a (Continued)

Incomplete outcome data Unclear risk Insufficient information to permit judgement (attrition bias)

All outcomes

\begin{tabular}{|c|c|c|}
\hline $\begin{array}{l}\text { Selective reporting (re- } \\
\text { porting bias) }\end{array}$ & High risk & $\begin{array}{l}\text { SD and SE not reported for graft function; complications such as infection or } \\
\text { malignancy not well reported }\end{array}$ \\
\hline
\end{tabular}

Other bias Unclear risk $\quad$ Funding source not reported

Mourad 1998

\begin{tabular}{ll}
\hline Methods & Study design: parallel RCT; stratified by centre \\
- Study duration: November 1995 to July 1997 \\
- Study follow-up: 12 months \\
\hline Participants & Country: France, Belgium \\
- Setting: multicentre (15) \\
- Inclusion criteria: 1 st or 2 nd DD kidney transplant recipients \\
- Number (randomised/analysed): treatment group (153/151); control group $(159 / 158)$ \\
- Mean age, range (years): treatment group (43.2, 18 to 66$)$; control group $(42.8,19$ to 60$)$ \\
- Sex (M/5): treatment group (97/54); control group (113/48) \\
- White/black/oriental/other: treatment group (136/9/3/3); control group $(141 / 7 / 3 / 7)$ \\
Exclusion criteria: positive T-cell cross-match on the most recent serum specimen; intolerant to \\
steroids, macrolides, HCO-60, or ATG; symptoms or had, during the last 5years, any history of neoplas- \\
tic disease of any type; systemic infections requiring therapy; a significant liver disease, active colla- \\
gen-vascular disease; pregnant or breast feeding; participation in another clinical study in the past \\
28 days; HIV positive; history of substance abuse; psychiatric disorder; condition of noncompliance; \\
receiving another organ transplant, other than a kidney
\end{tabular}

Interventions

Treatment group

- ATG: $1.25 \mathrm{mg} / \mathrm{kg} / \mathrm{d}$ for 10 days.

- TAC: started on day 9 at a dose of $0.2 \mathrm{mg} / \mathrm{kg} / \mathrm{d}$

Control group

- TAC: started within 24 hours of completion of anastomosis at an initial dose of $0.2 \mathrm{mg} / \mathrm{kg} / \mathrm{d}$

Immunosuppression (both groups)

- TAC: initial dose $0.2 \mathrm{mg} / \mathrm{kg} / \mathrm{d}$, target trough of 10 to $15 \mathrm{ng} / \mathrm{mL}$ for $1 \mathrm{st} 6$ weeks; target trough 5 to 10 $\mathrm{ng} / \mathrm{mL}$ to 3 months, then target $<10 \mathrm{ng} / \mathrm{mL}$

- MP: $500 \mathrm{mg}$ day $0,125 \mathrm{mg}$ day 1 , then $20 \mathrm{mg}$ PRED for 2 weeks tapered to $10 \mathrm{mg}$ from 1 to 3 months, then $5 \mathrm{mg} / \mathrm{day}$

- AZA: 1 to $2 \mathrm{mg} / \mathrm{kg}$ from day 0

\begin{tabular}{ll}
\hline Outcomes & Death \\
- & Graft loss \\
- & Biopsy-proven acute rejection \\
- & Adverse events \\
\hline Notes & 24 and 17 withdrawals in each group respectively. Results given as ITT. Main reason for withdrawal \\
& was early graft failure (e.g. primary non-function, thrombosis, refractory acute rejection), then adverse \\
events (neurologic events (2), worsening diabetes (2), acute respiratory distress syndrome (1) - all in & ATG group)
\end{tabular}


Mourad 1998 (Continued)

- Graft function similar at 12 months, not included as no SD given

- Funding source: Fujisawa $\mathrm{GmbH}$

\section{Risk of bias}

\begin{tabular}{|c|c|c|}
\hline Bias & Authors' judgement & Support for judgement \\
\hline $\begin{array}{l}\text { Random sequence genera- } \\
\text { tion (selection bias) }\end{array}$ & Low risk & $\begin{array}{l}\text { Randomisation list generated centrally. Patients randomised } 1: 1 \text { and stratified } \\
\text { by centre }\end{array}$ \\
\hline $\begin{array}{l}\text { Allocation concealment } \\
\text { (selection bias) }\end{array}$ & Low risk & Sealed envelopes opened post-op \\
\hline $\begin{array}{l}\text { Blinding of participants } \\
\text { and personnel (perfor- } \\
\text { mance bias) } \\
\text { All outcomes }\end{array}$ & Low risk & Unlikely to influence outcomes \\
\hline $\begin{array}{l}\text { Blinding of outcome as- } \\
\text { sessment (detection bias) } \\
\text { All outcomes }\end{array}$ & Low risk & $\begin{array}{l}\text { Unlikely to influence outcomes (all acute rejection was biopsy-proven acute } \\
\text { rejection) }\end{array}$ \\
\hline $\begin{array}{l}\text { Incomplete outcome data } \\
\text { (attrition bias) } \\
\text { All outcomes }\end{array}$ & Unclear risk & Relatively large drop out numbers in each group; ITT results reported \\
\hline $\begin{array}{l}\text { Selective reporting (re- } \\
\text { porting bias) }\end{array}$ & Low risk & All expected outcomes reported \\
\hline Other bias & High risk & Funded by Fujisawa GmbH (TAC manufacturers) \\
\hline
\end{tabular}

Niaudet 1990

\begin{tabular}{ll}
\hline Methods & - Study design: parallel RCT \\
& - Study duration: September 1987 to May 1988 \\
& - Study follow-up: not reported \\
\hline Participants & - Country: France \\
- Setting: single centre \\
- Inclusion criteria: children, 1st DD kidney transplant recipients \\
- Number: treatment group 1 (14); treatment group 2 (14) \\
- Mean age \pm SD (years): not reported \\
- Sex (M/F): not reported
\end{tabular}

- OKT3 (Cilag): $1 \mathrm{~mL} / 10 \mathrm{~kg}$ up to $40 \mathrm{~kg}, 5 \mathrm{~mL}$ if over $40 \mathrm{~kg}$, given for 21 days

* Given via peripheral vein over $2 \mathrm{~min}, 1$ st dose prior to reperfusion

Treatment group 2

- ALG (Merieux) $1 \mathrm{~mL} / \mathrm{kg}$ via AVF or CVC via IV infusion over $12 \mathrm{~h}$; given for 21 days

Immunosuppression (both groups) 
Niaudet 1990 (Continued)

- AZA: 0.75 to $1.5 \mathrm{mg} / \mathrm{kg} / \mathrm{d}$

- PRED: $60 \mathrm{mg} / \mathrm{m}^{2} / \mathrm{d}$, tapered to $30 \mathrm{mg} / \mathrm{m}^{2}$ by day 30

- CSA: $150 \mathrm{mg} / \mathrm{m}^{2}$ from day 18 , adjusted to maintain level 100 to $200 \mathrm{ng} / \mathrm{mL}$

\begin{tabular}{ll}
\hline Outcomes & Patient survival \\
- Graft survival \\
- Acute rejection \\
- Infection \\
- Other side effects \\
- Notes \\
- There wasle 1 , states similar for age, sex, previous blood transfusions, HLA, PRA, cold ischaemia time \\
- low and high dose groups did not appear to be randomised. This data therefore not included \\
\end{tabular}

\section{Risk of bias}

\begin{tabular}{lll}
\hline Bias & Authors' judgement & Support for judgement \\
\hline $\begin{array}{l}\text { Random sequence genera- } \\
\text { tion (selection bias) }\end{array}$ & Unclear risk & Insufficient information to permit judgement \\
\hline $\begin{array}{l}\text { Allocation concealment } \\
\text { (selection bias) }\end{array}$ & Unclear risk & Insufficient information to permit judgement \\
\hline $\begin{array}{l}\text { Blinding of participants } \\
\text { and personnel (perfor- } \\
\text { mance bias) }\end{array}$ & Low risk & Unlikely to influence outcomes \\
All outcomes & \\
\hline $\begin{array}{l}\text { Blinding of outcome as- } \\
\text { sessment (detection bias) }\end{array}$ & Low risk & Unlikely to influence outcomes \\
All outcomes & & \\
\hline $\begin{array}{l}\text { Incomplete outcome data } \\
\text { (attrition bias) } \\
\text { All outcomes }\end{array}$ & Low risk & All patient outcome data reported \\
\hline $\begin{array}{l}\text { Selective reporting (re- } \\
\text { porting bias) }\end{array}$ & Low risk & All expected outcomes reported \\
\hline \begin{tabular}{l} 
Other bias \\
\hline
\end{tabular} & Unclear risk & Funding source not reported \\
\hline
\end{tabular}

\section{Norman 1988}

\begin{tabular}{ll}
\hline Methods & Study design: parallel RCT \\
& - Study duration: July 1986 to August 1987 \\
& - Study follow-up: 4 to 16 months \\
\hline Participants & - Country: USA \\
- Setting: single centre \\
- Inclusion criteria: adult DD kidney transplant recipients \\
- Number (randomised/analysed): $80 / 72 ;$ treatment group (34); control group (38)
\end{tabular}


Norman 1988 (Continued)

- $\operatorname{Sex}(M / F): 42 / 38$

- Exclusion criteria: no exclusions based on age or underlying cause of kidney failure

Interventions
- OKT3: $5 \mathrm{mg} / \mathrm{d}$ for 14 days
-
-
- AZ: $500 \mathrm{mg}: 2 \mathrm{mg} / \mathrm{kg} / \mathrm{d}$ for 2 weeks; tapered to $1 \mathrm{mg} / \mathrm{kg} / \mathrm{d}$ by 9 months
- PRED: $0.5 \mathrm{mg} / \mathrm{kg} / \mathrm{d}$ for 2 weeks, tapered to $0.1 \mathrm{mg} / \mathrm{kg} / \mathrm{d}$ by $5 \mathrm{months}$
- CSA: from day 11 at $5 \mathrm{mg} / \mathrm{kg} / \mathrm{d}$ from day 14
Control group

- AZA: $2 \mathrm{mg} / \mathrm{kg} / \mathrm{d}$ for 2 weeks, tapered to $1 \mathrm{mg} / \mathrm{kg} / \mathrm{d}$ by 9 months

- PRED: $1 \mathrm{mg} / \mathrm{kg} / \mathrm{d}$ for 2 weeks, $0.5 \mathrm{mg} / \mathrm{kg} / \mathrm{d}$ for 2 weeks, tapered to 0.1 by 5 months

- CSA: $5 \mathrm{mg} / \mathrm{kg} / \mathrm{d}$ for 2 weeks, $4 \mathrm{mg} / \mathrm{kg} 4$ to 12 months, $3 \mathrm{mg} / \mathrm{kg}$ after 12 months

\begin{tabular}{ll}
\hline Outcomes & Death \\
- Graft loss & DGF \\
- Acute rejection & Graft function \\
\hline Notes & Acute rejection episodes treated differently \\
& $*$ OKT3 group: treated with increased oral PRED \\
& $*$ control group: treated with either OKT3 or oral PRED \\
& Funding source: supported by Ortho Pharmaceutical Corporation
\end{tabular}

\section{Risk of bias}

\begin{tabular}{|c|c|c|}
\hline Bias & Authors' judgement & Support for judgement \\
\hline $\begin{array}{l}\text { Random sequence genera- } \\
\text { tion (selection bias) }\end{array}$ & Unclear risk & Insufficient information to permit judgement \\
\hline $\begin{array}{l}\text { Allocation concealment } \\
\text { (selection bias) }\end{array}$ & Unclear risk & Insufficient information to permit judgement \\
\hline $\begin{array}{l}\text { Blinding of participants } \\
\text { and personnel (perfor- } \\
\text { mance bias) } \\
\text { All outcomes }\end{array}$ & Low risk & Unlikely to influence outcomes \\
\hline $\begin{array}{l}\text { Blinding of outcome as- } \\
\text { sessment (detection bias) } \\
\text { All outcomes }\end{array}$ & Low risk & Unlikely to influence outcomes \\
\hline $\begin{array}{l}\text { Incomplete outcome data } \\
\text { (attrition bias) } \\
\text { All outcomes }\end{array}$ & High risk & $\begin{array}{l}8 \text { patients excluded from analyses; } 6 \text { excluded as received grafts form donor } \\
\text { under age } 5 \text { years (historically poor outcomes); } 2 \text { excluded in OKT3 group as } \\
\text { only received } 1 \text { or } 2 \text { doses of OKT3 (reasons not reported) }\end{array}$ \\
\hline $\begin{array}{l}\text { Selective reporting (re- } \\
\text { porting bias) }\end{array}$ & High risk & Some expected outcomes not reported \\
\hline Other bias & Unclear risk & 'Supported by Ortho Pharmaceutical' (OKT3 manufacturers) \\
\hline
\end{tabular}


Norman 1993

\begin{tabular}{ll}
\hline Methods & Study design: parallel RCT \\
& - Study duration: not reported \\
& Study follow-up: 5 years \\
\hline Participants & Country: USA \\
- Setting: multicentre (5 centres) \\
- Inclusion criteria: adults and children DD kidney transplant recipients \\
- Number: treatment group (105); control group (102) \\
- Median age, range (years): treatment group (43, 12 to 73$)$; control group $(40,10$ to 66$)$ \\
- Sex (M/F): treatment group (67/38); control group (64/38) \\
- Transplant (1st/2nd/more than 1$)$ : treatment group (94/9/2); control group (85/16/1) \\
- Ethnicity (white/non-white): treatment group (77/28); control group (73/29) \\
- Diabetic: treatment group (23); control group (30) \\
- Exclusion criteria: donor < 2 years; evidence of fluid overload; evidence of congestive heart failure; \\
previous exposure to OKT3; lactating or pregnant women
\end{tabular}

- OKT3: $5 \mathrm{mg} / \mathrm{d}$ from day 0 for 10 to 14 doses

- MP: 0.5 to 2 g prior to 1 st dose OKT3

- AZA: $2.5 \mathrm{mg} / \mathrm{kg} / \mathrm{d}$, taper after day 11 as per centre protocol

- PRED: 0.25 to $0.5 \mathrm{mg} / \mathrm{kg}$ day 0 to 10 , taper to maintenance dose as per centre protocol

- CSA: 6 to $12 \mathrm{mg} / \mathrm{kg} / \mathrm{d}$, from day 11 onwards

Control group

- AZA: $2.5 \mathrm{mg} / \mathrm{kg} / \mathrm{d}$, taper as per centre protocol

- PRED-MP: 0.5 to $2 \mathrm{~g}$ MP prior to transplant; $1 \mathrm{mg} / \mathrm{kg} / \mathrm{d}$, then taper to maintenance dose as per centre protocol

- CSA: 6 to $12 \mathrm{mg} / \mathrm{kg} / \mathrm{d}$

\begin{tabular}{ll}
\hline Outcomes & - Death (5 years) \\
- Graft loss (5 years) \\
- Acute rejection (1 year) \\
- DGF \\
- Malignancy (2 years) \\
- Graft function (12 months) \\
\hline Notes \\
- Possibly continuation of study from Norman 1988 (however, intervention protocols documented are \\
different) \\
\hline
\end{tabular}

\section{Risk of bias}

\begin{tabular}{lll}
\hline Bias & Authors' judgement & Support for judgement \\
\hline $\begin{array}{l}\text { Random sequence genera- } \\
\text { tion (selection bias) }\end{array}$ & Unclear risk & Randomisation stated but insufficient information to permit judgement \\
\hline $\begin{array}{l}\text { Allocation concealment } \\
\text { (selection bias) }\end{array}$ & Unclear risk & Insufficient information to permit judgement \\
\hline
\end{tabular}


Norman 1993 (Continued)

Blinding of participants Low risk Unlikely to influence outcomes and personnel (performance bias)

All outcomes

\begin{tabular}{lll}
\hline Blinding of outcome as- & Low risk & Unlikely to influence outcomes \\
sessment (detection bias) &
\end{tabular}

All outcomes

Incomplete outcome data Unclear risk

(attrition bias)

All outcomes

\author{
Safety analyses 111 versus 104 included (215 total) \\ Efficacy analyses 105 versus 102 included (207 total) \\ 224 patients entered into the study
}

9 patients excluded after randomisation as 'not treated' (whether this means not transplanted or not treated as per protocol is not reported)

Additional 8 patients excluded from efficacy analyses and therefore included only in safety analyses ( 6 paediatric patients and 2 patients who did not follow randomisation schedule)

Selective reporting (re- Low risk $\quad$ All expected outcomes reported
porting bias)
porting bias)

\begin{tabular}{|c|c|c|}
\hline Other bias & High risk & $\begin{array}{l}\text { Funded by RW Johnson pharmaceutical research institute; corresponding au- } \\
\text { thor is an employee of RW Johnson }\end{array}$ \\
\hline
\end{tabular}

Norman 1993a

\begin{tabular}{ll}
\hline Methods & Study design: parallel RCT \\
- Study duration: July 1990 to August 1991 \\
- Study follow-up: 12 months \\
\hline Participants & - Country: USA \\
- Setting: single centre \\
- Inclusion criteria: 18 to 50 years; 1 st DD kidney transplant recipients \\
- Mean age (years): treatment group 1 (39); treatment group $2(37)$ \\
- Sex (M/F): treatment group (5/8); treatment group $2(11 / 2)$ \\
- Diabetic: treatment group 1 (4); treatment group 2 (1) \\
- Exclusion criteria: "entrance criteria were chosen to minimize both recipient and donor factors that \\
could lead to graft dysfunction or loss not due to immunologic causes"
\end{tabular}

Interventions

Treatment group 1

- High dose OKT3: $5 \mathrm{mg} /$ day for 12 days, starting in operating theatre

Treatment group 2

- Low dose OKT3: $1 \mathrm{mg} / \mathrm{d}$ for 2 days, then $2 \mathrm{mg} / \mathrm{d}$ for 10 days

Immunosuppression (both groups)

- AZA: $5 \mathrm{mg} / \mathrm{kg}$ (IV), then $2 \mathrm{mg} / \mathrm{kg}$ (oral)

- MP-PRED: MP $500 \mathrm{mg}$ in operating theatre then $125 \mathrm{mg}$ twice/d day 1 , then PRED $1 \mathrm{mg} / \mathrm{kg}$ day 2 tapered to $0.4 \mathrm{mg} / \mathrm{kg}$ by end of 1 month, tapered to $0.1 \mathrm{mg} / \mathrm{kg}$ by end of 5 months 
Norman 1993a (Continued)

- CSA: $7 \mathrm{mg} / \mathrm{kg} / \mathrm{d}$ at day 5

\begin{tabular}{ll}
\hline Outcomes & Death \\
- Graft loss \\
- Acute rejection \\
- DGF \\
- Infection \\
\hline Side effects \\
- More women and diabetics in high dose group (but only small numbers) \\
- in this review \\
- Fund patients in both groups had features of Cytokine Release Syndrome
\end{tabular}

\section{Risk of bias}

\begin{tabular}{|c|c|c|}
\hline Bias & Authors' judgement & Support for judgement \\
\hline $\begin{array}{l}\text { Random sequence genera- } \\
\text { tion (selection bias) }\end{array}$ & Unclear risk & limited info. 'The patients were randomised in blocks of four patients'. \\
\hline $\begin{array}{l}\text { Allocation concealment } \\
\text { (selection bias) }\end{array}$ & Low risk & Randomisation schedule kept by pharmacy \\
\hline $\begin{array}{l}\text { Blinding of participants } \\
\text { and personnel (perfor- } \\
\text { mance bias) } \\
\text { All outcomes }\end{array}$ & Low risk & Patients, nurses and doctors all blinded \\
\hline $\begin{array}{l}\text { Blinding of outcome as- } \\
\text { sessment (detection bias) } \\
\text { All outcomes }\end{array}$ & Low risk & Unlikely to influence outcomes \\
\hline $\begin{array}{l}\text { Incomplete outcome data } \\
\text { (attrition bias) } \\
\text { All outcomes }\end{array}$ & Low risk & All patient outcome data reported \\
\hline $\begin{array}{l}\text { Selective reporting (re- } \\
\text { porting bias) }\end{array}$ & High risk & SD/SE not reported for graft function and cannot be meta-analysed \\
\hline Other bias & Unclear risk & Funding source not reported \\
\hline
\end{tabular}

Norrby 1997

\begin{tabular}{ll}
\hline Methods & Study design: parallel RCT \\
& - Study duration: not reported \\
\hline Participants & Study follow-up: 6 months \\
\hline & - Country: Sweden \\
- Setting: single centre & risk group) \\
- Number: treatment group 1 (45); treatment group 2 (45)
\end{tabular}


Norrby 1997 (Continued)

- Mean age (years): treatment group 1 (49.1); treatment group 2 (47.8)

- Sex (M/F): treatment group 1 (28/17); treatment group 2 (29/16)

- LD/DD: treatment group 1 (4/41); treatment group 2 (1/44)

- Exclusion criteria: not reported

\begin{tabular}{|c|c|}
\hline Interventions & $\begin{array}{l}\text { Treatment group } 1 \\
\text { - ATG (Fresenius): } 5 \mathrm{mg} / \mathrm{kg} / \mathrm{d} \text { for } 4 \text { to } 7 \text { days } \\
\text { Treatment group } 2 \\
\text { - ATG (Merieux): } 2.5 \mathrm{mg} / \mathrm{kg} / \mathrm{d} \text { for } 4 \text { to } 7 \text { days } \\
\text { Immunosuppression (both groups) } \\
\text { - Not reported }\end{array}$ \\
\hline Outcomes & $\begin{array}{l}\text { - Acute rejection } \\
\text { - } \quad \text { CMV infection }\end{array}$ \\
\hline Notes & $\begin{array}{l}\text { - Outcomes of death, patient survival and graft function all reported as 'no significant difference'. No } \\
\text { numbers given, therefore not able to be included as outcomes in this review. } \\
\text { - Acute rejection rates are high in both groups in this study. Likely explained as patients are probably } \\
\text { a high risk group immunologically } \\
\text { - Funding source: Gothenburg University, Riksforbundet Njursjuka, Njursjukas forening i Vast Sverige, } \\
\text { and Gelins Minnesfond }\end{array}$ \\
\hline
\end{tabular}

\section{Risk of bias}

\begin{tabular}{|c|c|c|}
\hline Bias & Authors' judgement & Support for judgement \\
\hline $\begin{array}{l}\text { Random sequence genera- } \\
\text { tion (selection bias) }\end{array}$ & Unclear risk & Insufficient information to permit judgement \\
\hline $\begin{array}{l}\text { Allocation concealment } \\
\text { (selection bias) }\end{array}$ & Unclear risk & Insufficient information to permit judgement \\
\hline $\begin{array}{l}\text { Blinding of participants } \\
\text { and personnel (perfor- } \\
\text { mance bias) } \\
\text { All outcomes }\end{array}$ & Low risk & Unlikely to influence outcomes \\
\hline $\begin{array}{l}\text { Blinding of outcome as- } \\
\text { sessment (detection bias) } \\
\text { All outcomes }\end{array}$ & Low risk & Unlikely to influence outcomes \\
\hline $\begin{array}{l}\text { Incomplete outcome data } \\
\text { (attrition bias) } \\
\text { All outcomes }\end{array}$ & High risk & Denominators sometimes unclear \\
\hline $\begin{array}{l}\text { Selective reporting (re- } \\
\text { porting bias) }\end{array}$ & High risk & $\begin{array}{l}\text { Outcomes reported but actual numbers not given, therefore difficult to verify } \\
\text { data }\end{array}$ \\
\hline Other bias & Unclear risk & $\begin{array}{l}\text { Unclear due to limited information. Funding from } 4 \text { different groups: Gothen- } \\
\text { burg University, Riksforbundet Njursjuka, Njursjukas forening i Vast Sverige, } \\
\text { and Gelins Minnesfond. }\end{array}$ \\
\hline
\end{tabular}


Novick 1983

\begin{tabular}{ll}
\hline Methods & Study design: parallel RCT \\
- Study duration: October 1978 to October 1980 \\
- Study follow-up: to 42 months \\
\hline Participants & Country: USA \\
- Setting: single centre \\
- Inclusion criteria: 1st DD kidney transplant recipients with no history of allergic reactions or prior ex- \\
- posure to horse serum protein \\
- Mean age \pm SD (years): not reported \\
- Sex (M/F): treatment group (26/5); control group (30/6) \\
- Ethnicity (Caucasian/other): treatment group (28/3); control group (29/7) \\
- Exclusion criteria: not reported
\end{tabular}

\begin{tabular}{ll}
\hline Interventions & Treatment group \\
- ALG: $30 \mathrm{mg} / \mathrm{kg} / \mathrm{d}$ for 14 days \\
Control group \\
- Placebo: $30 \mathrm{mg} / \mathrm{kg} / \mathrm{d}$ of human albumin solution for 14 days \\
Immunosuppression (both groups) \\
- AZA: 3 to $5 \mathrm{mg} / \mathrm{kg}$ pre-op, then 1.5 to $2 \mathrm{mg}$ daily \\
- MP-PRED: $1 \mathrm{~g}$ in operating theatre, then $2 \mathrm{mg} / \mathrm{kg} / \mathrm{d}$ PRED post-op, rapid taper over 2 months to 0.6 \\
mg/kg/d, then slow decrease to $0.25 \mathrm{mg} / \mathrm{kg} / \mathrm{d}$ \\
\hline - Death \\
- Graft loss \\
- Acute rejection \\
- Adverse events \\
- ALG group: 4 excluded as received $<50 \%$ ALG dose
\end{tabular}

\section{Risk of bias}

\begin{tabular}{lll}
\hline Bias & Authors' judgement & Support for judgement \\
\hline $\begin{array}{l}\text { Random sequence genera- } \\
\text { tion (selection bias) }\end{array}$ & Unclear risk & Previously numbered drug vials' but not clear how sequence generated \\
\hline $\begin{array}{l}\text { Allocation concealment } \\
\text { (selection bias) }\end{array}$ & Low risk & Randomised via a central office at the University of Minnesota \\
\hline $\begin{array}{l}\text { Blinding of participants } \\
\text { and personnel (perfor- } \\
\text { mance bias) }\end{array}$ & Low risk & Unlikely to influence outcomes \\
$\begin{array}{l}\text { All outcomes } \\
\text { Blinding of outcome as- } \\
\text { sessment (detection bias) } \\
\begin{array}{l}\text { All outcomes } \\
\hline\end{array}\end{array}$ & Low risk & Unlikely to influence outcomes \\
\hline
\end{tabular}


Novick 1983 (Continued)

Incomplete outcome data Unclear risk Patients only receiving 50\% of ALG total dose or less were excluded from re(attrition bias) sults $(4 / 35 ; 10 \%$ of group ( 2 withdrew, 2 unable to tolerate due to side effects)

All outcomes

Not certain if these patients would have altered outcomes if included

Selective reporting (re- Low risk All expected outcomes reported

porting bias)

Other bias Low risk University of Minnesota ALG lab provided the ALG

\section{Perez-Tamajon 1996}

\begin{tabular}{ll}
\hline Methods & Study design: parallel RCT \\
& - Study duration: not reported \\
\hline Participants & Study follow-up: 20 months \\
\hline & - Country: Spain \\
- Setting: single centre & Inclusion criteria: 1 st DD kidney transplant recipients; PRA $<25 \%$ \\
& - Mean age \pm SD (years): not reported \\
& - Sex (M/F): not reported \\
- Exclusion criteria: not reported
\end{tabular}

Interventions

Treatment group 1

- ATG: $10 \mathrm{mg} / \mathrm{kg} / \mathrm{d}$ until $\mathrm{Cr}<3 \mathrm{mg} / \mathrm{dL}$

Treatment group 2

- OKT3: $2.5 \mathrm{mg} / \mathrm{d}$ until serum $\mathrm{Cr}<3 \mathrm{mg} / \mathrm{dL}$

Immunosuppression (both groups)

- CSA, PRED. AZA: dosage not reported

\begin{tabular}{ll}
\hline Outcomes & Death \\
- & Graft loss \\
- DGF & Acute rejection \\
\hline Notes & - Abstract-only publication \\
- Reported no difference in demographic data of recipients or donors, in HLA mismatch or cold is- \\
chaemia time \\
- Acute rejection reported as number of episodes/patient (not total number of patients with acute re- \\
- Nephrotoxicity, infections and other medical and surgical complications reported as similar in both \\
groups \\
- Funding source: not reported
\end{tabular}

\section{Risk of bias}

Bias Authors' judgement Support for judgement


Perez-Tamajon 1996 (Continued)

Random sequence genera- Unclear risk Insufficient information to permit judgement tion (selection bias)

Allocation concealment $\quad$ Unclear risk Insufficient information to permit judgement
(selection bias)

Blinding of participants Low risk Unlikely to influence outcomes
and personnel (perfor-
mance bias)
All outcomes

\begin{tabular}{lll}
\hline $\begin{array}{l}\text { Blinding of outcome as- } \\
\text { sessment (detection bias) } \\
\text { All outcomes }\end{array}$ & Low risk & Unlikely to influence outcomes \\
\hline $\begin{array}{l}\text { Incomplete outcome data } \\
\text { (attrition bias) } \\
\text { All outcomes }\end{array}$ & Low risk & All patient outcome data reported \\
\hline $\begin{array}{l}\text { Selective reporting (re- } \\
\text { porting bias) }\end{array}$ & High risk & All expected outcomes reported however unable to use acute rejection data \\
\hline Other bias & Unclear risk & Insufficient information to permit judgement and funding source not clear \\
\hline
\end{tabular}

\section{Pernin 2012}

\begin{tabular}{ll}
\hline Methods & Study design: parallel RCT \\
& - Study duration: not reported \\
\hline Participants & - Coudy follow-up: 1 year \\
- Setting: single centre \\
- Inclusion criteria: not reported \\
- Number: 31 (group assignment not reported) \\
- Mean age \pm SD (years): not reported \\
- Sex (M/F): not reported \\
\hline
\end{tabular}

\begin{tabular}{ll}
\hline Interventions & Treatment group 1 \\
& - \\
& ATG monitored by CD3: $1 \mathrm{mg} / \mathrm{kg} / \mathrm{d}$ day 0 and day 1 , then only if CD3+ count was above $10 \mathrm{~mm}^{3}$ until \\
& Treatment group 2 \\
& - Fixed dose ATG: $1 \mathrm{mg} / \mathrm{kg} / \mathrm{d}$ from day 0 to day 4 \\
\hline Outcomes & Acute rejection \\
& - Infection \\
\hline Notes & Lymphocyte subsets \\
& - Abstract-only publication \\
- No extractable data for our review & "The incidence of opportunistic infections or acute rejections were not significantly different between \\
the two groups"
\end{tabular}


Pernin 2012 (Continued)

$$
\text { - Funding source: not reported }
$$

\section{Risk of bias}

\begin{tabular}{lll}
\hline Bias & Authors' judgement & Support for judgement \\
\hline $\begin{array}{l}\text { Random sequence genera- } \\
\text { tion (selection bias) }\end{array}$ & Unclear risk & Insufficient information to permit judgement \\
\hline $\begin{array}{l}\text { Allocation concealment } \\
\text { (selection bias) }\end{array}$ & Unclear risk & Insufficient information to permit judgement \\
\hline $\begin{array}{l}\text { Blinding of participants } \\
\text { and personnel (perfor- } \\
\text { mance bias) }\end{array}$ & Unclear risk & Insufficient information to permit judgement \\
All outcomes & \\
\hline $\begin{array}{l}\text { Blinding of outcome as- } \\
\text { sessment (detection bias) } \\
\text { All outcomes }\end{array}$ & Unclear risk & Insufficient information to permit judgement \\
\hline $\begin{array}{l}\text { Incomplete outcome data } \\
\text { (attrition bias) }\end{array}$ & High risk & \\
\begin{tabular}{l} 
All outcomes \\
\hline $\begin{array}{l}\text { Selective reporting (re- } \\
\text { porting bias) }\end{array}$
\end{tabular} & High risk & Limited reporting of outcomes \\
\hline \begin{tabular}{l} 
Other bias \\
\hline
\end{tabular} & High risk & Has not been published as full paper \\
\hline
\end{tabular}

Raffaele 1991

\begin{tabular}{ll}
\hline Methods & - Study design: parallel RCT \\
& - Study duration: October 1987 to December 1989 \\
\hline Participants & - Ctudy follow-up: 24 months \\
- Country: France \\
- Inclusion criteria: DD kidney transplant recipients \\
- Number: treatment group 1 (70); treatment group 2 (73) \\
- Mean age \pm SD (years): not reported \\
- Sex (M/F): not reported \\
- Retransplantation: treatment group $1(20 \%) ;$ treatment group $2(16 \%)$ \\
- Exclusion criteria: not reported
\end{tabular}

- OKT3: $5 \mathrm{mg} / \mathrm{kg}$ for 10 days

Treatment group 2

- ATG (Merieux): $25 \mathrm{mg} / 20 \mathrm{~kg} / \mathrm{d}$ for 10 days

Immunosuppression (both groups)

- MP-PRED: MP $15 \mathrm{mg} / \mathrm{kg}$ pre-op, then PRED $1 \mathrm{mg} / \mathrm{kg}$ tapered to $20 \mathrm{mg}$ by 1 month 
Raffaele 1991 (Continued)

- AZA: 2 to $3 \mathrm{mg} / \mathrm{kg}$

- CSA: $1 \mathrm{mg} / \mathrm{kg}$ IV for 2 days, then oral $4 \mathrm{mg} / \mathrm{kg} / \mathrm{d}$, adjust as per trough

\begin{tabular}{ll}
\hline Outcomes & CMV infection \\
& $\cdot$ CMV disease (symptomatic) \\
\hline Notes & Acute rejection \\
& - Specifically looking at CMV infection \\
& - Not specified if given CMV prophylaxis \\
& - Funding source: not reported
\end{tabular}

\section{Risk of bias}

\begin{tabular}{|c|c|c|}
\hline Bias & Authors' judgement & Support for judgement \\
\hline $\begin{array}{l}\text { Random sequence genera- } \\
\text { tion (selection bias) }\end{array}$ & Unclear risk & Insufficient information to permit judgement \\
\hline $\begin{array}{l}\text { Allocation concealment } \\
\text { (selection bias) }\end{array}$ & Unclear risk & Insufficient information to permit judgement \\
\hline $\begin{array}{l}\text { Blinding of participants } \\
\text { and personnel (perfor- } \\
\text { mance bias) } \\
\text { All outcomes }\end{array}$ & Low risk & Unlikely to be influenced \\
\hline $\begin{array}{l}\text { Blinding of outcome as- } \\
\text { sessment (detection bias) } \\
\text { All outcomes }\end{array}$ & Unclear risk & $\begin{array}{l}\text { Not specified whether acute rejection episodes were biopsy-proven acute re- } \\
\text { jection }\end{array}$ \\
\hline $\begin{array}{l}\text { Incomplete outcome data } \\
\text { (attrition bias) } \\
\text { All outcomes }\end{array}$ & Low risk & All patient outcome data reported \\
\hline $\begin{array}{l}\text { Selective reporting (re- } \\
\text { porting bias) }\end{array}$ & High risk & $\begin{array}{l}\text { Expected outcomes reported given only short-term follow-up. However, graft } \\
\text { loss and death not reported. (may be none but would expect these outcomes } \\
\text { to be reported) }\end{array}$ \\
\hline Other bias & Unclear risk & $\begin{array}{l}\text { Insufficient information to permit judgement to assess and funding source not } \\
\text { declared }\end{array}$ \\
\hline
\end{tabular}

Rostaing 2010

\begin{tabular}{ll}
\hline Methods & Study design: parallel RCT \\
& - Study duration: not reported \\
& - Study follow-up: 1 month \\
\hline Participants & Country: France \\
- Setting: single centre \\
- Inclusion criteria: adult DD kidney transplant recipients; PRA > 30\% \\
- Mean age \pm SD (years): not reported \\
- Sex (M/F): not reported
\end{tabular}


Rostaing 2010 (Continued)

$$
\text { - Exclusion criteria: not reported }
$$

\begin{tabular}{|c|c|}
\hline Interventions & $\begin{array}{l}\text { Treatment group } 1 \\
\text { - rATG (Genzyme): } 6.2 \mathrm{mg} / \mathrm{kg} \pm 2.9 \text { over } 7 \text { days } \\
\text { Treatment group } 2 \\
\text { - hATG (Fresenius) } 22.6 \mathrm{mg} / \mathrm{kg} \pm 7.9 \text { over } 7 \text { days } \\
\text { Immunosuppression (both groups) } \\
\text { - MMF: } 2.5 \mathrm{~g} / \mathrm{d} \\
\text { - TAC: } \text { troughs of } 8 \text { to } 12 \mathrm{ng} / \mathrm{mL} \\
\text { - PRED: } 1 \mathrm{mg} / \mathrm{kg} / \mathrm{d} \text { for } 7 \text { days, then tapered to } 0.25 \mathrm{mg} / \mathrm{kg} / \mathrm{d} \text { by } 1 \text { month } \\
\text { Prophylaxis (both groups) } \\
\text { - PCP prophylaxis } \\
\text { - CMV prophylaxis }\end{array}$ \\
\hline Outcomes & $\begin{array}{ll}\text { - } & \text { Acute rejection } \\
\text { - } & \text { DGF } \\
\text { - Infection }\end{array}$ \\
\hline Notes & $\begin{array}{l}\text { - Designed to look at haematologic effects of the } 2 \text { different ATG preparations at } 1 \text { month } \\
\text { - Fall in platelet count more pronounced in hATG group at days 2, } 3 \text { and } 5 \text { post-op } \\
\text { - Mild leucopenia in } 1 \text { rATG patient only. } \\
\text { - Hb levels similar in both groups (roughly } 10 \mathrm{~g} / \mathrm{dL} \text { up to day } 10 \text { ) } \\
\text { - More EPO given in hATG group compared to rATG group } \\
\text { - Funding source: not reported }\end{array}$ \\
\hline
\end{tabular}

\section{Risk of bias}

\begin{tabular}{|c|c|c|}
\hline Bias & Authors' judgement & Support for judgement \\
\hline $\begin{array}{l}\text { Random sequence genera- } \\
\text { tion (selection bias) }\end{array}$ & Unclear risk & Insufficient information to permit judgement \\
\hline $\begin{array}{l}\text { Allocation concealment } \\
\text { (selection bias) }\end{array}$ & Unclear risk & Insufficient information to permit judgement \\
\hline $\begin{array}{l}\text { Blinding of participants } \\
\text { and personnel (perfor- } \\
\text { mance bias) } \\
\text { All outcomes }\end{array}$ & Low risk & Unlikely to influence outcomes \\
\hline $\begin{array}{l}\text { Blinding of outcome as- } \\
\text { sessment (detection bias) } \\
\text { All outcomes }\end{array}$ & Low risk & Unlikely to influence outcomes \\
\hline $\begin{array}{l}\text { Incomplete outcome data } \\
\text { (attrition bias) } \\
\text { All outcomes }\end{array}$ & Low risk & All patient outcome data reported \\
\hline $\begin{array}{l}\text { Selective reporting (re- } \\
\text { porting bias) }\end{array}$ & Low risk & All expected outcomes reported given short follow-up only \\
\hline
\end{tabular}


Rostaing 2010 (Continued)
Other bias
Unclear risk
Funding not declared

Sakhrani 1992

\begin{tabular}{|c|c|}
\hline Methods & $\begin{array}{l}\text { - Study design: parallel RCT } \\
\text { - Study duration: January } 1990 \text { to September } 1990 \\
\text { - Study follow-up: } 1 \text { year }\end{array}$ \\
\hline Participants & $\begin{array}{l}\text { - } \text { Country: USA } \\
\text { - Setting: single centre } \\
\text { - Inclusion criteria: adult DD kidney transplant recipients } \\
\text { - Number: treatment group } 1(46) \text {; treatment group } 2(37) \\
\text { - Mean age } \pm \text { SD (years): treatment group ( } 43 \pm 13) \text {; treatment group } 2(42 \pm 12) \\
\text { - Sex (M/F): treatment group ( } 31 / 15) \text {; treatment group } 2(21 / 26) \\
\text { - Exclusion criteria: not reported }\end{array}$ \\
\hline Interventions & $\begin{array}{l}\text { Treatment group } 1 \\
\text { - Minnesota ALG: } 10 \mathrm{mg} / \mathrm{kg} \text {; duration not reported } \\
\text { Treatment group } 2 \\
\text { - Minnesota ALG: } 20 \mathrm{mg} / \mathrm{kg} \text {; duration not reported } \\
\text { Immunosuppression (both groups) } \\
\text { - PRED: dose and dosage not reported } \\
\text { - AZA: dose and dosage not reported } \\
\text { - CSA: started when good graft function (good urine output and } \mathrm{Cr} \text { decrease to }<50 \% \text { pre transplant); } \\
\text { dose and dosage not reported }\end{array}$ \\
\hline Outcomes & $\begin{array}{l}\text { - } \text { Graft loss } \\
\text { - } \text { Acute rejection } \\
\text { - Severe infection } \\
\text { - Leucopenia }\end{array}$ \\
\hline Notes & $\begin{array}{l}\text { - Death not reported } \\
\text { - Funding source: not reported }\end{array}$ \\
\hline
\end{tabular}

\section{Risk of bias}

\section{Bias}

\section{Authors' judgement Support for judgement}

Random sequence genera- Unclear risk Insufficient information to permit judgment tion (selection bias)

\begin{tabular}{l}
$\begin{array}{l}\text { Allocation concealment } \\
\text { (selection bias) }\end{array}$ \\
\hline
\end{tabular}

Blinding of participants Unclear risk Unlikely to influence outcomes
and personnel (perfor-
mance bias)
All outcomes


Sakhrani 1992 (Continued)

Blinding of outcome as- Unclear risk Not stated how acute rejection was determined sessment (detection bias)

All outcomes

\begin{tabular}{lll}
$\begin{array}{l}\text { Incomplete outcome data } \\
\text { (attrition bias) } \\
\text { All outcomes }\end{array}$ & Unclear risk & $\begin{array}{l}\text { Kidneys did not function in } 4 \text { patients (2 in each group) and } 1 \text { patient from } \\
\text { each group moved out of the country }\end{array}$ \\
\hline $\begin{array}{l}\text { Selective reporting (re- } \\
\text { porting bias) }\end{array}$ & High risk & $\begin{array}{l}\text { Death not reported; results reported as percentages and could not be meta- } \\
\text { analysed }\end{array}$ \\
\hline Other bias & Unclear risk & Funding not reported \\
\hline
\end{tabular}

Samsel 1999

\begin{tabular}{ll}
\hline Methods & Study design: parallel RCT \\
- Study duration: November 1997 to April 1999 \\
- Study follow-up: 5 years \\
\hline Participants \\
- Country: Poland \\
- Setting: multicentre (2 centres) \\
- Number: treatment group (40); control group (39) \\
- Mean age \pm SD (years): treatment group (43 \pm 10$)$; control group $(40 \pm 12)$ \\
- Sex (M/F): treatment group (23/17); control group (25/14) \\
- Exclusion criteria: active bacterial, viral or fungal infections; thrombocytopenia; leukopenia; patients \\
known to be sensitized to rabbit immunoglobulins; patients with chronic liver disease
\end{tabular}

$\begin{array}{ll}\text { Interventions } & \text { Treatment group } \\ \text { - } & \text { hATG (Fresenius): } 9 \mathrm{mg} / \mathrm{kg} \text { given pre-op as single bolus, via CVC, prior to completion of anastomosis } \\ \text { Control group } \\ \text { - No ATG } \\ \text { Immunosuppression (both groups) } \\ \text { - MMF: } 1 \mathrm{~g} \text { twice daily, converted to AZA } 2 \mathrm{mg} / \mathrm{kg} \text { after } 4 \text { th month } \\ \text { - CSA: } 8 \mathrm{mg} / \mathrm{kg} \\ \text { - MP-PRED: } 500 \text { mg MP pre-op, then } 250 \mathrm{mg} \text { post-op, switch to PRED } 0.5 \mathrm{mg} / \mathrm{kg} / \mathrm{d} \text { on } 4 \text { th day } \\ \text { Prophylaxis (both groups) } \\ \text { - Antibiotic prophylaxis: piperacillin sodium and tazobactam for } 3 \text { days } \\ \text { - Patient survival } \\ \text { - Graft survival } \\ \text { - Acute rejection } \\ \text { - Graft function } \\ \text { - Complications }\end{array}$

\section{Risk of bias}

Polyclonal and monoclonal antibodies for induction therapy in kidney transplant recipients (Review) 
Samsel 1999 (Continued)

\section{Bias Authors' judgement Support for judgement}

Random sequence genera- Unclear risk Insufficient information to permit judgement

tion (selection bias)

Allocation concealment $\quad$ Unclear risk Insufficient information to permit judgement
(selection bias)

(selection bias)

Blinding of participants Low risk Unlikely to influence outcomes
and personnel (perfor-
mance bias)

\begin{tabular}{|c|c|c|}
\hline $\begin{array}{l}\text { Blinding of outcome as- } \\
\text { sessment (detection bias) } \\
\text { All outcomes }\end{array}$ & Unclear risk & Not all acute rejection was biopsy-proven \\
\hline $\begin{array}{l}\text { Incomplete outcome data } \\
\text { (attrition bias) } \\
\text { All outcomes }\end{array}$ & Low risk & $\begin{array}{l}\text { All patient outcome data reported; } 1 \text { patient excluded in control group as im- } \\
\text { munosuppression was withdrawn however was included in the safety analysis }\end{array}$ \\
\hline $\begin{array}{l}\text { Selective reporting (re- } \\
\text { porting bias) }\end{array}$ & Low risk & All expected outcomes reported \\
\hline Other bias & Unclear risk & Funding source unclear; ATG supplied by Fresenius Pharma Support \\
\hline
\end{tabular}

Sansom 1976

\begin{tabular}{|c|c|}
\hline Methods & $\begin{array}{l}\text { - Study design: parallel RCT } \\
\text { - Study duration: February } 1972 \text { to October } 1974 \\
\text { - Study follow-up: at least } 4 \text { months }\end{array}$ \\
\hline Participants & $\begin{array}{l}\text { - Country: UK } \\
\text { - Setting: single centre } \\
\text { - Inclusion criteria: adult DD kidney transplant recipients } \\
\text { - Number: treatment group ( } 43) \text {; control group }(42) \\
\text { - Mean age } \pm \mathrm{SD} \text { (years): treatment group }(36.3 \pm 11.1) \text {; control group }(36.0 \pm 12) \\
\text { - Sex ratio (M:F): treatment group (1.8:1); control group }(2.0: 1) \\
\text { - Exclusion criteria: not reported }\end{array}$ \\
\hline Interventions & $\begin{array}{l}\text { Treatment group } \\
\text { - ALG: } 2 \text { different types used and an intradermal test used to decide which variety to be given (anti-hu- } \\
\text { man thymocyte ALG; anti-cultured lymphoblast rabbit ALG) } \\
\text { * } 1 \mathrm{~g} \text { in } 500 \mathrm{~mL} \text { isotonic saline IV over } 4 \mathrm{~h} \text { for } 10 \text { days } \\
\square \text { Only used for } 1 \mathrm{st} 11 \text { patients as } 1 \text { patient died due to anaphylaxis after } 4 \text { th dose } \\
\text { * Route changed to } \mathrm{SC} \text { and dose decreased to } 500 \mathrm{mg} \text { for } 10 \text { days. } 32 \text { subsequent patients received } \\
\text { this } \\
\text { Control group } \\
\text { - No ALG } \\
\text { Immunosuppression (both groups) } \\
\text { - Hydrocortisone: } 200 \mathrm{mg} \text { pre-op }\end{array}$ \\
\hline
\end{tabular}


Sansom 1976 (Continued)

- AZA: $5 \mathrm{mg} / \mathrm{kg}$ IV pre-op

- PRED (post-op): $75 \mathrm{mg}$ for 10 days, tapered to 12.5 to $15 \mathrm{mg}$ by 4 to 6 months

- AZA (post-op): maximum daily dose to keep WCC $>3000 / \mathrm{mm}^{3}$

\begin{tabular}{ll}
\hline Outcomes & Death \\
- & Graft loss \\
- & Acute rejection \\
\hline Notes & 100 patients randomised, only 1st transplant recipients were analysed (not stratified) therefore only \\
& 85 patients analysed \\
- & Acute rejection reported as total number of episodes but not clear if some patients had multiple \\
episodes, therefore total number of patients with acute rejection unknown and not used in review \\
analysis \\
- Funding source: GD Searle and Queen Elizabeth Hospital Renal Research Fund
\end{tabular}

\section{Risk of bias}

\begin{tabular}{|c|c|c|}
\hline Bias & Authors' judgement & Support for judgement \\
\hline $\begin{array}{l}\text { Random sequence genera- } \\
\text { tion (selection bias) }\end{array}$ & Unclear risk & 'randomised numbers consecutively...' insufficient to permit judgement \\
\hline $\begin{array}{l}\text { Allocation concealment } \\
\text { (selection bias) }\end{array}$ & Unclear risk & Insufficient information to permit judgement \\
\hline $\begin{array}{l}\text { Blinding of participants } \\
\text { and personnel (perfor- } \\
\text { mance bias) } \\
\text { All outcomes }\end{array}$ & Unclear risk & Unlikely to influence reported outcomes \\
\hline $\begin{array}{l}\text { Blinding of outcome as- } \\
\text { sessment (detection bias) } \\
\text { All outcomes }\end{array}$ & Unclear risk & Unclear if acute rejection was biopsy-proven \\
\hline $\begin{array}{l}\text { Incomplete outcome data } \\
\text { (attrition bias) } \\
\text { All outcomes }\end{array}$ & High risk & $\begin{array}{l}\text { Higher immunological risk patients excluded ( } 2 \text { nd transplant patients) after } \\
\text { randomisation; no results given for these } 15 \text { patients }\end{array}$ \\
\hline $\begin{array}{l}\text { Selective reporting (re- } \\
\text { porting bias) }\end{array}$ & High risk & As above; acute rejection results could not be included in the meta-analysis \\
\hline Other bias & Unclear risk & $\begin{array}{l}\text { Funding source unclear "gift of rabbit ALG and financial assistance" provided } \\
\text { by GD Searle; Queen Elizabeth Hospital Renal Research Fund provided some } \\
\text { funding }\end{array}$ \\
\hline
\end{tabular}

Sharaf El Din 2006

\begin{tabular}{ll}
\hline Methods & - Study design: parallel RC; possibly 3:1 however not well described \\
& - Study duration: not reported \\
& - Study follow-up: 1 year \\
\hline Participants & - Country: Egypt \\
& - Setting: single centre \\
& - Inclusion criteria: LD kidney transplant recipients \\
\hline
\end{tabular}


Sharaf El Din 2006 (Continued)

- Mean age \pm SD (years): not reported

- Sex (M/F): not reported

- Exclusion criteria: not reported

\begin{tabular}{ll}
\hline Interventions & Treatment group \\
- Alemtuzumab: $20 \mathrm{mg}, 2$ doses day 0 and day 1 \\
- MP: $250 \mathrm{mg}$ prior to each treatment \\
- CSA: $4 \mathrm{mg} / \mathrm{kg} / \mathrm{d}$ from day 1 \\
- MMF: $500 \mathrm{mg}$ twice daily from day 1 \\
Control group \\
- MP: $250 \mathrm{mg}$ in operating theatre at induction and at declamping \\
- PRED: with gradual decrease to $10 \mathrm{mg} / \mathrm{d}$ by 3 months \\
- CSA: $8 \mathrm{mg} / \mathrm{kg} / \mathrm{d}$ from day 2 \\
- MMF: $1 \mathrm{~g}$ twice daily from day 2 \\
\hline - Patient survival \\
- Graft survival \\
- Acute rejection \\
- SCr \\
- Abstract-only publication \\
- Not clear if randomised but states that it was \\
- Attempted to contact author to clarify methods but no response
\end{tabular}

\section{Risk of bias}

\begin{tabular}{lll}
\hline Bias & Authors' judgement & Support for judgement \\
\hline $\begin{array}{l}\text { Random sequence genera- } \\
\text { tion (selection bias) }\end{array}$ & Unclear risk & Insufficient information to permit judgement \\
\hline $\begin{array}{l}\text { Allocation concealment } \\
\text { (selection bias) }\end{array}$ & Unclear risk & Insufficient information to permit judgement \\
\hline $\begin{array}{l}\text { Blinding of participants } \\
\begin{array}{l}\text { and personnel (perfor- } \\
\text { mance bias) }\end{array}\end{array}$ & Low risk & Unlikely to influence outcomes \\
All outcomes & & \\
\hline
\end{tabular}

$\begin{array}{ll}\text { Blinding of outcome as- } & \text { Unclear risk }\end{array}$
sessment (detection bias)

All outcomes

\begin{tabular}{lll}
\hline $\begin{array}{l}\text { Incomplete outcome data } \\
\text { (attrition bias) } \\
\text { All outcomes }\end{array}$ & Unclear risk & Insufficient information to permit judgement \\
\hline $\begin{array}{l}\text { Selective reporting (re- } \\
\text { porting bias) }\end{array}$ & Unclear risk & Insufficient information to permit judgement \\
\hline Other bias & Unclear risk & Insufficient information to permit judgement \\
\hline
\end{tabular}


Sheashaa 2008

\begin{tabular}{|c|c|}
\hline Methods & $\begin{array}{l}\text { - Study design: parallel RCT } \\
\text { - Study duration: } \text { not reported } \\
\text { - Study follow-up: } 5 \text { years }\end{array}$ \\
\hline Participants & $\begin{array}{l}\text { - Country: Egypt } \\
\text { - Setting: single centre } \\
\text { - Inclusion criteria: LD kidney transplant recipients } \\
\text { - Number: treatment group ( } 40) \text {; control group }(40) \\
\text { - Mean age } \pm \text { SD (years): treatment group }(30.3 \pm 13.1) \text {; control group }(31.7 \pm 10.45) \\
\text { - Sex (M/F): treatment group ( } 33 / 7) \text {; control group }(33 / 7) \\
\text { - Exclusion criteria: not reported }\end{array}$ \\
\hline Interventions & $\begin{array}{l}\text { Treatment group } \\
\text { - rATG (Fresenius): } 9 \mathrm{mg} / \mathrm{kg} \text { given in operating theatre prior to revascularization } \\
\text { Control group } \\
\text { - No ATG } \\
\text { Immunosuppression (both groups) } \\
\text { - Steroids: dose regimen not reported } \\
\text { - CNI: dose regimen not reported } \\
\text { - Anti-proliferative agents: dose regimen not reported }\end{array}$ \\
\hline Outcomes & $\begin{array}{l}\text { - Patient survival } \\
\text { - Graft survival } \\
\text { - Biopsy-proven acute rejection } \\
\text { - Side effects }\end{array}$ \\
\hline Notes & ource: not reported \\
\hline
\end{tabular}

\section{Risk of bias}

\begin{tabular}{lll}
\hline Bias & Authors' judgement & Support for judgement \\
\hline $\begin{array}{l}\text { Random sequence genera- } \\
\text { tion (selection bias) }\end{array}$ & Unclear risk & Insufficient information to permit judgement \\
\hline $\begin{array}{l}\text { Allocation concealment } \\
\text { (selection bias) }\end{array}$ & Low risk & Sequentially numbered, opaque, sealed envelopes \\
\hline $\begin{array}{l}\text { Blinding of participants } \\
\text { and personnel (perfor- } \\
\text { mance bias) }\end{array}$ & Low risk & Unlikely to influence outcomes \\
All outcomes & & \\
\hline
\end{tabular}

\begin{tabular}{lll}
\hline $\begin{array}{l}\text { Blinding of outcome as- } \\
\text { sessment (detection bias) } \\
\text { All outcomes }\end{array}$ & Low risk & Unlikely to influence outcomes \\
\hline $\begin{array}{l}\text { Incomplete outcome data } \\
\text { (attrition bias) }\end{array}$ & Low risk & All patient outcomes reported \\
All outcomes & \\
\hline
\end{tabular}


Sheashaa 2008 (Continued)

Selective reporting (re- Low risk $\quad$ All expected outcomes reported
porting bias)

Other bias Unclear risk No obvious source but funding source not declared

Shield 1993

\begin{tabular}{ll}
\hline Methods & Study design: parallel RCT \\
& - Study duration: June 1986 to January 1991 \\
- Study follow-up: 3 years
\end{tabular}

\begin{tabular}{ll}
\hline Participants & Country: USA \\
- Setting: single centre \\
- Inclusion criteria: DD kidney transplant recipients \\
- Number: treatment group (99); control group (31) \\
- Sex (M/F): not reported \\
- Exclusion criteria: possessed anti-mouse Ab; refused the drug \\
\hline
\end{tabular}

\begin{tabular}{l} 
Treatment group \\
Interventions $\begin{array}{l}\text { OKT3: } 5 \mathrm{mg} \text { IV bolus given in operating theatre after induction and intubation; no further information } \\
\text { provided }\end{array}$ \\
Control \\
- No OKT3 \\
Immunosuppression (both groups) \\
- MP: dose not reported \\
- AZA: dose not reported \\
- No patient received CSA within 36 h of the transplant \\
- Death \\
- Graft loss \\
\hline DGF \\
\hline - Records of all kidney transplant recipients analysed: 31 patients LD (no OKT3); all DD transplant re- \\
cipients received OKT3 intra-op unless they were 'randomised' to non-OKT3 arm (may not be truly \\
randomised) \\
- Authors made decision to include with sensitivity analysis \\
- DD only used for our comparisons
\end{tabular}

\section{Risk of bias}

\begin{tabular}{lll}
\hline Bias & Authors' judgement & Support for judgement \\
\hline $\begin{array}{l}\text { Random sequence genera- } \\
\text { tion (selection bias) }\end{array}$ & High risk & $\begin{array}{l}\text { Limited information but no reason for severe imbalance in LD vs DD patients } \\
\text { and unequal numbers in intervention and treatment groups. Likely selection } \\
\text { bias; possibly post-hoc report of unpublished RCT }\end{array}$ \\
\hline
\end{tabular}


Shield 1993 (Continued)

\begin{tabular}{|c|c|c|}
\hline $\begin{array}{l}\text { Allocation concealment } \\
\text { (selection bias) }\end{array}$ & High risk & As above \\
\hline $\begin{array}{l}\text { Blinding of participants } \\
\text { and personnel (perfor- } \\
\text { mance bias) } \\
\text { All outcomes }\end{array}$ & Low risk & Unlikely to influence outcomes \\
\hline $\begin{array}{l}\text { Blinding of outcome as- } \\
\text { sessment (detection bias) } \\
\text { All outcomes }\end{array}$ & Low risk & Unlikely to influence outcomes \\
\hline $\begin{array}{l}\text { Incomplete outcome data } \\
\text { (attrition bias) } \\
\text { All outcomes }\end{array}$ & High risk & $\begin{array}{l}\text { Percentages given but no actual numbers for survival and no causes of patient } \\
\text { or graft loss }\end{array}$ \\
\hline $\begin{array}{l}\text { Selective reporting (re- } \\
\text { porting bias) }\end{array}$ & High risk & Acute rejection not reported \\
\hline Other bias & Unclear risk & Insufficient information to permit judgement and funding not declared \\
\hline
\end{tabular}

\section{Slakey 1993}

\begin{tabular}{ll}
\hline Methods & Study design: parallel RCT; stratified for age $(>$ or $<50$ years), diabetes \\
& - Study duration: January 1988 to September 1990 \\
\hline Participants & - Coudy follow-up: to 4.5 years \\
- Setting: single centre \\
- Inclusion criteria: adult 1 st DD kidney transplant recipients with immediate graft function \\
- Number: treatment group (61); control group $(60)$ \\
- Mean age \pm SD (years): treatment group $(47.4 \pm 13.9) ;$ control group $(47.3 \pm 14.2)$ \\
- Sex (M/F): treatment group (36/25); control group $(33 / 27)$ \\
- ethnicity (Caucasian/Black/other): treatment group $(42 / 15 / 4) ;$ control group $(43 / 15 / 2)$ \\
- Exclusion criteria: not reported
\end{tabular}

- ALG (Minnesota): $5 \mathrm{mg} / \mathrm{kg}$ on day $1,10 \mathrm{mg} / \mathrm{kg}$ day $2,20 \mathrm{mg} / \mathrm{kg}$ days 3 to 7

- CSA: $10 \mathrm{mg} / \mathrm{kg}$, commenced on day 6

- AZA: $2.5 \mathrm{mg} / \mathrm{kg}$, adjusted as per WCC (aim > 4000 cells $/ \mathrm{mm}^{3}$ ).

- PRED: $1 \mathrm{mg} / \mathrm{kg} / \mathrm{d}$, decrease to $0.5 \mathrm{mg} / \mathrm{kg} / \mathrm{d}$ by 2 weeks, tapered to $0.15 \mathrm{mg} / \mathrm{kg}$ by 6 months

Control group

- CSA: $10 \mathrm{mg} / \mathrm{kg} / \mathrm{d}$ (oral) within $24 \mathrm{~h}$

- AZA: $5 \mathrm{mg} / \mathrm{kg} / \mathrm{d}$, tapered to $2.5 \mathrm{mg} / \mathrm{kg} / \mathrm{d}$ by day 8

- PRED: as for treatment group

$\begin{array}{ll}\text { Outcomes } & \text { - Death } \\ & \text { - Graft loss } \\ & \text { - Acute rejection } \\ \text { - Graft function }\end{array}$


Slakey 1993 (Continued)

- Infection

Notes $\quad$ Funding source: not reported

\section{Risk of bias}

\begin{tabular}{lll}
\hline Bias & Authors' judgement & Support for judgement \\
\hline $\begin{array}{l}\text { Random sequence genera- } \\
\text { tion (selection bias) }\end{array}$ & Unclear risk & Insufficient information to permit judgement \\
\hline $\begin{array}{l}\text { Allocation concealment } \\
\text { (selection bias) }\end{array}$ & Unclear risk & Insufficient information to permit judgement \\
\hline $\begin{array}{l}\text { Blinding of participants } \\
\text { and personnel (perfor- } \\
\text { mance bias) } \\
\text { All outcomes }\end{array}$ & Low risk & Unlikely to influence outcomes \\
\hline $\begin{array}{l}\text { Blinding of outcome as- } \\
\text { sessment (detection bias) }\end{array}$ & Low risk & \\
All outcomes & & Unlikely to influence outcomes \\
\hline $\begin{array}{l}\text { Incomplete outcome data } \\
\text { (attrition bias) }\end{array}$ & Low risk & All patient outcomes reported \\
\begin{tabular}{l} 
All outcomes \\
\hline $\begin{array}{l}\text { Selective reporting (re- } \\
\text { porting bias) }\end{array}$
\end{tabular} & Low risk & All expected outcomes reported \\
\hline \begin{tabular}{l} 
Other bias \\
\hline
\end{tabular} & Unclear risk & Funding not declared \\
\hline
\end{tabular}

\section{Smeekens 2013}

\begin{tabular}{|c|c|}
\hline Methods & $\begin{array}{l}\text { - Study design: parallel RCT; stratified by PRA and history of previous transplant } \\
\text { - Study duration: December } 2007 \text { to June } 2012 \\
\text { - Study follow-up: to } 6 \text { months }\end{array}$ \\
\hline Participants & $\begin{array}{l}\text { - Country: Netherlands } \\
\text { - Setting: single centre } \\
\text { - Inclusion criteria: LD or DD kidney transplant recipients; } 18 \text { years } \\
\text { - Number: treatment group (138); control group }(142) \\
\text { - Mean age } \pm \text { SD (years): treatment group }(50.8 \pm 13.2) \text {; control group }(49.8 \pm 12.3) \\
\text { - Sex (M): treatment group }(69.6 \%) \text {; control group }(63.4 \%) \\
\text { - LD/DD: treatment group ( } 58.7 / 41.3) \text {; control group }(57.0 / 43.0) \\
\text { - Ethnicity (white): treatment group }(94.9 \%) \text {; control group }(96.5 \%) \\
\text { - Exclusion criteria: HLA identical living donor; haemolytic uraemic syndrome as original kidney dis- } \\
\text { ease; focal segmental glomerulosclerosis that had recurred in a previous graft; } 3 \text { or more previously } \\
\text { failed grafts; a current or historic PRA }>85 \% \text {; total WCC }<3.0 \times 109 / \mathrm{L} \text {; platelet count }<75 \times 109 / \mathrm{L} \text {; active } \\
\text { infection with Hep B, Hep C or HIV; a history of tuberculosis; previous treatment with rituximab }\end{array}$ \\
\hline
\end{tabular}

Interventions

Treatment group

- Rituximab: single dose $375 \mathrm{mg} / \mathrm{m}^{2} \mathrm{IV}$ (500 mL bag) at the time of transplantation 
Smeekens 2013 (Continued)

\section{Control group}

- Placebo: identical $500 \mathrm{~mL}$ bag

Pre-med, immunosuppression and prophylaxis (both groups)

- PRED: $100 \mathrm{mg}$ at start of operation; $100 \mathrm{mg} / \mathrm{d}$ for 3 days; $15-5 \mathrm{mg} / \mathrm{d}$ and tapered to $0.1 \mathrm{mg} / \mathrm{kg} / \mathrm{d}$

- Clemastin: 2 mg at start of operation

- Standard antibiotic prophylaxis at start of operation

- TAC: $0.1 \mathrm{mg} / \mathrm{kg}$ twice daily, target trough 15 to $20 \mathrm{ng} / \mathrm{mL}$ for 2 weeks, then 10 to $15 \mathrm{ng} / \mathrm{mL}$ for 4 weeks, thereafter 5 to $10 \mathrm{ng} / \mathrm{mL}$

- MMF: $1000 \mathrm{mg}$ twice daily for 2 weeks, then $1500 \mathrm{mg} / \mathrm{d}$ thereafter (or $2000 \mathrm{mg}$ if weight $>90 \mathrm{~kg}$ ),

- Co-trimoxazole: $480 \mathrm{mg}$ daily for 3 months, then 3 times/week until 12 months

- Valganciclovir: for 3 months if CMV D+/R-

\begin{tabular}{ll}
\hline Outcomes & Biopsy-proven acute rejection \\
- Patient survival \\
- Graft survival \\
- Graft function $(\mathrm{CrCl})$ \\
- CAN \\
- Infection \\
- Malignancy \\
- Cost \\
\hline - Funding source: "Funding for the clinical trial was provided by Hoffmann-La Roche and Astellas Phar- \\
Notes
\end{tabular}

\section{Risk of bias}

\begin{tabular}{lll}
\hline Bias & Authors' judgement & Support for judgement \\
\hline $\begin{array}{l}\text { Random sequence genera- } \\
\text { tion (selection bias) }\end{array}$ & Low risk & $\begin{array}{l}\text { Computer generated list of random numbers, prepared by independent inves- } \\
\text { tigator }\end{array}$ \\
\hline $\begin{array}{l}\text { Allocation concealment } \\
\text { (selection bias) }\end{array}$ & Low risk & $\begin{array}{l}\text { Study numbers only available to authorised nurses who signed confidentiality } \\
\text { statements. Medication prepared by authorised nurses }\end{array}$ \\
\hline $\begin{array}{l}\text { Blinding of participants } \\
\text { and personnel (perfor- } \\
\text { mance bias) } \\
\text { All outcomes }\end{array}$ & Low risk & Medication in identical bags for rituximab and placebo \\
\hline
\end{tabular}

\begin{tabular}{lll}
\hline $\begin{array}{l}\text { Blinding of outcome as- } \\
\text { sessment (detection bias) } \\
\text { All outcomes }\end{array}$ & Low risk & Unlikely to influence outcomes \\
\hline $\begin{array}{l}\text { Incomplete outcome data } \\
\text { (attrition bias) } \\
\text { All outcomes }\end{array}$ & Low risk & All patient outcome data reported \\
\hline $\begin{array}{l}\text { Selective reporting (re- } \\
\text { porting bias) }\end{array}$ & Low risk & All expected outcomes reported \\
\hline $\begin{array}{l}\text { Other bias } \\
\text { Low risk }\end{array}$ & $\begin{array}{l}\text { None apparent. 'Both companies were informed of the results and had no role in } \\
\text { study design, data collection, analysis, interpretation or writing of the report.' }\end{array}$ \\
\hline
\end{tabular}


Spillner 1998

\begin{tabular}{ll}
\hline Methods & - Study design: parallel RCT \\
- Study duration: not reported \\
- Study follow-up: 1 year \\
\hline Participants & - Country: Germany \\
- Setting: single centre \\
- Inclusion criteria: 1st DD kidney transplant recipients; 18 to 60 years; cold ischaemia time $<48 \mathrm{~h}$ \\
- Number: not reported \\
- Mean age $\pm \mathrm{SD}$ (years): not reported \\
- Sex (M/F): not reported \\
- Exclusion criteria: history of malignancy; hyperimmunised patients; positive historical crossmatch
\end{tabular}

Treatment group
- Odulimomab: $30 \mathrm{mg}, 2 \mathrm{~h}$ pre-op. $15 \mathrm{mg} / \mathrm{d}$ for further 9 days.
- CSA: started day 9 at $8 \mathrm{mg} / \mathrm{kg} / \mathrm{d}$, then adjusted as per trough level
Control group
- CSA: $3 \mathrm{mg} / \mathrm{kg} / \mathrm{d}$ pre-op, then $8 \mathrm{mg} / \mathrm{kg} / \mathrm{d}$, as per trough level
Immunosuppression (both groups)
- AZA: 1.5 to $2 \mathrm{mg} / \mathrm{kg} / \mathrm{d}$
- PRED: $500 \mathrm{mg}$ in operating theatre, then $30 \mathrm{mg} / \mathrm{d}$, reduced by 5 mg every week to maintenance of 10
mg/d
- Acute rejection
- Patient survival
- Graft survival
- DGF
- Infections
- Graft function
- Acute rejection episodes recorded as 5 versus 12 episodes. Number of patients with acute rejection in
each group not specified (some patients may have had multiple episodes of acute rejection). Unable
to meta-analyse

\section{Risk of bias}

\begin{tabular}{lll}
\hline Bias & Authors' judgement & Support for judgement \\
\hline $\begin{array}{l}\text { Random sequence genera- } \\
\text { tion (selection bias) }\end{array}$ & Unclear risk & Insufficient information to permit judgement \\
\hline $\begin{array}{l}\text { Allocation concealment } \\
\text { (selection bias) }\end{array}$ & Unclear risk & Insufficient information to permit judgement \\
\hline $\begin{array}{l}\text { Blinding of participants } \\
\text { and personnel (perfor- } \\
\text { mance bias) }\end{array}$ & Low risk & Unlikely to influence outcomes \\
All outcomes & & \\
\hline
\end{tabular}

\begin{tabular}{l}
$\begin{array}{l}\text { Blinding of outcome as- } \\
\text { sessment (detection bias) }\end{array} \quad$ Low risk Unlikely to influence outcomes \\
\hline
\end{tabular}


Spillner 1998 (Continued)

All outcomes

Incomplete outcome data High risk $\quad$ All patient outcome data reported
(attrition bias)

(attrition bias)

All outcomes

Selective reporting (re- High risk Unable to meta-analyse acute rejection results
porting bias)

\begin{tabular}{lll}
\hline Other bias $\quad$ Unclear risk & Funding not reported
\end{tabular}

\section{Squifflet 1997}

\begin{tabular}{ll}
\hline Methods & - Study design: parallel RCT; stratified by 1st and 2nd graft \\
- Study duration: April 1995 to February 1996 \\
- Study follow-up: 6 months
\end{tabular}

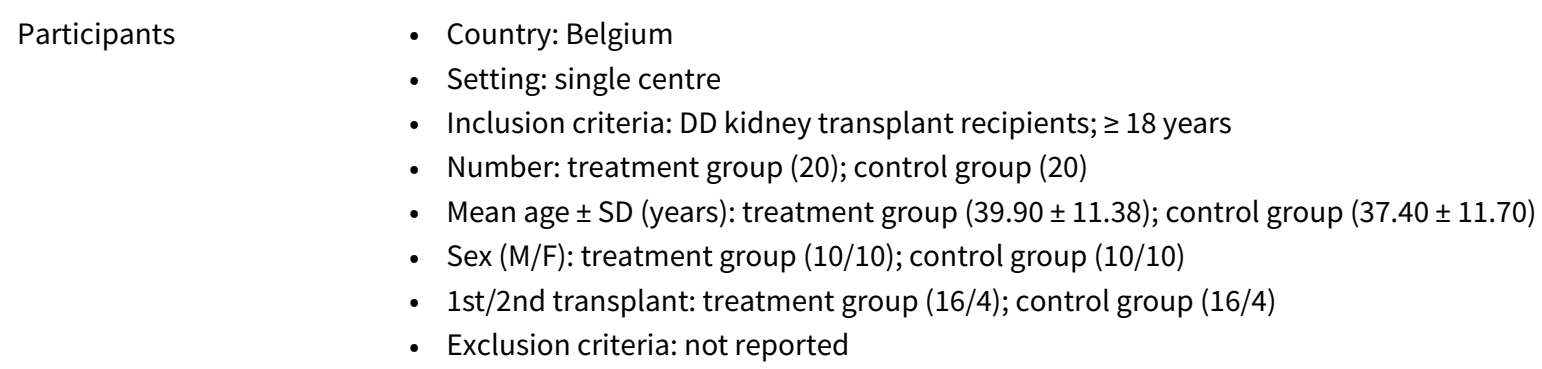

\begin{tabular}{ll}
\hline Treatment group \\
- Humanised anti-CD2 rat MAb: BTI-322 $5 \mathrm{mg} / \mathrm{d}$ IV for 10 days. 1st dose given in operating theatre prior \\
to vascular anastomosis \\
- MP: $250 \mathrm{mg}$ at unclamping and repeat $6 \mathrm{~h}$ later \\
- CSA, AZA, PRED as per control \\
Control group \\
- CSA: 3 to $8 \mathrm{mg} / \mathrm{kg} / \mathrm{d}$, adjust for trough 200 to $400 \mathrm{ng} / \mathrm{mL}$ \\
- AZA:' $1 \mathrm{mg} / \mathrm{kg} / \mathrm{d}$ \\
- PRED: $0.5 \mathrm{mg} / \mathrm{kg} / \mathrm{d}$ tapered to $0.1 \mathrm{mg} / \mathrm{kg} / \mathrm{d}$ by $9 \mathrm{months}$ \\
\hline - Patient survival \\
- Graft survival \\
- Biopsy-proven acute rejection \\
- Infection \\
- DGF \\
- Malignancy
\end{tabular}

\section{Risk of bias}

\begin{tabular}{lll}
\hline Bias & Authors' judgement & Support for judgement \\
\hline $\begin{array}{l}\text { Random sequence genera- } \\
\text { tion (selection bias) }\end{array}$ & Unclear risk & Insufficient information to permit judgement \\
\hline \hline
\end{tabular}


Squifflet 1997 (Continued)

$\begin{aligned} & \text { Allocation concealment } \\ & \text { (selection bias) }\end{aligned}$ Unclear risk Insufficient information to permit judgement

Blinding of participants Low risk Unlikely to influence outcomes

and personnel (perfor-

mance bias)

All outcomes

$\begin{array}{ll}\text { Blinding of outcome as- } & \text { Low risk }\end{array}$

(detection bias)

All outcomes

Incomplete outcome data Low risk All patient outcome data reported
(attrition bias)

All outcomes

Selective reporting (re- Low risk $\quad$ All expected outcomes reported
porting bias)

\begin{tabular}{lll}
\hline Other bias & High risk $\quad$ Supported by the manufacturers of BTI-322 \\
\hline
\end{tabular}

Steinmuller 1991

\begin{tabular}{ll}
\hline Methods & Study design: parallel RCT \\
& - Study duration: not reported \\
& - Study follow-up: 6 months \\
\hline Participants & Country: USA \\
- Setting: single centre \\
- Inclusion criteria: DD kidney transplant recipients; oliguria in first 24 to 36 hours; increase in SCr in 1 st \\
& 12 to 36 h post transplant \\
- Number: treatment group 1 (26); treatment group 2 (25) \\
- Mean age \pm SD (years): treatment group 1 (43.2 \pm 12.55$) ;$ treatment group 2 (42.5 \pm 10.9$)$ \\
- Sex (M/F): treatment group 1 (13/13); treatment group 2 (17/8) \\
- Exclusion criteria: not reported
\end{tabular}

Interventions

Treatment group 1

- ALG (Minnesota): 10 to $20 \mathrm{mg} / \mathrm{kg} / \mathrm{d}$ IV via CVC, dose adjusted CD2 and CD3 counts (aim to maintain at 20 to 40 cells/mm or below), stopped after 2 or 3 day overlap with CSA

Treatment group 2

- OKT3: initial dose $5 \mathrm{mg}$, dose adjust between 5 to $10 \mathrm{mg}$, depending on CD3 suppression (aim for 10 to 20 cells $/ \mathrm{mm}$ ), stopped after 2 or 3 day overlap with CSA

Immunosuppression (both groups)

- CSA: started when SCr decreasing and urine output established, adjusted for trough of 150 to $300 \mathrm{ng} /$ $\mathrm{mL}$ for month 1 , then 100 to $200 \mathrm{ng} / \mathrm{mL}$ thereafter

- AZA: 1 to $1.5 \mathrm{mg} / \mathrm{kg}$, adjusted as per WCC

- PRED: $30 \mathrm{mg} / \mathrm{d}$, tapered after 1 month

Outcomes

- Death

- Graft loss 
Steinmuller 1991 (Continued)

- Acute rejection

- Infection

- Side effects

Notes $\quad$ Funding source: not reported

\section{Risk of bias}

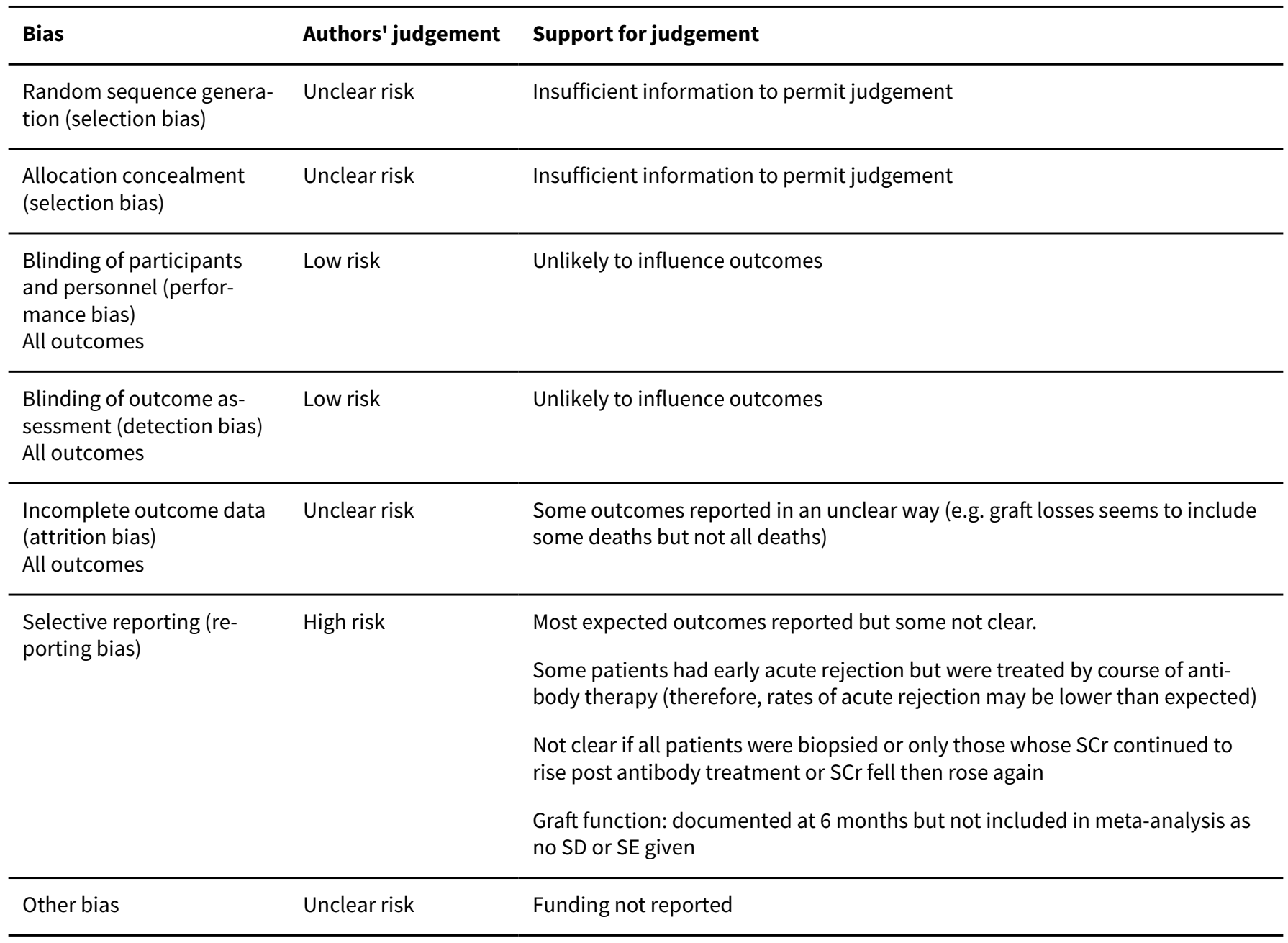

\section{Stevens 2008}

\begin{tabular}{ll}
\hline Methods & Study design: parallel RCT; stratified into 6 groups: white versus non-white, DD versus LD; listed for \\
& pancreas after kidney versus not listed \\
& - Study duration: April 2004 to December 2007 \\
- Study follow-up: 6 months & \\
\hline Participants & Country: USA \\
- Setting: single centre \\
- Inclusion criteria: 18 to 64 years; LD or DD kidney transplant recipients; 1 st or repeat transplant \\
- Number (analysed/randomised): treatment group 1 (70/79); treatment group 2 (72/81) \\
- Mean age \pm SD (years): treatment group 1 (45.5 \pm 12.4$) ;$ treatment group 2 (49.3 \pm 10.5$)$ \\
- Sex (M/F): treatment group 1 (46/24); treatment group 2 (45/27) \\
- White-Asian/other: treatment group 1 (62/8); treatment group 2 (61/11)
\end{tabular}

Polyclonal and monoclonal antibodies for induction therapy in kidney transplant recipients (Review) 
Stevens 2008 (Continued)

- LD/DD: treatment group 1 (30/40); treatment group 2 (31/41)

- Exclusion criteria: > 65 years; PRA > 75\%; HLA-identical recipients; required chronic steroids

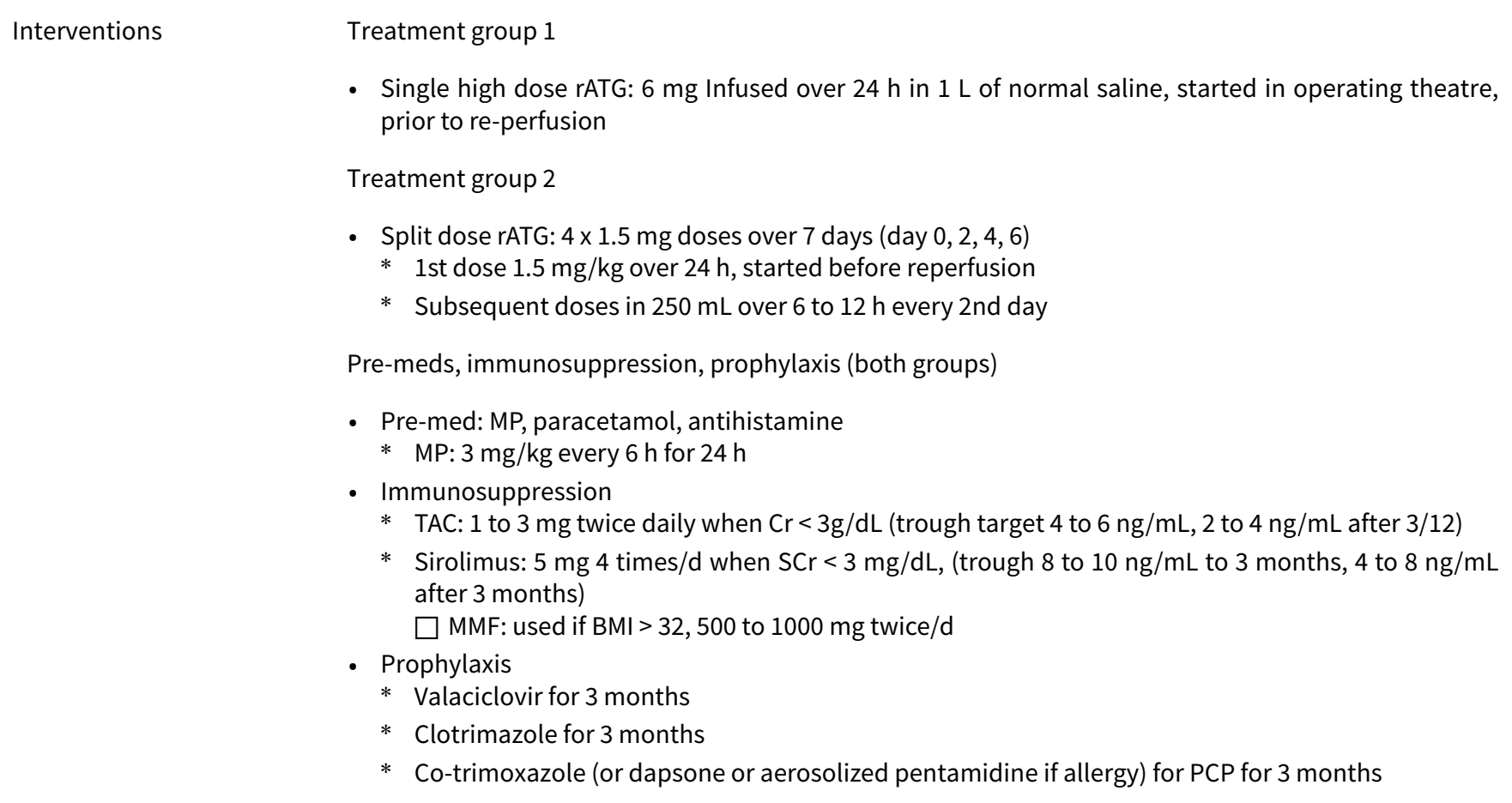

\begin{tabular}{ll}
\hline Outcomes & Kidney function (eGFR) \\
- & CAN by protocol biopsy at 6 months \\
- & Biopsy-proven acute rejection \\
- & Patient survival \\
- & Graft survival \\
- Safety profile & NODAT \\
\hline - Switch in maintenance immunosuppression at 6 months. Either CNI withdrawal and switch to MMF or \\
continued on TAC. $50 \%$ of each group. These results not reported, therefore outcomes only to $6 / 12$ \\
- Funding source: "supported by the Ann Goldstein-Cheryl Cooper New Frontiers in Transplant Medi- \\
cine Fund, a Research Support Fund grant from the Nebraska Medical Center and the University of \\
Nebraska Medical Center and an unrestricted research grant from Genzyme, Inc"
\end{tabular}

\section{Risk of bias}

\begin{tabular}{lll}
\hline Bias & Authors' judgement & Support for judgement \\
\hline $\begin{array}{l}\text { Random sequence genera- } \\
\text { tion (selection bias) }\end{array}$ & Low risk & $\begin{array}{l}\text { 'Randomly generated treatment group assignments' after stratification into 6 } \\
\text { different groups }\end{array}$ \\
\hline $\begin{array}{l}\text { Allocation concealment } \\
\text { (selection bias) }\end{array}$ & Low risk & 'Sequentially numbered sealed envelopes'. \\
\hline $\begin{array}{l}\text { Blinding of participants } \\
\text { and personnel (perfor- } \\
\text { mance bias) } \\
\text { All outcomes }\end{array}$ & Low risk & Unlikely to influence outcomes \\
\hline
\end{tabular}


Stevens 2008 (Continued)
Blinding of outcome as-
Low risk
All patient outcome data reported

sessment (detection bias)

All outcomes

\begin{tabular}{|c|c|c|}
\hline $\begin{array}{l}\text { Incomplete outcome data } \\
\text { (attrition bias) }\end{array}$ & Low risk & $\begin{array}{l}\text { Missing outcome data balanced in numbers across intervention groups, with } \\
\text { similar reasons for missing data across groups }\end{array}$ \\
\hline
\end{tabular}

All outcomes

similar reasons for missing data across groups

$\begin{array}{lll}\begin{array}{l}\text { Selective reporting (re- } \\ \text { porting bias) }\end{array} & \text { High risk } & \begin{array}{l}\text { Primary outcomes not well reported (graphs only, no figures reported for kid- } \\ \text { ney function) }\end{array}\end{array}$

Other bias Unclear risk Partly funded by Genzyme with unrestricted grant. (but ATG in both arms)

\section{Taylor 1976}

\begin{tabular}{ll}
\hline Methods & Study design: parallel RCT \\
- Study duration: not reported \\
- Study follow-up: 12 months \\
RCT \\
Multicentre - 12 centres across Canada \\
12 month follow up \\
- Country: Canada \\
- Setting: multicentre (12) \\
- Inclusion criteria: DD kidney transplant recipients \\
- Number: treatment group (87); control group (92) \\
- Mean age \pm SD (years): not reported \\
- Sex (M/F): not reported \\
- Exclusion criteria: ABO incompatibility; positive direct crossmatch; previous ALG therapy; positive skin \\
\end{tabular}

Interventions

\section{Treatment group}

- Horse ALG: $20 \mathrm{mg} / \mathrm{kg}$ IV over $8 \mathrm{~h}$ once/d for 10 days, starting post-op (some via CVC, some via AVF)

Control group

- No ALG

Immunosuppression (both groups)

- As per treating physician, could include:

* AZA

* PRED/hydrocortisone

* Actinomycin D

* Graft radiation

- 'Dose adjusted according to progress'

\begin{tabular}{ll}
\hline Outcomes & Death \\
- Graft loss \\
- Acute rejection \\
- Other complications
\end{tabular}


Taylor 1976 (Continued)

Notes - Funding source: Medical Research Council, Canada

\section{Risk of bias}

\begin{tabular}{|c|c|c|}
\hline Bias & Authors' judgement & Support for judgement \\
\hline $\begin{array}{l}\text { Random sequence genera- } \\
\text { tion (selection bias) }\end{array}$ & Low risk & Table of random numbers used \\
\hline $\begin{array}{l}\text { Allocation concealment } \\
\text { (selection bias) }\end{array}$ & Low risk & sealed envelopes with patient allocations, only opened during operation \\
\hline $\begin{array}{l}\text { Blinding of participants } \\
\text { and personnel (perfor- } \\
\text { mance bias) } \\
\text { All outcomes }\end{array}$ & Low risk & Unlikely to influence outcomes \\
\hline $\begin{array}{l}\text { Blinding of outcome as- } \\
\text { sessment (detection bias) } \\
\text { All outcomes }\end{array}$ & Unclear risk & $\begin{array}{l}\text { Insufficient information to permit judgement, in particular, not clear how } \\
\text { acute rejection episodes were diagnosed and what made them a minor versus } \\
\text { a major acute rejection episode }\end{array}$ \\
\hline $\begin{array}{l}\text { Incomplete outcome data } \\
\text { (attrition bias) } \\
\text { All outcomes }\end{array}$ & Low risk & All patient outcome data reported \\
\hline $\begin{array}{l}\text { Selective reporting (re- } \\
\text { porting bias) }\end{array}$ & High risk & $\begin{array}{l}\text { All expected outcomes reported; graft function reported at } 60 \text { days but not } \\
\text { able to be used in analyses of this review as no SD or SE given }\end{array}$ \\
\hline Other bias & Low risk & Appears free of other bias; funding by Medical Research Council, Canada \\
\hline
\end{tabular}

Thibaudin 1998

\begin{tabular}{|c|c|}
\hline Methods & $\begin{array}{l}\text { - Study design: parallel RCT; stratified by PRA into } 5 \text { groups } \\
\text { - Study duration: } 1991 \text { to } 1995 \\
\text { - Study follow-up: median } 25 \text { months }\end{array}$ \\
\hline Participants & $\begin{array}{l}\text { - } \text { Country: France } \\
\text { - Setting: single centre } \\
\text { - Inclusion criteria: adult LD or DD sensitised kidney transplant recipients; } 1 \text { st or } 2 \text { nd graft } \\
\text { - Number: treatment group ( } 47) \text {; control group }(42) \\
\text { - Mean age } \pm \text { SD (years): treatment group }(47 \pm 12) \text {; control group }(46 \pm 13) \\
\text { - Sex (M/F): treatment group ( } 28 / 19) \text {; control group }(30 / 12) \\
\text { - LD/DD: treatment group }(0 / 47) ; \text { control group }(/ 42) \\
\text { - } 1 \text { st/2nd transplant: treatment group }(34 / 13) ; \text { control group }(26 / 16) \\
\text { - Exclusion criteria: 3rd grafts; grafts performed against a positive historical T-cell crossmatch }\end{array}$ \\
\hline Interventions & $\begin{array}{l}\text { Treatment group } \\
\text { - rATG (Pasteur-Merieux): } 1.25 \mathrm{mg} / \mathrm{kg} / \mathrm{d} \text {, given once } / \mathrm{d} \text { for } 10 \text { days, dose adjusted by CD2 and CD3 counts, } \\
\text { done } 3 \text { times/week } \\
\text { - AZA: only introduced when ATG stopped } \\
\text { - CSA and PRED: as per control } \\
\text { Control group }\end{array}$ \\
\hline
\end{tabular}


Thibaudin 1998 (Continued)

- CSA: started pre-op at oral equivalent of $14 \mathrm{mg} / \mathrm{kg} / \mathrm{d}$, tapered every 2 nd day to $8 \mathrm{mg} / \mathrm{kg} / \mathrm{day}$ by end of week 1 , adjusted per trough of 100 to $300 \mu \mathrm{g} / \mathrm{L}$

- PRED: $30 \mathrm{mg} / \mathrm{d}$

- AZA: $2 \mathrm{mg} / \mathrm{kg} / \mathrm{d}$

\begin{tabular}{ll}
\hline Outcomes & Death \\
& - Graft survival \\
- Acute rejection & Side effects \\
- Graft function & \\
\hline Notes & - Time frame for some outcomes not entirely clear as not all patients followed to same time point \\
\hline
\end{tabular}

\section{Risk of bias}

\begin{tabular}{|c|c|c|}
\hline Bias & Authors' judgement & Support for judgement \\
\hline $\begin{array}{l}\text { Random sequence genera- } \\
\text { tion (selection bias) }\end{array}$ & Unclear risk & Insufficient information to permit judgement \\
\hline $\begin{array}{l}\text { Allocation concealment } \\
\text { (selection bias) }\end{array}$ & Unclear risk & Insufficient information to permit judgement \\
\hline $\begin{array}{l}\text { Blinding of participants } \\
\text { and personnel (perfor- } \\
\text { mance bias) } \\
\text { All outcomes }\end{array}$ & Low risk & Unlikely to influence outcomes \\
\hline $\begin{array}{l}\text { Blinding of outcome as- } \\
\text { sessment (detection bias) } \\
\text { All outcomes }\end{array}$ & Unclear risk & $\begin{array}{l}\text { Unlikely to influence outcomes } \\
\text { Not all acute rejection was biopsy proven ( } 72 \% \text { in ATG group and } 90 \% \text { in con- } \\
\text { trol) }\end{array}$ \\
\hline $\begin{array}{l}\text { Incomplete outcome data } \\
\text { (attrition bias) } \\
\text { All outcomes }\end{array}$ & Low risk & All patient outcome data reported \\
\hline $\begin{array}{l}\text { Selective reporting (re- } \\
\text { porting bias) }\end{array}$ & Low risk & All expected outcomes reported \\
\hline Other bias & Unclear risk & Funding source not reported \\
\hline
\end{tabular}

\section{Thomas 1977}

\begin{tabular}{ll} 
Methods & Study design: quasi-RCT \\
& - Study duration: January 1974 to May 1976 \\
& - Study follow-up: 1 to 3 years \\
\hline Participants & - Country: USA \\
- Setting: single centre \\
- Inclusion criteria: DD kidney transplant recipients aged 14 to 55 years \\
- Mean age (years): treatment group (38.79); control group (37.65)
\end{tabular}


Thomas 1977 (Continued)

- Sex (F): treatment group (35\%); control group (19\%)

- 1st transplant: treatment group (82\%); control group (78\%)

- Exclusion criteria: abnormal lower urinary tract

\begin{tabular}{ll}
\hline Interventions & Treatment group \\
- & High potency ALG: $1.5 \mathrm{mg} / \mathrm{kg} / \mathrm{d}$ IM for 5 days \\
Control group \\
- Low potency (group A) ALG: $1.5 \mathrm{mg} / \mathrm{kg} / \mathrm{d}$ IM for 5 days \\
Immunosuppression (both groups) \\
- AZA: 2 to $3 \mathrm{mg} / \mathrm{kg}$ \\
- PRED: $1 \mathrm{mg} / \mathrm{kg} / \mathrm{d}$ reduced to a mean 0 to $0.5 \mathrm{mg} / \mathrm{kg} / \mathrm{d}$ by 1 month \\
\hline - Acute rejection \\
- Death \\
- Graft loss \\
\hline - Funding source: supported in part BY NIH grants IRO Al12822-01 and R01 Al12586-01
\end{tabular}

\section{Risk of bias}

\begin{tabular}{lll}
\hline Bias & Authors' judgement & Support for judgement \\
\hline $\begin{array}{l}\text { Random sequence genera- } \\
\text { tion (selection bias) }\end{array}$ & High risk & 'randomisation usually on an alternate basis but not necessarily so'
\end{tabular}

\begin{tabular}{|c|c|c|}
\hline $\begin{array}{l}\text { Allocation concealment } \\
\text { (selection bias) }\end{array}$ & Unclear risk & Insufficient information to permit judgement \\
\hline $\begin{array}{l}\text { Blinding of participants } \\
\text { and personnel (perfor- } \\
\text { mance bias) } \\
\text { All outcomes }\end{array}$ & Low risk & $\begin{array}{l}\text { Reported as double blind "neither medical nor nursing staff aware of which } \\
\text { letter group was high potency (H.P.-A.L.G.) and which was moderate potency } \\
\text { (M.P.-A.L.G.)" Labelled group A and group B - low risk given hard outcomes }\end{array}$ \\
\hline $\begin{array}{l}\text { Blinding of outcome as- } \\
\text { sessment (detection bias) } \\
\text { All outcomes }\end{array}$ & Low risk & Unlikely to influence outcomes \\
\hline $\begin{array}{l}\text { Incomplete outcome data } \\
\text { (attrition bias) } \\
\text { All outcomes }\end{array}$ & Unclear risk & $\begin{array}{l}\text { Five patients excluded due to inadvertent major deviations from standard pro- } \\
\text { tocol }\end{array}$ \\
\hline
\end{tabular}

$\begin{aligned} & \text { Selective reporting (re- High risk } \\ & \text { porting bias) }\end{aligned}$

\begin{tabular}{ll}
\hline Other bias $\quad$ Low risk $\quad$ None apparent. Funded in part by $2 \times$ NIH grants \\
\hline
\end{tabular}

Thomas 2007

$\begin{array}{ll}\text { Methods } & \text { - Study design: parallel RCT } \\ \text { - Study duration: January } 2005 \text { to May } 2006 \\ \text { - Study follow-up: } 12 \text { months }\end{array}$


Thomas 2007 (Continued)
Participants
- Country: USA
- Setting: single centre
- Inclusion criteria: "high risk" DD kidney transplant recipients (either PRA > 20\% or previous failed transplant)
- Number: treatment group 1 (11); treatment group 2 (8)
- Mean age \pm SEM (years): treatment group 1 (43.5 \pm 4.1$)$; treatment group 2 (47.1 \pm 4.2$)$
- Sex (M/F): treatment group 1 (6/5); treatment group 2 (2/6)
- Caucasian/African-American/Hispanic/Asian): treatment group $1(5 / 2 / 4 / 0)$; treatment group 2 $(1 / 2 / 4 / 1)$
- Exclusion criteria: not reported

\begin{tabular}{|c|c|}
\hline Interventions & $\begin{array}{l}\text { Treatment group } 1 \\
\text { - Alemtuzumab: } 30 \mathrm{mg} \text { single dose, before reperfusion } \\
\text { - TAC: from day } 1 \text { post-op, trough target of } 10 \mathrm{ng} / \mathrm{mL} \\
\text { Treatment group } 2 \\
\text { - ATG: } 1.5 \mathrm{mg} / \mathrm{kg} \text { ATG pre-op; } 1.5 \mathrm{mg} / \mathrm{kg} / \mathrm{d} \text { for } 4 \text { days } \\
\text { - PRED: } 250 \mathrm{mg} \text { MP with } 2 \mathrm{nd} \text { dose of ATG; Oral PRED day } 3,50 \mathrm{mg} \text { twice daily, tapered to } 10 \mathrm{mg} \text { over } \\
5 \text { days } \\
\text { - MMF: started pre-op (dose not specified) } \\
\text { - TAC: started when } \mathrm{Cr}<3.0 \mathrm{~g} / \mathrm{dL} \text { or day } 3 \text { post-op (whichever earlier); trough target } 10 \mathrm{ng} / \mathrm{mL}\end{array}$ \\
\hline Outcomes & $\begin{array}{l}\text { - } \text { Death } \\
\text { - Graft loss } \\
\text { - Acute rejection }\end{array}$ \\
\hline Notes & $\begin{array}{l}\text { - } 2 \text { patients withdrew after randomisation and were excluded } \\
\text { - Infection reported but not able to be included in review analyses as reported as total numbers only } \\
\text { (number of patients with infections not reported). Results as follows: } \\
\text { * Alemtuzumab: UTI (9), wound (2), infected seroma (1), skin pustules (1) } \\
\text { * ATG: UTI (4), wound (1), colitis (1), west Nile virus meningitis (1) } \\
\text { - Funding source: not reported }\end{array}$ \\
\hline
\end{tabular}

\section{Risk of bias}

\begin{tabular}{lll}
\hline Bias & Authors' judgement & Support for judgement \\
\hline $\begin{array}{l}\text { Random sequence genera- } \\
\text { tion (selection bias) }\end{array}$ & Unclear risk & Insufficient information to permit judgement \\
\hline $\begin{array}{l}\text { Allocation concealment } \\
\text { (selection bias) }\end{array}$ & Unclear risk & Insufficient information to permit judgement \\
\hline $\begin{array}{l}\text { Blinding of participants } \\
\text { and personnel (perfor- } \\
\text { mance bias) }\end{array}$ & Low risk & Unlikely to influence outcomes \\
$\begin{array}{l}\text { All outcomes } \\
\text { Blinding of outcome as- } \\
\text { sessment (detection bias) } \\
\text { All outcomes }\end{array}$ & Low risk & Unlikely to influence outcomes \\
\hline $\begin{array}{l}\text { Incomplete outcome data } \\
\text { (attrition bias) }\end{array}$ & Low risk & All patient outcome data reported \\
\hline
\end{tabular}


Thomas 2007 (Continued)

All outcomes

Selective reporting (re- High risk Unable to analyse infection data
porting bias)

Other bias Unclear risk Funding source not reported

Toledo-Pereyra 1985

\begin{tabular}{ll}
\hline Methods & - Study design: parallel RCT \\
& - Study duration: not reported \\
& Study follow-up: 1 year \\
\hline Participants & Country: USA \\
- Setting: single centre \\
- Inclusion criteria: 1st DD kidney transplant recipients \\
- Mean age (years): treatment group 1 (47); treatment group $2(42)$ \\
- Sex (M/F): treatment group $1(18 / 7) ;$ treatment group $2(16 / 9)$ \\
- Black/white: treatment group $1(11 / 14)$; treatment group $2(5 / 20)$ \\
- Exclusion criteria: not reported
\end{tabular}

Interventions

Treatment group 1

- Horse or goat ALG: $20 \mathrm{mg} / \mathrm{kg} / \mathrm{d}$, starting 1 day post-op, for 14 days; adjust as per WCC and platelets (dose 5 to $20 \mathrm{mg} / \mathrm{kg} / \mathrm{d}$ )

* Dose adjusted if platelets fell to 50 to $100 \times 10^{3} / \mathrm{mm}^{3}$, or WCC 3000 to $5000 / \mathrm{mm}^{3}$

* Stopped if platelets $<50,000 / \mathrm{mm}^{3}$ or WCC $<3000 / \mathrm{mm}^{3}$

Treatment group 2

- hATG: up to $15 \mathrm{mg} / \mathrm{kg} / \mathrm{d}$, started 1 day post-op, continued for 14 days at dose 5 to $15 \mathrm{mg} / \mathrm{kg} / \mathrm{d}$

* Dose adjusted if platelets fell to 50 to $100 \times 10^{3} / \mathrm{mm}^{3}$, or WCC 3000 to $5000 / \mathrm{mm}^{3}$

* Stopped if platelets $<50,000 / \mathrm{mm}^{3}$ or WCC $<3000 / \mathrm{mm}^{3}$

Immunosuppression (both groups)

- AZA $5 \mathrm{mg} / \mathrm{kg} / \mathrm{d}$ on 1 st day post-op, then 1 to $2.5 \mathrm{mg} / \mathrm{kg} / \mathrm{d}$ as per WCC

- PRED: $1 \mathrm{mg} / \mathrm{kg} / \mathrm{d}$, reduced to 20 to $25 \mathrm{mg} / \mathrm{d}$ by $3 \mathrm{rd}$ or 4 th week

\begin{tabular}{ll}
\hline Outcomes & Death \\
& $\cdot$ Graft loss \\
& - Acute rejection \\
& Side effects \\
\hline Notes & - Funding source: not reported
\end{tabular}

\section{Risk of bias}

\begin{tabular}{lll}
\hline Bias & Authors' judgement & Support for judgement \\
\hline $\begin{array}{l}\text { Random sequence genera- } \\
\text { tion (selection bias) }\end{array}$ & Unclear risk & Insufficient information to permit judgement \\
\hline
\end{tabular}


Toledo-Pereyra 1985 (Continued)

\begin{tabular}{l}
$\begin{array}{l}\text { Allocation concealment } \\
\text { (selection bias) }\end{array}$ \\
\hline
\end{tabular}

\begin{tabular}{|c|c|c|}
\hline $\begin{array}{l}\text { Blinding of participants } \\
\text { and personnel (perfor- } \\
\text { mance bias) } \\
\text { All outcomes }\end{array}$ & Low risk & Unlikely to influence outcomes \\
\hline $\begin{array}{l}\text { Blinding of outcome as- } \\
\text { sessment (detection bias) } \\
\text { All outcomes }\end{array}$ & Low risk & Unlikely to influence outcomes \\
\hline $\begin{array}{l}\text { Incomplete outcome data } \\
\text { (attrition bias) } \\
\text { All outcomes }\end{array}$ & Low risk & All patient outcome data reported \\
\hline $\begin{array}{l}\text { Selective reporting (re- } \\
\text { porting bias) }\end{array}$ & Low risk & All expected outcomes reported \\
\hline Other bias & Unclear risk & Funding source not reported \\
\hline
\end{tabular}

\section{TRIMS Study 2010}

\begin{tabular}{|c|c|}
\hline Methods & $\begin{array}{l}\text { - Study design: parallel RCT; 2:1 randomisation } \\
\text { - Study duration: October } 2003 \text { to December } 2004 \\
\text { - Study follow-up: } 1 \text { year }\end{array}$ \\
\hline Participants & $\begin{array}{l}\text { - Country: USA } \\
\text { - Setting: multicentre (17) } \\
\text { - Inclusion criteria: LD kidney transplant recipients > } 18 \text { years; PRA < } 20 \% \\
\text { - Number: treatment group (103); control group (48) } \\
\text { - Mean age } \pm \text { SD (years): treatment group }(45.7 \pm 13.65) \text {; control group }(45.8 \pm 13.04) \\
\text { - Sex (M/F): treatment group }(61 / 42) \text {; control group }(27 / 21) \\
\text { - Caucasian/African American/Hispanic/Asian or other: treatment group }(65 / 13 / 19 / 6 / 1) \text {; control group } \\
\text { ( } 31 / 9 / 3 / 5 / 0) \\
\text { - Prior transplant: treatment group (1); control group (0) } \\
\text { - Exclusion criteria: HLA identical matched living-donor transplant recipient; }>2 \text { previous kidney trans- } \\
\text { plants; loss of first kidney transplant within one year; current PRA }>20 \% \text {; history of a positive cross- } \\
\text { match with the donor; donor or recipient serology positive for either HIV, HBV. HCV; chronic corticos- } \\
\text { teroids use except for inhaled corticosteroids to treat asthma; use of any investigational products } \\
\text { during the } 90 \text { d prior to screening; requirement for multiple organ transplant; subject without a func- } \\
\text { tioning urinary bladder; known contraindication to administration of rATG; currently abusing drugs } \\
\text { or alcohol, or patients at high risk for poor compliance or with significant medical or psychosocial } \\
\text { problems or unstable disease states that would warrant exclusion from the study in the opinion of } \\
\text { individual investigators }\end{array}$ \\
\hline
\end{tabular}

Interventions

Treatment group

- ATG: 5 to $6 \mathrm{mg} / \mathrm{kg}$ total dose, given in 4 equal divided doses over 4 days (spread over 7 days maximum if any delayed doses)

- PRED-MP: MP $500 \mathrm{mg}$ day 0 , then $1 \mathrm{mg} / \mathrm{kg}$ PRED tapered to $0.25 \mathrm{mg} / \mathrm{kg}$ by day 6 , then stopped

Control group

- PRED-MP: $500 \mathrm{mg}$ MP, then PRED $1 \mathrm{mg} / \mathrm{kg}$, tapered as per local protocol to minimum of $5 \mathrm{mg} / \mathrm{d}$ 
TRIMS Study 2010 (Continued)

Immunosuppression (both groups)

- TAC: $0.1 \mathrm{mg} / \mathrm{kg} / \mathrm{d}$, started within $24 \mathrm{~h}$ of operation, trough as per local protocol

- MMF: $1000 \mathrm{mg}$ day 0 , then $1 \mathrm{~g}$ twice daily till day 4, then as per local protocol

Prophylaxis (both groups)

- CMV: valganciclovir or ganciclovir if donor CMV +ve for 6 months. If recipient +ve but donor -ve, or both -ve received acyclovir for 3 months

- PCP: as per local protocol

\begin{tabular}{ll}
\hline Outcomes & Biopsy-proven acute rejection ( 6 and 12 months) \\
- Graft loss ( 6 and 12 months) \\
- Death ( 6 and 12 months) \\
- DGF \\
- Graft function \\
- Adverse events \\
- NODAT \\
\hline Notes & Funding source: sponsored by Genzyme
\end{tabular}

\section{Risk of bias}

Bias Authors' judgement Support for judgement

Random sequence genera- Unclear risk Insufficient information to permit judgement
tion (selection bias)

Allocation concealment Unclear risk Insufficient information to permit judgement
(selection bias)

Blinding of participants Low risk Unlikely to influence outcomes
and personnel (perfor-
mance bias)
All outcomes

Blinding of outcome as- Low risk Unlikely to influence outcomes
sessment (detection bias)

All outcomes

Incomplete outcome data Low risk All patient outcome data reported
(attrition bias)
All outcomes

\begin{tabular}{lll}
\hline $\begin{array}{l}\text { Selective reporting (re- } \\
\text { porting bias) }\end{array}$ & Low risk & All expected outcomes reported \\
\hline Other bias & High risk & Sponsored by Genzyme (rATG manufacturers) \\
& $\begin{array}{l}\text { NB: enrolment stopped early at 151 patients (planned to enrol 200) by study } \\
\text { sponsor - due to 'budget reasons' }\end{array}$ \\
\hline
\end{tabular}

Tsai 2012

\begin{tabular}{ll}
\hline Methods & - Study design: parallel RCT \\
& - Study duration: not reported \\
\hline
\end{tabular}


Tsai 2012 (Continued)

$$
\text { - Study follow-up: } 6 \text { months }
$$

\begin{tabular}{ll}
\hline Participants & Country: Taiwan \\
& - Setting: single centre \\
- Inclusion criteria: non-sensitised (PRA < 20\%), HLA-mismatched DD kidney transplant recipients \\
- Number: treatment group 1 (15); treatment group 2 (15); control group (16) \\
- Sex (M/F): $23 / 23$ \\
- Exclusion criteria: not reported
\end{tabular}

\begin{tabular}{|c|c|}
\hline Interventions & $\begin{array}{l}\text { Treatment group } 1 \\
\text { - Rituximab: single dose of } 375 \mathrm{mg} / \mathrm{m}^{2} \text { during surgery } \\
\text { - TAC: dose/trough level not reported } \\
\text { - Steroids: dose not reported } \\
\text { Treatment group } 2 \\
\text { - Rituximab: single dose of } 375 \mathrm{mg} / \mathrm{m}^{2} \text { during surgery } \\
\text { - Steroids: dose not reported } \\
\text { - MMF: dose between } 1000 \text { and } 2000 \mathrm{mg} / \mathrm{d} \text { to keep WCC between } 4000 \text { and } 6000 / \mathrm{mm}^{3} \\
\text { - TAC: dose/trough level not reported } \\
\text { Control group } \\
\text { - No induction } \\
\text { - Steroids: dose not reported } \\
\text { - MMF: dose between } 1000 \text { and } 2000 \mathrm{mg} / \mathrm{d} \text { to keep WCC between } 4000 \text { and } 6000 / \mathrm{mm}^{3} \\
\text { - TAC: dose/trough level not reported }\end{array}$ \\
\hline Outcomes & $\begin{array}{l}\text { - } \text { Acute rejection } \\
\text { - Infection } \\
\text { - Graft function }\end{array}$ \\
\hline Notes & $\begin{array}{l}\text { - Abstract-only publication } \\
\text { - Treatment group } 2 \text { and control group compared } \\
\text { - Funding source: not reported }\end{array}$ \\
\hline
\end{tabular}

\section{Risk of bias}

\begin{tabular}{lll}
\hline Bias & Authors' judgement & Support for judgement \\
\hline $\begin{array}{l}\text { Random sequence genera- } \\
\text { tion (selection bias) }\end{array}$ & Unclear risk & Insufficient information to permit judgement \\
\hline $\begin{array}{l}\text { Allocation concealment } \\
\text { (selection bias) }\end{array}$ & Unclear risk & Insufficient information to permit judgement \\
\hline $\begin{array}{l}\text { Blinding of participants } \\
\text { and personnel (perfor- } \\
\text { mance bias) } \\
\text { All outcomes }\end{array}$ & Low risk & Unlikely to influence outcomes \\
\hline $\begin{array}{l}\text { Blinding of outcome as- } \\
\text { sessment (detection bias) } \\
\text { All outcomes }\end{array}$ & Low risk & \\
\hline
\end{tabular}


Tsai 2012 (Continued)
Incomplete outcome data
Unclear risk
Insufficient information to permit judgement
(attrition bias)

All outcomes

Selective reporting (re- High risk
porting bias)

Other bias High risk Abstract only. Funding source unknown

Turcotte 1973

\begin{tabular}{ll}
\hline Methods & - Study design: parallel RCT, stratified by LD or DD \\
& - Study duration: March 1964 to November 1972 \\
\hline Participants & - Country: USA \\
- Setting: single centre \\
- Inclusion criteria: LD (all intra-familial) or DD kidney transplant recipients \\
- Number: treatment group (36); control group (35) \\
- Mean age \pm SD (years): not reported \\
- Sex (M/F): not reported \\
- LD/DD: treatment group (17/19); control group (18/17) \\
- Exclusion criteria: not reported
\end{tabular}

Interventions

Treatment group

- hATG: once/day via IM, starting 3 days pre-op for LD or immediately pre-transplant for DD, $3.5 \mathrm{mg} / \mathrm{kg} /$ $\mathrm{d}$ prior and for 7 days post-op, $1.8 \mathrm{mg} / \mathrm{kg}$ days 8 to $21,0.9 \mathrm{mg} / \mathrm{kg}$ days 22 to 35

- AZA: $3 \mathrm{mg} / \mathrm{kg}$ immediately post-op adjust as per WCC

- PRED: $0.6 \mathrm{mg} / \mathrm{kg} / \mathrm{d}$ for LD and $1.2 \mathrm{mg} / \mathrm{kg} / \mathrm{d}$ for DD, by week $80.5 \mathrm{mg} / \mathrm{kg}$ for $\mathrm{LD}$ and $0.75 \mathrm{mg} / \mathrm{kg}$ for DD

Control group

- AZA: $3 \mathrm{mg} / \mathrm{kg}$ immediately post-op adjust as per WCC

- PRED: double dose of treatment group, more rapid taper over 8 weeks, by week $80.5 \mathrm{mg} / \mathrm{kg}$ for LD and $0.75 \mathrm{mg} / \mathrm{kg}$ for DD

\begin{tabular}{ll}
\hline Outcomes & Patient survival \\
- Graft survival \\
- Graft function \\
- Complications \\
- Acute rejection
\end{tabular}

Notes

- Acute rejection: reported in study but not included in the review analyses as reported as total number of acute rejection episodes (rather than total number of patients with acute rejection)

- Infection: reported as total episodes rather than number of patients

- Adverse reactions to ATG: all had high fevers; urticarial (9), anaphylaxis ('mild') (2), serum sickness (1)

- Stopped early days 32 and 33 (2)

- Funding source: hATG provided by Upjohn Co; Maud T. Lane Fund and research grant from Public Health Service

\section{Risk of bias}


Turcotte 1973 (Continued)

\begin{tabular}{|c|c|c|}
\hline Bias & Authors' judgement & Support for judgement \\
\hline $\begin{array}{l}\text { Random sequence genera- } \\
\text { tion (selection bias) }\end{array}$ & Low risk & Separate sets of random cards for DD and LD recipients \\
\hline $\begin{array}{l}\text { Allocation concealment } \\
\text { (selection bias) }\end{array}$ & Low risk & Cards in sealed envelopes, not opened until the time of surgery \\
\hline $\begin{array}{l}\text { Blinding of participants } \\
\text { and personnel (perfor- } \\
\text { mance bias) } \\
\text { All outcomes }\end{array}$ & Low risk & Unlikely to influence outcomes \\
\hline $\begin{array}{l}\text { Blinding of outcome as- } \\
\text { sessment (detection bias) } \\
\text { All outcomes }\end{array}$ & Low risk & Unlikely to influence outcomes \\
\hline $\begin{array}{l}\text { Incomplete outcome data } \\
\text { (attrition bias) } \\
\text { All outcomes }\end{array}$ & Low risk & All patient outcome data reported \\
\hline $\begin{array}{l}\text { Selective reporting (re- } \\
\text { porting bias) }\end{array}$ & High risk & $\begin{array}{l}\text { All expected outcomes reported, however unable to use acute rejection or in- } \\
\text { fection data }\end{array}$ \\
\hline Other bias & Unclear risk & $\begin{array}{l}\text { Unclear: hATG provided by Upjohn Co (therefore partially funded by them) } \\
\text { Also funded by Maud T. Lane Fund and research grant from Public Health Ser- } \\
\text { vice }\end{array}$ \\
\hline
\end{tabular}

\section{Tyden 2009}

\begin{tabular}{|c|c|}
\hline Methods & $\begin{array}{l}\text { - Study design: parallel RCT } \\
\text { - Study duration: November } 2005 \text { to May } 2007 \\
\text { - Study follow-up: } 3 \text { years }\end{array}$ \\
\hline Participants & $\begin{array}{l}\text { - } \text { - Sountry: Sweden } \\
\text { - Inclusion criteria: } \geq 18 \text { years, recipient of } 1 \text { st or } 2 \text { nd transplant from LD or DD; single organ only } \\
\text { - Number: treatment group ( } 68) \text {; control group }(68) \\
\text { - Mean age } \pm \text { SD (years): treatment group }(51.3 \pm 12.0) \text {; control group }(47.0 \pm 13.4) \\
\text { - Sex (M/F): treatment group }(46 / 23) \text {; control group }(44 / 24) \\
\text { - } \mathrm{DD} / \mathrm{LD} \text { : treatment group }(49 / 19) \text {; control group }(43 / 25) \\
\text { - } 1 \text { st/2nd transplant: treatment group }(68 / 0) \text {; control group }(62 / 6) \\
\text { - Exclusion criteria: HLA-identical siblings; receiving immunosuppressive therapy within the preceding } \\
28 \text { days; PRA }>50 \% \text { within } 6 \text { months before enrolment; history of malignancy; active infection; preg- } \\
\text { nant or lactating females; women of child bearing potential not willing to use reliable form of contra- } \\
\text { ception }\end{array}$ \\
\hline
\end{tabular}

- Rituximab: $375 \mathrm{mg} / \mathrm{m}^{2} \mathrm{BSA}$, within $24 \mathrm{hr}$, given mixed in $500 \mathrm{~mL}$ 5\% dextrose

Control group

- Placebo: $500 \mathrm{~mL}$ 5\% dextrose 
Tyden 2009 (Continued)

Immunosuppression (both groups)

- TAC: $0.1 \mathrm{mg} / \mathrm{kg}$ twice daily, trough $10 \mathrm{ng} / \mathrm{mL}$ st month, 5 to $10 \mathrm{ng} / \mathrm{mL} 2 \mathrm{nd}$ month, $5 \mathrm{ng} / \mathrm{mL}$ thereafter

- MMF: $1 \mathrm{~g}$ twice daily, adjusted per AUC, target 90 to $180 \mu \mathrm{mol} / \mathrm{L} \mathrm{h}$

- PRED: $100 \mathrm{mg}$, reduce by $10 \mathrm{mg} / \mathrm{d}$ to $20 \mathrm{mg}$, continued for 1 month then tapered to $5 \mathrm{mg}$ by 4 months

Prophylaxis (both groups)

- CMV: either valganciclovir or valaciclovir

- PCP: co-trimoxazole for 6 months

\begin{tabular}{ll}
\hline - & Acute rejection (6 months) \\
- & Death (6 months) \\
- Graft failure (6 months) \\
- Graft function \\
- Infection \\
- Adverse events \\
- Malignancy \\
\hline - All acute rejection was biopsy proven \\
- 3 year follow-up: poor follow-up of initial patient groups \\
$*$ Rituximab: $53 / 68$ (15 declined); of the 53 , graft failed (1), deaths (8) \\
* Placebo: $48 / 68$ (20 declined): of the 48, graft failed (1), death (0) \\
- Funding source: grants from Roche, Sweden and Astellas Pharma 'Had advisory input into study de- \\
sign, collected data via electronic reporting and monitored study conduct'
\end{tabular}

\section{Risk of bias}

\begin{tabular}{|c|c|c|}
\hline Bias & Authors' judgement & Support for judgement \\
\hline $\begin{array}{l}\text { Random sequence genera- } \\
\text { tion (selection bias) }\end{array}$ & Unclear risk & $\begin{array}{l}\text { Insufficient information to permit judgement ("...in randomization blocks of } \\
\text { four") }\end{array}$ \\
\hline $\begin{array}{l}\text { Allocation concealment } \\
\text { (selection bias) }\end{array}$ & Low risk & Randomisation performed at hospital pharmacy department \\
\hline $\begin{array}{l}\text { Blinding of participants } \\
\text { and personnel (perfor- } \\
\text { mance bias) } \\
\text { All outcomes }\end{array}$ & Low risk & $\begin{array}{l}\text { Infusion bags marked 'Mantra study medication' with content blinded to both } \\
\text { the patient and the investigator }\end{array}$ \\
\hline $\begin{array}{l}\text { Blinding of outcome as- } \\
\text { sessment (detection bias) } \\
\text { All outcomes }\end{array}$ & Low risk & Unlikely to influence outcomes \\
\hline $\begin{array}{l}\text { Incomplete outcome data } \\
\text { (attrition bias) } \\
\text { All outcomes }\end{array}$ & Unclear risk & $\begin{array}{l}\text { Most expected outcomes reported but no mention of malignancy in the study; } \\
\text { poor follow-up at } 3 \text { years }\end{array}$ \\
\hline $\begin{array}{l}\text { Selective reporting (re- } \\
\text { porting bias) }\end{array}$ & Low risk & All expected outcomes were reported \\
\hline Other bias & High risk & $\begin{array}{l}\text { Grants from Roche, Sweden and Astellas Pharma } \\
\text { 'Had advisory input into study design, collected data via electronic reporting } \\
\text { and monitored study conduct' }\end{array}$ \\
\hline
\end{tabular}


van den Hoogen 2013

\begin{tabular}{|c|c|}
\hline Methods & $\begin{array}{l}\text { - Study design: parallel RCT; stratified for age }(<50 \text { or } \geq 50) \text { and warm ischaemia time }(<30 \text { min or } \geq \\
30 \text { min) } \\
\text { - Study duration: January } 2008 \text { to June } 2010 \\
\text { - Study follow-up: 3months }\end{array}$ \\
\hline Participants & $\begin{array}{l}\text { - } \text { - Setting: multicentre (4) } \\
\text { - Inclusion criteria: adult 1st DD kidney transplant recipients } \\
\text { - Number: treatment group (28); control group (24) } \\
\text { - Mean age, range (years): treatment group }(54,21 \text { to } 70) \text {; control group }(56,24 \text { to } 68) \\
\text { - Sex (M/F): treatment group (18/10); control group (17/7) } \\
\text { - Exclusion criteria: previous transplant or proposed transplant with multiple organs; blood group in- } \\
\text { compatibility; current pregnancy or history of more than } 3 \text { pregnancies; lack of consistent data on a } \\
\text { PRA; known presence of antibodies against rabbit immunoglobulin or previous treatment with rabbit } \\
\text { immunoglobulin; known intolerance to any component of basal immunosuppression; HIV-positivity; } \\
\text { leukocytes < } 3.0 \times 10^{9} / \mathrm{L} \text { and/or platelets < } 50 \times 10^{9} / \mathrm{L} \text { before transplant; (cured) malignancy (with the } \\
\text { exception of basocellular or spinocellular skin cancer); pulmonary oedema or other signs of overhy- } \\
\text { dration }\end{array}$ \\
\hline
\end{tabular}

\begin{tabular}{|c|c|}
\hline Interventions & $\begin{array}{l}\text { Treatment group } \\
\text { - ATG (Fresenius): } 9 \mathrm{mg} / \mathrm{kg} \text { in } 500 \mathrm{~mL} \text { normal saline, single dose intra-op, given over } 4 \mathrm{~h} \\
\text { - MP: } 250 \mathrm{mg} \text { IV prior to ATG } \\
\text { Control group } \\
\text { - MP: } 250 \mathrm{mg} \text { intra-operatively } \\
\text { Immunosuppression (both groups) } \\
\text { - TAC: } 0.2 \mathrm{mg} / \mathrm{kg} / \mathrm{d} \text {, adjusted to level of } 15 \text { to } 20 \mathrm{mg} / \mathrm{L} \text { for } 2 \text { weeks, then } 10 \text { to } 15 \mathrm{mg} / \mathrm{L} \text { for } 4 \text { weeks, } \\
\text { thereafter } 5 \text { to } 10 \mathrm{mg} / \mathrm{L} \\
\text { - PRED: } 100 \mathrm{mg} \text { IV for } 3 \text { days then as per local policies } \\
\text { - MMF: } 2000 \mathrm{mg} / \mathrm{d} \text { for } 2 \text { weeks then } 1500 \mathrm{mg} / \mathrm{d} \text { unless weight }>90 \mathrm{~kg} \\
\text { Prophylaxis (both groups) } \\
\text { - PCP: co-trimoxazole } 480 \mathrm{mg} / \mathrm{d} \\
\text { - CMV: valganciclovir if } \mathrm{D}+\mathrm{R} \text { - }\end{array}$ \\
\hline Outcomes & $\begin{array}{ll}\text { - } & \text { DGF } \\
\text { - } & \text { Death } \\
\text { - } & \text { Graft loss } \\
\text { - } & \text { Acute rejection } \\
\text { - } & \text { Adverse events (infection, malignancy, other serious adverse events) }\end{array}$ \\
\hline Notes & $\begin{array}{l}\text { - Terminated early due to 'lower than anticipated inclusion rate'. } 180 \text { planned (only } 54 \text { recruited) } \\
\text { - Funding source: "This study was financially supported by Fresenius Biotech GmbH, Gräfelfing, Ger- } \\
\text { many. The company had no input in study design, data collection, data analysis, and writing or editing } \\
\text { of the manuscript" }\end{array}$ \\
\hline
\end{tabular}

\section{Risk of bias}


van den Hoogen 2013 (Continued)

Random sequence genera- Low risk Computer derived algorithm at coordinating centre
tion (selection bias)

$\begin{array}{ll}\begin{array}{l}\text { Allocation concealment } \\ \text { (selection bias) }\end{array} & \text { Low risk } \\ & \begin{array}{l}\text { Printed on paper and put into sealed, numbered envelopes. patients assigned } \\ \text { a consecutive number in the order in which they entered the study }\end{array}\end{array}$

\begin{tabular}{ll}
\hline Blinding of participants & Unclear risk \\
and personnel (perfor- & \\
mance bias) & \\
All outcomes & \\
\hline
\end{tabular}

\begin{tabular}{|c|c|c|}
\hline $\begin{array}{l}\text { Blinding of outcome as- } \\
\text { sessment (detection bias) }\end{array}$ & Unclear risk & $\begin{array}{l}\text { DGF was primary outcome and decision regarding need for dialysis post-op } \\
\text { may be quite subjective; unlikely to influence other outcomes }\end{array}$ \\
\hline
\end{tabular}

All outcomes

Incomplete outcome data Low risk All patient outcome data reported
(attrition bias)
All outcomes

\begin{tabular}{|c|c|c|}
\hline $\begin{array}{l}\text { Selective reporting (re- } \\
\text { porting bias) }\end{array}$ & Low risk & All expected outcomes reported \\
\hline \multirow[t]{2}{*}{ Other bias } & High risk & Terminated early due to poor recruitment \\
\hline & & $\begin{array}{l}\text { 'This study was financially supported by Fresenius Biotech } \mathrm{GmbH} \text {, Gräfelfing, } \\
\text { Germany. The company had no input in study design, data collection, data } \\
\text { analysis, and writing or editing of the manuscript'. }\end{array}$ \\
\hline
\end{tabular}

Vela 1994

\begin{tabular}{ll}
\hline Methods & Study design: parallel RCT \\
& - Study duration: January 1989 to January 1993 \\
\hline Participants & Study follow-up: 12 months \\
\hline & - Country: France \\
- Setting: single centre \\
- Number: treatment group 1 (23); treatment group 2 (15) \\
- Mean age \pm SD (years): treatment group 1 (48 \pm 2$)$; treatment group $2(42 \pm 3)$ \\
- Sex (M/F): treatment group 1 (11/12); treatment group 2 (5/10) \\
- Exclusion criteria: not reported
\end{tabular}

Interventions

Treatment group 1

- ALG (Merieux): 3-4 'vials'/d

- CSA: $10 \mathrm{mg} / \mathrm{kg} / \mathrm{d}$, started when $\mathrm{SCr}<200 \mu \mathrm{mol} / \mathrm{L}$

* ALG stopped when CSA trough reached 150 to $200 \mathrm{ng} / \mathrm{mL}$

Treatment group 2

- OKT3: $5 \mathrm{mg} /$ day, stopped on day 10

- CSA: $10 \mathrm{mg} / \mathrm{kg} / \mathrm{d}$, started day 8

Immunosuppression (both groups)

- AZA: $150 \mathrm{mg} / \mathrm{d}$ 
Vela 1994 (Continued)

$$
\text { - PRED: } 20 \mathrm{mg} / \mathrm{d}
$$

\begin{tabular}{ll}
\hline Outcomes & Patient survival \\
- Graft survival \\
- Acute rejection \\
- Viral infections \\
- Other side effects \\
- Graft function \\
- 3 patients assigned to OKT3 were switched to ALG group due to fluid overload. \\
- All side effects higher in the OKT3 group compared to ALG, except for rash \\
- Numbers with cytokine release syndrome not given but 100\% in OKT3 group had fever, compared to \\
- $13 \%$ in ALG group \\
- Funalyses \\
- Funding source: not reported
\end{tabular}

\section{Risk of bias}

\begin{tabular}{|c|c|c|}
\hline Bias & Authors' judgement & Support for judgement \\
\hline $\begin{array}{l}\text { Random sequence genera- } \\
\text { tion (selection bias) }\end{array}$ & Unclear risk & Insufficient information to permit judgement \\
\hline $\begin{array}{l}\text { Allocation concealment } \\
\text { (selection bias) }\end{array}$ & Unclear risk & Insufficient information to permit judgement \\
\hline $\begin{array}{l}\text { Blinding of participants } \\
\text { and personnel (perfor- } \\
\text { mance bias) } \\
\text { All outcomes }\end{array}$ & Low risk & Unlikely to influence outcomes \\
\hline $\begin{array}{l}\text { Blinding of outcome as- } \\
\text { sessment (detection bias) } \\
\text { All outcomes }\end{array}$ & Low risk & Unlikely to influence outcomes \\
\hline $\begin{array}{l}\text { Incomplete outcome data } \\
\text { (attrition bias) } \\
\text { All outcomes }\end{array}$ & Low risk & All patient outcome data reported \\
\hline $\begin{array}{l}\text { Selective reporting (re- } \\
\text { porting bias) }\end{array}$ & Low risk & All expected outcomes reported however unable to use graft function data \\
\hline Other bias & Unclear risk & Funding source not reported \\
\hline
\end{tabular}

\section{Vigeral 1986}

\begin{tabular}{ll}
\hline Methods & - Study design: parallel RCT \\
& - Study duration: not reported \\
\hline Participants & - Country: France \\
& - Setting: single centre \\
& - Inclusion criteria: 1 st DD kidney transplant recipients
\end{tabular}


Vigeral 1986 (Continued)

- Number: treatment group (6); control group (7)

- Mean age \pm SD (years): treatment group (34.3 \pm 9.2$)$; control group $(35.7 \pm 11.2)$

- Sex (M/F): treatment group (3/3); control group (4/3)

- Exclusion criteria: not reported

Treatment group
- OKT3: $5 \mathrm{mg} / \mathrm{d}, \mathrm{IV}$ for 14 days starting 1 day pre-transplant (pre-treatment skin test prior) then stopped
- AZA: $3 \mathrm{mg} / \mathrm{kg} / \mathrm{d}$ from day 14
Control group
- AZA: $3 \mathrm{mg} / \mathrm{kg} / \mathrm{d}$, given from 1 day pre-op
- PRED: $5 \mathrm{mg} / \mathrm{kg} / \mathrm{d}$ for 5 days, then tapered to $0.25 \mathrm{mg} / \mathrm{kg} / \mathrm{d}$ over 11 weeks
- Death
- Graft loss
- Acute Rejection
- Bacterial infection
- CMV disease
- Tolerance of OKT3
- If episode of acute rejection, OKT3 was stopped and patient was switched to PRED and AZA
- Very early study possibly 1 st using OKT3 as prophylaxis
- Pre CNI maintenance
- All patients in OKT3 group had side effects with fever, chills, anxiety and diarrhoea for 1 st infusion and
then not after (? vs none in control group although not actually reported)
- All developed antibodies to OKT3
- Not effective as single agent (worse outcomes compared to controls)
- Funding source: not reported, however 1 author an employee of Ortho Pharmaceuticals

\section{Risk of bias}

Bias Authors' judgement Support for judgement

Random sequence genera- Unclear risk Insufficient information to permit judgement tion (selection bias)

\begin{tabular}{lll}
\hline $\begin{array}{l}\text { Allocation concealment } \\
\text { (selection bias) }\end{array}$ & Unclear risk & Insufficient information to permit judgement \\
\hline $\begin{array}{l}\text { Blinding of participants } \\
\text { and personnel (perfor- }\end{array}$ & Low risk & Unlikely to influence outcomes \\
$\begin{array}{l}\text { mance bias) } \\
\text { All outcomes }\end{array}$ & \\
\hline
\end{tabular}

\begin{tabular}{|c|c|c|}
\hline $\begin{array}{l}\text { Blinding of outcome as- } \\
\text { sessment (detection bias) }\end{array}$ & Unclear risk & $\begin{array}{l}\text { Most cases of acute rejection were biopsy-proven acute rejection but not all. } \\
\text { Clinical decision for acute rejection without biopsy could be prone to bias }\end{array}$ \\
\hline
\end{tabular}

Incomplete outcome data Low risk All patient outcome data reported
(attrition bias)
All outcomes

\begin{tabular}{ll}
\hline $\begin{array}{l}\text { Selective reporting (re- } \\
\text { porting bias) }\end{array}$ & Low risk \\
\end{tabular}


Vigeral 1986 (Continued)

$\begin{array}{ll}\text { Other bias } \quad \text { High risk } & \begin{array}{l}\text { Funding source not declared; one of the authors is from Ortho Pharmaceutical } \\ \text { Corporation (OKT3 manufacturer) }\end{array}\end{array}$

Wechter 1979

\begin{tabular}{ll} 
Methods & - Study design: parallel RCT \\
& - Study duration: November 1971 to June 1972 \\
\hline Participants & - Study follow-up: 2 years \\
- Country: USA \\
- Setting: multicentre (3) \\
- Numblun criteria: DD kidney transplant recipients \\
- Mean age \pm SD (years): not reported \\
- Sex (M/F): not reported \\
- Exclusion criteria: not reported
\end{tabular}

Interventions Treatment group

- ATG: $7 \mathrm{mg} / \mathrm{kg}$ IV once/d for 4 days, $3.5 \mathrm{mg} / \mathrm{kg}$ once/d for 26 days, $7 \mathrm{mg} / \mathrm{kg}$ twice weekly for 8 weeks, then $7 \mathrm{mg} / \mathrm{kg}$ once weekly for 4 weeks; given in $250 \mathrm{~mL}$ saline over at least 3 hours

- AZA: dosage not reported

- PRED-MP: dosage not reported

Control:

- AZA: dosage not reported

- PRED-MP: dosage not reported

\begin{tabular}{ll}
\hline Outcomes & Death \\
& - Graft loss \\
& - Acute rejection (within 28 days) \\
& NODAT \\
\hline \multirow{2}{*}{ Notes } & - Other side effects only reported for ATG \\
& - Funding source: not reported, contact author employee of Upjohn company (manufacturer of ATG)
\end{tabular}

\section{Risk of bias}

\begin{tabular}{lll}
\hline Bias & Authors' judgement & Support for judgement \\
\hline $\begin{array}{l}\text { Random sequence genera- } \\
\text { tion (selection bias) }\end{array}$ & Unclear risk & Insufficient information to permit judgement \\
\hline $\begin{array}{l}\text { Allocation concealment } \\
\text { (selection bias) }\end{array}$ & Unclear risk & Insufficient information to permit judgement \\
\hline $\begin{array}{l}\text { Blinding of participants } \\
\text { and personnel (perfor- } \\
\text { mance bias) }\end{array}$ & Low risk & Unlikely to influence outcomes \\
$\begin{array}{l}\text { All outcomes } \\
\begin{array}{l}\text { Blinding of outcome as- } \\
\text { sessment (detection bias) }\end{array}\end{array}$ & High risk & $\begin{array}{l}\text { Acute rejection episodes mainly diagnosed clinically; lack of blinding may } \\
\text { have influenced reporting of adverse outcomes. }\end{array}$ \\
\hline
\end{tabular}


Wechter 1979 (Continued)

All outcomes

Incomplete outcome data Unclear risk Side effects not well reported for control group
(attrition bias)

All outcomes

\begin{tabular}{lll}
\hline $\begin{array}{l}\text { Selective reporting (re- } \\
\text { porting bias) }\end{array}$ & Low risk & All expected outcomes reported \\
\hline Other bias & High risk & Contact author an employee of Upjohn company \\
\hline
\end{tabular}

\section{Yussim 2000}

$\begin{array}{ll}\text { Methods } & \text { Study design: parallel RCT } \\ & \text { - Study duration: not reported } \\ & \text { - Study follow-up: } 2 \text { years }\end{array}$

- Country: Israel
- Setting: single centre
- Inclusion criteria: low and high risk 1st or retransplant kidney transplant recipients
- Number: treatment group (19); control group (19)
- Mean age \pm SD (years): not reported
- Sex (M/F): not reported
- Exclusion criteria: not reported

\begin{tabular}{|c|c|}
\hline Interventions & $\begin{array}{l}\text { Treatment group } \\
\text { - } \text { rATG (Fresenius): single dose of } 9 \mathrm{mg} / \mathrm{kg} \text { given as IV infusion in } 500 \mathrm{~mL} \text { saline prior to revascularistion } \\
\text { - MP: } 500 \mathrm{mg} \\
\text { Control group } \\
\text { - No ATG } \\
\text { Immunosuppression (both groups) } \\
\text { - PRED: as per protocol, started post-op; dosage not reported } \\
\text { - AZA: as per protocol, started post-op; dosage not reported } \\
\text { - CSA: as per protocol, started post-op; dosage not reported }\end{array}$ \\
\hline Outcomes & $\begin{array}{l}\text { - } \text { Death } \\
\text { - Graft loss } \\
\text { - Acute rejection } \\
\text { - } \text { DGF } \\
\text { - Infection }\end{array}$ \\
\hline Notes & $\begin{array}{l}\text { - Graft function reported but timing not specified and no SD or SE given, cannot be meta-analysis } \\
\text { - Funding source: not reported }\end{array}$ \\
\hline \multicolumn{2}{|l|}{ Risk of bias } \\
\hline Bias & Authors' judgement Support for judgement \\
\hline
\end{tabular}


Yussim 2000 (Continued)
Random sequence genera- Unclear risk
Insufficient information to permit judgement tion (selection bias)

Allocation concealment $\quad$ Unclear risk Insufficient information to permit judgement
(selection bias)

Blinding of participants Low risk Unlikely to influence outcomes
and personnel (perfor-
mance bias)

\begin{tabular}{lll}
\hline $\begin{array}{l}\text { Blinding of outcome as- } \\
\text { sessment (detection bias) } \\
\text { All outcomes }\end{array}$ & Low risk & Unlikely to influence outcomes \\
\hline $\begin{array}{l}\text { Incomplete outcome data } \\
\text { (attrition bias) } \\
\text { All outcomes }\end{array}$ & Low risk & All patient outcome data reported \\
\hline $\begin{array}{l}\text { Selective reporting (re- } \\
\text { porting bias) }\end{array}$ & High risk & All expected outcomes reported however SD/SE not reported for graft function \\
\hline \begin{tabular}{l} 
Other bias \\
\hline
\end{tabular} & Unclear risk & Insufficient information to permit judgement \\
\hline
\end{tabular}

ALG - antilymphocyte globulin; ANC - absolute neutrophil count; ATG - antithymocyte globulin; ATGAM - horse ATG; ATN - acute tubular necrosis; AZA - azathioprine; BKV - BK virus; CAN - chronic allograft nephropathy; CMV - cytomegalovirus; CNI - calcineurin inhibitor; CSA - cyclosporin A; DD - deceased donor; DGF - delayed graft function; DEX - dexamethasone; EBV - Epstein-Barr virus; eGFR - estimated glomerular filtration rate; ESKD - end-stage kidney disease; GI - gastrointestinal; hATG - horse ATG; Hep - hepatitis; HIV - human immunodeficiency virus; HLA - human leukocyte antigen; IL-2RA - interleukin 2 receptor antagonist; IV - intravenous; LD - living donor; mALG - Minnesota ALG; M/F - male/female; MMF - mycophenolate mofetil; MP - methylprednisolone; NODAT - new-onset diabetes after transplantation; post-op - post-operative; PRA - panel reactive antibodies; PRED - prednisone; PTLD - post-transplant lymphoproliferative disease; rATG - rabbit ATG; RBC - red blood cell; RCT- randomised controlled trial; SCr - serum creatinine; SD - standard deviation; SE standard error; SEM - standard error of the mean; WCC - white cell count

Characteristics of excluded studies [ordered by study ID]

\begin{tabular}{ll}
\hline Study & Reason for exclusion \\
\hline Alloway 1993 & $\begin{array}{l}\text { Study includes kidney-pancreas recipients, results not reported separately for kidney only recipi- } \\
\text { ents }\end{array}$ \\
\hline Kirsch 2006 & $\begin{array}{l}\text { No outcomes relevant to this review (critical circulating DC subsets, i.e. myeloid (DC1) versus lym- } \\
\text { phoid (DC2) DC) }\end{array}$ \\
\hline Kumar 2002b & $\begin{array}{l}\text { "Due to financial constraints randomization was based on affordability to bear the cost of ATG. } \\
\text { Those who could afford the cost were included in the study group and those who couldn't became } \\
\text { the control" }\end{array}$ \\
\hline NCT00000936 & Study terminated; no data available \\
\hline NCT01312064 & Study terminated; no data available \\
\hline
\end{tabular}

ATG - antilymphocyte globulin 
Characteristics of studies awaiting assessment [ordered by study ID]

NCT00089947

\begin{tabular}{ll}
\hline Methods & Randomised, open-label, parallel assignment (phase 2) \\
\hline Participants & 150 participants, $\geq 18$ years, LD kidney transplant recipients \\
\hline Interventions & $\begin{array}{l}\text { rATG with rapid discontinuation of steroids versus steroids per hospital standards for at least 1st } 90 \\
\text { days after transplant }\end{array}$ \\
\hline Outcomes & Primary: kidney transplant rejection, organ loss and death at 6 months \\
Secondary: kidney function after transplantation and overall safety of rATG
\end{tabular}

\section{NCT00861536}

\begin{tabular}{ll}
\hline Methods & Randomised, open-label, parallel assignment (phase 4) \\
\hline Participants & 40 participants, $\geq 18$ years, recipients of kidney transplants of high immunological risk \\
\hline Interventions & ATG (Fresenius) versus thymoglobulin \\
\hline Outcomes & Primary: adverse events \\
& Secondary: rejection, graft function, patient survival, graft survival \\
\hline Notes & This study has been completed but no study results have been posted on Clinicaltrials.gov \\
\hline
\end{tabular}

\section{NCT01046955}

\begin{tabular}{ll}
\hline Methods & Randomised, open-label, parallel assignment (phase 4) \\
\hline Participants & 38 participants, age $>14$ years, 1st LD kidney transplant recipients \\
\hline Interventions & ATG versus alemtuzumab versus daclizumab \\
\hline Outcomes & Primary: effectiveness and toxicity at 3 years, patient and graft survival at 1 and 3 years \\
& Secondary: incidence of adverse reactions at 1 and 3 years \\
\hline Notes & This study has been completed but no study results have been posted on Clinicaltrials.gov \\
\hline
\end{tabular}

\section{NCT01354301}

\begin{tabular}{ll}
\hline Methods & Randomised, open-label, parallel assignment (Phase 4) \\
\hline Participants & 300 participants, $\geq 18$ years, low risk kidney transplant recipients \\
\hline Interventions & Single dose ATG and everolimus versus basiliximab and everolimus versus basiliximab and MMF \\
\hline
\end{tabular}


NCT01354301 (Continued)

Outcomes

Primary: incidence of CMV infection or disease at 1 year

Secondary: incidence of treatment failure at 1 year (composite of biopsy-confirmed acute rejection, graft loss, death, loss to follow-up)

Notes

This study has been completed but no study results have been posted on Clinicaltrials.gov

Stevens 2016

\begin{tabular}{ll}
\hline Methods & Double-blind, double-dummy RCT \\
\hline Participants & 18 to 65 years DD or LD kidney transplant recipients \\
\hline Interventions & Single dose rATG versus divided dose rATG \\
\hline Outcomes & Primary: composite endpoint of fever, hypotension, hypoxia, cardiac events, DGF \\
& Secondary: patient survival; graft survival acute rejection; incomplete ATG infusion; eGFR \\
\hline Notes & Results yet to be incorporated \\
\hline
\end{tabular}

CMV - cytomegalovirus; DGF - delayed graft function; LD - living donor; MMF - mycophenolate mofetil; rATG - rabbit antilymphocyte globulin

Characteristics of ongoing studies [ordered by study ID]

\section{NCT00733733}

Trial name or title

(NHB) donor

\begin{tabular}{ll}
\hline Methods & Randomised, open-label, parallel assignment (Phase 3) \\
\hline Participants & 180 participants, recipients of DD kidney transplants \\
\hline Interventions & rATG versus no intervention \\
\hline Outcomes & Primary: incidence of initial DGF (defined as need for dialysis) within 3 months \\
& $\begin{array}{l}\text { Secondary: duration of initial DGF, incidence of primary never-functioning grafts, incidence of biop- } \\
\text { sy-proven acute rejection within } 3 \text { months, kidney function (MDRD) at } 1,2 \text { and } 3 \text { months, protein- } \\
\text { uria at } 1,2 \text { and } 3 \text { months, } \% \text { of patients with arterial hypertension at } 3 \text { months, \% of patients with } \\
\text { antihypertensive drugs at } 3 \text { months, \% of hyperlipidaemic patients at } 3 \text { months, \% of post-trans- } \\
\text { plant DM at } 3 \text { months, incidence of CMV infection at } 3 \text { months, incidence of tumours/PTLD at } 3 \\
\text { months, patient and graft survival at } 3 \text { months, incidence of other infections at } 3 \text { months, microal- } \\
\text { buminuria at } 1,2 \text { and } 3 \text { months }\end{array}$ \\
\hline
\end{tabular}

\begin{tabular}{ll}
\hline Starting date & January 2008 \\
\hline Contact information & Radboud University (Prof. Dr Andries Hoitsma, UMC St Radboud Hospital) \\
\hline Notes & $\begin{array}{l}\text { Estimated study completion date was June 2010; recruitment status unknown; study details last } \\
\text { verified in August 2008 }\end{array}$ \\
\hline
\end{tabular}


NCT01154387

Trial name or title
Evaluating safety and efficacy of TOL101 induction versus anti-thymocyte globulin to prevent kidney transplant rejection

\begin{tabular}{ll}
\hline Methods & Randomised, open-label, parallel assignment (Phase 1 and Phase 2) \\
\hline Participants & 85 participants, age 18-60, first kidney transplant recipients \\
\hline Interventions & ATG versus TOL101 dose A versus TOL101 dose B \\
\hline Outcomes & $\begin{array}{l}\text { Primary: safety and tolerability of ascending doses of TOL101 and effectiveness of TOL101 to target } \\
\text { and down regulate T cells at } 6 \text { months }\end{array}$ \\
& $\begin{array}{l}\text { Secondary: effects of ascending doses of TOL101 on CD3+ T lymphocyte numbers and other im- } \\
\text { mune cell subsets at } 14 \text { days and } 6 \text { months, pharmacokinetic profile of TOL101 and exposure-re- } \\
\text { sponse relationship over time at } 14 \text { days, biopsy-proven acute organ rejection at } 6 \text { months, graft } \\
\text { survival at } 6 \text { months, patient survival at } 6 \text { months, kidney function by measured GFR at } 6 \text { months } \\
\text { and urine protein to creatinine ration at } 3 \text { and } 6 \text { months, DGF at } 7 \text { days, immunogenicity of TOL101 } \\
\text { by measurement of anti-TOL101 antibodies at } 14 \text { and } 28 \text { days, presence of DSA at } 3 \text { months and } 6 \\
\text { months }\end{array}$ \\
\hline
\end{tabular}

\begin{tabular}{ll}
\hline Starting date & July 2010 \\
\hline Contact information & Tolera Therapeutics Inc (Stuart Flechner MD, The Cleveland Clinic) \\
\hline Notes & $\begin{array}{l}\text { Estimated study completion date was June 2013; recruitment status was active; not recruiting; } \\
\text { study details last verified in June } 2013\end{array}$ \\
\hline
\end{tabular}

\section{ReMIND Study 2013}

\begin{tabular}{|c|c|}
\hline Trial name or title & RituxiMab INDuction in renal transplantation (ReMIND) \\
\hline Methods & Randomised, open-label, parallel assignment (phase 4) \\
\hline Participants & 612 participants, $\geq 18$ years, recipients of LD kidney transplants \\
\hline Interventions & Rituximab and 1 week prednisolone versus continued prednisolone \\
\hline \multirow[t]{2}{*}{ Outcomes } & Primary: eGFR at 1 year \\
\hline & $\begin{array}{l}\text { Secondary: biopsy proven acute rejection at } 1,2,3,4 \text { and } 5 \text { years, allograft survival at 1, 2, 3, } 4 \text { and } \\
5 \text { years, patient survival at 1, 2, 3, } 4 \text { and } 5 \text { years, infection rate at } 1 \text { year, changes in B and T cell } \\
\text { repertoire }\end{array}$ \\
\hline Starting date & November 2010 \\
\hline Contact information & Guy's and St Thomas' NHS Foundation Trust (Nizam Mamode, MD, FRCS(Gen) \\
\hline Notes & $\begin{array}{l}\text { Estimated study completion date is October 2023; active, recruiting participants; study details last } \\
\text { verified August } 2016\end{array}$ \\
\hline
\end{tabular}

ATG - antilymphocyte globulin; CMV - cytomegalovirus; DD - deceased donor; DGF - delayed graft function; DM- diabetes mellitus; GFR - glomerular filtration rate; LD - living donor: MDRD - Modification of Diet in Renal Disease; PTLD - post-transplant lymphoproliferative disease; rATG - rabbit ATG 
DATA AND ANALYSES

\section{Comparison 1. ATG versus placebo/no treatment}

\begin{tabular}{|c|c|c|c|c|}
\hline Outcome or subgroup title & No. of studies & $\begin{array}{l}\text { No. of partici- } \\
\text { pants }\end{array}$ & Statistical method & Effect size \\
\hline 1 Death & 16 & & Risk Ratio (M-H, Random, 95\% Cl) & Subtotals only \\
\hline 1.1 At 3 to 6 months (+ CNI) & 3 & 523 & Risk Ratio (M-H, Random, 95\% Cl) & $0.41[0.13,1.22]$ \\
\hline 1.2 At 1 to 2 years $(+\mathrm{CNI})$ & 5 & 632 & Risk Ratio (M-H, Random, 95\% Cl) & $0.75[0.27,2.06]$ \\
\hline 1.3 At 1 to 2 years (no $\mathrm{CNI}$ ) & 6 & 621 & Risk Ratio (M-H, Random, 95\% Cl) & $1.03[0.86,1.22]$ \\
\hline 1.4 At 5 years $(+\mathrm{CNI})$ & 2 & 159 & Risk Ratio (M-H, Random, 95\% Cl) & $0.94[0.11,7.81]$ \\
\hline 2 Graft loss (all cause) & 13 & & Risk Ratio (M-H, Random, 95\% Cl) & Subtotals only \\
\hline 2.1 At 3 to 6 months (+ CNI) & 4 & 638 & Risk Ratio (M-H, Random, 95\% Cl) & $0.60[0.34,1.05]$ \\
\hline 2.2 At 1 to 2 years $(+\mathrm{CNI})$ & 3 & 549 & Risk Ratio (M-H, Random, 95\% Cl) & $0.65[0.36,1.19]$ \\
\hline 2.3 At 1 to 2 years (no $\mathrm{CNI}$ ) & 4 & 500 & Risk Ratio (M-H, Random, 95\% Cl) & $0.70[0.49,1.01]$ \\
\hline 2.4 At 5 years $(+\mathrm{CNI})$ & 2 & 159 & Risk Ratio (M-H, Random, 95\% Cl) & $1.13[0.62,2.05]$ \\
\hline $\begin{array}{l}2.5 \text { At } 1 \text { to } 2 \text { years (all stud- } \\
\text { ies) }\end{array}$ & 7 & 1049 & Risk Ratio (M-H, Random, 95\% Cl) & $0.71[0.53,0.95]$ \\
\hline $\begin{array}{l}3 \text { Graft loss (death cen- } \\
\text { sored) }\end{array}$ & 10 & & Risk Ratio (M-H, Random, 95\% Cl) & Subtotals only \\
\hline 3.1 At 1 to 2 years (+ CNI) & 2 & 82 & Risk Ratio (M-H, Random, 95\% Cl) & $0.57[0.19,1.75]$ \\
\hline 3.2 At 1 to 2 years (no CNI) & 6 & 299 & Risk Ratio (M-H, Random, 95\% Cl) & $0.55[0.38,0.78]$ \\
\hline 3.3 at 5 years $(+\mathrm{CNI})$ & 2 & 148 & Risk Ratio (M-H, Random, 95\% Cl) & $1.64[0.20,13.18]$ \\
\hline $\begin{array}{l}3.4 \text { At } 1 \text { to } 2 \text { years (all stud- } \\
\text { ies) }\end{array}$ & 8 & 381 & Risk Ratio (M-H, Random, 95\% Cl) & $0.55[0.39,0.77]$ \\
\hline 4 Acute rejection & 17 & 2044 & Risk Ratio (M-H, Random, 95\% Cl) & $0.63[0.51,0.78]$ \\
\hline 4.1 At 1 to 2 years (+ CNI) & 12 & 1491 & Risk Ratio (M-H, Random, 95\% Cl) & $0.61[0.49,0.76]$ \\
\hline 4.2 At 1 to 2 years (no $\mathrm{CNI}$ ) & 5 & 553 & Risk Ratio (M-H, Random, 95\% Cl) & $0.65[0.43,0.98]$ \\
\hline 5 Delayed graft function & 9 & 1304 & Risk Ratio (M-H, Random, 95\% Cl) & $0.93[0.78,1.10]$ \\
\hline 6 Infection & 13 & & Risk Ratio (M-H, Random, 95\% Cl) & Subtotals only \\
\hline 6.1 Any infection & 7 & 824 & Risk Ratio (M-H, Random, 95\% Cl) & $1.05[0.88,1.26]$ \\
\hline 6.2 CMV infection & 6 & 1072 & Risk Ratio (M-H, Random, 95\% Cl) & $1.55[1.24,1.95]$ \\
\hline
\end{tabular}




\begin{tabular}{|c|c|c|c|c|}
\hline Outcome or subgroup title & No. of studies & $\begin{array}{l}\text { No. of partici- } \\
\text { pants }\end{array}$ & Statistical method & Effect size \\
\hline $\begin{array}{l}\text { 6.3 Other viral infection (not } \\
\text { CMV) }\end{array}$ & 4 & 664 & Risk Ratio (M-H, Random, 95\% Cl) & $1.11[0.43,2.87]$ \\
\hline 6.4 Viral infection (all cause) & 3 & 197 & Risk Ratio (M-H, Random, 95\% Cl) & $1.38[0.56,3.39]$ \\
\hline 6.5 Bacterial infection & 5 & 775 & Risk Ratio (M-H, Random, 95\% Cl) & $1.15[0.96,1.37]$ \\
\hline 7 Leucopenia & 4 & 920 & Risk Ratio (M-H, Random, 95\% Cl) & $3.86[2.79,5.34]$ \\
\hline 8 Thrombocytopenia & 4 & 848 & Risk Ratio (M-H, Random, 95\% Cl) & $2.41[1.61,3.61]$ \\
\hline 9 Malignancy or PTLD & 7 & & Risk Ratio (M-H, Random, 95\% Cl) & Subtotals only \\
\hline $\begin{array}{l}9.1 \text { Malignancy at } 1 \text { to } 2 \\
\text { years }(+\mathrm{CNI})\end{array}$ & 3 & 611 & Risk Ratio (M-H, Random, 95\% Cl) & $0.94[0.22,3.94]$ \\
\hline $\begin{array}{l}\text { 9.2 Malignancy at } 5 \text { years }(+ \\
\text { CNI) }\end{array}$ & 2 & 159 & Risk Ratio (M-H, Random, 95\% Cl) & $0.94[0.14,6.23]$ \\
\hline $\begin{array}{l}9.3 \text { Malignancy at } 1 \text { to } 2 \\
\text { years (no CNI) }\end{array}$ & 2 & 121 & Risk Ratio (M-H, Random, 95\% Cl) & $0.0[0.0,0.0]$ \\
\hline $\begin{array}{l}\text { 9.4 PTLD at } 1 \text { to } 2 \text { years }(+ \\
\text { CNI) }\end{array}$ & 1 & 151 & Risk Ratio (M-H, Random, 95\% Cl) & $0.0[0.0,0.0]$ \\
\hline 10 Other adverse outcomes & 6 & & Risk Ratio (M-H, Random, 95\% Cl) & Subtotals only \\
\hline 10.1 NODAT & 6 & 935 & Risk Ratio (M-H, Random, 95\% Cl) & $1.01[0.56,1.84]$ \\
\hline 10.2 Serum sickness & 1 & 371 & Risk Ratio (M-H, Random, 95\% Cl) & $60.67[3.74,984.93]$ \\
\hline 10.3 Tremor & 1 & 371 & Risk Ratio (M-H, Random, 95\% Cl) & $0.93[0.46,1.87]$ \\
\hline 11 Serum creatinine & 5 & & $\begin{array}{l}\text { Mean Difference (IV, Random, 95\% } \\
\mathrm{Cl} \text { ) }\end{array}$ & Subtotals only \\
\hline 11.1 At 6 months (+ CNI) & 2 & 503 & $\begin{array}{l}\text { Mean Difference (IV, Random, 95\% } \\
\mathrm{Cl} \text { ) }\end{array}$ & $-5.34[-13.44,2.75]$ \\
\hline 11.2 At 1 year $(+\mathrm{CNI})$ & 2 & 222 & $\begin{array}{l}\text { Mean Difference (IV, Random, 95\% } \\
\mathrm{Cl} \text { ) }\end{array}$ & $-10.56[-21.81,0.69]$ \\
\hline $\begin{array}{l}\text { 11.3 At } 1 \text { year: LD recipients } \\
\text { (no CNI) }\end{array}$ & 1 & 30 & $\begin{array}{l}\text { Mean Difference (IV, Random, 95\% } \\
\mathrm{CI})\end{array}$ & $-9.70[-67.32,47.92]$ \\
\hline $\begin{array}{l}\text { 11.4 At } 1 \text { year: DD recipients } \\
\text { (no CNI) }\end{array}$ & 1 & 19 & $\begin{array}{l}\text { Mean Difference (IV, Random, 95\% } \\
\mathrm{Cl} \text { ) }\end{array}$ & $-23.0[-62.70,16.70]$ \\
\hline 11.5 At 5 years $(+\mathrm{CNI})$ & 1 & 55 & $\begin{array}{l}\text { Mean Difference (IV, Random, 95\% } \\
\mathrm{Cl} \text { ) }\end{array}$ & $-32.70[-68.98,3.58]$ \\
\hline
\end{tabular}


Analysis 1.1. Comparison 1 ATG versus placebo/no treatment, Outcome 1 Death.

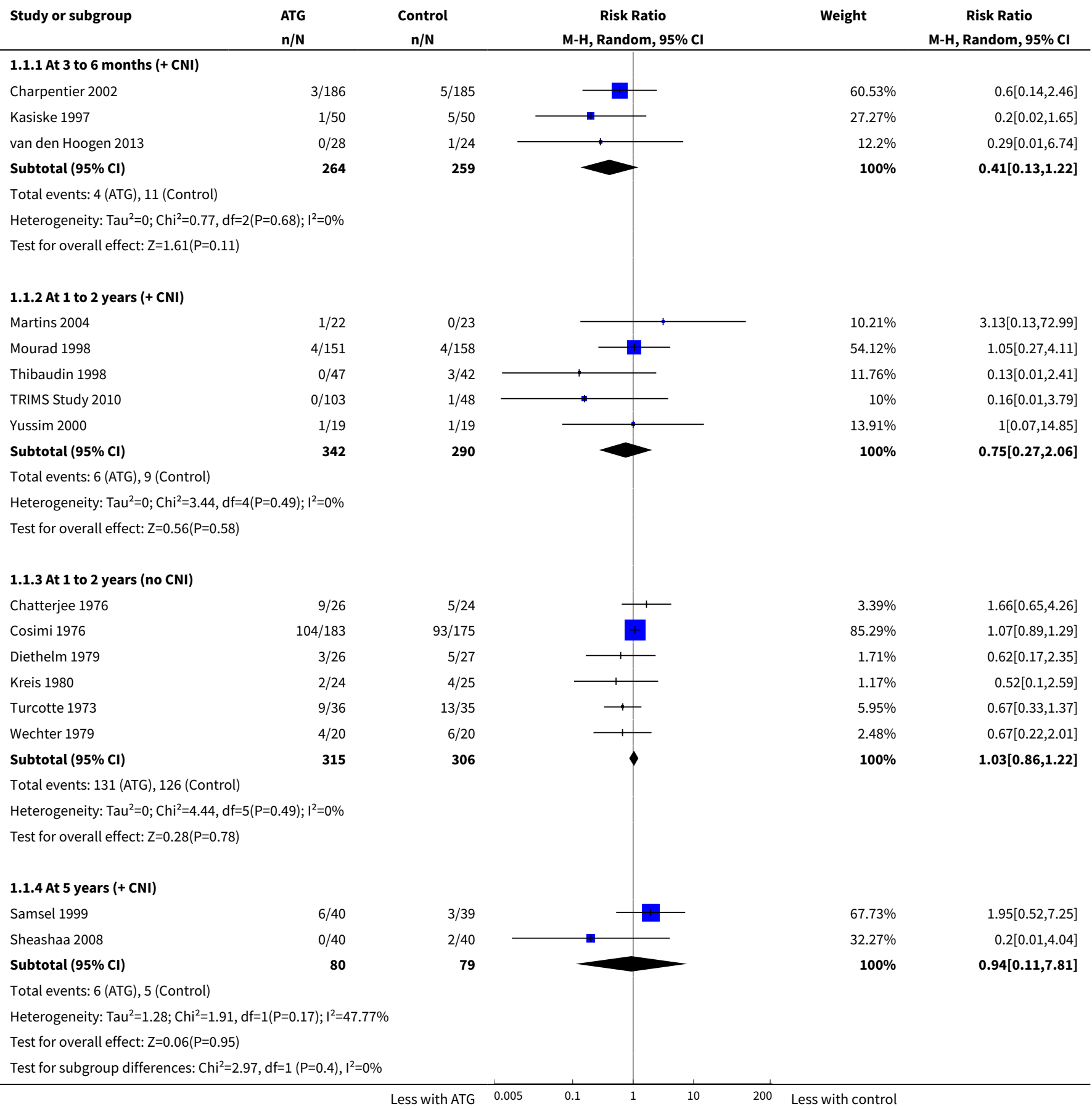

Analysis 1.2. Comparison 1 ATG versus placebo/no treatment, Outcome 2 Graft loss (all cause).

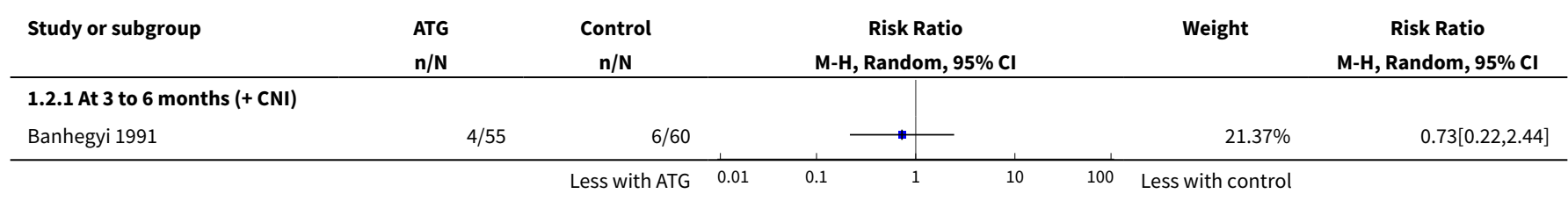




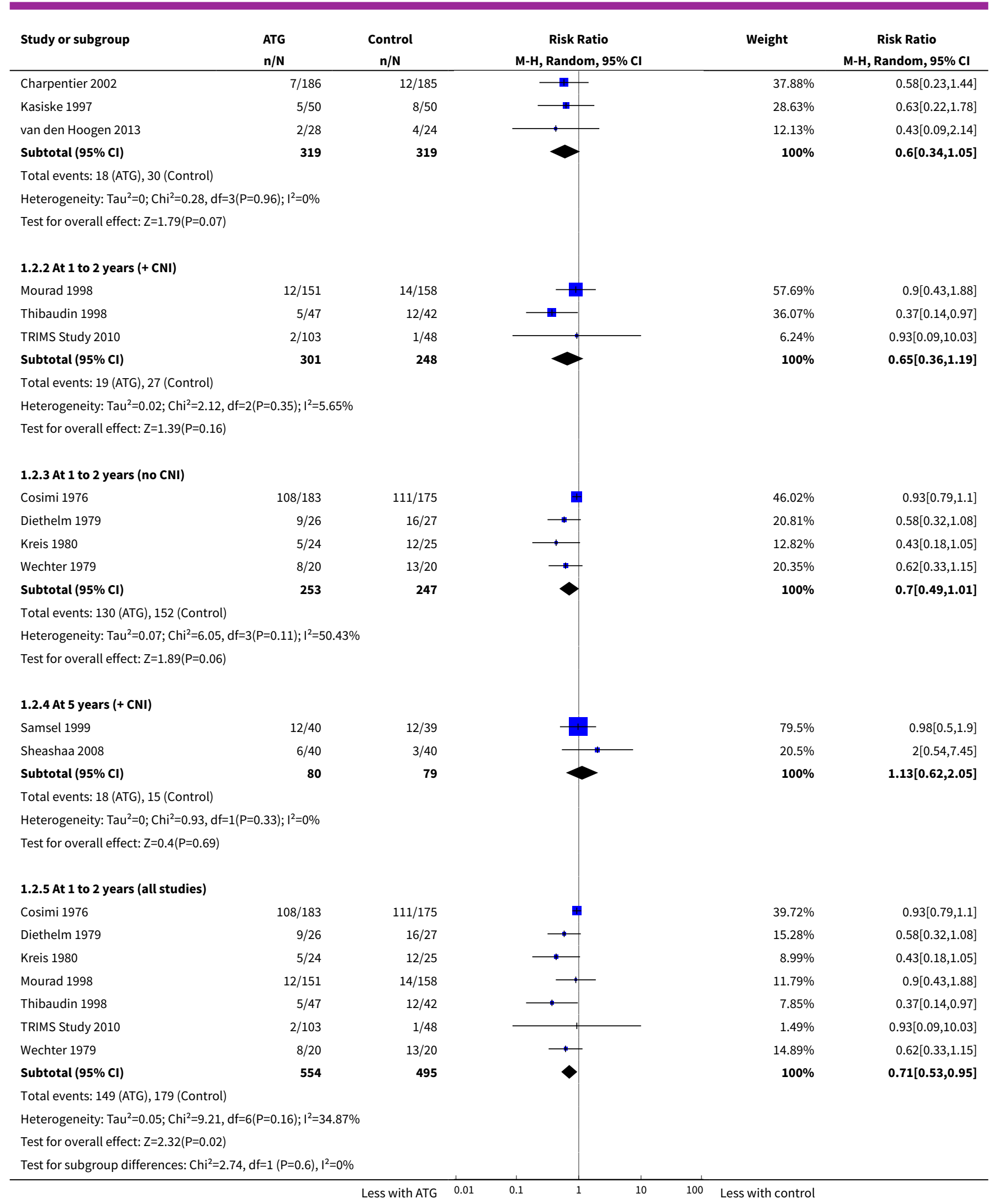


Analysis 1.3. Comparison 1 ATG versus placebo/no treatment, Outcome 3 Graft loss (death censored).

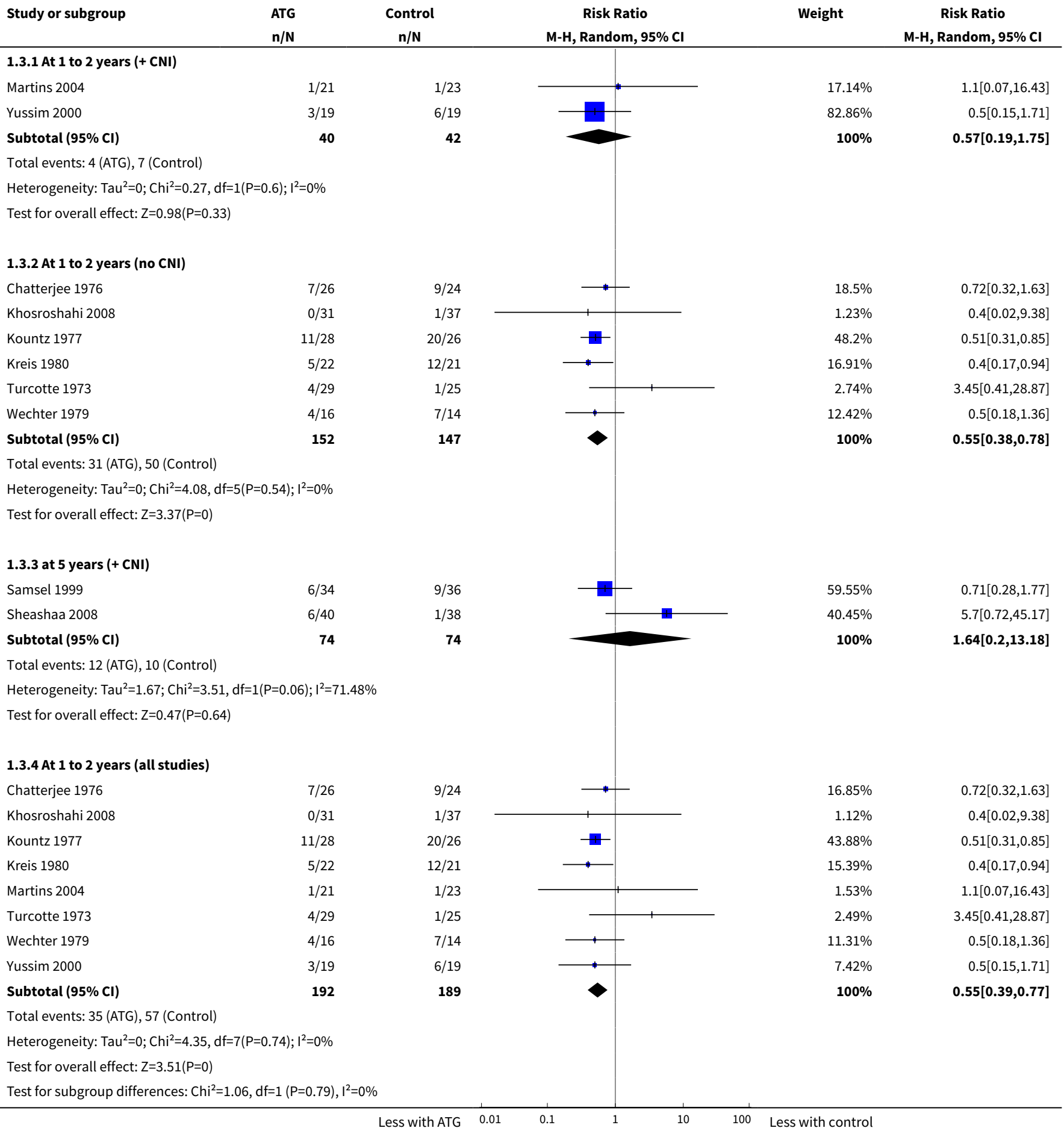


Analysis 1.4. Comparison 1 ATG versus placebo/no treatment, Outcome 4 Acute rejection.

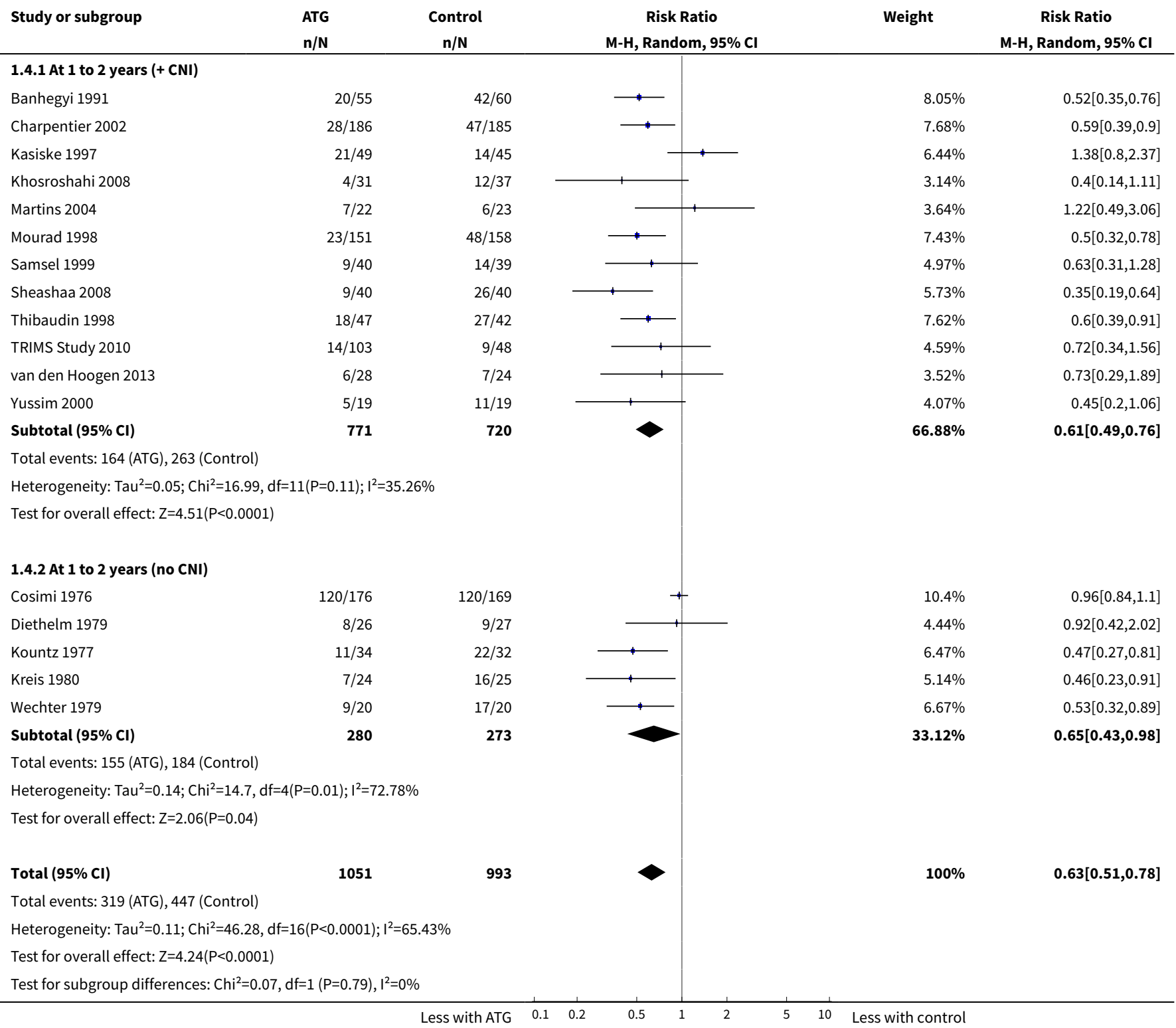

Analysis 1.5. Comparison 1 ATG versus placebo/no treatment, Outcome 5 Delayed graft function.

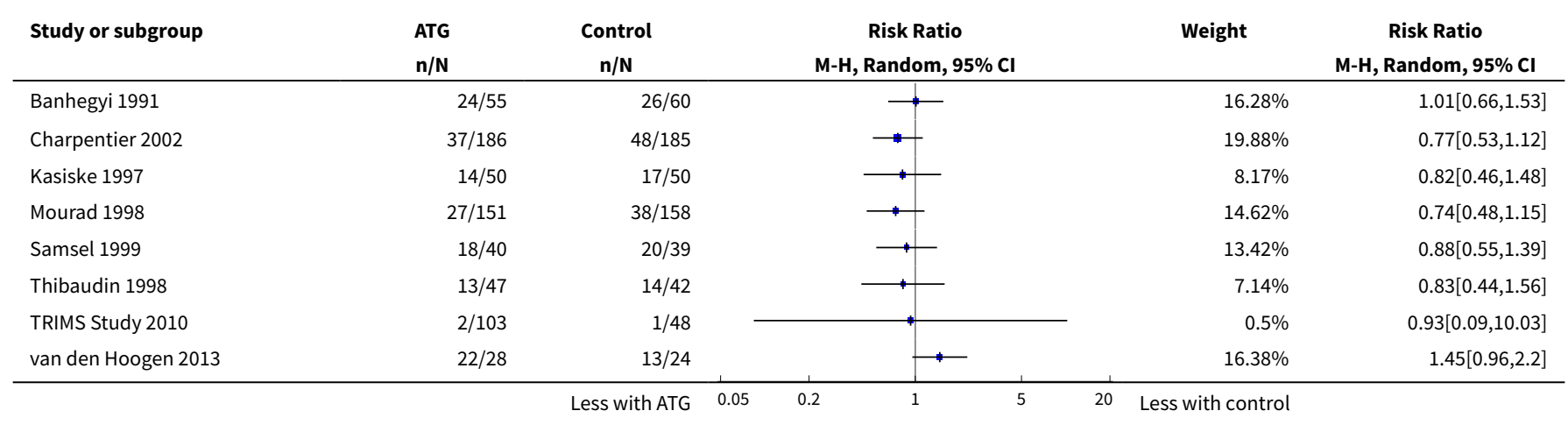




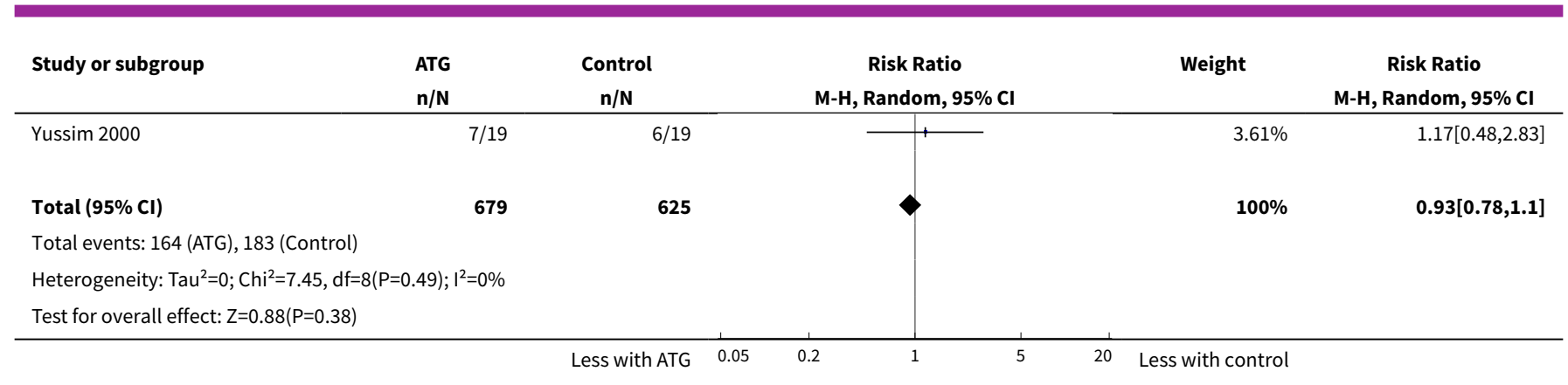

Analysis 1.6. Comparison 1 ATG versus placebo/no treatment, Outcome 6 Infection.

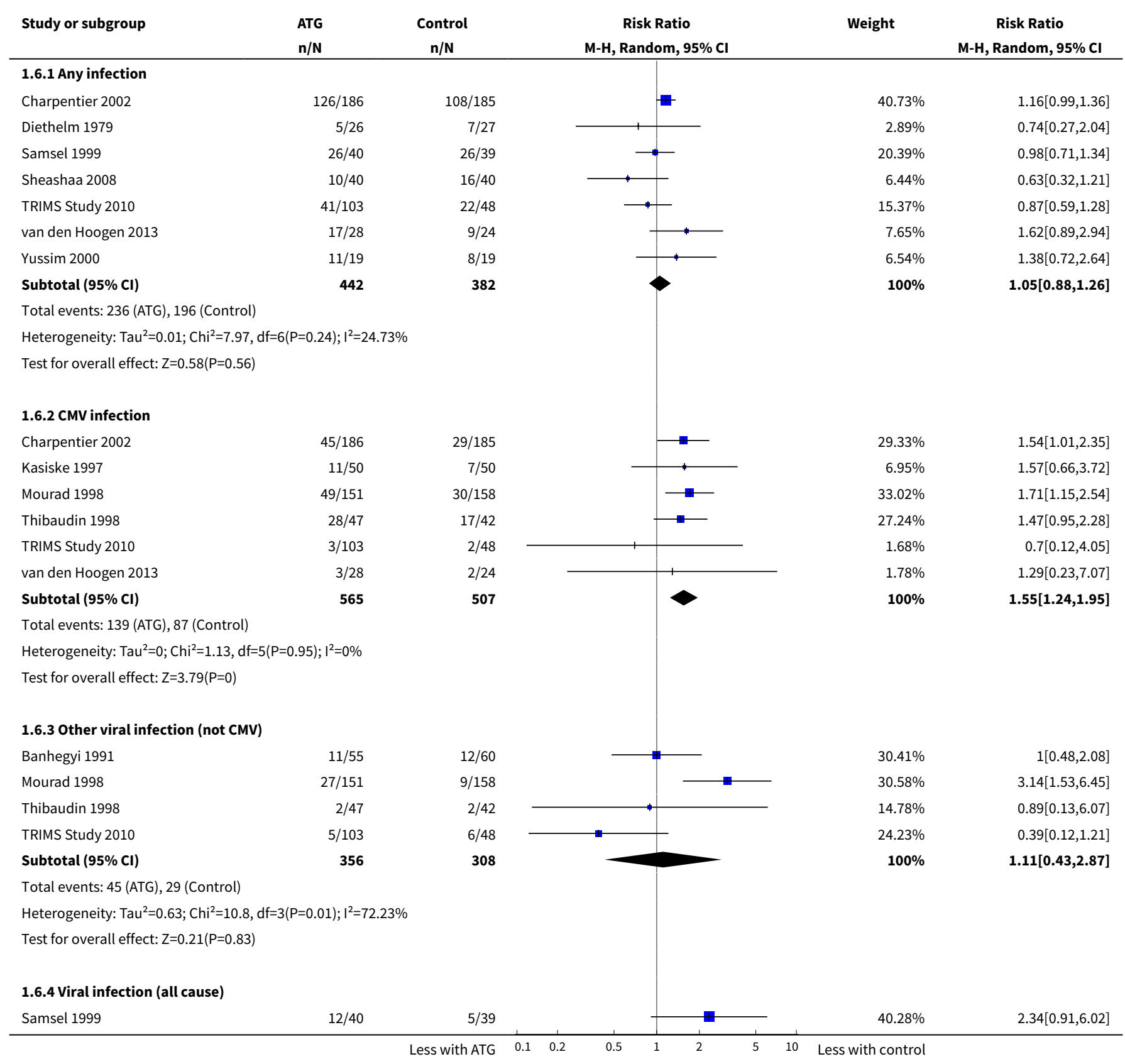




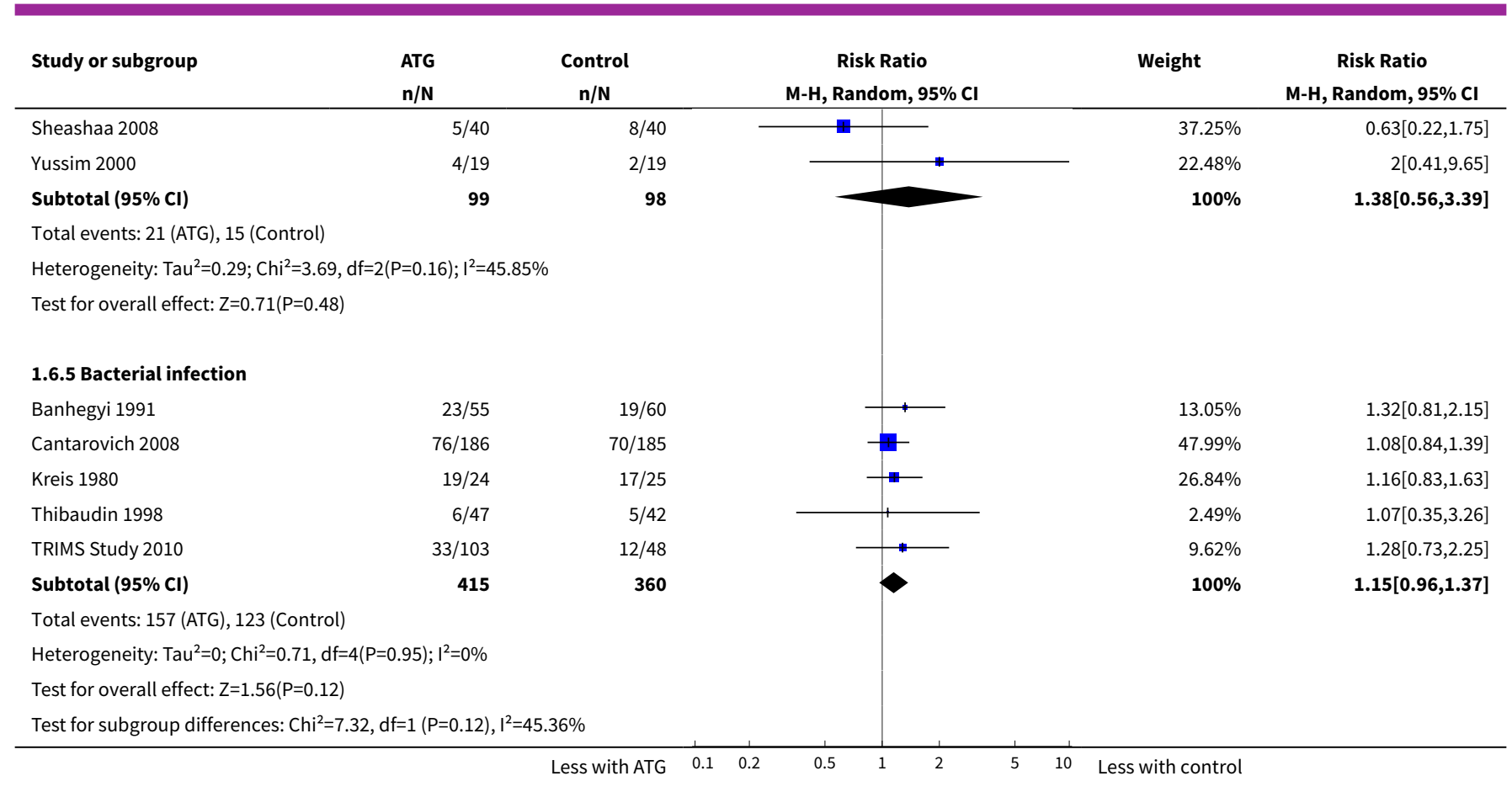

Analysis 1.7. Comparison 1 ATG versus placebo/no treatment, Outcome 7 Leucopenia.

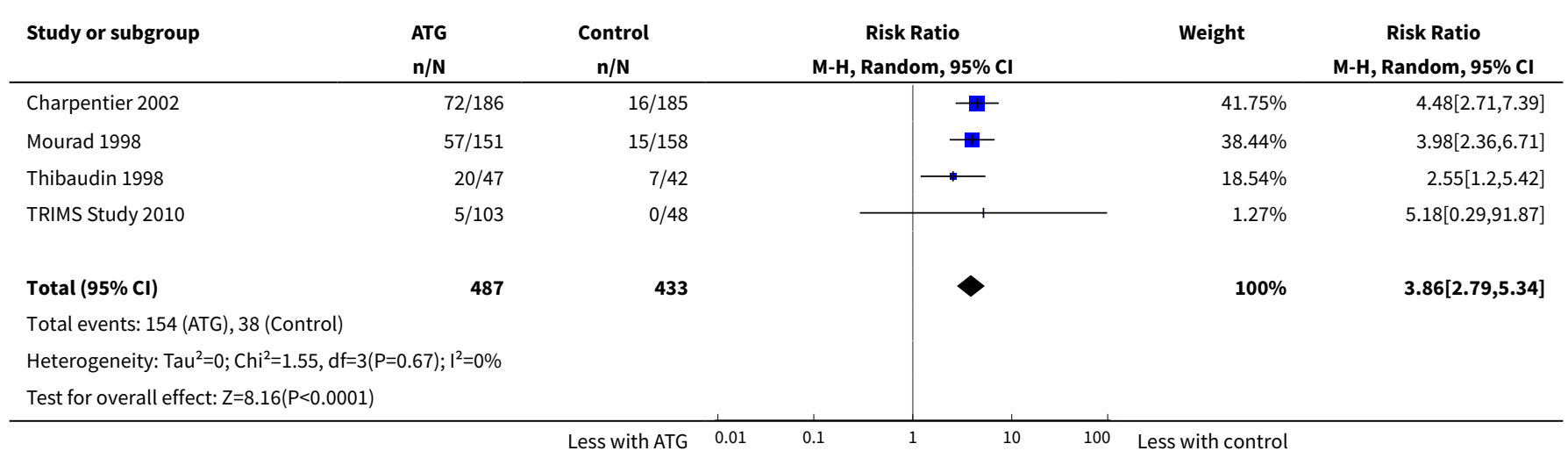

Analysis 1.8. Comparison 1 ATG versus placebo/no treatment, Outcome 8 Thrombocytopenia.

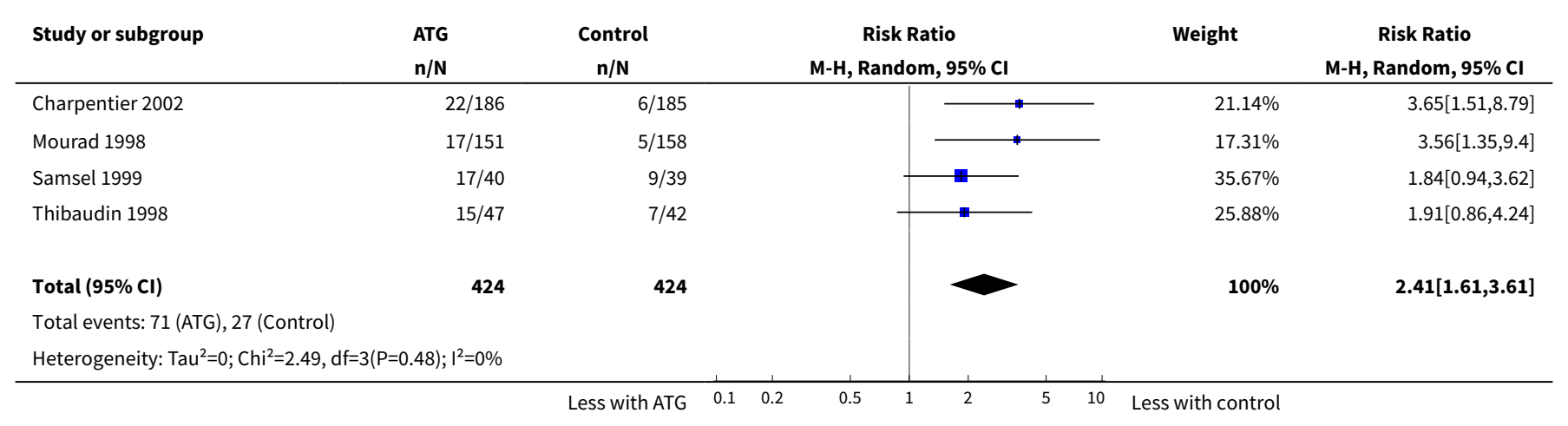




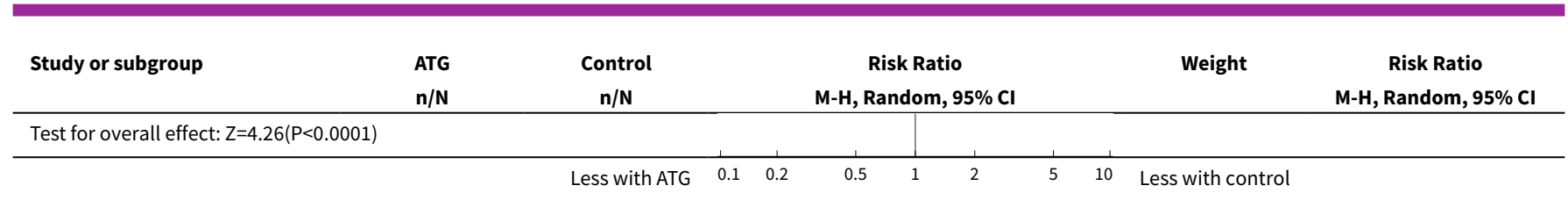

Analysis 1.9. Comparison 1 ATG versus placebo/no treatment, Outcome 9 Malignancy or PTLD.

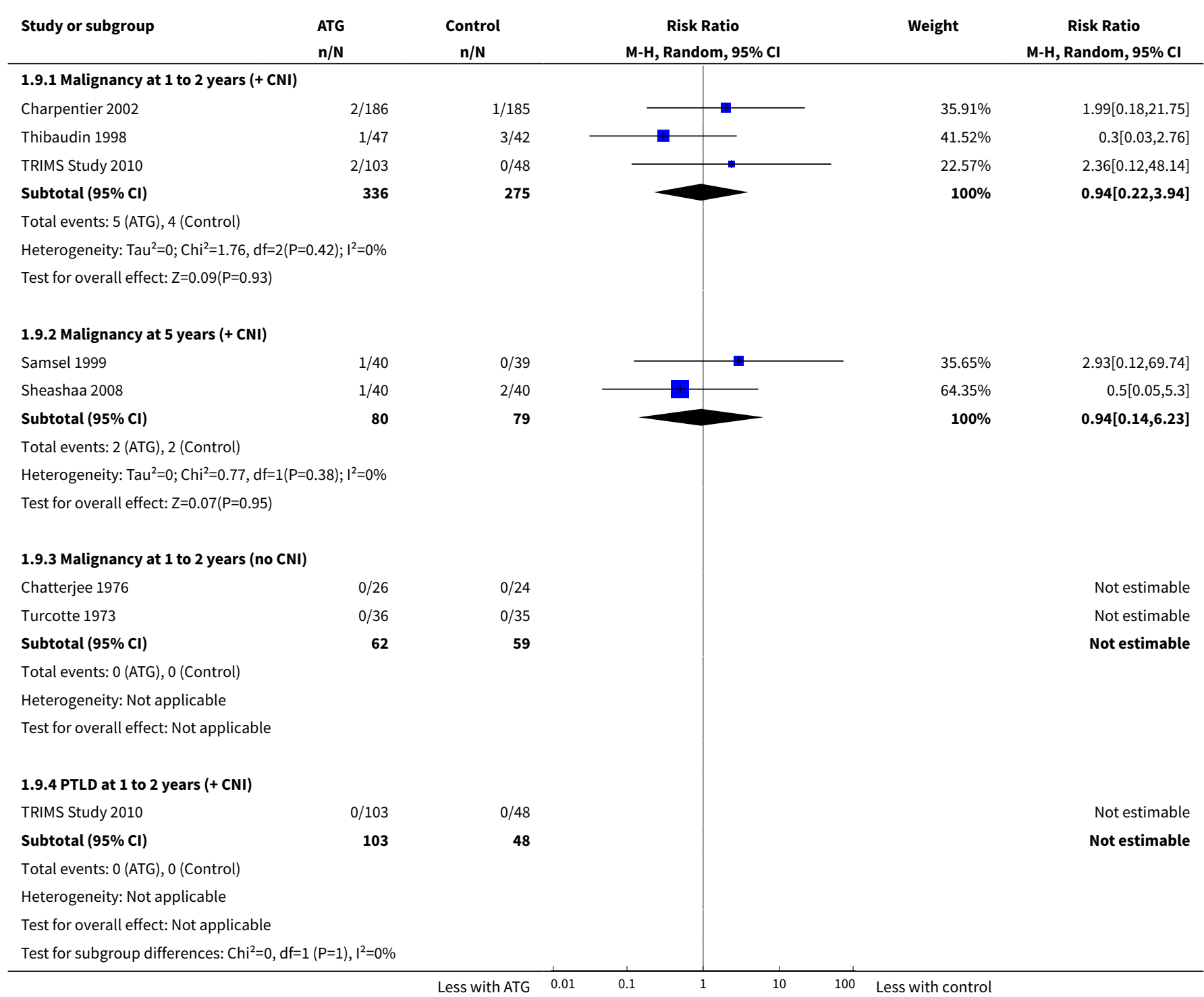

Analysis 1.10. Comparison 1 ATG versus placebo/no treatment, Outcome 10 Other adverse outcomes.

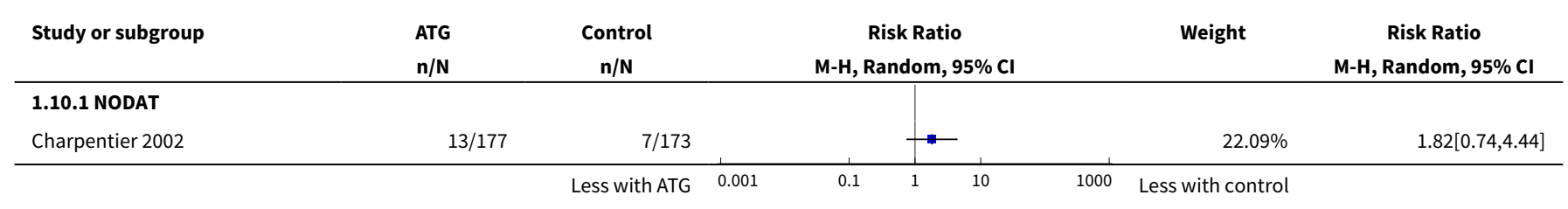




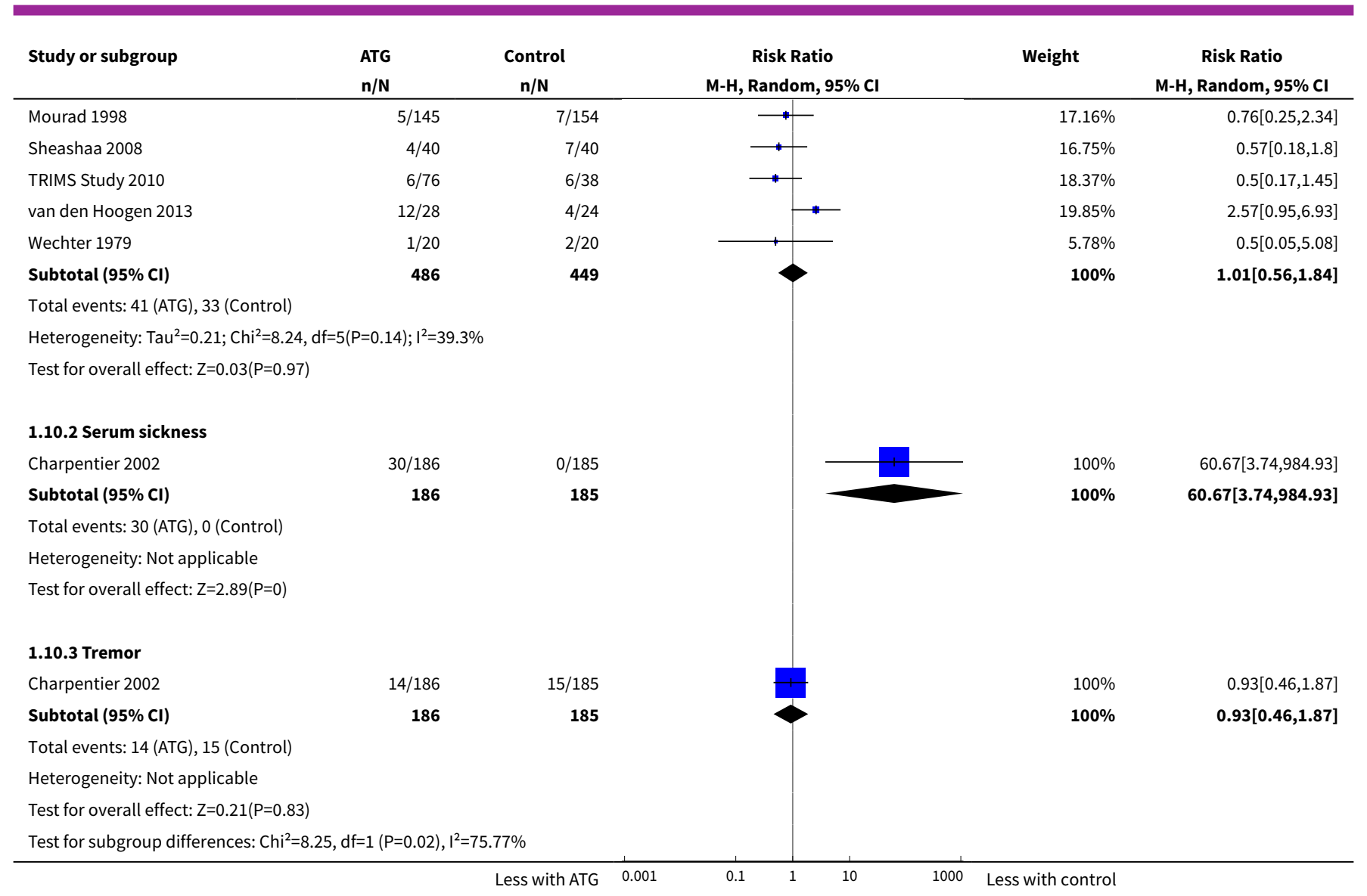

\section{Analysis 1.11. Comparison 1 ATG versus placebo/no treatment, Outcome 11 Serum creatinine.}

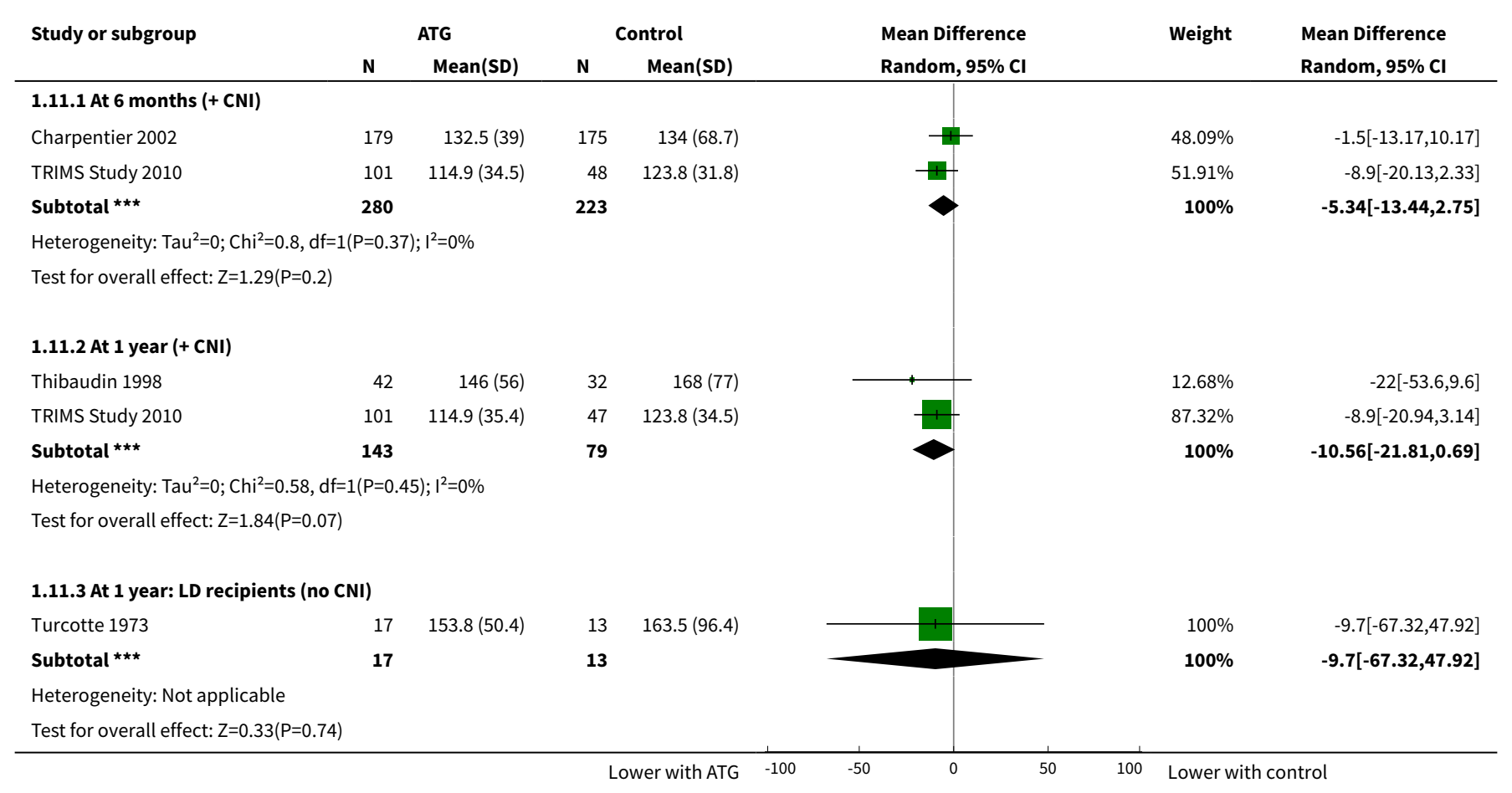




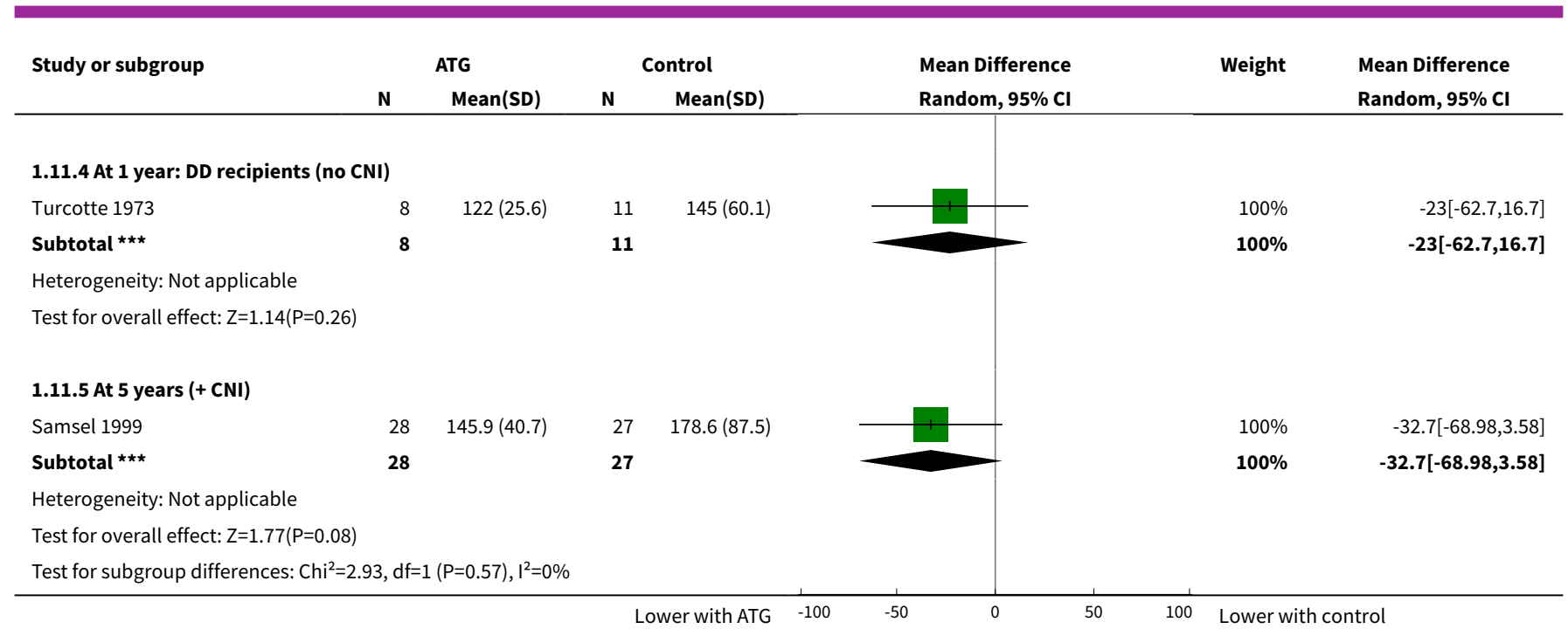

\section{Comparison 2. Rabbit ATG versus horse ATG}

\begin{tabular}{|c|c|c|c|c|}
\hline Outcome or subgroup title & No. of studies & $\begin{array}{l}\text { No. of partici- } \\
\text { pants }\end{array}$ & Statistical method & Effect size \\
\hline 1 Main outcomes & 3 & & Risk Ratio (M-H, Random, 95\% Cl) & Subtotals only \\
\hline 1.1 Death at 1 year & 2 & 139 & Risk Ratio (M-H, Random, $95 \% \mathrm{Cl}$ ) & $0.41[0.07,2.30]$ \\
\hline 1.2 Death at 10 years & 1 & 72 & Risk Ratio (M-H, Random, 95\% Cl) & $0.75[0.35,1.59]$ \\
\hline $\begin{array}{l}1.3 \text { Graft loss (all cause) at } 1 \\
\text { year }\end{array}$ & 2 & 139 & Risk Ratio (M-H, Random, 95\% Cl) & $0.31[0.08,1.27]$ \\
\hline $\begin{array}{l}1.4 \text { Graft loss (all cause) at } \\
10 \text { years }\end{array}$ & 1 & 72 & Risk Ratio (M-H, Random, 95\% Cl) & $0.96[0.58,1.58]$ \\
\hline $\begin{array}{l}1.5 \text { Acute rejection at } 1 \\
\text { month }\end{array}$ & 1 & 16 & Risk Ratio (M-H, Random, 95\% Cl) & $0.0[0.0,0.0]$ \\
\hline 1.6 Acute rejection at 1 year & 1 & 72 & Risk Ratio (M-H, Random, 95\% Cl) & $0.17[0.04,0.76]$ \\
\hline 1.7 Delayed graft function & 1 & 16 & Risk Ratio (M-H, Random, 95\% Cl) & $0.50[0.06,4.47]$ \\
\hline 2 Other adverse outcomes & 3 & & Risk Ratio (M-H, Random, 95\% Cl) & Totals not selected \\
\hline 2.1 Infection (all cause) & 1 & & Risk Ratio (M-H, Random, 95\% Cl) & $0.0[0.0,0.0]$ \\
\hline 2.2 CMV disease at 1 year & 1 & & Risk Ratio (M-H, Random, 95\% Cl) & $0.0[0.0,0.0]$ \\
\hline 2.3 Leucopenia & 1 & & Risk Ratio (M-H, Random, 95\% Cl) & $0.0[0.0,0.0]$ \\
\hline 2.4 Malignancy at 10 years & 1 & & Risk Ratio (M-H, Random, 95\% Cl) & $0.0[0.0,0.0]$ \\
\hline 2.5 Headache & 1 & & Risk Ratio (M-H, Random, 95\% Cl) & $0.0[0.0,0.0]$ \\
\hline
\end{tabular}




\begin{tabular}{lllll}
\hline Outcome or subgroup title & No. of studies & $\begin{array}{l}\text { No. of partici- } \\
\text { pants }\end{array}$ & Statistical method & Effect size \\
\hline 3 Serum creatinine & 1 & $\begin{array}{l}\text { Mean Difference (IV, Random, } 95 \% \\
\mathrm{Cl})\end{array}$ & Totals not selected \\
\hline 3.1 At 6 months & 1 & $\begin{array}{l}\text { Mean Difference (IV, Random, } 95 \% \\
\mathrm{Cl})\end{array}$ & $0.0[0.0,0.0]$ \\
\hline 3.2 At 10 years & 1 & $\begin{array}{l}\text { Mean Difference (IV, Random, } 95 \% \\
\text { Cl) }\end{array}$ & $0.0[0.0,0.0]$ \\
\hline
\end{tabular}

Analysis 2.1. Comparison 2 Rabbit ATG versus horse ATG, Outcome 1 Main outcomes.

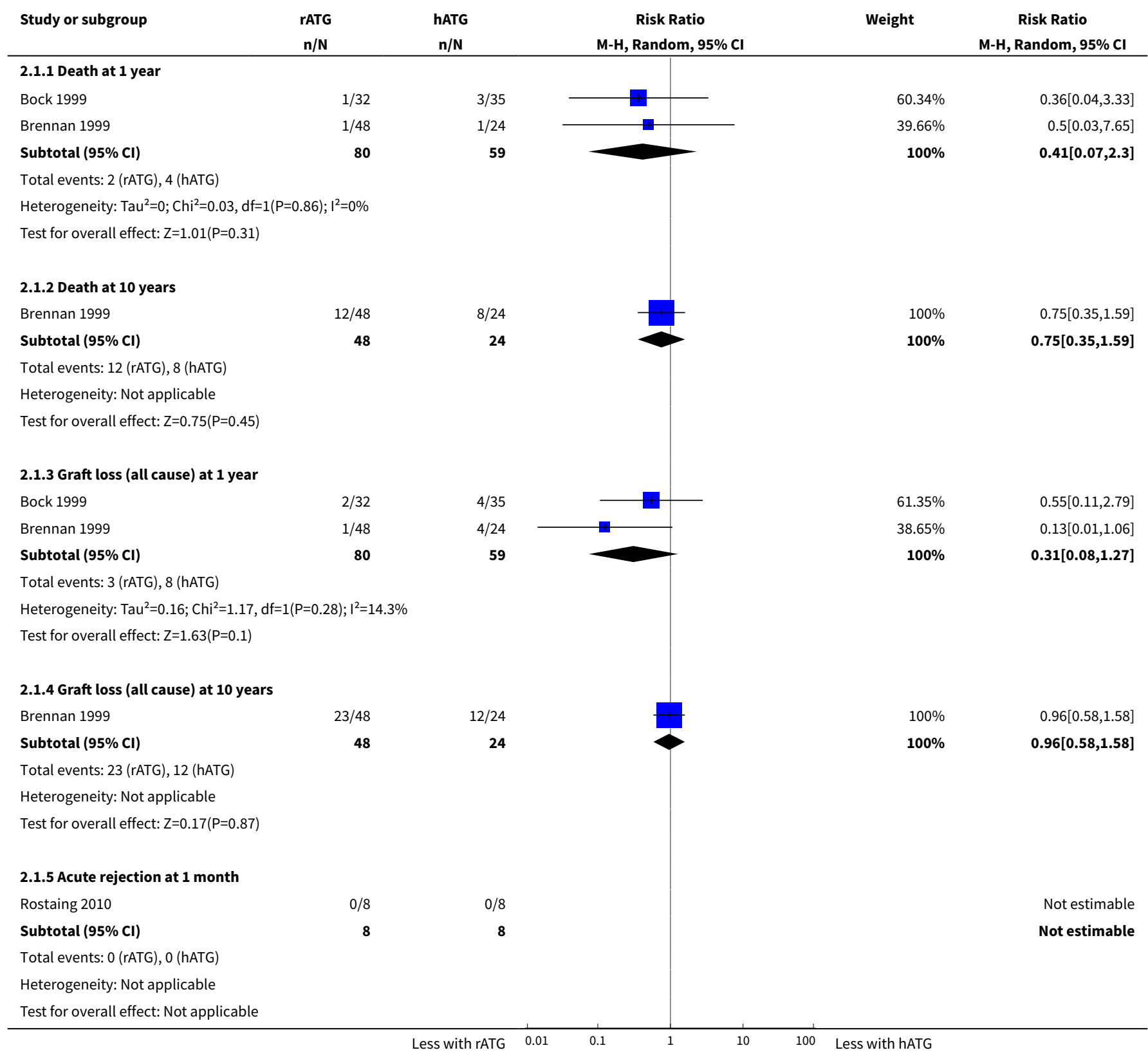




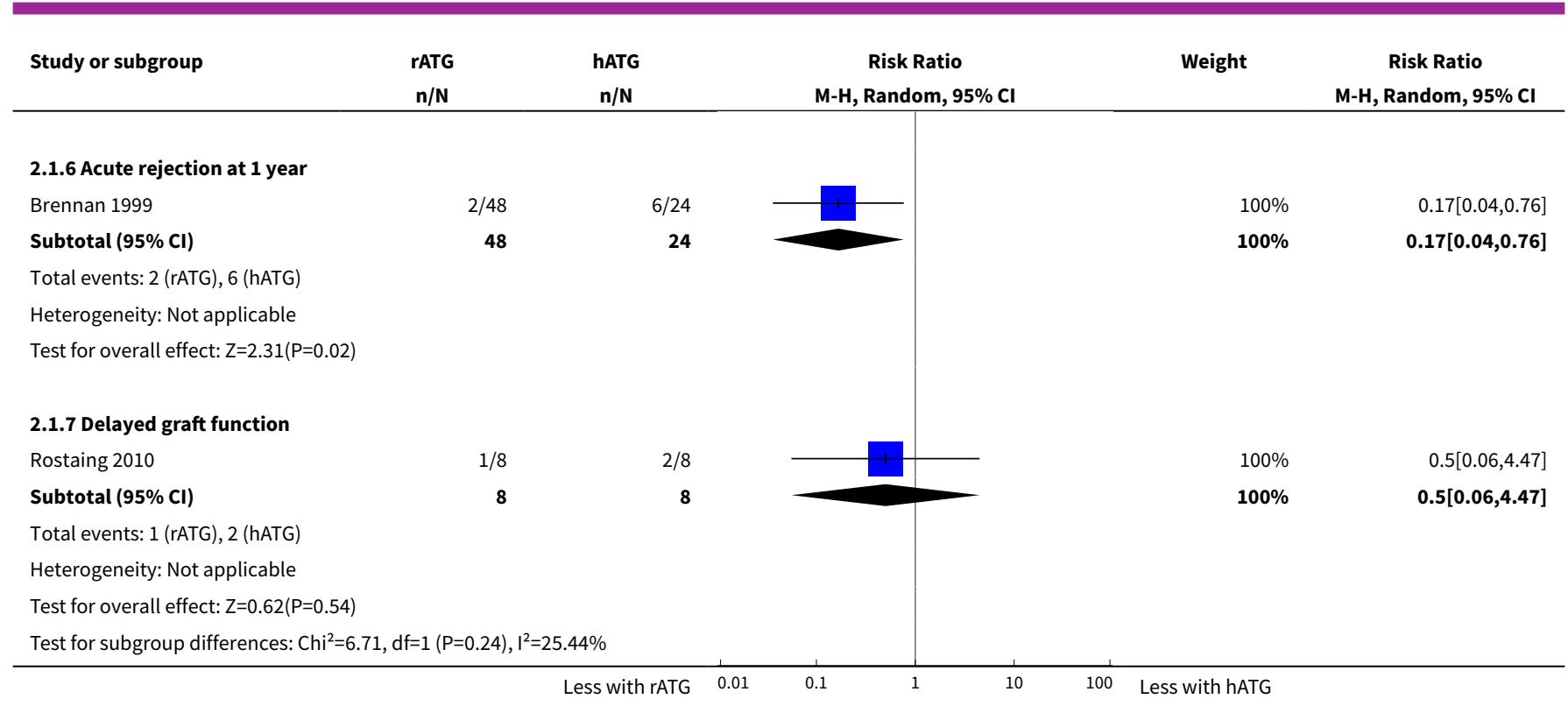

Analysis 2.2. Comparison 2 Rabbit ATG versus horse ATG, Outcome 2 Other adverse outcomes.

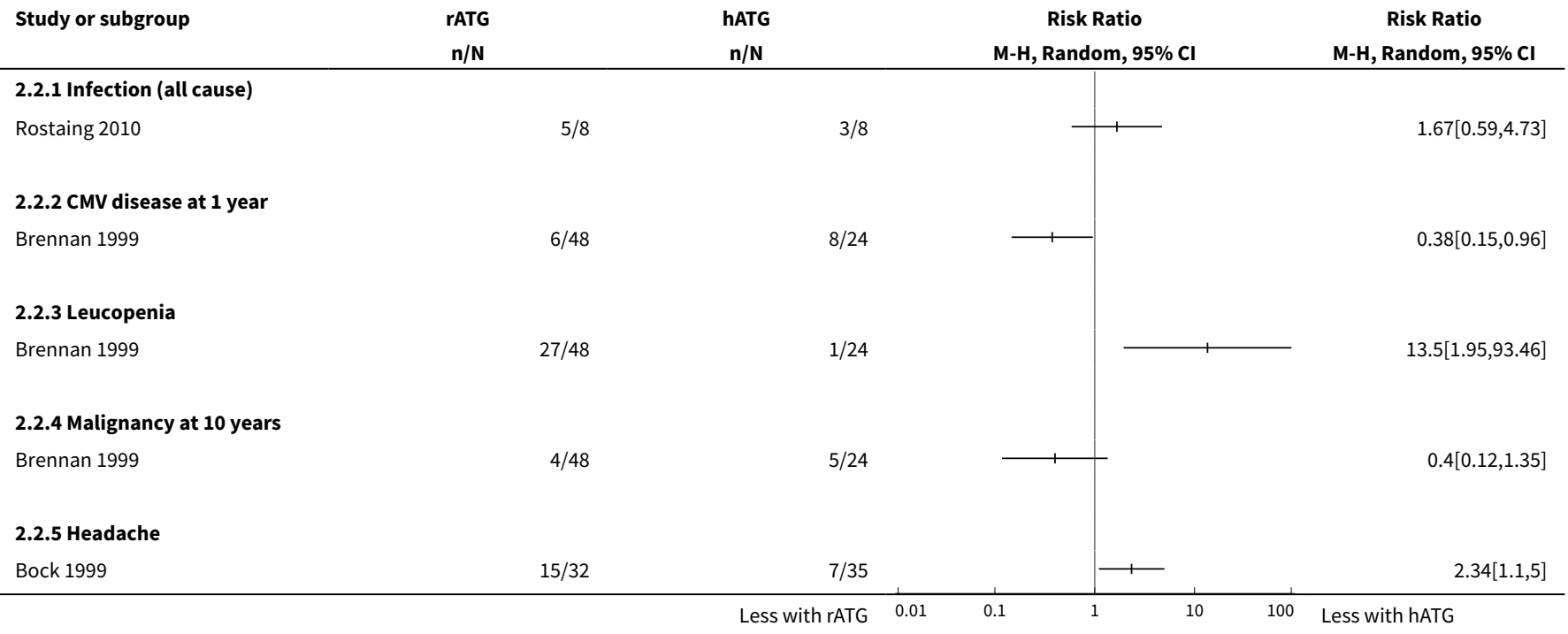

Analysis 2.3. Comparison 2 Rabbit ATG versus horse ATG, Outcome 3 Serum creatinine.

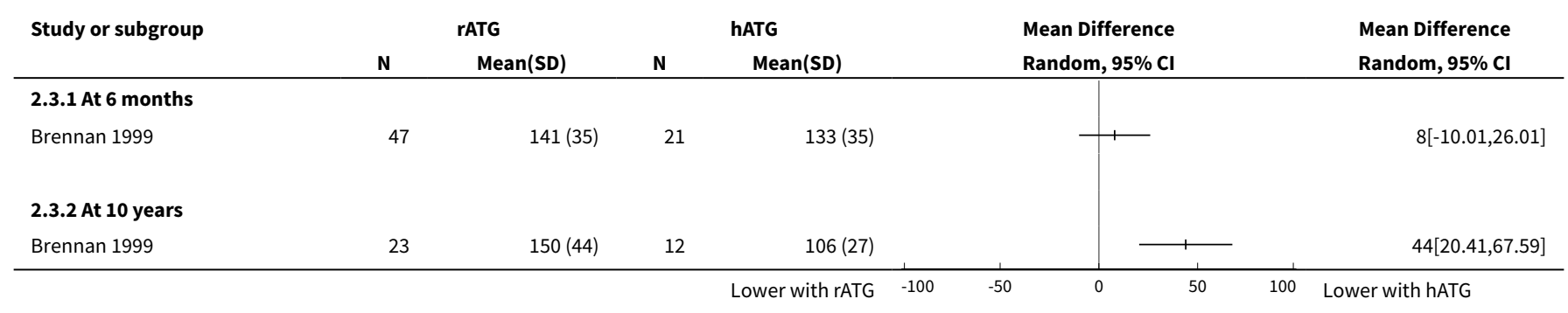


Comparison 3. Alemtuzumab + early steroid withdrawal (ESW) or minimisation versus ATG \pm ESW

\begin{tabular}{|c|c|c|c|c|}
\hline Outcome or subgroup title & No. of studies & $\begin{array}{l}\text { No. of partici- } \\
\text { pants }\end{array}$ & Statistical method & Effect size \\
\hline 1 Death and graft loss & 6 & & Risk Ratio (M-H, Random, 95\% Cl) & Subtotals only \\
\hline 1.1 Death at 1 year & 2 & 41 & Risk Ratio (M-H, Random, 95\% Cl) & $0.39[0.06,2.42]$ \\
\hline 1.2 Death at 2 to 3 years & 3 & 225 & Risk Ratio (M-H, Random, 95\% Cl) & $0.67[0.15,2.95]$ \\
\hline $\begin{array}{l}1.3 \text { Graft loss (all cause) at } 1 \\
\text { year }\end{array}$ & 2 & 41 & Risk Ratio (M-H, Random, 95\% Cl) & $0.39[0.12,1.30]$ \\
\hline $\begin{array}{l}1.4 \text { Graft loss (all cause) at } 2 \text { to } \\
3 \text { years }\end{array}$ & 3 & 379 & Risk Ratio (M-H, Random, 95\% Cl) & $0.98[0.47,2.06]$ \\
\hline $\begin{array}{l}1.5 \text { Graft loss (death censored) } \\
\text { at } 1 \text { year }\end{array}$ & 2 & 37 & Risk Ratio (M-H, Random, 95\% Cl) & $0.38[0.08,1.81]$ \\
\hline $\begin{array}{l}1.6 \text { Graft loss (death censored) } \\
\text { at } 2 \text { to } 3 \text { years }\end{array}$ & 2 & 186 & Risk Ratio (M-H, Random, 95\% Cl) & $2.45[0.67,8.97]$ \\
\hline 1.7 Delayed graft function & 2 & 86 & Risk Ratio (M-H, Random, 95\% Cl) & $0.62[0.13,3.07]$ \\
\hline 2 Rejection & 6 & & Risk Ratio (M-H, Random, 95\% Cl) & Subtotals only \\
\hline $\begin{array}{l}2.1 \text { Acute rejection at } 3 \text { to } 6 \\
\text { months (ESW both arms) }\end{array}$ & 3 & 341 & Risk Ratio (M-H, Random, 95\% Cl) & $0.47[0.17,1.30]$ \\
\hline $\begin{array}{l}2.2 \text { Acute rejection } \geq 1 \text { year (all } \\
\text { studies) }\end{array}$ & 6 & 446 & Risk Ratio (M-H, Random, 95\% Cl) & $0.68[0.44,1.05]$ \\
\hline $\begin{array}{l}2.3 \text { Acute rejection } \geq 1 \text { year } \\
\text { (ESW both arms) }\end{array}$ & 4 & 360 & Risk Ratio (M-H, Random, 95\% Cl) & $0.57[0.35,0.93]$ \\
\hline $\begin{array}{l}2.4 \text { Acute rejection } \geq 1 \text { year } \\
\text { (ESW with alemtuzumab only) }\end{array}$ & 2 & 86 & Risk Ratio (M-H, Random, 95\% Cl) & $1.27[0.50,3.19]$ \\
\hline $\begin{array}{l}2.5 \text { CAN (biopsy proven) (ESW } \\
\text { with alemtuzumab only) }\end{array}$ & 2 & 86 & Risk Ratio (M-H, Random, 95\% Cl) & $2.45[1.02,5.94]$ \\
\hline 3 Infection & 4 & & Risk Ratio (M-H, Random, 95\% Cl) & Subtotals only \\
\hline $\begin{array}{l}3.1 \text { All cause (moderate-se- } \\
\text { vere) }\end{array}$ & 4 & 247 & Risk Ratio (M-H, Random, 95\% Cl) & $0.94[0.63,1.41]$ \\
\hline 3.2 CMV infection & 3 & 225 & Risk Ratio (M-H, Random, 95\% Cl) & $1.08[0.46,2.56]$ \\
\hline 3.3 BK virus infection & 2 & 86 & Risk Ratio (M-H, Random, 95\% Cl) & $3.0[0.13,70.83]$ \\
\hline 4 Other adverse effects & 4 & & Risk Ratio (M-H, Random, 95\% Cl) & Subtotals only \\
\hline 4.1 Leucopenia at 1 month & 1 & 60 & Risk Ratio (M-H, Random, 95\% Cl) & $21.0[1.29,342.93]$ \\
\hline 4.2 Leucopenia at 2 years & 1 & 53 & Risk Ratio (M-H, Random, 95\% Cl) & $3.12[0.35,28.06]$ \\
\hline
\end{tabular}




\begin{tabular}{lllll}
\hline Outcome or subgroup title & No. of studies & $\begin{array}{l}\text { No. of partici- } \\
\text { pants }\end{array}$ & Statistical method & Effect size \\
\hline 4.3 NODAT & 2 & 69 & Risk Ratio (M-H, Random, 95\% Cl) & $0.41[0.12,1.40]$ \\
\hline 4.4 Malignancy & 3 & 187 & Risk Ratio (M-H, Random, 95\% Cl) & $4.93[0.59,41.11]$ \\
\hline 4.5 PTLD & 2 & 165 & Risk Ratio (M-H, Random, 95\% Cl) & $0.0[0.0,0.0]$ \\
\hline 4.6 Cytokine release syndrome & 1 & 22 & Risk Ratio (M-H, Random, 95\% Cl) & $0.2[0.01,3.74]$ \\
\hline 4.7 Any serious adverse event & 1 & 139 & Risk Ratio (M-H, Random, 95\% Cl) & $0.81[0.59,1.12]$ \\
\hline 5 Creatinine clearance & 2 & & $\begin{array}{l}\text { Mean Difference (IV, Random, } \\
95 \% \text { Cl) }\end{array}$ & Subtotals only \\
\hline 5.1 At 6 months & & & $\begin{array}{l}\text { Mean Difference (IV, Random, } \\
95 \% \text { Cl) }\end{array}$ & $-13.35[-23.91,-2.80]$ \\
\hline 5.2 At 24 months & 2 & 83 & $\begin{array}{l}\text { Mean Difference (IV, Random, } \\
95 \% \text { Cl) }\end{array}$ & $-12.86[-23.73,-2.00]$ \\
\hline
\end{tabular}

Analysis 3.1. Comparison 3 Alemtuzumab + early steroid withdrawal (ESW) or minimisation versus ATG \pm ESW, Outcome 1 Death and graft loss.

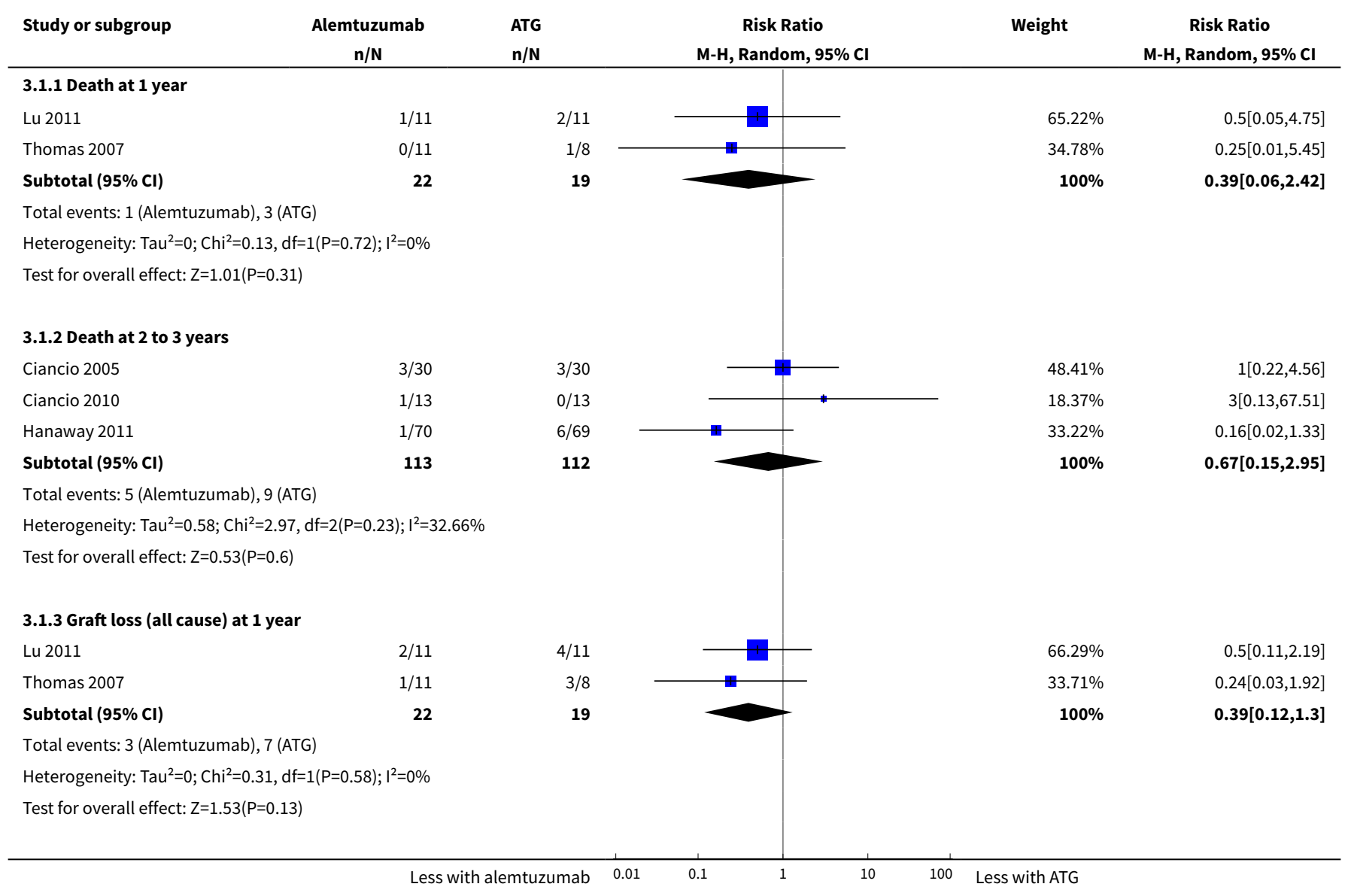




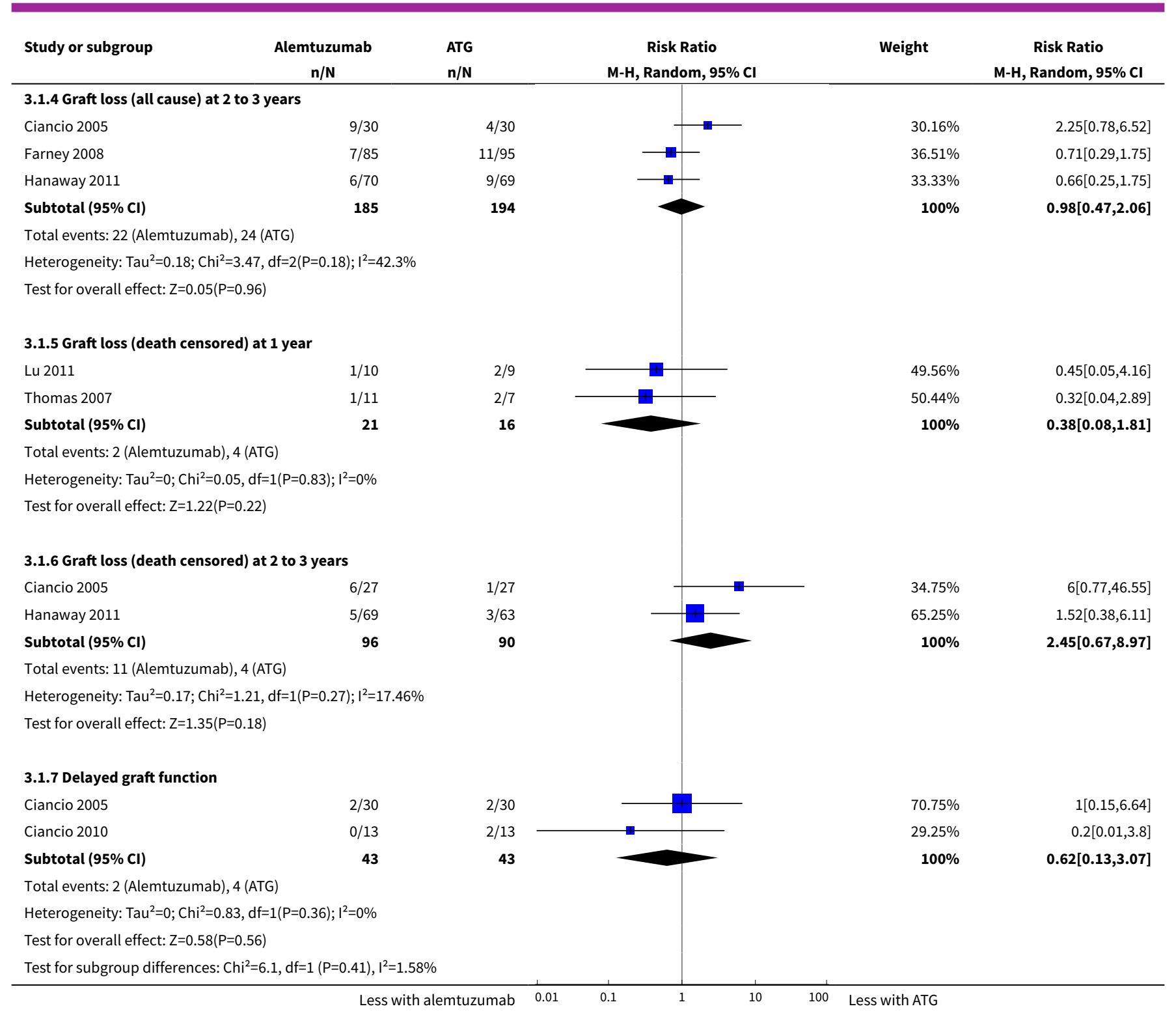

\section{Analysis 3.2. Comparison 3 Alemtuzumab + early steroid withdrawal (ESW) or minimisation versus ATG \pm ESW, Outcome 2 Rejection.}

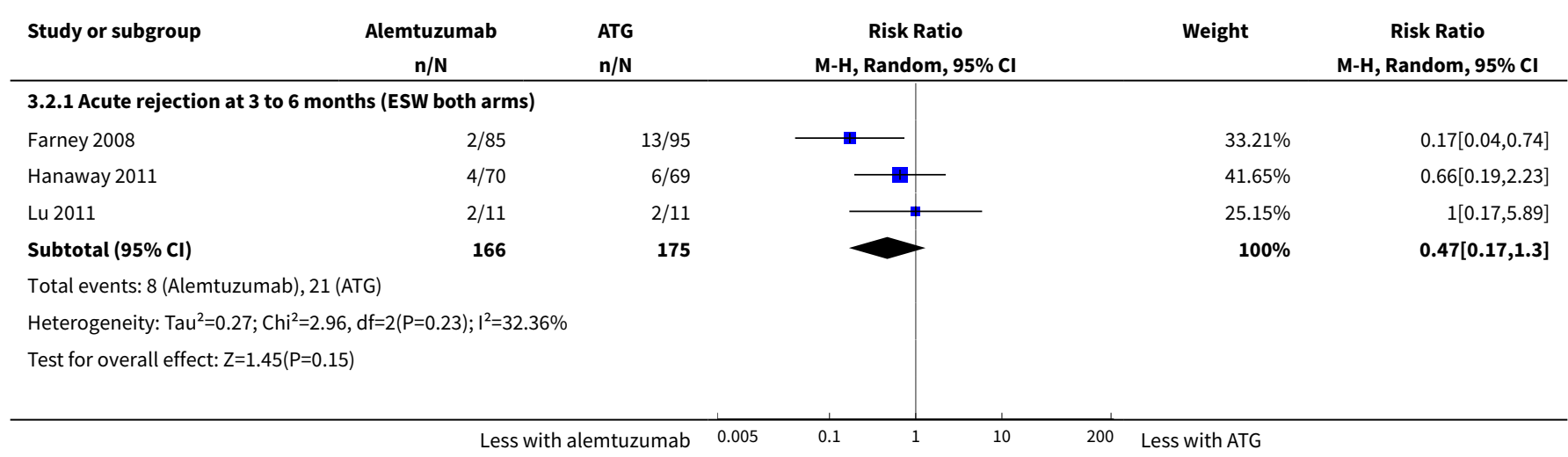




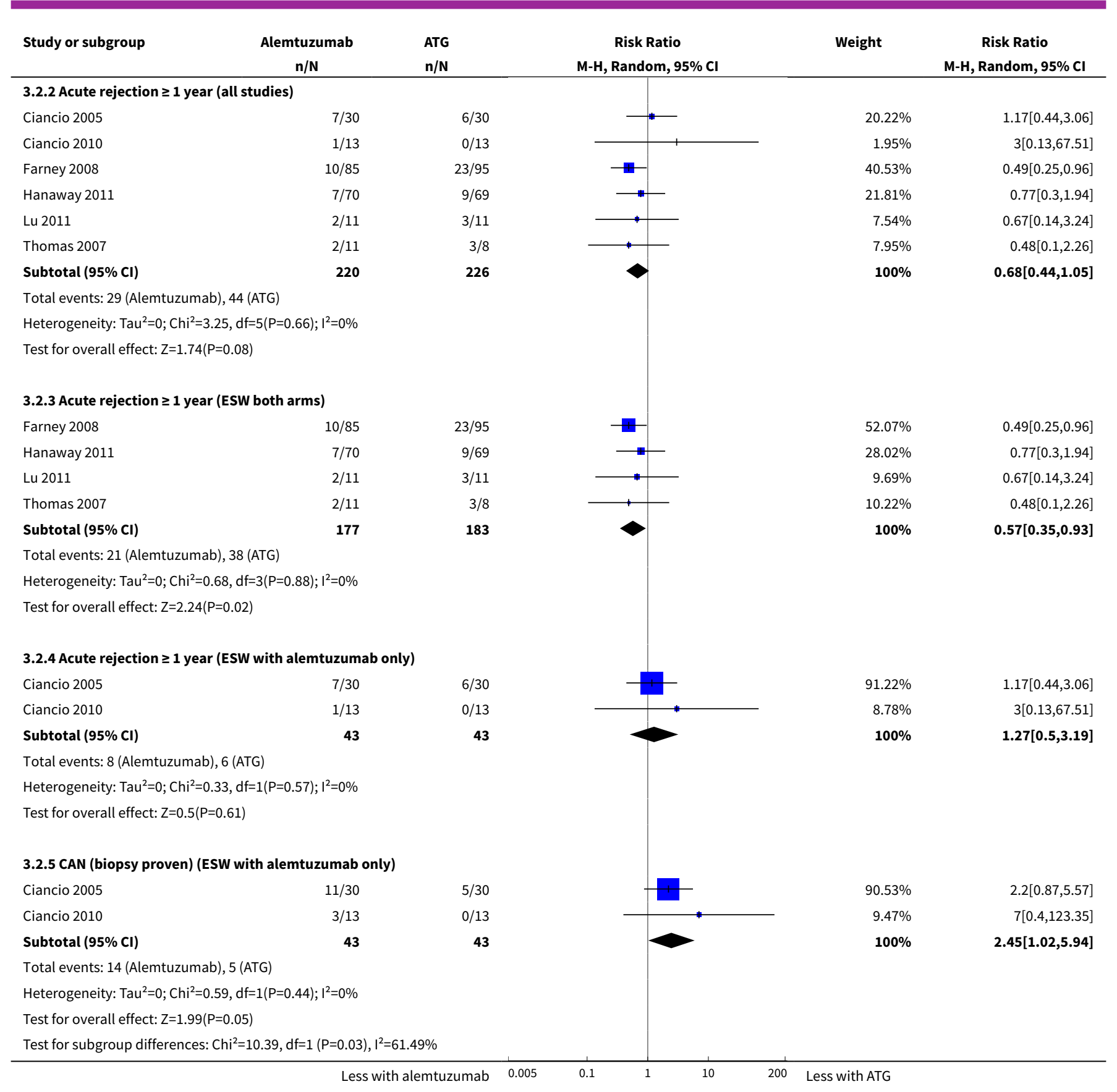

\section{Analysis 3.3. Comparison 3 Alemtuzumab + early steroid withdrawal (ESW) or minimisation versus ATG \pm ESW, Outcome 3 Infection.}

\begin{tabular}{|c|c|c|c|c|c|}
\hline Study or subgroup & $\begin{array}{c}\text { Alemtuzumab } \\
\mathrm{n} / \mathrm{N} \\
\end{array}$ & $\begin{array}{l}\text { ATG } \\
\mathrm{n} / \mathrm{N}\end{array}$ & $\begin{array}{c}\text { Risk Ratio } \\
\text { M-H, Random, 95\% Cl }\end{array}$ & Weight & $\begin{array}{c}\text { Risk Ratio } \\
\text { M-H, Random, 95\% CI }\end{array}$ \\
\hline \multicolumn{6}{|c|}{ 3.3.1 All cause (moderate-severe) } \\
\hline Ciancio 2005 & $8 / 30$ & $8 / 30$ & $\longrightarrow$ & $23.07 \%$ & $1[0.43,2.31]$ \\
\hline Ciancio 2010 & $3 / 13$ & $1 / 13$ & 1 & $3.59 \%$ & $3[0.36,25.21]$ \\
\hline Hanaway 2011 & $19 / 70$ & $23 / 69$ & - & $62.81 \%$ & $0.81[0.49,1.35]$ \\
\hline
\end{tabular}




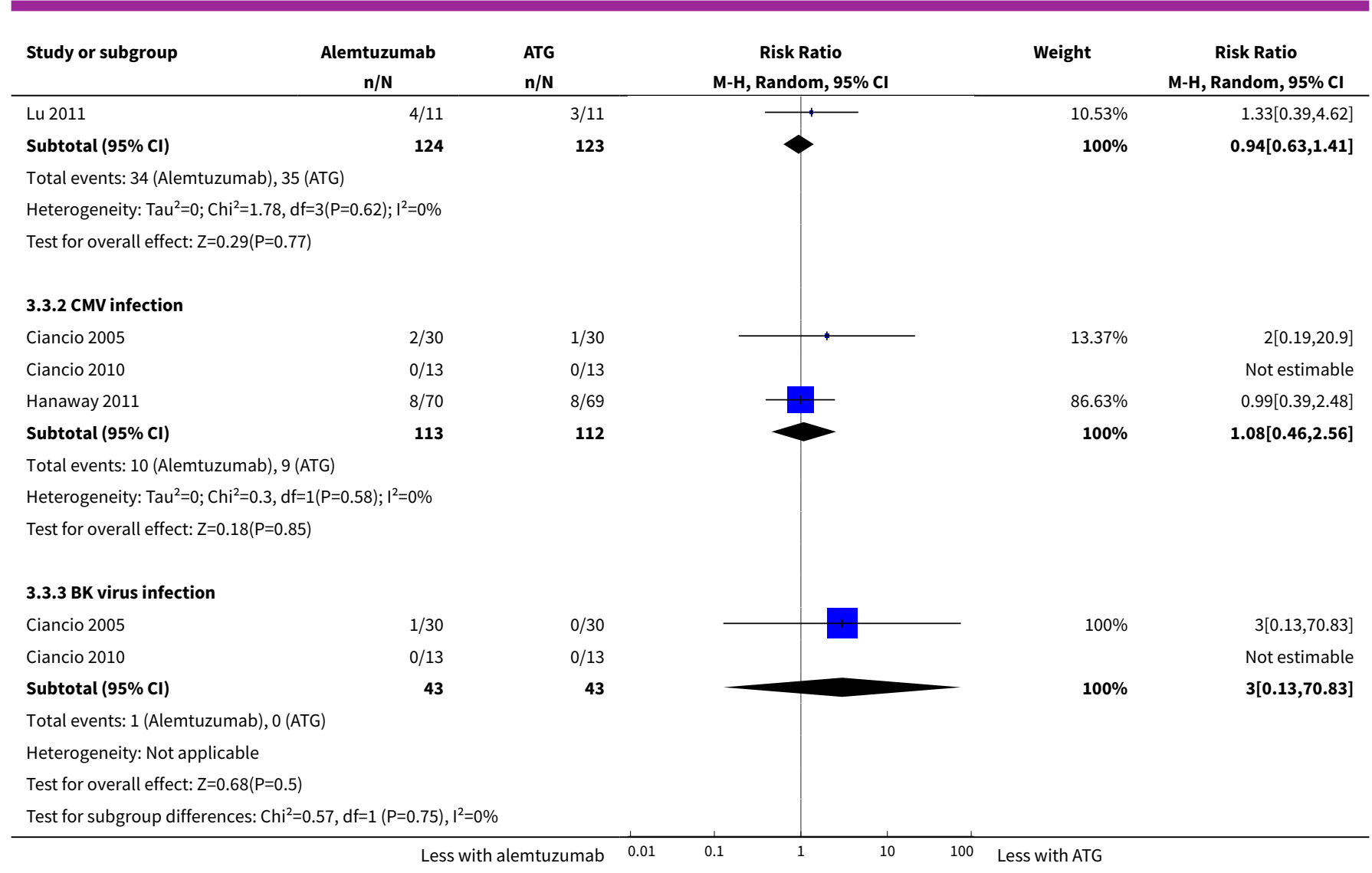

Analysis 3.4. Comparison 3 Alemtuzumab + early steroid withdrawal (ESW) or minimisation versus ATG \pm ESW, Outcome 4 Other adverse effects.

\begin{tabular}{|c|c|c|c|c|c|}
\hline Study or subgroup & $\begin{array}{c}\text { Alemtuzumab } \\
\mathrm{n} / \mathrm{N} \\
\end{array}$ & $\begin{array}{l}\text { ATG } \\
\mathrm{n} / \mathrm{N}\end{array}$ & $\begin{array}{c}\text { Risk Ratio } \\
\text { M-H, Random, } 95 \% \mathrm{Cl}\end{array}$ & Weight & $\begin{array}{c}\text { Risk Ratio } \\
\text { M-H, Random, } 95 \% \mathrm{Cl}\end{array}$ \\
\hline \multicolumn{6}{|c|}{ 3.4.1 Leucopenia at 1 month } \\
\hline Ciancio 2005 & $10 / 30$ & $0 / 30$ & & $100 \%$ & $21[1.29,342.93]$ \\
\hline Subtotal $(95 \% \mathrm{CI})$ & 30 & 30 & & $100 \%$ & $21[1.29,342.93]$ \\
\hline \multicolumn{6}{|c|}{ Total events: 10 (Alemtuzumab), 0 (ATG) } \\
\hline \multicolumn{6}{|c|}{ Heterogeneity: Not applicable } \\
\hline \multicolumn{6}{|c|}{ Test for overall effect: $Z=2.14(P=0.03)$} \\
\hline \multicolumn{6}{|c|}{ 3.4.2 Leucopenia at 2 years } \\
\hline Ciancio 2005 & $3 / 26$ & $1 / 27$ & & $100 \%$ & $3.12[0.35,28.06]$ \\
\hline Subtotal $(95 \% \mathrm{Cl})$ & 26 & 27 & & $100 \%$ & $3.12[0.35,28.06]$ \\
\hline \multicolumn{6}{|c|}{ Total events: 3 (Alemtuzumab), 1 (ATG) } \\
\hline \multicolumn{6}{|c|}{ Heterogeneity: Not applicable } \\
\hline \multicolumn{6}{|c|}{ Test for overall effect: $Z=1.01(P=0.31)$} \\
\hline \multicolumn{6}{|l|}{ 3.4.3 NODAT } \\
\hline Ciancio 2005 & $2 / 18$ & $6 / 27$ & - & $67 \%$ & $0.5[0.11,2.21]$ \\
\hline Ciancio 2010 & $1 / 13$ & $3 / 11$ & \begin{tabular}{l|l}
$-1+$ \\
-
\end{tabular} & $33 \%$ & $0.28[0.03,2.34]$ \\
\hline Subtotal $(95 \% \mathrm{Cl})$ & 31 & 38 & & $100 \%$ & $0.41[0.12,1.4]$ \\
\hline \multicolumn{6}{|c|}{ Total events: 3 (Alemtuzumab), 9 (ATG) } \\
\hline
\end{tabular}




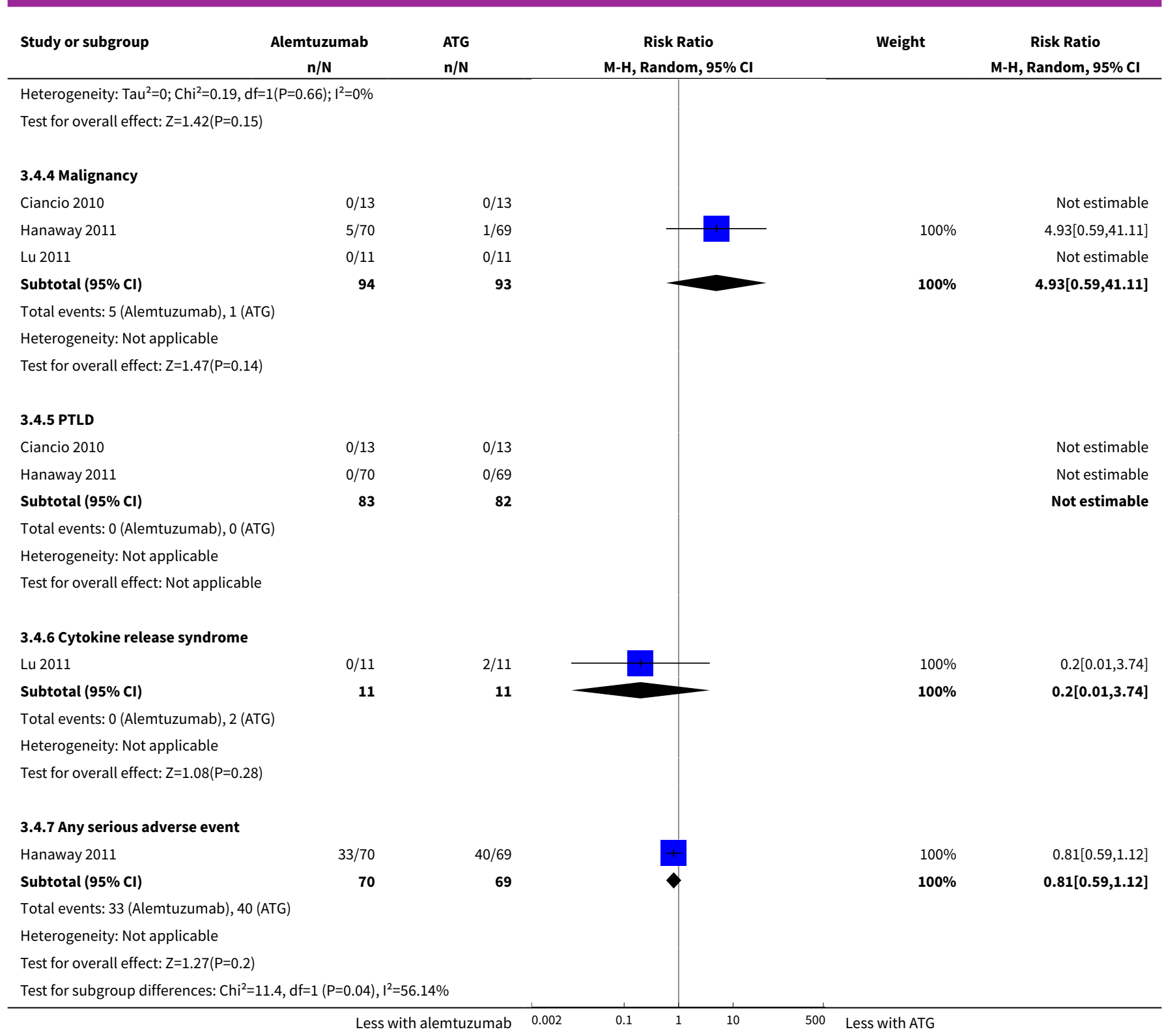

Analysis 3.5. Comparison 3 Alemtuzumab + early steroid withdrawal (ESW) or minimisation versus ATG \pm ESW, Outcome 5 Creatinine clearance.

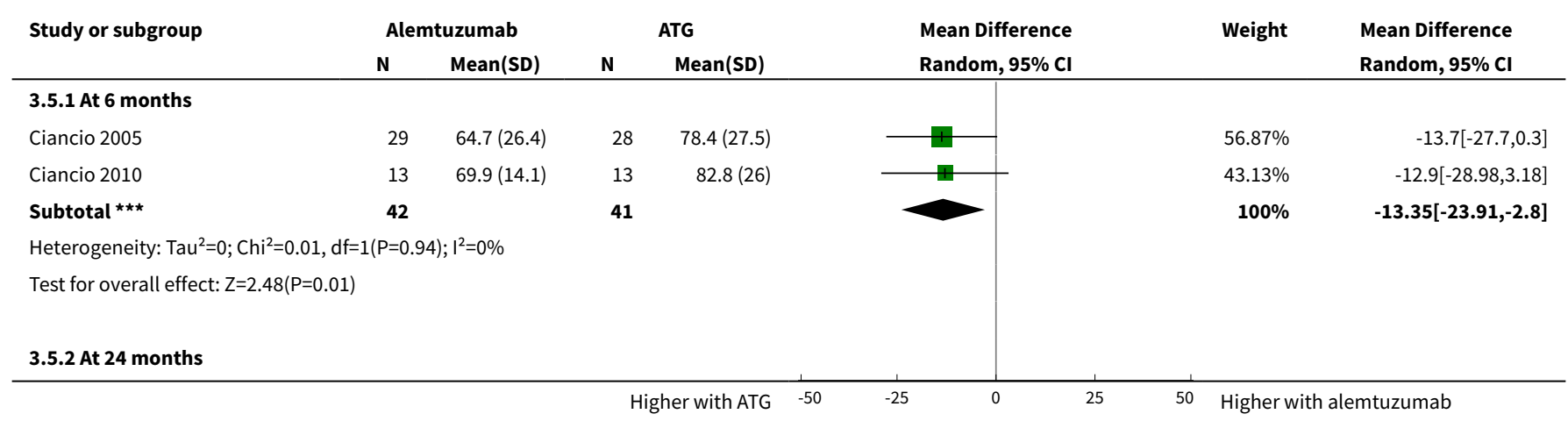




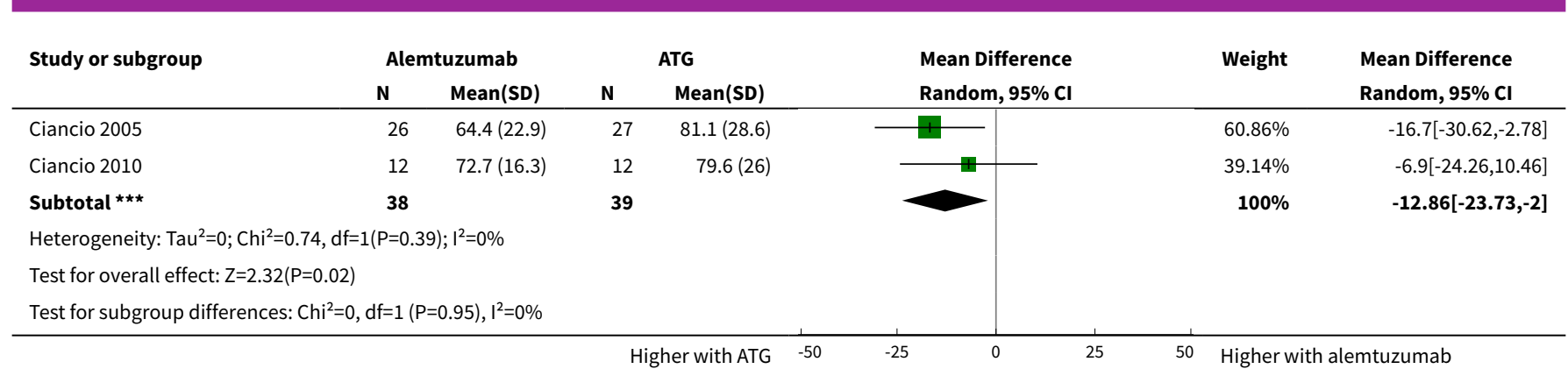

Comparison 4. Alemtuzumab + early steroid withdrawal (ESW) versus no induction

\begin{tabular}{|c|c|c|c|c|}
\hline $\begin{array}{l}\text { Outcome or subgroup ti- } \\
\text { tle }\end{array}$ & No. of studies & $\begin{array}{l}\text { No. of partici- } \\
\text { pants }\end{array}$ & Statistical method & Effect size \\
\hline 1 Main outcomes & 4 & & Risk Ratio (M-H, Random, 95\% Cl) & Subtotals only \\
\hline $\begin{array}{l}1.1 \text { Death at } 6 \text { to } 12 \\
\text { months }\end{array}$ & 4 & 296 & Risk Ratio (M-H, Random, 95\% Cl) & $1.54[0.60,4.00]$ \\
\hline $\begin{array}{l}1.2 \text { Graft loss (all cause) at } \\
6 \text { to } 12 \text { months }\end{array}$ & 4 & 296 & Risk Ratio (M-H, Random, 95\% Cl) & $0.86[0.47,1.59]$ \\
\hline $\begin{array}{l}1.3 \text { Acute rejection at } 6 \\
\text { months }\end{array}$ & 3 & 213 & Risk Ratio (M-H, Random, 95\% Cl) & $0.72[0.48,1.08]$ \\
\hline 1.4 Acute rejection $\geq 1$ year & 3 & 244 & Risk Ratio (M-H, Random, 95\% Cl) & $0.89[0.42,1.87]$ \\
\hline 1.5 Delayed graft function & 1 & 30 & Risk Ratio (M-H, Random, 95\% Cl) & $2.0[0.26,15.62]$ \\
\hline 2 Other adverse outcomes & 3 & & Risk Ratio (M-H, Random, 95\% Cl) & Subtotals only \\
\hline 2.1 CMV infection & 2 & 161 & Risk Ratio (M-H, Random, 95\% Cl) & $2.28[1.18,4.40]$ \\
\hline 2.2 Infection (all cause) & 3 & 213 & Risk Ratio (M-H, Random, 95\% Cl) & $1.15[0.46,2.89]$ \\
\hline 2.3 NODAT & 2 & 161 & Risk Ratio (M-H, Random, 95\% Cl) & $0.57[0.13,2.46]$ \\
\hline 2.4 Thrombocytopenia & 1 & 30 & Risk Ratio (M-H, Random, 95\% Cl) & $1.33[0.45,3.96]$ \\
\hline 2.5 Malignancy or PTLD & 1 & 30 & Risk Ratio (M-H, Random, 95\% Cl) & $0.0[0.0,0.0]$ \\
\hline 3 Serum creatinine & 3 & & Mean Difference (IV, Random, 95\% CI) & Subtotals only \\
\hline 3.16 months & 1 & 27 & Mean Difference (IV, Random, 95\% CI) & $-5.0[-28.90,18.90]$ \\
\hline 3.21 year & 2 & 108 & Mean Difference (IV, Random, 95\% CI) & $-2.89[-43.29,37.52]$ \\
\hline
\end{tabular}




\section{Analysis 4.1. Comparison 4 Alemtuzumab + early steroid withdrawal (ESW) versus no induction, Outcome 1 Main outcomes.}

Study or subgroup

Alemtuzumab

Control
Risk Ratio

M-H, Random, $95 \% \mathrm{Cl}$

Weight

$\mathbf{n} / \mathbf{N}$

M-H, Random, $95 \% \mathrm{Cl}$

\subsubsection{Death at 6 to 12 months}

CAMPASIA Study 2005

Friend 1987

Margreiter 2008

Sharaf El Din 2006

Subtotal $(95 \% \mathrm{Cl})$

$1 / 20$

$5 / 26$

$1 / 65$

$7 / 63$

174

Total events: 14 (Alemtuzumab), 5 (Control)

Heterogeneity: $\mathrm{Tau}^{2}=0 ; \mathrm{Chi}^{2}=0.65, \mathrm{df}=3(\mathrm{P}=0.88) ; \mathrm{I}^{2}=0 \%$

Test for overall effect: $Z=0.89(P=0.37)$

\subsubsection{Graft loss (all cause) at $\mathbf{6}$ to 12 months}

CAMPASIA Study 2005

Friend 1987

Margreiter 2008

Sharaf El Din 2006

Subtotal $(95 \% \mathrm{Cl})$

$\begin{array}{rr}3 / 20 & 0 / 10 \\ 8 / 26 & 8 / 26 \\ 2 / 65 & 6 / 66 \\ 8 / 63 & 3 / 20 \\ 174 & 122\end{array}$

Total events: 21 (Alemtuzumab), 17 (Control)

Heterogeneity: $\mathrm{Tau}^{2}=0 ; \mathrm{Chi}^{2}=2.48, \mathrm{df}=3(\mathrm{P}=0.48) ; \mathrm{I}^{2}=0 \%$

Test for overall effect: $\mathrm{Z}=0.47(\mathrm{P}=0.64)$

\subsubsection{Acute rejection at 6 months}

CAMPASIA Study 2005

Friend 1987

Margreiter 2008

Subtotal $(95 \% \mathrm{CI})$

111

Total events: 27 (Alemtuzumab), 36 (Control)

Heterogeneity: $\mathrm{Tau}^{2}=0 ; \mathrm{Chi}^{2}=1.46, \mathrm{df}=2(\mathrm{P}=0.48) ; \mathrm{I}^{2}=0 \%$

Test for overall effect: $Z=1.6(P=0.11)$

\subsubsection{Acute rejection $\geq 1$ year}

CAMPASIA Study 2005

Margreiter 2008

$\begin{array}{rr}9 / 20 & 2 / 10 \\ 13 / 65 & 21 / 66 \\ 5 / 63 & 2 / 20 \\ 148 & 96\end{array}$

Sharaf El Din 2006

Subtotal $(95 \% \mathrm{Cl})$

148

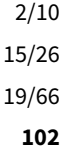

102

Total events: 27 (Alemtuzumab), 25 (Control)

Heterogeneity: $\mathrm{Tau}^{2}=0.16 ; \mathrm{Chi}^{2}=2.95, \mathrm{df}=2(\mathrm{P}=0.23) ; \mathrm{I}^{2}=32.17 \%$

Test for overall effect: $\mathrm{Z}=0.32(\mathrm{P}=0.75)$

\subsubsection{Delayed graft function}

CAMPASIA Study 2005

$4 / 20$

20

Subtotal $(95 \% \mathrm{CI})$

Total events: 4 (Alemtuzumab), 1 (Control)

Heterogeneity: Not applicable

Test for overall effect: $\mathrm{Z}=0.66(\mathrm{P}=0.51)$

Test for subgroup differences: $\mathrm{Chi}^{2}=2.84, \mathrm{df}=1(\mathrm{P}=0.59), \mathrm{I}^{2}=0 \%$

*

$9.33 \%$

$37.84 \%$

$11.97 \%$

$40.86 \%$

$100 \%$ 
Analysis 4.2. Comparison 4 Alemtuzumab + early steroid withdrawal (ESW) versus no induction, Outcome 2 Other adverse outcomes.

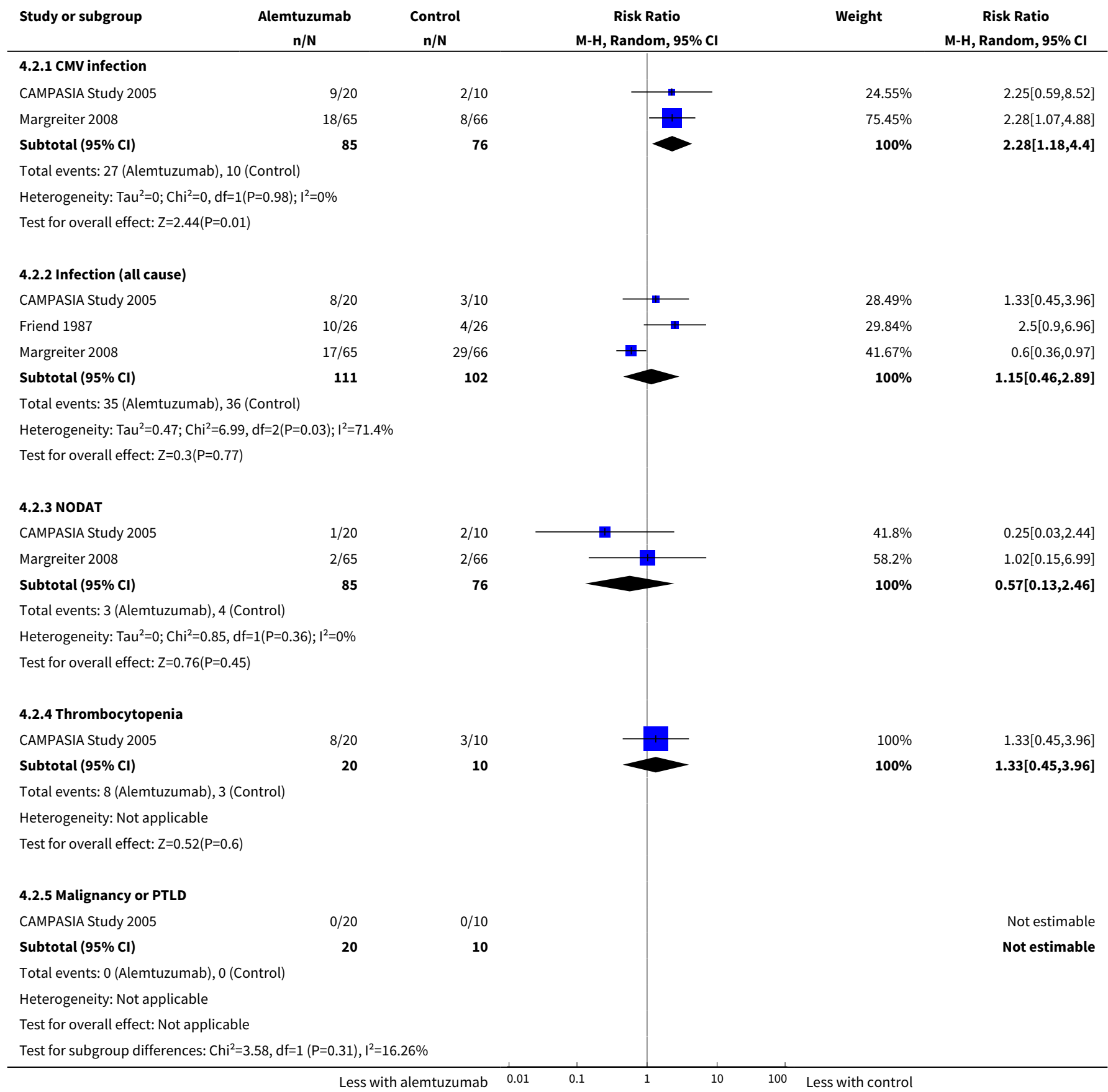

Analysis 4.3. Comparison 4 Alemtuzumab + early steroid withdrawal (ESW) versus no induction, Outcome 3 Serum creatinine.

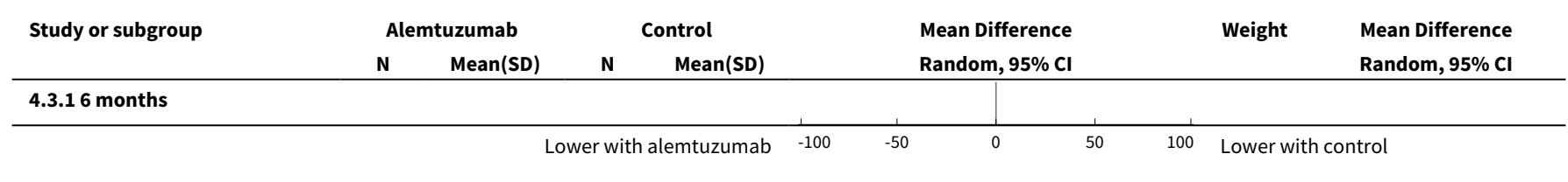

Polyclonal and monoclonal antibodies for induction therapy in kidney transplant recipients (Review) 


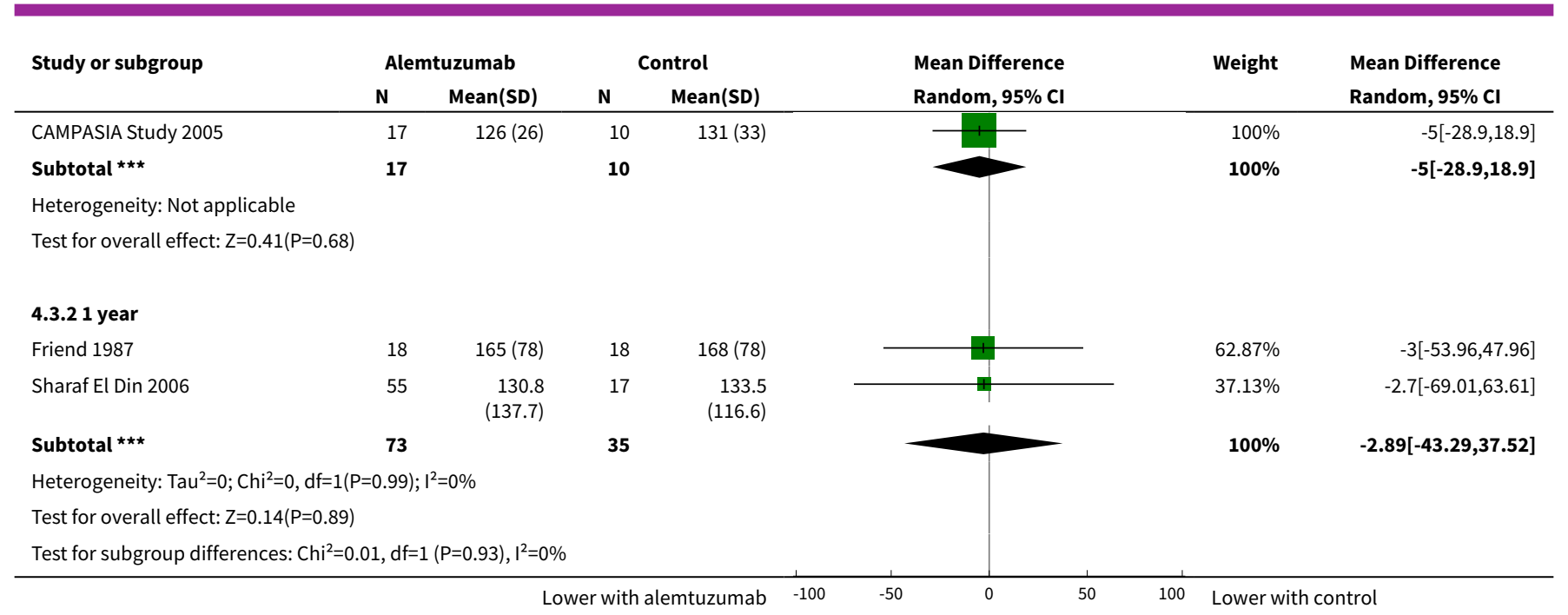

\section{Comparison 5. Rituximab versus placebo}

\begin{tabular}{|c|c|c|c|c|}
\hline Outcome or subgroup title & No. of studies & $\begin{array}{l}\text { No. of partici- } \\
\text { pants }\end{array}$ & Statistical method & Effect size \\
\hline 1 Main outcomes & 3 & & Risk Ratio (M-H, Random, 95\% Cl) & Subtotals only \\
\hline 1.1 Death at 6 months & 3 & 447 & Risk Ratio (M-H, Random, 95\% Cl) & $0.55[0.18,1.71]$ \\
\hline 1.2 Death at 3 to 4 years & 2 & 381 & Risk Ratio (M-H, Random, 95\% Cl) & $2.06[0.27,15.64]$ \\
\hline $\begin{array}{l}1.3 \text { Graft loss (all cause) at } 6 \\
\text { months }\end{array}$ & 2 & 416 & Risk Ratio (M-H, Random, 95\% Cl) & $0.58[0.26,1.28]$ \\
\hline $\begin{array}{l}1.4 \text { Graft loss (death cen- } \\
\text { sored) at } 6 \text { months }\end{array}$ & 2 & 405 & Risk Ratio (M-H, Random, 95\% Cl) & $0.55[0.21,1.46]$ \\
\hline $\begin{array}{l}1.5 \text { Acute rejection at } 6 \\
\text { months }\end{array}$ & 3 & 447 & Risk Ratio (M-H, Random, 95\% Cl) & $0.73[0.48,1.10]$ \\
\hline 1.6 Delayed graft function & 1 & 280 & Risk Ratio (M-H, Random, 95\% Cl) & $1.07[0.65,1.76]$ \\
\hline 2 Other adverse outcomes & 3 & & Risk Ratio (M-H, Random, 95\% Cl) & Subtotals only \\
\hline 2.1 CMV infection & 2 & 416 & Risk Ratio (M-H, Random, 95\% Cl) & $1.36[0.75,2.47]$ \\
\hline 2.2 BK virus infection & 1 & 136 & Risk Ratio (M-H, Random, 95\% Cl) & $0.25[0.03,2.18]$ \\
\hline $\begin{array}{l}2.3 \text { Fungal infection at } 6 \\
\text { months }\end{array}$ & 3 & 447 & Risk Ratio (M-H, Random, 95\% Cl) & $0.80[0.50,1.27]$ \\
\hline 2.4 Leucopenia at 6 months & 2 & 416 & Risk Ratio (M-H, Random, 95\% Cl) & $8.15[2.00,33.15]$ \\
\hline 2.5 Malignancy at 2 years & 1 & 280 & Risk Ratio (M-H, Random, 95\% Cl) & $1.03[0.40,2.66]$ \\
\hline $\begin{array}{l}3 \text { Graft function at } 6 \text { months } \\
\text { (eGFR) }\end{array}$ & 2 & 388 & $\begin{array}{l}\text { Mean Difference (IV, Random, 95\% } \\
\mathrm{Cl} \text { ) }\end{array}$ & $0.32[-3.34,3.97]$ \\
\hline
\end{tabular}


Analysis 5.1. Comparison 5 Rituximab versus placebo, Outcome 1 Main outcomes.

\begin{tabular}{|c|c|c|c|c|c|}
\hline \multirow[t]{2}{*}{ Study or subgroup } & Rituximab & $\begin{array}{l}\text { Placebo/no } \\
\text { induction }\end{array}$ & Risk Ratio & \multirow[t]{2}{*}{ Weight } & \multirow{2}{*}{$\begin{array}{c}\text { Risk Ratio } \\
\text { M-H, Random, } 95 \% \mathrm{Cl} \\
\end{array}$} \\
\hline & $n / N$ & $n / N$ & M-H, Random, $95 \% \mathrm{CI}$ & & \\
\hline \multicolumn{6}{|c|}{ 5.1.1 Death at 6 months } \\
\hline Smeekens 2013 & $3 / 138$ & $6 / 142$ & 口十 & $69.57 \%$ & $0.51[0.13,2.02]$ \\
\hline Tsai 2012 & $0 / 15$ & $1 / 16$ & & $13.28 \%$ & $0.35[0.02,8.08]$ \\
\hline Tyden 2009 & $1 / 68$ & $1 / 68$ & & $17.15 \%$ & $1[0.06,15.66]$ \\
\hline Subtotal $(95 \% \mathrm{Cl})$ & 221 & 226 & & $100 \%$ & $0.55[0.18,1.71]$ \\
\hline \multicolumn{6}{|c|}{ Total events: 4 (Rituximab), 8 (Placebo/no induction) } \\
\hline \multicolumn{6}{|c|}{ Heterogeneity: $\mathrm{Tau}^{2}=0 ; \mathrm{Chi}^{2}=0.27, \mathrm{df}=2(\mathrm{P}=0.88) ; \mathrm{I}^{2}=0 \%$} \\
\hline \multicolumn{6}{|c|}{ Test for overall effect: $Z=1.03(P=0.3)$} \\
\hline \multicolumn{6}{|c|}{ 5.1.2 Death at 3 to 4 years } \\
\hline Smeekens 2013 & $18 / 138$ & 20/142 & & $61.06 \%$ & $0.93[0.51,1.67]$ \\
\hline Tyden 2009 & $8 / 53$ & $1 / 48$ & —- & $38.94 \%$ & $7.25[0.94,55.82]$ \\
\hline Subtotal $(95 \% \mathrm{Cl})$ & 191 & 190 & & $100 \%$ & $2.06[0.27,15.64]$ \\
\hline \multicolumn{6}{|c|}{ Total events: 26 (Rituximab), 21 (Placebo/no induction) } \\
\hline \multicolumn{6}{|c|}{ Heterogeneity: $\mathrm{Tau}^{2}=1.66 ; \mathrm{Chi}^{2}=3.82, \mathrm{df}=1(\mathrm{P}=0.05) ; \mathrm{I}^{2}=73.81 \%$} \\
\hline \multicolumn{6}{|c|}{ Test for overall effect: $\mathrm{Z}=0.7(\mathrm{P}=0.48)$} \\
\hline \multicolumn{6}{|c|}{ 5.1.3 Graft loss (all cause) at 6 months } \\
\hline Smeekens 2013 & $7 / 138$ & $14 / 142$ & & $82.91 \%$ & $0.51[0.21,1.24]$ \\
\hline Tyden 2009 & $2 / 68$ & $2 / 68$ & & $17.09 \%$ & $1[0.15,6.9]$ \\
\hline Subtotal $(95 \% \mathrm{Cl})$ & 206 & 210 & & $100 \%$ & $0.58[0.26,1.28]$ \\
\hline \multicolumn{6}{|c|}{ Total events: 9 (Rituximab), 16 (Placebo/no induction) } \\
\hline \multicolumn{6}{|c|}{ Heterogeneity: Tau $^{2}=0 ; \mathrm{Chi}^{2}=0.38, \mathrm{df}=1(\mathrm{P}=0.54) ; \mathrm{I}^{2}=0 \%$} \\
\hline \multicolumn{6}{|c|}{ Test for overall effect: $Z=1.35(P=0.18)$} \\
\hline \multicolumn{6}{|c|}{ 5.1.4 Graft loss (death censored) at 6 months } \\
\hline Smeekens 2013 & $5 / 135$ & $10 / 136$ & & $87.35 \%$ & $0.5[0.18,1.43]$ \\
\hline Tyden 2009 & $1 / 67$ & $1 / 67$ & & $12.65 \%$ & $1[0.06,15.66]$ \\
\hline Subtotal $(95 \% \mathrm{Cl})$ & 202 & 203 & & $100 \%$ & $0.55[0.21,1.46]$ \\
\hline \multicolumn{6}{|c|}{ Total events: 6 (Rituximab), 11 (Placebo/no induction) } \\
\hline \multicolumn{6}{|c|}{ Heterogeneity: Tau $^{2}=0 ; \mathrm{Chi}^{2}=0.21, \mathrm{df}=1(\mathrm{P}=0.65) ; \mathrm{I}^{2}=0 \%$} \\
\hline \multicolumn{6}{|c|}{ Test for overall effect: $Z=1.2(P=0.23)$} \\
\hline \multicolumn{6}{|c|}{ 5.1.5 Acute rejection at 6 months } \\
\hline Smeekens 2013 & $23 / 138$ & $30 / 142$ & & $72.51 \%$ & $0.79[0.48,1.29]$ \\
\hline Tsai 2012 & $0 / 15$ & $4 / 16$ & & $2.16 \%$ & $0.12[0.01,2.02]$ \\
\hline Tyden 2009 & $8 / 68$ & $12 / 68$ & $\rightarrow$ & $25.34 \%$ & $0.67[0.29,1.53]$ \\
\hline Subtotal $(95 \% \mathrm{CI})$ & 221 & 226 & & $100 \%$ & $0.73[0.48,1.1]$ \\
\hline \multicolumn{6}{|c|}{ Total events: 31 (Rituximab), 46 (Placebo/no induction) } \\
\hline \multicolumn{6}{|c|}{ Heterogeneity: $\operatorname{Tau}^{2}=0 ; \mathrm{Chi}^{2}=1.77, \mathrm{df}=2(\mathrm{P}=0.41) ; \mathrm{I}^{2}=0 \%$} \\
\hline \multicolumn{6}{|c|}{ Test for overall effect: $\mathrm{Z}=1.51(\mathrm{P}=0.13)$} \\
\hline 5.1.6 Delayed graft & & & & & \\
\hline Smeekens 2013 & $26 / 138$ & $25 / 142$ & & $100 \%$ & $1.07[0.65,1.76]$ \\
\hline Subtotal $(95 \% \mathrm{Cl})$ & 138 & 142 & & $100 \%$ & $1.07[0.65,1.76]$ \\
\hline Total events: 26 (Rit! & bo/no induction) & & & & \\
\hline Heterogeneity: Not a & & & & & \\
\hline
\end{tabular}




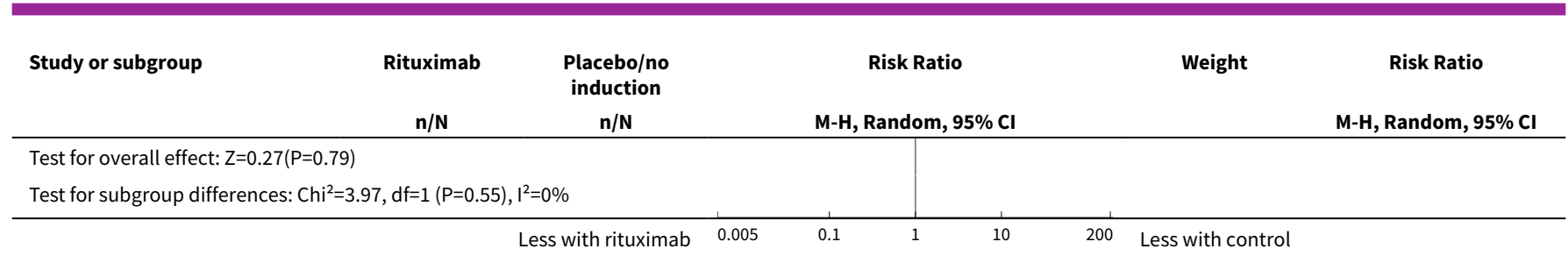

Analysis 5.2. Comparison 5 Rituximab versus placebo, Outcome 2 Other adverse outcomes.

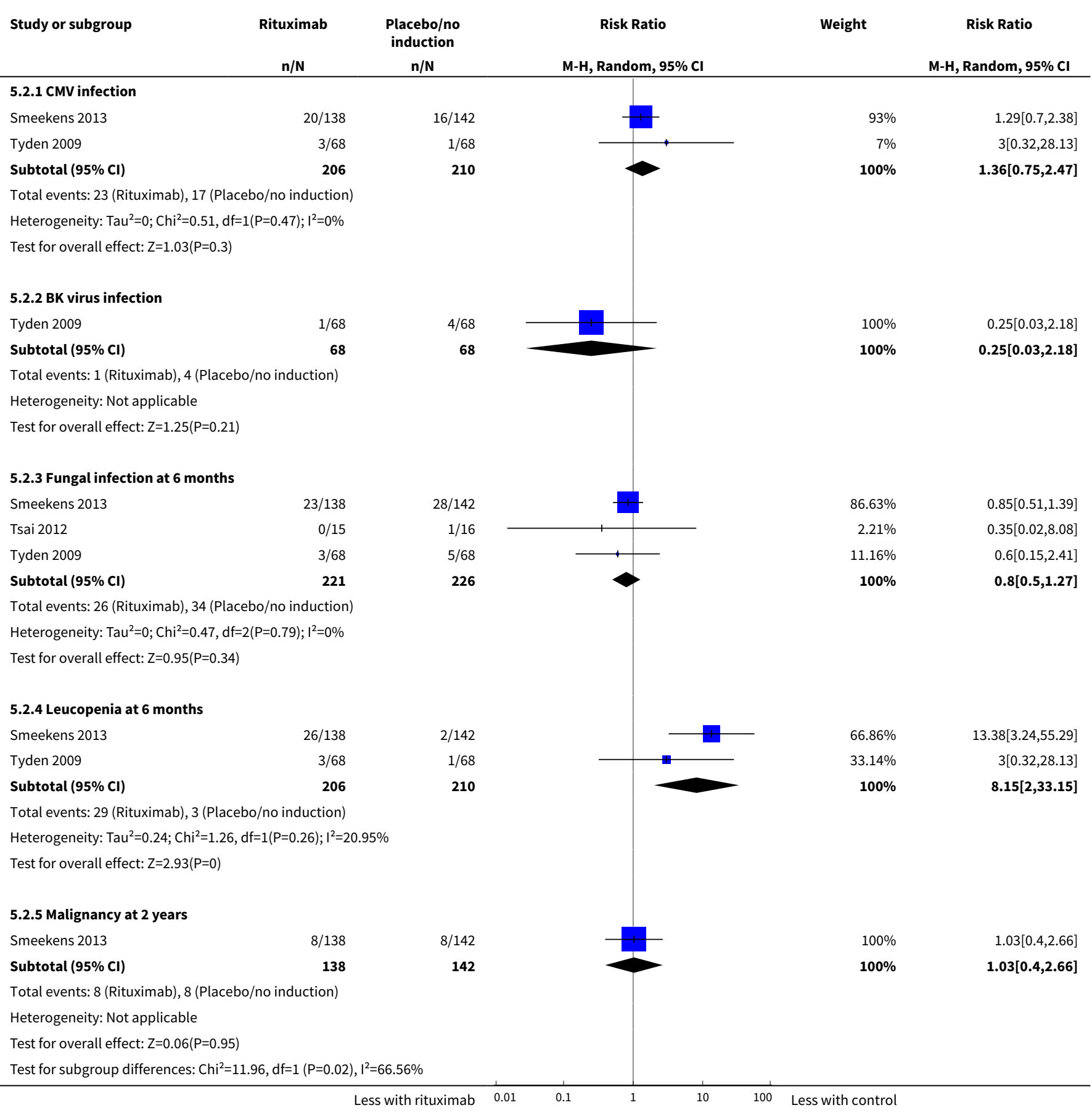


Analysis 5.3. Comparison 5 Rituximab versus placebo, Outcome 3 Graft function at 6 months (eGFR).

\begin{tabular}{|c|c|c|c|c|c|c|c|}
\hline \multirow[t]{2}{*}{ Study or subgroup } & \multicolumn{2}{|c|}{ Rituximab } & \multicolumn{2}{|c|}{$\begin{array}{l}\text { Placebo/no } \\
\text { induction }\end{array}$} & \multirow{2}{*}{$\begin{array}{l}\text { Mean Difference } \\
\text { Random, 95\% CI }\end{array}$} & \multirow[t]{2}{*}{ Weight } & \multirow{2}{*}{$\begin{array}{l}\text { Mean Difference } \\
\text { Random, } 95 \% \mathrm{Cl}\end{array}$} \\
\hline & $\mathbf{N}$ & Mean(SD) & $\mathbf{N}$ & $\operatorname{Mean}(S D)$ & & & \\
\hline Smeekens 2013 & 130 & $51.3(16.9)$ & 126 & $50.6(17)$ & 1 & $77.36 \%$ & $0.7[-3.45,4.85]$ \\
\hline Tyden 2009 & 66 & $66(22)$ & 66 & $67(23)$ & \# & $22.64 \%$ & $-1[-8.68,6.68]$ \\
\hline Total $\star \star \star$ & 196 & & 192 & & & $100 \%$ & $0.32[-3.34,3.97]$ \\
\hline \multicolumn{3}{|c|}{ Test for overall effect: $\mathrm{Z}=0.17(\mathrm{P}=0.87)$} & & & & & \\
\hline
\end{tabular}

\section{Comparison 6. ATG versus OKT3}

\begin{tabular}{|c|c|c|c|c|}
\hline Outcome or subgroup title & No. of studies & $\begin{array}{l}\text { No. of partici- } \\
\text { pants }\end{array}$ & Statistical method & Effect size \\
\hline 1 Main outcomes & 6 & & Risk Ratio (M-H, Random, 95\% Cl) & Subtotals only \\
\hline 1.1 Death at 6 to 12 months & 5 & 451 & Risk Ratio (M-H, Random, 95\% Cl) & $1.29[0.64,2.60]$ \\
\hline $\begin{array}{l}1.2 \text { Graft loss (death cen- } \\
\text { sored) at } 6 \text { to } 12 \text { months }\end{array}$ & 5 & 439 & Risk Ratio (M-H, Random, 95\% Cl) & $1.00[0.64,1.57]$ \\
\hline 1.3 Acute rejection at 1 year & 4 & 450 & Risk Ratio (M-H, Random, 95\% Cl) & $0.76[0.53,1.09]$ \\
\hline 1.4 Delayed graft function & 3 & 235 & Risk Ratio (M-H, Random, 95\% Cl) & $0.80[0.52,1.24]$ \\
\hline 2 Other adverse outcomes & 5 & & Risk Ratio (M-H, Random, 95\% Cl) & Subtotals only \\
\hline 2.1 CMV infection & 3 & 274 & Risk Ratio (M-H, Random, 95\% Cl) & $1.13[0.88,1.46]$ \\
\hline 2.2 Bacterial infection & 1 & 50 & Risk Ratio (M-H, Random, 95\% Cl) & $0.51[0.20,1.32]$ \\
\hline 2.3 Leucopenia & 1 & 104 & Risk Ratio (M-H, Random, 95\% Cl) & $1.92[0.78,4.74]$ \\
\hline 2.4 Thrombocytopenia & 1 & 104 & Risk Ratio (M-H, Random, 95\% Cl) & $4.81[0.24,97.91]$ \\
\hline 2.5 Malignancy at 1 year & 1 & 104 & Risk Ratio (M-H, Random, 95\% Cl) & $0.0[0.0,0.0]$ \\
\hline $\begin{array}{l}\text { 2.6 Unable to complete in- } \\
\text { duction due to side effects }\end{array}$ & 2 & 131 & Risk Ratio (M-H, Random, 95\% Cl) & $1.96[0.10,39.72]$ \\
\hline 3 Serum creatinine at 1 year & 1 & & $\begin{array}{l}\text { Mean Difference (IV, Random, 95\% } \\
\mathrm{CI})\end{array}$ & Subtotals only \\
\hline
\end{tabular}


Analysis 6.1. Comparison 6 ATG versus OKT3, Outcome 1 Main outcomes.

\begin{tabular}{|c|c|c|c|c|c|}
\hline Study or subgroup & $\begin{array}{l}\text { ATG } \\
\mathrm{n} / \mathrm{N}\end{array}$ & $\begin{array}{l}\text { OKT3 } \\
n / N\end{array}$ & $\begin{array}{c}\text { Risk Ratio } \\
\text { M-H, Random, } 95 \% \mathrm{CI} \\
\end{array}$ & Weight & $\begin{array}{c}\text { Risk Ratio } \\
\text { M-H, Random, } 95 \% \mathrm{Cl} \\
\end{array}$ \\
\hline \multicolumn{6}{|c|}{ 6.1.1 Death at 6 to 12 months } \\
\hline Bock 1995 & $2 / 53$ & $4 / 51$ & $\longrightarrow$ & $17.96 \%$ & $0.48[0.09,2.51]$ \\
\hline Cole 1994 & $9 / 83$ & $6 / 83$ & - & $50.38 \%$ & $1.5[0.56,4.03]$ \\
\hline Fukuuchi 1996 & $5 / 37$ & $1 / 44$ & & $11.11 \%$ & $5.95[0.73,48.66]$ \\
\hline Kumar 1998a & $2 / 26$ & $2 / 24$ & & $13.89 \%$ & $0.92[0.14,6.05]$ \\
\hline Perez-Tamajon 1996 & $1 / 26$ & $1 / 24$ & & $6.66 \%$ & $0.92[0.06,13.95]$ \\
\hline Subtotal $(95 \% \mathrm{Cl})$ & 225 & 226 & & $100 \%$ & $1.29[0.64,2.6]$ \\
\hline \multicolumn{6}{|c|}{ Total events: 19 (ATG), 14 (ОKT3) } \\
\hline \multicolumn{6}{|c|}{ Heterogeneity: $\mathrm{Tau}^{2}=0 ; \mathrm{Chi}^{2}=3.69, \mathrm{df}=4(\mathrm{P}=0.45) ; \mathrm{I}^{2}=0 \%$} \\
\hline \multicolumn{6}{|c|}{ Test for overall effect: $\mathrm{Z}=0.71(\mathrm{P}=0.48)$} \\
\hline \multicolumn{6}{|c|}{ 6.1.2 Graft loss (death censored) at 6 to 12 months } \\
\hline Bock 1995 & $3 / 51$ & $7 / 47$ & & $12.11 \%$ & $0.39[0.11,1.44]$ \\
\hline Cole 1994 & $19 / 83$ & $16 / 83$ & & $57.92 \%$ & $1.19[0.66,2.15]$ \\
\hline Fukuuchi 1996 & $6 / 37$ & $8 / 44$ & & $21.8 \%$ & $0.89[0.34,2.34]$ \\
\hline Kumar 1998a & $2 / 24$ & $2 / 22$ & & $5.78 \%$ & $0.92[0.14,5.96]$ \\
\hline Perez-Tamajon 1996 & $3 / 25$ & $0 / 23$ & & $2.39 \%$ & $6.46[0.35,118.71]$ \\
\hline Subtotal $(95 \% \mathrm{Cl})$ & 220 & 219 & & $100 \%$ & $1[0.64,1.57]$ \\
\hline \multicolumn{6}{|c|}{ Total events: 33 (ATG), 33 (ОКT3) } \\
\hline \multicolumn{6}{|c|}{ Heterogeneity: Tau $^{2}=0 ; \mathrm{Chi}^{2}=3.95, \mathrm{df}=4(\mathrm{P}=0.41) ; 1^{2}=0 \%$} \\
\hline \multicolumn{6}{|c|}{ Test for overall effect: $Z=0.01(P=0.99)$} \\
\hline \multicolumn{6}{|c|}{ 6.1.3 Acute rejection at 1 year } \\
\hline Bock 1995 & $14 / 53$ & $23 / 51$ & $\rightarrow-$ & $21.38 \%$ & $0.59[0.34,1.01]$ \\
\hline Cole 1994 & $32 / 75$ & $54 / 78$ & - & $32.49 \%$ & $0.62[0.46,0.83]$ \\
\hline Kumar 1998a & $6 / 26$ & $6 / 24$ & . & $9.97 \%$ & $0.92[0.34,2.47]$ \\
\hline Raffaele 1991 & $50 / 73$ & $47 / 70$ & \# & $36.16 \%$ & $1.02[0.81,1.28]$ \\
\hline Subtotal $(95 \% \mathrm{Cl})$ & 227 & 223 & 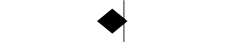 & $100 \%$ & $0.76[0.53,1.09]$ \\
\hline \multicolumn{6}{|c|}{ Total events: 102 (ATG), 130 (OKT3) } \\
\hline \multicolumn{6}{|c|}{ Heterogeneity: $\mathrm{Tau}^{2}=0.08 ; \mathrm{Chi}^{2}=9.08, \mathrm{df}=3(\mathrm{P}=0.03) ; \mathrm{I}^{2}=66.94 \%$} \\
\hline \multicolumn{6}{|c|}{ Test for overall effect: $\mathrm{Z}=1.5(\mathrm{P}=0.13)$} \\
\hline \multicolumn{6}{|c|}{ 6.1.4 Delayed graft function } \\
\hline Bock 1995 & $14 / 53$ & $15 / 51$ & $\rightarrow$ & $48.98 \%$ & $0.9[0.48,1.67]$ \\
\hline Fukuuchi 1996 & $9 / 37$ & $16 / 44$ & $\rightarrow$ & $39.4 \%$ & $0.67[0.34,1.33]$ \\
\hline Perez-Tamajon 1996 & $4 / 26$ & $4 / 24$ & 4 & $11.62 \%$ & $0.92[0.26,3.29]$ \\
\hline Subtotal $(95 \% \mathrm{Cl})$ & 116 & 119 & & $100 \%$ & $0.8[0.52,1.24]$ \\
\hline \multicolumn{6}{|c|}{ Total events: 27 (ATG), 35 (ОКT3) } \\
\hline \multicolumn{6}{|c|}{ Heterogeneity: Tau $^{2}=0 ; \mathrm{Chi}^{2}=0.44, \mathrm{df}=2(\mathrm{P}=0.8) ; 1^{2}=0 \%$} \\
\hline \multicolumn{6}{|c|}{ Test for overall effect: $Z=1(P=0.32)$} \\
\hline Test for subgroup diffe & $=1(P=0.52), 1$ & & & & \\
\hline
\end{tabular}

Analysis 6.2. Comparison 6 ATG versus OKT3, Outcome 2 Other adverse outcomes.

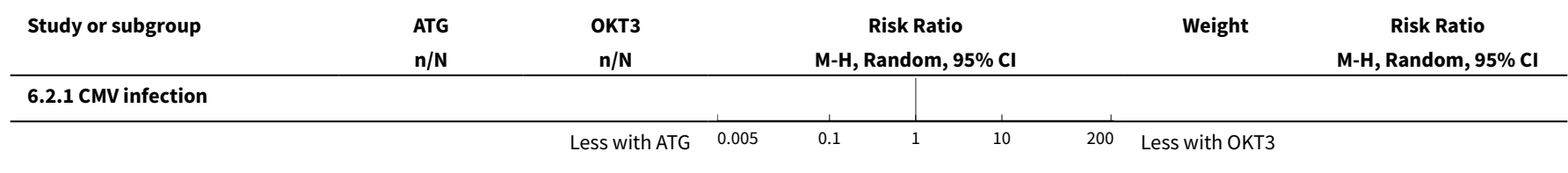




\begin{tabular}{|c|c|c|c|c|c|}
\hline Study or subgroup & $\begin{array}{l}\text { ATG } \\
\mathrm{n} / \mathrm{N}\end{array}$ & $\begin{array}{l}\text { OKT3 } \\
\mathrm{n} / \mathrm{N}\end{array}$ & $\begin{array}{c}\text { Risk Ratio } \\
\text { M-H, Random, } 95 \% \mathrm{CI}\end{array}$ & Weight & $\begin{array}{c}\text { Risk Ratio } \\
\text { M-H, Random, } 95 \% \mathrm{Cl}\end{array}$ \\
\hline Fukuuchi 1996 & $25 / 37$ & $29 / 44$ & & $61.5 \%$ & $1.03[0.75,1.4]$ \\
\hline Kumar 1998a & $3 / 26$ & $4 / 24$ & & $3.29 \%$ & $0.69[0.17,2.78]$ \\
\hline Raffaele 1991 & $34 / 73$ & $23 / 70$ & & $35.21 \%$ & $1.42[0.94,2.15]$ \\
\hline Subtotal $(95 \% \mathrm{Cl})$ & 136 & 138 & & $100 \%$ & $1.13[0.88,1.46]$ \\
\hline \multicolumn{6}{|c|}{ Total events: 62 (ATG), 56 (OKT3) } \\
\hline \multicolumn{6}{|c|}{ Heterogeneity: $\operatorname{Tau}^{2}=0 ; \mathrm{Chi}^{2}=2.07, \mathrm{df}=2(\mathrm{P}=0.35) ; \mathrm{I}^{2}=3.5 \%$} \\
\hline \multicolumn{6}{|c|}{ Test for overall effect: $Z=0.98(P=0.33)$} \\
\hline \multicolumn{6}{|c|}{ 6.2.2 Bacterial infection } \\
\hline Kumar 1998a & $5 / 26$ & $9 / 24$ & & $100 \%$ & $0.51[0.2,1.32]$ \\
\hline Subtotal $(95 \% \mathrm{Cl})$ & 26 & 24 & & $100 \%$ & $0.51[0.2,1.32]$ \\
\hline \multicolumn{6}{|c|}{ Total events: 5 (ATG), 9 (OKT3) } \\
\hline \multicolumn{6}{|c|}{ Heterogeneity: Not applicable } \\
\hline \multicolumn{6}{|c|}{ Test for overall effect: $Z=1.39(P=0.16)$} \\
\hline \multicolumn{6}{|l|}{ 6.2.3 Leucopenia } \\
\hline Bock 1995 & $12 / 53$ & $6 / 51$ & & $100 \%$ & $1.92[0.78,4.74]$ \\
\hline Subtotal $(95 \% \mathrm{Cl})$ & 53 & 51 & & $100 \%$ & $1.92[0.78,4.74]$ \\
\hline \multicolumn{6}{|c|}{ Total events: 12 (ATG), 6 (OKT3) } \\
\hline \multicolumn{6}{|c|}{ Heterogeneity: Not applicable } \\
\hline \multicolumn{6}{|c|}{ Test for overall effect: $\mathrm{Z}=1.42(\mathrm{P}=0.15)$} \\
\hline \multicolumn{6}{|c|}{ 6.2.4 Thrombocytopenia } \\
\hline Bock 1995 & $2 / 53$ & $0 / 51$ & & $100 \%$ & $4.81[0.24,97.91]$ \\
\hline Subtotal $(95 \% \mathrm{Cl})$ & 53 & 51 & & $100 \%$ & $4.81[0.24,97.91]$ \\
\hline \multicolumn{6}{|c|}{ Total events: 2 (ATG), 0 (OKT3) } \\
\hline \multicolumn{6}{|c|}{ Heterogeneity: Not applicable } \\
\hline \multicolumn{6}{|c|}{ Test for overall effect: $Z=1.02(P=0.31)$} \\
\hline \multicolumn{6}{|c|}{ 6.2.5 Malignancy at 1 year } \\
\hline Bock 1995 & $0 / 53$ & $0 / 51$ & & & Not estimable \\
\hline Subtotal $(95 \% \mathrm{Cl})$ & 53 & 51 & & & Not estimable \\
\hline \multicolumn{6}{|c|}{ Total events: 0 (ATG), 0 (OKT3) } \\
\hline \multicolumn{6}{|c|}{ Heterogeneity: Not applicable } \\
\hline \multicolumn{6}{|c|}{ Test for overall effect: Not applicable } \\
\hline \multicolumn{6}{|c|}{ 6.2.6 Unable to complete induction due to side effects } \\
\hline Fukuuchi 1996 & $0 / 37$ & $1 / 44$ & & $47.5 \%$ & $0.39[0.02,9.41]$ \\
\hline Perez-Tamajon 1996 & $4 / 26$ & $0 / 24$ & & $52.5 \%$ & $8.33[0.47,147.07]$ \\
\hline Subtotal $(95 \% \mathrm{Cl})$ & 63 & 68 & & $100 \%$ & $1.96[0.1,39.72]$ \\
\hline \multicolumn{6}{|c|}{ Total events: 4 (ATG), 1 (OKT3) } \\
\hline \multicolumn{6}{|c|}{ Heterogeneity: $\operatorname{Tau}^{2}=2.35 ; \mathrm{Chi}^{2}=1.99, \mathrm{df}=1(\mathrm{P}=0.16) ; \mathrm{I}^{2}=49.65 \%$} \\
\hline \multicolumn{6}{|c|}{ Test for overall effect: $Z=0.44(P=0.66)$} \\
\hline Test for subgroup diff & $f=1(P=0.28)$, & & & & \\
\hline
\end{tabular}


Analysis 6.3. Comparison 6 ATG versus OKT3, Outcome 3 Serum creatinine at 1 year.

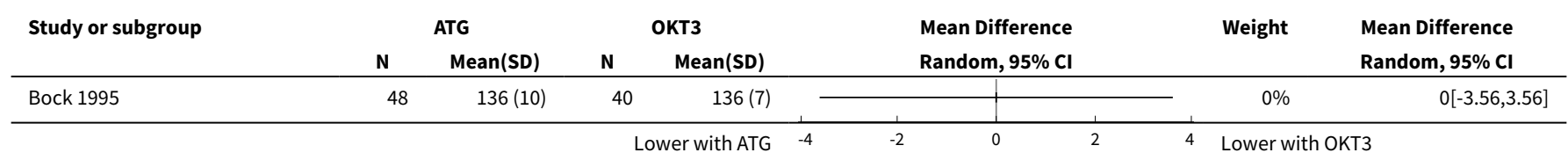

\section{Comparison 7. ОKT3 versus placebo/no induction}

\begin{tabular}{|c|c|c|c|c|}
\hline Outcome or subgroup title & No. of studies & $\begin{array}{l}\text { No. of partici- } \\
\text { pants }\end{array}$ & Statistical method & Effect size \\
\hline 1 Main outcomes & 12 & & Risk Ratio (M-H, Random, 95\% Cl) & Subtotals only \\
\hline 1.1 Death at 1 to 2 years & 6 & 491 & Risk Ratio (M-H, Random, 95\% Cl) & $0.41[0.18,0.97]$ \\
\hline 1.2 Death at 3 to 5 years & 5 & 768 & Risk Ratio (M-H, Random, 95\% Cl) & $0.72[0.37,1.44]$ \\
\hline $\begin{array}{l}1.3 \text { Graft loss (all cause) at } 1 \\
\text { to } 2 \text { years }\end{array}$ & 7 & 416 & Risk Ratio (M-H, Random, 95\% Cl) & $0.55[0.30,1.02]$ \\
\hline $\begin{array}{l}1.4 \text { Graft loss (all cause) at } 3 \\
\text { to } 5 \text { years }\end{array}$ & 5 & 768 & Risk Ratio (M-H, Random, 95\% Cl) & $0.73[0.47,1.14]$ \\
\hline $\begin{array}{l}1.5 \text { Acute rejection, any } \\
\text { episode }(+\mathrm{CNI})\end{array}$ & 8 & 968 & Risk Ratio (M-H, Random, 95\% Cl) & $0.60[0.43,0.83]$ \\
\hline $\begin{array}{l}1.6 \text { Acute rejection at } 3 \\
\text { months (no CNI) }\end{array}$ & 3 & 85 & Risk Ratio (M-H, Random, 95\% CI) & $0.70[0.33,1.46]$ \\
\hline 1.7 Delayed graft function & 6 & 494 & Risk Ratio (M-H, Random, 95\% Cl) & $1.08[0.70,1.65]$ \\
\hline 2 Other adverse effects & 6 & & Risk Ratio (M-H, Random, 95\% Cl) & Subtotals only \\
\hline 2.1 Infection (all cause) & 1 & 108 & Risk Ratio (M-H, Random, 95\% Cl) & $1.38[1.04,1.82]$ \\
\hline 2.2 Bacterial infection & 3 & 366 & Risk Ratio (M-H, Random, 95\% Cl) & $1.01[0.76,1.34]$ \\
\hline 2.3 Viral infection (all cause) & 2 & 353 & Risk Ratio (M-H, Random, 95\% Cl) & $0.99[0.72,1.37]$ \\
\hline 2.4 CMV infection & 3 & 332 & Risk Ratio (M-H, Random, 95\% Cl) & $1.52[0.82,2.84]$ \\
\hline 2.5 HSV infection & 1 & 215 & Risk Ratio (M-H, Random, 95\% Cl) & $1.45[0.89,2.38]$ \\
\hline 2.6 Fungal infection & 3 & 568 & Risk Ratio (M-H, Random, 95\% Cl) & $1.26[0.33,4.89]$ \\
\hline 2.7 Malignancy or PTLD & 3 & 610 & Risk Ratio (M-H, Random, 95\% Cl) & $1.34[0.52,3.50]$ \\
\hline 3 Serum creatinine & 5 & & $\begin{array}{l}\text { Mean Difference (IV, Random, 95\% } \\
\mathrm{CI} \text { ) }\end{array}$ & Subtotals only \\
\hline 3.13 months & 3 & 226 & $\begin{array}{l}\text { Mean Difference (IV, Random, 95\% } \\
\mathrm{Cl} \text { ) }\end{array}$ & $-0.93[-15.78,13.93]$ \\
\hline
\end{tabular}




\begin{tabular}{lllll}
\hline Outcome or subgroup title & No. of studies & $\begin{array}{l}\text { No. of partici- } \\
\text { pants }\end{array}$ & Statistical method & Effect size \\
\hline 3.21 year & 2 & 261 & $\begin{array}{l}\text { Mean Difference (IV, Random, 95\% } \\
\text { Cl) }\end{array}$ & $-6.22[-18.21,5.76]$ \\
\hline 3.33 to 4 years & 2 & 38 & $\begin{array}{l}\text { Mean Difference (IV, Random, 95\% } \\
\text { Cl) }\end{array}$ & $-21.10[-49.81,7.61]$ \\
\hline
\end{tabular}

Analysis 7.1. Comparison 7 OKT3 versus placebo/no induction, Outcome 1 Main outcomes.

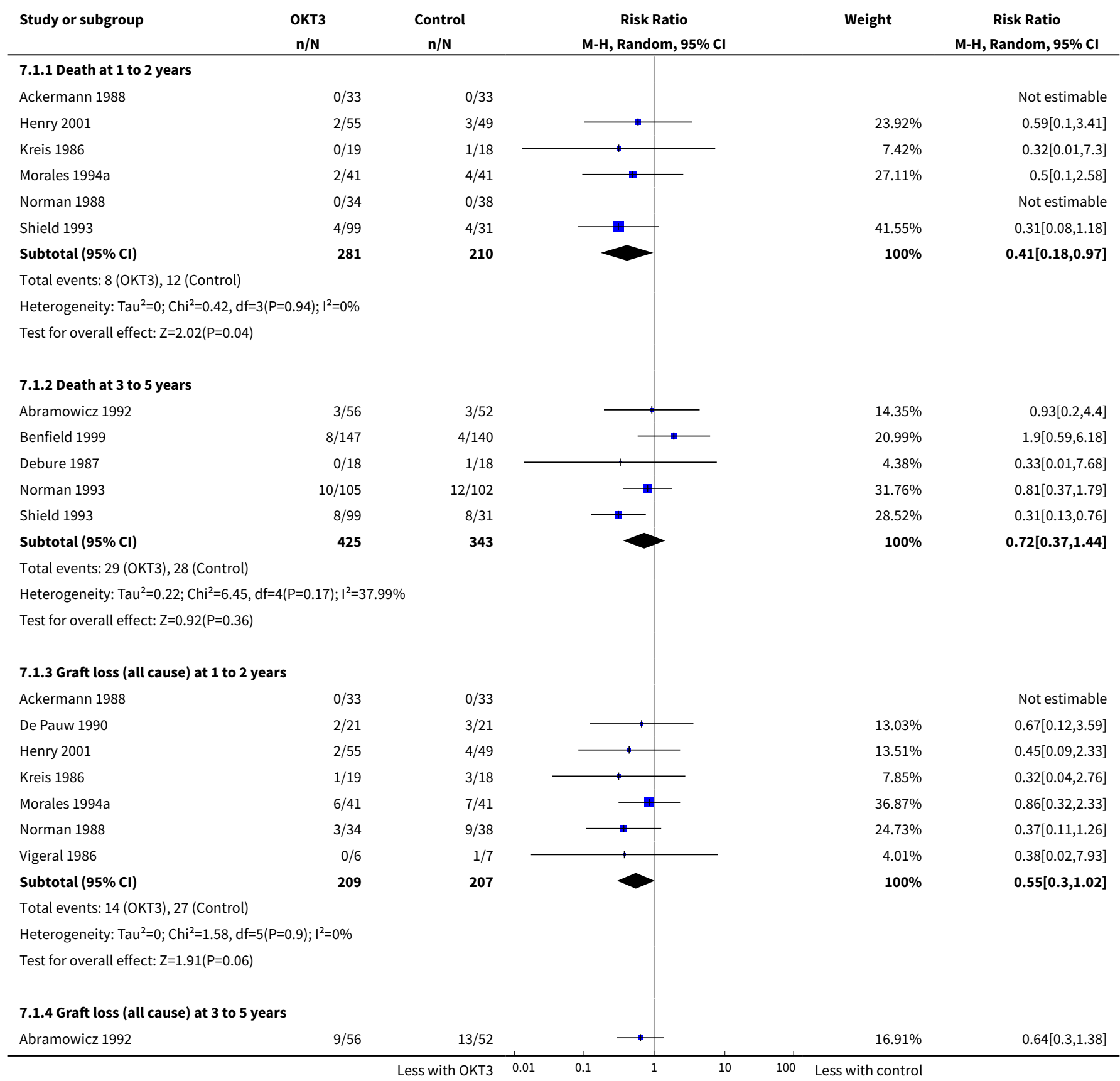




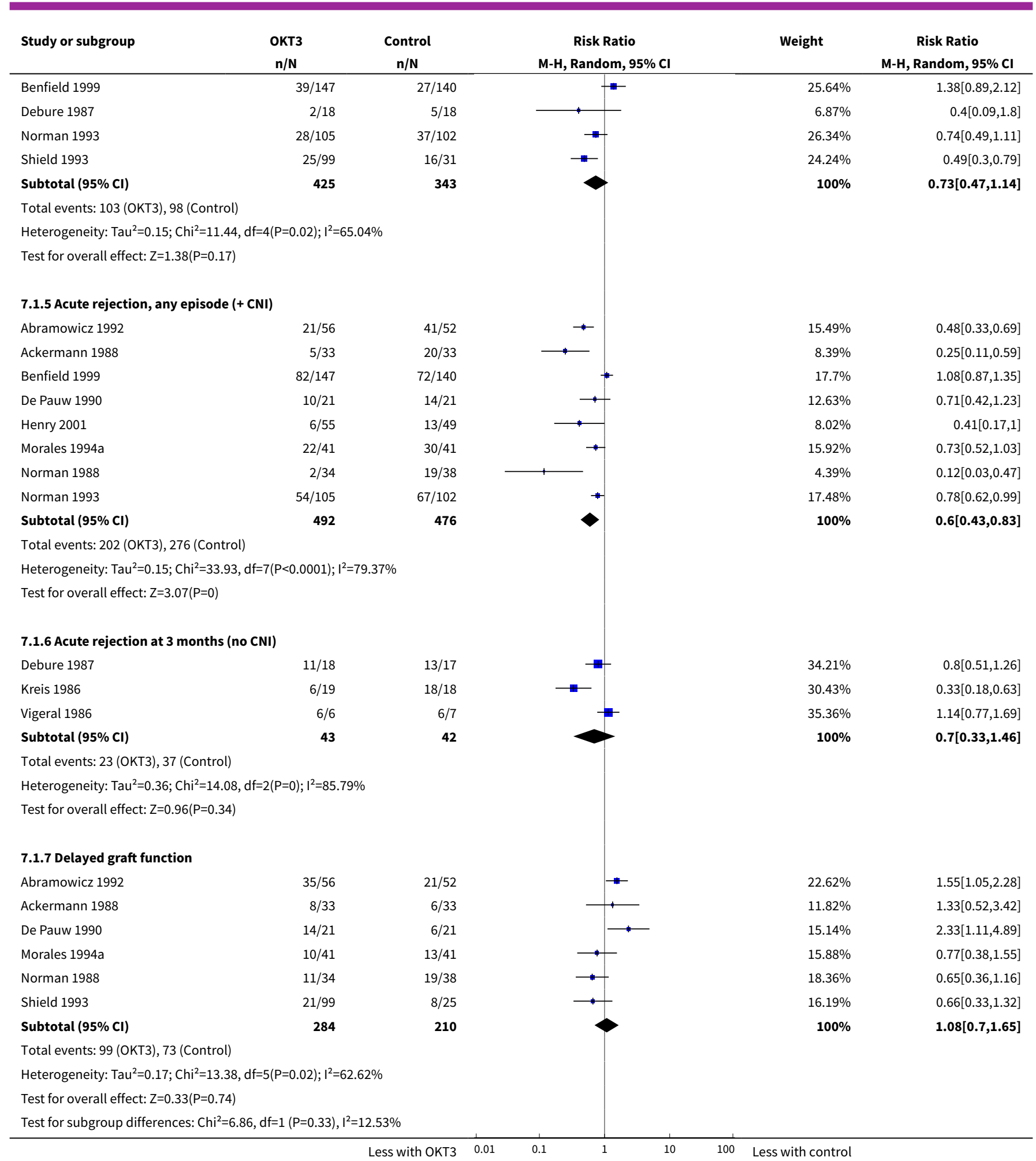


Analysis 7.2. Comparison 7 OKT 3 versus placebo/no induction, Outcome 2 Other adverse effects.

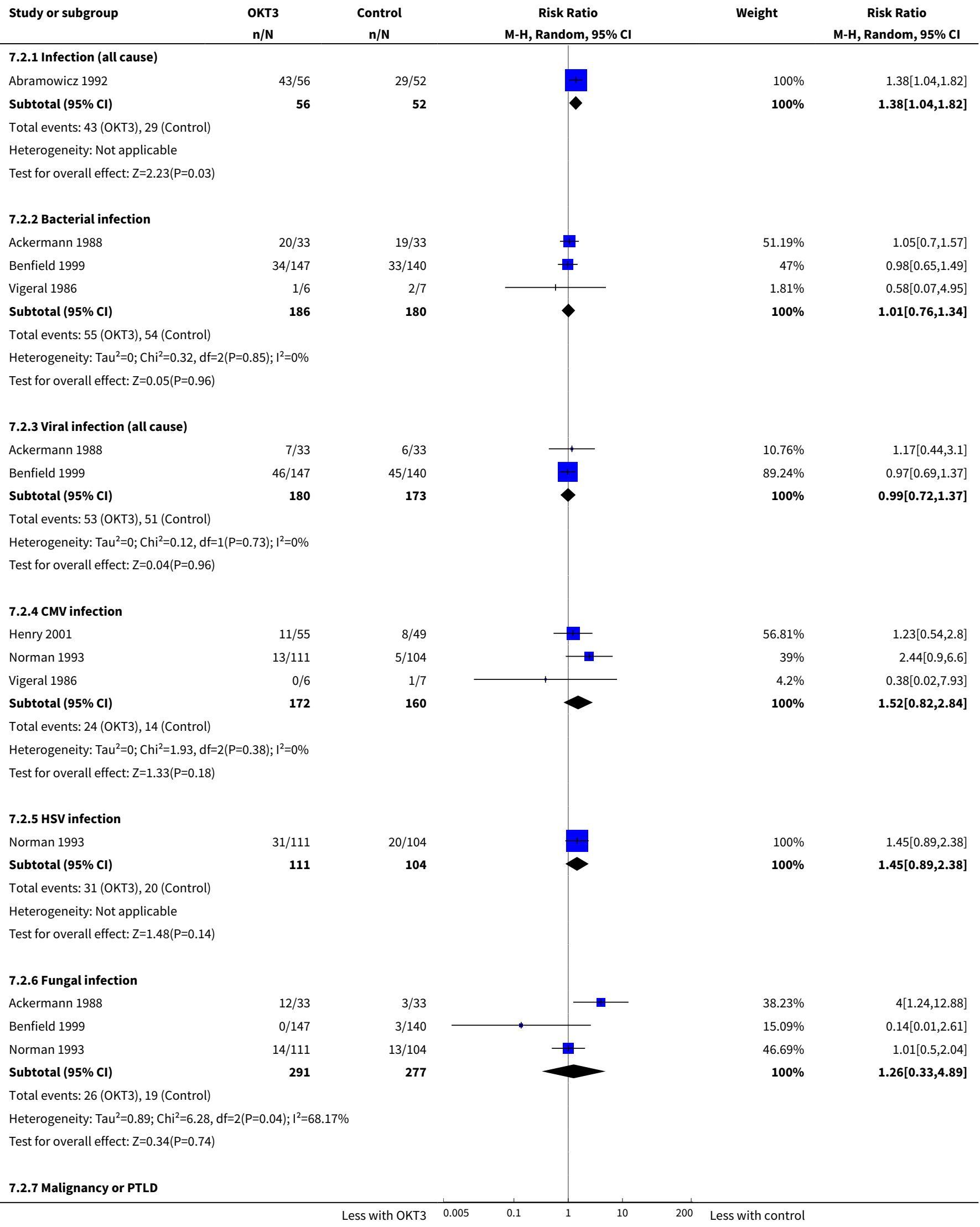




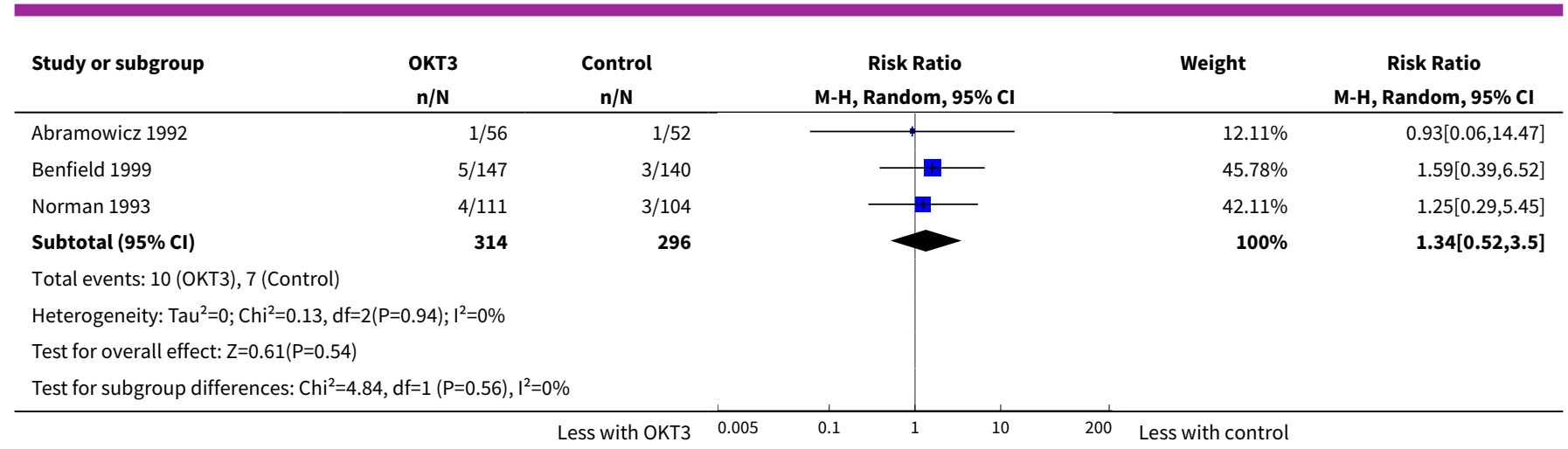

Analysis 7.3. Comparison 7 OKT3 versus placebo/no induction, Outcome 3 Serum creatinine.

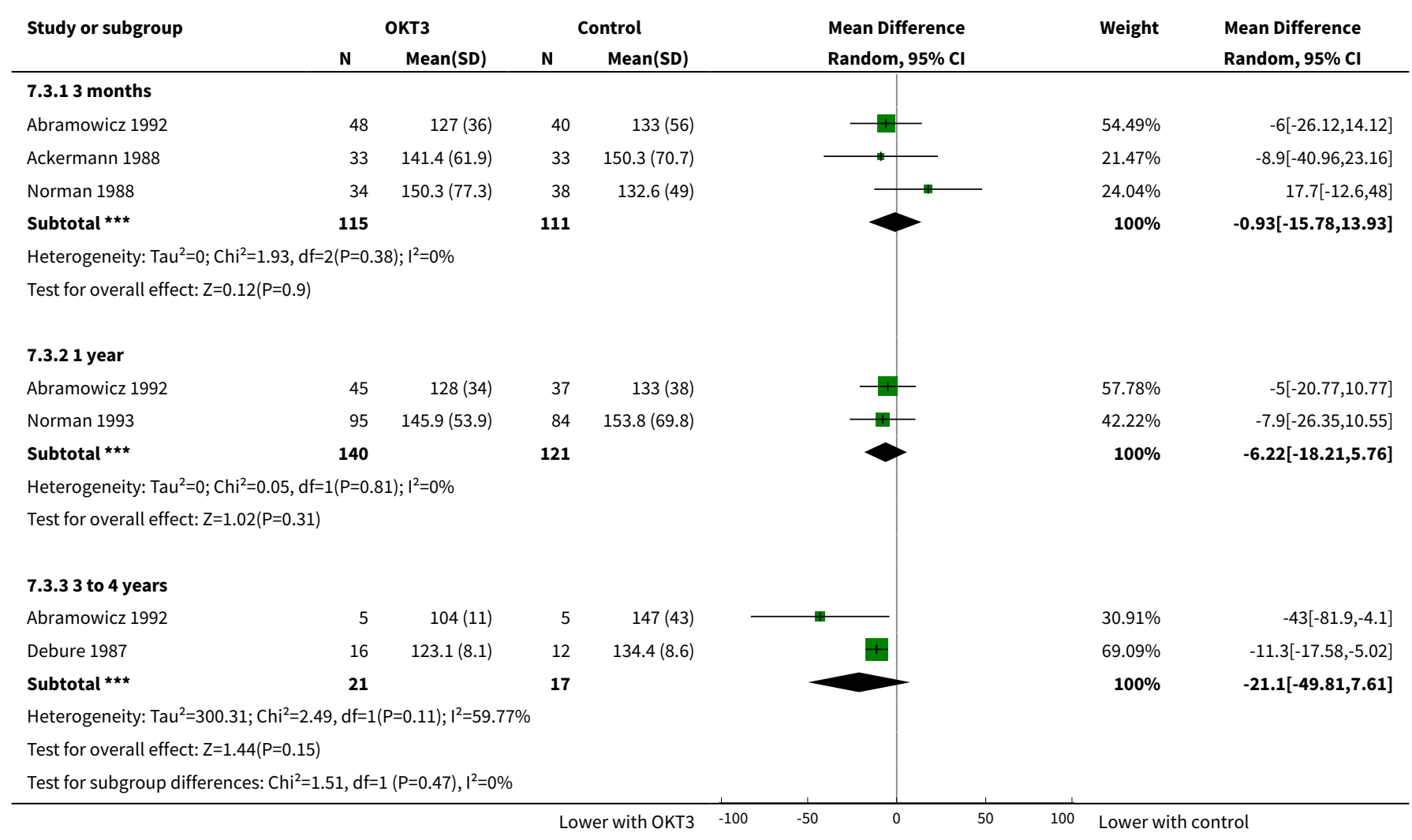

\section{Comparison 8. ALG versus OKT3}

\begin{tabular}{llllll}
\hline $\begin{array}{l}\text { Outcome or subgroup ti- } \\
\text { tle }\end{array}$ & No. of studies & $\begin{array}{l}\text { No. of partici- } \\
\text { pants }\end{array}$ & Statistical method & Effect size \\
\hline 1 Main outcomes & 6 & & Risk Ratio (M-H, Random, 95\% Cl) & Subtotals only \\
\hline 1.1 Death at 1 to 2 years & 3 & 300 & Risk Ratio (M-H, Random, 95\% Cl) & $2.00[0.62,6.47]$ \\
\hline 1.2 Death at 3 years & 2 & 265 & Risk Ratio (M-H, Random, 95\% Cl) & $1.03[0.13,8.09]$ \\
\hline
\end{tabular}




\begin{tabular}{|c|c|c|c|c|}
\hline $\begin{array}{l}\text { Outcome or subgroup ti- } \\
\text { tle }\end{array}$ & No. of studies & $\begin{array}{l}\text { No. of partici- } \\
\text { pants }\end{array}$ & Statistical method & Effect size \\
\hline $\begin{array}{l}1.3 \text { Graft loss (all cause) at } \\
1 \text { to } 2 \text { years }\end{array}$ & 3 & 300 & Risk Ratio (M-H, Random, 95\% Cl) & $1.01[0.57,1.80]$ \\
\hline $\begin{array}{l}1.4 \text { Graft loss (all cause) at } \\
3 \text { years }\end{array}$ & 2 & 265 & Risk Ratio (M-H, Random, 95\% Cl) & $1.08[0.68,1.70]$ \\
\hline $\begin{array}{l}1.5 \text { Acute rejection (any } \\
\text { episode) }\end{array}$ & 6 & 593 & Risk Ratio (M-H, Random, 95\% Cl) & $0.97[0.83,1.13]$ \\
\hline 1.6 Delayed graft function & 3 & 310 & Risk Ratio (M-H, Random, 95\% Cl) & $0.78[0.61,0.99]$ \\
\hline 2 Other adverse outcomes & 6 & & Risk Ratio (M-H, Random, 95\% Cl) & Subtotals only \\
\hline 2.1 CMV infection & 4 & 431 & Risk Ratio (M-H, Random, 95\% Cl) & $1.53[0.82,2.85]$ \\
\hline $\begin{array}{l}\text { 2.2 Viral infection (not } \\
\mathrm{CMV} \text { ) }\end{array}$ & 1 & 148 & Risk Ratio (M-H, Random, 95\% Cl) & $0.75[0.34,1.65]$ \\
\hline 2.3 Serious infection & 1 & 124 & Risk Ratio (M-H, Random, 95\% Cl) & $0.8[0.19,3.43]$ \\
\hline $\begin{array}{l}2.4 \text { Viral infection (all } \\
\text { cause) }\end{array}$ & 2 & 66 & Risk Ratio (M-H, Random, 95\% Cl) & $1.35[0.69,2.64]$ \\
\hline 2.5 PCP & 1 & 28 & Risk Ratio (M-H, Random, 95\% Cl) & $0.50[0.05,4.90]$ \\
\hline 2.6 PTLD & 1 & 124 & Risk Ratio (M-H, Random, 95\% Cl) & $0.0[0.0,0.0]$ \\
\hline 3 Serum creatinine & 3 & & Mean Difference (IV, Random, 95\% CI) & Subtotals only \\
\hline 3.11 year & 2 & 245 & Mean Difference (IV, Random, 95\% CI) & $-15.85[-28.55,-3.15]$ \\
\hline 3.22 years & 2 & 223 & Mean Difference (IV, Random, 95\% CI) & $12.50[-13.52,38.52]$ \\
\hline
\end{tabular}

Analysis 8.1. Comparison 8 ALG versus OKT3, Outcome 1 Main outcomes.

\begin{tabular}{|c|c|c|c|c|c|}
\hline Study or subgroup & $\begin{array}{l}\text { ALG } \\
\mathrm{n} / \mathrm{N}\end{array}$ & $\begin{array}{l}\text { OKT3 } \\
n / N\end{array}$ & $\begin{array}{c}\text { Risk Ratio } \\
\text { M-H, Random, } 95 \% \mathrm{Cl}\end{array}$ & Weight & $\begin{array}{c}\text { Risk Ratio } \\
\text { M-H, Random, } 95 \% \mathrm{Cl}\end{array}$ \\
\hline \multicolumn{6}{|c|}{ 8.1.1 Death at 1 to 2 years } \\
\hline Frey 1991 & $6 / 71$ & $2 / 67$ & 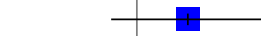 & $56.44 \%$ & $2.83[0.59,13.54]$ \\
\hline Grino 1991 & $2 / 60$ & $1 / 64$ & $\square$ & $24.52 \%$ & $2.13[0.2,22.92]$ \\
\hline Vela 1994 & $1 / 23$ & $1 / 15$ & & $19.04 \%$ & $0.65[0.04,9.65]$ \\
\hline Subtotal $(95 \% \mathrm{Cl})$ & 154 & 146 & & $100 \%$ & $2[0.62,6.47]$ \\
\hline \multicolumn{6}{|c|}{ Total events: 9 (ALG), 4 (OKT3) } \\
\hline \multicolumn{6}{|c|}{ Heterogeneity: $\operatorname{Tau}^{2}=0 ; \mathrm{Chi}^{2}=0.86, \mathrm{df}=2(\mathrm{P}=0.65) ; \mathrm{I}^{2}=0 \%$} \\
\hline \multicolumn{6}{|c|}{ Test for overall effect: $Z=1.15(P=0.25)$} \\
\hline \multicolumn{6}{|c|}{ 8.1.2 Death at 3 years } \\
\hline Broyer 1993 & $1 / 71$ & $3 / 77$ & + & $49.92 \%$ & $0.36[0.04,3.4]$ \\
\hline Hanto 1991 & $3 / 59$ & $1 / 58$ & 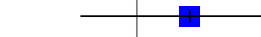 & $50.08 \%$ & $2.95[0.32,27.54]$ \\
\hline Subtotal $(95 \% \mathrm{Cl})$ & 130 & 135 & & $100 \%$ & $1.03[0.13,8.09]$ \\
\hline
\end{tabular}




\begin{tabular}{|c|c|c|c|c|c|}
\hline Study or subgroup & $\begin{array}{l}\text { ALG } \\
\mathrm{n} / \mathrm{N}\end{array}$ & $\begin{array}{c}\text { OKT3 } \\
\mathrm{n} / \mathrm{N}\end{array}$ & $\begin{array}{c}\text { Risk Ratio } \\
\text { M-H, Random, } 95 \% \text { Cl }\end{array}$ & Weight & $\begin{array}{c}\text { Risk Ratio } \\
\text { M-H, Random, 95\% Cl }\end{array}$ \\
\hline \multicolumn{6}{|c|}{ Total events: 4 (ALG), 4 (OKT3) } \\
\hline \multicolumn{6}{|c|}{ Heterogeneity: $\mathrm{Tau}^{2}=0.9 ; \mathrm{Chi}^{2}=1.69, \mathrm{df}=1(\mathrm{P}=0.19) ; \mathrm{I}^{2}=40.86 \%$} \\
\hline \multicolumn{6}{|c|}{ Test for overall effect: $Z=0.03(P=0.97)$} \\
\hline Frey 1991 & $14 / 71$ & $9 / 67$ & + & $42.96 \%$ & $1.47[0.68,3.16]$ \\
\hline Grino 1991 & $7 / 60$ & $7 / 64$ & $\longrightarrow$ & $28.67 \%$ & $1.07[0.4,2.86]$ \\
\hline Vela 1994 & $5 / 23$ & $6 / 15$ & & $28.37 \%$ & $0.54[0.2,1.47]$ \\
\hline Subtotal $(95 \% \mathrm{Cl})$ & 154 & 146 & & $100 \%$ & $1.01[0.57,1.8]$ \\
\hline \multicolumn{6}{|c|}{ Total events: 26 (ALG), 22 (OKT3) } \\
\hline \multicolumn{6}{|c|}{ Heterogeneity: $\mathrm{Tau}^{2}=0.05 ; \mathrm{Chi}^{2}=2.43, \mathrm{df}=2(\mathrm{P}=0.3) ; \mathrm{I}^{2}=17.8 \%$} \\
\hline \multicolumn{6}{|c|}{ Test for overall effect: $Z=0.04(P=0.97)$} \\
\hline \multicolumn{6}{|c|}{ 8.1.4 Graft loss (all cause) at 3 years } \\
\hline Broyer 1993 & $16 / 71$ & $16 / 77$ & & $56.28 \%$ & $1.08[0.59,2]$ \\
\hline Hanto 1991 & $13 / 59$ & $12 / 58$ & & $43.72 \%$ & $1.06[0.53,2.14]$ \\
\hline Subtotal $(95 \% \mathrm{CI})$ & 130 & 135 & & $100 \%$ & $1.08[0.68,1.7]$ \\
\hline \multicolumn{6}{|c|}{ Total events: 29 (ALG), 28 (OKT3) } \\
\hline \multicolumn{6}{|c|}{ Heterogeneity: Tau $^{2}=0 ; \mathrm{Chi}^{2}=0, \mathrm{df}=1(\mathrm{P}=0.97) ; \mathrm{I}^{2}=0 \%$} \\
\hline \multicolumn{6}{|c|}{ Test for overall effect: $Z=0.31(P=0.76)$} \\
\hline \multicolumn{6}{|c|}{ 8.1.5 Acute rejection (any episode) } \\
\hline Broyer 1993 & $49 / 71$ & $56 / 77$ & & $56.08 \%$ & $0.95[0.77,1.17]$ \\
\hline Frey 1991 & $32 / 71$ & $23 / 67$ & + & $13.73 \%$ & $1.31[0.86,2]$ \\
\hline Grino 1991 & $8 / 60$ & $12 / 64$ & 1 & $3.57 \%$ & $0.71[0.31,1.62]$ \\
\hline Vela 1994 & $12 / 23$ & $8 / 15$ & $\longrightarrow$ & $6.39 \%$ & $0.98[0.53,1.81]$ \\
\hline Subtotal $(95 \% \mathrm{Cl})$ & 298 & 295 & 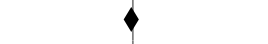 & $100 \%$ & $0.97[0.83,1.13]$ \\
\hline \multicolumn{6}{|c|}{ Total events: 130 (ALG), 134 (OKT3) } \\
\hline \multicolumn{6}{|c|}{ Heterogeneity: $\operatorname{Tau}^{2}=0 ; \mathrm{Chi}^{2}=4.46, \mathrm{df}=5(\mathrm{P}=0.49) ; \mathrm{I}^{2}=0 \%$} \\
\hline \multicolumn{6}{|c|}{ Test for overall effect: $Z=0.41(P=0.68)$} \\
\hline \multicolumn{6}{|c|}{ 8.1.6 Delayed graft function } \\
\hline Broyer 1993 & $37 / 71$ & $53 / 77$ & & $80.55 \%$ & $0.76[0.58,0.99]$ \\
\hline Grino 1991 & $13 / 60$ & $12 / 64$ & $\longrightarrow$ & $11.85 \%$ & $1.16[0.57,2.33]$ \\
\hline Vela 1994 & $6 / 23$ & $7 / 15$ & $\longrightarrow$ & $7.6 \%$ & $0.56[0.23,1.34]$ \\
\hline Subtotal $(95 \% \mathrm{Cl})$ & 154 & 156 & $\nabla$ & $100 \%$ & $0.78[0.61,0.99]$ \\
\hline \multicolumn{6}{|c|}{ Total events: 56 (ALG), 72 (OKT3) } \\
\hline \multicolumn{6}{|c|}{ Heterogeneity: $\mathrm{Tau}^{2}=0 ; \mathrm{Chi}^{2}=1.86, \mathrm{df}=2(\mathrm{P}=0.4) ; \mathrm{I}^{2}=0 \%$} \\
\hline \multicolumn{6}{|c|}{ Test for overall effect: $Z=2.04(P=0.04)$} \\
\hline Test for subgroup dif & $f=1(P=0.49)$ & & & & \\
\hline
\end{tabular}

Analysis 8.2. Comparison 8 ALG versus OKT3, Outcome 2 Other adverse outcomes.

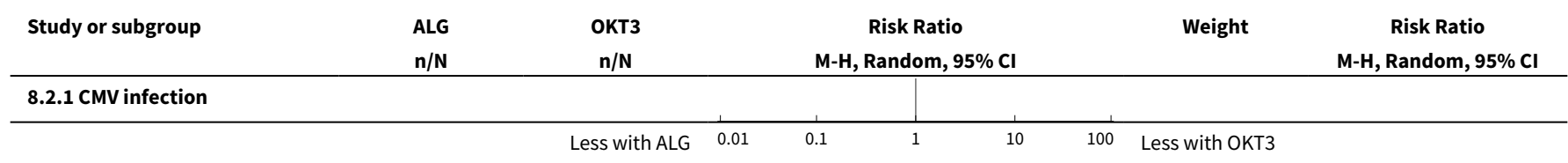




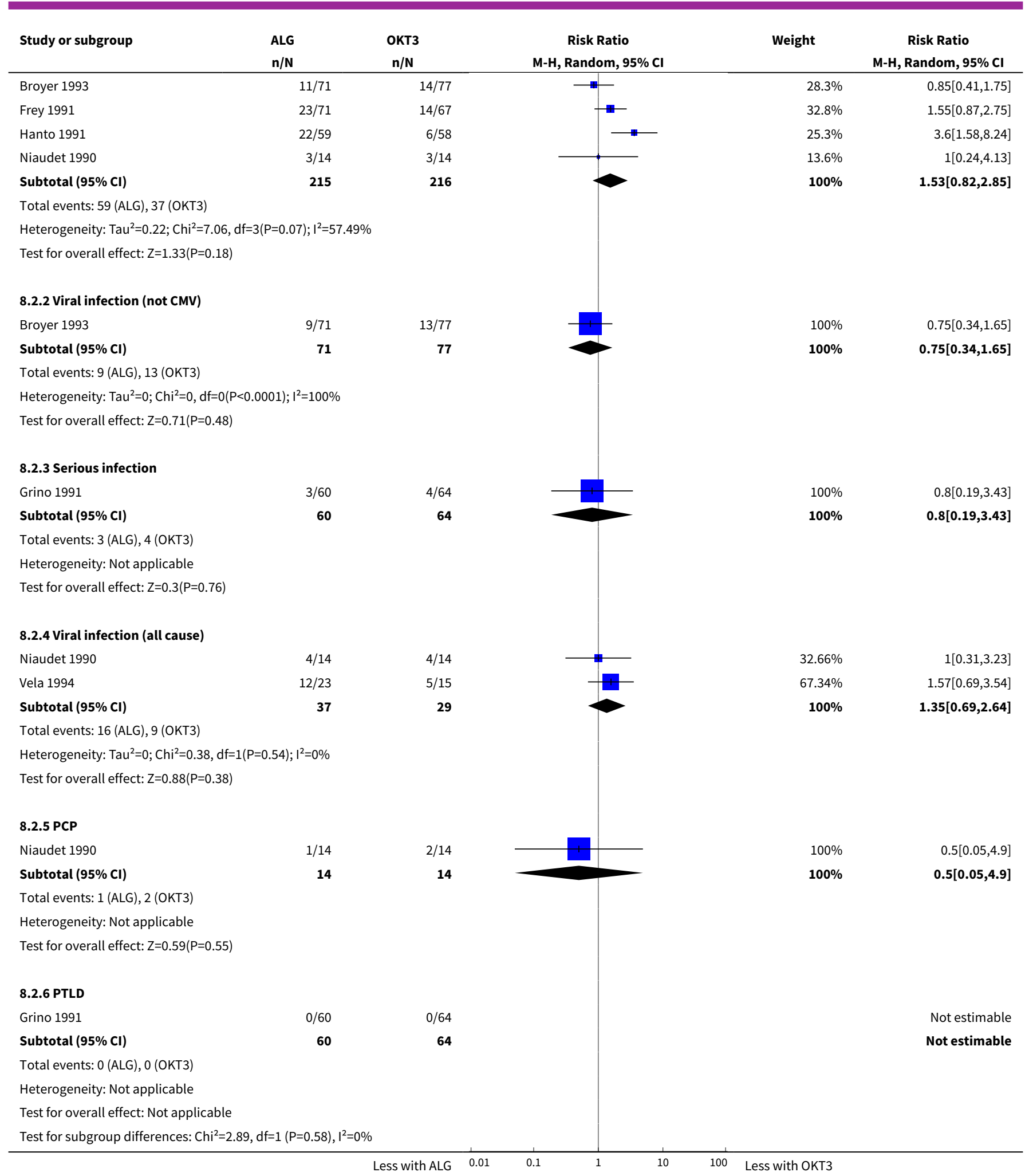


Analysis 8.3. Comparison 8 ALG versus OKT3, Outcome 3 Serum creatinine.

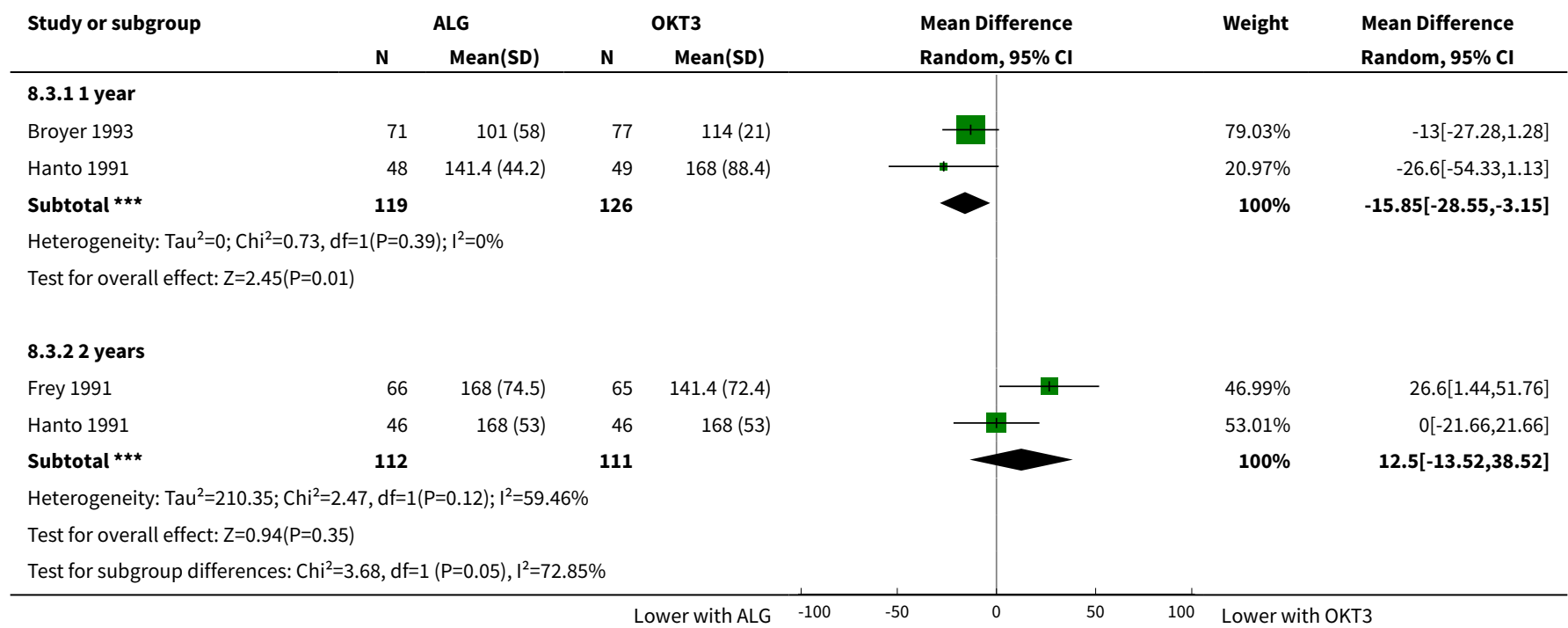

\section{Comparison 9. ALG versus placebo/no induction}

\begin{tabular}{|c|c|c|c|c|}
\hline $\begin{array}{l}\text { Outcome or subgroup ti- } \\
\text { tle }\end{array}$ & No. of studies & $\begin{array}{l}\text { No. of partici- } \\
\text { pants }\end{array}$ & Statistical method & Effect size \\
\hline 1 Main outcomes & 16 & & Risk Ratio (M-H, Random, 95\% Cl) & Subtotals only \\
\hline 1.1 Death at 1 to 2 years & 12 & 1180 & Risk Ratio (M-H, Random, 95\% Cl) & $1.27[0.96,1.69]$ \\
\hline 1.2 Death at 3 to 5 years & 2 & 406 & Risk Ratio (M-H, Random, 95\% Cl) & $1.00[0.67,1.50]$ \\
\hline 1.3 Death at 15 to 20 years & 2 & 223 & Risk Ratio (M-H, Random, 95\% Cl) & $0.92[0.40,2.10]$ \\
\hline $\begin{array}{l}1.4 \text { Graft loss (all cause) at } \\
1 \text { to } 2 \text { years }\end{array}$ & 11 & 1049 & Risk Ratio (M-H, Random, 95\% Cl) & $0.91[0.75,1.09]$ \\
\hline $\begin{array}{l}1.5 \text { Graft loss (all cause) at } \\
3 \text { to } 5 \text { years }\end{array}$ & 3 & 527 & Risk Ratio (M-H, Random, 95\% Cl) & $0.80[0.47,1.39]$ \\
\hline $\begin{array}{l}1.6 \text { Graft loss (all cause) at } \\
15 \text { to } 20 \text { years }\end{array}$ & 2 & 223 & Risk Ratio (M-H, Random, 95\% Cl) & $0.95[0.67,1.34]$ \\
\hline 1.7 Acute rejection & 13 & 1575 & Risk Ratio (M-H, Random, 95\% Cl) & $0.69[0.53,0.92]$ \\
\hline 1.8 Delayed graft function & 5 & 615 & Risk Ratio (M-H, Random, 95\% Cl) & $0.55[0.31,0.97]$ \\
\hline 2 Other adverse outcomes & 10 & & Risk Ratio (M-H, Random, 95\% Cl) & Subtotals only \\
\hline 2.1 CMV infection & 3 & 289 & Risk Ratio (M-H, Random, 95\% Cl) & $2.45[1.23,4.85]$ \\
\hline 2.2 Any viral infection & 2 & 324 & Risk Ratio (M-H, Random, 95\% Cl) & $2.71[1.86,3.95]$ \\
\hline 2.3 Bacterial infection & 4 & 742 & Risk Ratio (M-H, Random, 95\% Cl) & $1.18[0.92,1.52]$ \\
\hline
\end{tabular}




\begin{tabular}{lllll}
\hline $\begin{array}{l}\text { Outcome or subgroup ti- } \\
\text { tle }\end{array}$ & No. of studies & $\begin{array}{l}\text { No. of partici- } \\
\text { pants }\end{array}$ & Statistical method & Effect size \\
\hline 2.4 Fungal infection & 1 & 230 & Risk Ratio (M-H, Random, 95\% Cl) & $1.11[0.63,1.95]$ \\
\hline 2.5 Thrombocytopenia & 1 & 67 & Risk Ratio (M-H, Random, 95\% Cl) & $12.19[3.10,47.92]$ \\
\hline 2.6 Leucopenia & 2 & 297 & Risk Ratio (M-H, Random, 95\% Cl) & $20.31[0.61,676.54]$ \\
\hline 2.7 Malignancy or PTLD & 4 & Risk Ratio (M-H, Random, 95\% Cl) & $0.60[0.27,1.31]$ \\
\hline 2.8 NODAT & 1 & 105 & Risk Ratio (M-H, Random, 95\% Cl) & $0.93[0.22,3.93]$ \\
\hline 3 Serum creatinine & 6 & Mean Difference (IV, Random, 95\% Cl) & Subtotals only \\
\hline 3.1 At 1 to 2 years & 4 & 369 & Mean Difference (IV, Random, 95\% Cl) & $-16.94[-50.86,16.97]$ \\
\hline 3.2 At 10 to 20 years & 2 & 221 & Mean Difference (IV, Random, 95\% Cl) & $-3.77[-41.06,33.53]$ \\
\hline
\end{tabular}

Analysis 9.1. Comparison 9 ALG versus placebo/no induction, Outcome 1 Main outcomes.

\begin{tabular}{|c|c|c|c|c|c|}
\hline Study or subgroup & $\begin{array}{l}\text { ALG } \\
\mathrm{n} / \mathrm{N}\end{array}$ & $\begin{array}{c}\text { Control } \\
\mathrm{n} / \mathrm{N}\end{array}$ & $\begin{array}{c}\text { Risk Ratio } \\
\text { M-H, Random, } 95 \% \mathrm{CI}\end{array}$ & Weight & $\begin{array}{c}\text { Risk Ratio } \\
\text { M-H, Random, } 95 \% \mathrm{Cl}\end{array}$ \\
\hline \multicolumn{6}{|c|}{ 9.1.1 Death at 1 to 2 years } \\
\hline Belitsky 1991 & $2 / 57$ & $3 / 53$ & 1 & $2.62 \%$ & $0.62[0.11,3.57]$ \\
\hline Bell 1983 & $19 / 86$ & $17 / 87$ & - & $23.64 \%$ & $1.13[0.63,2.02]$ \\
\hline Gianello 1987 & $6 / 58$ & $2 / 66$ & 1 & $3.29 \%$ & $3.41[0.72,16.26]$ \\
\hline Grundmann 1984 & $5 / 47$ & $2 / 47$ & 1 & $3.18 \%$ & $2.5[0.51,12.25]$ \\
\hline Halloran 1982 & $1 / 31$ & $0 / 37$ & $\longrightarrow$ & $0.8 \%$ & $3.56[0.15,84.46]$ \\
\hline Jakobsen 1981 & $13 / 30$ & $7 / 30$ & $\rightarrow$ & $13.64 \%$ & $1.86[0.86,4]$ \\
\hline Launois 1977 & $3 / 21$ & $2 / 15$ & - & $2.9 \%$ & $1.07[0.2,5.65]$ \\
\hline Maiorca 1984 & $1 / 30$ & $0 / 33$ & & $0.8 \%$ & $3.29[0.14,77.82]$ \\
\hline Novick 1983 & $4 / 31$ & $9 / 36$ & $\longrightarrow$ & $6.94 \%$ & $0.52[0.18,1.51]$ \\
\hline Sansom 1976 & $17 / 43$ & $10 / 42$ & + & $18.69 \%$ & $1.66[0.86,3.2]$ \\
\hline Slakey 1993 & $4 / 61$ & $6 / 60$ & 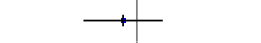 & $5.44 \%$ & $0.66[0.19,2.21]$ \\
\hline Taylor 1976 & $15 / 87$ & $14 / 92$ & * & $18.05 \%$ & $1.13[0.58,2.21]$ \\
\hline Subtotal (95\% Cl) & 582 & 598 & $\bullet$ & $100 \%$ & $1.27[0.96,1.69]$ \\
\hline \multicolumn{6}{|c|}{ Total events: 90 (ALG), 72 (Control) } \\
\hline \multicolumn{6}{|c|}{ Heterogeneity: $\mathrm{Tau}^{2}=0 ; \mathrm{Chi}^{2}=9.36, \mathrm{df}=11(\mathrm{P}=0.59) ; 1^{2}=0 \%$} \\
\hline \multicolumn{6}{|c|}{ Test for overall effect: $Z=1.67(P=0.1)$} \\
\hline \multicolumn{6}{|c|}{ 9.1.2 Death at 3 to 5 years } \\
\hline Condie 1985 & $17 / 81$ & $18 / 79$ & 1 & $47.63 \%$ & $0.92[0.51,1.65]$ \\
\hline Minnesota Study 1982 & $20 / 115$ & $21 / 131$ & 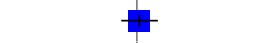 & $52.37 \%$ & $1.08[0.62,1.9]$ \\
\hline Subtotal $(95 \% \mathrm{Cl})$ & 196 & 210 & 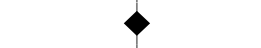 & $100 \%$ & $1[0.67,1.5]$ \\
\hline \multicolumn{6}{|c|}{ Total events: 37 (ALG), 39 (Control) } \\
\hline \multicolumn{6}{|c|}{ Heterogeneity: $\operatorname{Tau}^{2}=0 ; \mathrm{Chi}^{2}=0.16, \mathrm{df}=1(\mathrm{P}=0.69) ; \mathrm{I}^{2}=0 \%$} \\
\hline \multicolumn{6}{|c|}{ Test for overall effect: $Z=0.02(P=0.99)$} \\
\hline \multicolumn{6}{|c|}{ 9.1.3 Death at 15 to 20 years } \\
\hline Cantarovich 2008 & $28 / 60$ & $23 / 63$ & 田 & $61.41 \%$ & $1.28[0.84,1.95]$ \\
\hline Grino 1990 & $6 / 50$ & $11 / 50$ & $\rightarrow$ & $38.59 \%$ & $0.55[0.22,1.36]$ \\
\hline
\end{tabular}




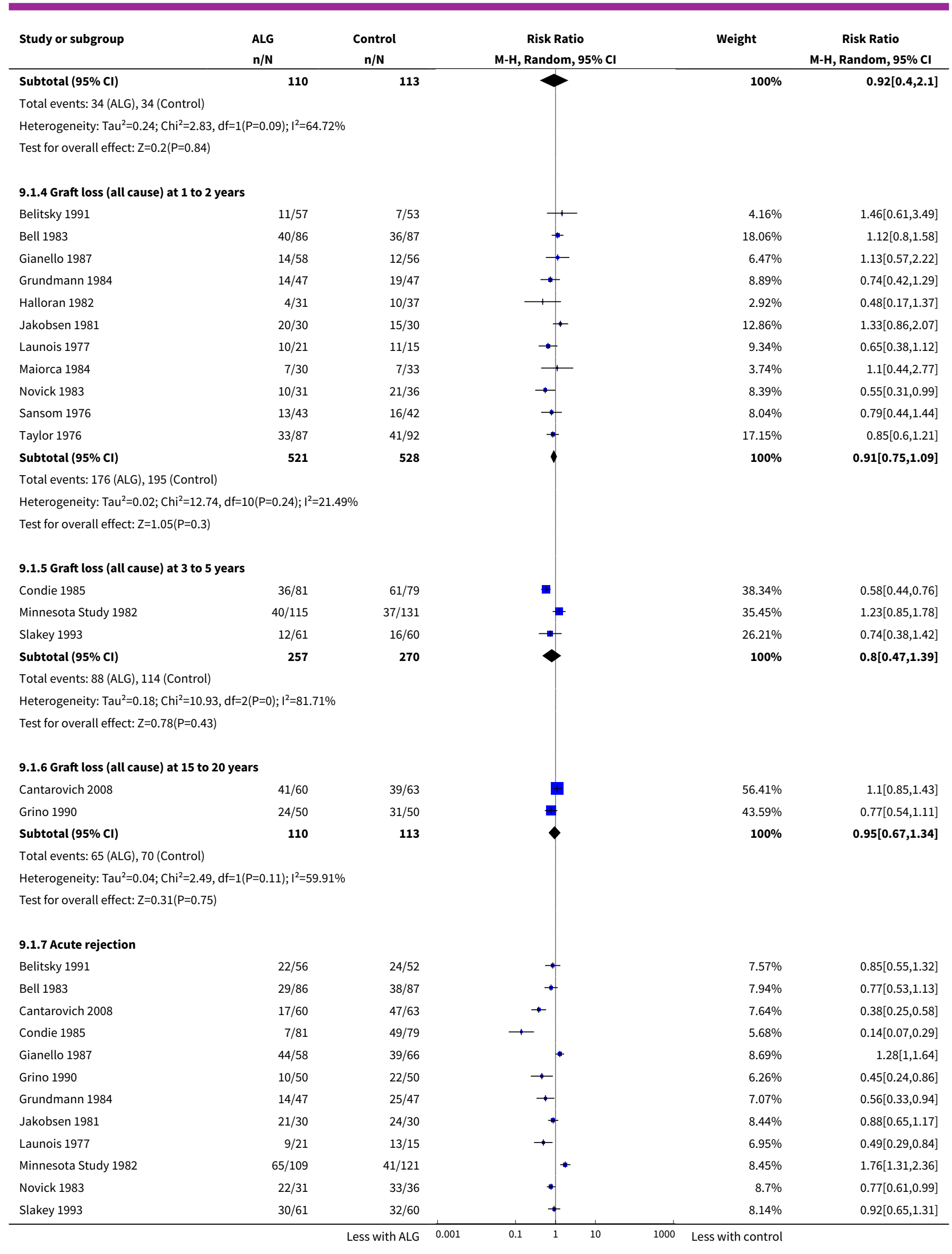




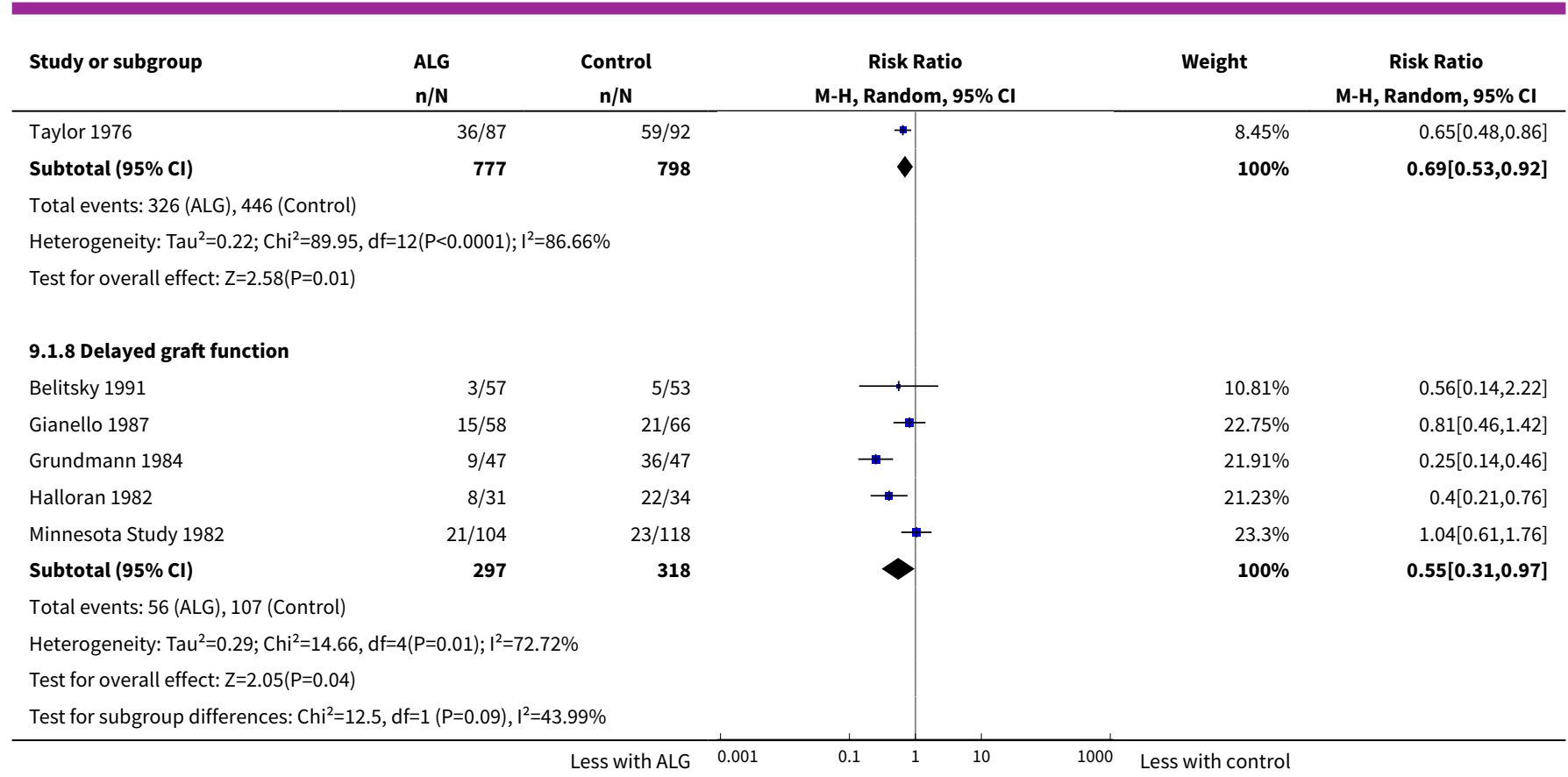

Analysis 9.2. Comparison 9 ALG versus placebo/no induction, Outcome 2 Other adverse outcomes.

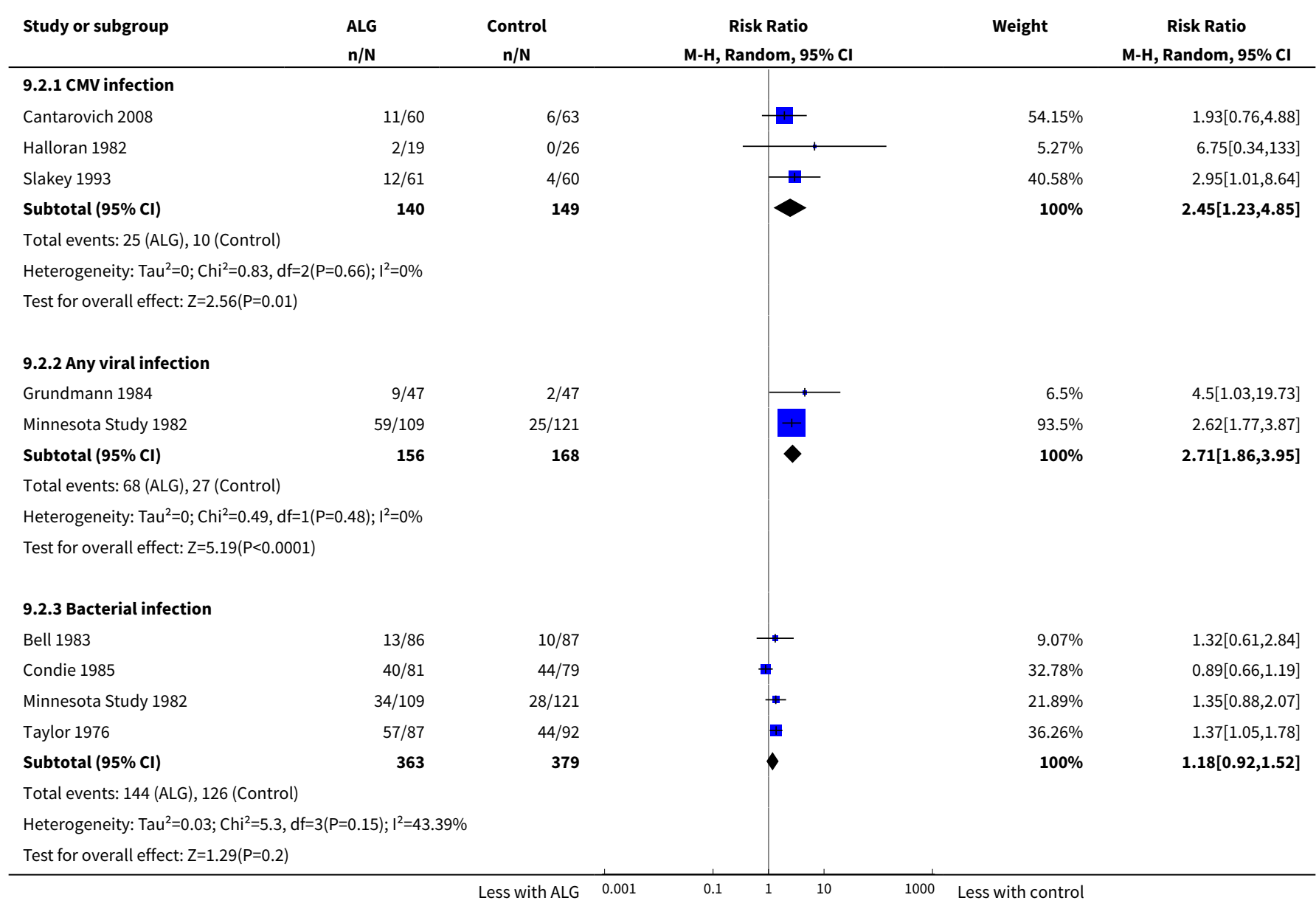




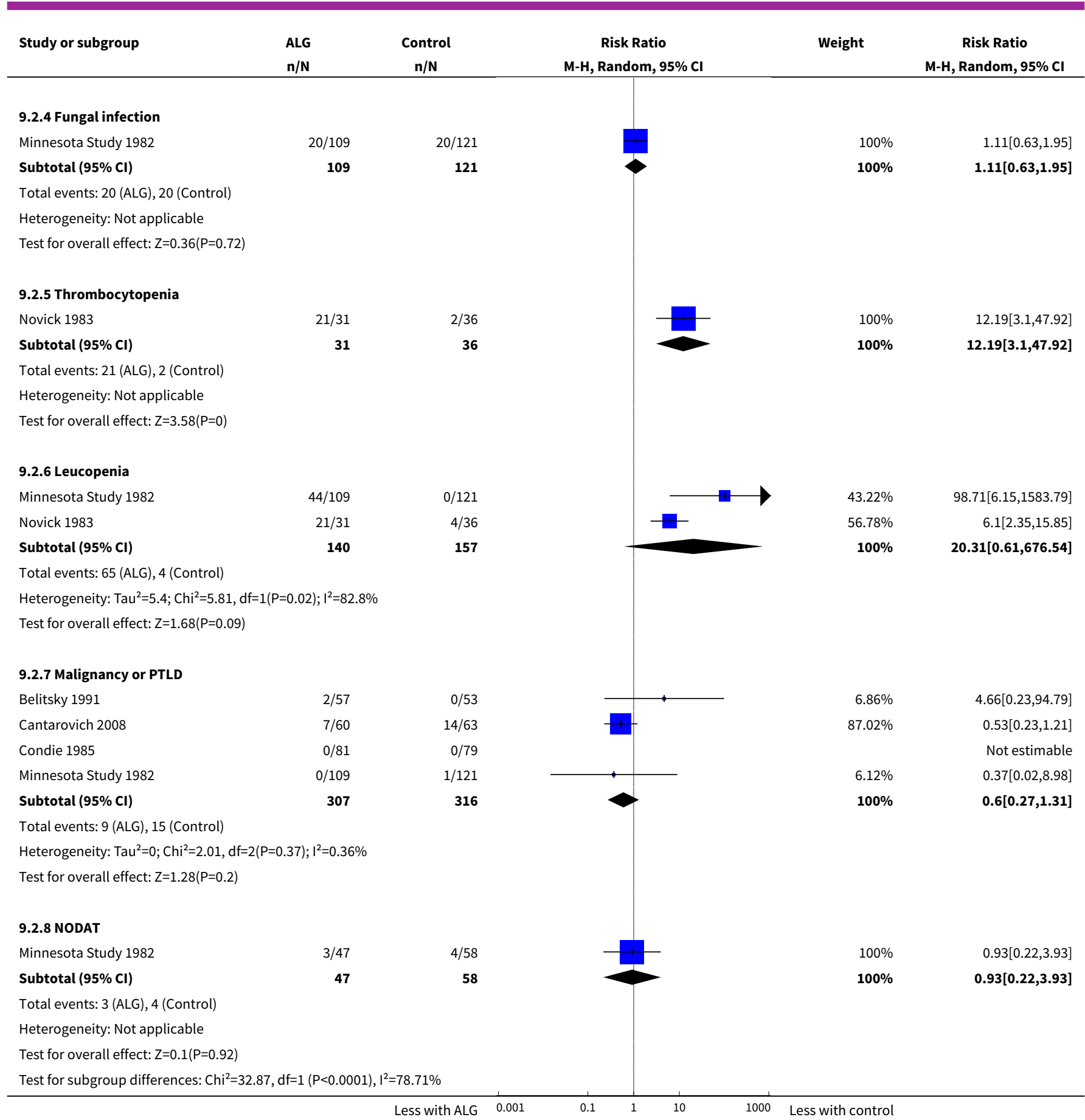

Analysis 9.3. Comparison 9 ALG versus placebo/no induction, Outcome 3 Serum creatinine.

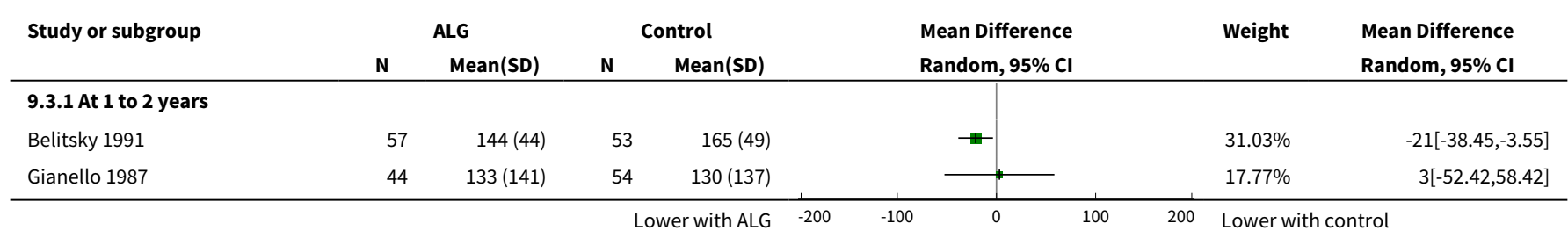




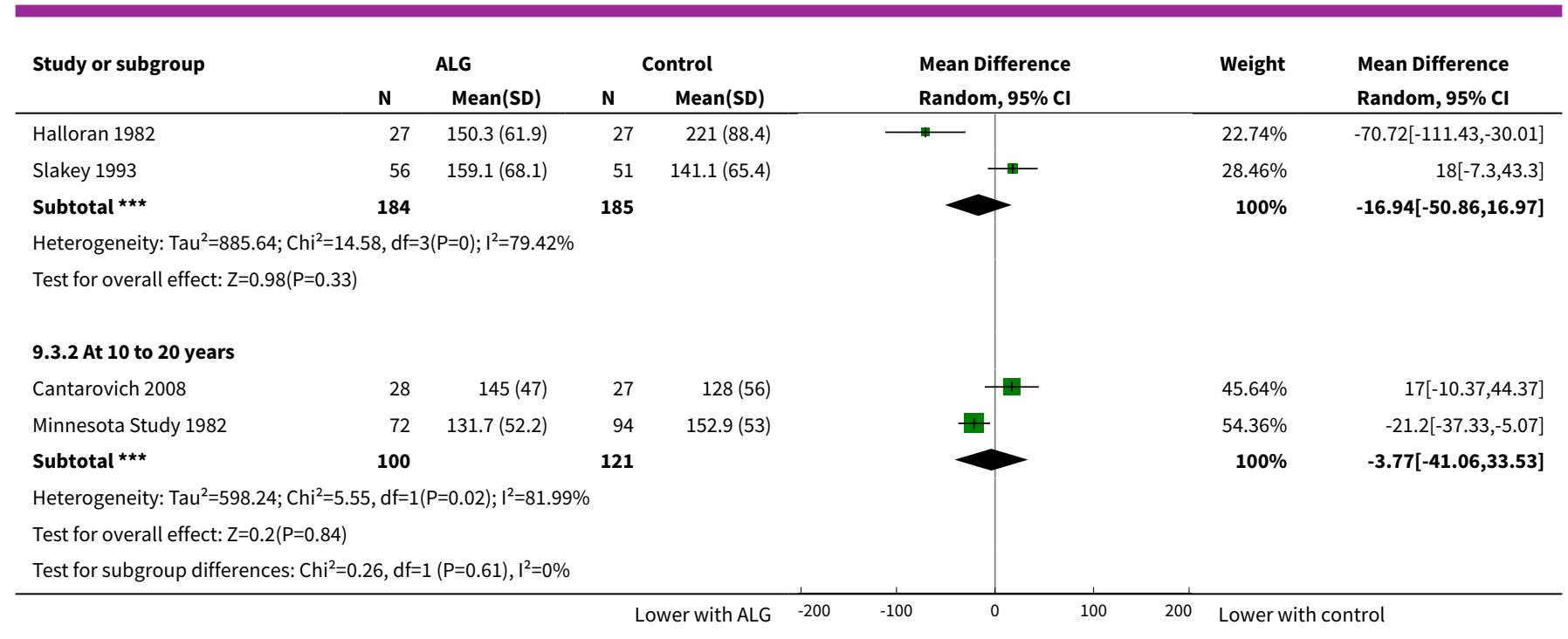

\section{APPENDICES}

\section{Appendix 1. Electronic search strategies}

\begin{tabular}{|c|c|}
\hline Database & Search terms \\
\hline CENTRAL & 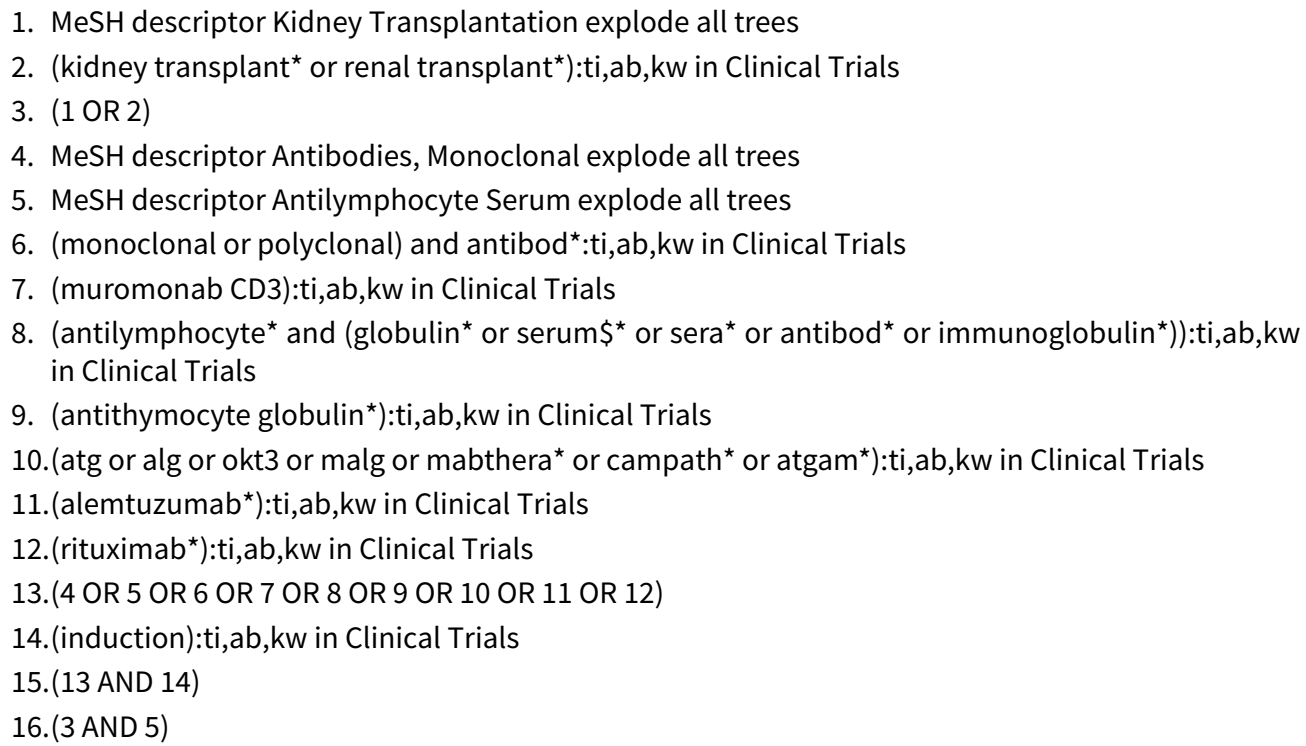 \\
\hline
\end{tabular}

MEDLINE (OvidSP)
1. kidney transplantation/
2. exp antibodies, monoclonal/
3. ((monoclonal or polyclonal) and antibod\$).tw.
4. muromonab-CD3.tw.
5. exp Antilymphocyte Serum/
6. (antilymphocyte\$ and (globulin\$ or serum $\$$ or sera $\$$ or antibod $\$$ or immunoglobulin\$)).tw.
7. antithymocyte globulin\$.tw.
8. (atg or alg or okt3 or malg or mabthera $\$$ or campath\$ or atgam\$).tw. 

9. alemtuzumab.tw.
10.rituximab.tw.
11.or/2-10
12.induction.tw.
13.and/11-12
14.and $/ 1,13$

EMBASE (OvidSP)
1. kidney transplantation/
2. exp monoclonal antibody/
3. polyclonal antibody/
4. lymphocyte antibody/
5. thymocyte antibody/
6. (atg or alg or okt3 or malg or mabthera $\$$ or campath or atgam\$).tw.
7. (alemtuzumab or rituximab).tw.
8. or/2-7
9. induction.tw.
10.and $/ 8-9$
11.and $/ 1,10$

\section{Appendix 2. Risk of bias assessment tool}

\section{Potential source of bias \\ Random sequence genera- tion}

\section{Assessment criteria}

Selection bias (biased allocation to interventions) due to inadequate generation of a randomised sequence

Low risk of bias: Random number table; computer random number generator; coin tossing; shuffling cards or envelopes; throwing dice; drawing of lots; minimization (minimization may be implemented without a random element, and this is considered to be equivalent to being random).

High risk of bias: Sequence generated by odd or even date of birth; date (or day) of admission; sequence generated by hospital or clinic record number; allocation by judgement of the clinician; by preference of the participant; based on the results of a laboratory test or a series of tests; by availability of the intervention.

Unclear: Insufficient information about the sequence generation process to permit judgement.

\section{Allocation concealment}

Selection bias (biased allocation to interventions) due to inadequate concealment of allocations prior to assignment
Low risk of bias: Randomisation method described that would not allow investigator/participant to know or influence intervention group before eligible participant entered in the study (e.g. central allocation, including telephone, web-based, and pharmacy-controlled, randomisation; sequentially numbered drug containers of identical appearance; sequentially numbered, opaque, sealed envelopes).

High risk of bias: Using an open random allocation schedule (e.g. a list of random numbers); assignment envelopes were used without appropriate safeguards (e.g. if envelopes were unsealed or non-opaque or not sequentially numbered); alternation or rotation; date of birth; case record number; any other explicitly unconcealed procedure.

Unclear: Randomisation stated but no information on method used is available.

\section{Blinding of participants and personnel}

Performance bias due to knowledge of the allocated interventions by participants
Low risk of bias: No blinding or incomplete blinding, but the review authors judge that the outcome is not likely to be influenced by lack of blinding; blinding of participants and key study personnel ensured, and unlikely that the blinding could have been broken. 
(Continued)

and personnel during the study
High risk of bias: No blinding or incomplete blinding, and the outcome is likely to be influenced by lack of blinding; blinding of key study participants and personnel attempted, but likely that the blinding could have been broken, and the outcome is likely to be influenced by lack of blinding.

Unclear: Insufficient information to permit judgement

\section{Blinding of outcome assess- ment}

Detection bias due to knowledge of the allocated interventions by outcome assessors.
Low risk of bias: No blinding of outcome assessment, but the review authors judge that the outcome measurement is not likely to be influenced by lack of blinding; blinding of outcome assessment ensured, and unlikely that the blinding could have been broken.

High risk of bias: No blinding of outcome assessment, and the outcome measurement is likely to be influenced by lack of blinding; blinding of outcome assessment, but likely that the blinding could have been broken, and the outcome measurement is likely to be influenced by lack of blinding.

Unclear: Insufficient information to permit judgement

\section{Incomplete outcome data}

Attrition bias due to amount, nature or handling of incomplete outcome data.
Low risk of bias: No missing outcome data; reasons for missing outcome data unlikely to be related to true outcome (for survival data, censoring unlikely to be introducing bias); missing outcome data balanced in numbers across intervention groups, with similar reasons for missing data across groups; for dichotomous outcome data, the proportion of missing outcomes compared with observed event risk not enough to have a clinically relevant impact on the intervention effect estimate; for continuous outcome data, plausible effect size (difference in means or standardized difference in means) among missing outcomes not enough to have a clinically relevant impact on observed effect size; missing data have been imputed using appropriate methods.

High risk of bias: Reason for missing outcome data likely to be related to true outcome, with either imbalance in numbers or reasons for missing data across intervention groups; for dichotomous outcome data, the proportion of missing outcomes compared with observed event risk enough to induce clinically relevant bias in intervention effect estimate; for continuous outcome data, plausible effect size (difference in means or standardized difference in means) among missing outcomes enough to induce clinically relevant bias in observed effect size; 'as-treated' analysis done with substantial departure of the intervention received from that assigned at randomisation; potentially inappropriate application of simple imputation.

Unclear: Insufficient information to permit judgement

\section{Selective reporting}

Reporting bias due to selective outcome reporting
Low risk of bias: The study protocol is available and all of the study's pre-specified (primary and secondary) outcomes that are of interest in the review have been reported in the pre-specified way; the study protocol is not available but it is clear that the published reports include all expected outcomes, including those that were pre-specified (convincing text of this nature may be uncommon).

High risk of bias: Not all of the study's pre-specified primary outcomes have been reported; one or more primary outcomes is reported using measurements, analysis methods or subsets of the data (e.g. subscales) that were not pre-specified; one or more reported primary outcomes were not prespecified (unless clear justification for their reporting is provided, such as an unexpected adverse effect); one or more outcomes of interest in the review are reported incompletely so that they cannot be entered in a meta-analysis; the study report fails to include results for a key outcome that would be expected to have been reported for such a study.

Unclear: Insufficient information to permit judgement

\section{Other bias}

Bias due to problems not covered elsewhere in the table
Low risk of bias: The study appears to be free of other sources of bias.

High risk of bias: Had a potential source of bias related to the specific study design used; stopped early due to some data-dependent process (including a formal-stopping rule); had extreme baseline imbalance; has been claimed to have been fraudulent; had some other problem. 
Unclear: Insufficient information to assess whether an important risk of bias exists; insufficient rationale or evidence that an identified problem will introduce bias.

\section{CONTRIBUTIONS OF AUTHORS}

- Study selection: PH, NC, NB, SP

- Screening of articles: PH, NC, NB, SP

- Disagreement resolution: PH, NC, NB, SP

- Data extraction: PH, NC, NB, SP

- Data entry: PH

- Carry out the analysis: PH, NC, NB, SP

- Interpret the analysis: $\mathrm{PH}, \mathrm{NC}, \mathrm{NB}, \mathrm{SP}$

- Draft the final review: AW, PH, NC, NB, SP

- Update the review: AW, PH, NC, NB, SP

\section{DECLARATIONS OF INTEREST}

- AW: Nothing to declare

- NC: Nothing to declare

- $\mathrm{PH}$ : Nothing to declare

- NB: NB is a co-investigator of the ongoing randomised, controlled clinical trial, ReMIND (RituxiMab INDuction in renal transplantation, NCT01095172).

- SP: Nothing to declare

\section{INDEX TERMS}

\section{Medical Subject Headings (MeSH)}

*Kidney Transplantation [adverse effects] [mortality]; Acute Disease; Alemtuzumab; Antibodies, Monoclonal [therapeutic use]; Antibodies, Monoclonal, Humanized [*therapeutic use]; Antilymphocyte Serum [adverse effects] [ ${ }^{\star}$ therapeutic use]; Calcineurin Inhibitors [*therapeutic use]; Cytomegalovirus Infections [etiology]; Graft Rejection [mortality] [ ${ }^{*}$ prevention \& control]; Immunosuppression [ ${ }^{*}$ methods]; Immunosuppressive Agents [adverse effects] [*therapeutic use]; Muromonab-CD3 [therapeutic use]; Randomized Controlled Trials as Topic; Receptors, Interleukin-2 [immunology]; Steroids [therapeutic use]

\section{MeSH check words}

Humans 